

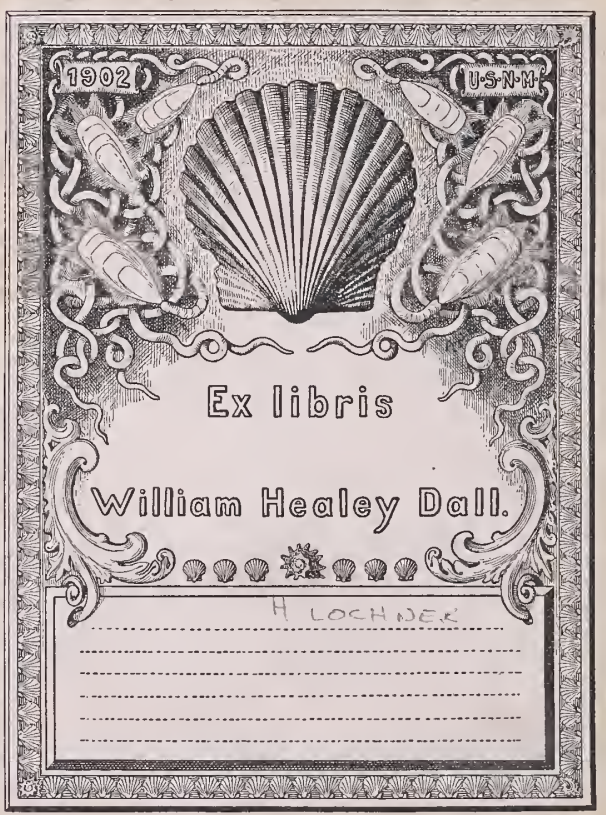








\section{$-7-$}

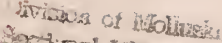

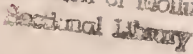

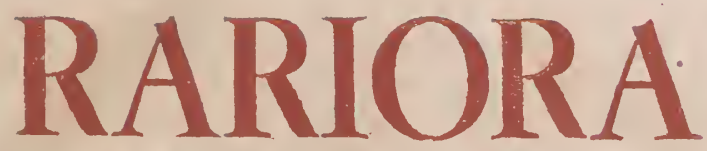

MVSEI BESLERIANI

\section{B ASILIVS}

et

MICHAEL RVPERTVS

BESLERI

AENEISOVE TABVLISS AD VIVVM INCISA EVVLGARVNT:

aunc commentariolo illuftrata

JOHANNÉ HENRICO

\section{LOCHNERO,}

VT VIRTVTI TOY MAKARITOY EXSTARET MONVMENTVM, DENVO LVCI PVBLICAE COMMISIT ET LAVDATIONEM EJVS FVNEBREM ADJECIT

MICHAEL FRIDERICVS

\section{LOCHNERVS}

ARCHIATER CAES. ACAD, LEO POLD. CAROL. NAT, CVR, EPHEM. DIRECTOR.

ANNO O. R. MDCC XVI. 


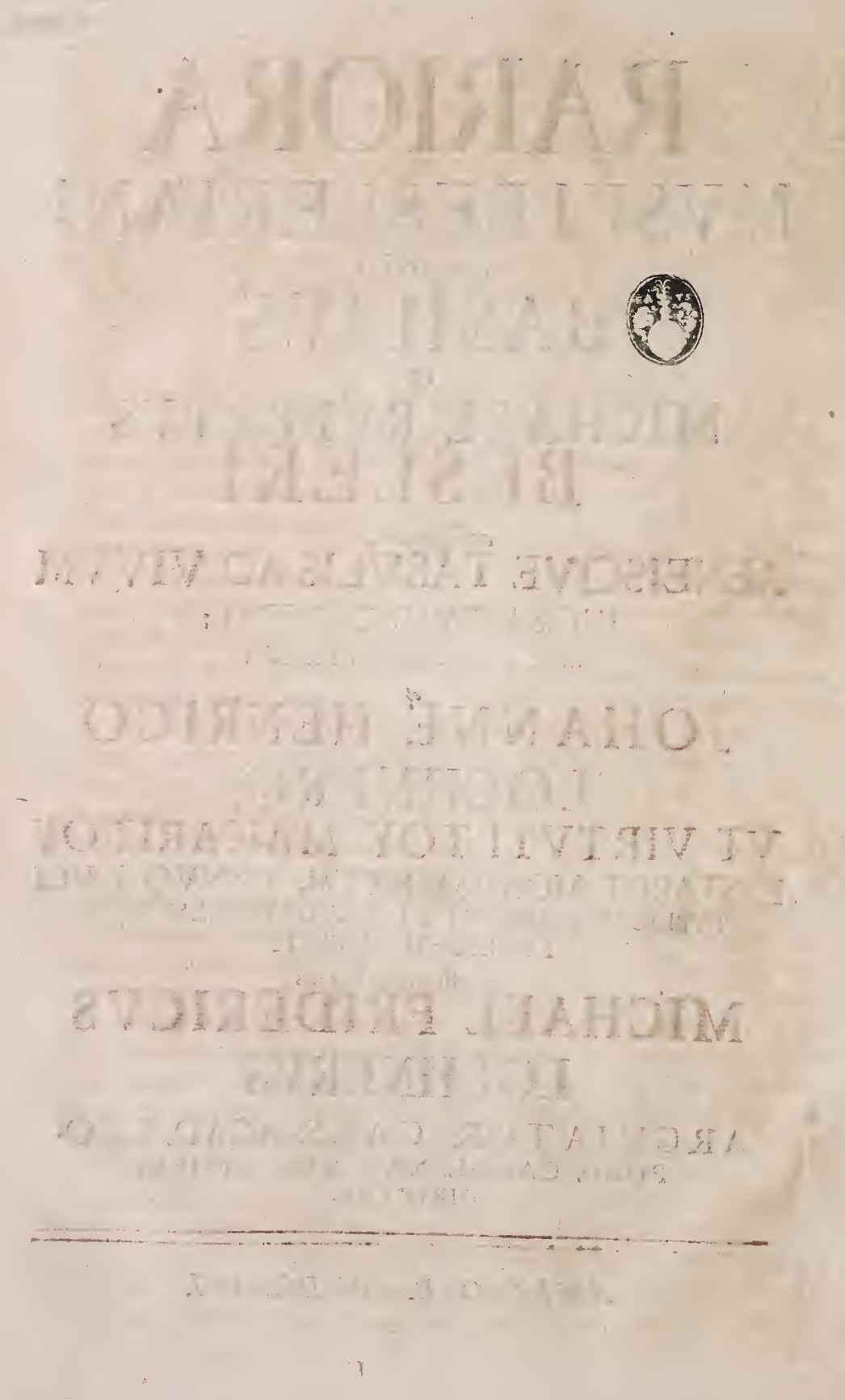



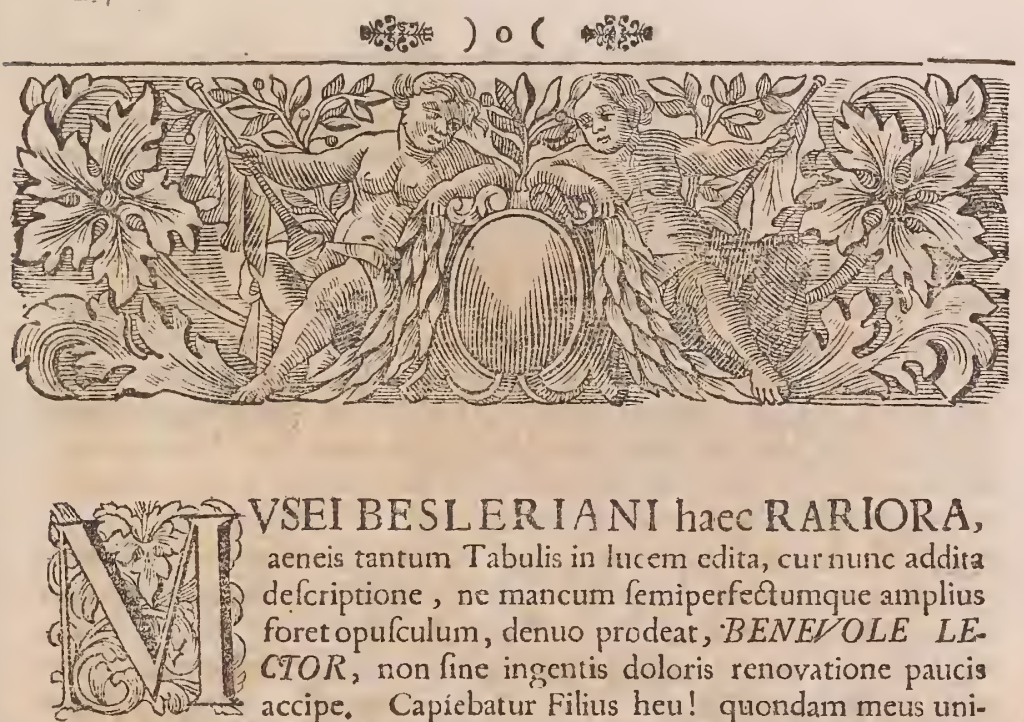

VSEI BESLERIA NI haec RARIORA, aeneis tantum $T$ abulis in lucem cdita, curnunc addita defcriptione, ne mancum femiperfectumque amplius foret opufulum, denuo prodear, $B E N E V O L E L E$. CTOR, non fine ingentis doloris renovatione paucis accipe. Capiebatur Filius heu! quondam meus unicus, a prima ftatim ftudiis apta Juventute, ut Jibrorum et liberalium artium, ita maxime Hiftoriae naturalis amore, ad quam ab Auctoribus, qui in fupellectile mea libraria, pro modulo tenuitatis meae fuperfunt rariores, elegantifimisque figuris aeriincifis infrucli, magis magisque alliciebatur. Auxerat praeterea in ftudio hoc progreflus Theca officinalibus uti vocant referta, majoraque defuper incrementa eidem dederat confortium, quod cum commilitone contraxit, Juvene ad optima quaeque nato, acomnibus animi formaeque dotibus inftructifimo, Engellandio Funiore, cujus Parens Bafilii Besleri Mufeum, ad fe haereditatis jure devolutum polfidet, Amicorum, quos a prima ftatim aetate mihi concilisveram, certiffimus. Occafio hinc illi nata, toties de rarioribus hoc in Mufeo contentisdifferendi, et quorum hactenus in aeneis tabulis viderat tantum ectypa, prototypa nunc infpiciendi. Audiverat me olim circa Praxeos medicae initia, nudis his Tabulis, a tot Viris doctiflimis expetitam defcriptionem deftinafle, cumque ob tot Praxeos catenata certe impedimenta me praepeditum cerneret, fe manum huic labori admoverevelle, fpopondit. Repreffi primitus hos juveniles praecocesque impetus, alt quoties, illo acrius inftante, onus humeris ejus minime ferendum praedicerem, toties enixiflimis precibus obftabat, meamque ad hoc opus perficiendum implorabat opem operamque. Laceffitus tot precibus, viciustandem, ne igniculos ergaftudium elegan . tisfimum reftinguerem, fed nutrirem potius, magisque refufitarem, me tandem exorare paffus fum, Detexi ipfi fontes Hiftoriae naturalis in Bibliothecula mea exftantes, et qua jam olim circa Clinices primordia, de his Beslerianis Rarioribus fchedis illeyeram confufaneis, ipfi porrigo, Meminiffe dolet, imo horret animus, quo perfufus gaudio has 
lacinias exceperit, tanquam futura prima hujus opúfculi rudimenta. Collectis quotidie ex variis Auctoribus optimis fubfidiis, crevit fub manibus, in hanc quam cernis molem. Noricas tandem cum Virebergenfibus $\mathrm{Mufis}$ commutacurus, toc quicquideft, mihi reliquit, ulterius in itineribus per Belgium, Angliam Galliasque tandem fufcipiendis, locupletaturus, ultimamque in reditu limam et manum cum DEO et die admoturus. Sed fpes hominum fallaces! Numini etenim placuit iter in Patriam ipfi coeleftem imperare, ut fpretis his naturae terreftribus, coeleftibus frueretur gazis. Infelicem felicifimiFilii parentem, qui animi aegritudine ob Nati unici praematurum obitum obrutus, quotidie fere morior, quippe

\section{Homo toties moritur, quoties amittit fros.}

Sed quid amifum doleo et mortum, quem tenet Olympus. Vivit ille vita aeternum meliore nactus aevum; Derelictum me potius queror et expofitum tot aerumnis, tot calamitatibus, tot mundiimenundiillecebris, tot inquietudinibus, fruftra enim quietem quaerimus anxii, dum terra caeli nos tenet exules. O ! fi liceret cumillo conjungi, chorisque beatis intereffe; haec votorum fumma meorum ! Placuit tamen et placebit femper, DEO quod placet, nec enim plus dolori et luetui, quam voluntati Divinae concedo, cui refragari nefas femper duxi morte piandum; haec Divini Numinis Voluntas, modum ut hactenus fic porro quoque maerori ponat precor; quippe

\section{Hoc meo levamen}

\section{Dolori dolor ipje fert, mibique}

quo doleo magis; eft minus dolendum.

Sed redeundum mihi in viam, et ad triftes beatiffmi Filii fedulitatis has reliquias, quas toties repofui, quoties illas literato orbi tradere, feculo hoc maleferiato, judicandique prurigine refertifimo, in animum inducerem. Obluctabatur maxime argumenti tenuiras, cum Mufea Besleriana, illo tempore Jucem confpexerint, quo Hiftoria naturalis primitus excoli coepit, hodieque proletaria illa, quae rariora credidit Besleri aevum.; accelfit et hoc, quod methodo accuratiffima, qua naturalis Hiftoriae Studium hodie fulget, minimegaudeant, fed in Tabulis his, praefertim quae lapides continent, indifpofita paene omnia, nulloque decenti congefta ordine, et quae plura adhuc alia fuperfunt, dentatis et aculeatis vitilitigatorum, rigidiorumque Cenforum morfibus expofita. Dubius fic haerens de manumiffione hujus opufculi, vicit tandem publicae utilitatis ftudium, praefertim cum Rariora haec Beslerorum, figuris folis tantum conftuntia, tanto tamen literati orbis dignata fuerint favore, ut Viri in ftudio naturali vere Principes, illa ob figurarum elegantiam, et ad naturae leges expreffam concinnitatem, non laudare tantum, fed impenfius commendare haud erubuerint. Acceffit 


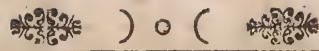

follicita efflagitatio plurimorum, has Tabulas commentariolo illuftratas defiderantium, cum melioris fpei pollicitatione, fore ut cum alia Mufea, licet tempore pariter illo, quo prima hiftoria naturalis incrementa cepit, edita fuerint, in pretio tamen exiftant, fingulari ftudio conquirantur, et de novo recudantur; his Rarioribus Beslerianis pariter non de. futuros emptores, Maxime autem me movit defideratiffimi Filii $\tau \tilde{s}$ raxaeirr impenfus hifce labor, et adhibita in iisdem eruendis ex tot Auctoribus (citra pinautian hoc dictum efto, ) affiduitas, quo temporis illud fpatium, quod juvenilis aetas alias ludicris ttanfigere confuevit, huic impendere conftituit operi. Quod fi decorille defit pagellis his, judiciique acumen, quod ftudium hoc poftulat, defideratque aevi hujus iтrorupid, omniaque nunc cenfentium illicita licentia, quibus Veneris etiam fandalium calumniari non eft piaculum, meminerint quaefo, hoc quidquid elt, e manu Juvenis XVII. annorum, vixdum in phyficis tironis, et de grege nuvitiorum in arte medica prodiifle, ut non mirum fit, naevulis hincinde confperfas effe pagellas, Limatiora hoc in ftudio forte dediffet, fi haec ipfa poft abfolutum ftudium, iterque ad exteros praemeditatum, adhibitis pofterioribus et fapientioribus cogitationibus, (praefifcini dixerim) manumittere licuiffet. Quod ipfe manus medicas opellae non admoverim, prohibuit partim recrudefcens ftatim labore hoc fufcepto dolor, cum fluentes lacrymae calami delevere lituras; partim obftitit medica in ampla hac et populofa urbe, qua obrutus fum, Praxis, ubi Horatianum illud quotidie mihirepetendum:
Hic vifum vocat, hic anditum iriftia, /pretis
Omnibus officiis: cubat bic incolle Quirini,
Trans Tiberim longe cubat bic prope Calaris bortos,
Ille extremo in Aventino vijendusuterque.

Sed fufficiant haec de dulcifimi Filii conatibus, qui quamvis commendatione magna digni non fint, tamen ejus laudanda yoluntas, quoniam in magnis voluiffe fat eft. Cenforem quod fi evitari haud queat, illud Sapientis occidendum reputo:

\section{Carpe quod eft lubitum, modo non injurius efto.}

Quippe juxta tritum illud:

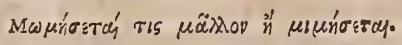

Ad Besleros quod attinet, haud exiguam in Cholis medicis promeruerelaudem; et $B A S I L I V S$ quidem aetate major, Michaëlis Besleri Theologi urbis hujus Celeberrimi Filius, et Hieronymi Medici feliciffni Frater erat. Humanioribus cum Fratre literis expolitus, et $a b$ ineunte ftatim aetate rei herbariaeftudio mirifice, (uti ipfemet praefat.in Hort. Eyftädtenfem fatetur) captus, hac occafione in magno ifto naturae Volumine evolvendo non parum ftudii et diligentiae pofuit, indeque factum eft, ut arti fe addiceret Pharmacevticae, utpote in cujus of- 
ficinis pleraque ex herbís, plantis, floribus, radicibus, feminibusque prae. fcripta et praeparata conftare, ibique verum iftarum rerum ufum difci cerneret. Adeum etiam finem hortulum quendam privatum inftituerat, quo animum ulterius in ftudio Botanico progredi geftientem exfatiaret. Nec effectu caruit nobilis hic ardor : peperit quippe Beslero Sum. morum Imperii Romani Procerum favorem, celeberrimorumque Botanicorum amicitiam. Primos inter erat praecipue REVERENDISSIAIVS ET CELSISSIMVS EPISCOPVS ET'ST ADTENSIS, DN. JOH.CONRADVS a GEMINIINGEN, feliciffimae memoriae Princeps, qui de notitia Resleri Botanica edoctus, non folum hortis fuis elegantifimis, quibus arcem epifcopalem in D. Willibaldi monte cinxit, ac quaqua verfum jucundiffimo ac amoeniffmo profpectu beavit, excolendis Beslerum dignatus eft, fed et illorum defcriptionem, et aeterni operis Editionem, reluctante licet illo, demandare ac delegare non dubitaverit. Interintimos Bafilii amicoserat Florae illud Delitium, Carolis, Clufius, MAXIMILIANI 1I. gloriofiffimae memoriae CAESARIS, Archiater hortique Caefarei Praefectus; hic Vienna redux, urbemqueNoricam tranfiens, firmiori amicitiae nexu cum Beslero copulabatur. Extitit tunc Bafilius nofter Reverendiffimo Epifcopo Auctor Suaforque, ut virum hunc Boravixwiraror, qui nunquam fatis laudando Principi jam notus effet, et primatum inter feculi Botanicos haberet, operi admoveret: verum perfuadere Principi non potuit, qui Beslerum viriderii Eyflädn. ten/is Patrem ac Patronum appellare dignabatur. Nil tamen hocim. pediebat, arctiffimam Cliffii cum Besleronecefitudinem, fed promovebat potius, ut in Belgium poftea a Curatoribus Academiae LugdunoBatavae evocatus Clufius, ubi latiffimum ftudii naturalis campum nactus, omnia paene Exotica cum Beslero communicaverit, Fafciculoque Rariorum Mufei, fundamenta jecerit. Clufii amicitia noftro Aucto. ri notitiam Archiatri Caefarei ftudiique Viennenfis Profefloris DN. Fobannis Aicholzii peperit, cujus convictor domefticus Viennae Clufins extiterat; cum hic effufifime ftudium amaret Botanicum, ut ex Pannonicis Clufii liquet, facillime nectebatur Beslero, et ex hac familiaritate factum, ut fuafore ipfolaudatiffim us Aicholzius Illuftriffino Noricorum Senatui aliquot florenorum millia ea conditione elocaverit, ut cenfus quotannis inde fluens inM edicinae Candidatos, quos Collegium Medicum Noribergenfe, cui curailla commifla, idoneos judicaverit, ad ifinera in exteras regiones aptius fufcipienda derivaretur; et quia ftipendium hoc C. florenis aureis conftitit, hinc ftipendii Aurei Aichol ziani nomen obtinuit. Nec apud exteros tantum volitabat per ora virum Beslerus, in patria quoque laus ejus celebrata a viris doctiffimis. Quid de Camerario Patre dicam, vero Noricorum Aefculapio Collegiique Medici Fundatore; et hic pariter cum Florae delitias reliquis ftudiis antepofuiffer, Beslerum hoc in ftadio decurrentem impenfe addmavit, quod et a Michaële Roetenbeccio Patre, naturalis ftudii 
optimo Mylta, ob ftudiorum paritatem factum. Ludovico Funger. manno, aft quanto Botanico! in concinnando Eyfädtenfi Horto ulum effe Beslerum, e Programmate Academico funebri retulit $\mathrm{Cl}$ Freherus in Theatr. pag. 138. cujus tamen Beslerus nufpiam meminit. Vniverfo autem Collegio Medico amiciffimum fuiffe, inde liquet, quod Decanus et Collegium commendatitias operi Eyftädtenfi praefigi curaverit, ut Besleriani indefe ffl laboris et patientiae aliquod exftaret cum Elogioteftimonium. Nec Medicis tantum laudatus Beslerus, fed ab aliis aevi fui doct:ffimis viris cultus; loco omnium eritillud Confultiflimi Georgii Remi, Patricii Auguftani et Reipublicae Noricae a Confilizs, Besleri fuffixum Iconi in Ayftadtienfi Horto:

BESLERVM Mlyptes BASILEION imagine pulcra

Quisquis es 0! Hojpes reddidit ecce tibi.

Nempe Viri vultus dedit heic atque ora tweri:

Cernere vis mentis dona fagacis? age,

HERBARVM magnum boc et PLANT ARVM Am-

$$
\text { phitheatrum }
$$

Infpice, quas dotes AREATINVS babet

Divitiasque HORTVS. Paradeifon dixeris ip fum:

Condiditimmortale boc BASILEIVS opus.

$\mathrm{Nec}$ Beslero mortuo ejus nominis gloria periit; viget adhuc illa, vigebitque ceu primae magnitudinis ftella, in Scholis Botanicorum obimmortale, quod luci publicae communicare geftit, opus. Firmat hoc maxime novum Plantarum genus, ab ejus nomine nomen ducens, $\mathrm{Fa}$ cta haec Plantae nominis impofitio feculo fere poft Besleriobitum, et, quod adhuc magis mireris, a Botanico Gallo, Reverendo nempe P.Carolo Plumier, Ordinis Minimorum in Provincia Franciae et apud Infulas Americanas Botanici Regii, in Tract. infcripto: Nova Plantarum Ame. ricanarum genera, impreff.Pariᄃ. 1703 . Eft autem Besleria Plantae genus flore monopetalo anomalo tubulato bilabiato aut perfonato. Ex ejus calice furgit piftillum, pofticae floris parti ad inftar clavi affixum, quod deinde abit in fructum mollem carnolum, ovatum, feminibusque foetum exiguis. Besleriae pecies funt : Besleria meliflae, tragi facie. Besleria virgae aureae foliis flore luteo, major et minor. Besleria fcandens criftata, fructu nigro. Perennabit fic in Planta Besleri memoria, ne viro de fludio Botanico optime merito apud feram pofteritatem laudes defint. Erat caeteroquin in Beslero noftro mira comitas, fumma morum temperies, tantaque modeftia, ut fummis aevi fui Botanicis comparandus, ftudiofititulum affectarit, ut ex ejus fepulcrali in Coemiterio D. Johannis n 2117. obvia Infcriptione apparet: Credo Refurredionem carnis. Bafilius Besler Noricus, artis Pharmacerticae Chymicae Amator fingularis, rei berbariae Studiofus. 1629 . Vna cuftodia Pie- 
tas. Vnicum reliquitfilium, quo absque liberis mortuo, vidua ejus Hen. rico Engellandio nupfit, ficque Besleriana haereditas ad virum integerrimum Joh. Chr. Engellandium, Amicum conjunctifimum devoluta eft, gui Tabulas Fafciculi aeneas publico ulterius invidere noluit, adeoque eas, ut recuderentur, benevole communicarit. De Nummo in Besleri memoriam culo alibi dicendi locus erit.

Reftat, ut de Viro Excellentiffimo, Medico quondam Vrbishujus celeberrimo, DN. Michä̈le Ruperto Beslero, quaedam memorem; cujus non integrum quidem Gazopbylacium, cum Tabulae aeneae nefcio quo fato perierint, fed quae a Viro Exc. DN.Valentini in Mufeo Mufeorum, lau. datiffimo certe opere, non referuntur, in Tabulas aencas conjecta, hilce Bafilii Besleri rarioribus juncta funt. Lucem haufit primam M. R. Beslerus hic Noribergae Anno 1607. Patre Hieronymo Beslero, primo in Collegium ab Illuftri Camerario tum erectum recepto Medico; Ma. tre Apollonia Buchneria ex antiqua nobilique familia oriunda. Cum Frater Bafilii eflet Hieronymus, tanta pariter in fudium Hiftoriae na. turalis ferebaturcupidine, ut vix parem aevum tulerit, ideoque factum, ut per 36 .integros annos $V i$ it tatoris Perpetui Pharmacopoliorum munere cum amplo falario annuo functus fit. Haufit has fudii naturalis delitias a Patre et Patruo a prima ftatim juventute Michaël Rupertus, quas, pofitis prius in Gymnafio Brandenburgico Heilbronnenfi fundamentis fudiorum humaniorum ac Philofophiae, in Italicas excuriens Academias, acrius in fectatus elt, et difcendi ardore virorum aevi et ftudii fui illufrium favorem promeruit perennem, quos omnes recenlere non erit hujus loci. Inter omnes tamen indulgentiffime illum amavic Mlarcus Aurelius Severinus Cratbigena Tarjienfis Medicus Pbilofophus acutisfimus, Regins in Auditorio Neapolitano Anatomiae et Chi. rurgiae primus Profeffor, idque univerfo literato orbi palam fecit, non tantum Trimembrem Chirurgiam, in qua Diaetetico-Chirurgica, Pharmaco - Chirurgica et Chymico-Chirurgica tradidit, (ut libri Titu. lus habet, ) fed et Tr. de Lapide Fungifero nomini Michä̈lis Ruperti Besleri infcribendo. Relictis tandem Athenis Italicis, huic Vrbi redditus, in Patria Academia exantlatis rite examinibus, habita. que prius de fanguine fecundum et praeter naturam difputatione inaugurali Anno $10_{3} 1$. fummos in Medica arte honores obtinuit, viventeque applaudinteque adhuc Parente, locum in Collegio Medico obtinuit fequente Anno, qui fitalis Parenti extitit, Anno quippe 1632. d. 22. Novembr. aetatis 66. defundto. Exhibuit ftatim Patriae, quas in exteris re. gionibus collegit ingenii opes, habitaque $A_{1} 16_{3} 3$. in Orphanotrophio viri ob fce!era decollati Anatome publica, dexteritate fecandi, demonftrandique peritia facundiaque fe omnibus probavit, quod ulterius Icriptis A natomicis luci publicae commiffis, quorum Titulus, Admirandae Fabricae bumanae Anulieris partiun, tam ante quam pof partum Generationi potiffmum infervientium, et Foetus bumani, delineatio I abulis 


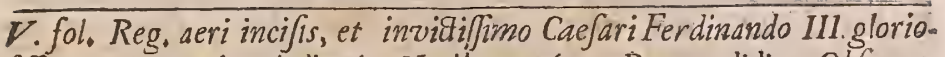
fiffimae Memoriae dedicatis, Noriberg. I 640. Porro edidit: Objervationem Anatomico-Medicam, Mulieris tres filios viventes naturalis magnitudinis enixae E'c. Éc. Anno 1644. Nec Anatomicis lolum vacavit, fedftudium rerum naturalium et Botanices huic pariter indefeffo fociavit labore, cujus teftes Viretum admirandum Norib.1646. cujus Tabulae aeneae partem dedere Gazophylacii rerum naturalium Anno 1642 . in Fol. impref]. et quidem $e$ regno vegetabili ; funtque potifimum Icones florum herbarumque tunc temporis pro rarioribus habitarum v.g. Ingular is Aconiti jpecies foliis Tanacetiex Alpibus Tridentinis cum floribus albicantibus, Gentiana infignis Alpina floribus aureis, Gentiana Alpina foribus punctatis nigricantibus flavejcentibus, Amarantbus Mexicanus cum Baccis rubris, Papaver pumofum foliis gramineis, Scabiofa latifolia Floribus fubrubris, Scabiofa Cretenfis arborefcens floribus albicantibus, et commatis hujus plura, proletaria nunc, Beslert tamen aevo infrequentia; quas Tabulasaeneas, pluresque adhuc alias, nifallor, Aultario Horti Ey/f̈̈dtenfis, quod vir folertiffimus meditabatur, deftina verat; fed morte praeventus haud, quod dolendum, abfolverat. Dubium tamen Libris an Liberis illuftrior Beslerus nofter, focminina praefertim progenie. Filia quippe Barbara, e prima Conjuge Nata Mulzia de Scboenfeld, in fundatiflimam non minus ac generofam familiam fponfa collocata eft, antiquae nempe nobilitatis meritisque adbuc illuftriori $D_{N}$. Joachimo Nuzelio, Judicii tunc Alfeflori, poltea Senatori Vrbis hujus et Prafidi Collegii Medici fplendidiffrmo, quae plena aetate et virtutibus adhucdum fuperftes, ex Generofiffimo Filio inclytae Reipublicae noftrae quoque Senatore fulgidiffimo (qui ut publico egregie promovendo diu fuperefle et perennare poffit, ex animo voveo) feros (pectabit nepotes. Altera e fecunda conjuge Foh. Rofae Arcbiatri quondam Palatini, poltea Ratisbcnen/is Medici feliciflimi Filia prognata Rebecca Barbaranomine, Collegii MiediciNoriciSeniori quondam primario, Brandenburgico Confiliario et Archiatro, illuftri $D_{N}$. Chriftophoro Theophilo Scheurelio a Däfersdorff elocata eft. Filius autem Joachimus Hieronymus, dum ftudio medico, avi patruique Patrisqueinfiftens veftiziis, operam dare cupit, infelici lapfu e fä. la: et vitam et Beslerorum extinxit familiam; cum jam ante triftia haec Filii unici fata, Parens Michäl Rupertus Beslerus ab aliquot annis cachexia fcorbutica, cum pedum tumentium exulceratione excruciatus, accedente tandem catharro fuffocativo, e vinculis corpo. ris tanquam e carcere ad fuperos evolarit. Sed haec de Auctoribus Rariorum Mufei Beslerorum, edendique caufis praefationis loco dicta Sufficiant.

Vnum adhue te volo, B. L., in Tab. IX. Fig. 8. depictam quidem effe avicularum fere minimam, non tamen deferiptam, "cum $x)(x$ Bea. 
Beatus Filius, me ejus defcriptionem occafione Ananafae cujus fuavitatem mire infectatur praepetum haec minutula, daturum fciret, id quod in commentationc de Ananafa five Nuce. pinea Indica, vulgo Pinhas dieta, factum. Generale Avicularum. nomen Gvinambi vel Gvainumbi; cum earum variae fpecies, (quippe Marggravius jam olim novem defcripfit, ) varia quoque obtinuerunt nomina, prout pariter varia eanm magnitudo, colo. rúmque diverfitas. Tantae enim earum fpecici certae eft corporis levitas, ut unum duntaxat Tomino Hifpanicum five XII, grana pendat, unde nomen ejus Tomineo fluxit. Nec mihor in capite pro fpecierum diverfitate varietas, earum enim illa, quae a Rochefortio et $B$ lumio Colybri dicitur, plumeam in fummitate capitis coronam gefat, quam in criltam pro hubitu erigere valet, quam folis illuftratam radis, pretiofiffimis lapidibus diftinctam et corulcantem, et oculos parvulos par adimantum, chalybi politiflimo cacrulefcenti infixum e Rocbefortii men. te quis judicet; noftra tamen avicula corona hac plumea deftitituitur. Rofellum eft fubrotundum, aequale, tenue er valde a cuminatum, rectum paululum tamen verlus extremitatem deorfum vergens. Lingua bifecta tenuifima inftar ferici fili tenuiffmi, quam extra roftellum longe exferit, ut florum melleum rorem extrahat et lambat, unde a Sinentibus Tunchonfung, e flore Tonchon quafi genita, Germanice Silumen: Spedt vocatur. Crura et pedes minimi brevesque, cum Ebeni ligni nigredine certantes, quatuor digitis inftuct: Alarum remigium lingulare prae cacteris avicularum habent, optime a ALarggravio defcriptum, hujus ope per fat longum temporis $\int p a t i u m$ in aëre ivelut quietae fe librant, mox tanta pernicitate fe movent, ut vifu percipi motus vix poffit, et alis carere videantur ; fonitum tamen inter volandum edunt apicularum bombifationi non diffmilem, Anglis hine Hum. mingbird dictae. Maxima Avicularum harum venuftas fplendorque in plumulis capitis, colli Juperioris, dorfi totius et alarum initiis, quarum admiranda varietas nomen Ouriffae five radiorum Solis, Gvarigcobae et Gvaracaiba capillorum Solis peperit. Illam quam tabula noftra ex. hibet, vivis quaf coloribus depinxit difertifimus P. Biffelins: Pennularum nitor, lcribit, verficolor lucet, fic ut finaragdinum virorem /plen. dor Sapbirinus, purpuram vero luseus aurei fulgor provocet. Denique quicquid oculus trabit colorum, id omme Jupra Pavonum ac Iridis, (Adnirationis fliae a veteribus didae) varietatem, in illo Volucris breviario natura mi/cet, miftumque denuo Jecernit, baud ineleganti compofitae venufatis difcordia. Piftorum tormentum invidiamque d:xeris, aut profecto manus Apelleae folers compendium. Hinc factam . elt, quod a Plarygionibus admodum experantur plumulae hae verficolores, ut aureis intertexant ftaminibus ; et licet mors aviculae plurimum plumularum venuftati detrahat, a foeminis tamen loso inaurium 
geftantur, cum pretioliffimis certantium. Ambram Mofchumque redolere has aviculas, Rochefortius fcribit. Nidulos e tenuifimis Ananafae Pita dictae fibris filamentisque conficit, ac Xylifloccis plumulise que lericum ipfum fuperantibus implet, quibus ovula albiffima, margaritas majores aequantia, foemella imponit. Quae Cl. Pifo de avicularum harum generatione et transmutatione ex Erucis Brafilienfibus Lagartas dos Vergos Lufitanis dictis habet, ejusdem veritatis elt, acillud allertum, has aviculas hyeme morifcu potius obdormifcere, verevero revivifcere; unde Antillarem Infulis renatae dicuntur; cum tamen diligentiffimus Marggravius has aviculas magno numero in fylvis per totum annum obfervaverit. Strepitum cicadarum fufurro aemulum, non cantum edunt, qui Gomanbuchae avicularum harum fpeciei convenit. Cinis hujus Aviculae, Reccho Hoitzitzlin dictae, epilepfiae mederi dicitur. Surinamenfis Sacrificuli in gulae oblectamentum expetunt, hoc avicularum minutias. Hoftem expcriuntur acerrimum, arenearum genus maximum, Nhamdli Gvacu diclum, quodillis infidiatur non tantum, dum in Nidulo ovulis incubant, fed et cum floribus, infident, ubi ungulis arreptas jugulat. Cum vero de lltupendo hoc DEI ludere geft tent is in rebus minimis opificio, abunde egerim loco fupra citato, Ichediafma illud ut confulas haud gravatim, LECTOR BENEVOLE, praetẹreaque fphal. mata, fi qua irrepferunt, pro Tua humanitate emendes, enixe rogo, contendo, TEque valere jubeo.

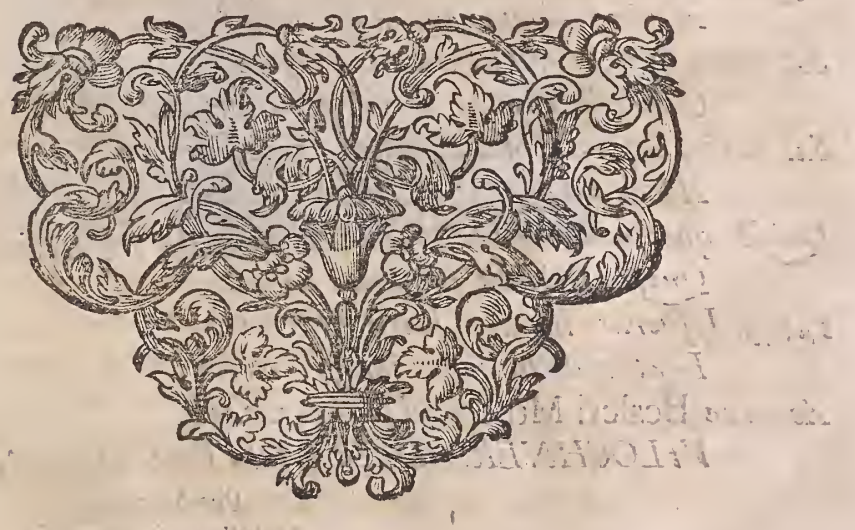


Vam fallax bominum jpes fit, quam vita caduca,

Locbnerus Juvenum flosque decusque docet.

Quid non Jperandum Patriae! Solertia magna,

ingenium, ftidium forna perampladabant.

Sed praecox fatum fubito Jperm disfipet omnem,

corpus et exanimum terra aliena tegat,

non obiit totus, vivit poft funera virtus,

Lochneri in Scripto boc vita perennis erit.

His demulcere illuftris DN. Patris ex optimi

Filii obitu conceptum dolorem ftuduit

LVCAS SCHROECKIVS, M. D.

Archiater et Comes Pal. Caefar. Nobilis, Acad.

Caef: Leop. Carol. Nar. Cur. Praefes, Rcip. Augurt.

Phyf. primarius.

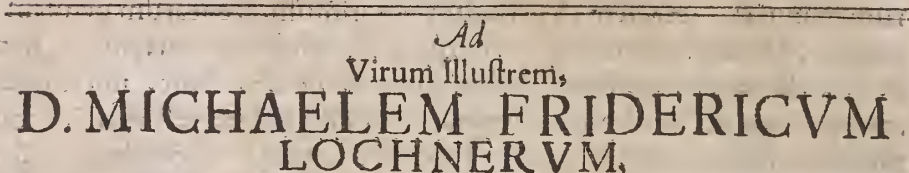

cunt Filio defideratiffimo, Eidemque unico, Monumentum, quod vivus fibi Iple parare coeperat, aere perennius exigeret。

D $V$ dolor et Nati TIBI mors praecordia pafcunt,

Gaudia qui quondam deliciaeque Tuae:

Quisnon follicito certat, VIR 'SV $M M E$, labori

Auxilia alloquio dulcia ferre pio?

Sat vixit, dicunt, artes cui doctus Apollo

Cum Medicis Latias Cecropiasque dedit.

Sat vixit, Superis comes, additus. Ecce futuram

Ad vitam gradus eft exitus alterius.

Quid? quod non moritur, laudis monumenta fuperfes

Quifibi jpectata fedulitate parat.

'untuxov Isfuerat movocio:. Rara juventus!

Figatur doctos inter imago, meret,

As nova Besleri Mufeo ad limina vitae

VILOGHNERIADEN Mufa Paterna vocet.

Piis Manibus

Nobilisfimi Juvenis

JO. HENRICI LOCHNERI, Medicinae Candidati digniffimi, fui quondam Awditoris perindufrisi, parentativrus fortbebat.

Erhardus Reufchius. 


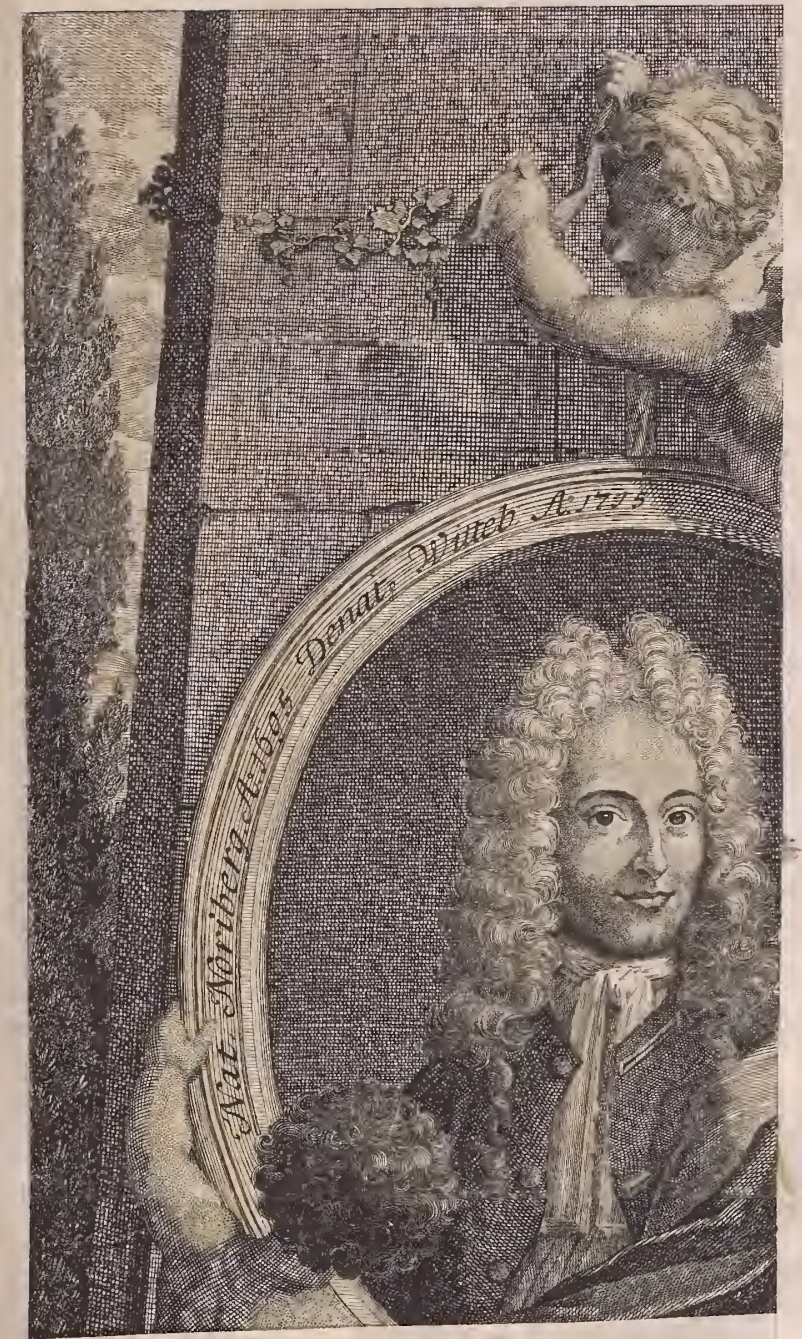





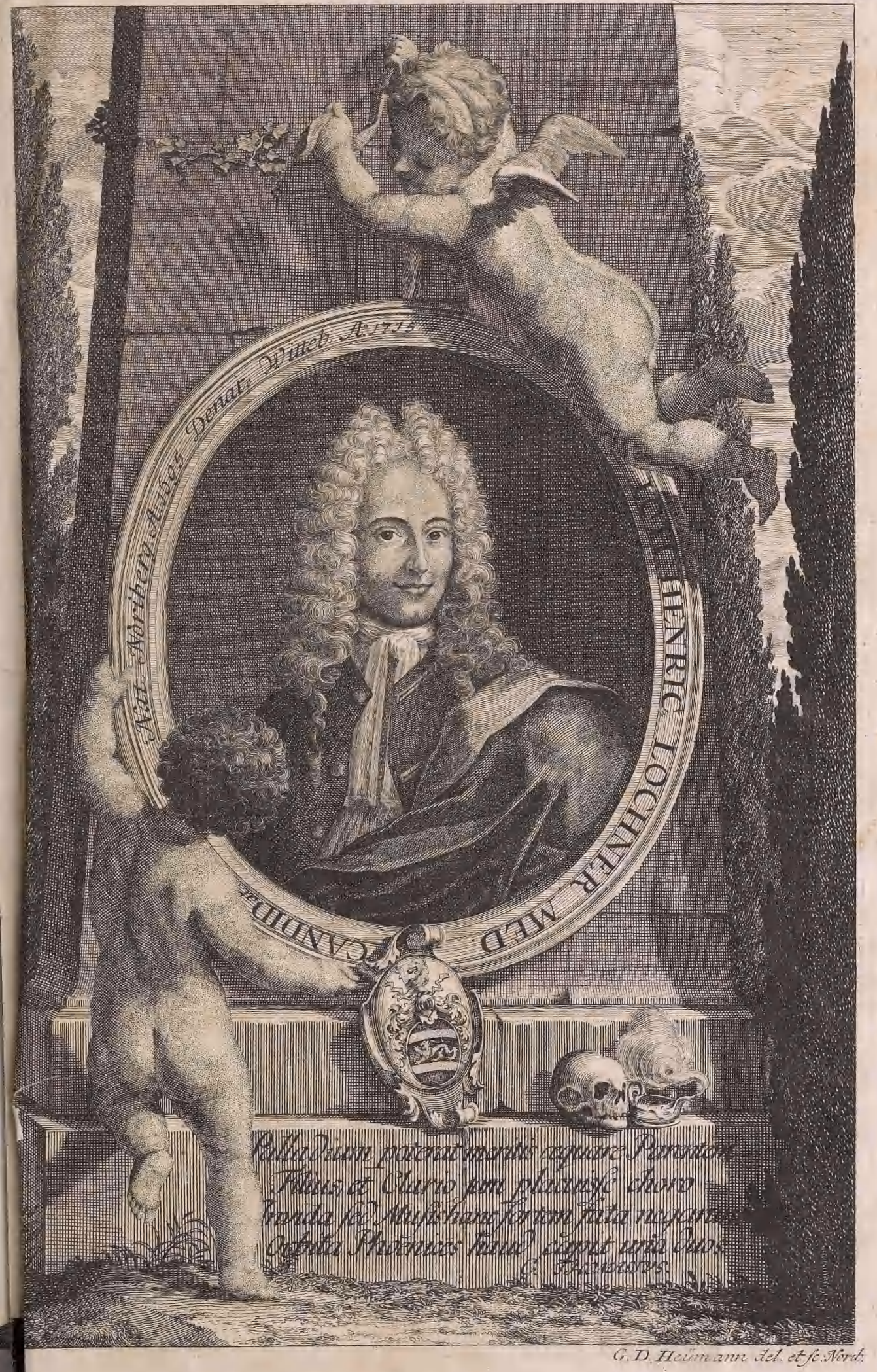





\section{LAVDATIO FVNEBRIS,}

IN SPLENDIDIS EXEQUIIS FVVENIS NOBILISSIMI,

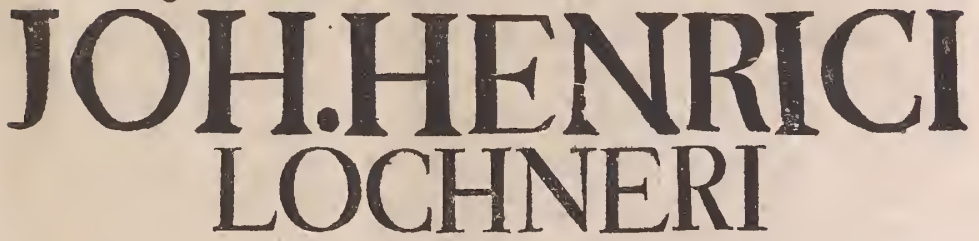

$\mathrm{DE}$

\section{HVMMELSTEIN,}

MEDICINAE CANDIDATI DIGNISSIMI,

\section{VIR I}

ILLVSIRIS EXCELLENTISSIMIQUE

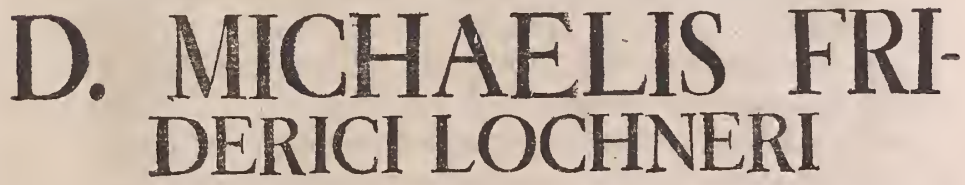

DE

HVMMELSTEIN,

SACRAE CAESAREAE MAJESTATIS AR. CHIATRI EJVSQUE PERSONAE IMPERIALIS MEDICI, S.R. I. NOBIIIS, COMITIS PALATINI, ACADEMIAE LEOPOLDINO-CAROLINAE NATVRAE CVRIOSORVM EPHE-

MERIDVM DIRECTORIS, COLLEGII MEDICI NORIBERGENSIS SENIORIS,

FILII VNICI ET DESIDERATISSIMI,

Vitembergae $I V . N o n . J a n . c I o l s c c X V$, pie placideqne extincti, coram

Magna Patrum ac Civium Academicorum

frequentia

ex memoria recitavit

M. Christ. STEPHANVS KaZAVERVS;

Heroldsberga Noricus, Ord. Phil. Affeffor. 


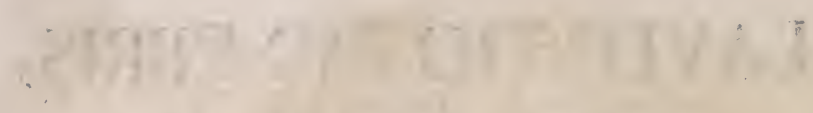
271

$158^{3}$
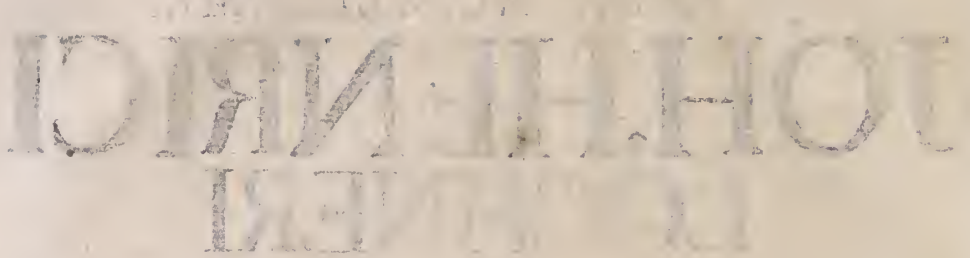

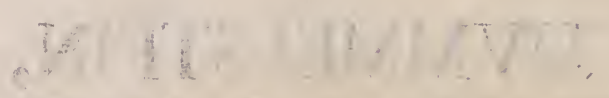

Digugh Th hot M \& $2: 1+1-1-$

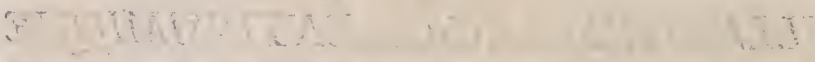

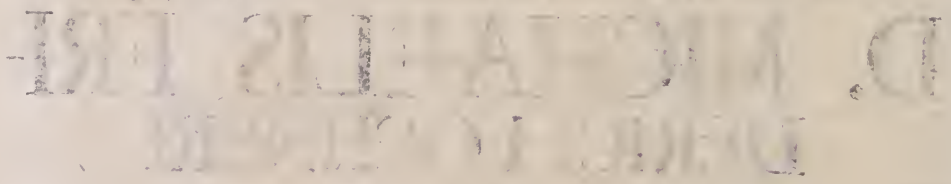

\section{WH W MMLTH}

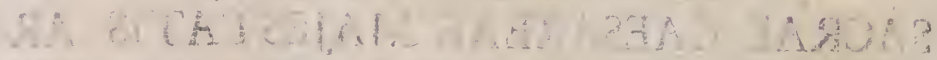

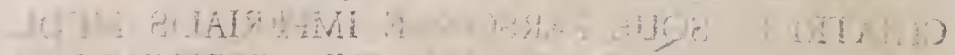

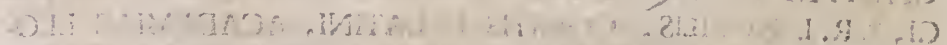

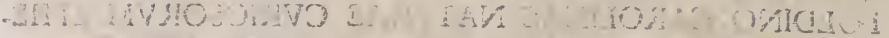

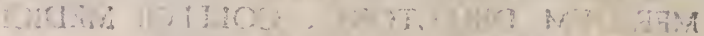

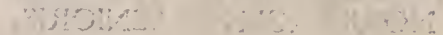

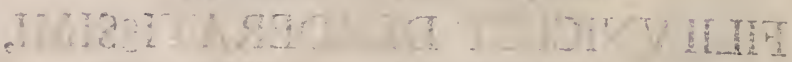

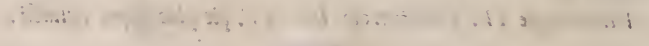

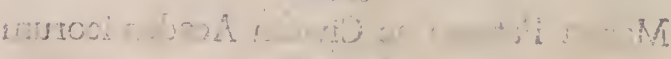
. $1=\sin ^{2}$

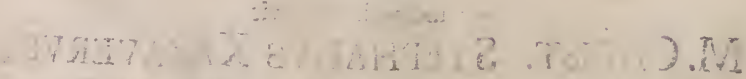

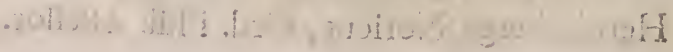




\section{PRORECTORACADEMIAE MAGNIFICE,}

PATRES CONSCRIPTI, VIRI SVMME REVERENDI, CONSVLTISSIMI EXPERIENTISSIMI, AMPLISSIMI, PRAECELLENTISSIMIQUE, ET VOS RELIQUI ORDINVM OMNIVM HONORATISSIMI EXEQUIATORES!

(7) . . hidicendi effet facultas, confiderem utique, quas (G) - In praefenti partes fufcepi, aliquo faltem modo a and me peragi poffe. Nunc, cum animus adhuc dolore fit occupatus, quem ex obitu nec opinato Nobiliffimi Juvenis JOHANNIS HENRICI LOCHNERI, patria Norici, falutaris Artis Candidati digniffimi, folutis jam exequiarum juftis rite humandi, jure concepi, equidem nefcio, magishe temeritas mea fit culpanda, qui ad hoc laudationis funebris munus animum induxerim, quam commendanda pietas, qui illud ipfum non detrectarim.' 'Minime enim putavi faciendum, ut officium, quantumvis lacrymarum ac moeroris plenum, ab aliis paterer occupari, quippe quod mihi neceffitudo et amici et civis multo quidem conjunctiffimi vindicare videbatur et imperare. Atque hocipfum tamen munus, quo mihi libentius imponi finebam, eo vehementius angebar, animique pendebam, unde orationem reperirem, quae univerfae Defuncti vitae, quam pro more hic retexere debeo, par effet, et nunc demum intelligebam, verum effe illudSapientis Romani: Antritit diffcilins effe, quam magno dolori paria verba invenire. Hac dum premebar folicitudine, forte fortuna fub afpectum meum venit nummus, quem, nifi fallor, anno fuperioris feculi nonagefimo, Divus Comes Leosteinensis, Evcharivs Casimirvs, nefcio, qua occafione, cudendum curavit. Refert is uno latere ipfum Comitem llluftriffimum, averfo autem arborem, in quam Vir quidam fecurim ftringit, cum hac infcriptione, DUM SCINDOR, FR ANGOR.' Mequidem latet, quid fibi hoc nummo voluerit Divus; nithilo minus quotidiana, quod in illo nobis ob oculos ponitur, experientia docet. Quemadmodum enim nihil tam praeclarum, vel ab arte, vel a natura 
producitur, quod non cum vita hominis comparari poffit, ita in arboribus potiffimum reperiuntur, quae plus fatis vitae mortalium refpondent. Arbor tam ditu fuccrefcens atque efflorefcens, quamdiu non fit expofita violentis manibus, aut rempeftatibus turbulentis, interdum praeter omnem agricoJae opinionem ab hifce invaditur hoftibus, fuorumque fpem et expectationem fructuum eludit. Pari modo homines incrementum et confervationem vitae fuae ab Autore Naturae benigne conceffae fibi femper pollicentur, at quam fruftra laepe fpem in ea ponimus aetate, quae propter vigorem atque alacritatem procul abeffe a morte vulgc exiftiniatur. Certe Nofter vix limen attigerat juventutis, cum decedendum ipfi de vita fuit.

Quodfi hunc luctuofifimum cafum Symbolo aliquo delineare deberem, in fimilitudine quidem arborum facile manerem, pace tamen aliorum paullo mutarem figuram nummi, poneremque ftirpem arboris, ex qua prodirent duo rami, quorum unus altero brevior nonnihil atque imbecilior effet. Hunc manus e coelo demiffa arriperet, atque a ftirpe fua revelleret, quo ipfo fimul alter ramus denfior una cum fipite ita inclinaretur, ut vel penitus frangatur, vel ab interitu quam proxime abfit, his infcriptis verbis, DUM SCINDOR, FR ANGOR. Erat Nofter unicus ac minime degener.llluftris fui Parentis filius, neque aliter quam ramus a generofa ftirpe divellitur, cum quo, fi non nominis et familiae, ftirpis tamen ac lineae virilis occidunt infignia et ornamenta. Quod eo facilius ad Defunctum me accommodare poffe, cenfeo, quo propius ille ad fimilitudinem arboris acceffit. Sunt omnino, funt, ut in generofis arboribus, fic in praeftantibus familiis femina quaedam, quae propagantur ad pofteros, et tempertiya cura aluntur utique, et ramos longe lateque emittunt. De Lochnero noftro, ex illuftri Lochnerorum virtutibus ac meritis apud nos florentifimorum ftirpe fato, me vel tacente, optima quaeque promittere Vobis potentis, Exequiatores omnium Ordinum Honoratiffmi, co praefertim Genitore, qui non folum nobilitate generis, fed etiam, quod caput eft gloriae, fingulari femper eruditione, virtute, fide, gravitate, auctoritate, confpicuus fuit. Eftille, prout optime noftis, Virllluftris Excellentiffimusque MICHAEL FRIDERICUS LOCHNERUS, Sacrae Caefareae Majeftatis Archiater Ejusque Perfonae Imperialis Medicus, Sacri Romani Imperii Nobilis, Comes Palatinus, Academiae Naturac 


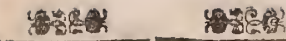

Curioforum Ephemeridum Director, Collegii Medici Notim bergenfis Senior graviffmus, Vir decus omne laudis com. plexus. Sialias non fpernendae funt maternae neceffitudines, fed dignitatem natis conciliant, et cultum elegantiamque faepe in filios propagant, certe Defuncti noftri Mater non praetereunda erit, Matrona Nobiliffima ANNA MARIA, ex infigni Vierzigmannorum gente prognata, Matrona omnibus, quae vel regendae familiae vel educandae foboli expediunt, dotibus exornata, meamque laudaturi facultatem longe multumque fupergreffa. Hi tanti Parentes Johannem hunc fuum anno praeteriti feculi quinto et nonagefimo, quarto Nonarum Septembris coelefti munere fufceperunt, ipfumque facro fonte initiatum omni cura, quae pios Parentes decet, fovendum putarunt.

Quaedam arbores in pretio habentur ideo, quod nobilioribus in hortis provenerunt, licet ipfa nonnunquam rura aliquid minus vulgare largiantur, et inter raftra faepe adoleverint animae magnae. Non reprehenderim tamen Simonidem, qui inter ceteras felicitatis humanae partes illuftrem Patriam quoque numeravit, neque non putaverin gratulandum Nóftro, qui percelebrem ac libertate Imperii donatam Noricorum civitatem natalem habuit et altricem. Manat quidem a Deo, tanquam demiffus ab fole radius, vis animi divinior, quae nos virtutis et magnarum artium capaces reddit; fed ut emicet illa et adolefcat quafi, roburque ac vires accipiat, fomentis etiam externis indiget, neque excitanda folum exemplis egregis eft, fed moderanda dif́ciplinis quoque praeclaris. Quarum rerum ut non ubique copia fuppetit, ita illuftribus civitatibus vix unquam deert. Noribergae itaque, illuftri illa Imperii civitate, cum lucem ac fpiritum haufffet Nofter, quae nunquam non Viris magnis et omni laude excellentibus aut incunabula praebuit aut domum; quid mirum, fil litterarum honeftiffinarumque artium amorem vel mature induit animo, vel indole ipfa ftatim oftendit. Quam praeclara haec fuerit, vel inde agnofcere licet; quod, cum Patruus Ejus, $\mathrm{Ve}^{-}$ nerandus nunc Paftor Heroldsbergenfis, quibusdam Academiae Candidatis initia linguae fandtae panderet, hic puer decennisfi non promtius ac felicius, certe aeque facile dikta arriperet, verborumque fenfum erueret, quam illi ipfi, quibus eadem tradebantur. Proin hoc adolefcentis naturale bonum velut arborem teneram Parens Illuftris flectendam excolendamque dedit peculiaribus, eaque de cauffa largo ftipendio 
conductis hortulanis, Praeceptoribus inquam, quorum unus coelo jam receptus eft, alii coetibus Chriftianorum, Scholae alii,etiam nunc magna cum laude praefunt. Inter eos, qui, HENRICI noftri animum literis, linguis ac philofophia im-, buerunt, non poffum non commemorare binos, quos et ego, quoad vivam, perfancte colam, Praeceptores, quibus etiam. multa fe debere, faepe multumque non fine gratae mentis argumento folebat profiteri Defunctus. Primus eft Johannes, Henr Icvs MüLleRvs, in celeberrima Patriae Academia hodie Mathematum et Philofophiae Naturalis Profeffor Publicus, cujus infigniain Academiam et rem litterariam merita teftibus haud:ullis egent; quippe a quo amorem erga Mathefeos facra concepit, altum poftea a Cl. DopPELMAXERO, Profeffore Norico, quem curiora Naturae arcana explicantem vicetertia audivit. Müllerum adiAcademiam evocatum fequebatur Erhardvs Revschivs, Liberalium Artium Magifter, et Poëta Laureatus.Caefareus, cujus pariter luculenta ingenii divini monimenta extant, qui defun\&to praecipue in literis tam la. tinis quam graecis lumen praetulit,ut inoffenfo gradu ad tantam metam contendere poffet, quippe in hifce Duce nominato adeo profecit, ut difficiliora loca e Scholiaftis Euripidis, Nicandri aliorumque promte interpretaretur ac latina civitate donaret.

Inter alias fingulares dotes, quas rerum naturalium Interpretes in defcribendis arboribus recenfent, non funt poftremae, quod quaedam arbores non facile crefcant, nifi adhuc tenerae exalio in alium transferantur locum, radis folas ribus optime foveantur, humore item conveniente irrigentur, unde etiam ad fluminum ripas optime fuccrefcant. Haud $a b$ fimili modo a Parente Sapientiffimo Lochnerus, cum nomen Academiae Patriae paullo ante dediffet, in hanc felicem ad Albim fitam Mufarum fedem eft dimiffus. Meditabatur nempe tunc temporis Vir Hluftris Godofredvs THOMasivs iter in Saxoniam. Rogavititaque Noftri Parens Optimus fingularis amicitiae et muneris vinculo fibi conjunctum, ut filio unico Vitembergae quafi viam pararet, ducemque eligeret, cujus, et hofpitio et conviatu et ductu Juvenis uti poffet. Hoc facto, Lochnerusnofter ante fpatium annuum et trimeftre defiderii fui portum tenere coepit;noftramq; Vitembergam f́pe optima plenus falutavit. Quo.fimulatque pervenit, itatim, qua fingulari erat difcendi cupiditate, ducem fibi delegit exoptatiffimum, eumque ipfius llluftris Parentis judicio probatum, $\mathrm{ADA}$ Müs 
MUM BRENDELIVM, Boctorem ac Profefforem in Academia Noftrate Medicum, cujus do\&rina exquifita et peritia in arte medendi pereximia meam dicentis infantiam excedunt. Huic publice privatimque adhaefit, hujus ex ore pependit, hoc privatos intra parietes continenter eft ufus. Eodem fuafore, fuaque ipfius animi inductione adire geftit Saxoniae Hippocratem, Hlluftrem Archiatrum BERGERvm, cujus nomen, doctrinam, merita ne trans mare quidem ignorari fentiebat. Ab hoc tam avide omnia, quae ad artis medicae decus pertinebant, in illo difciplinarum, quas docebat, orbe haufit, ut incredibilem quandam fitim fuam reftinguere nunquam. fatis poffe videretur.

Vt autem de arborum bonitate boni fructus teftantur,arborumque nonnullaemelquoque, mane fummo creduntur exfudare, fic Juvenis optimus primo jam aetatis flore apis inStar melleum aliquid colligebat. Non jam dicam de fpecimine, quod domi jam paraverat, cum Schedialma hiftoricum de Foffato Magno, quo Carolus Magnus in agro Norico tentaverat conjunctionem Rheni et Danubii, ope Almionae et Regnefi fingulari confriberet diligentia. Neque alia conamina nunc, quorum plura moliebatur, commemorabo. lllud folum fpecimen fufficiat citaffe, quod dedit in fchedis, quas, non fine omine faufto de Apio Veterum pro inaugurali Differtatione reliquit, cxjus berhae, ut ipfis Noftii verbis utar, ozmibus notae, cuncto telluri amicae atgre cognitzze, olimqque et a Diis ett ab hominibus bonoratax virthites, el quicquid de ipja cognitu dignum reperiri pofete, ex antiquitate ernere, ex gemmis, nummis, fatuis et marmoribus illyftrare moliebatur. Liceat mihi teften pulcherrimi hujus aliorumque conatuum appeltare Brendelium, peridoneum Defundti ftudiorum exiftimatorem. Hoc cnim potiffimum Doctore eoque domertico Nofter, dum viveret, ufus eft, ipfumque ingenii, judicii ac morum fuavitatibus fic fibi conciliavit, ut ab eo velut in deliciis haberi videresur. Nullum laudis genus eft, quo Lochnerum fuum minus dignum judicaret Excellentiffinus ille Vir, faffus ultro, inexpectatum Juvenis clariffimi chariffimique cafum fibi peracerbum effe. Neque alias Nofter litteras hic negligebat, maxime humaniores illas, in his praecipue graecas, quibus $M e$ dicum carere haudquaquam poffe, jam pridem ab Optimo Parente fuerat edoaus. Hinc in quo domi jam elaboraverat, in eo nunc totus erat occupatus, ut Poëtrias Graecas, quas olim Fulvius Vrfinus collegerat, nova verfione notisque confpedui Eruditorum exponeret. Cum autem praeter alias 
animi dotes, in quibus naturam fautricem nactus erat, memoria quoque valeret, hiftoria delectabatur mirum in modum, figillatim naturali et literaria. Hujus cognofcendae amorem jam inde ab adolefcentia confirmarat Bibliotheca paterna, felectifimorum in omni genere librorum apparatu inftructifima. Illius excolendac tanto flagrabat ardore, ut port largos epularum miffus, queis ingenii formatores Eundem pafcebant, haec I fe laborum veluti condimenta avide appeteret. Vix ullus extabit Hiftoriae Naturalis auctor rarior, quem affidua is lecrione fibi non familiarem reddiderit. Quidquid ab orbe extremo novum vidit Europa, latere ipfum non poterat. Et gaudio exfultabat, fiquid tale Noribergae vel in horto celeberrimoJohannis Georgil Volcameri, Excellentisfimi Noricorum Botanici, Amici paterni conjunctiffimi, vel in officinis pharmacevticis, praecipue peritorum Engellandi et Dieterici, oculis contueri liceret. Teftis erit Mufeum Beslerianum, cujus rariora a Parente olim defcripta in fchedis invenerat. "In quas cum incidiffet, facile ab Eodem impetravit, ut digereret iftas orbi erudito exponendas. Cum vero abcundum ipfi effet in Academias, patriae redditus hunc labo. rem maturo magis judicio perficere ftatuerat, quem nunc moeftiffimo Parenti proferendum relinquit. Denique neque illud hic praeternittendum cenfeo, tantumabeffe, ut Viten)bergae, fingularis ille impetus, quo olim ferebatur in eas difciplinas, quae in pulvere verfantur, deferbuerit, ut potius ad illas intimius pernofendas, Magnificum Doctorem KLAvSINGIVM, Venerandum Hofpitem meum adierit, Praecellentiflimi etiam Weidleri opera in iisdem adjutus.

Praeclara atque eximia funt, quae hactenus de Lochnero noftro praedicavi;modica tamen prae illis, quae nunc effent, commemoranda. Quanta enim modeftià, quanta comitas, quis incorruptus candor in eo fuerit, nemo quisquam corum, quibus ille cognitus fuerit, infitias ibit. Quis porro in dictis ejus aut factis, in geftibus moribusve affectatum quicquam, aut firtum arte deprehendit unquam ac notavit? Intemerata cuncta, fine fuco, fine fallaciis omnia erant. Hinc adulatores, homines vanos,futiles atque otiofos ab fe repellebat, confuetudine ipforum adeo non deleckatus, ut ne aures quidem his praeberet. Quid dicam, quo incredibili amore, quanta pietate ac reverentia Parentes fuos Nofter fit complexus? Quam vere mihi videor poffe contendere, poenitere $\mathrm{Pa}$ trem nunquam potuiffe hunc a fe filitrm effe genitum, $\mathrm{Ma}$ - 
tremque veras gaudendi caufas habuiffe, tam nobile pignus conceptum $a b f e, a c$ in lucem editum fuiffe. Parentum enim animos nunquam offendit, nifi hoc uno, quod turbato mortalitatis ordine, naturae debitum praemature nimis perfolvit. Hinc illae lacrymae, hinc tot genitus et querelae, hinc, verba fefe negant Parentes comminifi poffe, quibus vel hujus atrocitatem vel exquifitiffimi doloris fui fenfum explicare fatis poffint.

Vix dum arbor fuccrefcit et integra eft, praeter omnem fpem oritur ventus, molemq; profternit, nec modo faftigium, fed fundamentum quoque evellit. Perinde ut firpes ita homines opinione citius affligit tempeftas et opprimit, nec juveni et innocenti aetati parcit, atque eo gravius afficit et perturbat. Non meliora fata Lochnerus Nofter habuit. Dum enim laeta omnia Parentes de illo cum novi anni aufpicio augurantur, dum maxima quaeque expectant, eum nihil tale opinantem invafit pridie Calendas Januarias vehemens ardor, qui ipfum adeo reddidit debilem atque exhaufit, ut maximo fefe morbo, quem Epinyctin feu papularum Medici vocant, tentari, ipfemet facile praevideret. Neque fua ipfum opinio fefellit, cum fecundo die variolae fe confpiciendas praeberent. Excellentiffimus Hofpes omni ratione remediisque amovendo malo aut infringendae faltim vehementiae morbi multo periculofiffimi omnem mature dedit operam, et accedente mox vehementi fanguinis eruptione, in confilii auxiliique focietatem afcivit Aefculapium Saxoniae, Magnum Socerum fuum, qui nec ipfe quicquam omifit, quodad reprimendum morbi impetum conducere videretur. Sed tanta illius rabies erat, tantus effervefcentis fanguinis aefus, ut omnem generofiffimorum alias remediorum vim praefentiffimam eluderet: atque adeo hac ratione demonftraret, ne in optimi quidem Medici arte femper effe fitum, ut aeger convalefcat. Quod ipfum aegrotus cum fentiret, de pretiofo contra graviffimam animi labem atque noxam antidoto potius profpiciendum fibi effe arbitrabatur, Venerandum ideo Urbis hujus Ecclefiaften $M$. Wolffium accerfendum curavit, ea ipfa quidem nocte, quae fatalis ei fuit. Hic eum, folo nixum Servatore Suo, atque a ReverendoReifmanno Ordinario Confeffionario contra mortis et inferorum terrores jam praemunitum, epulo facro tanquam certiflmo coeleftis itineris viatico recreavit. Quo quidem pignore reconciliatae cum Deo gratiae accepto, dum VirPerrevendus commutationem extremam veluti praefagiens; oratione $0-$ mnis divini folatii plena, animam, coelo, cuinatus exat,com- 
mendallet, fatalis ille terminus, unicuique mortalium femel praefcriptus, appropinquavit, et Lochnertis nofter inter cantilenas facras, Eodem, quèm dixi, Interprete divino, Excellentiffimo item Hofpite, me praeterea et alio Cive, quem in contubernium defunctus receperat, praefentibus, pie placideque obdormivit, annum aetatis nonum et decimum vix egreflus. Sic exemplo etiam fuo docuit, praecocia, atque ob fingularem inveniendi et affequendi folertiam admiranda ingenia plerumque non effe diuturna, celeriterque emori, perinde, ac fi natura ita ftatuiffet, ut inufitatae uberrimaeque dotes ftatim velut flores effunderentur, qui perpulchri et optimi interdum opinione citius decerpuntur, et vix fe explicantes, languidi compreffique jacent, nec fine faftidio afpiciuntur.

Meum nunc effet, ut Vobis, Exequiatores Omnium Ordinum Honoratiffimi, ob oculos ponerem irreparabilem jacturam, quam Illuftres Parentes ob chariffimi fili obitum fecerunt, ut Amicorum, quibus Lochneri venuftas, fides atque integritas, auro quovis pretiofior erat, defiderium indicarem. Sed in exaggerando hoc malo quis immorari diutius, quis recens vulnus exafperare aufit et adaugere?

Fuit,fuit,Lochnerus arbori fimilis pretiofae, quam prudens horti praefectus in extrudtas eo confilio cellas recondit, ut a tempefatum vi et contumelia fit immunis. Haud aliter Deus, nobile illud gentis fuae germen, ex terreftri hoc horto, plantarumarborumque noxiarum pleno, ex hac impetuofiffimae tempeftatis hyeme, in hortum coeleftem ac femper virentem transportavit, ubi Servatori fuo dulciffimo conjun tus in ejus amplexibus vulneribusq; pafcit tantifper, quoadVer illud perpetuum, vera, inquam, finceraque veris aeterni gaudia Ipfi cum omnibus piis intueri licebit, quo tempore ineffabili cum exultatione, comitante omni civium coeleftium choro charisfimis Parentibus fuis reftituetur. Quibus nunc non ultimi loco folatii erit, audire Filii Johannis fui funus tam frequenti fplendidoque Exequiatorum comitatu, tamque prolixe hic celebratum fuiffe, ejus inquam Filii, quem nifi tantopere vivum curae cordique habuiffetis, mortuum vix ac ne vix quidem tali modo profequendum judicaretis. Quare et me, jusferunt, fuoVobis nomine gratias agere et habere tantas, quantas infignis Veftra Humanitas, in honore fupremo Defuncti noftrimanibus praeftando abunde perfpedta, promeretur, addita vicisfim fponfione, omni tempore et occafione, maxime tamen laetiori, officio Vobis ftudioque fue, nunquam, nunquam, defuturos effe. 


\section{ODE \\ FVNEBRIS}

I N

OBITVM

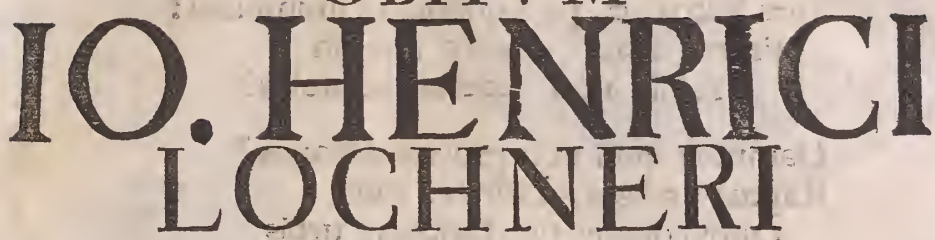

:NORIMBER GENSIS

CANDIDATI MEDICINAE

IVVENIS

ANTIQVITATE GENERIS

ET

BONARVM LITERARVM STVDIIS

C LARISS I M I

D I V I

BENE MERENTI

$F$

ADAMVS BRENDEL, D. P. P

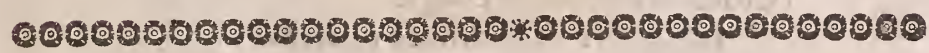

(3.) Agax recludit Phafias Aefonis

in Mucrone diftricto iugulum, nouis

(19) Et fracta, profufo cruore,

Membra replet, recreatque, fuccis.

Queis intus actis, en! polita, comae Viuum colorem, canitie, bibunt,

Supplentur adiectoque rugae

Corpore, luxuriantque uires.

Quin pulfa deformis macies fugit,

Et pallor exanguis, putris et fitus:

Miratur Aefon, feque denos

Hunc meminit quater ante foles. 
O! Colchis, umbris excita, furgeret, Hauftumque LOCHNERVM nece pallida

Nouaret: $\mathrm{O}$ ! fuccos rigentes Poeonii recreent liquores.

Sed, D Iv E, quo Te proripis, unica Spes.Patris, et pars quondam animi mei?

Promiffa non moefto Parenti Talia, non dederasque nobis?

Damnofa quid non proruis Atropos? Raptus malignis uariolis, cadit Luftro quater uix functus, urbis

Noridis, Euphrofinesque, alumnus.

Deo uacabat dedita mens, bonis Et literis. O! quanta fcientia Artis falutaris tenacem Finxerat ingenii uigorem.

Quicquid Pelafgum, Mufa Quiritium Quicquid, repoftum condiderat libris, LOCHNER V S infixum tenebat Pectore, palladiaque lingua.

Heu! fata, quot, quot compulit horrida Virga fatus Maia tenui gregi

Ciues, acerbos et coegit

Leucorin ingeminare queftus.

Aeuum fed anguftum hoc habet anxiac Vitae, diu quum uiuere nitimur,

- Decumbimus, morbis fubacti,

Mox ftygias fubeamus undas.

Aft non redit iam fanguis imagini, $\mathrm{Nec}$ fas: locatus fiderea domo,

Deum canit, terrena ridet,

Atque, malis uacuus, triumphat.

Hinc Offa ducto molliter aggere

Cubate, dum quondam addimur aetheri.

LOCHNERA gens mox furgat, acta

Per titulos, memoresque faftos. 


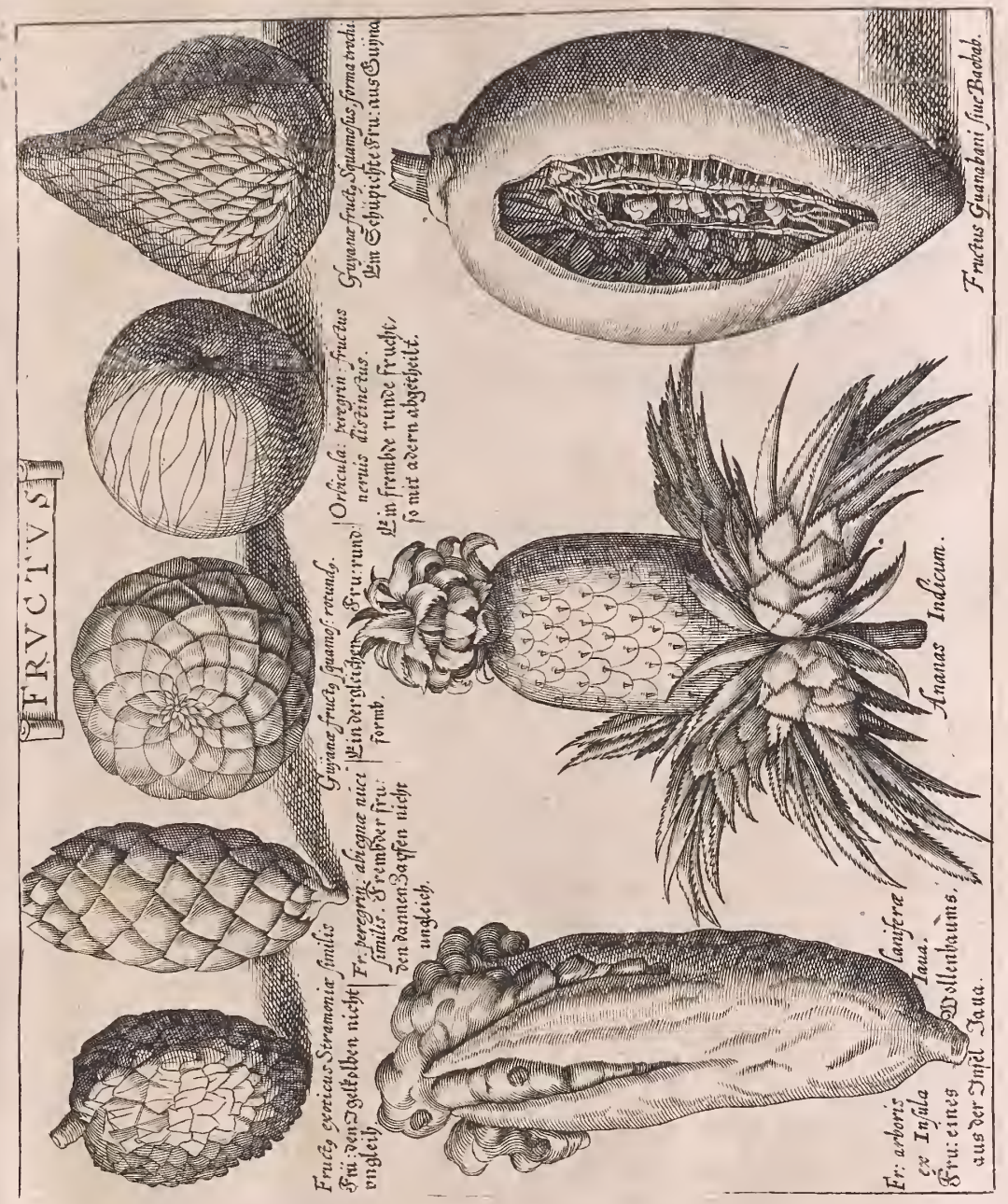




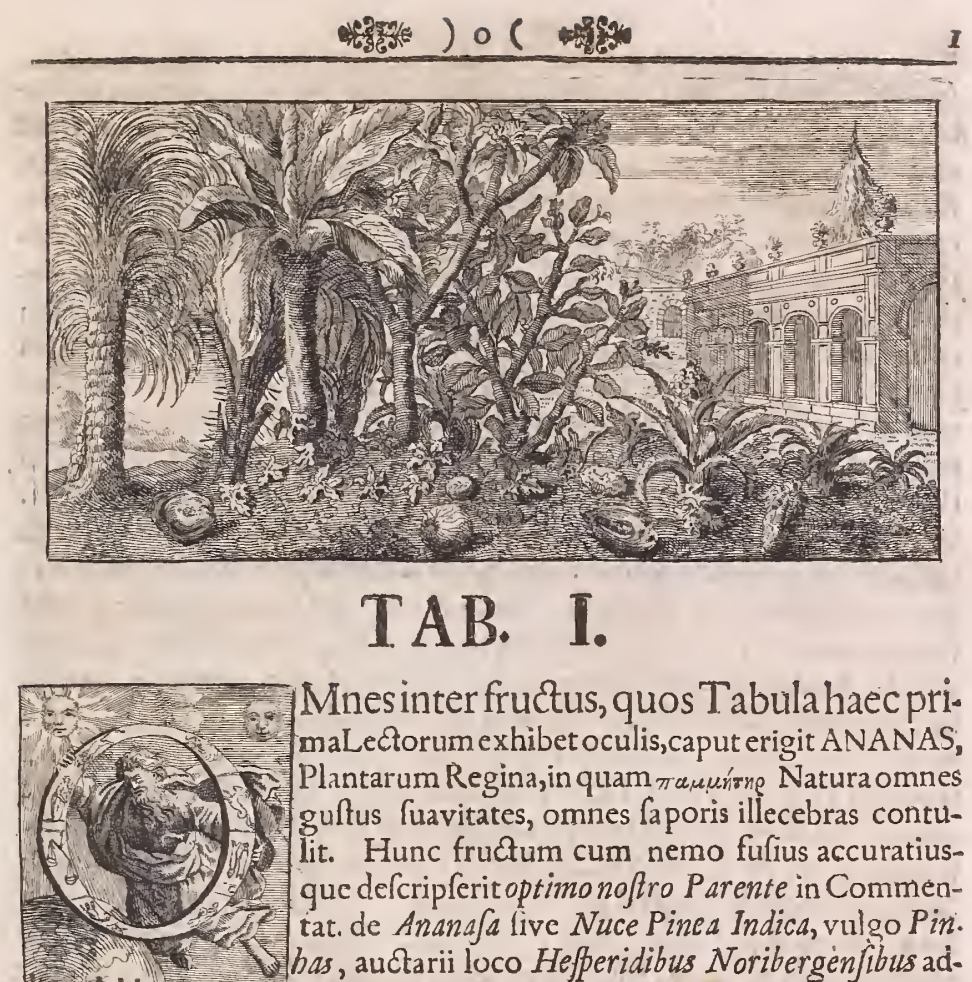

Mnesinter fructus, quos Tabula haec primaLectorum exhibet oculis, caput erigit ANANAS, Plantarum Regina, in quam тании́rne Natura omnes guftus fuavitates, omnes faporis illecebras contulit. Hunc fructum cum nemo fufius accuratiusque defcripferit optimo noftro Parente in Commentat. de Ananafa five Nuce Pinea Indica, vulgo Pin. al:a, delibare ex ea nonnulla licebit. Americam hăec Planta agnofcit patriam, et quidem in illa Novi orbis parte Brafiliam, quamvis. Mexicanae et Haytanenfes Ananafae quoque praeftantiflimae, ac in Antillarum Infulis, Famaica, Francia Aequinoțiali, Cajenne et Gvajanenfi tractu laete propullulent. Apud omnes tamen Hiftoriae naturalis fcriptores in confeffo eft, e Brafilienfi et quidem St. Crucis Provincia in Orientalen Indicam transplantatam fuifle hancPlantam, fucceflu equidem adeo felici, utBrafilienfes fructus proceritate et deliciis faporis paene vicant. Sic in Fava imajori, Malabar, Sinenfi Imperio, Siamen $f$, , Bengalenfi, Ceylonen $f i$ regnis, maxima Ananalarum jam copia. Nec $A$ frica hoc pariter vacat fructu;e Gvinea enim ante feculum Belgium accepit, et Horto in Capite bonae Spei dicto,a Belgis ad munimentum inibi exftructo, e Batavia intulit Amplifimus Senator Cleyerus. Nec ab aliis Africae Infulis Mafcurenibas five Borbonia,St. Mauritii \&c. \&c. extorres hodiefunt. Ante aliquotluftra Europae Germaniaeque tandem noftrae illatae, ut in Illuftriff. L. B. de Munnichbaufen, Magnae BritanniacRegis Eleitorisque Hannoverani Conflilet Thejaur arii Horto Srwebbertiano aliquot centenae Ananafarum laete in invidiam Brafilienfium progerminent, et nunc vegetam quoque, vigentem et floridam in horto Noribergenfi domeftico Excell. Dn. D. Volkameri intueri licuerit, quam Saccharo incrultatam in Besleriano 
apudoptimum Virum Dn, Engellandium Muleo nuncobviam, et in Tabula hac depictam admiratus fum. A diverfitate Regionum fructus hic varias obtinuit denominationes : nec enim Ananas, Ananafa, Ananafes, Nana et Nanana apudomnes audit, fed a primis Brafiliae incolis $P$ anacous et Hoyriri vocabatur, Sinenfibus Vnglay et Fan-polo-mie, Siamenfibus Saparot, Malabarenfibus Kapa Tfiaka, Mexicanis Mazatli. Oviedus tria impofuit nomina, Yayama, Boniama et Fajagva, quibus totidem defignantur fructus hujus fpecies. Sunt autem Ananafae vel veraevel jpuriae. Et verae inter fe differunt fructuum figura vel ovata, vel conica majore et minore, vel fapore magis et minus acri, vel foliorum colore et figura, vel Aculeorum fitu et frequentia, colore et ablentia; vel corona denique, in quo diademate herbaceo regiae fubolis futurae primordia, plantaeque efatifcente morienteque genetrice revivilcentis, rudimenta delitefcunt, a plaftica terrae vi temporis fucceflu evolvenda et eruerenda; qua corona fylveftres Ananafae deftituuntur. Ad has referendae Kaidae fpecies, item Nana brava Acoltae, Marggravii, non aculeata Pita five Metle, Kerbita fpecies Karagvatae, Cbicariri, er Nana Pacoba; de quibus omnibus dilectiflimus Parens in modo laudata commentatione fufe egit, accuratamque totius Plantae Anatomen addidit, e qua, quod fructum in Tabula noftra expreffum concernit, mutuofumimus. Eft autem frudus nofter in aere depictus, Ananaf a frudu iu maximo conico, fic diAa, quod ad fimilitudinem Sacchari in conicam figuram, Gallis Pain de Sucre, noftratibus Bucterbut/ effigiata fit. "Strobil formis Pini Italici fructum refert, cinarae inftar, ad quod Plantarum genus a plurimis Botanicis refertur, foliis futurorum forum operculis eleganti fpecie confructis, circumftantibus. Putamine hoc fructum quafi obfidentefracto, nucletus pulpaque maturi fructus prodit. Caro ex albicante, (provarietate tamen fructus) flavefcit, fucculenta, Saporis prae caeteris fructibus gratifimi, acido dulcis et vinofi. In fructus meditullio fylus feu corculum eft oblongum, rotundum, duriufculum, ex albo flavefcens, carne fubdura, quae lignofis intus eft pertexta fibris. Credit dilectiff. Parens, ftylum hunc per fructus longitudinem ad coronam foliaceam usque pertingentem, nil aliud quam caudicis caulisque prolongationem e variis fibrarum fafciculis compaginatam, ubi mox triplex filtularum lignearum collectio, geminos trachearum ordines intercipit et ambit, mox gemini trachearum fafciculi unicum fibrarum acervum amplexantur et urgent, ceu e fructu per longitudinem difecto patefcit, In fructu autem transverfim incifo, oblongae et radiofae ftriae apparent, e corculo fiveftylo medio fructus egredientes et ad corticem excurrentes, quarum caro magis fucculenta et flavefcens; continet enim pulpa Ananafae fibrarum reticulares plexus, una cum contentis tracheis, et globulisfive nodis acido dulcem five vinofum fuccum continentibus firmatur; areae vero utriculis lympham affervantibus perbelle replentur, atque hiin meditullium hiant, veluti in corde accidit, carneis lacertis et fibris valvulas in. 
ibi firmantibus. Haec fructus ftructura, omnes faporum oddorumg̨ue fuavitates continens, ut vere nominare Ananafam queamus

Fructum fructibus omnibus priorem,

Qui funt, qui fuerant, erunt, priorem,

Nanam fructibus eminentiorem,

Quantum Junt teneris cedri Jalictis.

Plura qui de ejus Cultura, propagatione, viribus medicis, praeparand modo, Vino inde confecto, noxisque ex intemperato ufu nolle cupit, confulat modo citatam Parentis Commentationem.

Junctus Ananafae FRVCTVS GVANABANI five BAABAB ALPINI, Anonam agnofcens matrem, et quidem maximam, foliis latis fplendentibus, fructu maximo conoide, tuberculis feu fpinulis innocentibus afpero fecundum Excell, Sloane inCatal,Plantar. Famaic,p+2 ${ }_{4}$. Eft autem fructus fecundum Cl. Wormium in Muf. lib.2,c.2 8.p. $2 \mathrm{O}_{4}$ magnitudinis mali citrei mediocris, denfo duroque corice ut cucurbita veftitus, nullis . excurrentibus fulcis, extrema ejus parte mucronata qua arbori adbaefit, pediculo craffo et firmo, fulcorum rudimenta cernuntur, in quibus lanugo quaedam est, quemadmodum in malis cydonits reliquo corpore laevis. Altera extremitas in noftra figura in conum quoque, in Wormiana in obtufam definit rotunditatem, colore fufco. Pulpam continet fubrubram, friabilem, quae facile in pollinem refolvitur acidam, ori gratam, per quam fparfa funt femina, renibus animalium fimilia, du ro cortice, qui rubente quadam materia tegitur. Interna frudura in Auctoris noftri. figura quoque expreffa, ideoque ab Excell. Grem. in Muf.Societat. Reg.: Anglic. P. II. cap. 3. p. 195. his verbis commendata: BESLER HATH A GVOD FIGVRE HEROF, REPRESENTAY IT CVT OPEN, TO SHEWVTHE SEEDS. Confer, quoque Cluf. Exot. Libr.II, cap, 1. p. m. 21. feqq. Cl.Legatum in Muf.Copian. L.2.c.25+p. m.137. Mufeum Calceol. fub nomine fructus Kabub.p. 598. Mur, Mofcard, Libr, III. cap. 167. Varias Gvanabani fpecies recenfet R, P. Plumier de novis Plantarum generibus $\mathrm{p} \cdot 4^{2}$, Rev.P. Bonanni in Muf,Kircher. Cl. VII. $n_{*}, \mathrm{O}$. p. 240 .

FRVCTVS ARBORIS LANIFERAE EX INSVLA JAVA, CEIBA five Cerba, a Brachmanis Valli Sanvari, a Malabarenfibus Moul-elevau dicitur. Arbor ipfa procera eft et admiranda altitudine. quinquaginta, craffitie octodecim pedum menfuram haud raro fuperans. Panjaefive Arboris Lanigerae fpeciesin Horto Malab, T. III. Tab. LI, defcriptae efle videtur, et fructus quoque Panjae, fructibus his plane fimiles oblongo-rotundi, intus in quinque loculamenta, alba ac nitente lanugine ceu golfypio referta, divifi, intra quam lanuginem, dehifcente demum fructu, obfervantur femina numerofa, rotunda, glabra nitentia, non tamen triplici, ut in Panja, led duplici ordine locata. Plura vid. in Hort. Malab. T. III. Tab. 52, Excell. Plukenetius in Phytograph. Tab. 89. Fig. 2, Iconifmum exhibet noftro perfimilem, magis tamen apertum, ergolly pina veliera in majus fpatium diffundenten, quem fru- 
ctum ab infigni Botanico Dn. Gvilelm: Courtene dono accepit, arboremque definit: Xylon five GolJypium orientale, foliis digitatis per marginem crenatis, fructu quinquecapfulari conoide lanugine leucophaea refer$t a$; quae lanugo propter brevitatem carminari non poteft, neque lintea inde confici, Sed ledulis et pulvinaribus conficiendis infervit. Cavendum tamen, ne lana haec flammam, vel minimam fcintillam excipiat; nam ignis zenaciter inhaerendo late ferpit, nec aqua reftingui valet. Vid, Bontius Hift, nat, et medic, Libr.6, c, 14, p. 105. Muy. Worm. p. 205. Cluf. Exot, 1. I, c. 12, Muf. Soc, Reg. Angl,pag. 19 s. feqq. Nifi omnia me fallunt, haec Arbor quoque in Gvinea crefcit, et a Cl, Bofmanno in delcriptione Gvineae p. 307. delineatur. Confer et Chabraettm Sciagr, Stirp.p. 26.

FRVCTVS EXOTICVS STRAMMONIAE SIMILIS, quam arborem matrem agnofcat, ignoramus; idem certe fructus eft ac ille a Fob. Ba ubin. T. I. libr. III, defcriptus Strammoniae modo tuberculis obf $b$ tus: vel fruituovali ex fueco fubrufefcens, tuberculis mucronatis obfitus C. Baubin, in Pinac. p. 406. Cl. Sloane hunc fructum faepifime collegit in Infulae Jamaicae littus ejectum, cum aliis marinis recrementis. Annon frudus echinatus fecundus Chabraei Stirp. Sciagr.p. 21.

FRVCTVS PEREGRINVS ABIEGNAE NVCI SIMILIS ille cft, quem omnium optime defcripfit Clufius Exot. libr. II. c. 3. forma nempe Cylindroide, multis fquamis imbricummodo dippofitis conftans, in medio nonnibil compreffis oris tenuioribus et quodammodo villojis, inftar abiegni frobili, fedbrevior, colore jpadiceo gravis et nucem vel nucleum continet. Qualis arbor hujus fructus, et Cl. Clufum latet, credit tamen vir Botaviratare plurimum accedere ad $P$ almampinum a Lobelio defcriptam; vel exmente Ill. Gren in Muf. Soc. Reg. P. 200, ad Palmann coniferam. In Curis pofterioribus Clufius ramum undecim fructibus his gravidum recenfet, ubi infimul figuram ab Ill. Fabricio de Peirefce melius delineatam exhibet. Annon Pecotl Muf. Worm.p.204. feqq.

GVA |ANAE FR VCTVM SQVAMOSVM ROTVNDVM Aucto. ris noftri ex Anonae fpecie quadam originem trahere vix a mbigo, determinare tamenillam non audeo. Chufii defcriptio accuratiffima, quamexhibet Exot.1. 2. c. 3. p. 25. Fuglandem, externum illum viridem corticem adbuc retinentem crafjitudine fuperat, orbicularis paene figurae, magis tamen depreffae, et quafi in umbilicum fidentis fuprema et ima par. te (inter quas trium fere unciarum eft interftitium) et paene fex unciarum ambitu; conflat vero veluti fquamis eleganti ferie in obliquum dijpofitis, ab extimoverfus petiolum tendentibus, illisque quodammodo $\int e-$ gis et lacunam babentibus per longitudinem; fquamulae autem petiolo proximae furfum vergere nonnibil videntur. Nucis color plendens et padiceus, eaque nucleum continet; nam commota et agitata ftrepitum edit, valde tamen levis est proejus craffitudine. Videtur hunc fruchum quoque $\mathrm{Cl}$. Olearius in Mufeo Gottdorff. Tab. XIX. fig. 3. defripliffe, cr Chabraeus Sciagr. Stirp. p. 2 1. fub nomine Nucis Indicae te fellatae. 


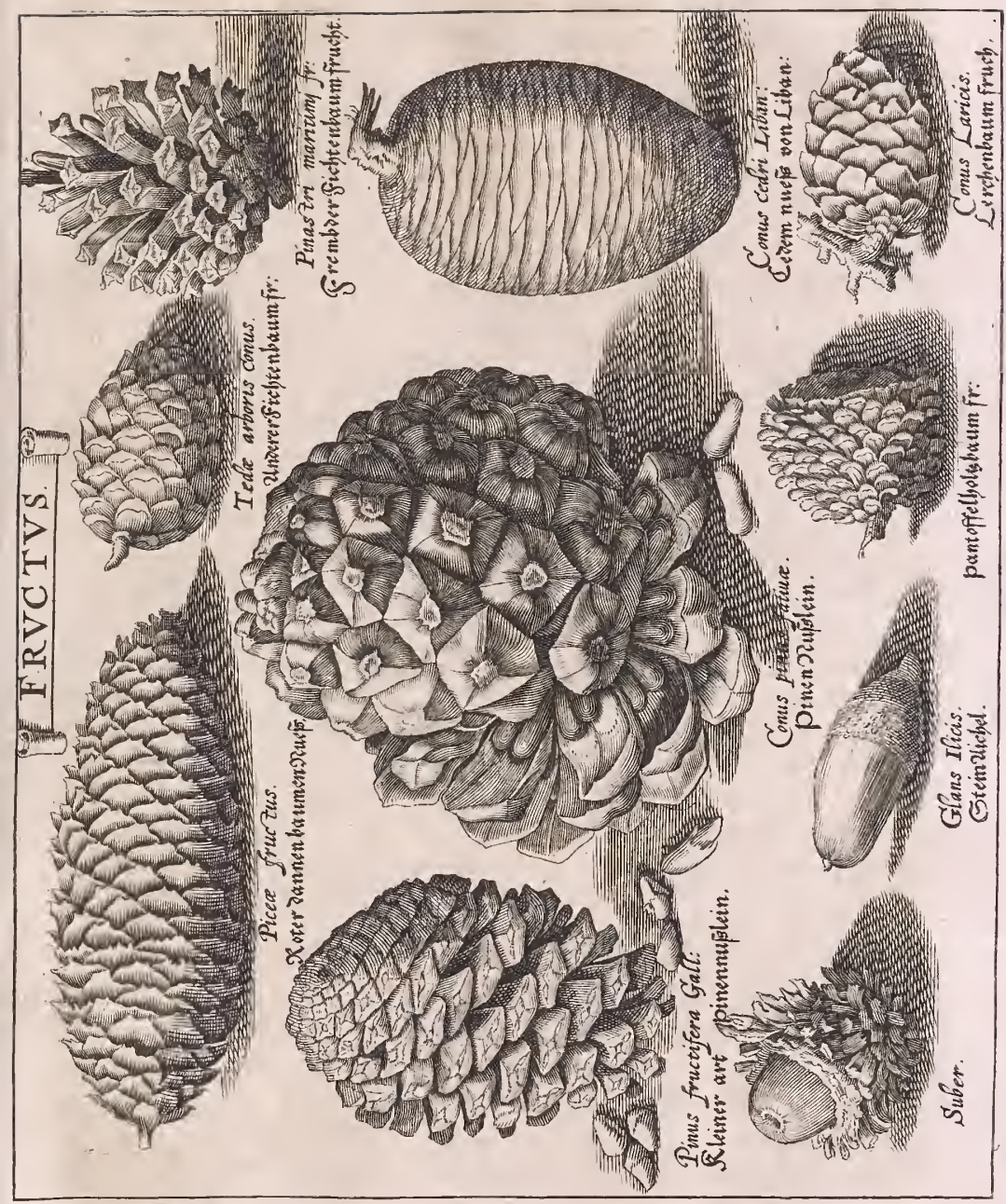




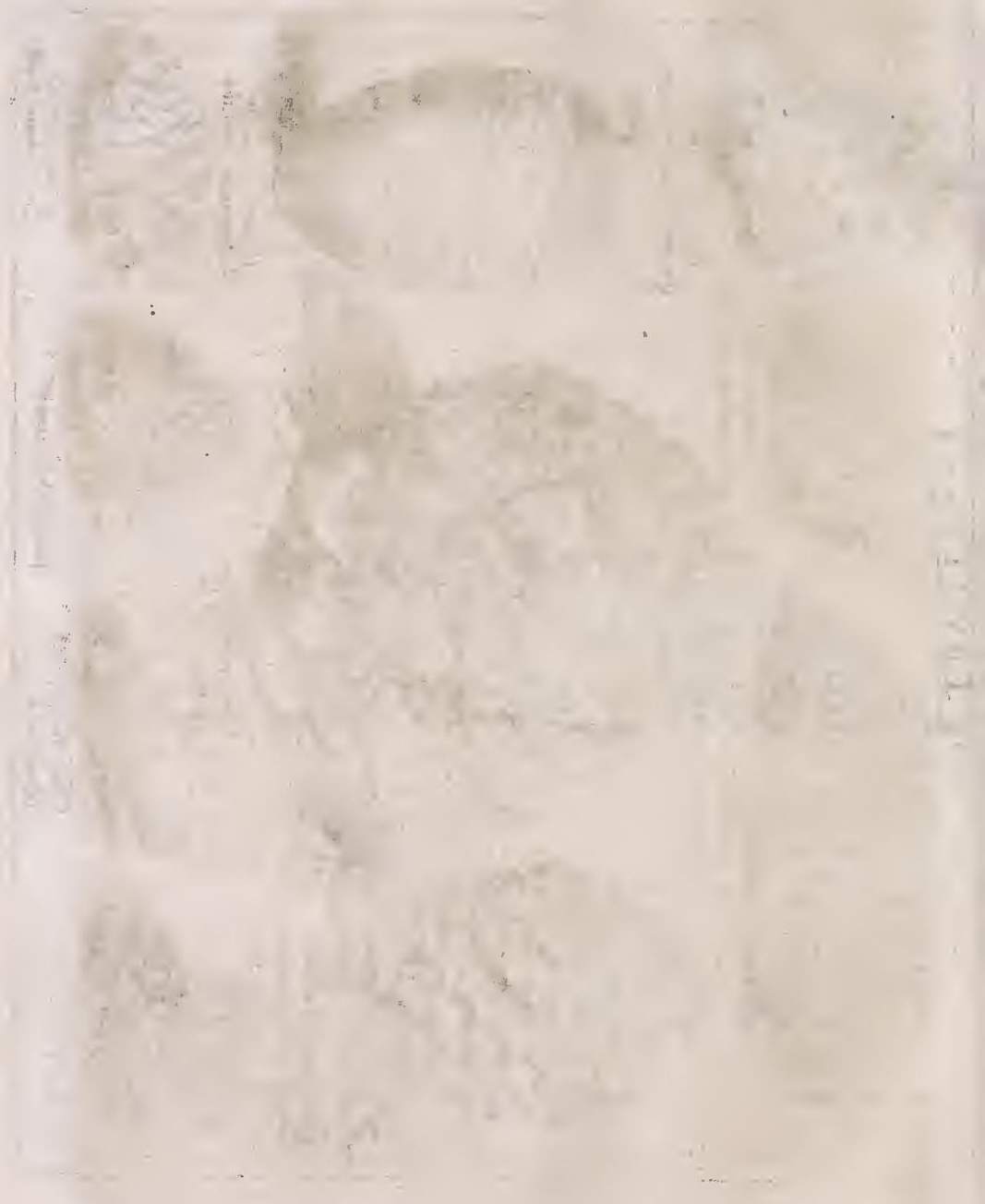


ORBICVLA PEREGRINA, FRVCTVS PEREGRINVS NERVIS DISTINCTVS, confimilis videtur illi fructui, quem Clufus Exot. 1. 2.c 9. fig. 2, exhibuit, orbicularem, qui pulvinato aliquo integumento inclufus fuiffe vifus, conjectura facta e tibrarum, quibus putamen praeditum fuerat, veftigiis impreffis. Vel certe pertinet adillos, nervis difinctos peregrinos fruct us, quos cap. X. fequenti defcripfit.

GVAJANAE FRVCTVSSQVAMOSVS FORMA TROCHI, eft ex Arbore Anona foliis odoratis minoribus, fructu conoide fquamofo dulci violaceo, fecundum $\mathrm{Cl}$. Hermannum in Catal. Plantar, fruatu purpureo eft in Ejusd. Paradif. Batav. Illuftr. Rajus fructum viridem conoidem pronuntiat; Excell. Plukenetius autem Phytograph. Tab. 13 4. Fig. 3. fruldum e viridi et luteo cortice qquamato apero, nucleis nigricantibus parvis, (cui nofter perfimilis) delineat. In Hort. M11lab.T.III. p. 2I. fub nomine Ata-maram defcribitur fruials five Conus, qui maturus magnitudinem babet citri vulgaris, exterius viridis ac flria. tus, interius vero albicans, nec non medulla jucculent a faporis grati, adoris que fuavis refertus. Sed ut verum fatear, nimium quantum Figurae Iconifmus a noftro difcrepar. Peromnia autem noltro aequalem exhibet Clufius, e Baly Infula Javae vicina delatum fructum, cujus accuratam addere delcriptionem confultum duxi : „Suprema parte eft anguftior ${ }^{\text {t8 }}$ et velut in metam definens, ut quodammodo ficus aut Pyri formam " aemuletur; afpero tectus eft cortice, et ab infima parte furfum verfus " denfis ordinibus, veluti fquamularum fibi mutuo incumbentium orna. ${ }^{*}$ to, quae fejungi nequeunt, fed cum integro ordine non valde denfosis eximi poffunt, flavefcentis coloris, dum recens ex conditura exem. " rus, deinde fubfurci. Continet pulpam albam, odoratam, inftar py- 'c ri formatam, fapore acrem, continentem in medio officulum folidum '? in metam affurgentem. "Plura vid. apud citat. Clufium.

\section{TAB. II.}

COnis glandibusque dives haec Tabula exhibet primo PICEAE FRVCTVM, five Conum Abietis marinae a Bauhino et Bellonio fufe defcriptae; in Alpibus Burgundicis et Bosphoro Thracico paffim obviae. Meminit hujus Beslerianae piceae Illuftr. Grew in Mufeo Societ, Reg, Anglic, P. II, cap. V.p. 212. fubnomine $A$ cone of the Male Firr, optimeque fculptam enle praedicat curiosly pitur'd by Besler; nec mirum, cum ubique in fylvis noftris abundet, perennetque.

TEDAE ARBORIS CONVS fructus eft Pinaftri five Pinus fylveftris Hifpanicae majoris Clufii, quae ab Anglis Hortulanis, teite Ex. cell. Plukenetio, de mountaine Pine dicitur. Vid, quoque Matthiol. in Diofcorid. p.10o. Paffim in fylvis Noricis laete progerminat.

CONVS PINVS SATIVAE C. B.P. proles arboris Coniferae five fructus fquamofos et ficcos, polylpermos in coni feu metae for- 
mam plerunque turbinatos habentis, foliis longioribus, binis ex eadem theca leu tubulo prodeuntibus; nuclei funt oblongi candidi inclufi, (mediante tunica rutila,) officulis craffis et duris fquamato cono difpofitis, faporis fubdulcis impinguantis, qui cum in omnibus officinis abunde proftent, fatius duxi de his filere quam proletaria proferre. Strobili Pini magnae proceritatis habentur, e quorum numeroet nofter hinc Martialis L. XIII, Epigr.

$$
\begin{aligned}
& \text { Poma fumus Cybeles; procul binc difcede, Viator, } \\
& \text { Ne cadat in mijerum noftra ruina caput. }
\end{aligned}
$$

CONVS PINVS FRVCTIFERAE GALLORVM, fativae quo. que pinus trobilus, qui a priori non nifi magnitudine differt, hinc nuclei e pinu hac prodeuntes les petits pignons dicuntur Gallis.

CONVS CEDRI LIBANI, fructus arboris a Bellonio et Lobelio uberrime defcriptae et delineatae; coniferae nempe foliis perpetuis anguftis agminatim in tuberculos five penicillos velut congeftis, conis magnis furfum fpectantibus, ut Excell. Rajo placet, Olearius in Mufeo Gotdorff. figuram coni hujus cedrini exhibet a Fratre Ja-. cobi Golii, Linguae Arabicac Vindicis, in Libano monte degente ipfi transmiff, fed ab Iconismo Besleriano nonnihil difcrepat, cum alias optime figurae inter fe conveniant, ut ovum vix ovo fimilius, Hunc Auctoris Cedri conum ceu exactum extollit Excell. Nebem. Grew in Muf. Soc, Reg. P. II. p+212. (in mbich Besler is more exä,) qui curiofa de proceritate arboris hujus adduxit. Coni hi femper in caelos fpectant, ramufculorum extremitatific agglutinati, ut decerpi nequeant, nifi ramufculi particula una evellatur. Vid. Muf. Septal.Terzagip. 67. ct Scarabell.p.1 34. Aluf. Worm. p. 195. Mlattbiol, in Diolcorid. I 22. Muf. Molcard. Libr.III, cap. 87. p. 251.

SVBER vel potius GLANS SVBERIS arboris glandiferae apudanti-

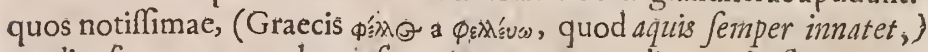
caudicofae parumque hamofae, procerae tamen, ligno robufto, cortice uno craffo, disrumpique folito, folio fraxini craffo, oblongiori et deciduo, fructu glandofo Agriae fimili, calice autem proxime ad illum accedens, quem ab Anglis ex Windecan allatum $\mathrm{Cl}$. Clufius defcripfit, et a V'irginiae Hiftoriae fcriptoribus Mangunnaukappellatur. Vid. pariter Matthiol. in Diofcorid. p. 180. Excell. Valentini Muf. Mul. T. I. p. 257 . et prae omnibus Pomet l'Hiftoire generale de Drogu. T. I. Libr. IV, cap. 9. p. 136.

GLANS ILICIS MAJORIS Arboris foliis perpetuis aculeatis cocciglandiferae, quae in Hifpania, tefte Cluf. rar.Stirp. Hifl. libr.I. c. 5. Carafca nuncupatur, cujus glandibus inibi in fecundis menfis pro caflaneis ve: fcuntur, quibus etiam haec noftra accenfenda. Differt tamen haec llicis glandiferae in proceras arbores adolefcentis fpecies ab Ilice coccigera Monfpelienfium, quae exilitate difcrepat, et quod Coccos Kermes di. ctos non glandes ferat ab Hifpanis Cafcoja, a Gallis Arbres de la Grain 


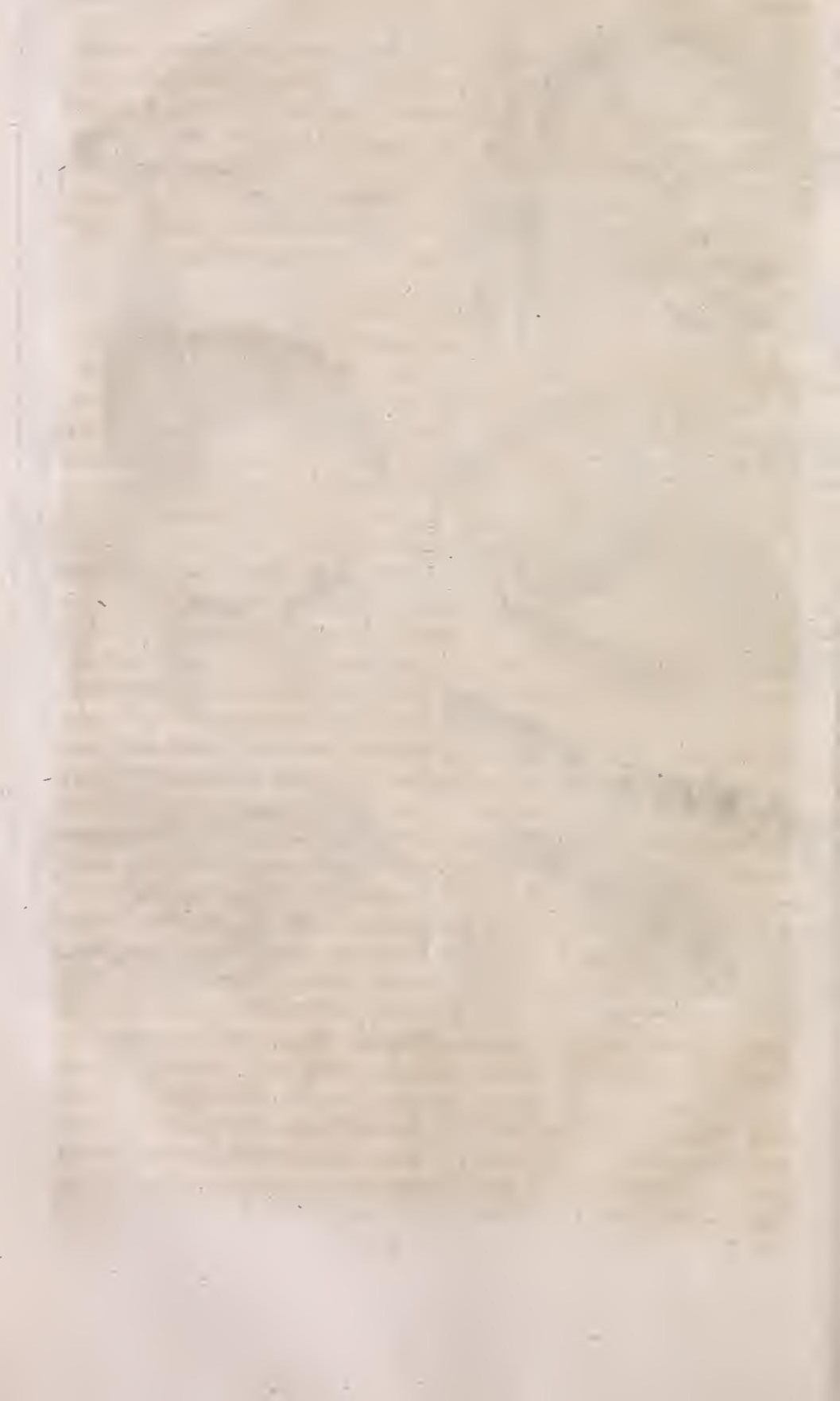


dEfcarlatte dicitur. Vid. Strobelberg Tr. de Cocco Baphica cap. I. Matthiol in'Diofcorid. p. I 30,727. Pomet l'Hifoire generale de Drogues P. II livr. I. chap.XXVI.

CONVS LARICIS Arboris coniferaè et refiniferae, cui funt femina plura foliacea bina juncta cum nucleo intus candido, pericarpio fquamofo duriori feu cono hic expreffo ex plurimis fquamis compofito breviori inclufa. Flores a fructibus fejunctim perfecti, folia acuminata decidua. Totius Plantae habitus eft arboreus procerioris ftaturae. In Alpibus Rhaeticis Tyrolenfibus aliisque fponte nafcitur, atque in Agronoftro, rarius licet, hodie obvia, Therebinthinam fundit, Agas ricumque fungum Officinis fuppeditat, ceu omnibus notum.

\section{TAB. III.}

A D illuftrandam Aromatum Hiftoriam haec infervit Tabula, ubi A primo loco fe fiftit PIPER CAVDATV $M$, quod optime defcriptum a Clufio Not, in Garc. ab Orto L. I. c. 22. p. 183. 184 . feq. et a Cl. Wormio in Mufeo p. 214 . qui Piper Benin effe fufpicatur, quas caudati Piperis uvas Lufitani Pimenta del Rabo nominant, cubebis fere fimiles. Cl. Marggravius Hift. Braf. L. II. c. 13. fub nomine Nharndu Brafilienfium, et Lufitanorum Behe Piper caudatum exhibet, quod tamen a noftro plane diverfum êfe videtur.

PIPER NIGRVM crefcit in Planta Molago Codì a Malabarèn * fibus, a Bramanis Miri dicta, farmentofa, imbecilli et caduca inftar Lupuli falictarii, quae ut fulciatur; pedamentis indiget, quocirca Indiad Arborem Faufel, Siamenfes ad Ipinofam arboretn Moe ton lang ferere folent, quam circumviolvendo fcandit? farmeñta habet frequentibus nodis et geniculis diftincta, quae humi fparfa radices agunt, Ad fingulos nodos, fingulare protrudit folium fubrotundum acuminatum riervofum, flofeulis I picatis monopetalis tripartitis. Ad racemorum internodia uvae na. fcuntur conftantes ex acinis rotundis, racematim in petioloviridi, viginti imo triginta fimul proveniunt; primutri virides et aequali fuperficie, dein rubri; ad naturitatem perducti decerpuntur, a quo tempore cortex nigrefcit, ceu fufe haec legi poffunt in Hort. Malab. T.VII. p. 23. et dans le $\int e-$ cond Voyagedu Pere Tachard au Royaume de Siam p. 247. feqq Nieu. boof en de gedenkneerdige Zee en Land Reize p. 259. De differentia, delectu viribusque curiofiffima, uti folet, collegit Excell. Valentini in Muf. Mufeorump. 297. .eqq. et literas quoque Herberti de Jäger de cultura Piperis in India Orientali Appendici Muf. Mue. p. 9o, adjunxit. Clufius quoque confulatur Exot. L. 2.c. 19.p. 18. feqq. Elsholz Diaetetic. L. V. cap. 1. p. 247, Pomet l' Hiftoire generale de Drogues P.I. livr. VII. chap. 2, qui piperis nigri a Belgis nobis Europaeis transmiffi tres - fpecies a natali folo differentes conftituit, nempe Piper ex Malabar, ex Jamby et ex Bilipatbam, pluresque alii Hift, nat. Icriptores, quos pagina non capit, 
PIPER $A L B V M$ a nigro, fi optimis hodoeporicorum fcri. ptoribus fides habenda, non differt, et licet in Hort. Malab. T. VII. Tab. XII1. Cattu Molago Planta fylveltris, a Lufitanis Piementa. Domatio, a Belgis Witte Peper oculis exhibeatur, et acini cum vero pipere conveniant, nunquam tamen merx haec apudindigenas pro Pipere ve. nit, cum plane infipida fit. Nec nos movet, quod Ludovicus Romanus apud Wormium in Mufeo arborem albi piperis feracem, craffiorem et proceriorem effe referat, cum jam olim $\mathcal{P} i f o$, et poft eum Her. bertus de $\mathrm{J}$ äger in Epiltola Indica Muf. Muf. Valentiniano annexa, et Horti Malabarici Commentator fucum annotarint, quod nempe cortice nigro in aqua macerato, et creta cineribusque poftea afperfis, dealbatio Piperis fiat; vid. pariter Dale in Pharmacol.p. 446. Contrarium tamen probare nititur Pomet l'Hiftoire gener. de Drog. P.I. libr. VII, cap. I. P. I92. qui plurimum proalbo pipere militat.

PIPER LONGVM proles eft Plantae Bengalenfium Pimpilim a Pifone in Mant. Aromat. p. 183. et Mexicanorum Mecaxochitl ab Hernandez apud Nard Anton. Recchum in Hiftor. Mexic. p.144. et Bramanum Tirpali Malabarenfium Cattu Tirpali H. Mal.T. VII. Tab. I 4. et 27. defcriptae. Lufitanis dicitur Pimentalonga, Belgis lange Peper. Caules hujus Plantae rotundae virides, nodulati minus lignofi, novos hincinde ejiciunt furculos claviculatos. Folia circa nodos caulium, longiffmis interne ftriatis petiolis erumpunt, forma ut Cattu-Alago, eft longiore minus cufpidata, fufcioris viroris quam Mlolago Codi, circa bafin incifa, textura valde tenui et molli, fuperficielenia, viroris in recta parte fufci, in finiltraclari. Flores monopetali, quinque vel fex partiti, arctiffime fruttibus infidentes, qui oblongo rotundi funt, fpiris obliquis parallelis in fuperficie ex diverfis partibus Itriati in I pirarum interfectionibus veluti parvis rotundis foliolis fcutiformiter obducti ; inter fpiras gemmae apparent, quibus flores infederunt, eminent es et nigricante puncto notatae, primo ex viridi flavae, carne intus ex flavo albicante; dein viridifufcae, carneviridi fufca; maturae et ficcae e cinereo nigricantes. In fructibus transverfim diffectis interftitiavidentur, in quibus femina oblonga et nigricantia continentur. Nec te moveat B. L. Iconifmum Horti Malabarici a nofro Besleriano differre, quippe illius fructus planta adhuc virenti delineatus atque ideo tam craffi et plenifucci, cum apud Auctorem noftrum exficcati, multoque tenuior es longioresque appareant. Nieremb. Hift, natur. Libr. XV. cap. XIII, p. 340, fub nomine Tlatlan cuya piper longum defcribit. Vid, quoque Cluf. Exot. libr. I. c. 20, p. 20. De Pipere longo Sinenfi Cao Patria Sinenfis in Defcript. Sin. Art. XXIll.p. 215.

PIPEN AETHIOPICV MI Matthioli et Piper Nigrorum Serapionis eft apud Bauhin. Lib, XV.c. 46. Provenit fecundum Wormium in Mufeo, in filiquis nigris racematim Piforum aut Phafeolorum modo, granis Pipere nigro minoribus et pertinaciter filiquis intaerentibus. De. 
fribitur pariter ab Illuftr. Neh. Grew in Minf. Soc. Reg. fubnomine An. glico, Aetbyopian Peeper, ubi Auctoris noftri figura aeri incifa laudatur, by Beslercuriously figur' d. Pomet dans l'Hifloire generale de Drogues P. I. lib. VII. cap. VIII. p. I97. hoc Piper grana de Zelime dicta vult. Vid. quoque Calceolar. Mufeum p. 589 . Matthiol, in Diofcorid. p.434.Muf. Muf.Excell, Valent. p. 299. Muf, Mofcard. Libr. III. cap. 89, p. 252.

CINAMONI FRV CTVS ab Audtore aeri incifus, cum reliquis a probatifimae notae friptoribus oculis exhibitis apte convenit: Mercium haec Indicarum delicatiffima, ex optimi Senis Excell. Wedelif judicio, optimum in Terra Majeftatis divinae exemplum praebet inver Aromata cinanomum. Peculiaribus differtationibus expofuerunt Joh. Phil. Hoechlatetterus fub Praefidio J. T. Schenckii Jenae 1670. ibidemque paucis ante Annis fub Wedeliano Praefidio G. Ch. Titius Anno 1707. Cl. Dechsbach difp. inaugur. Marpurg. A nno 1690. habita de Casfia Cinamomea et Alalabatbro; et Traject. ad Rhen. Anno 1709. Ch. Lud. Göller Ratisbonenfis, cujus ultimi Schediasma ideo reliquis praeftantius videtur, quod ipfi exoptatifima occafio data fuerit, cum viro quodam Clariffimo, ac indefeffo curiofarum rerum per: frutatore, colloquendi per literas. Is ipfe autem caput et Praefectus eorum, quibus Corticis Cinamomi in Infula Ceylon collectio incumbit, et per viginti jam annos, et quod excurrit, in iis Indiae Orientalis locis hoc officio fungitur, omniague fedulo inquirendi occafioneminime de: fituitur. Ab hochonoratifimo viro, cum non folum literas acceperit Cl. Göllerus, fed et ciftulam variis rebus curiofis refertam, interque illas, quae praecipue ad varias Cinamomi fpecies pertinent, novamque Arboris Hiforiam, decorticandi modum, cinamomum propagandi et crefcendi, non ingratum fore B. L. judicavi, froccafione fruetus ab Auctore. noftro delineati, quaedam ab alis forte nondum animadverfa e differtatio. neGölleri, qui in Patriam redux in flore jam aetatis caelitum adfriptus choro, promercm. Et quidem quod ad ipfam Arborem Cinanomiferam attinet, eam nec ad nucifer arum, nec pruniferarum, nec glandiferarum genus referri poffe docet, fed anomalam conftituere, diverfaeque effe al. titudinis et amplitudinis, cum aliae crefcant in magnitudinem mali Perficiauí Pruni, aliae amnofiores nempe tiliis, quercubus et populis proceritate non cedant, ita ut circumferentia Cinamomiferarum $A r$ borum ad odo vel nousem pedum latitudinem affurgat. Annofaetales Arbores cortice teguntur craffo, juniores tenui. RAMOS arbor babet multos eosque longos fatis et craffos atque enodes, non contortos fed reCos magis, qui perpendiculariter quafi in altum afcendunt. Ex bifce ramis emittuniur RAMVLI minores, e quibus enafcuntur FOLIA, quae modo bina proveniunt, modo folitaria, amnexa petiolis brevibus et tenuibus. FOLIORVM FORMA eft oblongo rotunda, lauri Cera. fi foliis non multum ab fimilis; longitudo duplo major circiter eft latitudine, ex bafi latiori in acumen definit, differt vero ratione arboris bujus 
bujus pecierum. COLOR eorum grata et dilut a viriditate $\int e$ commendat, et vifum recreat; altera vero parte funt pallidiora. Quae de Peculiari Charattere Foliorum annotavit Auctor, attentionem certeme-. rentur. FLORE $M$ arbor babet jucundifimum, quiex iisdem ramulis, e quibus folia ena fcuntur, excrefcit, et admodum eftparvus, colore candido Juperbiens vel ex candido vire fcente, eftque monopetalos, infundibiliformis ftellatus: quippe flos ille monopet alos in fex folia difpe fcitur, quae flellae in formaim fe explicant, in medio totidem faminula ex furgunt pal. le centia, infidetque calici exiguo viridefcenti. Florere incipit menfe Fanuario, et flos odore fuo gratifimo Jatis fe commendat, quo ad $L i$ lium convallium accedit. Defluxo Flore emergunt FRVCTVS, qui funt baccae oblongo rotundae, minoris olivae magnitudine et figura, primo funt virides, binc quo magis ad maturitatem vergunt, eo magis incipiunt ruffefcere, donec tandem perfectam adeptae maturitatem nigre cant, vel potius ex fufco incaeruleum colorem abeant, cum egre. gio.quodam nitore. Conftant veropellicula tenui, totam baccam am. biente, quae includit pulpam feu carnem paucam, fub qua continetur nucleus unus grandis, totam explens cavitatem, oblongo rotundus et glaber, qui cingitur Cortice tenui quidem, Jed fortiori tamen cartilaginea, qua ademta nucleus apparet, qui per medium fisus in du.ns dividiturpartes; pulpa conftat den $\int a$, quae coloris eft quafi incarnati feu ex albo in rubrumvergentis. B BCCAE hae infident CALICISIVE CVPV. $L A E$, quae ex cupidibus acuminatur, fulcis variis exalperatur, et co. lore praedita eft vire fcente, fufco, non aliter ac quercus frutus capulis fuis. Longius fui in fruetus defcriptione excerpenda, cum haec apte cum figura ab Aultore noftro expreffa conveniant. Lignum arboris albicantem habet colorem, neque adeo durum et folidum eft, fed mollius magis et porofius; adhibetur tamen, Baldaeo in defcript. Inful. Ceylon tefte, $a b$ incolis ad exftruendas aedes : faporis et odoris omnis expers eft. Radix pro Arboris proceritate variat, cortice teeta exterius obfcure ruffefcente, interius ejusdem coloris non nihil exaltati odorem fpirante fortem camphoraceum et fapore eodem confpicuum. Suavitas igitur omnisaromatica refidet in Cortice arboris Cinamomi, quo triplici tegitur, externo uno, altero mediano, tertio interiori, qui immediate ligno adjacet, et non nifi pellicula eft tenuiffima et fubtiliffima, plurimis planeincognita, nifi Excellentiffimo Hermanno, qui vim Cinamomi in interiori hac pellicula adeo concentratam efle tradebat, ut ejus fcrupulus unus plus praeltiterit, quam integri Corticis uncia dimidia. Plurima hac de fragrantiffima pellicula, cortici mediano fragrantiam communi. cante fequuntur, item de $I X$. vel $X$. Cinamomi peciebus, de Propagan. di, colligendi et crefcendi ratione, quae omnia praetereo, curiofifima licet fint, ne B.L. nimia prolixitate taediofus exiftam. Confer quoque - Herbert. de Jäger in Append. Muf. Muf. qui Hiftoriam Cinamomi naturalem illultrantia quamplurima luppeditavit, et Pomet l'Hiftoire ge- 
neral. de Drogues P.I. L.IV. chap. I. p. 125 . ut alios Auctores innumeros, qui proletaria de Cinamomo tractant, filentio praeteream. Imprimis de Sinenli Cinamomo, uberrime in Provincia Quoaryfi proveniente, vid: Dion. Cao, ipfe Sinenfis, in Patriac defcriptione Art, XXIII p. 216.

RAMV $M$ nunc CARYOPHTLLIS ARO MATICIS GRAVI: DV $M$ porrigit tabula, adjunctis $A N T H O P H \eta^{\prime} L L O R V M$ binis fchemátibus, immaturis nempe et maturis fructibus arboris Caryophylliferae, Tfinka, vel fecundum Linfchotanum Chamke dictae, olim Moluccenfum folum Infularum incolae, nunc autem non amplius ibidem obviae, cum Regis Moluccani confenfu omnes eradicatae fuerint, inque Amboinam Belgici regiminis Infulam transplantatae, ubinunc fo: lummodo luxuriant, lucripetae Belgarum voluntati expofitae, cujus aromatis pretium prolubitu augent minuuntve, et Moluccàrum Regulo, quod omnes in regno caryophylliferas arbores aboleverit, fingulis annis 24000 . florenos folvunt, referente hoc Excell. Muntingio en de naurkeurige befchryving der Aerdgewafen p. 149. In Sina tamen Caryophylliferas pariter provenire arbores, teltis eft Sinenfis Cao in defcript. Patriae 1.c. Celeb. Plukenetius in Pbytograph. Tab. is 5. ramum pariter exhibet caryophyllis partim capitellis convexis, operculis $\mathrm{flo}_{\mathrm{F}}$ rum, partinfloribus expanf is infructum, vifui.jucundiffmum; omnes tamen elegantia vincit Caryophyllorum ramus apud $N e u b o f i u m$ in de gedenkweerdige Zee en Land Reize p. 3 1.-depictus -et defiriptus; Procera alias arbor caryophyllifera, cujus Caudex ad corporis humani craflitiem accedit, et nobiliff. Wurfbeinius, Beatill. Hermetis Parens, in Itiner, vernacula lingua confcripto arbores caryophyllos ferentes oblervavit, quaebinas cum femifle emenfae fuerint ulnas. Folia laurinis latioribus fimilia, oblonga, lata, glabra, et fplendentia, odore aromatico. Flos fragrans primo albicans, poltea viridis et tandem ruffefcens, ubi le expandit tetrapetalos, quam vis $\mathrm{Cl}$. Tournefortio polypetalos rofaceusaudiat. Fructus autem Caryophyllorum aromaticorum nomine venientes funt immaturi, oblongi inftar clavis angulofi, depreffi, rugofi, e rubigineo-nigricantes quatuor decuffatim ftellatis apiculis notati, cum medio capitelio convexo, et cavo futurifloris rudimento e Cl. Hermanni delineatione; cum e contrario Anthophylli fint fructus maturi, caryophyllis craffiores et tumidiores, includentes fub Cortice duriufculo femina oblonga, fufca, faporis et odoris ejusdem cum Caryophyllis, qui Saccharo conditi pariter ex India ad nos adducuntur, Caryophyllis virtutibus longe inferiores. Inferviunt tamen arborum propagationi, cumexillis deciduis nova iterum enafcatur arbufcula. Haec de Aromate ubivis obvio fufficiant, cum hanc materiam penitus exhau ferit fub Praefidio Excell. Hofmanni Hallenfis D. Fridel. Halae 1701. ubi Auctorum, qui hoc de Aromate fcripferunt, latiflima colledio: Prae omnibus vid. Ponnet l' Hiftoire general. de Drogves P. I. Livr. V lI. chap.X p:198.

$$
\text { C } 2
$$


NVCES MOSCHATAE VARIAE CVM FLORIBVS ab Auftore hac tabula depictae, tantum meruere applaufum, ut Dn. Diezius difp. inaugurali Gieffae Anno 1682 . hac de Nuce habita, et Excell. Nat. Curiof. Arion, in Mofchocaryograpbia, five Nucis. Mo fchatae curiofa defcriptione, eas mutuare, operibusque praefigere non veriti fint, ut omnibus, qui hoc infpicere dignantur patet; congeffit Excellentiffmus Paullini omnia, quae hac de Nuce dici poffunt, cui $\mathrm{fi}$ Cl. Scbulzii differt. Medicam Anno 17 09. Vltrajecti demum habitam addes, vix defiderare amplius hoc de aromate quid poteris. Exhibet ultima haec diFfertatio figuris elegantiffmis aeneis, non folum Ramulum enuce myriftica progerminantem, fed et, quod ab Auctore noftro factum, Nucem integram cum operimento, et binas Nuces uno calice tetas, Nucern Maci involutam, cum teftaceo et nuci proximo involucro, Nucem mofchatam marem et foeminam, cum nucibus vulgo regiis diotis. Delibabimus ex hoc fonte, multis hiftoriae naturalis feriptoribus indicta et prae. tervifa. Excell. Rajus arborum Nucis hujus pruniferis accenfet, Schulzius non contemnendis rationibus nuciferis vendicat. Banda prac caeteris orientalibus regionibus arborem harum feracifima, ut bis et juxta nonnullos, ter in anno, prout nempe tempeftas illis arriferit, colligi poffint. Lignum arboris fpongiofum, nullam vero habet peculiarem cavitatem, ut aliis placuit; Folia aliquo modo conveniunt cum laurinis, maxime cum Lauro-Cerafi foliis, non tamen in ambitu ferrata, qualis Matthioli error, brevipediculo nitentia, quibus e ramis dependent, laete viridefcentia, fplendentia, fubrotunda, in poftica parte cinerea notato unico nervo cum plufculis venis per folii longitudinem oblique decurrentibus; fpirant recentia, et per multos adhuc annos ficca, fuavem a romaticumque nuci aemulum odorem, fi paululum terantur. Arborum Nucis hujus fylveftrium plures dantur fpecies, quam cultarum. Flores funt conflati ex quinque albicantibus fimbriatis petalis, quas Excell. Muntingius ceraforum et Pomorum floribus fimiles autumat. Frutus circa pediculum nonnihil turbinatus, triplici tunica feu operimento cum nucleo rotundo medio inclufo. Tunica feu integumentum illud exterius primum eft craffum villofum fungofum, er quafi pulvinatum, molle equidem, fed fatis denfum ut in juglandibus et caftaneis coloris viridefcentis. Cum maturefcit fructus, fiunt fldvae purpureaeque maculae confpicuae in Calice, quae promaturitatis figno ab incolis habentur; hinc dehifit, in ea parte ubi fulcus illud dividit, et oftendit alterum fub eo latentem Corticem, quiduriorem et ligneum iftum reticulatim certis in locis ambit, et pertinacius circa pediculum haeret, alioquin liber ubi levi compreffione facile aveliendus, hic admodum rubentem et elegantem in principio habet colorem, fed fi faltem per paucas horas aëri exponatur, ftatim elegantiam amittit et in flavefcentem abit; dantur tamen nuces, fub quarum calyce nullum macis veftigium; Sic macis quoque non rubente et flavefente colore, led albido 
repertu datur, quoda vermibus, materiam oleofam intra has membranas contentam exedentibus, fieri credit diligentifimus Loemenboe* kius. Involucro macis (quod improprie florem, Germani Mlifcat: Sllutfy vocant, cum nihil minus exiftat quam flos, fed potius membrana, feu medium nucis operimentum ) fubjacet adhuc aliud durum teftaceum, corticolum ex fpadiceo ruffefcentis coloris, lignofum quaf, nullo nec fapore, nec odore, multis fulcis hinc inde apparentibus; hocce immediate nucleum rotundum, folidum, albicantibus et f padiceis lineis reticulatim interpolatum includit. In cortice hoc duro duo funt di.. ftincta foramina, quae fibi mutuo adjacent, unum fine dubio ad corticem, alterumvero, uti videtur, ad nucem alendam, quod Loenenhoekii experimento confirmatur; nec nuce ficcata cortex hic durus dehifcit, quod Clufio olim vifum, fed vi potius fecernitur, tuncqueprodit nux myriltica officinarum, figurae olivaris, coloris fere cinerei, extús rugola, intus multis fpadiceis. venis, et ex flavo albicantibus lineis undatim, vel ut Hofmanno exprimere placuit, multis Arabicis literis referta; quae praecaeteris eligenda, fit infuper ponderofa, recens, pinguis intus ex fufcofubrubra, multis venis oleum vehentibus gravida, cum lineae albae pabulum fint vermium, denfa porro, bene compacta, acuque puncta oleum emirtens, odorem et faporem aromaticum, acrem, jucundum fundens. Haec de Nuce myriftica communifatis: fupereft, ut aliquid de majcula oblongiori nuce, quam Auctor quoque nofter expreffit, addam; non hae e gemmis, uti vulgotradunt, fed, Neuhofiotefte, ramorum extremitatibus nafcuntur, et Pala Java, a Bandenfibus Pala-Metfiri, a Belgis Mlannekens-Nooten appellantur, quiá plebecula fibi perfuadet, hancin cibis nucem viris datam, eoš potenter ciere in venerem et folito fertiliores reddere. Eft vero nucum harum forma oblonga, faepe fere quadrata, aliquando rimam habent magnam et fatis profundam; coloris funt obfcurioris, faporem habent longe debilio. rem, hae quantum faeminis nucibus majores, tantum etiam debiliores, pauperioresque oleo: et hanc ob caufam in affectibus ventriculi et capitis commodiores habentur a nonnullis. Sic Macis, Nucem mofchatammarem amplectens, licet afpectu pulchrior, multo tamen debilior eft ejus vis aromatica; hinc ab Incolis nullohabentur pretio, et inter arbores fylveftres, Neubofio telte, numerantur; nefcio tamen cur noltrates has, reliquis faemellis praeferant, nifi hoc praejudicio concepto fiat, ac $\mathrm{fi}_{\text {, }}$ quae mares appellantur, nobiliores foem ellis exiftant. Dantur etiam $N u$. ces Mofchataeregiae dictae, ab Auctore noftro in hac Tabula omiflae, quae funt omnium ininimae, in una parte utplurimum rotundae, in altera planae, quanquam talem formam non femper habeant, fed modo in uno latere planae, modo undique rotundae, magnitudine vix pifo faepius grandiores, fucculentia tamen et odoris fragrantia majores fuperantes. Sufficiant haec e differtatione Schulziana excerpfifle; plura enim defiderantijam fontes indicavi. De Sinenfum Nucibus Mofchatis Cao in defcript. Chinael. c. 
Admirationem merentur, quae de Nuce Mofchata Theving dicta Act. Philofoph. Anglic. Menf. Januar. r669. memorant, quod toto Mofchatarum nucum acervo immixta, quamvis unica fit, omnes tamen reliquas corrumpat; qua de exitiali nuce, altum apud omnes Hiftoriae, na: turalis fcriptores filentium; nec Pomet dans l'Hiftoire gener. des Drogres Livr. VII. Chap. XII.p. 2 or. feqq. hujus meminit.

\section{TAB. IV.}

D Efiit in Aromatum Hiftoria Tabula prior : haec fequens in enarratione ulteriori pergit, et primo ftatim intuitu TRIA CARDAMO AIORV MI OENERA, MAFVS, MEDIV M ET MINVS exhibet. Communem hic veterum, imprimis quoad figurarum expreffionem Calceclarii in Mufeo p. 596. Mlatthiol. in Diofcorid. Edit. Bauhin. p. 27. aliorumque erravit errorem, dum binae illae oblongae thecae Ficoides, funt conditoria granorum $P$ aradi $f$, Meleguette vulgo nominatorum, ab Africae VrbeMelega dicta fecundum Pomet. $l$ Hiftoire. gener.des Drogves P.I.Livr,I.cap. 28.p.40. quae eGvinea ad nos transportantur, tefte Cl. Bofmanno dans la Defcription du Coté de Gvinee p. 318. grana nempe angulofa extus fpadicea, intus alba, fapore acri et fervido inter Cardamomum et piper, cum quo pofteriori virtutibus coincidunt, et, quod peffimum, priori faepius fubftituuntur. Videntur nonnullis ef fe fructus Cardamomi majoris Africani Arborefcentis Excell. Muntingii en de nauvkeurige Befchryving der AerdgeroafJen Lib. II. cap. 62. p. m. 256 . defcripti, quam Arborem tamen ab Arbore ac fruticibus Malaguettiferis diftinguit modo citatus Bofmannus 1. c. p. 3 18. Binae reliquae fpecies, videlicet oblonga illa pro Cardamomo majori Plantae Indicae Benzal dictae; minores pro minori accipi poffunt. Omiffum. tamen Cardamomum medium racemofum, quod pro Antomo Plinii nonnullihabent, quippe verum cardamomi genus eft, de quo videndus. Nobil. Maronea Comment. in Traa. Diofcorid. et Plinii de Amomo. Amomum verum autem Arboris Americanae Caningae dictae funt baccae rotundae. Vid, Hermann, Mat. med. p, 125 . Cluf. Exotic. Lib. 2. c. 17. et Ferrant. Imper. Hilt. natural. Lib. 28. p. 676. edit. noviffmae Italicae in Folio. Muf. Molcard. Libr. III. cap.97. p. 257. Caeterum quae de faluberrimo Cardamomi aromate dici poffunt, in eruditiffimam inauguralem dilfertationem congeffit Jen. 1704.Cl. Rhein, ad-, junctis e Bontio Plantarum majoris et minoris fchematifmis, quos jan antea Cl. Elsholzius Diaetet. L. V. cap. r. §. s.p. 2 so. inferuit. Vid. quo-, que Pomet l'Hiftoire general. des Drogv. I.c. Sed dolendum, defcriptionem et figurastrium Cardamomi pecierum ex Horto Malabarico fub nomine Elettari planc omiffam effe, quaecum nimium a Bontianis figuris difcrepent, ut huic defectui fupplementum accedat, nonnulla ex Horto hoc mon ubique obvio, cardamomi fpecies concernentia fuppeditabi. 


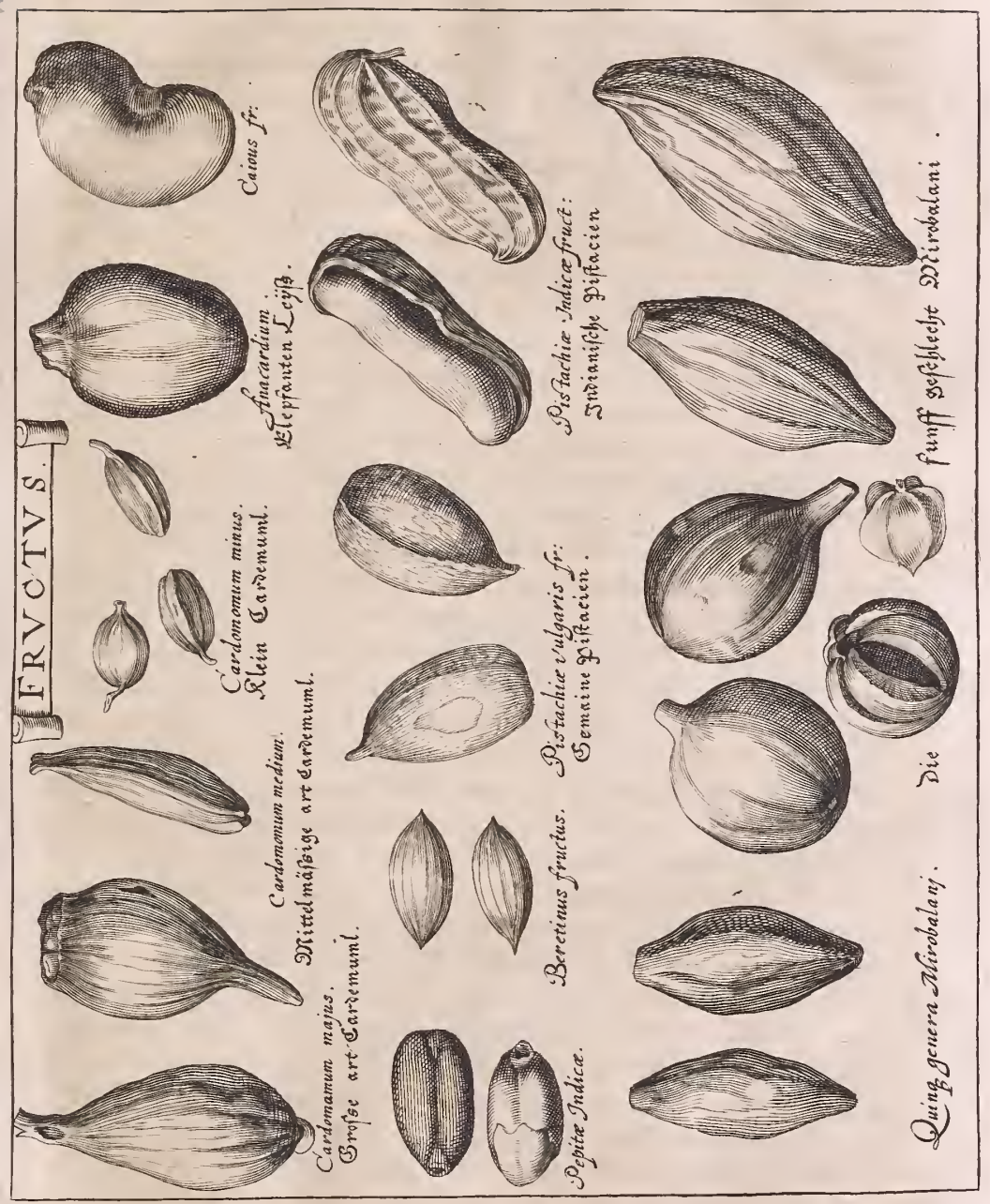



mus, quod equicem cum bona B. L. venia fieri confidimus. Radix oblonga crafjefcit, geniculata, albicans tortuofa, furfum virens, e lateri. bus innumeras fibrofas emittit radiculas, quibus velutipedibus, perinde ac radix Zingiberis, proferpit. Caules, qui e radice emergunt, rotundi, glabri virentes, latum ferme pollicem Juo emetiuntur diametro, fipite fimplici infarar arundinis, cujus texturam aemulantur, furgentes, albicante vappidaque medulla, lignofis filamentis, quorum extrematransverfin -diffeda, eriguntur, inftruta; e quorum corculis fubtilia, aquea, telae aranearum inftar, candicantia educi poffunt fila; foliorum ba $l i$, quae fuperioribus radicum geniculis innititur, theciformibus fuis involucris infi: funt. Diftralti, manibusque triti aromaspirant. FOLIA illis Manjukua non abjimilia funt, quatuor circiter pitbamas longa lata, viridia parallelis exilibusque venis friata, odore ac fapore forti, jubacri aromati: co. COSTA MEDIA in adverfa parte viridi, diluta, in obver \& viridior. FLORES un fruatigero racemo, vel radicali farculo plures, plerumque tres quatuorve, ejusdem oblongis foliolis, veluti capfulis inpliciti; nullus enim in foliaceo boc involucro conpicitur biatws. Teg. mine boc autem aperto tetrapetalus fe fe offert flos, quorum tria magnitudine convesiumt, oblongo angufia, viridialbicantia, membranofa quantum quod prioribus ex adverfo jacet, tenui fylo, lingulaque donatur, paulo latius ac minus oblongum eft interius fitum ac viride, Lingula $a b$ longo angufta ef, crafjufcula, in interiori facie, quae intimo foliolo ex adverfo opponitur accumbitve, fulco friata, in fupremo apice bifida, diiute rubefcens, fuoque fulco exilem, candicantem fylum, qui in tenue pla: numque definit capitulum, recipit. FRVCTVS radicalibus frudipromisque racemis appendent, qui uvis et forma et fapore baud perperam af: fimilantur, orbiculati enim funt et grate fubacidi, viridi, cras iufculo, carnofo aqueoque cortice obducti, friis admodum tenubus juxta longitudinem pertexti, intres difindtos loculos cancellatim diflintos, ita ut quodlibet interjepimentum, in Juimedio, membranacea fibrilla etiamnum, jed levi ingreffu bifecetur, ficque feminum conceptacula efficiunt: adeo ut fex ordinibus, combinat a triangularia, pres is planisque lateribus fruitus, copiofa infideant grana aromatica, quae medio flylo trigono, cui mediante membranaceo Jepto affiguntur, cupidibus fuis adbaere cunt. In aprico frudtus bi exficcantur folo, ubi Cortex, qui primo crafjus viridisque, extenuatur, et ex ruffo albefcit; funtque ip iffimum CARDAMONV $M$, nomine Elettari in tres cognitas pecies divifum, quarum. prima badenus defcripta, plane rotundos ac albicantes profert frudus, cujus natale folun, fupra COCHIN et CALICVI in locis montanis, triginta circiter a marimilliaribus, pretioque ob praefantiores vires, reliquis praevalet. Secunda pecies oblongior eft, fed vilior, tertia viliffima et plane acuminata; quae pofteriores juxta CANONOI aliaque Indiarum loca inveniuntur. Tantum de Cardamomi tribus fpeciebus. DeV Juomnibus cognito addere quid, fuperfluum judico. 
ANACARDIVM ORIENT ALE Cardamomi fpecies fequitur, fructus veteribus Graecis incognitus, recentioribus tamen a cordis cumprimis exficcati, tum fimilitudine, tum colore a'var á $\oint^{\prime}$ เov nominatus, vocatur etiam Faba Malaccana, tefte Rev. P. Bonann, in Mulco Kircher. Clafl. VII. de fructibus n. I s. Proles eft arboris Indicae pruniferae foliis geminatis glabris, flofculis exiguis tetrapecalis luteis racematim difpofitis, fructu conoide, cortice pulvinato nucleun unicum, nullo officulo tectum claudente; fructus autem compreffus aviculae cordis figura, nigricans ac fplendens, includens fubduplici involucro, corticofo et duro albicantem nucleum faporis lubdulcis, et inter involucri duplicaturam mucaginem oleofam, nigram, faporis acris ac exurentis, ut ex Illuftr. Rajo hoc refert $\mathrm{Cl}$. Dale in Pharmacol. qui infimul addit, Anacardium effe Oepatam Horti-Malabarici T. 4. Fig. 48. Sed fi accuratius infpiciatur ArborOepata, five Vpata Malabarenfium et Salgeira Lufitanorum, et folia, flores fructusque examini fubjiciantur, magnam quidem cum Anacardio habent fimilitudinem, procerto tamen vix quis affirmare poterit; quippe et Excell.Plukenetius et Comelinus, prior in Almag. Botanico, pofterior Notis in Hort. Malabar. hoc dicere muffant. Confer. Excell. Valentini Muf. Mufeorum. p. 30r. Pomet. I' Hiftoire General. des Drogves L. VII,chap. XVII.p.20 9. Muf, Mofcard. libr.III.c. 95.p. 255.

Orientalifubjungitur AN ACARDIUM OCCIDENT ALE, fpeciesAcajaiba et Acajuba Brafilienfum, cujus fructus Acajou et vulgo Cajou dicitur, fecundum Marggrav. Hift. Plant. Lib. III. p. 95. Hinc Cl. Hermanno p. 36. audit Anacardium occidentale Cajou dictum, officuli reni lepo. ris figura. A nobiliffimo Rajo autem Arbordicitur pomifer a five potius prunifera anomala Indica, foliis oblongis glabris, fine ordine ramis adhaerentibus flofculis pentapetalis, vel ex K.P. Plumerii relatione, monopetalis infundibiliformibus multifidis, e cujus Calice furgit pifillum capillamentis fipatum, pofticae floris parti adinftar clavi infixum, quod deinde abit in fructum turbinatum, mollem; cui adnafcitur capfula reniformis femine foeta ejusdem formae, Cajou dicta. Capfula five Caftanea innalcens pomo, renis ovilli figuram habet, tecta cortice cinereo craffo ac intus fpongiofo, qui oleum in fe continet acre et mordicans, ita ut cuti etiam leviter illitum, ignis modo urat, et fi quis incautus dentibus comminuat, ita linguam et labia exurit, ut magno dolore exinde afficiantur; nucleus quoque Renis figuram habet albus, cuticula flava veltitus, quae feparanda. Haec Marggravius, et luculentiora adhuc Hort.Malabar.T.III.Tab. 54.p.65.qui fub nomineKapamaram five Kasjavomar am arborem hanc fructumque optime defcribit, addendo e fructibushifce potum exprimi, qui debito modo fermentatus, virofus evadit et inebrians. Vfum praeterea Medicum et Mechanicum, ex his fructibus promanantem, haurire qui cupit,ipfos Auctores laudatos adire poterit; cui addendus Rochefort l' Hiffoire naturelle des Isles Antilles Chap. VI. 
Artic. VII. p. m. 72.86. Excell. Sloane teltatur, fructum hunc in hortis et agris Infulae Jamaicae et Caribearum ubique provenire, in Catal. Plant.Inful.Jamaic, p.is7. et ab Anglis verriacula lingua The Cashem or Acaju Three, vocari. Vid. quoque Garc. ab Orto L. I.c. 3 o. Muf. WVormian. p.183. 192. Mur. Molcard. Libr.IIll cap. 99. F.258. Pifo Hift. Brafil. p.120. Bont. Hift. Indic.p. 192. Pomet l' Hiftoir. gen. des Drogv. P.I.Livr. VII. chap. XVIII. p. 210, quide Gummi Acajou ab aliis indicta profert in Append. p.Iz.

PIST ACHIAE INDICAE fructus a Brafilienfibus dicuntur MunZuby, Lufitanis Anenduinas, Lerio Mlanobi, Peruvianis tefte, Monarde Anchic, Hilpanis $V$ bimani; videtur effe fructus fub terra nalcens Monardis, vel Peruanus amygdaloides fubterraneus Jok. Bauh. T.I.p. 292. Ab Excell. Pukenetio in Almag. Botanico p. 341. defcribitur ceu fenna tetraphylla five Abfi congener hirfuta Madsraspatenfis, flore flavo filiquis punctatis, fabris, folliculos fub teram condens. Certe folliculits, in Phytograph. Tab.6o.f. 2. delineatus, non abludit ab his piltachiae Indicae a Beslero nofro aeri incifis. Mlarggravius more folito optime Hift. Plant. L.1.p. 37. defcribit: folliculos nempe ex albicante gry feos radicibus adnafci, figurae minimae. cucurbitae, oblonga magnitudine Myrobalani, fragiles: quilibet autem continet in fe duos nucleos, pellicula faturate purpurea vefitos, carne intus alba, oleaginofa, fapore piftaceorum, qui comeduntur coci $i$, et inter bellaria apponuntur. Plures Botanicos, yuifructum hunc defcripferunt, memorat Excellent. Sloane in Catal.Plant. infulae $\mathrm{F}$ amaicae, adjungens fimul, fructum hunc in Horto Dn. Harrifon in loco Liguanee dicto, feri et laete provenire, et ab Anglis ibidem degentibus vocari Earth muts or Pindalls. Vid, quoque R.P. Francifcus Sterrebek in Theatr. Fungor. Tract. I. Part. III. en de Anwy ing ende natuer der Aerdbuylen. P. 3i4.

PISTACHIAS vulgares in eum tantum finem his Indicis adjunxit Auctor, ut differentiam notaret, quae cum in omnibus Officinis et. ubique proftent, inque Horto Volkameriano crefcat Arbor, ideoque abipfo in Hefperid. Norimberg. opere delcripra, nil amplius addo.

BERETINVS FRVCTFS elt ex Infulaehujus nominis Arbore, quam Fr. Drake e navigatione illa, qua orbem circumivit, retulit, isque Clufiotunc Londini commoranti, communicatus eft. Arbor fructus hujus fatis procera elt, quercu major, laurinis foliis craffis fplendentibus, in ambituminime ferratis; Fructus ipfe oblongiufculus exiguis iligneis glandibus fimilis, nullo tamen calice inclufus, tenui cortice coloris cineracei, interdum etiam atri teetus nucleumque cóntinens oblongiufculum candidum, nullo manifefto fapore praeditum, tenui membrana imbutum; hunc fructum edulem efle, eoque more leguminum elixo, aut in farinam trito, et pultisinfrar infpifla to et cocto, alterius cibi penuria famem compefcere poffe, ab Infulae incolis fuere edocti. Pertinet igitur fructus hic ad Laurifoliam exoticam Ternatenfem. 
Cajp. Baubin. in Pinac. L. XII.Sect.I. p. 461. inque Moluccis quoque repertu datur Vid. Müf. Calceolar. p. Gor.

PEPITAE INDICAE fruetus funt, amygdalo Peruanae fimiles, fụfci vel fpadicei coloris linea candida Ca/p. Baubin. in Pin. L. XI. Sect. VI. p. m. 442. a Clu/io Exot. Libr. 2. Pepitae del Peru five acini Peruani dicuntur. Secundum Excell. Plukenetium Almag. Botan. p. 28. funt fructus fecundus Simonis Tovar, five Almendras del Peru, Walgonne Bengalentibus dictus. Pineae nucis referunt nuclens, licet magna ex parte noftris fint longiores et craffiores, durum fimiliter illis putamen et idem color. Plani et oblongiufculi, altera parte latiores et laeves.

MYROB AL ANORVM QVINQVE GENER A ubivis in officinis Pharmacevticis obvia, Auctor nobis ab oculos ponit. Nil hic de barbaro nomine Myrobalani five Vnguentariae glandis a pofterior bus efficto Graeculis dicam, nil de incerto numero, qui ab A rabibus, Perfis, Indis caeterisque Orientalibus ad ternarium, Halilejum nempe, Amjelutn et Belilejum reftringitur, dicam; nil de efficacia fructuum horum, cum illos effoetos fegnesque, et in prunorum noftrorum adfluentia fupervacaneos, et ex hyberbolica Arabum commendatione inutiles plane cenfeat maxima Medicorum cohors, quas lites aliis exercitatioribus in hac palaeftra dirimendas relinquimus; fed producamus quas Beslerus. nofter aeti incidi curavit figuras, quarum (r.) Chebulas five Cabulenfes fiftit; Myrobalanos maximos oblongos angulofos pituitam purgantes C. B.P. arboris Folia Perficac fimilia, Arboris Myrobalanifera Perficae foliis Jonfoni fructus oblongi rugofi, coloris obfcure fufci; includentes fub putamine carnofo officulum oblongum craffum et cavernofum faporis fubacris. Arbor fecundum HEKMIANNVAI Queboli dicitur vel potius Cabul. (2) Belliricae, vel fecundum eruditiffinum Weljchium Belilejae, funt fructus Arboris pruniferae Lauri folio fub. cinericio Jonfton. rotundi, faepe angulofi, gallae majoris magnitudinis, in pedunculum craffum definentes, ex rubigineo flavefcentes, includentes officulum durum fub putamine carnofo duriufculo, faporis adfringentis poft fubdulcis. Arabibus Belleregi fecundum Hermannum, Welfchio autem Belilei dicuntur. (3) Emblicae five Amlejae, fructus. Arboris foliis fecuridacae Cl. Breynii et Nilicacamaram Horti Malabarici, Palmae magnitudine, rotundi, fexangulares Belilej;s minores, feffiles e cinereo nigricantes, includentes fub pericarpio carnofo, in fex partes per maturitatem dehifcente, officulum turgidum hexagonum, fenis vel fecundum Hermannum tribus cellulis infignitum, in quo nucleus pomaceus fpadiceus triangularis ; faporis acerrimi. Arbor Embelli vel Amleja dicitur. (4) Citrinae five flavae, Arboris Myrobalaniferae forbi foliis Azafar dictae fructus oblongi rotundi, pentagoni, teretes rugofi Cabulenfibus minores, coloris citrini, includentes fub putamine carnofo officulum angulofum. (5) Indae five nigrae Indicae 


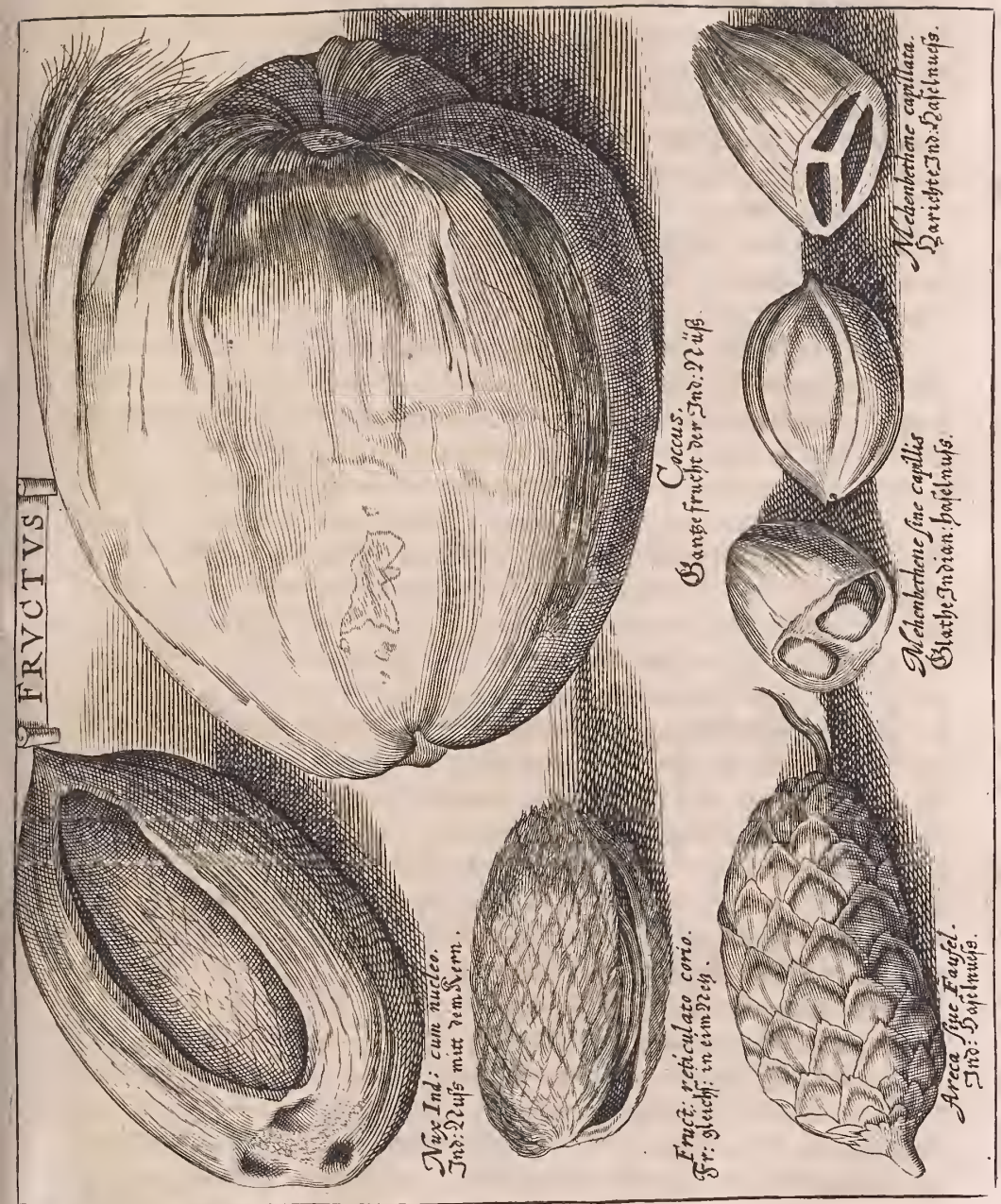



Arboris Myrobalaniferae falicis folio, Asvar Arabibus, fructus oblongi reliquis tenuiores fuperficie octangulari, folidi et duri, rugofi, intus et extus coloris nigri, bituminis inftar Judaici, faporis fubacidi acerbi et adftringentis. His ab Auctore noltro delineatis Myrobalanis addi poteft (6) Myrobalanorum genus Sinenfe a Jac. Bontio indigitatum, et a Cl. Welfchio depictum et explicatum in Dec.I. Ephem. Nat, Curiof. Ann.III. obferv. 32 . Fructus olivae fimilis, nullis ftriis aut incifuris notatus roftratus e verfione Ebn-Sinae Plempiana, quod tamen melius Welchius acuminatus vertit, cum vox Arabica, non tantum roftrum, fed quemvis apicem cujusvis reifignificet, et olivae quaed m reperiantur acuminatae, et quod caput rei eft, rcftra volucrum non omnia acuta, fed quaedam praeterea lata, atque obtufa fpectentur. Vid. Excell. Welfchius de Vena Medinen $i \mathrm{~L}$ cap. X, de Myrobalanis Syriacis Rauwolfii Chabraeus Stirp. Sciagr. p.14.

\section{TAB. V.}

TAc in Tabula confpicimus Nucem illam Indicam, $\operatorname{coccos}$ com1 muni nomine dictam, Avicennae Janfiat Indi, Arabum Maron, Indorum Tegamaram et Lanba, Brafilienfium Inaja Gvacuiba, Mexicanorum Coyolli, Zeilonenfium Polgaba, Malabarenfium Tenga, Bramanum Mado, Lufitanorum Coqueyro, e Palma Indica coccifera, angulofa ortum ducens, quam Arborem polt Clufium, Garciam ab Orto, Nardum Antonium Recehum, Marggravium, Pifonem, Rochefortiumque nemo fecundum minimas circumftantias me. lius, accuratiusque delineavit et explicavit, Illuftriffimo Horti Malaba. rici Editore Tom. I. quo naturae miraculo, mirandi operis initium fecit. Referamus ex illo tantum, quae nucem ab Auctore delineatam concernunt, cum reliqua arboris memoranda hujus opufculi limites excludant. Fructus Coccos praegrandes funt, magnitudine caput humanum aequant, faepius fuperant, et ad Nuces referendi. Figura illis triquetra, et ut ex Auctore noftro patet, ovalis. Conftant operimento lignofo, qui interius ad fuperficiem interiorem operimenti feu teftae medulla alba obducti funt, ac intus larga cavitate, quae aqua feu liquare repleta eft. Hi dum teneri funt, et ex capfa cum fpicis erumpunt, forma rotunda funt, colore flavo - albicantes, et calyce flavo - albicante, qui e rotundis foliis mutuo circumvolutis conftat, arete et in totum obducti, intus fub Corticibus, quibus circumteguntur, carne denfa albicante, nulla cavitate donati, poftmodum vero cum aetate increícentes forma oblongo - angufta funt in longitudinem maxime aucti, minus vero in latum, in cortice exterius cum nitore viridefcentes, calycis foliis, ex quibus cum fuperna parte emicant, ex rufo rubefcentibus, proditque fe in is primum nota parva, oblongo - angufta, cavitatis cum majore incremento introducendae in ima parte fẹu ad exortum fructus, ante- 
quam autem cavitas fe offert, fruthus bi teneri Malabarenfibus Bellach, Lufitanis Coquinhos, cavitate autem jam introducta Fruttus primo fola aqua repleti funt, ac tum d Sti Malabaribus Caricì, Lufitanis Caricà, abfoluto vero cavitatis incremento, poltquam omni fua repleti aqua funt, medulla ad interiorem operimenti fuperficiem obducuntur. Elt autern medulla fructus, quae ad certum temporis intervallum angefcir, expetita in edulis, primum tenera et albicans ac fubcacrulea, fapore dulci ac grato, minime vero oleofo, deinalbicans ac magis magisque indurefcens, cun dura fapore nucis, acquo vetuftior feu durior, faporis magis oleofi, contrita ac tufa lacteum liquorem, qui et lapore lactis st, fed nonnihil oleofi fundens; cum vetuftiffima eft maxime oleofa ac ex oleo caerulefcens, odorem fortem oleofum, qui ingratus eft, fpirans Pro diverfa medullae confiftentia Fruitus variis nominibus funt denati, cum ea tenera eft et lacti fimilis ac mollis, dicitur Malabaribus Corumba, cum completa eft, et non amplius augetur, Elani, Lufitanis Lania, cum nonnihil dura eft, Malabaribus utet Lufitanis, Mlaninga, cum dura eft Tenga, Lufitanis Cocquo, cum adhuc durior Barettu Tenga, ac cum maxime dura Cotto Tenga, Lufitanis Coccoficco. Quod ad Aquam, quae eft intra cavitatem, haec in fruclu tenero, Caricù dicto, eft priimum fubadftringens, fubfalfa et fubacida, minus vero dulcis, dein quo fructus vetuftior fit, magis ct magis dulcefcens; in fructu vetufto ut Barettu - Tenga fimul valde dulcis et falfa, ante medullae proventum clara et valde limpida eft inftar aquae; medulla autem proveniente turbida Teu minus limpida et pallide albicans; ex fructu Caricù, qui jam omni fua aqua repletus eft, facto angufto foraminulo per operculum magna vi radiatim exfilit, minus vero ex fructu, qui medulla repletus elt, ut Corumba feu Lania; Aqua in Mlaninga id proprium haber, quod ut liquor dietus Sieri fermentatione ad oculum notabilicietur, cum medulla dura eft, in fructu exficcari incipit, in ollam infura et aëri expofita faporem dulcem ilico amittit et fubacida redditur, idque ocyus fi vento moveatur, fine ulla tamen fermentatione, quin et aqua fructus Maninga hoc modo omnem fuam fermentationem amittit. Quodad operimentum, aquam et medullam continens, illud primum tenerum, elque in fructu Corumba adhuc molle et efculentum, ac fapore nucis juglandis; quo vetuftior fit fructus ac medulla durior, etiam magis indurefcit, ac cum maxima duritie eft, feetioni minus pervium, eftque exterius tribus futuris eminentibus in longum ftriatum, ac in parte inferiori inter futuras tribus quafi oculis claufis donatum, quorum unus latior et minus durus eft, inter futuras, quae latius diftant, fitus, uti e FIGVRA SECVNDA TABVLAE noftrae omnibus pater. Ef et alia minor Nux Indica Coccos Cercopitbeci caput repraefentans, defcripta in Mifcell.Nat. Curiof. Dec. I Ann. VI. et VIl, et apud ChabraeumStirp,Sciagraph. p. 21 . nomine Nucum Indicarum velut larvas oftendentium. Operinentum hoc medium nucis adeo durum eft, nuce penitus exfic- 
cata, ut poliri poffit, aurificibusque ob ferventem flammam in ufu Cortex exterior operimentum medium obducens, in exteriori fuperficic primum eft albicans, ut in fructibus de Coquinbos cum tenerrimi funt, dein viridefcens ac cum majori aetate ex viridi flavefcens, cum auteni fructus vetuftior eft, ac exficcari incipit, eft tandem ficcus cinereo fufcus, et primo quidem mollis ac tenuis eft, dein conltans intus carne denfa, albicante et molli, quae in Lania adhuc tenera mollss et fectioni facie pervia eft, ac calce illita flavo colore tingitur, poft magis ac magis indurefcens intus in carne plurimis lignofis ac fupeis filamentis, in figura. prima Tabulae bujus optime expreffis, ad funiculos conficiendos idoneis, quae operimento lignofo exterius arete adhaerent, eft intertextus. Haec de frußtu Coccos ejusque medulla, contento fucco, e quo liquor. Suri conficitur, ejusque operimentis five corticibus fufficiant. Arborem Cocciferam quod attinet, Palmis accenfendam recte de illis judicat ingeniofiffimus Rajus, quia toto vultu, habitu et conftitutione, partiumque fere omnium forma texturaque $\mathrm{ab}$ aliis arboribus omnibus differunt, non immerito pro fingulari et diftincto ab is genere haberi de-. beant; hinc a Pl. Rev. P. Plumier Palmac, inter nova Plantarum Ane. ricanarum genera primus locus et prima decreta tabula. Non pollum quin Excell. Plukenetii Judicio de Coccifera claudam Arbore, quod babet in Almag. Botanic.p. 135. Arborum barum Dominos non minus; emolumenti ab iis percipere, quam Europaeos a pecore, nam fingulae. pleraque ad vitam necefjaria praeftant. E Ligni materia naves fa: bricantur, e ramis, qui in Malabar olla vocantur, aedium fiunt tecta, navium tabulat a et opercula, fr agula, culei aliaque ejus generis utenfilia. Nucis extimum villofum involucrum infervit nautis, nam ex eo rudentes et funes navibus nece fjarios conficiunt, qui in aqua marina incor.. rupti manent; illo quoque tanquam jtupa naves obturantur et fipantur. Ecortice duro Vafatornantur et Scyphi, ac carbones funt auri: fabris utiles. Medulla ipfa tenera et delicata inftar amygdalarum eft. benenutrit, cum Saccharo aut Jagra editur. Exea trita, ut ex Amygdalis, lac exprimitur, cum quo oriza coquitur, aliaque edulia. Ex]ic-: cata baecmedulla Copra dicitur, quae alio defertur ac venditur, eaque utuntur ut caftaneis, neque minus grata palato eft. Ex eadem ita: exficcata torculari exprimitur oleum dulce, non modo utile ad lucer$n .1 s$, fed et ad oryzam condiendam. Refinam etiam fundere hanc $P$ al. mam coloris Jubfufci et pellucidi, faporis lenti, ac praepinguis, tefis eft Clar. Syen Not. in Hort. Malab. T. 1. p.8. Liquor, quem fundit et Sura dicitur; binc Belgis Suraboom vocatur, eft inftarmufti et decoquitur ut diutius confervari poffit, atque tum Oraque five Arak vocant. Defillatur quoque ex eo Spiritus, quem Futa dicunt, Spiritui V ini plane. fimi-. is facultatibus et viribus; $f$ joli exponatur, antequam defilletur, in. Acetum degenerat. Solis aeflu exficcata et coggulata in Saccharum co. gitur, quod Sagra dicitur. Ex quibus omnibus hactenus recenfitis pa. 
lam fit, vix Arborem efle, quae majorem in vita communi habeat ufum, hacipfa. Figuraenucis coccos hac tabula expreflae omnem certe merentur laudem, hinc Excell. Gren in Auf. Societ. Reg. fcribit : There is a good Figure in Besler. Vltra jam citatos fcriptores vid. Foh. Baubin. Tom. I. p. 37 s. Linfchot. P. IV. Ind. Orient. c. 12. Muf. Reg. Olig. Jacob.Sect. VI. p. 27. Terzag. Muf.Septal.p. 65. Scarabell. nel MIuf. Settal.p. I 1 . et qui elegantiffima ePoêtis de Nuce hac collegit Eruditiff. Lorenz. Legato nel Muf. Coppian. L. II. c. 24. p. 134. Valent. Muf. Mufeorum P. 324. Mifcell.Germ. Curiof. Decur.II. Ann.VII. P. 47 6. Nieremberg. Hiftor. nat. Libr. XIV. cap. VIII. p. 296. Clufus five potius Garcias ab Orto Arom. Hift. Lib. I. c. 26. Pomet l' Hift. gen. des Drogves P.I. Livr. VII. chap. XXIV.p. 214.

Quam pro $A R E C C A$ five $F A V F E L$ hic depingere curavit Bes: lerus nofter figuram, nil aliud eft quam fructus peregrinus abiegnae nuci fimilis, ab Excell.Grem in Muf. Soc. Reg.P. 2. cap. 5. p. 200. poft Clufium pro fructu Palmaepinus habitus, qui errorem Auctoris feq. verbis annotavit: this fruit is 'pidur'd in Besler but miftakenly for the Arecca or Faufel.

FRVCTVS RETICVLATO COR1O, optime convenit cum deIcriptione CLVSIANA, minime autem cum figura inibi, Exoticorum nempe Lib. II.c.XI.p. 30 . expreffa, quod ipfemetfatetur, iconem non adeo fcite ut decuerat in Tabula depictam effe; eft enim duro corio et multis fibris retis in modum quodammodo inter fe intertextis et duris, contecto praeditus, foris quidem inaequali et rudi, intus vero laevi et Iplendente, coloreque ad fpadiceum tendente, fuperna in gibbum extuberans, inferna planus fere, nucleum continens craftum, plenim, et fucculentum. Meminit fructus hujus, citato Beslerinomine et figura, Excell. Grew in Muf. Societ. Reg. P. II. cap. V. p. 2 I 3 . fub nomine Fibrolls Lobe; et jam ante p.19r. fub nomine Netted Stoone, fructus quo-

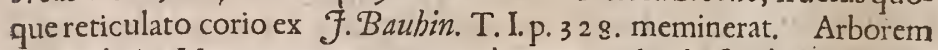
fructus hujus Mameyam vocant, et arborem Juglandi fimilem pronun. tiat C. B. in Pin. Excell. Sloane autem credit effe malum perficam maximam foliis rotundioribus fplendentibus glabris, fructumaximo, fabro rugofo, fubrotundo, pulpadura fublutea, unum vel plura officula filamentofa cingente. Ab Anglis Jamaicam Infulam inhabitantibus the Mammee Three vocatur, ibique in omnibus fylvis montofis abundat.

$M E H E N B E T E N A E$ CAPILLAT $A E$ et fine capillis nucis unguentariae vel avellanae Indicae fpecies videntur, inter quas referunt C. B. in Pin. et Mlatthiol. in Diofcorid.p. 22 8. Edit.ult. Baubin. et Excell. Gren in Muf.Societ. Reg. p. 206. Mebembetene like a Hasle in Nero Spain. Differt tamen fpecies fine capillis, ab altera capillata, quod illa duas cellulas habeat, in quarum fingulis nucleus oblongus albus dulcisque; haec vero tres cellulas habet, in quibus nuclei totidem, ejusdem cum reliquis faporis colorisque. Vid. Cluf. Not. in Garc. ab Ort. Aromat. 


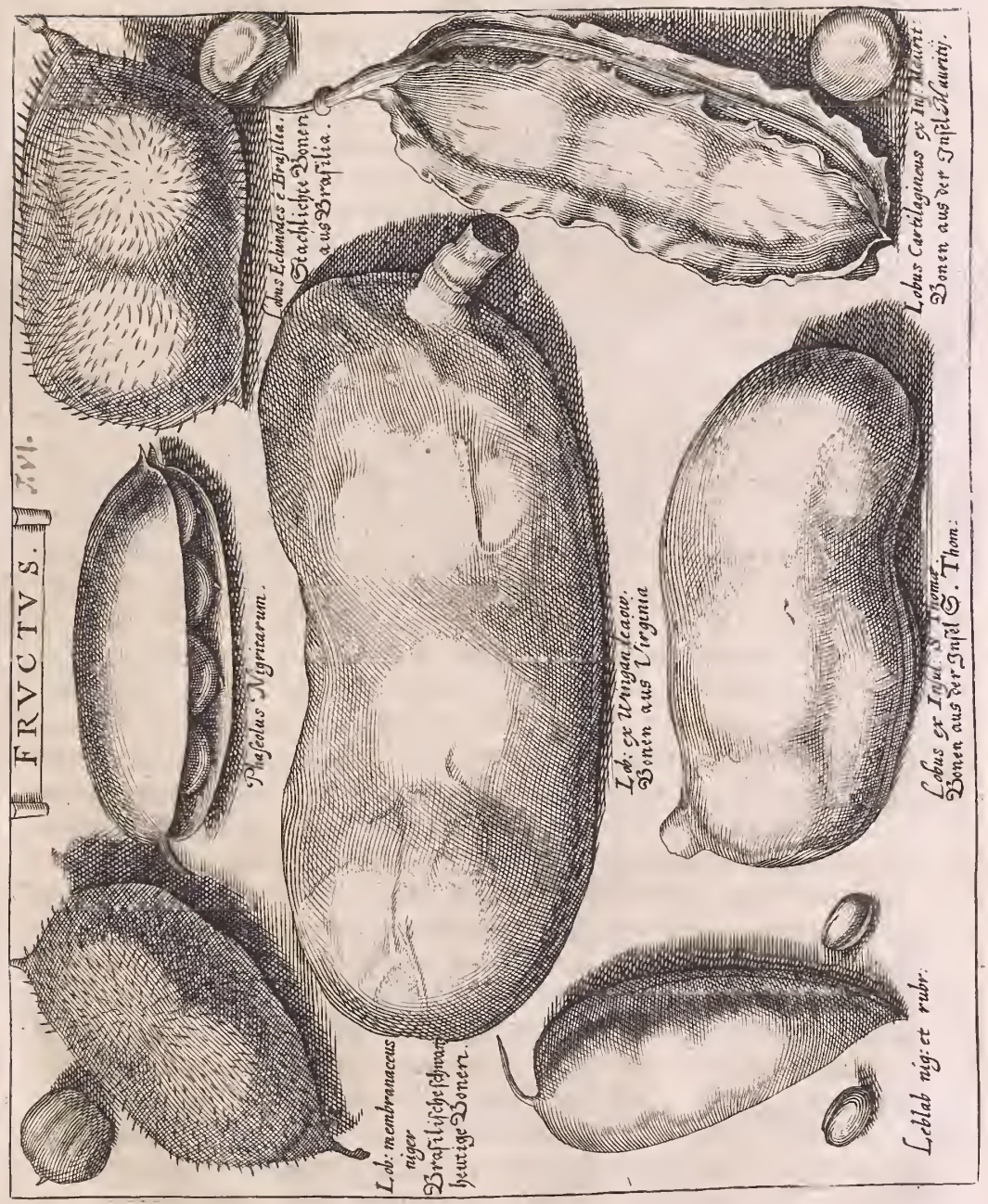



Hift. Lib. I. cap. 26. et Chabr. Stirp. Sciagraph.p. 20. qui Mełenbetene Cortufi villofas et villis deftitutas exhibet, aliasque adhuc Cortufianas ab Auctore noftro omiffas fubftituit.

\section{TAB. VI.}

L

$O B O S$ haec Tabula continet, et quidem $L O B V$. AI Exwrión e Bram filia, qui fecundum Marggravium et $\mathcal{P}$ ifonem crefcit in Frutice afpere echinato et vix tractabili, in fylvis arenofis et litoribus fitientibus pullulante et jucunde virefcente, Brafilienfibus Snimaboa, Lufitanis Silva de Praya, et reliquis Indis BONDVCH dieto. A Cafp. Baub. in Pin. ad arborem exoticam fpinofamlentifi foliis refertur. A Clariff. Breynio in Prodr. defcribitur ceu frutex fpinofus fpicatus platylobis, echinoidibus Glycyrrhizae foliis, Excell. Plukenetio autem in Almagefto eft Acacia gloriofa lentifci foliis fpinofa flore fpicato luteo, filiqua magna muricata. Sed ut verum fatear, Lobus, ab ipfo Tab.II. Fig. 2. Phytograph, delineatus, nimium quantum a noftra Besleriana figura difcrepat et abludit. Si Horti Alalabar. T.II. p. 35 . confulimus, videtur efle Mucunae fpecies, de qua Pifonarrat, quod loborum echini et letae pungentes faciem et manus usque adeo infecerint, ut ardentiffimas puftulas excitarent, quae vel optimis fuccis anodynis ef refrigerantibus ultra octiduum adhibitis vix cedebant. An phafeolus Surrattenfis, fummum fpecificum antihydropicum Cl. Raji Hift. Plant. L. i s.c. 1.p. 877? Conftat autem hic Lobus Cortice membranaceo fufco fubrubente et frequentibus fpinulis hirfuto, magnitudine differt, nofter quippeClufiano minor. Vid. plura apud CluJ. Exot. Lib. II. cap. XV. p. 70. Rev. P. Bonann. Bonduch ab infantibus Aegyptiís amuleti loco geftari refert in Muf. Kircher. Claff. VII. n. 17.

PHASEOLVS NIGRITARV $M$ a Clufio pariter Exot. L. II. c. XI. fufe defcriptus, eft Mucuna fecunda Pifonis, quae figura et forma imbellis apparet plana finuofis oris, cortice non valde craflo praedita, externa parte nigro, non tamen adeo rugofo, (ut in Clufiana defcriptione) tumenteque, qua parte Phafeoli inclufi, interna cineraceo, cufpide longa et mucronata, dorfo fatis elato, in quo terni aut plures fru. ctus, quibusdam velut cellulis diftincti, orbicularis fere in plano formae, coloris fufci et tanquam annulo five circulo totum paene ambiente.

LOBVS MEMBRANACEVS niger Flacourtii Voatalalac efle videtur, et $\mathrm{Cl}$. Breynii Crifta Pavonis Glycyrrhizae folio minor re. pens fpinofifima, flore luteo fpicato minimo, filiqua latifima echinata, femine rotundo cinereo, lineis circularibus cincto majore.

LOBVS EX WINGENDECO AW, Americae verfus feptentrio onem tendentis Provincia ad Poli Arctici Elevationem XXXV. gradibus fita, quam Angli Duce Walth. Raleigh detectam, Virginiam nun- 
cuparunt, videtur effe Mucuna Guaçu Pifonis in Hiftoria natur. Brafil. crefcens ex arbore ejusdem nominis. Faba autem haec nigra pelle lapidis fere duritiei, pilis flavis molliter eft veftita, manum longa et tres digitos lata. Vi effracta (nam dicitur a Clufio unciam denfa elle, quo nomine vapulat Muf. Societ. Reg. Angl. P.II. cap. V. p. 213.) pulcherrimi globuli interltitiis divifi inde prodeunt tres quatuorve, punicei et rubri coloris, rotundi laeves, magno hilo. Venenatis fabis accenfetur, qualitas tamen deleteria extinguitur, fi in Aqua macerentur globuli.

LOBVS CARTILAGINEVS EX INSVLA MAVRITII hoc nomine quoque a Clufio exhibetur; ab Excell. Plukenetio Tab. 213. Fig. 2. Almag. p. 292 . autem dicitur Phafeolus Americanus frutefcens foliis glabris lobis pluribus villofis purigentibus fructu orbiculari plano, hilo nigro, tanquam annulo totum fere ambiente. Cap. Baubin in Pin. eft lobus Cortice cartilagineo rugofo fufco duplici crifta finuofa donatus. Fob. Baubino vero T. II. Libr. 17.p. 272 . Lobus Cartilagineus ex Infula Mauritii phafeolo feu faba nigra; Ejus accuratam delcriptionem dabit Mufeuin Wormian. p. 198.

LOBVS EX INSYLA S. THOAIAE, eft Lobus crafus Infulae $S$. Thomae Clufii duro craffoque Cortice conftans, coloris e cineraceo fufci, de craffo pediculo pendens : videtur autem differre a $F$ aba purgatrice et corde $S$. Thomae, cum figura Cor minime referat, et figura noftra plane non conveniat cum illa in Mufeo Calceolariano p. 6or. Fig. VIII. exhibita. Vid. Chef. Exot. Libr, III. cap. VIIl. Muf. Worm, p. 198. Muf. Molcard. Libr, III. cap. 101.p. 259.

LEBLAB NIGRVM et RVBRVMI ef Phafeolus Aegyptiacus femine nigro et ruffo C. B. P. vel Pifum Americanum coccineum, aliis Abrus J. B. vel Arachus Indicus five Africanus Parkinfoni. Videntur tamen hae Plantae probe dividendae, cum Alpinus matrem hujus fructus arborem farmentofam ad vitis magnitudinem crefcentem, farmentisque vitis modo fe extendentem, Clufius vero cum Excell. Rajo Hift.Plant. libr. XVIII. cap. I.p. m. 888 . et 88 g. contrarium fentiat. Siliqua, quam Auctor nofter habet, fpadicei eft coloris foris, unciam aut paulo amplius longa, femiunciam lata, illaque aliquantu. lum plana, mucrone aliquantulum incurva, femina duriffima ovalis figurae partim rubra, cum hilo eminenti candido, partim nigra, cum hilo quoque albo continentia. Excell. Rajus refert prorfus rubra et nitentia ac inftar Coralii expolita illa exiftere, quae probe matura funt, fumma autem parte, qua filiquae inhaerent, omnino atra et prae laevo. re fplendentia effe. Probe omnia expendenti crederem certe Lablab Alpini five Pifum Indicum coccineum five Abrus, plane diverfas Plantas efle; quam tamen conjecturam nemini obtrudere cupio; in Mufeo quoque Calceolariano p. 585 . apertediftinguuntur. Auctoris certeno: 


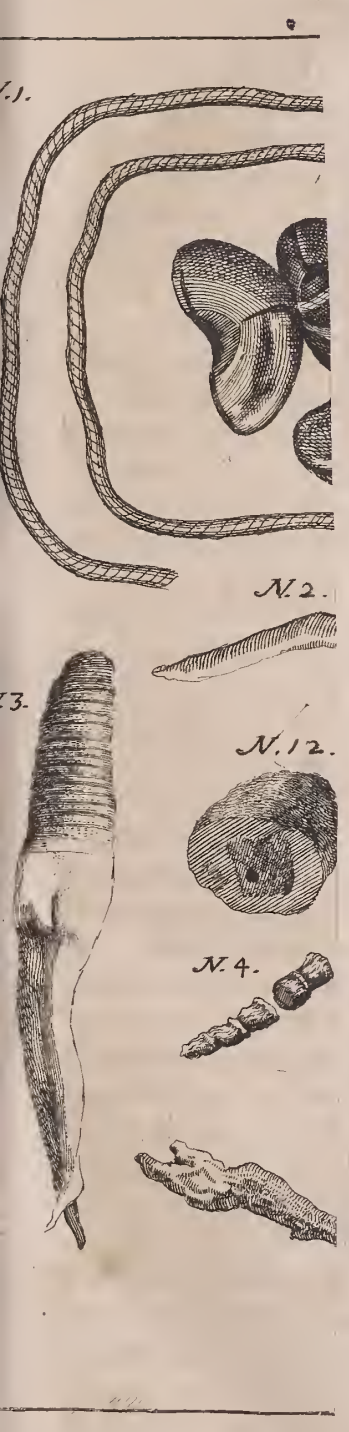





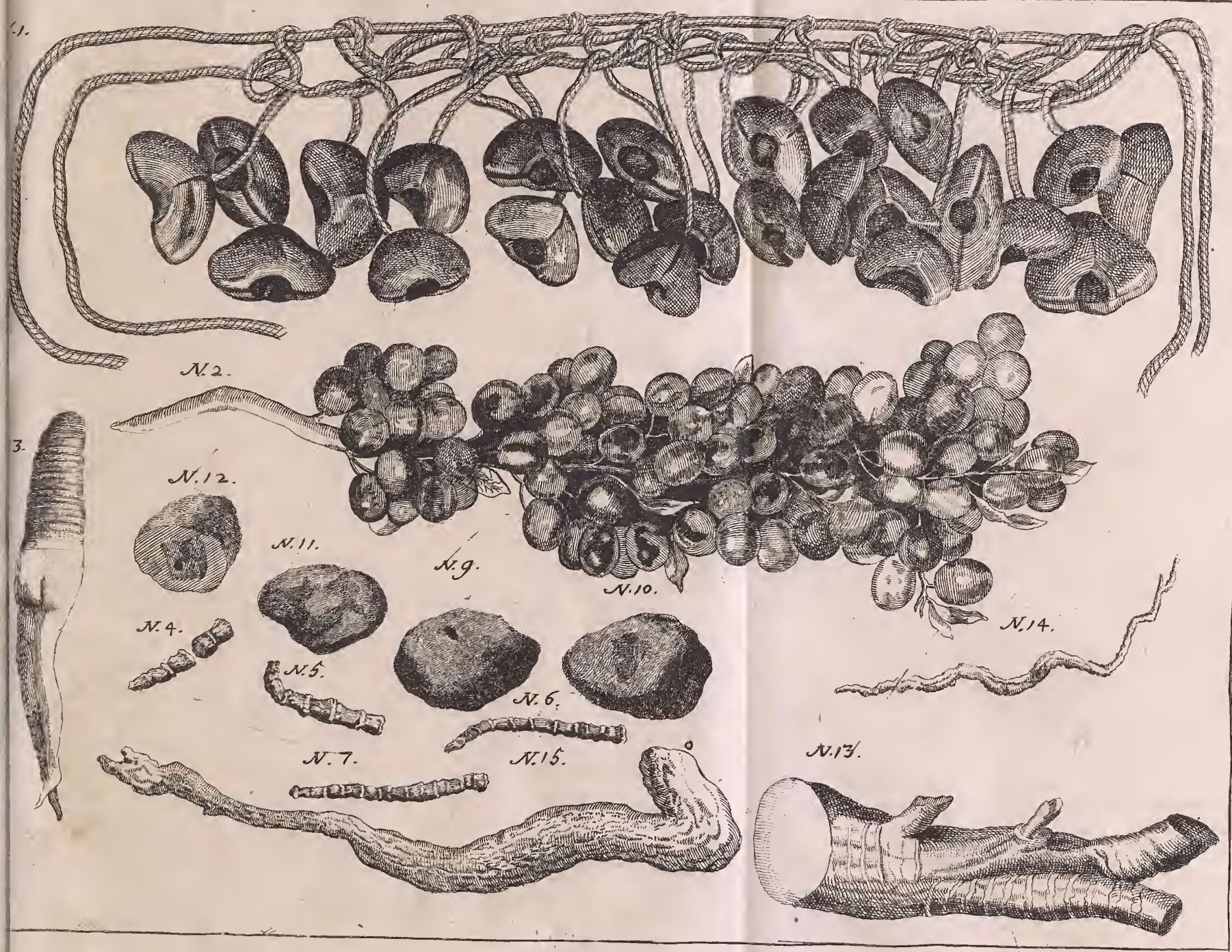




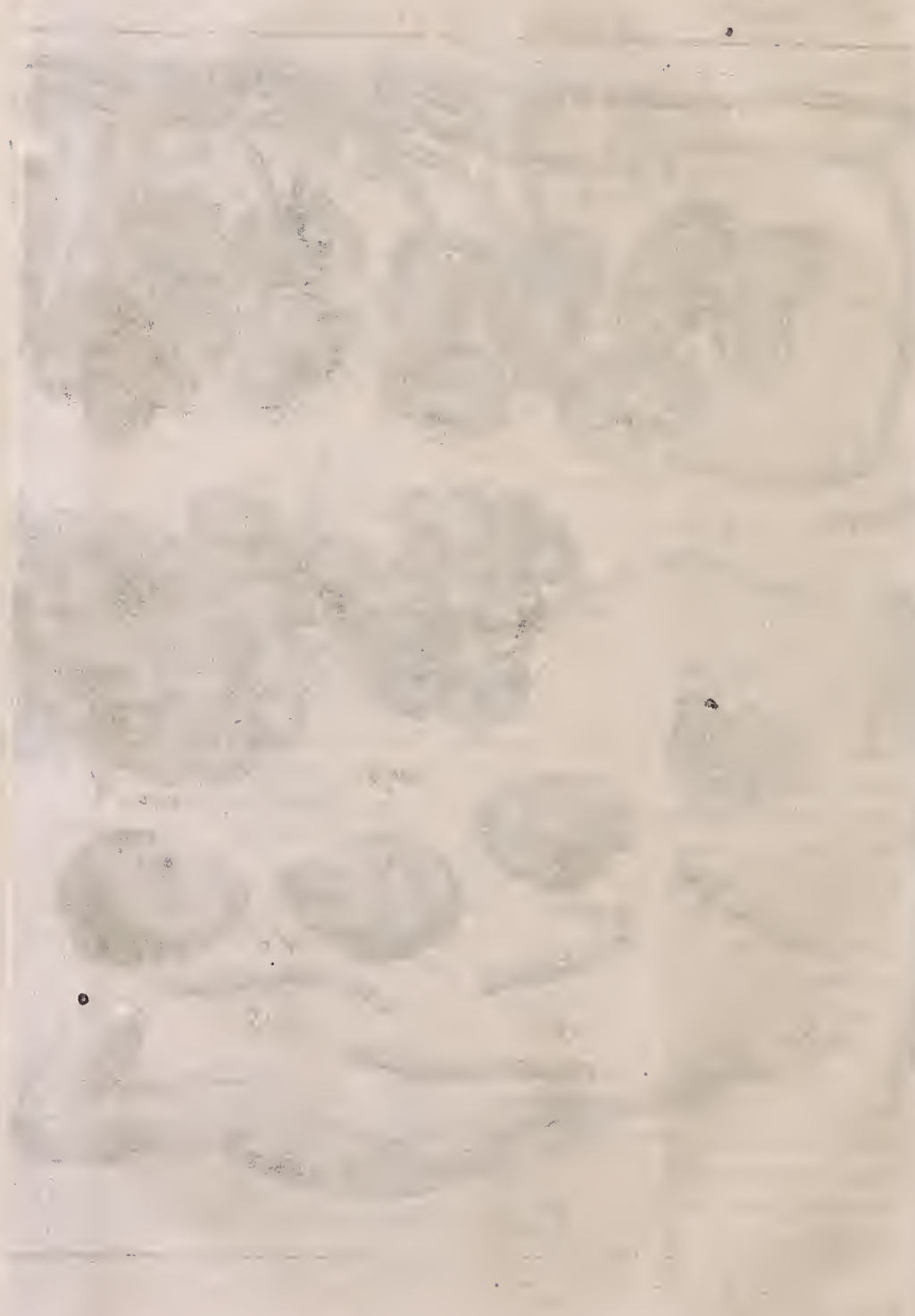


nipi figuram Lablab cle credimus.' Confer. Mul. Mofcard. Lib. III. cap. 103. P, 26 r. Kev. P. Bonann. Muf. Kircher. Clant. VII. n.19.

\section{TAB. VII.}

N. . HOVAI fructus in Gazopbylacio D. M. R. Besleri exPar, 1 quem his Beslerianis rarioribus adjungere placuir; nafcitur hic fructus in Arbore Abovai, a Theveto et. Lerio primitus defcripta, quam Arboribus pruniferis anomalis accenfet Illuftr. Rajus: Excell, autem Tournefortius, e Piumerii relatione, characterifticas astribuit Florem monopetalon, infundibiliformem, multifidum, e cujus calyce furgit piftillum, infimae floris parti adinftar clavinfixum, quod deince abit in fructum carnofum quodammodo pyriformem, officulo foetum fere trigono, proxime accedens ad lir. $\Delta$ graecortum, nucleum condente; antea enim, priusquam hoc a Plumerio edocti fumus, officulum pro fructu habuere fcriptores ; quod praeterea duriffimum eft et timulum, unde a Barbaris tintinnabulorum loco ufurpatur, et beachis cruibusque circumdatur ornasus gratia, id quod e plurimis Ahovai officulis contextum, in figura noftra exhibetur, clavis et iam fuiset fecuribus, aliisque inftrumentis alligant. Arbor dicitur effe eximiac proceritatis Pyri majoris magnitudine, foliis femper virentibus er mali noftratis non abfimilibus. Teterrimum autem haec arbor fpirat odorem, Alitum c Lerii relatione fuperantem, ut fi fendatur arbor, odor tolerari vix queat, propterea a barbaris ne ad pyras quidem ufurpa. rur. Addo Coronidis loco, quae D. D. Mich. Rup. Beslerus in Gazophyl, huic fructui adicribi curavit: Frulins arboris AHOV AI diita mirabilis, cujus Nucleus praefentiffmumeft venenum, quod Indiarum Incola in odio conjugati, viri uxoribus infenfi et contra uxores viris indignatae propinare non verentur. Eæemt a medulla, frudus flo Xylino annedunt, unde ex mutua collifione, nolarum ac tintinnabulorum infar fonitum edunt, binc in fallationibus, ad majorem animi bilaritstem excitandam crutribus ad texturan banc jecundum naturalens magnitudinem affabre deltneatam, alligare confuevere. Confer. Mur. Mnfcard. Libr. III. cap. g6. p. 256, Add. de Frulu Abovai, in Lapide fffrli Manebachenfi exprefito, Dn. Nylium in Saxon Subterr.pag. 30.

N. 2. RAMIVS hic ex eodem Gazophylacio Besleriano deprom. tus, his verbis defcribitur: Racemns infignis Anno 1641. ab Arboris trunco recifus brotrum magis reprae entans, a qua prunorum Alyrobaliznoriun, numero Centum et viginti dependebant, vifu mirabilis; ponderistres civiles Libras et $\frac{\pi}{7}$.

N. 3. NINZIN Sinenfium et Gapanenfinm Panacea eft, cujus primam mancam licet mutilumve notitiam dediffe nobis videtur Celeb. Wormius in Mlufec, et Cl. Pifo in Aromat. Mantiff. Mirade hac radice referunt, quac fidem pacne praefertin circa perennitatem vitae, fu- 
perant; habet tamen congruentia quaedam cum fabulola illa herba Achaemenidon five Achaemenis, de qua Plinins Libr. XXIV. cap. IT. Varia radicis hujus ñomina, dicitur quippe Sincnfibus Gin Sen Excell. Alenzelio e textuSinenfi interprete Dec.11. Epbem. Nat. Cur. Ann.V. obferv. $X X X I X$. ex hom inis comparatione five fimilitudine, quod radix haec cum hominis effigie comparctur, Gin enim hominem, et Serz comparationem fignificat; E quo vocabulo detortum Gen fingh Solertiffimus Kaempferus. Amoenit. Exot. Fafciculo V. Claff.uII plura plantae nomina fuppeditar, nempe Sjusjin, vulgo Nifii, Nindfin et Dfindfon, item Som. Tartarice Sonfai. Nominum varietas peperit quoque lententiarum difcrimen, cui Plantarum generi accenfenda foret. Sic Wormius ad Eryingia, plures ad Mandragoris, nonnulli ad Petrofelini radices, $\mathrm{Cl}$ Kaempferus denique ad certum genus retulit, et Sifarum montanum Coraeenfe, radice non tuberofa pronuntiavit. Coraeen fe vocavit, quod in Cor aede Infulae montibus et Catbajae Provincia Sjam $\int_{a}$ utplurimumcrefcat. Mart. Martinius in Atlant. Sinico, regio illo opere, radicis hujus in defcriptione regionis J Jugping meminit: asaváro P. Kircherus in Chin, Provinciam Leaotoung Orientem verfus Coraea fram, (per quam Provinciam Tartari, Sinenfis nunc imperii Domini, primum fibi adicum pararunt, ) nutriculam hujus radicis ftatuit, et hac parte confentienteñ habet P.le Comite in Itiner. Sinic quibus Dion. Cao ipfe Sinienfis in defcript. Patriae pariter accedit. In Hortis urbis Macao coliet'magis quam in ipla Patria luxuriare, fed virtute fere exortem elle, toties laudatus Kaempferus teftis eft, hinc probe a vera Coraeana five Sinica difcernendam elfe Japonicam radicem, optime monet diligentiffimus Brènius in eruditiflima de Gin Senfive Nifi babita differt. Lugd. Batav. 1700 . 'qui radicem lequentibus optime defcribit, ac potius Petrofiliniquam Páfinacae (ad quam Exccll. Rajus retulit) iilant fimileiti credit, longe tamen.rinorem, 'coloris tam interne quam externe e flavo albelcentis, zeretem präeterea, rugofam, compluribus fffuris jubtiliffimis fufcis imprimis in 'suprema radice denfe circinatam, ac Mandragorde tasidem de more plerunque in duos, (ut in moftra hac figu$\mathrm{ra}$ ) : quos cruradiceres, rarius in tres divaricatul ramos, fi vero, guod rariffime contingit, in quatuor, ut ita non tanium crura, fed et bracbia referat humana, unica radix tefle Cl Rumphio in Epbem. Nat Cur. Dec. II. Ann. V. "Alagnatibits S!nicis aliquando, centenis redimitur imperialibus, et Laris inftar colitur. Subftantia Poeonide radicum folidiore, conftat. Si transwerfim diffecetur, circulus in medio apparet rejino. Jus, ruffefcens. Parte infina faepius aliquantulum diaphana eft. Sapore praiedita eft dulci ad Glycyrrbizam vergente, quanquam tonge fuavio. ri cumlevi amaritie, et occult a five leviori vi a roinatica linguam blan. de excalefaciente, conjundio. Odorem pene nullum; digitilongitudinem, crafjitiem auricularis rarius obtinent, plures multo breviores, calami majoris crajfitien vix excedunt. Faponica radix Ninzin circularibus 
iftis lincis in Cordecpfindigitatis paene caret; intus albaet minus folida eft, faporeque et wirtutibus magis deflituitur. Plantan radicis fecundum omnes partes accuratiffime, uti folet, defcripfit Kaempferus, uti et colligendi et praeparandi modum. Vires attribuuntur hyperbolicae, efle tamen optimum virium amiffarum reftaurans, inque febribus malignis herculeum remedium, nemo, qui radicem exhibuit negabit, opti. musque Parens laepius illud Martinii de hac radice, acternae veritatis effe fillus eft: moribundis ita vitales quandoque vires reddere, ut fae. pe illis adbuc tempus fit fumendis aliis medicamentis, fanitatique recuperandae. Plura de hac radice praeter jam citatos Auctores Illuftr. Redi Experinn. circa Res Natur. ex Ind. all. Excell. Valentinim Alufeo Alufeorum; Ephem. Nät. Curiof. Ann. IV. Dec; II. Obferv. II. cum eruditiff. Scholio Alagnif. Praefidis, Cl. DEKKERVS Exercit. pradtic. p. 667. cl. Hernamus in Gynofur. Miat. Med. Pomet l' Hiftoire generale des Drogves in App. p.4. Helvetius dans le Traitté de maladies les plus frequents, et des Remedes pecifiques, $\sigma^{2}$ c. in fine fuppeditant.

N. 4. 5. 6.7. IPECACOANHAE RADICIS frufula funt, celebratinimae illus Dyfenteriae victricis, quam primitus Clufius in Alonard. fimpl. Medicam. Hiffor. fub nomine Bexugo del Peru, (hinc adhuc hodie Bexrugillo dicitur;) polt illum Duumviri Braflienfis Hiftoriae folertiflimi Pifo et Mlarggravins fuflus expofuere, et publico notitiam medicaminis hujus vere incomparabilis dedere. Siluere tamen a tempore horum Auftorum encomia remedii optimi, usque dum in Gallia, occafione Centum et quadraginta radicis hujus librarum a Merca. tore Gallo Dn. Grenier allatarum, et cum Dn. Hadr. Helvetio Ducis Aurelianenfis Archiatro divifarum, diffidium ob lucrum inde hauftum, crtum, in gloriam Ipecacoanhae et tot aegrorum falutem vergens; qua de revid. Illuftris Leibnizius, miraculum jeculinoftri, in Relat. ad Societat. Nat. Curiof. Leopold. Imperial. de novo Annericano antidyfenterico. Habebatur a plurimis $\mathrm{Cl}$. Helvetius ille ipfe, qui primitus ad dy fenteriae diras abigendas hoc remedii genus produxerit, Pometus tamen daqs lHifloire generale des Drogves aliud evincere videtur oftendens, hanc radicem vigintiet plures annos prius extitife in officina Pharmacevtica Dn Claquenzelle, quam ab Helvetio in ufum vocata fuerit. Dividitur autem radix haecin gryfeam five cineream, fubnigricantem five fufcam et albam a materiae Medicae fcriptoribus, quibus flavefcens non geniculat addi potelt, de qua Excell. Rajus ex relatione Dn. Sherardi, nationis Anglicae Smirnen/is Confulis fulgidiffimi, quaedem retulit, HIatrem agnofcit haec radix periclymenon parvum Brafilianum alexipharma. cam $F$ xcell Plukenetii in Almag. Botanico; a Morifono in Hiflor. Plantar. Oxonienf. dicitur Periclymeno accedens Planta Brafiliann, flofyulis congeftis albis, ab Illuftr. Rajo autem Herba Paris Brafiliana polycoccos five racemofa, unde ab Herba Paris dita differt. Stupendae Radicis hujus vires in depellendis cruentis alvi flux bus anfäm dedere, 
ut Excell. $V$ alentini peculiarem hac de radice differtat, confcripferit, editam Giejf. Haffor. Anno I 60,8. Hunc fecuttis CI. Dn. Leinker, practicus in patria hac urbe fclicifimus, difputationem inauguralem jenae fub Wedeliano praefidio Anno 1705. defendit de ipecacoanba Americana et Germanica; quibus binis differtationibus omne id continetur, quicquid hac de radice dici poteft, ut, ni lliada polt Homerum fribere velim, nihil mihi reliquum, quam ut Coronidis loco cum. Excell. Hermanno de. frniamus Ipecacoanban effe radicem digitum et amplius longam flexuo. fam calano tenuiorem, nodofan et quafi geniculatam, in fuperficie ex numerofis circulis vel annulis exalperatam, foris fufcam, intus. pallidam vel buxei coloris, Japoris fubacris amzaricantis et ingrati quodammodo naufeofi. Conftat blando fale volatili, et vis ejus in cortice confiftit, qui quo recentior, eo quoque potentior. Vid practerea $P$ o. met l' Hifkoire generale des Drogues p. 46.47. et in App. Cl. Dekker Exercit. Prad. P. 28I. et imprimis Helvetius Traité des maladies le plus frequentes, et de Remedes Speciflqu.p. I.57. Edir. Eyben. Belgicae.

N. 8.9.10. 1wet i2. Variae FABAE S. IGNATII vulgo dićtae, proles Cuclirbitiferae Malabatbri foliis fcandentis Caialongay et Cantara Pbilippinis Orientalibus appellatae. E mente Canzelli nu⿰ haec Vomica legitima Serapionis Igafur denominata. Nuclei Pepitae de Byfayas aut Catbalogan, item Managog, id eft, vittoriof nuncupati, tefte Excell. Plukenet. Almag. Botanic. Mantiff. Inveftuntur lanata quafi tunica, ģuae dum in aqua macerantur, fecedit, et fubstantiam fub fe monltrat nodolam, duriflimam, diaphanam ac quafi corneam, quac in rafuram melius ac citius quam in pulverem redigi ac comminuipoteft; colorisinter album et:glaucum, faporis intenfius amaricantis, ad Centaurii minoris amarorem accedentis, quae tamen non impedit, quo minus a vermibus; ut $n$. 10 . apparet, arrotatur. Internam frutturam quodattinet, patet ex n. 12. alięuali medulla haec concreta non delt tui, indeque e fabarum confortio relegantur. Vires affignantur his Scrapionis legitimis nucibus vomicis alexipharmacae, et virtus quartanas, nulla alias arte fuperabiles, abigendi; dum vero vertiginem producunt, et ad vomitum ftimulant, angvem in herbadateredocent. Ana Anglicana primitus hujus remedii Anno r699. poltea AdA Eruditorum Lipl. Anno soo, Menf. Decembr. meminerunt; deniqgue Excell. Valent thi in Polycbre. fits Exot. Ti/p. fufus has Serapionis vomicas et in Mlus. Alufeor. deicrippit; add. Rev.P. Bonan. in Mufeo Kircher. et paffim alii.

N. 3. Novum Americanum calculi remediun fiftit $P A R R E I$. RAM BRAVAM1, natam Caapebae Bryoniae et Snilacis asperae offinis Plantae, Sororem radicis di Nolfa Senhora, a quanon nifi ratione aetatis indegue dependentis magnitudinis fibrarumque duritic differt; brachium haec radix facpius adaequat mole, cutis ejus afpera, colori $n$ :gricantis, eminentiis interdumnon tamen in omnibus pracdita. Sapoxem habet ziuxúrsıon, odorem, fi blando calori admoveatur, liquinitiae 

JÄBVIIL 20

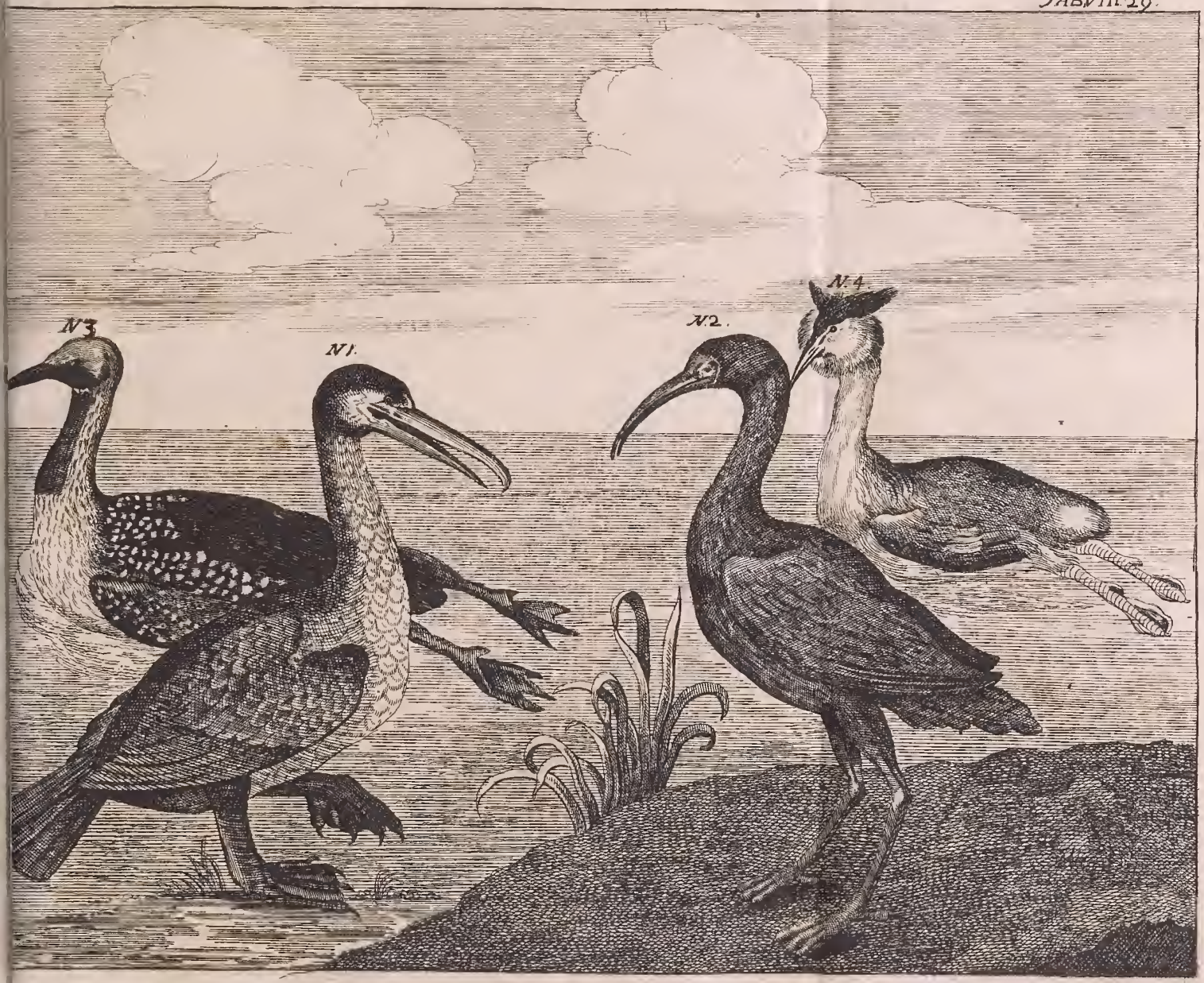



aemalum. In omnibus calculi affertibus fpecificam poffidet leniendi et evacuandi vim, dum vilcida incidit, attenuat et per $V$ rinam eliminat, hinc in Aftbmate quoque laudatur quam maxime. Hura non addo, cum $P$ arens dilediff. luculentum hac de radice ediderit Schediafma Centur. I. et II. Ephem. Nat. Curiof. annexum, in quo, quae radicem hanc concernunt, collegit.

N. 14.et15. Radices funt MVNGOS vel $110 N G V S$, ab animalculo mufteliformi fic dictae ; crebro vagoque flexu intortae colubrino chematiaccedunt, cortice firmiter adnata fungofa, rufa, rugo$\mathrm{fa}$, fubftantia lignofa, dura, fibrarum exorte et fragili, coloris albidi, faporis amarillimi, gentianae inftar, fed fubtilioris et haud aeque ingrati, a quo amarore nomen Malaicum Hampaddu. Tanab i. e. FEL TERRAE obtinuit. Planta eminus confpecta faciem exhibet Centauriiminoris fecundum Excell. Kaempfer.in Amoen. Exot. Cl. Rumphius tamen. et Herbert. de Fäger Clematiti Indicae foliis Perficae fructu Periclymeni vindicant. Exploratum haec radix antidotum contra Venenum ferpentis Cobra di Capellos dictae; maxima radiculae celebritas enata a virtute, quam adverfus toxicum Mlacafarenfe exitiale praebet, cuiveneno ante radicis hujus notitiam debellando, nullum aliud remedium, quam Stercus bumanum exficcatum fupererat. Feliciffime. quoque haec radix nunc exhibetur in febribus malignis, inprimis in purpura puerperarum, huicque analogo affectu, ceu multiplici edoctus experientia teltatur optimus parens in Mungo Animalculo et radice de. Soript. et Cent III. et IV. Ephem. Nat. Curiof. Append. annex.

\section{TAB. VIII.}

$\mathrm{H}$ As quas junctim exhibemus $A V I V M S P E C I E S$, in tot Tabulis feparatim exhibuit Excell. Mich. Rup. Beslerus in Gazopbylacio fuo. Natantes et Aquae adftantes aeri incidi curavit, quod in Agri noftri fluentis, tanquam infolitae et nunquam his in terris noftris vilae holpites comparuerint.

Et quidem quod fub $N$. I. delineatum CORVV $M A Q V A T I C V M$ attinet, ille Anno O.R. MDCL. in vivario publico, quod ex duodecim in unum confluxit, hincque nomen Dutzetteich ipfi impofitum, a viro, cui cura lacus hujus commilla, dum pifcibus infidias ftrueret, globo trajectus eft. Ab Excell. Charltono Phalacrocorax vocatur, licet alii corvum hunc Aquaticum a Phalacrocorace diftinguant, ut apud lonftonum de Avibus Libr. IV. cap. V.p. m. 131.patet. A Clariffimo Rajo in opere IVillugbejan de Avib. Libr. III. SeAt. II. Membr. I. cap.3. refertur inter aves pa'mipedes tetradactylas, quibus digiti omnes membranis intercurrentibus connexi funt. Vocatur Anglice Cormorant, in Cornubia autem, Excell. Charltono tefte, the Shagge. In rupibus Preftol. mae Infulae prope Belium marifcum tujus corvi nidum, et complures 
alios in excelfis illis arboribus prope Sevenhuyfen in Hollandia reperit Generofiff. Dn. Willugbejus ; idque notatu digniflimum reputat, cum praeter hanc et Graculum palmipedem five Corvum Aquaticum minorem, nullam avem palmipedem noverit Arboribus infidentem, nedum in iis nidulantem. Cl. Sibbaldus in Prodrom. Hiftoriae Naturalis ScotiaeP. II. Libr. 3. cap. VI. in rupibus aeftuarii Forthae frequentes corvos hos marinos ftabulari refert. In agro noftro rara certe avis

\section{Nigroque fimilima Cycno.}

In reliquis tamen Germaniae provinciis illam repertu dari, nomen evincit, ubi Scetab vocatur, et detorto forte ab hoc vocabulo nomine Scliciben/ quamvis aliam plane hujus nominis Etymologiam apud Cl. Job. Fabr. Schol. in Animal.Novae Hifpan. Nard. Ant.Recchi p. m. 694. inveniamus; cum enim Avis haec Carbonem Aquaticum Alberticredat, nunc Scharbum dici putat a Corvo, quiltalis Corboet Corvo dicitur, vel ab atro Carbonis colore, nam Galli carbonem vocant Charbon, in qua fententia etiam Albertus fuiffe videtur, Carbonem Aquaticum hanc avem nominans, vel ab acumine marginum roftri ejus; noftri Germani enim acutum dicunt $\mathbf{S} \mathfrak{a})$ ff. Conje气tura minus abfona, quam fi vocem Cormorant, quis per corvum morientem interpretari velit, quod tamen Cl. Claudio le Fevre Parifino placuit, a quo dum Sequana Pari*. fios inundaret, horum corvorum Aquaticorum haud pauci obfervati. Mlagnitudine avem ad Anferem accedere ftatuit IIl. Rajus; longitudinem quatuoret amplius Spithamarum tribuit Generof. Eques Calfianus a Puteo, quir infuper de colore lcribit, nigrum in hoc praepollere, nifi. quod Capitisvertex capillatus, colli fupremi mediocris portio, et fub capite ad roftri principium plumae albefcant, macula inter hanc albedinem nigriufcula et non parva interclufa. Sub ventre quoque ad crura praecipue candidae funt pennae; reliquae corporis omnes nigricant, verum non tam faturo atroque colore, ut in corvis noftris, fed aliquid cinerei fubobfcuri atroque rubentis et in collo fubcaerulei admixtum. Ora pennarum in cauda quoque albet, quae palmum et dimidium longa ultra pedes extenditur, extrema circumfcriptione cum expanditur fubrotunda, interius concava, pennis 14 . conftat rigidis et duriufculis, nullis ei neque in prona, neque in fupina parte incumbentibus longioribus pennis. Rofrum (in noftro quatuor digitos et quod excedit longum) luteolum, et hocpeculiare obtinet, quod fuperior ejus pars in fine, ut e figura expreffa elucet, acumen habeat, quo unco veluti harpagone acutiffimo, ad extrahendos firmandosque pifces dexterrime utitur. Mandibula fuperior nigra marginibus acutis; mandibulae inferioris margines compreff, lati. Oculi propius ad aperturam oris fiti funt, quam in aliis plerisque avibus, iridibus cinereis. Lingua exigua et fere nulla. Gulam patentifimam habeat oportet, cum hacc quatuor et fex eriam mediocrium pifcium priusquam in ventriculum detrudantur, capax exiftat, Ventriculus membranaceus, fuperior ejus pars 
glandulofa denfa. Inteftina longa, aliquot vicibus revoluta. Appendices feu caecaperexigua, fecundum du Hamel Reg. Scient. Acad. Hift. L.I. Set. XI. cap. IV . p. I 35. nulla plane. Hepar ei amplum, in duos divifum lobos, quorum dexter major. Pediculis pallide ruffis, qui in medio dorfo magnam maculamnigram habet, infeltatur. Crura valida, brevifima, crafla, lata, et comprefla faltem in junioribus. Pedes et $V_{n}$ gues nigri, cute tecti in fquamas non integras fed cancellatas divifa. Digiti quatuor, omnes antici lata et nigra membrana fimul juncti, extimus longiflimus elt, reliqui ordine breviores. Medii unguis parte interiore ferratus eft. Strultura haec pedum natationi vifa eft maxime accommodata : triplici enim membrana quatuor digiti una colligati aquam magna fucilitate retrorfum agunt. Quin etiam, Gesnero tefte, pede altero praedam furfum vehunt, cum interim pedum digitis et membranisintrorfum deflexis aquam fubventre recta pellunt; nec corpus huc illuc deflectit. Secus eveniret, fi digiti extrorfum prominerent: tum enim idem accideret, quod in fcapha cernimus, dumuno duntaxat remo impellitur; ea quippe in orbem agitur, non recta promovetur: ac pedum brevitas huic quoque rei fervit. Nam fi pes longior effet; obliquus magis foret natatus, ac pes non resta ventri fubjectus, facile huc illuc deflecteret. Haec ingeniofiff.du Hamel.l.c. qui plurima infuper deftruotura interna partium avis hujus retulit. Hodoeporicorum Scriptores Indici, quomodo corvi hi aquaticiad pifcium praedam affuefacti fint, referunt, fed non opus eft, ut in Indiam recurramus, cum Anglis Gallisque, imo Germanis quoque noftris, hoc artificium non lateat, et corvos pilcationem edoctos, ab Eminentiffimo Celfifimoque quodam Electore Viennam miffos, hac in Vrbe ante aliquot menfes confpexerimus.

N. 2. Exhibet Gallinaginem fylveftrem Aquaticam, a nemine no: mine hoc defcriptam. Roftrum fi exceperis, plurimum cum Ciconia nigra a Generol. Equite Caffiano a Puteo defcripta convenit. Hanc Auctor nofter Tabellae defcriptionem fubjunxit. Rara haec Avis efl in locis paludo is vidum quaeritans, colore atro et ruffo, per totum corpusinfiar boloferici jplendefcente, roftrum oblongum quodammodo incurvum, crura alta et fufca, digitos longos babet.

N. 3. Quam Autor fingularem HIRVNDINIS Aquaticae exo. ticae ßpeciem exhibet, nihil ferme cum Hirundine commune habet, ideoque notatus ab Excellentiffino Rajo in opere Willugbejano de Avibus, etjam olim a Wormio in Alifeo p.306. Qui Colymborum generi afferit, et Avern hanc apud nos hic alias incognitam, in Pegnefo tamen captam, Colymbum Arcticum Wormii Lumme dictum credit, cujus Carolus Clufius in Auctario, et multo fufits Excell. Wormius in Mufeo meminit. Addo Auloris noftri M. R. Besleri verba, e Gazophylacio avi huic fuffixa: quis non in volucri paluftri fummam colorum va. rietatem miretur: a capite enim inchoando juperior pars candet, infe- 
vior floccorumnivis inflar albicat, in dorfi principio pennae duae nigricantes, albis puntis difintale exurgunt. Alins dorfum univerfum, una cum cauda ferruginei coloris, alae quidem nigricant, pundis tamen niveis ornamenti inftar diftinguuntur. Pedes exporreiti fubfufci coloris, roftrum nigricans ad fubulae formam effigiatum, quopijces quafi bamo excipere folet. In Figuris aeri incifis; quarum titulus: Oyjeaux de la Menagerie de.Verfailles Tab. 6 . haec avis quoque delineata, fub nomine Plongean de la mer ecbiquete.

Quam N. 4. fub nomine ADMIRANDAE AVIS CVCVLLATAE AQV ATICAE exhibuit Cl. Beslerus, videtur effe Colymbi Criftati fpecies, a nemine hactenus, quam Auctore noftro et poft illum a Cl. Wormio fub nomine Colymbi Criftati five Auriti delcripta: verba e Gazophylacio jungo: Animal hocce capite monftrofum, in aquis natare, ex decubitu naturali conjicere licet. Comam quam in fronte cernis ferruginei coloris; ex partemaxillarum, plumaeflave/cen. tes repullulant, quae in extremitate nigriores factae, circulum egregie repraefentant. Collum cum Ventre albicat, dorfumcum Alis cineritiieft coloris, extremitas tandern in albas definit plumas, pedes cum adnatis membranulis, Semicirculis diftindtis albicant, ubi in quolibet $\mathcal{P} e$. de unicum tantum unguem animadvertere licet.

\section{TAB. IX.}

N.1.T Ectorum oculis exhibetur AVIS illa PARADISIACA 1 fic dicta, vel ob Colorum venuftatem corporisque fpeciem, vel quod ubi locorum nafcatur, unde venerit, quo fe recipiat, hactenus non certo conftet. Manucodiata diciturfecundum $E x$ cell. Valentin. in Mufeo Aufeorum, a vocabulo Moluccano corrupto Maotto Tirvata, quod Dei avem denotat. Vocatur pariter Apus Indica, quod illam pedibus deftitui credideriot Hiftoriae naturalis fcriptores alias diligentiflumi, tanto hoc deliniti praejudicio, ut incomparabilis alias Aldrovandis Antonio Pigafetae, qui primus hujus Avis notitiam Europae noftrae dedit, dicam fcribere non erubuerit, quod avi huic tribuerit pedes, id quod Auẹtori queque noftro contigit, qui Avem Paradifracam apodem pronunciavit, quo nomine et Firmamento Sobiefiano five V ranographiae Ill. Hevelii illata, plurimisquie fe!lis illuftrata cernitur. Pro Epicheremate quoque Apus fuir Laur. Pignorio, cum infriptione: TELLVREAL PRESSISSE PVDET. Nec hic fubftitit error, peperit plura credendi levitas de hac ave figmenta, quae recenfere, refutare eft; eam fcilicet caeleft rore nutriri et vivere, cume $x$ avium rapaciumfit genere; perpetuum exercere volatum, nec nifi alis in fublimi expanfis acquiefcere, nunquam vivam capi, fed mortuan tantum in terras praecipitari; dariin mafculorum dorfo cavitatem quan. dam, in qua foemellae, quibus venter etiam cavus fit, ova fua deponant, 


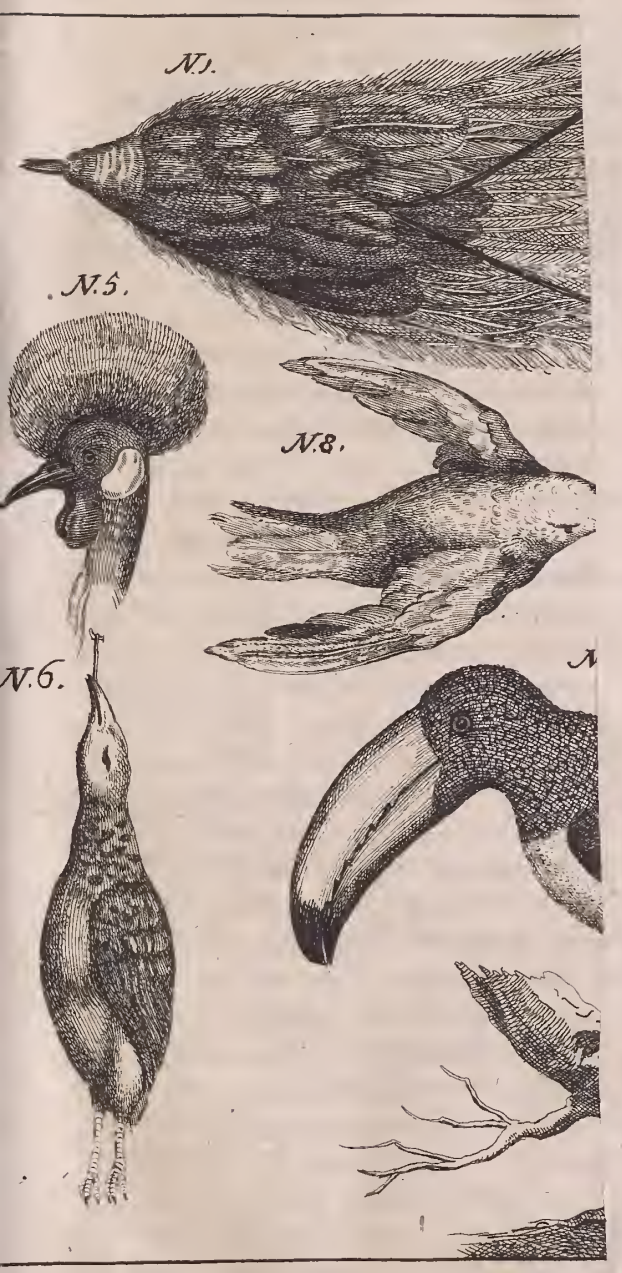



TAB.IX.P.32.

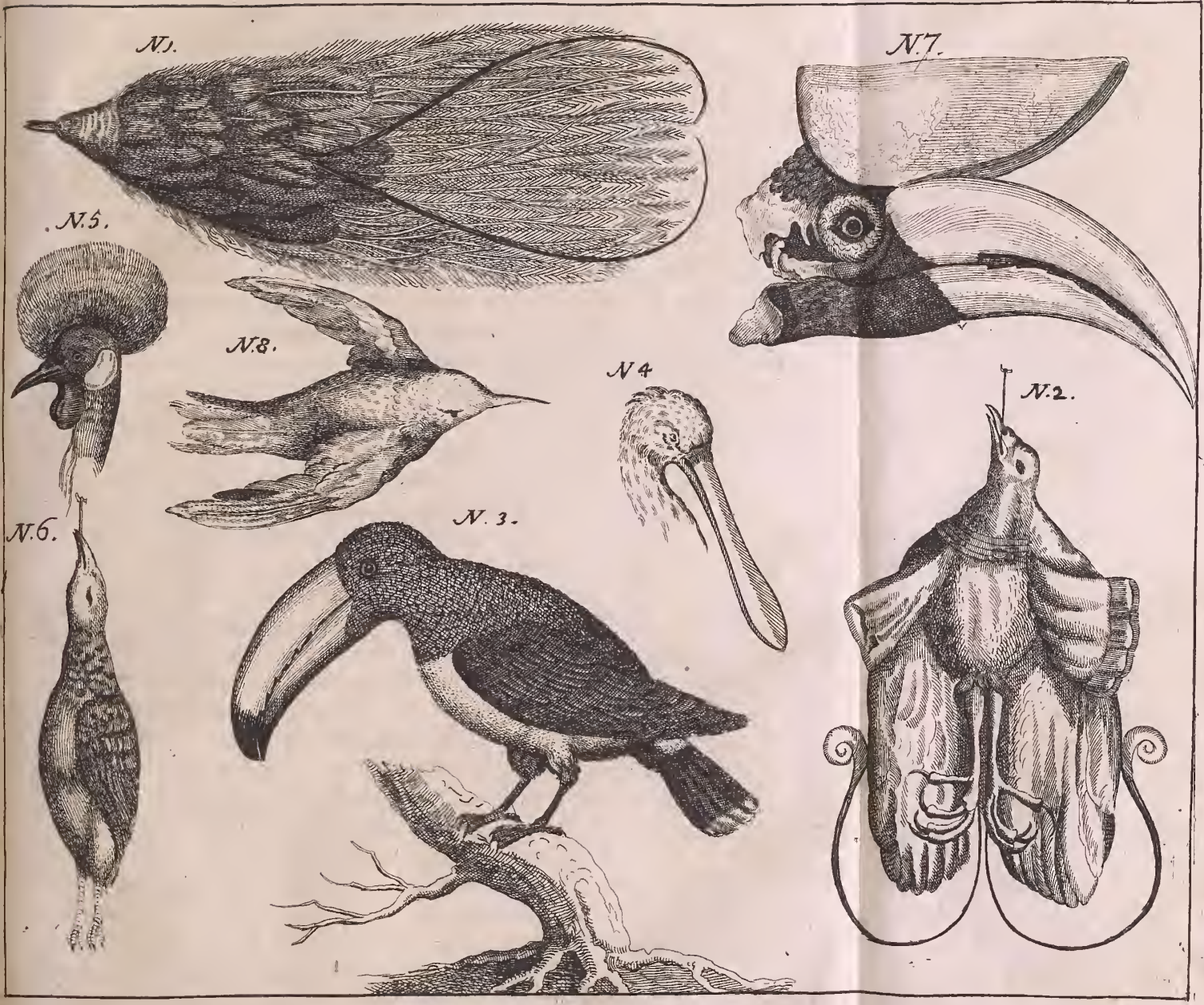




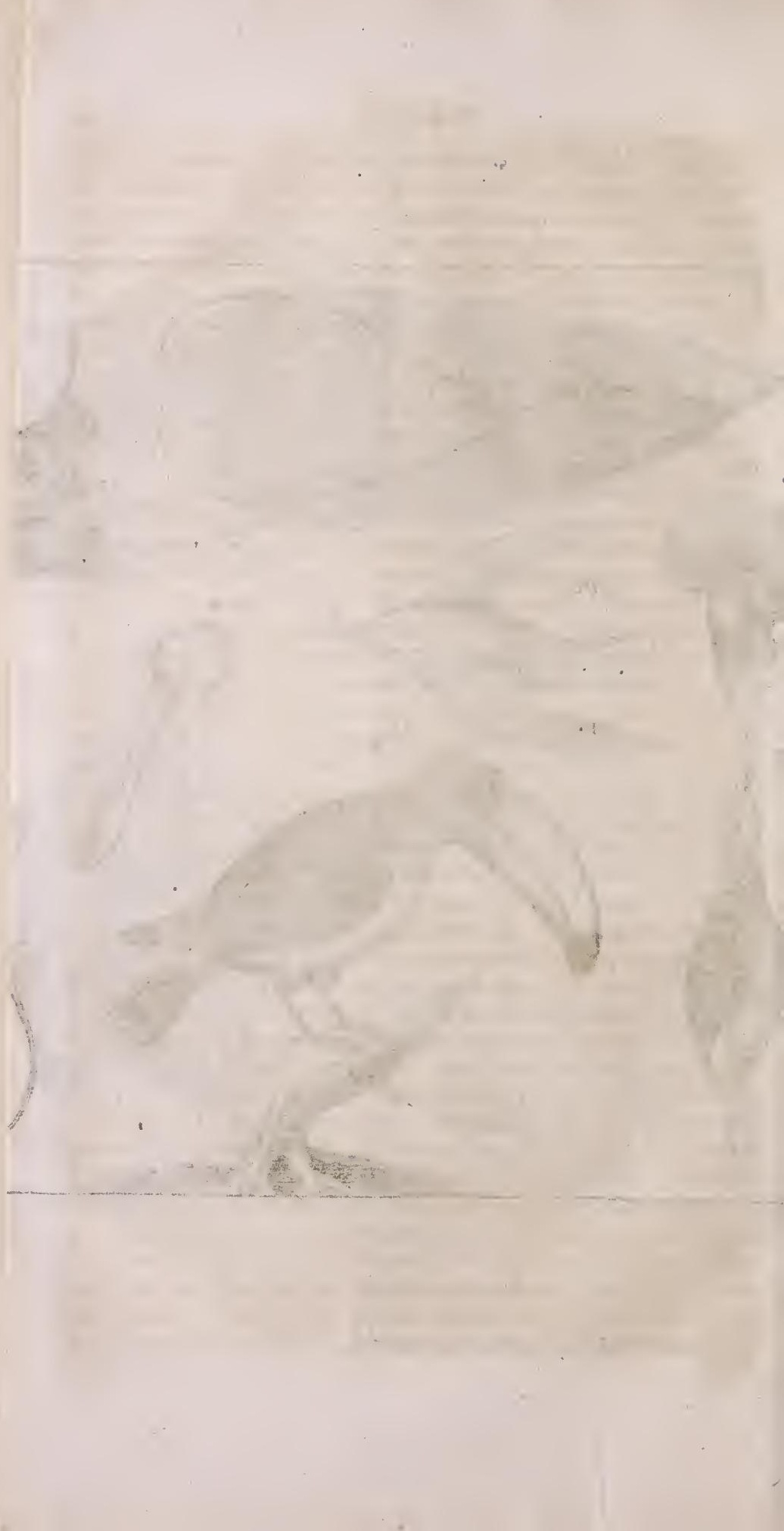


atque itautriusque cavitatis auxilio, ea incubari, quae otioforum credulorumque hominum commenta non tantum ex Foh. de Laet, Clufio, Wormio, II arggravio, imprimis autem Bontio, fabulola elle probat Excell. Rajus in opere Willugbej. de Avibus, fed et veritatem ex avibus integris allatis pedibusque inftructis evincit. Bontii locus omnem dirimit litem Hiftor. natural. et Medic. Ind. Oriental. Libr. V. cap. 12. Tantum abeft, Icribit, has Paradifi aves vel pedibus carere, vel Aëre nutriri, ut unguibus incurvis et peracutis parvas aviculas Chlorides, fringillas et fimiles venentur, easque mox ficut reliquae rapaces aves devorent: ut necillud verum fit, eas non nifi mortuas inveniri, cum et Ar. boribus infideant, et fagittis a Tarnacenfibus figantur; unde etiam a celeri et reciproco volatu hirundineo hirundines Tarnacenfes ab Indis vocentur; Vid.quoque Rev.P. Bonann. in Muf. Kircher. ClafJ.VII.n.g. p.227. Quid de ave hac Cl.MI.R. Beslerus, in Gazophylacio habeat, receniebimus: Pennarum. fcribit, ambitus difcolor eft, fed admodum venufus, plumae enim fuperiorem capit is partem exornantes funt molles, tenuesve et ex cyaneo mire virides, quae mentum tegunt pijfae, colore luteo egregie micantes. Roftrum birundini prolixius, corporis moles tota pennis fulvis in ruffum vergentibus obducitur, quae in peEore et ventre collocant ur latiffmae, colore nitidiffmo fulvae funt. Alarum Pennae inter nigrum et ruffum fulgent: Dorfo fila gemina anneGuntur tres palmos longa, nec exade rotunda, nec perfedte angulata, $\int e d$ media figura,nec nimium craffa,nec fumme tenuia, verum futoris filo baud diffimilia, fila tamen bina nigredine fplendefcunt. Pedibus carent. Haec Auctor nofter, cui error de pedibus eo magis condonandus, quod cum maximis viris errorem hunc erraverit. Quod autem fila illa five cirros attinet, nil aliud quam pennarum fcapos plumis deftitutos judicat Excell. Rajis, illosque vim ullam mufculofam obtinere aflerit. Addit tamen optandum elfe, ut qui Indiam Orientalem adnavigant, e.zsve regiones petunt, in quibus Manucodiat ae inveniuntur, ab incolis diligenter exquirerent, ubi et quomodo nidificent, cuique ufui inferviant tum pennae illae longiffmae, e lateribus pectoris binc inde magno numero enatae, quae tum ultra caudam in longum aliquous que procurrunt, tum in latum diffunduntur, tum praccipue $\int$ capi illi longißimifupra didi, quorum ufus, ut verum fateamur, nobis battenus incompertus eft.

N. 2. $M A N V C O D I A T A$, Regis titulo infignita exhibetur, quae rariffima A vis cum e Besleriano Mufeo in Maenlinianum dela.ta, cum illo ex urbe hac aliorfum venit. Interim delineatio cum illa Marggraviana optime convenit, ex defcriptione, quam $\mathrm{Cl}$. Her. bertus de Jäger apud Excell. Valentinumin Mufeo Mufeorum dedit, fupplenda. Arouenfis Infulac, a nova Guinea 2o. circiter milliaribus diffitae, imperio hodie Bantamenfi fubjectae incola eft. Caput illi parvulum, fummitas coloris miniati, collum digitum longum, coloris cum cervice fanguinei; oculi parvuli, cum macula nigra; pectus plumulis 
caltaneis ad grifeum accedentibus oblitum, apparet inıbi femilunaris macula, e plumulis fubtilifimis holofericum aemulantibus, coloris ex nigro fplendenti viridique caeruleoguc mixtis. Roltrum reclum, fatis craffum, acuminatum, fesquidigitum longum. Colore ex viridi et caeruleo mixto, verfus acumen tamen albicans. Corporis autem longitudo a collo ad caudae exortum vix trium digitorum et femis. Alae fupra feprem longae. Cauda lata et fex digitos longa. Ala et cauda pennas habet latas et fortes, d giti latitudine. Totum dorfum, infimus venter, alae, cauda, elegantis funt brunni coloris. Sub alis in lateribus inter alas et crura exoriuntur multae pennae pedem plus vel minus longae, elegantis ftructurae, quae fupra caudam longe extenduntur. Inter has pennas duo quafi fila extenduntur, totius aviculae adaequantes magnitudinem, prope exortum flavi feu aurei coloris, ac verfus extremum incurvata umbilicataque, fecundum Marggravium obfcure brunni coloris, fecundum Herbert um de Jägerautem coloris Smaragd niin citrinum definentis, ex minimis contexta plumulis, elegantiffimae ftructurae, id quod maximam in pulcherrima hac avicula meretur admirationem. Pedibus minime deftituitur, quod $\mathrm{Cl}$. Olearius in Itiner. Ind. Mandesl. L. 3. voluit; fed fi ảurórtau Marggravium audiamus, habet duo crpra, quodlibet inferius duos digitos longum; quatuor digitos in pedibus, tresantrorfum, unum retrorfum verfum more communi: medius anteriorum paulo longior caeteris ; pofterior etiam fatis longus; quilibet ungue lunato, feu adunco, accipitrino, forti praeditus. Suntque cruraet pedes fatis craffi ac ad rapinam comparati.

N.3. MONSTROSA HAEC avis in Mufeo Bafil. Besleri, quod ad $D_{N}$. Engellandium haereditatis Jure devolutum, confpicitur, licet roftro arte corpus affictum fit. Monftrat autem avem a variis nationibus varie appellatam. A Brafilienfibus vocatur Toucana Plumis nigris, quibus ad faltandum utuntur ; Peruani Tacataca, a continuo percuffionis arborum fono, qui Tac Tac eft, appellarunt; hinc non invenufte Hifpani vernaculo lermone fuo pariter hanc avem Carpintero, hoc eft, fabrum Lignarium nominarunt. Mexicanis, Nierenbergio tefte, Xocbitenacatl dicitur; OviedoPicuto, et quidem fecundum Joh. Fabrum Lynceum non a Pica vel Pico, quarum generi avis haecaccenfetur, fed a roftro, quod Hifpani fuo idicmatePico,et ItaliBecco appel litant. Accenfetur alias ab ornithologis Picarum familiae, quod poft diligentiffimum Aldrovandum etiam ab Excellentiffimo Rajo in opere Willugbejano faclum; modo ciratus autem Fo. Faber Pricis potius Mlartiis annumerat, idque fumptis rationibus ex nidi figura, locoque, ac pedibus frmat. Quod ad pedes, fuboluit Excell. Rajo, quod res eft, qui defcriptioni avis hujus ex Aldrovando defumptae, haec adjungit et notat: Ju/picor ego digitos pedum in bac ave, Picorum more difpofitos effe, nimirum binos ante, totidem retro; nam et talis eft conformatio pedum Aracari Marggravii, avis buic fimillimae; Aldrovandus vero roftratae buic Avi in 
ormibus Iconibus tres digitos ante, et linum procalce appinxit. Abfineo a longiori Avis hujus defcriptione, roftrum tantummodo avis confideraturus, cum reliquum corpus in AIufeo Besleriano huic avi affictum; et a Carolo Antonio a Puteo tquite doctifimo, ex viva ave, quam ipfeapud Galliarum Regem in Fontebellaquenfi atrio optime delineatum, quod expofitioni in Animalia Novae Hifpaniae Nardi Antonii Recchi inleruit totics citatus Fob. Faber Academ, Lync. Rollrum igitur huic aviadmodum latum, palmum fere unum et duos longum, ab inferioris partis initio adfuperioris extremitatem dimenfum. Inferior pars ubicrafjor eft, videlicet prope oculos, duplo minor ef Juperiori, et prope finem, ubi recurvum eft, etiam triplo. Subftantia tenuifima licet, offea tamen, Jplendida, levifima cava, atque Aërs intus capacifjima, ideoque naribus praeter reliquarum avium morem carere quis crediderit. Siquidem tenuitatem ejus Äer facile penetrare poteft. Nam fiquid aperti in eo naturamolita fuiffet, idextrinfece fraidurae roftrum obnoxium reddere potuifet. $V$ nde fortaffis etiam velut quibusdam dentibus infrudum effe voluit, quos ita dipofuit, ut roftrun omnino claudi nequeat, aërisque ingreffum facile admitti. Eft autem ferratum, et velut e fquamulis quibusdam compofitum, quae unguibus nullo negotio divelluntur. Color roftri Jecundum Aldrovandum flavefcit, fed in infima magis quam in fupina parte. Carol. Anton. a Puteo, fuperiori fua parte, ubi Capiti adhaerefcit, viridiufculo colore tindum effe, et ex eodem virore ad acumen lineam producere refert, inferiore vero parte capiti quoque commifja caeruleolucens colore. Totum reliquum roftrum inflar ligni ferpentini atro rubentis intercurfantibus nigris maculis ac lineis quamplurimis pidum. Interna fua partecroceo verfus extremitatem tamen. caeruleo fulgebat colore. Promeruit Avis noltra Tacataca, ut cum ramo myrilticae Arboris, quem roltrotenet et quam arborem faepius forte pulfat, fub nomine Anferis Americani vel Toucan, e novem ftellis fixis conftans, Firmamento Sobiefciano inter Phoenicem Eridanumque infereretur.vid. Prodr. Aftronom. cum Catal. Fixar. Illuftri Hevelii p. Ir 9. et 320. Reverendifr. Anton. a Burgundia in Linguae vittis et remediis Emblematice expreffis, pro linguajactabunda exprimenda, Ave Toucan utitur, hoc lemmate: Minor ore fuo eft, et addita explicatione :

\section{Burbara Pica, fuo minor ore, (ita teftis Vlyjes)}

Non babitat terras, Belgica Nympha tuas.

Errat buccofuiminor eft dum laudibus oris;

Belgicanonne fuo picafit ore minor.

ubi per Vly Jem, Aldrovandum, per Bucconem, hominem tumentibus buccis five jactabundum intelligir. Traditur a nonnullis, hanc avem effe Piperivor an live Piperis voracifimam, fed ab Americanis amicis, yui. 
bus familiariter ulus fuit Foh. Faber, nil refcifcere hac de re potuit, ut non fine ratione hoc de afferto dubitet; magis adhuc dubiae veritatis erit Ambrae gryfeae excretioper inferiora hujus Avis, quam fub nomine Afchibobuch intelligere videturAlegiferus in defcript. Inful. Madagafcar; id quod lepidifima expreffit Fcone Klobius de Ambra. p.41. Commemorant hanc avein in Aëre vifam, cum Chriftiani A nno i $57 \mathrm{r}$. ductu Gohannis Auftriaciad Naupactum five Lepantum in finu Corinthiaco, celeberrimailla navali pugna Turcas fuperarent, ac in ipfovola. tu telo confoffam, in pugnantium globum decidiffe. Vid. plura alia curiofa hac de Ave in defcript. Alufei Academici Lugduno-Batavi, in quo Roftrum hujus avis obvium. V'id. quoque Olear, in Muf. Tab.XIII, n. 7. et Pettiver in Gazophylac. Art. et Nat. 44.13. C. 523.

N.4. CAPVT ROSTRVALVE PLATRRINCHI a Ges. nero Wormioque optime defcripti, quae avis, quod roftrum coch leare figura referat, Germanis Die Loffel $=\mathbb{S}$ ans / Anglis the Jpoonbill $d$ Duck dicitur. Apex partis fuperioris roftrivel incuria vel temporis longaevitate abrupta, ut dubium mihi injecerit, an caput hoc ro. ftrumque non extiterit $P$ hafianimarini ab Excell. Charltono in elegantiffrmis Exercitationibus de Differentiis et Nominibus animalium, accuratiffime defcripti, cujus Phafiani roftrum ad extremitatem inftar cochlearis quoque expanfum compreflumque; fed cum Apophyfis incurva defit, anceps haereo. Simile caput avis vid. apud Olear. in Minf. Tab, XIII. n. 4 .

N. 5. CAPVT GRVIS BALEARICAE vel FAPONICAE, cum Crifta in Capite denfa, rotunda, e fetis quaquaverfum diffufis, porcinis fimilibus, colore finularum Erinacei vulgaris compofita, qua nota ab omnibus aliis avibus primo ftatim afpectu facile diftinguitur. Prae vetuftate, quae omnibus minitatur interitum, calvitium paene huic gruis criftae inductum, ut rariffimae adhuc fetae appareant. Num avis haec Bosmanni dans la defcription de laCoté deGuinee XV. lettr.p. 273 . quam, Belgae avem Coronatam five Kroonvagel nominant? An avis regia, cujus in Hiftor. Scient, Reg. meminit du Hamel libr. III. Sect. IV cap.2. p.264.An Catrea Aeliani, vel Pavo marinus Clufii, Exot.Lib.V.c.XI.p.ıos.

N. 6. AVIS eft inter Anlerem et Anatem feram media, coloris fufci maculis nigris albicantibusque interdiftincta; Anati, plumis molliffimis Eider dictae, per omnia fere fimilis, cujus accuratiffima in. Mufeo Wormiano p. 3 02. defcriptio. Notum eft hocavium genus plumis molliffimis, culcitris magnatum fulciendis aptiflimis, quae in exigua copia fe valde dilatant, et prae reliquis calefaciunt, et nomine (EDDerthun omnibusnotiffimae. Videtur haec Anas eadem effe cum Colca Scotica ave, de quibus Buchananus de rebus Scoticis L.I. ubide Infula Svilskeraja agit: In bac Infula, fcribit, rarumet aliis regionibus ignotum genus avisconfpicitur: Colcam vocant, magnitudine paulo infra Anferem: ea fingulis annis Vere eo adventat; Pullosque exclufos eo usque educat, 


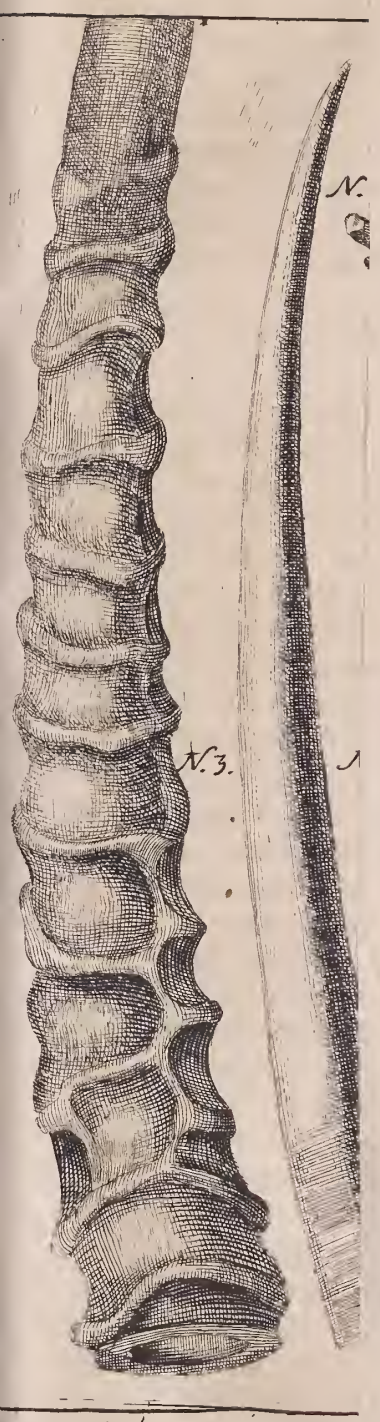





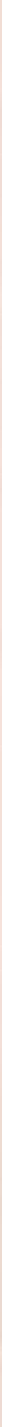



dum ip/i fibipropicere pos fint. Adid fere tempus Plumae ponte defuen. tes e toto corpore nudam deftituunt ac tum demum admare fe recipit, nec ante proximum Ver usquam conjpicitur. Illud quoque eis eft fingu. lare, quodearum pennae caulem non babent, fed levi, et cui nibil pror. fus duri adeft, pluma totum corpus velut lanugine veftiunt. Cl. Sibbaldus. avem hanc fub nomine Capricaleaedelineavit in Tab, aenea XVIII. quae quoad omnia cum figura Auctoris noftri convenit; in Prodr. tamen Hilf. Natural.Scot.P.II. L.III. cap.ó. p. 2 r. Colcae non tamen Capricalcae meminit. Sic in Indice Operis W illugbejani: Capricalca avis Scotica omifla,cum ejus nec in Tabulis aeneis, nec in defcriptione ulla injecta fuerit mentio.

N. 7. ROSTRVM ET CAPVT eft RHINOCEROTIS $A V I S$, five Indici cornuti corvi Bontii, de quo fequentia habet Beslerus in Gazopbylacio: Hujus avis infolens magnitudo, caput duorum dodrantum, cirris ornatum nigris. Roftrum recurvum non rapacium more, fedinfiar arcus cujusdam. Cornue fronte enafcitur Rbinocerotis cor. nu non diffimile, fed in fine recurvum (id quod Glyptes in Tabula aerea non accurate expreffit) Color in fuperiore et inferiore parte miniaceus, in media luteus, in margine linea nigra obducitur; fubfantia hujus Cornu eft leviffima et cava. An avis Rbinoceros fit Tragopan Plinii, difquirit Cl. Olearius in Mufeo. Ill. Ludolfus in comment. Hift. Aethiop. Libr.I.cap. XII. num. LXXXIX. pag. 162. per Tragopana Avem Cafuaruim five Emeu potius exprimi credit. In Mufeo Kircheriano Rhinoceros avis cum Toucan ave confunditur ; addit Rev. P. Bonanni virtute haec roftra conftare alexipharmaca, hinc ab Indis maxime fieri. Vid. quoque Excell. Valentin. Muf. Muf.T. II. p.156. qui figuram no. ftram Beslerianam citat.

\section{TAB. X.}

D

Vicit nos Rbinocerotis avis cornu ad Tabulam Cornibus dicatam. Hacc inter maximas certe VNICORNV VERV $M$ dedit contro. verfias, cui animalium fit generi accenfendum. Catelanus in $D i f$ fertat. de V nicornu omnium pene fabulas collegit aerique impreffit animalia unico cornu inftructa. Poft hunc aureum de Vnicornu Tr. fcriplit, omnis eruditionis literariae promus condus Bartbolinus. Et nemo pariter citius Wormio, ipfoque Barholino detexit, natales non inter quadrupedia Animalia, fed inter Pifces inprimiscetos quaerendos effe; quibus Ampliffimus Amiterodamenfium Conful Tulpins in obferv. Medicis jungendus eft. Accuratius nemo Sacbfio in Alonocerologiafive Differt. de Genuinis unicornibus, qui defriptionem Vnicornis a Cetariis Hamburgenfibus capti Anatomice dedit, de celebrioribus. Vnicornibus Mantillam fubjunxit, Pifcisque $N a b r v a l$ plenariam cognitionem omnibus exhibuit. Veterum praejudicio occoecatus M. R. Beslerus haec verba ad Vnicornu latera agglutinavit: Inter animalia Mo- 
nocerata palmam praeripit illud, quod procerius eft pullo equino 30. menfium, in fronte cornu trium cubitorlim longitudine, ubique tereti, et quafi fafciis ab imo ad Jurmum afcendentibus, diftinito prominet. Coloris eftid Animal equi muftelini, caput Cervi inftar, rariffimaeque jubae $a b$ altera parte dependentis. Tibins graciles binnuli inflar ba. bet, ungulas bifidas, pofteriorum tibiarum pars villofa, ferum quiderm vifu animal, fed ferocitatem natura fingulari comitate condivtt. Haec ex veterum fabulis Audtor nofter, led gerrae haec hodiefunt, atque aedepol lirae lirae; et certe mutaffet lententiam, fi unicornu cum Capite Pifcis Nahrval, quod Artificis manus poft Besleri fata affixit, intueri licuiffet. In America quoque Pifcem hunc Monoceratem non extorrem effe, Rupifortius in Hiftoria naturali Infularum Antillarum cap. 18. abunde docuit, ut non folius feptentrionis Europae Incola, quod hactenus factum, credi debeat. Confulatur 1lluftriffmus Willougbejus in Regio de Hiftoria Pifcium opere Libr.II. cap. IX. qui in Tabula, ubi Pifcis Monoceros ejusque cornua variorum auctorum exhibita, Embryonis alicujus cornu quoque aeri curavit incidi. Sed quid de bifce Vnicornibus cenfendum, disquirit modo laudatus Sachfus 1, c. Add. Pomet l'Hiftoire generale des Drogues P. II. Livr. I, c. 33.p. 73.

N. 2. Ectypon CORNVVMVACCAE, quae primo intuitu cervina mentiuntur, quorum prototypon in Bibliotheca noftra. Hujus naturaelufus meminit Leibnizius in MemorabilibusBibliothec Noribergenfis p.18. creditque matris hoc vitio contigiffe, quam aut de communicando foetu Cervus convenit, aut impenfe nimis imagine facta ertare permifit natura. Quae fi Romanis olim eveniffent, aut hoftiis majoribus expiaffent, aut lectifternia indixiffent.

N. 3. et 4. CORNV eft CAPR1 BEZO ARDICI, duriacrigidi, fibris redtis per longitudinem Cornu excurrentibus, foris ab ima ampliore parte nodofum, circulis eminentibus tanquam callis, (nefcio an Aetarum indicibus) ad medium circiter, ubi fenfim elanguefcunt quafi, aut planiores redduntur, exafperatum, intus cavum. Sic graphice cornua haec defcripfit Acad. Nat. Curiof. Phofphorus Excell. Major Ephem.Nat. Cur. Dec. I. Ann. VIII. obferv. I. quae ab illo fcripta, optime cornibus in Muleo Beslero - Engellandiano obviis conveniunt, maxime autem ab illis capri Bezoardici cornubus differunt, quae ab Oleario in Gottdorpienfi Mufeo exhibentur. Putat autem Excell. Major rationem differentiae in difcrimine vel fpeciei, vel aetatis, vel fexus effe quaerendam. Pomet l'Hiftoire generale de Drogves P. II. Livr. I. chap. 3.p.ro. Capram Bezoardicam depinxit, fed cornua pariter noftro non conveniunt.

Fig. 5. Genuinum CORNV LEPORINV M exhibet, quod non amplius infolitum, cum plurima cornutorum Leporum exempla proftent, quae collegit laboriofiffmus Paulini in Lagographia curiofa Sect. I. cap. 3. S. I. 



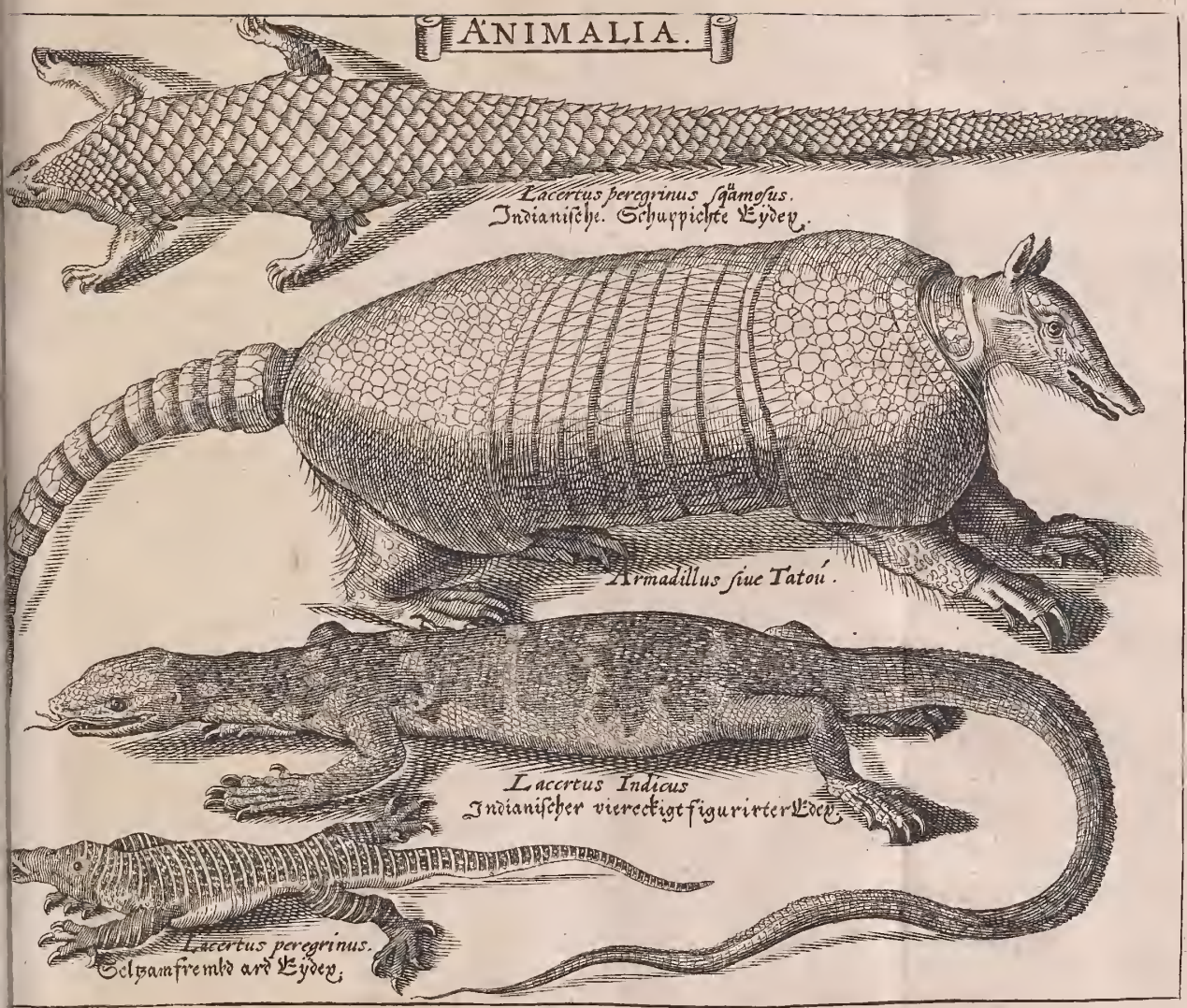




$$
\begin{aligned}
& \frac{31}{n c} \\
& \text { m } \\
& \text { et } \\
& \text { co } \\
& \text { ju } \\
& \text { vu } \\
& p c \\
& \mathrm{Pi} \\
& \text { Cu } \\
& \text { cी } \\
& \text { ab } \\
& \text { ne } \\
& \mathrm{R}_{1} \\
& \text { L. } \\
& \mathrm{cu} \\
& \text { ce } \\
& \text { re }
\end{aligned}
$$$$
\text { vii }
$$$$
\text { ra }
$$$$
\text { p. }
$$$$
\text { do }
$$$$
\text { mi }
$$$$
\text { piz }
$$$$
\text { res }
$$$$
\text { pa }
$$$$
\text { tat }
$$$$
\text { áu }
$$$$
\text { nu }
$$$$
\mathrm{EF}_{\mathrm{F}}
$$$$
\text { mi }
$$$$
\mathrm{m} \text { : }
$$$$
\text { O! }
$$$$
\text { Mi }
$$$$
\mathrm{xu}
$$$$
\text { I. } 6
$$$$
\text { Itr }
$$$$
\text { pli }
$$$$
\text { qu }
$$ 
3. S. 1. pag. 47. et Ephem, Nat. Cur. Dec. II. Ann. Vl. Obfervat. CLXXXIII. p. 368.

Abludit tamen plerisque CORNV LEPORINV A1 figurae6.Quod fubfuficoloris et gyratum eft. Confer quae de cornu Leporino botryoide, et alpidoide habet Excell. Welfchius Hecatolt. I. Obferv. XX.

Fig. 7. A flerit Auctor nofler effe elegans CORNV CERVAE ideae protuberans, caputque avis in fummitate repraefentans.

Fig. 8. INCVRVATVA BICEPS CORNV CERVINVAL cum cranii particula, ubi futura confpicua eft.

\section{TAB. XI.}

COrnibus inftructa animalia, fquamis et loricis tecta in hac Tabula 1 fequuntur. Etquidem LACERTVS HIC INDICVS SQVAHIS undique munitus et armatus, Audori noftro Indionifde fouppiote Ende/ a Siamenfibus Lin, ab Infulae Formofae Incolis Diabolus Tajonanicus, (hoc enim Caftelli in hac Infula extrueti no* men erat,) tefte Cl. Bontio Hift. Nat. et Medic. Ind. Orient, Libr. V. c. 8. p. 6o. a Lulitanis Bicho vergonhofo infectum verecundum vocatux. Anglis et quidem in Mur, Societ. Reg. P.I. Seet, 2. p 46. the Scaly - Li: zard dicitur elogio addito: optime et perbelle figura aenea exprefjum effe a Beslero noftro (he is mell pittur'd in Besler.) A PI. Rev. Yatre Tachard dans le Second Voyage au Royaume de Siam, Lacertus echind: tus vel Erinaceus nominatur, quod ad inftar hujus animalculi ingruente metu fe contrahat et corruget, ac mucronatis fquamis, quibus totum corpus, gutture excepto et parteVentris infima anterioribusque cruribus, horridum, minas quafi intentat ; cusn tamen innocentiflima fit beftio1 , nemini nifi formicis infidias ftruens, ut nil minus quam diaboli Tajawanici nomen mereatur, fic fentiente Straulfio in Itimer.p.3 I. Dn. du Hamel in Reg. Acad. Scient. Hift. L. II. Sett. XI. cap. 2. p. 227. ideo Diabolicas beftias nominari credit, quod talparum more terram fuffodiant, oryzam, imo et tectorum fundamenta fubruant. Duorum utplurimum pedum longitudinem attingit; Scarabella nell Mufeo di Settalla c. 30. p. 160. ducrum cubitorum pronuntiat. Vulpeculam proceritate aequat. Squamarum pariter pro partium diverfitate magnitudo, omnes tamen ad exortum ftriatae corneae obfcure flavefcentes, fecundum $\mathrm{Cl}$. Facobaeum Ahu. Reg.p.9. imo offibus lolidiffimis duriciepures AIuf. Soc. Reg. Angl. ct ex mente Cl. Olearii in MIuf. Gottdorf.pag. 7. 8. lamellis fructus Abietis exficcatae (Dem Durren Tamnapfin) non abfimilibus: Hllae quae collum et capitis fupre. mam partem tegunt, (ut Cl. Clufii in Audtar, Exot. p. 375 . verbis me expediam) femiunciam non longae funt, atque mediam corporis par. tem inter crura comprehenfam muniunt, binas uncias longae, et fesquiunciam latae, quae deinde per eandem longitudinem. Pparguntur: 
a deo smplae non funt, fed fenfim verlus ejus extremum procedendo minuuntur, ut extremam caudam occupantes, iisquae collum tegunt, vix ampliores fint, quae autem caudae latera utrinque claudunt, forma prorfus a reliquis d.fimiles, nam planae non funt, aliarum inftar, fed cavae quafi incurvatae, quia pronam et fupinam laterum partem tegunt. Cauda aurem valida et pedem fere longa, in fuperiori parte rotunda, in inferiori aliquantum plana cum parva excrefcentia carnis albicantis in extremitate, fecundum Rev. P.Tachard l.c, Capite et promufcide Lacertus hic non eft porcino, ut Armadillo, fed tenuiori et acutiori Talparum more, quo terram commodius evertat. Collo plane deftituitur. Pedes breviufculi palmam circiter longi, qui duriorbus pilis leporinis veRtuntur, iidemque pili hinc inde erumpunt in dorfo ex ipfis fquamis; fic guttur quoque et ventris ima pars, nigris obfita villis. Pofteriores pedes quinque unguibus brevioribus, anteriores tribus oblongis craffis, fed imbelle curvis armatur, ficut in Brafilenfi Tamandoa, quibus aeque ac illa Formicarum et vermium latebras, detegit; praedam qualemcunque mordicus tenet, et ut $P$. Tachard credit, anterioribus arripit. Oris apertura, exigua plana, praelonga tamen Lingua, teres quam lerpentisad inftar ejaculat, fed absque ullo damno. Tachardus miratur, animalculum hoc neque legumina comedere, neque fructus ullos, neque Oryzam, neque pifces vel carnem, aut aliud quicquam efcae loco ipfi objectum, fed mirari defillet, fi läcertum hunc formicarum immifffet acervo, tunc enim confpexiffet, linguam vifido humore gitutinofam formiceto immittere, formicisque invilcatis obfitam extrahere, hocque alimento victum quaerere, telte avtopta Straulfio in Itiner. Bontius tamen lacertulis quoque infidias ftruere fcribit, illisque pingtiefere, unde ejus carovefca non folum, fedficut magnae lacertae Brafilienfes Leguanae et Tatou, inter epulas ab omnibus paffim incolis expetitur. An Lacertus hic fit Varcbiero, cujus G. P falmanazar e Formofa Infula oriundus in Infulae bujus defcriptione meminit c. 24. p. 170. vix. determinare audeo. Anatomen et internam fruturam bujus Lacerti noffe qui cupit, illam in toties citati P. Tachardi itinere fecundo Siamen$\mathrm{fi}$, curiofiffimis locupletatam obfervatis inveniet, qui oculis quoquelegentium obtulit, quomodo lacertulae hae fquamatae juniores, matris dorfo infideant. Vid. pariter du Hamel Reg. Acad. Scient. Hiltor. Libr. II. Sect.XI.c. 2.p. 227. Haec ex optimi Parentis Myrmecologiae Manufcript. Capite de bofibus formicarum deprompfiffe fufficiat.

Hoc animal Brafilienfes TATOV, vel lecundum Thevetum Tatoram et Tatufiam, Mexicani Ajatochtlem, Novae Hifpaniae Incolae Chircquinturn, quafi caniculum cucurbitam, Oviedus Bardato, unde Italorum quoque Bardalo, tefte Scarabell. in Mufeo Setthlian. cap. 30. p. 157. fluxit; Hifpani Amudillo et Lufitani Encovertado, quod panopliam, et cataphracium denotat, vel fecundum P. Mar . tyrem phaleratum, Angli Great Strell'd Hedgog, Belgae Schildver- 
kennominant. Nonnulli Armadillo màgnitudinem Porcelli, alii canis Melitenfis afignant, unde facile patet, diverlas Tatou elfe fpecies. Exprimunt autem Brafilienles generice nomine Tatou totum hoc genus loricatum, variasque illarum fpecies peculiari addito cognomine diftinguunt; quarum Marggravius L. Iv. Hiftor. Brafil. p. 23 r. et PifoHift. natural. et Med.L. VI. p. 1 o1. tres recenfet; Tatupeba, Tatuete, quae et $V$ erdadeiro Lufitanis dicitur, et Tatuapara, quarum differentias his ex Auctoribus Excell. Rajus Synop). Animal.Quadruped inferuit, et quartam fpeciem Tatou muftelinum e Murf. Soc. Reg. Anglic. ab Illuftr. Nebem. Greno defcripto, adjunxit. Nobis fufficit noitratis dediffe defcriptionem, ex quibus facile quis fubfumere potelt, cui fit accenfenda fpeciei haec beftiola. Magnitudine porcellum optime aequat et figura et corporis proceritate, os certe porcinum acutum et prominulum, riclus mediocris, haud adeo magnis in qualibet maxilla, lecundum Marggravium, octodecim dentibus horridus, oculi parvi et profundi, aures longae et erectae patulac membranaceae, tenues. Caput refpectu corporis tenue ct exile, VI. pollicum eit ad aures usque, ab auribus ad caudae initium totum corpus duos ferme pedes adaequat, cauda ultra pedem, ambitus pedis cum femife. Prope occipitium duas habet juncturas, ut Collum moveri polfit. Dorfum fupra fcapulas amplo et lato tegitur fcuto, ex orbiculatisjuxta Wormium teffellis conftante, nifi, quod lon.giores aliquando fint verfus extremum. Reliquum dorfi novem ambitur conjuncturis et circulis, figuris pyramidalibus depictis, lumbos tegit lamina fimilis ei, qua fcapulae teguntur. Conftatautem Lorica figuris pentagonis, eleganti ordine difpofitis, inter commiffuras vero conftat fecundum Pifonem (qui aliquoties hos erinaceos Brafilienfes cataphraEtos diffecuit, ut fcifcitaretur, quomodo loricam extendere et contrahere poffent) parallelogrammis et quaelibet figura fquamis lenticularibus, coloris ex albo fubflavefcentis. Commiffurae conftant cute admodum lenta. Haec ratio eft, quod dormituriens, aut Venatorem eludere volens, prioribus ac pofterioribus pedibus collectis more infantum in Vtero jacentium, ac auriculis introtractis cum cauda capite, et ad caput relatis, inflar pilae fe componat, atque per commiffuras incurvato dorfo acclypeo, ita lateralibus extremitatibus, ac antica et poftica parte confertis, ut nihil appareat nifi Lorica capitis ac caudae: adeoque inftar Conchae firmiter fe claudit, ut ne a validifima quidem manu aperiri et dilatari fe patiatur. Obfervavit Marggravius in diffeetione horum animalculorum in quolibet latere mulculum infignem longum, et figuram $X$ habentem, plurimis fibris ita decuffatim difcurrentibus fecundum longitudinem, quorum ope validiffime fe contrahere et continere poteft, hosque mufculos Marggravius cmciformes appellat. Cauda, praeterquam quod annulis confter duodecim, paulatim magnitudine decrefcentibus, ac telfulis quafi Rhomboideis pictis, in apicem fquamofum et acutum terminatur. Ventercum gutture, natibus et parte cri!- 
rum, nulla crufta tectus, fed villis obfitus. Pedes et crurum pers eis vicina teffellis etiam obducitur. Haec 'e Wormio mutuo fumta, egregie. in noftrum Armadillo guadrant. In pedibus anterioribus quatuor tantum. digitos habet, duos médios áequales, in pofterioribus quinque, tribus me-" diis aequalibus, duobus lateralibus parvis. Monardi ficredimus, talpis in terra potiflimum nutritur, et Wormio referente, in Ipecubus ut cuniculus conditur, ut una nó vix tamen fe includi patitur. Pifo quoque nàrat, in Aquis Amphibii inftar degere, quod et Wormius confirmat, inque uliginofis lacu. bus verfari ait, ubiPifcibus, Lumbricis er Vermiculis páfeitur. Formicis Tequenti infidiaturmodo: Cubat fupinus Armadilló, cauda ori admota; qua recta procedentes formicac incidunt in infidias et cibum deludenti fuggerunt. Caeterum fructibus Batatis, Pacobis ac Melonibus caete. risque Plantaris, imo Gallinis velcitur, 'quamobrem rufticis exofum animal, cui perpetuo vel decipulis vel caniculis infidiantur; quem modum Neuhofius docet in de Brafiliaenfe Zee en Land Reyfen. Caro quippe Tatou non folum velca, fed ob teneritatem et albedinem apud magnates delitiarum loco eft, hinc aflata, elixa, 'et in artocreatis modum condita, porcellorum et cuniculorum carni praeferturPifone teftc. Marggravius Tatuete optimi präe caeteris faporis efle affirmat. De V'irtute medica poft Manardem et Ximenem haec notavit Barlaeus in reb. geft. Jub Com. Maurit. in Brafilia p.m. 360 . Laminas in pulverem comminutas et Drachmae pondere hauftas e Salviae decocto, provocare fu. dorem; et fingulare contra Luem Veneream exiftere remedium. Penultimum autem caudae officulum, quo corpori conjungitur, in fubtilifimum pulverem redactum, 'et cum. Aceto rutaceo in pilulas coactum et auribusinditum,'miräculi inftar eam tollit furditatem, quae a caufa calida eft. Laminae pariter in pulverem comminurac, et mixta Aqua in maffam coactae, extrahunt fpinas, e quavis corporis parte Haec Barlaeus et poft eum Scarabell. in Niuf. Settal. cap. 30. p. i 58. Fed meras fabulas effeIlluftr. Patritius Arctinus Redi in Experim. circares nasural.ex Ind. allat. P. 77. afferit; Hinc Pifo hás ipfi virtutes incompertas efle ait; Mlarggravius autem planefilentio in volvit. Haecquoque e Iilyrmecologia Manufcript. optimi Parentis et quiden'cap. de Hofribus Formicarum defumpta funt.

LACERTVS INDICVS Germanice Auctori nof ro Jnois anifdye vierectid)te figurirte (EvDer/vocatur. Illuftr. Rajus in $S y$ nopf. Animal. quadruped. unum eundemque effe credit, quem Clufins Exot. Libr. $V$.cap. 30 . et Worm. Mluf. fub nomine quoque Lacerti Indici cap. XXII, et : MIIL. Societ. Reg. nomine Bugelugey defcripfit, curn noftro; aft in plurimis a citatis deffectit delineationibus. Longitudo enim vix dimidium Wormianae et Clufianae adaequat, cauda in longum et tenuem mucronem definens fesquipedem et aliquot uncias explet, fubruffo colore, per totum corpus variegatus, fed variis maculis 



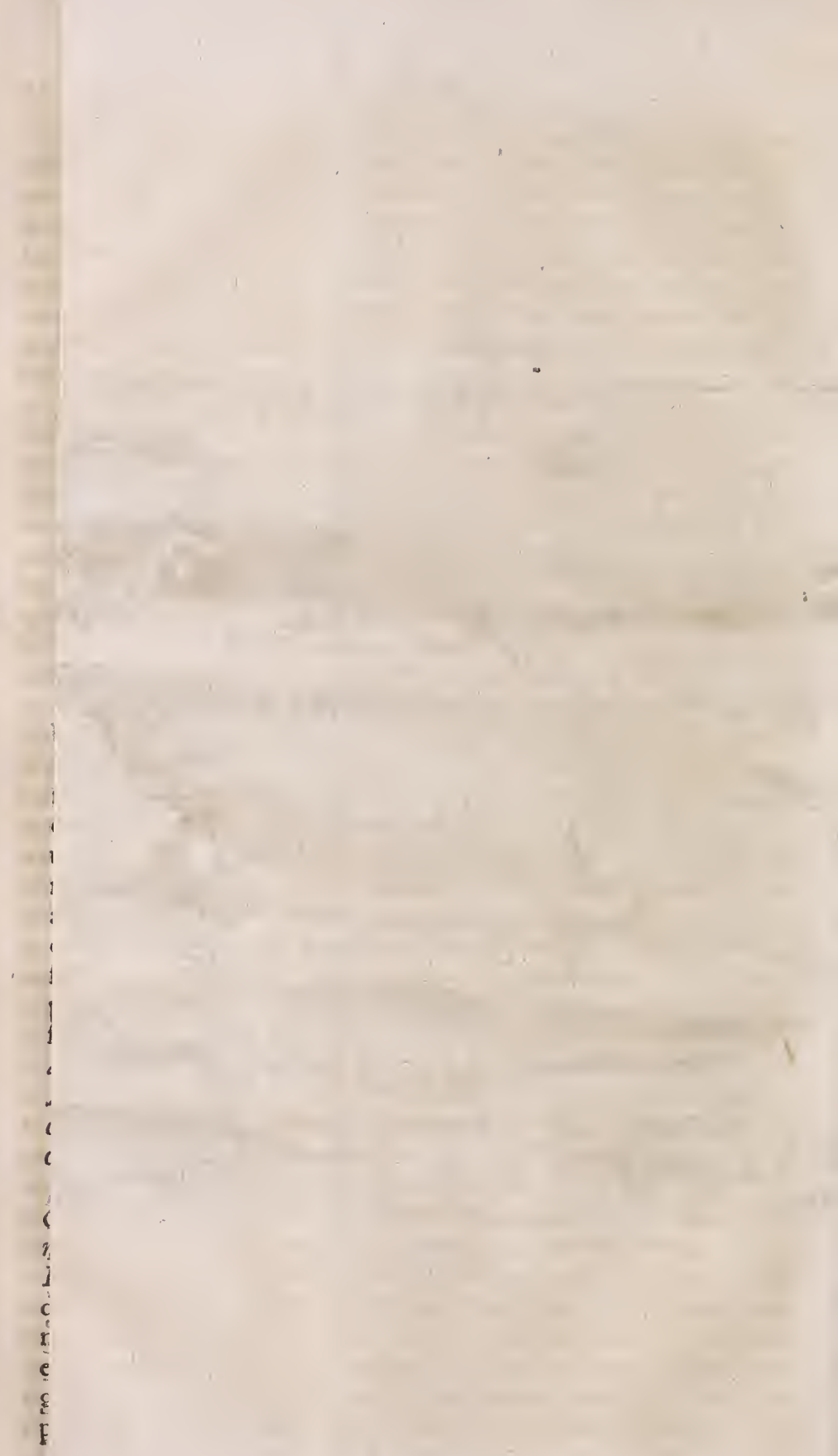


ex albo ad cinereum vergentibus nigrisque intermixtis, nunc majoribùs nunc minoribus quadratis et forma Rhomboidea inordinate difpofitis, non tamen accurato 'chemate illo, quod Clufius et Wormius exhibent. Cutis fquamae circa caput et collum potius oblongae quám rotundae, in dorfo quadratae, percaudam oblongae et quoque circulariter difpofitae. Caput vix duarum unciarum, nec mandibula fuperior mobilis, uti in Crocodilo fecundum Wormium, nec cruftis indifcrete politisveftita; ficin apice quoque foramina duo defunt, oblongae tamen oculorum orbitae, et ad collum foramina dùo, auditui forte deftinata. Ritus plane a Wormiano differt, quippe Lacertorum frmilis, lingua Viperina bifulca, dentes perexigui. Anteriora crura minora et graciliora potterioribus, fuperne majoribus, inferne minoribus fquamis dotatà. 'Pedes graciles quinque'digitis ungulisque incurvis praediti, quorum bini medii reliquis praceminent. Pofteriora crura non multumanterioribus craffiora, tongiora tamen et majoribus munita fquamis. Pedes pariter graciles, fed longis quinque digitis 'et ungulis praediti, valde aequalibus, quippe tres intermedii ferme aequales, primus et ultimus perbrèves.

Vt Lacertum Indicum in Clufio, fic in Besleri noltri Tabula PEREGRINVS LACERTVS fequitur, longitudinis duorum et amplius pedum, in ambitu vix feptem adaequat uncias. Collum craffum oblongiufculo capiti acutoque hiante rictu annexum, mandibula inferior fuperiore largior, parvis acutisque dentibus utrinque armata. Dorfum aliquantulum fupereminens circulis albis, cui maculae fufci nigrique ac cinerei coloris infperfae, interdiftinctum, qui circuli annulique caudam quoque in longum mucronem definentem cingunt et ambiunt. Quatuor habet crura aliorum Lacertorum inftar, lineis pariter albis fignata, finguli pedes tribus digitis antrorfum fpectantibus, et breve calcar pofteriorem pedis partem five calcaneum occupat. Plura quaere in Clufio.

\section{TAB. XII.}

Q Vam fub nomine SCINCI MAFORIS hic vifui fiftit figuram, fub Lucii terreftris, Brochet de Terre, nomine exhibet Nobiliff. Kochefort dans '' Hiffoire desIsles Antilles chap. i 3.Art.VII.p m. I 49.ut ovum vix ovo fit fimilius, et fi pedes demas, cum Lucio pi fce plurimum

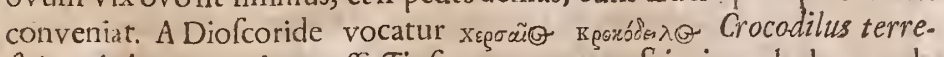
fris. Avicennaevidetur effe Tinfa, ex corrupto Scincivocabulo; unde vero nomen Thyro obtinuerit, quod a rufticis Africanis his Scincis tribui afferit Ferrant. Imper. Hift. natur. Libr.XXVIII. latet. Pinnarum loco huic animalculo pedes funt adeo debiles, ut potius ferpentum more repere quam incedcre videatur; plani latique funt humanae manus inftar, digiti breviores, unguiculi nulli. Maximi horum Scincorum de- 
cem vix pollices excedunt, cutis fquamulis lucidis, fufcis gryfeo argenteis munita, caput oblongum, rictus quafi acuminatus, dorfum latius magis quam in Lacertis, Venter quadantenus pedibus quafi alatus, cau. da rotunda lacertorum more, fed breviore, et circa finem incurva. Cum cavernas et fcopulorum latibula inhabitent, noctu lugubrem fonum edunt, ranis coaxantibus nondum perfectis fimilem; hinc eft, quod cir. ca Vefperam ingruentem tantum compareant, tefte Rochefortio loc. modo citat. Ferrant. Imper. 1. c. Lorenzo Legat, nel Alufeo Coppiano. Libr.I, cap. VIII p. 35.

SCINCVS MINOR, quem in fine Tabulac Auctor exhiber, melius inter lacertulas et Salamandras refertur ab Excell. Wurfbeinio Salamandrol. cap. VI. \$. 8. pag. 57. ubi figurae Beslerianae expreffe meminit, et Scincis Rhafis effe videtur. Cum palfim omnibus in officinis Pharmacevticis proftent Scinci, abftineo ulterioridefcriptione, Experientiaeque commito, an Sale volatili blando fcateant, ob quod diureticum effe perhibentur, et an habeant infimul virn aliqualcm alexipharmacam, et adverfus Lepram generofum exiftant remedium, veneremque fimulans. Vid. Pomet L' Hiftoir. Generale de Drogves P. II. Livr. I. cap. 29. . . 68 .

C.H.AMAELEONTIS, quam Auctor delineari curavit, effigiem pluribus, circa oculos, pellem, pedes et anteriores pofterioresque aliaque notat Illuff. Nebemias Grew Muf. Societ. Reg. Atrenuus in reliquis Mufei noftri Besleriani Encomiaftes; fed erit hoc, loco excufationis legitimae Auctori noltro, quod animalculum non vivum, fed nefcio quibus pơf mortem annis aeri incifum dederit, in quo membra omnia collapfa, contracta, et a ftatu naturali recedentia deprehenduntur; nec enim figura Alufei Calceolariinoftra melior, nec Olearii in Gottdorffienfi Miufeo, quae penitus ad ductum noftrae, uti pleraeque a liae ejus figurae, efformata et depicta ; et Jonfroni Chamacleontis effigies quoque Illuftri Gren difplicet, fic enim de illa Fonftoni Figura, cpecially as tothe feet, very falfe. Nec Parifienfium, quam Anatome Animalium intulit folertiffimus Blafius, quoad omnia exacte convenit cum illis, quas recentiores hodoeporicorum fcriptores Illuft. Whelerus et Sponins, Cornel. Le Brun et Guilelm. Bofmanm exhibuere, Et horum pariter differunt Chamaeleontum delineationes; quippe Aegyptii differunt ab Africanis Americanisque. Vereorigitur, neillud mihi quoque in defcriptione Animalculi hujus contingat, quod Auctori noftro circa delineationem, praecipue in tot Scriptorum circa Cha. maeleontem fententiarum divortiis. Non equidem nobis animus, illa veterum de hoc Animalculo promere praejudicia fabulasque apud Zoographos fufe relatas: hoc enim noftrae non conveniret brevitati. Vide. experientia, veritatis indubia magiftra, firmavit. Praceuntem habemus Illuftr. Rajum in SynopS. Animal. Quadr. qui, quicquid Panarolus, Pa-. is rifi- 
rifienfes et Foh. Faber Lynceus aliique in Anatome animalis hujus annotarunt, exhibuit. Eft autem Chamaeleon e quadrupedum oviparorum. genere, Lacertis affinis et fimilis, praeteryuam, quod caput, et dorfum non deprefla et plana funt Lacertinorum inftar, guodque crura habeat. longiora, Aegyptii Chamaeleontes magnitudine Afraticos et Africanos fuperant, quippe hi pofteriores fex plerumque uncias longitudine non excedunt; Auctoris igitur noftri Aegyptium exiftere longitudo undecim pene digitorum evincit. Moles feu corporis craffities pro regio. num varietate, et animalculo fe vel dilatante vel contrahente, va. riat; haec autem incumefcentia et contractio non tantum per thoracem et abdomen extenditur, fed ad pedes usque priores et pofteriores, et iplam etiam caudam pertinet. Mox enim corpulculum tumidum et inflatum apparet; mox contractum vacumque, adeoque macilentum, ut fpina valde acuta videatur, coltae omnes facile numerari poffint, et pedum tam anteriorum quam pofteriorum tendines, valde clare et diftincte nudo etiam cernantur oculo, ut Tertullianus Chamaeleonten nibil aliud effe quam pellem vivam, non ineptedixcrit. Caput, ut Panarolo videtur, quandam cum fue fimilitudinem habet, fed propter acutiem arietinum a emulatur; a medio capite retrorfum offea pars triquetra eminet, reliqua antrorfum colligitur cava er quafi caniculata, eminentibus utrinque offeis marginibus afperis et leviter ferratis, optime in figura noftra expreflis. Parifienfes Pifcis affimilant capiti, optima ad. dita fimilitudinis ratione. Crifta in vertice erigitur, et duae aliae fupra oculos: inter has criftas in fummo capite cavitates five convalles duo fecundum longitudinem extenduntur. Immobile huic animalculo ex omnium pene relatione caput, illud tamen oculorum compenfat morus ct ftructura, quae $\mathrm{ab}$ aliorum Animalium peculiare quid et diverfum. obtinet, ceu pluribus $P$ arifienfes annotarunt lectu certe digniffimis, recenfioni noftrae autem longioribus; hoc tantum annotafle nobis fufficiat, Chamaeleontem, unooculo aliquando immoto, alterum volvere, unum furfum, alterum deorfum; unum dextrorfum, alterum finiftrorfum flectere; imo quod omnem fere admirationem fuperat, motus hi adeo notabiles et excefivivi funt, ut oculos fub crifta, fupercilium efficiente, cousque ad canthos circumagat Animalculum absque ullo capitis, qucd fcapulis affixum eft, motu, ut non minus clare, quae directe retro fita funt aut geruntur, cernat, quam quae ante; teftes hujus reicito avtaptas, Illuftres Whelerum et Sponium dans le Voyage de Dalmatie de Gre. ce et de Levant.p. 240. leq. et Cornel. le Brun.Pictorum folercifimum in nitidiffmo, et innumeris ad vivum ab ipfo delineatis aereis figuris refertiffimo operc,infcriptoVoyage auLevant c. 3r.p. 16r. Rititum feu os Chamaeleontis quod attinet, adeo arcte claufum effenonnulli retulere, ut nullum habere videatur, maxillis linea vix perceptibili junctis, hinc per foraminula duo in roftri extremitate hoc tantim animalculum relpirare crediderunt; idquod Bosmannus quoque dans le Voyage de Gui. 
nee Lettr. XIV.p. 265 . annotavit, fe nunquam Chamaeleontes Africos rictu vel gula aperta exertaque obfervafe Lingua: modocitatus $B r u$ nius tamen multiplici experientia comprobat, Chamaeleontes, quorum quatıor Smirnae fimul alebat, quoties illos A ëri liberiori mare verfus expofuiffet, auram ore latiffime diducto haufife, prominulaque lingua et longiufcule exporrecta incautas mufcas Formicasque glutine linguae invifcatas devorafle. Sic Whelerus quoque refert de Chamaeleonte, quem in terra reptantem manibus prehendit, rictum illum diduxiffe, fibilumque inftar ferpentum dediffe. Brunius infuper modum, quo mufcarum capturae, tanquam efcae folitae invigilant, fufe defcribit Ruit fic praeconceptum illud praejudicium, quo, ut Ovidius olim cecinit,

\section{- ventis animal nutritur et aura}

Confer clegantiffimam Difjert. Tubingae anno I 681 . a Cl. Hopfero de Vidu ä̈reo, feu mirabili potius inedia Chamaelecntis habita. Linguam iplam, quam ad vivum delineavit. Brunius, quod attinet, teres ilia Pici martii in modum, lumbrico terreftri quodammodo fimilis, per totum concava et ficci inftar vel Elephantis probofcidis in fummo aperta, in cujus extremo fpongiofus quidam et glutinofus nodus, feu ut alii volunt, caruncula lata et rotunda, caput aciculae referens, quam linguam mira velocitate et velut momento Sagittae inftar in longum ad 7. aut 8. pollices evibrans, mulcas, formicas, aliaque infecta agglutinata corripit, ori. que, poftea ac ventriculo ingerit, quas plures inibi detexerunt hodierni Anatomici. Inteftina ampla hoc in animalculo detexere Parifienfes, Brunius nullum, qui apertum Abdomen triginta tantum ovulis, filo quafi connexis refertum reperit. Et Panarolus quoque memorat, vifcera exiguum in abdomine fpatium occupare, ut aërc potius plenum videatur quam vifceribus : hinc Whelerus nullo ex Chamaeleonte, quem aluit, Excrementa ex Inteftinis vidit prodeuntia. Ovailla, quibus abdomen refertum vidit Brunius, avium affimilat ovis, notatus ideo a Bosmanno, qui lacertorum potius ovis fimilia effe, omni teीta duriori deftituta, afferit. Reliquum corporis truncum quod attinet, quique Thoracem et abdomen continet, tota fere thorax eft absque ullo Abdomine, coltáe enim, quarum in quovis latere XVIII. triplicis fecundum Parifienfes conditionis, ad ilia usque delcendunt, cum in aliis multis animalibus in Lumbis vertebrae transverfas tantum apophyfes habeant, non coltas adnexas. Pulmones $W$ belerts per totum fere corpus fubtiliffime expanfos in duos lobos divilos credit, vafis fpiralibus five trache is in Plantis hoc pacto limilibus; vel Cyprini pifcis veliculis lecundum du $\mathrm{Ha}$. melinReg. Ccientiar. Acad. Libr.II. Set.XI.c. 2 P.1 27. Pedes omnes fimiles funt e 5. dig tis, tribus antrorfum, duobus retrorlum lpectantibus compofiti, prfticis duobus anticos tres magnitudine aequantibus: Differunt, quod pedes anteriores duos ab externa, tres autem ah interna parte digitos habeant, vic everfa polteriores duos ab interna, tres ab externa. V ngues re- 
curvi funt.Gre $\int$ Jus huicAnimalculo teftudineus in terra; fupra arhores velociores, ut volatum pene aenulentur. Cauda cum inflata rotundatur, gliris caudam bene fatis referens, alias tres fecundum longitudinem. eminentias habet e lpinofis et obliquis vetebrarum A pophyfibus compofitas, duas infuper, hinc inde unam ex apophyfibus transverfis factas. Catida etiam ramis circuimvoluta, praefertim quando ab arboribus defcendit, corpus firmat, eaque tanquam manu utitur. Pellis, qua corpulculum obductum, innumeris granulis isque perpolitis diftincta, tenuiffma et pellucida ferme transparensque, quo ipfo multum ad radiorum variam modificationem indeque dependentem colorum varietatem confert ; nec enim praejudicio occoecati, abfolute illud Ovidianum credimus :

\section{Protinus affimilat, tetigit quoscunque colores:}

fed reftringuntur maxime colorum illae Chamaeleontis varietates. Latifimus hic dicendicampus; fed brevitatis memores, quid aivión tns de illis Brunius, quem Bosmannus quoque exfcribere dignatus elt, annotarit, ipfiffimis verbis e Gallica translatis adjungimus: Color, quem utplurimum recipiunt Chamaeleontes, laete viridis eft maculis intermixtus flavefcentibus, adeo concinno quidem Schemate, ut penicillo havid expriwiqueat; maculae interdum etiam brunni coloris apparent, et totum corpus ad caudam usque colore boc inficiunt. Saepius etiam nigricantis coloris funt inflar talparum. Color ordinarius illorum gry.feus five potius pilorum gliris; pellis tenuiffima et ferme transparens; faepius colorem mutant, idque patio dimidio borae terna Saepius vice fatum memini. AfJertum autem quod attinet, has beftiolas omnies rerum, quibus imponuntur, colores affuntere, experientia toties edocus fcribo, Naturalis Hiftoriae fcriptores hoc articulo deceptos effe, nec enim vel rubrum, vel coeruleum, aliumque affumere. Albi tamen coloris lepidum illi contigit experimentum. Inter quatuor, quos aluerat Smyrnae, Chamaeleontes elegantifimum vefpera ingruente perdiderat, quem cum fruftra in omnibus camerae angulis cum fervo quaefiviffet, tandem in veftis cubicularis ferico albo confecti fummitate, cjusdem cum vefte albedinis reperit. Hoc illuftri quoque Whelero contigit, quod cum ad ulteriorem confirmationem eorum, quae Corn. Brunius in hoc animalculo obfervavit, faciat, bona cum L ectoris venia referendum cenfeo. Poftquam hujus generis plurimas beftiolas, in muroSmyrnenfis arcis repentes, ejusdem cum muro mufco viridi obducto, coloris vidiffet, tandem Cliamaelcontem in ramo quoque Prunellac fpinolae fedentem confpicit, laete viridefcentis coloris, fed fatim oculis ejus fe fub= ducentem folumque petentem. Cum defixis oculis fugtentem undique frultra quaefiviffet, tandem foramini rupis adrepentem detegit, ejusdem cum terra pluvia made $f_{a}$ cta coloris brunnideprehendit. Hunc fus dario linteo aliquantulum impofitum, ejusdem coloris albicantis reperit; 
macul is fufcis rubentibusque intermixtis. Haec Whelerus Bruniusque circa Colorum varietatem, quibus Bosmannus quoque affentit, in hoc tamen a Brunio diflentiens, quod Chamaeleontes tot annos vivos aluerit, quot Brunius illosmenles, in arboribus illos repentes relinquendo. Quomodo autem colorum illa modificatio fiat, et an pro diverfis affectibus varios colores induat Chamaelcon, inquirit du Hamel Reg. (cientiar. Acad. Hift. l. c. Tantum de Chamaeleonte e Myrmecologia Parentis. Obliti pene fuifemus Excell. Pechlini, qui defcriptione Chamaeleontis in ejus Obferv. Aledico. Phy fic. Libr. II. obl. 70 . reliquos fupereminet omnes.

LACERTVS VIRIDIS, veteribus Graecis ouñea $\chi^{\lambda}$ cíga et re* centioribus $\chi^{\lambda \omega}$ ges ãven, Italiac aliarumque regionum calidiorum incola, ubi nonnulli obfervarunt, eorum multos fimulegredientes morbos praefagiifle Epidemicos. In arboribus aeftivo tempore nidulantur, et ranunculorum viridium more fonitum edunt. Communibus Lacertis, quales noftri, majores funt, faepiusque bicaudatae inveniuntur. Color viridis intermixtus maculis coeruleis, hincque lacerta eleganter variegata. Capite eft triquetro, rictu dentibus urrinque minimis licet, acutis tamen praedito, hinc cum ferpentibus aefivo tempore praeliatur, eo:que adoritur, unde Sylvaticus huic Lacertae nomen Opbiomachae tribuit. Duo narium foramina habet in extrema et acuminata maxillaefuperioris parte fita, oculos pro corporis magnitudine mediocres, aurium. meatus ad collum. Crura pofteriora prioribus craffiora majora et longiora, digitis quinque praediti funt pedes, ungulis incurvis et acutis armati, quorum is, qui indicis fitum habet longiflimus; dorfum pulcherrime variegatum, venter vero flavelcentibus tegitur fquamulis. Plura vid. apud Worm. in Alufeo. De V fu medicomaximum Aldrovandum, ejus Epitomatorem Fonfron. de (2uadruped.p.191. aliosque. De Cauda Lacertis abfciffa et renafcente curiofifima refert DN. Perrault Effais de Pbyfique ou recueil de plufieurs traitez touchant les chofes naturelles. T. IV.p.S.

\section{SALAMANDRA haec AQVATICA MINOR in Sald-} mandrologiae Tab. I. Lit, L, ab Excell. Wurfbeinio ex hoc Besleriano Schemate relata, lacertulorum potius quam Salamandrarum generi accenfenda: quantum enim ab his differat, ex definitione Salamandrae Wurfbeiniana, quam ex ejus modo laudata Salamandrologia defumimus, omnibus pater. Definitur autem, quod Salamandra fit reptile quadrupes figura externaque corporis facie praeter capitis et ventris craffitiem, lacertae viridi quam fimilimum, caudam breviorem, ef in pelle pingui atque renitente colorem nigrum, maculis luteis plerumque refperfum habens, locorum frigidorum et humidorum amantiffmum, tardigradum, pluviam apparitione fua praenuncians, et falfo quondam creditum in igne non cremari. Omnia haecSalamandrarum acci- 


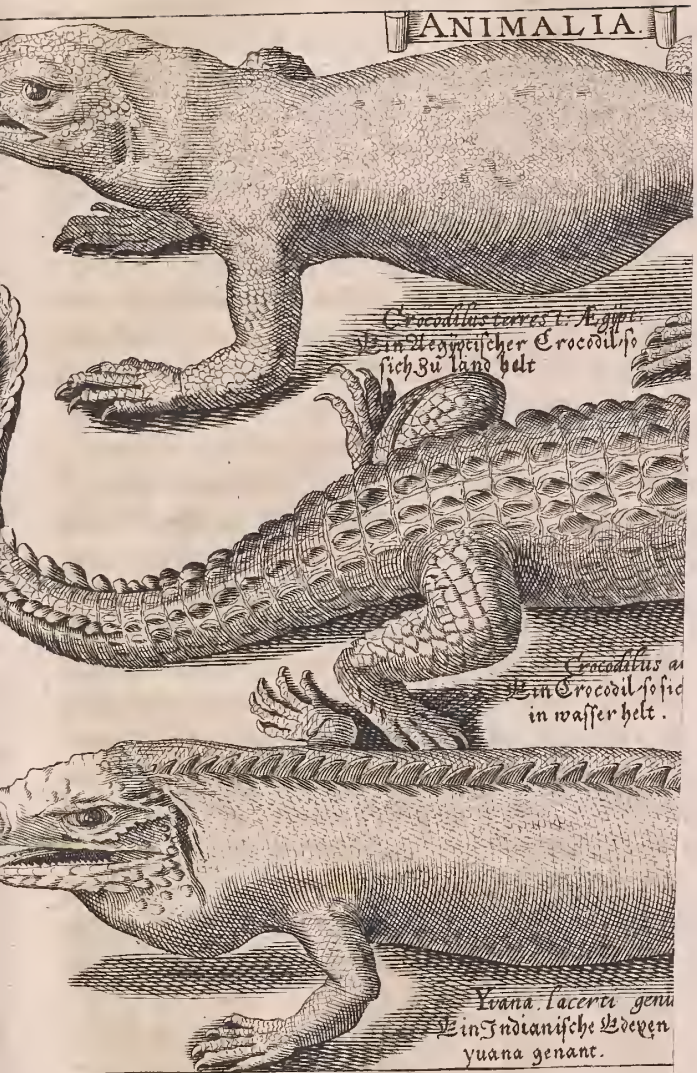
yuana genant. 



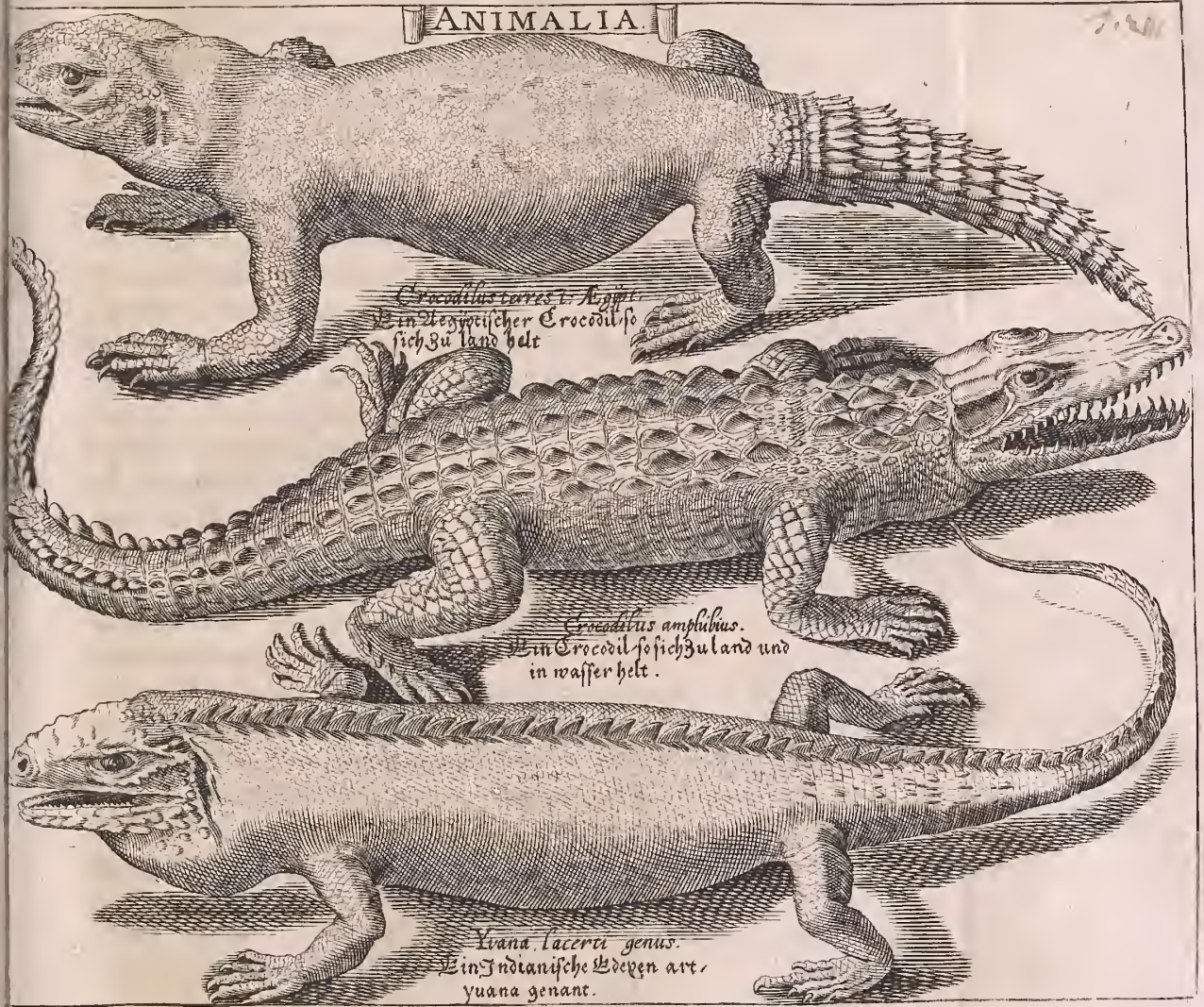




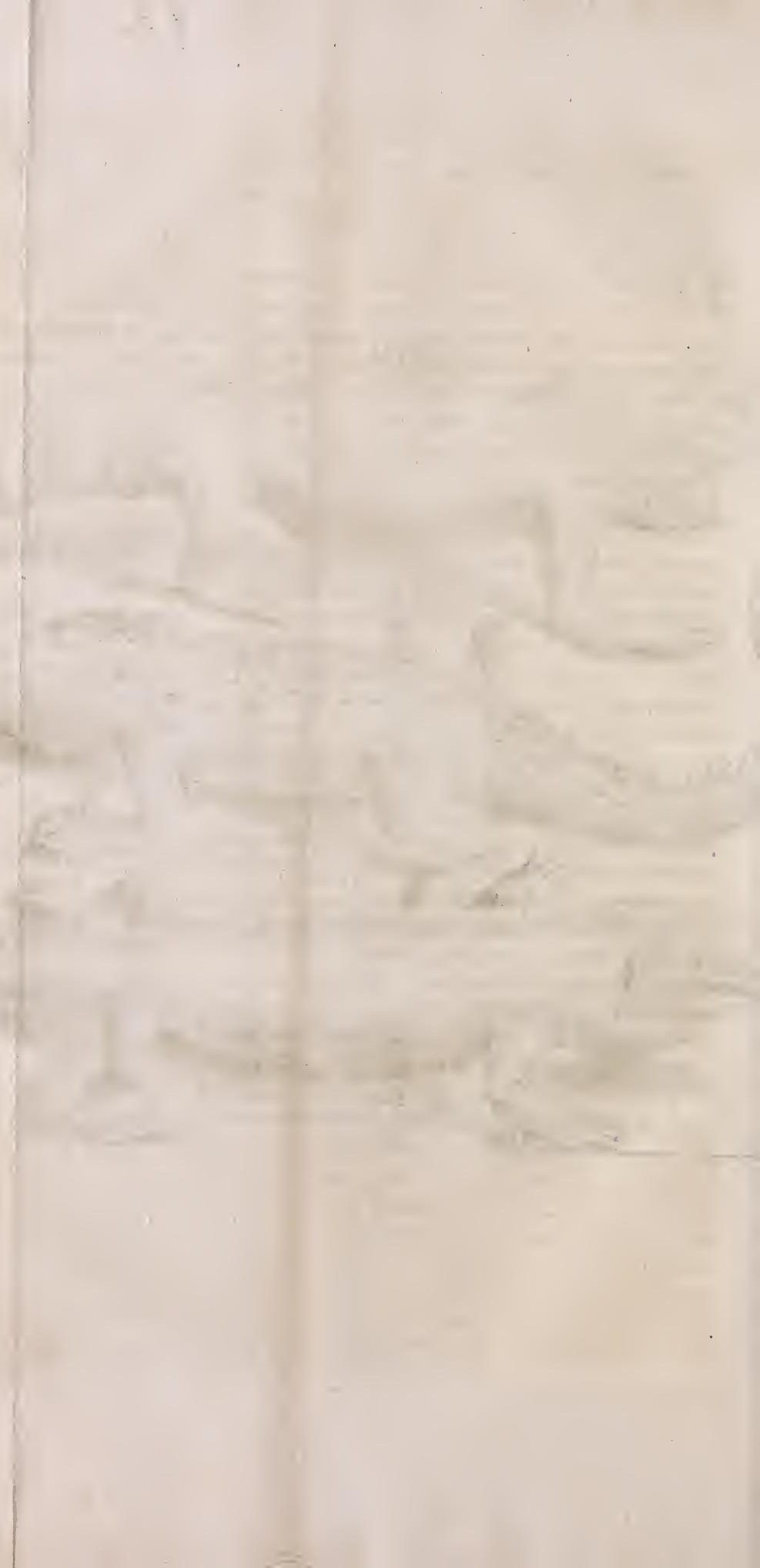


accidentia, differentiasque adeo rimatus eft vir quondam diligentifimus; ut actum agere videar, fi plura adderem.

\section{TAB. XIII.}

\section{$\mathrm{H}$} Ac in Tabula medium tenet locum CROCODILVS AMP HIBIVS NILOTICVS, Lacertorum omnium maximu,, e Mufei Regii Anglici teftimonio optime depictus; curiously figur'd by Besler) a quo Aethiopum Cayman et Brafilienfium Jacaré non nifi mole corporis differre videtur, cum nilotici XXV. cubitos excedant, et fi fides Fob. de Lopez Hift. Indic. L.VI. c. l. habenda, ut et Joh. Lerio, ultra centum pedes in longitudine circa Panamam excrefcant, Brafilienfes vero decem vel quindecim ad fummum pedes haud attingant. Cum omnis frigoris impatiens fit hoc animal, atque in fervidis tantum regionibus vivat, non mirum Galliis illatum non diu fupervixiffe, et duos integros menfes nil manducafle. 1lluftr. Rajus in $S_{y-}$ nopf. Animal. quadruped. defcriptionem crocodili e $W$ Wormiano promit; quae ab aliis quoque recentioribus annotata fupplebimus. Caput latum eft et pene totum fola pelle veftitum, roftrum ferme fuillum; in extremo roftri apice fecundum $D n$. de la Hire, qui Crocodilum Verfaliis mortuum et diffectum delíneavit, foramen eft rotundum mo!li carne oppletum; ibi duo funt parva foramina, ubi nares : Sic duo alia fupra oculorum orbitas pofita foramina, duplici quafi veloobducta, aures funt, quae fubducta pellis appendice funt confícuae. Altera pellis appendix inftar palpebrae eft mobilis fibris carncis inftructa : ductus brevis in tympani membranam definit. Reliquae organi hujus partes codem fere modo funt difpofitae, quo in avibus, nifi quod ea cavitas, quae veftibuli loco eft, multo fit latior, et canales femicirculares fint excavati. Oculi fecundum nonnullos fuilli, Marggravius tamen Brafilienfibus non fuillos, fed magnos, rotundos claros caefios pupilla nigra attribuit. Ridus maximus usque ad locum aurium patens; dentes, quibus :ißtus horridus in utraque maxilla funt acuti albi, robufi, multi, numero incerto, qui fortaffe pro aetate etiam variant; in nonnullis fexaginta numerati, imo in Aldrovandini Mufei Crocodilo feptuaginta deprehenfi, tefte Cl. Legato in Muf. Coßpiano aneffo al famof. Aldrov. Libr. I. cap. VIII. p. 30. Conjunglintur hi dentes initar pectinis, et pro infallibili per contactum dolentium habentur dentium remedio. Vid. Illuftr. Redi in Experim. circa Res natur. ex Ind. allat. Lingua pene nulla, guod tamen Cl. Thom. Brown, erroribus popularibus in Y feudodox. Epidem. annumerat; Linguae loco Pifo membranam oblervavit, quae mandibulae interiori interjacet, et Linguae figuram refert in longum exporrectam, fed anguftiorem, quam fuftallere non potelt; Cui confentir Cl.Dn.duVerney in diffet. Crocodili Verfaliis facta, qui infimuladdit, hanc membranam Linguae aemulum varïs pertufarm foritN mint. 
minulis praecipuum effe guftus organon, Vid. Excell. du Hamel Reg. Scient. Acad. Hiftor. Lib.II. cap. 2. p.m. 208. Recentiores plures Ariftotelem fecuti Crocodilum folum ex animalibus maxillam fuperiorem movere, inferiori fcilicet immobili, tradiderunt. Illuftr. tamen Gren in Mufeo Regio ex Sceleto a Generofo Dn. Roberto Southrell fuppeditato, ct aeri incifo, demonltrat ex offum ftructura, hoc eft articulatione non folum occipitis cum colli vertebris, fed etiam maxillae inferioris cum fuperiore, quae in hoc animali conformis eft cum reliquis, manifeftum effe, Crocodilum eodem prorfs modo, quo alia animalia, maxillam. inferiorem movere. Hacc illuftris Anglus; jungam huic Gallum Illuft. duVerneyum I. c. Maxilla, fcribit, inferior cum temporum offibus duplici articulatione ficnectitur, ut furfum et deorfum tantummodo moveatur, non dextrorfum et finiftrorfum, ut in aliis animantibus; cum enim dentes illius acuti fic difponantur, ut fibi non occurrant, fed in fpatia gingivarum dentibus vacua incurrant, maxilla ad laterainflecti non deburt, fed furfum deorfumve, ut dentium apices fibi aptata formina fubirent. Totum reliquum corpus hactenus defcripto capite excepto, uti optime in figura noftra expreffum, fquamis pene obductum rozundis in collo et cruribus, in tergo et in fummitate caudae velut fafciae quaedam fquamofae apparent, fulcis et caelaturis diftinctae, adeo ut fquamaenon imbricatim, ut in majoribus pifcibus, fed quafi teflellae juxta fe pofitae viderentur, ac fafciae illae ob dorfi verteb ras hinc inde ad lumbos usque, ita fint porrectae, utinter eas diftincta fint intervalla fquamis deftituta. Atque in iis folis intervallis locus eft vulneri. Nam fquamae ipfae funt adeo firmae et durae, ut pene fint impenetrabiles, mediam inter os et cartilaginem nactae naturam, non fragiles ut offa, fed flexibiles; hinc de juncturis fafciarum intelligendum, quae Bontius de vulneribus Crocodilo circa moenia civitatis Bataviae in palude capto, bipennibus in dorfo ac alibi inflictis, memorat. Nam et dorfi et caudae fquamaecrifta quadan muniuntur, ut galeae et caffides et in eundem pene ufum. Tenuiores funt fub Ventre, cauda, cruribus, collo et maxilla inferiori, nec crifta munitae, fed uti quadrati lapides difpofitae, continuatas fifcias ut in dorfo non exhibent, neque eam refiftendi vimhabent, utillis in locis facile gladio fauciari poffint. Caudae longitudo reliquum corpus aequat: annotavit porro Pifo caudae medietatem, firma pinna fuperius erecte ftante, ad finem usque dotatam effe, qua inter natandum, more pifcium fe gubernet. Crura cum pedibus acutifimis unguibus armatis in latera flectuntur. Interiores partes quod attinet, illae elegantiffimae defcriptae funt in Anatome Crocodili Verfaliis diffecti apud du Hamel. in Reg. Scient. Acad. Carne Crocodili funt candidiffima, quam $\mathrm{Cl}$. Bontius comedit, et agrefte ipfi et paludofum fapiebat, imo choleram exinde lethalem ferme contraxiffe queritur. Hift. nat. et med. Libr. $V$. c. 30.p. 33. Adeps animalis vulneraabipfo illata optime fanat, Pifone tefte; qui tefles quoque myrothecium redolentes care divendi tra- 
dit. Hinc Crocodili Americani aquam dulcem inhabitantes adeo mofchiodore fragrant, ut aër ad centum paffus inde afficiatur, hocque fingulari divina providentia factum credit Rochefort dans l'Hiftoire naturelle des Antilles, ut homines animantiaque fragranti odorequafi moneantur, ne incaute hunc in praedatorem incurrant. Parifienfes quoque jam faepius laudati in diffectione Crocodili annotarunt, circa medium inferioris maxillae utrinque fuifle glandulam, liquorem fuavi/fimiodoris fundentemet jpargentem. Colore croceo quibusdam efle ftatuitur : Crocodilus, fed utplurimum ad gryfeum et cinereum declinat, quod in noftro quoque accidit. Forfan vivus ad croceum vergit. Animal pigrum nec facile in latus vertitur, recto femper procedens tramite, ut illi, quos beftia profequitur, fi hinc inde currant, eam faepius queant evitare. Ova parit Niloticus. Anjerinis fimilia, fed Brafilienfis Gallinarum ovis magnitudine, non figurae oblongae, fed cylindroideae fecundum Olearium; haec ova arena obruit, ubi folis fota calore absque ullo incubatu fponte foetus excluditur. Curiofum efl, modo verum, quod Acofta de Arom. Libr. $V$. p. 59. memorat; nunquam compertum effe, iis qui Cymbis e Mambu confedis, (in quibus nafcitur Tamaxir) crocodilos oppetiiffe, fed faepenumero conjpeta effe baec animantia natantia proxime illas Cymbas, attamen praeseriije fine noxa. Omnia quae de Crocodilo dici poffunt, congeffit ex omni antiquitate philologicisque rivis ftupendi Laboris Aldrovandus; hanc Beftiampeculiari Differt. defcripfit Kirchmaier. Leviathanem Jobi aliaque fcriptura loca, ubi de Draconibus fermo, per Crocodilum inteipretatur Excell. Ludolfus in Comment. ad Hifror. Aetbiop. L. I. cap. XI n.86. cui jungi poteft incomparab. Bochartus in Hierozoic. De Crocodili lacrymis peculiarem Differt, edidit Lipf. I662. Chr. Krabe.

Praecedit Crocodilo noftra in Tabula CROCODILVS TERRESTRIS AEGTPTIVS, magnitudinis pene ejusdem delineatus, licet maxime mole ipfa corporis differat. Eft autem Animal fub nomine Cordyli, Vromaftigis et Caudiverberae melius apud Zoographos notum, nomenque ultimum obtinuit, quod cauda in modum clavae tuberculis eminentioribus afpera, corpora quibus appropincjuat, atrociffime verberare cred tur. Hinc Graeciadimitationem Latini vocabuli Vromsfigen nominare confueverunt. Figura, quam in Mufeo Calceolarius ex-. hibuit, non minus ac noftra, impenfe laudatur Excell. Grew in Muf. Reg. Soc. Anglor. p. 46. (in Calceolari's Mufeum there is a curious Pi. Gure bierof unde the Name of Crocodilus Terreftris, as alfo in Besler.) Apud folertiffimum naturae myftam Gesnerum e communicatione Th. Erafi optime defcribitur. Capitis et oris frgura Teftudini relpon. det, brevi collo et parte interiori tumido ; duo circa ritum for amina obfervantur, quae an branchiae, fecundum Bellonium et Rondeletium, non facile detcrminari poteft, quarum mentio apud Boffvetum de Aquat. natnr.p.13I. Pedesipf quatuor, quinis digitislacertarum more dffine 
cti. Corpus pelle duriufcula inftar coriiveftitum, e fquanis duriffmis et quodammodo ofleis et quafi quadrangulis, quae parum cavaefunt, ut caudam rotundam efficiant, alioquin Iquamae in cauda tanquam tegulae, quae domorum culmina cooperiunt, fimul junguntur : extremitas cujuslibet fquamae in fpinam acutiflimam definit, funt autem fquamse pellucidae, flavefcentes five pallentes cornu adinftar. Animalis hujus venter magis quam in Crocodilo tumet. Tergus latum et quodammodo planum. Vocatur autem vulgo Crocodilus terreftris (quae denominatio Scinco potius convenit) quod aquae adeo fit impatiens, ut fi quis Aquam ori infundat, ftatim exinde moriatur; contrarium autem Boffretus dedit. Vid. Cl. L. Legatus in Mlufeo Colpian. p. 34. Muf. Reg. Soc. Angl. P. I. p. 46. fub nomine Sibaptad-Lizard. Alle. Alofcard.Lib. 111. cap.62.p.223. aliique Zoographi.

Dubbis Lacertis tertium adjungit Indicum nempe, SENEMBI, Caraibis OVAY AMACA et XGVANAM lecundum PISONEMI corrupte pro $L E G V A N E$ dictam, licet Figura Legvanae a Bontio luppeditata differat. Ejus corpus utplurimum duos vel tres pedes longum; ficut et cauda, a mbitus vel craffities decem digitorum ad fummum, Cum Mufeum Societ. Reg. Angl. figuram hane noftram optime aeri incifam, et Marggravii Wormiique defriptionen prae reliquis celebret, ( riously figur'd by Besler. Wel defcrib'd by Mlarggravius and after bim, Wormius) ad hos quoque Auctores B. L. ablegamus. Johannes de Laet amphibium effe tradit Animal, cui MIr. Rochefort Hifloir. natur. des Isles Antill. contradicit. Marggravius cutem eleganter viridem, fed maculis nigricantibus et albis in modum panni undulati binc indevariegatam; Rupifortius differentis coloris effe pro regionum varietate afferit; unde a Lufitanis, improprie licet, Chamaelcontis nomine veniunt, refert porro utplurimum foemellas ad viridem, mares ad grylcum accedere, qualis in noltro Besleriano con/picitur, quamvis tergum verfus pallide viridefar. Cutis conftat e fquamulis in dorfo, cruribus et caudae initio, paulo majoribus, quam in reliquis partibus. A cervice ad extremam caudam, feriem habet planarum fed mucronatarum inftar ferrae, fpinarum, fecundum dorfi longitudinem etiam viridefcentis coloris, funtque fpinae iftae ad cervicem majores, femperque minores fiunt, minimae in caudae extremitate. Caput longitudinem habet utplurimum duorum digitorum fere et paulo minorem, fingularibus fquamis maioribus quam in aliis partibus tectum, colli longitudo fesquidigiti, craffities quinque. Singula mandibula exiguos et nigricantes brevesque dentes habet. Os linguam craffam. Pone caputin utroque latere emicat albicans macula inftar branchiarum Pifcis; naribus eft patulis, oculis nigricantibus magnis; rictu eft diducło et patulo. Sub mento ingluviem ad pectus usque propendentem maxinam partem nigricantis coloris habet, quam contrahere poteft, et quando iralcitur vel terrore afficitur, propendere finit. Cibum, telte $P$ ifone, ad inglu- 


\section{r.tor}
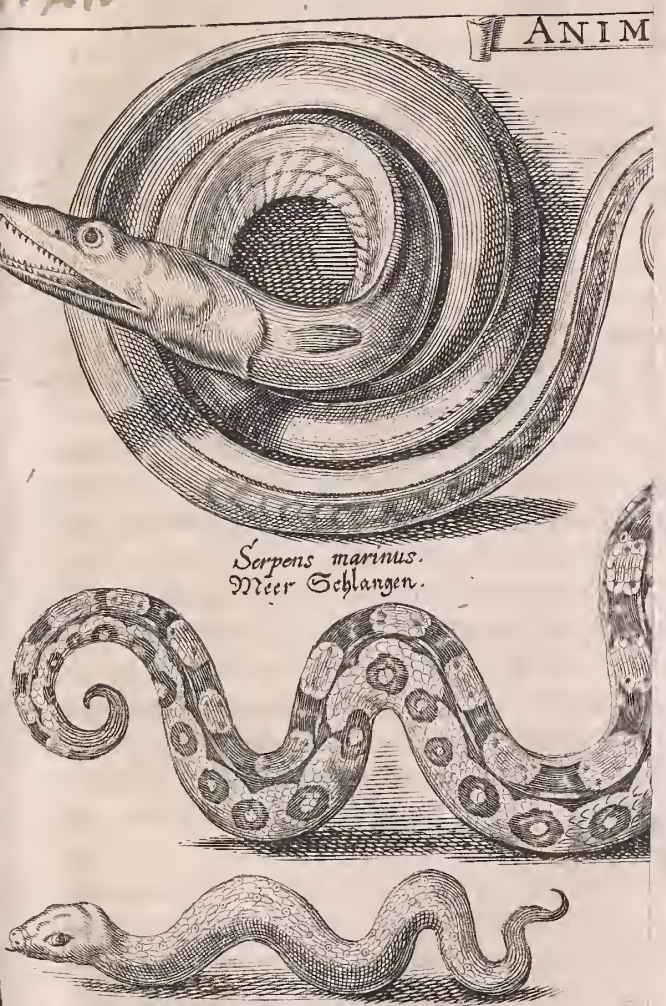

Taculus Serpens.

迄 in, Xhooifer Scljlang: 



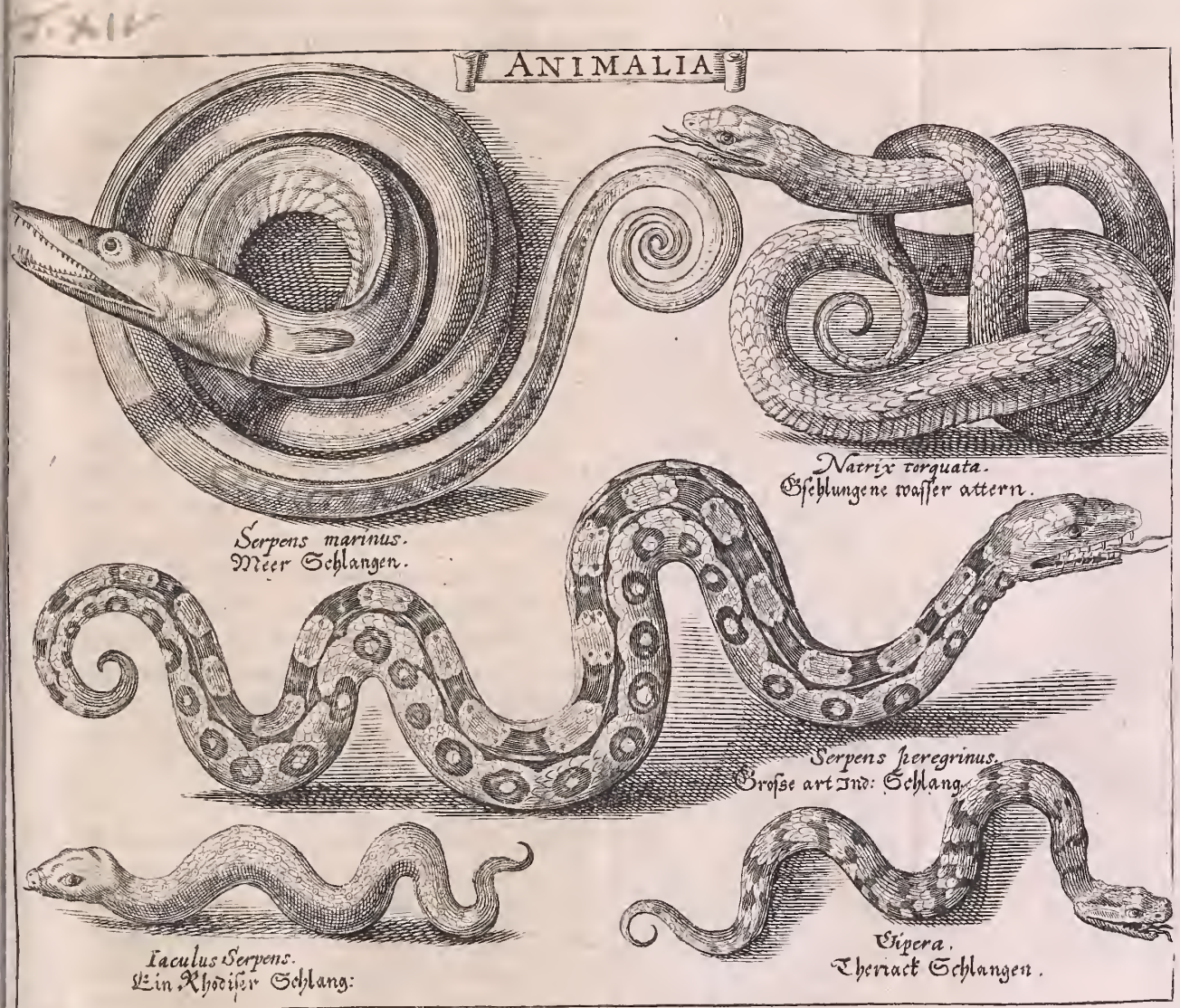



viem illam pendulam dimittit. Crura non folum, fed et eorum digiti, perpetuis quoque fquamis veftiti, et varïs a rticulationibus praediti, quac omnia accuratifime Marggravius recenfet. Crura polteriora anterioribus quidem majora, fed omnia paribus únguiculis curvis armata. Inédiam diutifime tolerare potelt, ut Marg gravius ad duos et tres menfes fine ullo cibo ac potu habuerit, nec dubitat diutius famem ferre adhucpoffe. Aegerrime moriuntur pariter hi Lacerti vitae tenaciflimac, ut tribus quatuorve plumbeis globis trajecti, et inteftinorum praecipua parte abfumta, tamen adhuc vivant, Rupifortio tefte. Sic. Llarggravius refert, quod pelle detracta vixerit, et cor exemptum fubfilierit." Caro bonieft faporis, cocta et diu frixabutyro, et aeque bene fapit, ac. caro pullorum aut cuniculorum, fr Marggravio credimus; Rupifor tius tamen fuadet, a romatibus probe condiendam efle. Laetius e Fran-? cifco Ximene refert, in bujus animantis capite interdum lapillos reperiri, quipraefentisfimo auxilio Renum lapides comminuunt et for as proji ciunt, fi Drachmae pondere e liquore idoneo bauriantur, aut corpor etiam admoveantur. Marggravius vidit eximi lapidem e ventricula. Senembi, ovigallinae mediocris magnitudine et figura, ied comprefliorepaulo, exterius glabrum albicantem, interius compofitum e tunicis inftar cepae, ita ut una ab altera feparari potueritlapide contufo. Coforis erat interius albicantis feu gryfis, durae fubftantiae ut Bezoar: Quomodo arboribus utplurimum infidentes, capiantur hi Lacerti, $M$ Iarggravius fufiusque adhuc Rupifortius in Antill. Hift. natur. p. 144. recenfent.Plura defiderantibus fuppeditabunt IVorm. Aluf.Cluf. Exot.Libr; V.c. 22.p.116. Pijo Hift. Brafit p.104.Bont. Hif. nat. et Med. p. s6, Hif. Mexic. Nard. Ant. Recchii p. 744. Nierènberg. Hifor. Nat. pag: 27r. Mul. Societ. Reg. Angl. Muf. Calceol. et omnium optime Alarg; grav. Hift. quadr. et ferpent. L.VI.p. 236.

\section{TAB. XIV.}

7 Acertis SERPENTV M Tabulam jungimus, ubiltatim te offert NATRIX TORQV ATA, quae Myagros veterum eflecreditur, fuve Virgilii Coluber tettis affvetus, et ops on ferpens Ariftophanis, OrophiaNicandri, Hydros Theophrant, Nerophis hodiernorum Graccorum, cujus mas Scorzone, et femina Scorzonere Hilpanis dicitur. Obtinuit autem Natricis torquatae nomen, quod collum circulö quodam velut torquecingatur. Praeter Aldrovandum, Gesnerum, Jonfto: num aliosque Zoographos, illufris Rajus in Synop. method. Serpentis hujus pleniorem reliquis deforiptionem dedit.

SERPENS PEREGRINVS Clufianae delineationi Libr. Exot. V.c. 18: obviae, optime convenit, nifi, quod ha ee, refcillo capite, Auctoris noftri tota aeri fit incila, meliusque colorum elegantiflima congeries exprefla. Caput Jquamulas babet albas, cubicas, ad oras nigras:- 
Tota autem pellis fquamis tecta, Serie quadam difpofitis, prona quidern. parte minoribus, jupina vero majoribus, quemadmodum in reliquis jerpentibus obfervare licet, et illis jane variorum colorum, et elegantifjma ferie diftinctorum; nam dorfum a capite ad extremam paene caudam continuo ordine fecundum longitudinem nigricantibus veluti clypeiformibus maculis eft ornatum, latera autem alterius formae nigricantibus maculis depida, venufta fane ßpecie, fubfufcus autem quem contraxit ex fumo, ut arbitror, color, valde elegantiam deformat, ip $\int a$ vero

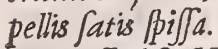

$\mathcal{F} A C V L V S S E R P E N S$ ita dicitur, quod Jaculi inftar fe

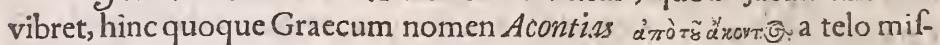
fili fluit, et Bellonio tefte in Lemno Infula Sagittari, ab Italis Saettone, vocantur hiferpentes. Bellonius, qui in Rhodo Infula probe obfervavit, tres palmos longum, unius digiti craffitiem vix aequantem, pronuntiat. Color ei cinercus fub ventre albus, fquamis juxta dorfum et laminis juxta ventrem reliquorum ferpentum more munitus. A cervice, nigra, duae albae lineae per longitudinem dorfi ad caudam usque per.; currunt, deinde maculis nigris oculi figuram aemulantibus, d ftinguun. tur, quae notae lenticula majores non funt, quapropter non abs re aliqui hunc ferpentem lenticularem nominarunt. Vid. plura apud Illuftr. Aldrovandum Hift. Serpent. et Drac. Excell. Raj. in SynopJ. method. Scrpentin. Gener.p.290. aliosque.

De VIPER A nil habeo quod addam, cum ubique proftent, et Cl. Severinus in elegantiffimo de Vipera Pythia Tractatu omnium hac de re loculos exculferit. Anatomen fi quis tamen accuratiorem defideset, inveniet illam in diligentiffrmi Tyfonis anatomica Viperae caudifonae defcriptione apud Rajum in:Method, fynopf. ferpent. generis; quae in plerisque cum Viperis Theriacae compofitionem ingredientibus convenit. Quae $\mathrm{Cl}$. Redi et Charafium inter de Viperae veneno ortae lites, omnibus jam notae funt.

SERPENS MARINVS eft a Rondeletio, Bellonio, Salviano, Aldrovando aliisque Ichtyographis jam defcriptus, nullus tamen accuratiorem fuppeditavit Delineationem Excell. Rajo in aureo opere Willugbejano de Pifcibus Libr.IV.cap.3.p. 107 . qui Romae abilluftriff. Audore vifam et examini fubjectam communicavit. Capiti congro perfimilis; longitudo $V$. circiter pedum, corpore exatte tereti, gracili, aequalis fere ubique crafjitiei, nifi quod prope caudam fenfim gracilefcat. Color in dorfo feumedietate fuperiore fordide flavicans, qualis in averfa parte membranarum vetuftiorum cernitur. Inventre feumediet ate inferiore caeruleus lucidior. Roftrum longum, tenue, acutum; ridus immanis; in maxills inferiore prope ejus angulum feu apicem dentes IV. aut $V$. majores acuti, intror fum recurvi ordine pofiti, reliqui qui in ea funt minimi et vix conpicui, fibi mutuo vicini: juperior maxilla in ipfo apice dentes habet majores quatuor; reliqui qui binc inde funt mini- 




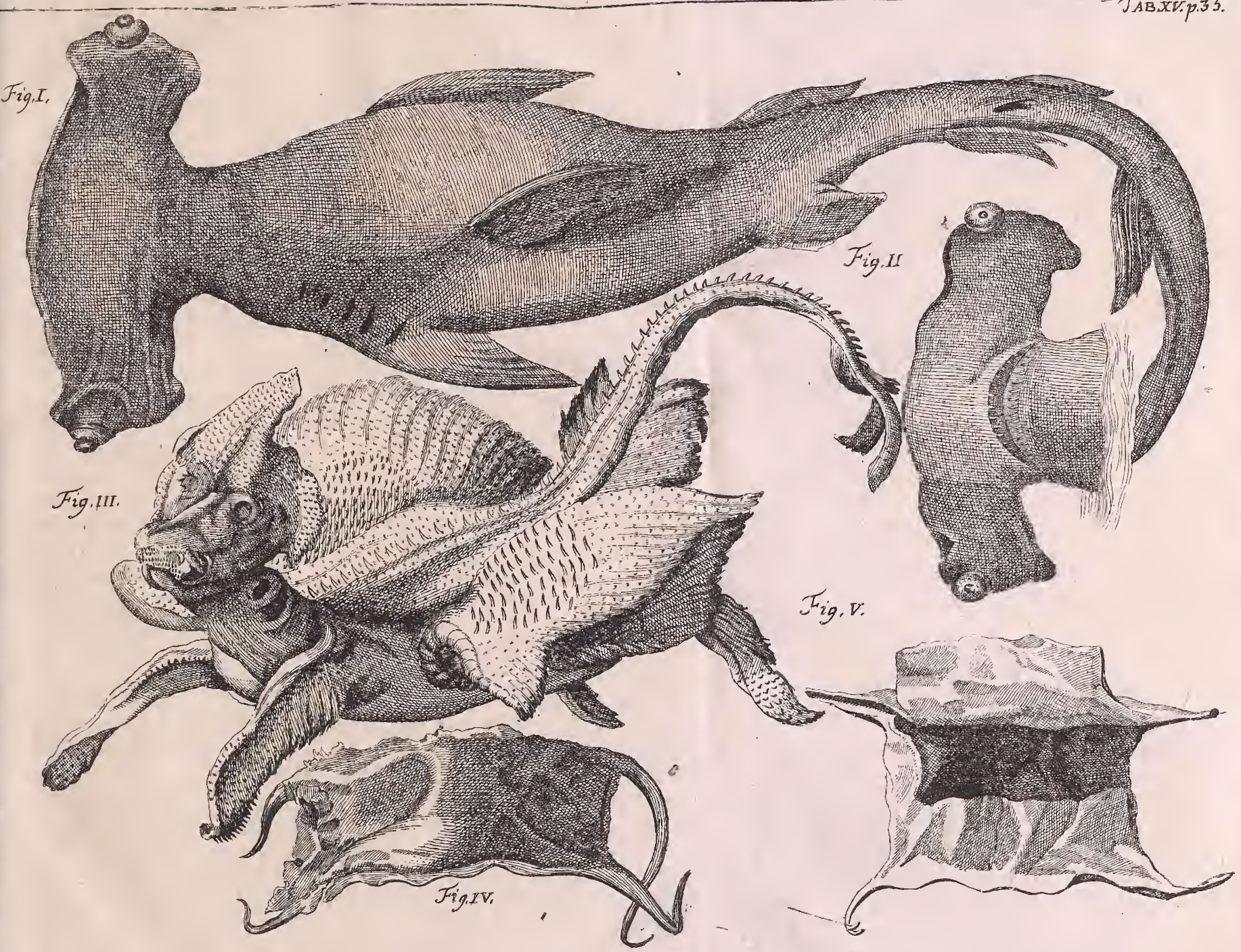



mi, iisque qui in maxilla inferiore fmiles; ampliffimi omnes funt, qui inimedio palato conftituti, redam lineam efficiunt. Oculi in fuperiori maxilla fiti parvi, iridibus aureis, pundulis fu/cis crebris reperfi, toti. autem cute denfiore, diaphana tamen conteguntur. Pinnarum unum duntaxat habetpar, nimirum ad branchias. Sunt autem pinnae exiguae fuperius fitae, ejus dem cum dorfo coloris, radiis cartilagineis circiter 16. inftructae, quorum medii longifimi, reliqui binc inde fenfim lreviores. Foramina branchiarum ut in angvillis a capite funt remotiora. Pinnadorfi paulo infra brancbiarum pinn.zs inchoata, ad extreinan caudam, uno minus digito exienditur, eftque ima fui parte dorfo concolor, fumme nigra, initio et fine bumilior, in medio altior. Cauda non plana ut in Angvilla, Jed teres, pmulatim tenuior, donec in acutum apicem definat, nullis pinnis fimbriata Jecus quam in congroet anguilla. Brevitatifudens filentio involvo, quae circa internarum partium conftitutionem vir eruditifimus annotavit.

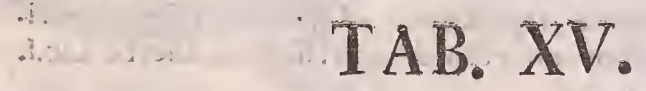

Erpentem marinum hac Tabula excipiunt alia marina monftra. Et $\mathrm{S}$ quidem Pifcem exhibet Tab. Fig.I. Cetaceis accenfendum, cum fivera funt, quae veteres fribunt, ad Cetorum magnitudinem quandoque excrefcat. A Bellonio, Rondeletio, Salviano, ZTGAENA vocatur. Monftrola capitis figura, qua a reliquis omnibus pifcibus differt, variaipfi peperit nomina; quia tò cujòv imitatur, quo transverfum librile, ex quo lances dependent, fignificatur, Zygaenae nomen, telte Exc. Charltono de different. Animal. obtinuit; hinc Anglis the Balance Fifch dictus. Maffilienfes Peis Jouziou frve Pifcem Judaeum a fimilitudinetegumenti capitis; quo olim Judaei in Provincia utebantur, dicunt, tefte Rondeletio; fic a transverfo Capitis fitu in Italia Pefce baleftra, et Pefcemartello appellatur, quod arcum malleumque itidem imitetur; unde eft quod Gillius hunc Pifcem veterum Sphyraenam effe crediderit, quoniam roves malleus eft. Alio nomine Romae Ciambetta dicitur. Hifpanis Peis limo, Limada, Toilandolo. Aldrovandus et polt illum in opere Willougbejano Excell. Rajus, Galeis potius quam Cetis accenfendum putant. Nolter, quem Tabula haec exhibet, qui nefcio quo fato e Besleriano Mufeo in manus Amici naturalium rerum fagaciffimi venit, tres ulnas non excedit longitudine, vix dimidiamlatitudine. Apte in illam defcriptio Aldrovandina quadrat. Monftrofa Capitis figura non rotunda eft, non roltrata, non faftigiata neque in latera comprefla, qualis in Pifcibus reliquis effe folet, fed in latera extenfa atque transverfa. Cujusquidem frons anteriorve pars, quae utraque clauditur oculo, uti anterius in femicirculum fere extuberat, fic ita in aciem acuitur, ut dum celeriter $P$ ifcis natat, pifces fecare poffe credatur, quod ctiam natantibus hominibus, fi qui obvii occurrant, fieri allolet, 
unde qui pifcandi, aut quavis alia caufa longius a litore per pelagus. natant, haud abs re eam exhorrelcunt; ideoque, ut Aelianus memo: riae prodidit, occurfus ejus jam olim navigantibus infauftus habebatur. Boufuetus de Nutur. Aquatil. Zygaena appectu torvo borribilique fioura eft, Aupiciis nautis confpicienda malis.

In medio extremae utriusque lareralis partis capitis, funtoculi magni ro. tundi, deorfum potius, quam in latus aut furfum fpectantes. In utroque, praeterea ultima frontis parte oculis proxima oblongum infculptum elt foramen auditui olfatuive, aut utrique ut arbitror fubferviens. Os, fubtus inferiore parte permagnum habet, dentibus validiffimis, planis fecundum Rondeletiumlatis, inque latus ferrae modo vergentibus, triplicique, vel Bellonio fic fentiente, quadruplici ordine digeltis, armatum, id quod e Fig. II. quam ideo aeri incidi curavimus; patet; hifcedentibus quicquid illi obvium, dilaniat, a qua faevitia Máfitienfibus Cagnola dici.. tur, et ab Oppiano Leoni opponitur et praefertur : fic enim Alievtic. Lib.I. v. 367 . Edit. Rittershuf. p.169.

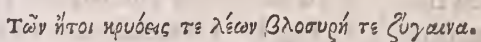

Ex quibus (Junt) horridusque leo, torvaque Zygaena.

et Libr. V. v. 37 . n. 33 I.

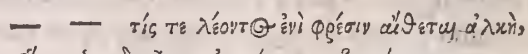

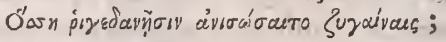

-- Quae autern Leonis in praecordiis ardet vis (tanta)

ut horridis comparari queat Zygaenis?

Reliquam corporis fructuram vid. apud Ichtyographos citatos; imprimis apud Illuftr. Rajum in Synop $i$ Method. Pifcium p. 20. Efui ob infuavern faporem interdictus; vid. Bouffuetus l.c.

Fig. 2. Monftrum monftrat alpectu horridum, a Calceolario olim in Mufeo itidem exhibitum, quod cum optime Besleriano hic depicto conveniat, illius quoque defcriptionem addere licebit: MonftruoJum boc Animal, quod pectandum exbibetur, formamillius virulentiffi. mi Bafilifci imitari dices: Caput namque (non fecus ac boc delineatur) veluti diademate, ac corona Regia exornatum babet; non abfinilem coronaeilli, qua antiquitus Latronum Reges coronari confveve. runt, guod latrocinandi arte Praefulgerent. Corpus eft paufillo, colore fufco, a cujus utraque parte inferiore pinna perinde ac alae in altum eminent, ut fatereris alatum effe Draconem et ad volan. dum agilem, nimare ip fum boc aleret: fcias namque, ne quidmendacii boc noftro in Nomenclatore reperiatur, Bafilifcum non effe, non effe Draconem, fed effe Pifcem maris alumnum, RAJAM nimirum, laevem, in 


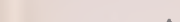

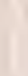

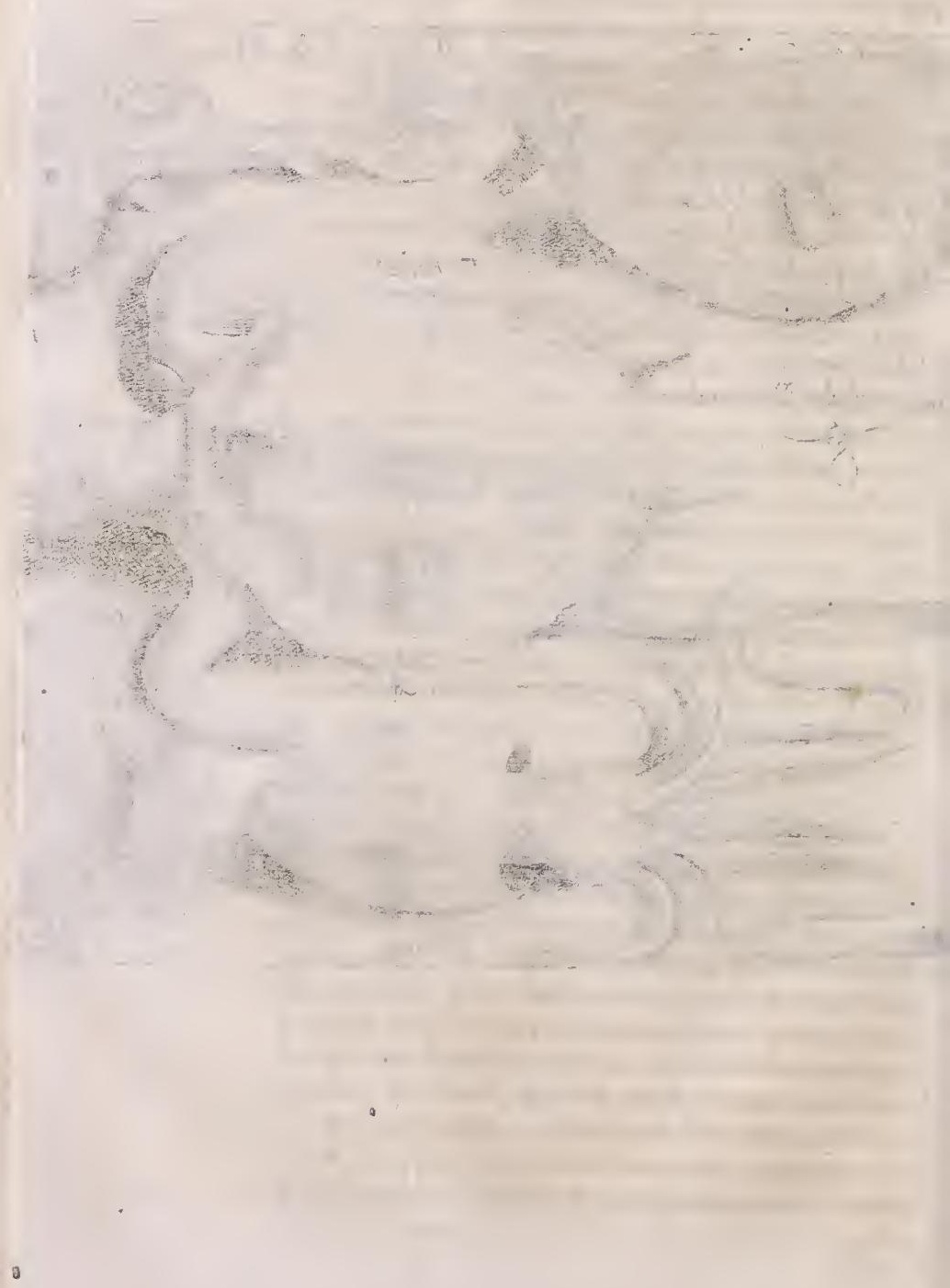


banc formam artificis manu fabrefactam. Haec Calceolarius, vel qui fub ejus nominelatet Benedictus Cerutus. Confer. Mufeum Kircherianum a P. Buonann. edit.Claff.VIII.p.270. MuJ. Mofcard. Libr. 1II. cap. 73. P. 232.

Rajae in Draconem artis ope effigiatae junguntur Fig. 3. et 4. OV ARIA RAFAE PISCIS, quae vulgo MARINI dicuntur $M V$. $R E S$, exiftuntque fpecificum haemorrhoidum dolentium remedium. Figuram primus exhibuit Rondeletius Libr. XII.cap.IV. et polt eum faepius laudatus Bouffoetus, qui Carmine de natura Aquatilium Rondeletii opus de pifcibus marinis, ovariumque Rajae ovis propendentibus gravidum icone expreffit. A prima ftatim Mufei Besleria$n i$ inftitutione delituit hac ovarium, nec inter rariora aereis expreffa tabulis alia caufa omifium, nifi quod Auctorem lateret, cui Claffi foret accenfendum, cumque omnibus rarioribus Schedulae affixae effent, deftituebatur hac ovarium, certiffimo ignorantiae indicio. Praetulit tamen figura Rondeletiana et Bouffuetiana lucem, ideoque hic expreffa, cum in officina, imprimis Dietericiana, proftet haemorrhoidalis doloris certiflimus averuncus; paucis vero cognitus ante diligentiffimum naturae myftam Spenerum, qui fcripta ad Excell.Valenitinum de marinis bis muribus Epifola, rationem nominis, ftructuram et virtutes murium marinorum e variis Auctoribus, imprimis defcriptione Brakenboferiani Alufei Manufcript.illuftravit, ad quem lectorem, qui plura his de ovaris noffe cupit, ablegandum cenfeo. Exhibet autem Figura 3. Murem fic dictum marinum tam ratione magnitudinis quam figurae cum fuis IV. extremitatibus longioribus, ejus apertura, quae pilofa apparet, extremitatibus brevioribus foramini ab oppolito confpicuis foliaceis, quae interdum caudam repraefentare videntur. Fig. 4. autem internam oculis fubjicit murium figuram, eorum corpora e ftriis conflata : item locum aperturae, ac exactiflimam extremitatum duplica= turam.

\section{TAB. XVI.}

Legantiffima certe TORPEDINIS Figura, quam Auctor aere exhibuit, ut vix Salviani, elegantia cedat. Recenfetur haec pifcis inter Pelagios cartilagineos planos et a Graecis, ob ftupefacientem,

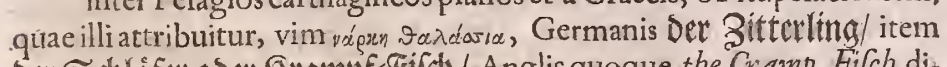

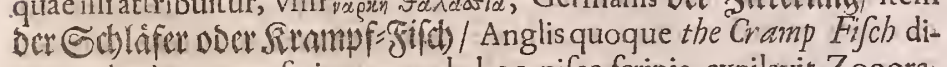
citur. Antiquorum fcriptorum de hoc pifce fcrinia expilavit Zoographorum doctiffimus immortalis Gloriae Aldrovandus, et qui in nimis angufum compendium redegit Fonflonus. Salviants ftructuram internam et externam rimatus eft, intimius adhuc Titiopolitanus Epifcopus Steno, et nunquam fatis laudandus Fr. Redi; et ingeniofifimus auctor Borellus, rationes pro explicanda vi hujus:Pilcis ftupefetiva fug- 
geffit, quas latius adhuc expofuit in peculiari libello infcripto: Offervationi intorno alle Torpedini di Stefano Lorenzini Flor. 1678 . edico, quod opufculum excerpfit, et latiali toga indutum Ephem. Nat. Curiof. Dec.I Ann.X. inferuit PI. Rev. P. Adam. Adamandus Kochansky S.J.Presb. His indigitatis fontibus, quin animus fciendi cupidus exfatiari pofit, nullus plane dubito. Nobis fufficiat breviter annotalle, Figuram Pifcis dempta cauda circularem fere effe, fegmento ad funmum caput ablato. Variae funt ejus fpecies, colore, maculis, appendicibus prope caudam, oculis, foraminibus poft oculos \&c. a fe invicem difinctae, hinc magnitudine quoque utplurimum differunt. Sunt enim quae uncias fex pondere non excedunt, funt aliae, quae libras XVIII. pendunt: Illufer. Redi quandam XXIV. librarum appendit, cum Salvianus tamen fcribat, fe nunquam obfervaffe, quae fenas libras excederent, Oculinon admodum magni cute fere cooperti, differentis figurae in diverfis fpeciebus. Retro oculos foramina duo lunulata in gyrum cre. nata, in palatum pervia, per quae nonnihil aquae exforptae rejectant; creditque Excellent. Rajus in Willugbejano opere de Pifcibus, auditui haec foramina infervire. In partibus lateralibus dorfi apparent veftigia five lineamenta duorum corporum foliatorum, quae foris mollis funt fubltantiae, e plurimis veficulis irregularibus Aqua repletis compofita; ablata pelle obfervantur effe duo mufculi pulcherrimi, ex fibris multis mollibus, aibis, calamo anferino craffioribus, figurae cylindricae a cute dorfum integente perpendiculariter adillam, qua pectus veftitur, tendente compofiti, quarum anteriores breviores funt pofterioribus, Fi. brarum harum extremitates, variarum irregularium figurarum vefigia fui relinquunt in pelle dorfi aeque ac pectoris, er colore, figura ac firu, veris ac realibus veficulis fimillima apparent. Separantur ab invicem fibrae per alias transverfales nervosque manifefte recipiunt, per transverfum eis fe applicantes, ita ut jure fibrae motrices vocari poffint. Accu. ratius et latius horum corporum falcatorum injećta mentio, cum fecun. dum Excellentiff. Redi et Lorenzini vis fupefactiva et dolorifica Torpedinis in mulla alia parte niff in illis corporibus five fatcatis mulculis duobus refideat. Cacterum Acephalos videtur hic pifcis, adeo latum eftei caput, neca corpore divifum. Os Rajae orifimile, latitudine digitali, rictusque fecundum proportionem corporis amplifimus; in utra. que maxilla Dentium minimorum durorum, uncinatorum, verfus fauces incurvorum multi ordines. Infra hunc quinque foraminum fal= catorum paria ducunt ad branchias: quibus ex utroquelatere, junguntur modo dictorum corporum falcatorum lineamenta. Supinajacente, nares apparent, quarum fuperficies interna fimplicifima, per laminas aut corpus quoddam aliud neutiquam multiplicata, unde torpedine fine dubio olfactus obtufiffimus. Pinna corpori utrinque tuna, in forma Limbi, jungitur. Cauda pluribus inftructa eft: ad initium ejus utrinque unacarnofd; in dorfo hujus duae fpinofae; extremae alia quodammo. 
dammodo bifurcata, itidem fpinofa additur. Anus prope caudam fat grandififfura patet: in cujus labris verfus caudam duo foramina falcata confpiciuntur. Cutis feu pellis Torpedinis infinitis foraminibus, majoribus et minoribus pertufa eft, quibus totidem canaliculi diverfae item magnitudinis, humore vifcofo, pellemque lubricante, referti annectuntur. Separata pelle canaliculi majores in dorfo circa partes convexas utriusque corporis falcati, in duos fafciculos collecti obfervantur altera fui extremitate omnes conjunctim terminari inter oculos et anteriorem extremitatem capitis, ubi quivis canaliculorum fenfion affixus eft exiguo globulo cryftallino, frmili femini Coriandri, natanti in humore quodam albo giutinofo. Minores vero funt ramuli alterius cujusdam canalis gemini, corpora modo dicta falcata utrinque cingentis, productaque per totam pellis longitudinem ramificatione, in caudam terminantis. Internam partium fruAuram omittimus, optime apud citatos Auctores reperiundam, cum Auctor externam Torpedinis figuram exhibue it. Torpedinem moríuam non ftupefacere, fed impune tractari poffe, teftatur Ill. Rajus in SynopR.Method. Pifcium p. 29. Pifcis eft peffimae famae: hinc Venetiis, ne in foro pilcario vendatur, Praefecti fanitatis Auctoritate cautum eft. Maffiliae ramen, Genuae et alibi a tenuioris fortunae plebe efui expetitur.

Torpedini ORBIS SPINOSVS in Tabula noftra appofitus

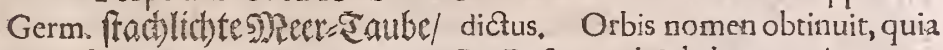
rotundus totusque pene capite conftar.Refertur ab ichthyographis, praefertim Excell. Rajo in Willugbejano de Pifibus aeterno opere et Synopf. method. Pifc. pag. 42. inter Pifces corpore contractiore, et qui plerique infolentis figurae funt, corpore globofo, et ut Marggravius loquitur, corpora fua utris more inflare poffunt. Convenit autem $a b$ Auctore nof ro delineatus orbis exactifime cum orbe maritimo muricato altero Clufii in Exoticorum Litbr. VI. cap. XXIV. defcripto, us ovum vix ovo fimilius videatur; hinc ejus quoque defcriptionem adjungimus noftro orbi apprime quadrantem: Per univerfum corpus muricatis munitus finis, coloris in dorfo fufci, et multis nigris maculis conperfi, in ventre autem cineracei; Jupercilia funt elata, os aliquantulum prominulum et duobus albis offrbus praeditum; binae in lateribus pinnae non adeo magnae; aliae irem binae, quarum una in extremodorjo paulo fupra caudam, alterapoft podicem fufci coloris, nigrisque maculis notat a, quemadmodum et illa, quae extremam caudam finit. Hunc orbem Excell. Rajus eundem effe credit cum orbe Batracboide A1u. Societ. Reg. et MLarggravii Gvamajacu atinga five orbe muricato Ra. nae ritu.

Orbi muricato jungimus ORBEA NON SPINOSVM, a Salviano Aegyptiacum dictum, eo quod in Nili of tiis capiatur. Figura, fi caudam excipias, eft fphaerica, prorfus a fquamis nudus; cute admodum dura tegitur, quam afperam eff:ciunt aculei parvi, quibus tota 
confperfa elt, quorum refpectu improprie non Ipinofus dicitur. Ore eft parvò, dentibus quatuor albis munito. Unicum utrinque foramen et pinnam iunicam habet utrinque ad branchias Caprifi modo; pinnulam aliam in prona parte prope caudam; aliam huic fere refpondentem in fupina. Cauda in unicam et latam definit. Pifcem hunc Plinit orbem, vel ut alii legunt, orchin effe credunt; verba Plinii haec funt: Duriffmum effe Pifcem conflat, qui orbis (orcbis) vocetur; rotundus eft et fine fquamis, totisque Capite confat. E mari Nilum fubirecreditur; minime tamen efculentus eft : totus enim capite vel potius ventre conftat; hinc exficcatus vel Alga et tomento oppletus et fufpenfus cocli partem, a qua flatventus, roftro ad eam converlo indicat; unde a quibusdam Germanis See $=5$ abn five Gallus marinus vocatur, quod verum efle experimento comperit in parvulo fuo orbe, Wormius in Mufeo. Vid. quoque MuI. Molcard. Libr, III. c. 66. p. 227.

Tabulac medium occupat TESTVDO MARINA, Germ.

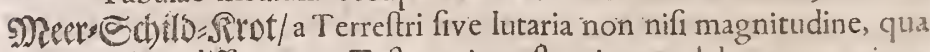
eam excellit, differens. Telta enim elt minus pulchra et conciruma molliore, pedibus pifcium pinnis non abfimilibus, ad natandum com. paratis, In ingentem magnitudinem excrefcit, ut in Brafilia et Antillarum Infulis unius caro, 80 . vel centum hominibus in prandium fufficiat, tefte Rupifortio in Hift. natural. Inful. Antill cap. 2 1. Art. II. p. 246. A capacitate tegminis teftacei, nomen Teftudinis apud Latinos, apud Graecos $\chi^{\prime} \lambda_{\nu} u_{5}$ er $\chi^{\prime} \lambda_{15}$ obtinuit, a verbo $\chi^{\prime} \dot{\varepsilon}$, capax fum. Nolorevocare equidem Veterumfabulas, Solini imprimis, qui in mari Indico tam. grandes effe fribit Teftudinum teftas, ut duabus fuperna parte junctis et inferne deductis, âedes fuas conftruant. Nec Aeliani, qui in Taprobana Infula aedium tecta ex Teltudinum teftis conftare credit. Nec Diodori Siculi, qui populos Chelonophagas Aethiopiae et alios Caramanniae vicinos, ejusmodi Córticibus Teftudinum, pro cymbis, quibus ad continentem navigant, item pro Tentoriis uti refert; de quibus omnibus o 7 ávu Salmafius in Plinian. Exerc. in Solin. p. 837. Licet haec a veteribus de Teftudinum magnitudine fidem pene fuperent, tantae tamen in India exiftunt, ut parum fit pariter credibile, ni viris omni exceptione majoribus fidem denegare omnem velimus. Generof. Anglus. Herbertus in mari Indico Teftudines tantae molis fe vidiffe jactat, ut quatuordecim homines unius dorfo infiftere potuerint, Foh. Faber Lynceus in Expofit. Animal. Novae Hifpin. Nard. Ant. Recchi p. 731. Nicolaum Trigautium maximum illum in Sinam Miffionarium, certo ipfi afleverafle memorat, in mari illius Regni tantae magnitudinis vidiffe Teftudines, quantae ejus cubiculum, quod palfus erat longum decem, latum feptem. Mlarggravius Hiftor. quadrup. et ferpent. Lib.VI. p. 24\% tantac in Brafilia molis pronuntiat, ut a yua. tuor robuftis viris vix poffint moveri; imo Laëtius in tantam magnitudinem excrelcerc f́cribit, ut quinque viros tefta fua fultineant, ct cum 
isdem prorepant; hinc non mirum, tam firmam illis teftam a natura impertitam, ut rotis plauftri onufti currentis minime conteri poffint, tefte Wormio in Muf, p. ${ }_{3}$ 16. Noftra Teftudinis telta e mediocribus, tantae tamen magnitudinis exiflit, ut commode quis eo pro fcuto uti poffit, quod de Centurione Mario memorat Nierenbergius Hift. Nat. Libr. XI.cap. 54.P. 260. Pollicem craffitie excedit; varias habet futuras, e variis variarum figurarum tellulis coagmentatas quafi, haud adeo concinnas, coloris nigri fplendentis, lineis flavis vix vifibilibus. Partium Animalis hujus ftructuram fufius recenfere, rem fupervacaneam judico, cum illud jam praeftiterit Severinus in Zootom. Democrit. p. 321 . feq: poft sum Gerard. Blafius in Animal. Anat. cap.36.pag. I 18. Edit. in IV. du Hamel in Reg. Scientiar. Acad. Hiftor. Libr. I. cap. VII. Illuftr. Redi nell' offervaz. intorno agli Animali viventi che fi trowano negli animaliviventi. pag. 95 . 140 . feq. et omnium accuratiffime in peculiari libro, Italice Illuftr. Fr. Redi infripto: Giov. Caldefi Aretino nell offervazioni Anatomicbe, intorno alle Tartarughe marittime, d' Acqua dolce et terreftri, plurimis figuris aeneis illuftrato opufculo, etimpreflo Florent, Anno I 687. in 4 to; et licet haec Telfudinis folertiflima Anatome omnem mereatur laudem, nitidiorem adhuc habuiffemus, ni mors invida abripuiffet virum omni elogio fuperiorem, Chriftophorum Gottsoaldum, Podalirium Dantifcanum, naturae Myftam folertiffimum, ceu exaeneis Mufei Anatomiciejusfiguris, quae apud Nobiliffimam Viduam una cum Conchyliorum elegantifimis, et omnes, quas hactenus videre contigit, delineationes fuperantibus, fuperfint, fatis patet. Cum explicatione et uberiore deftituatur defcriptione opus fere Regium, Tabulas tantum recenfere placuit, ut falivam moveamus erudito orbi, et Bibliopolarum curiofioribus, quo Virum in Hiftoria naturaIi promovenda folertiffimum, paternis gloriofe infiftentem veftigiis Foh. Pbil.Breynium, Medicum pariter Dantıfcanum celeberrimum, Reg: Soc. Angliae Socium digniffimum, fub cujus directione et manibus, precibus et pretio exorent, ut in publicam tandem lucem opus fplendidiffimum prodeat. " Continent autem, quae Teftudines concernunt Tabulae, et quidem prima et fecunda Teftudinis marinae et, ceu e delineationeaccuratiffima patet, Tartarugae Lufitanorum five FuracuaeBrafilienfium, quibus alae quafi loco pedum, fummam et imam faciem. Tabula Tertiafaciem anteriorem; Quarta partium internarum fitum naturalem, certe omnibus hactenus editis anteferendam. Quinta, Gulae fruduram: Sexta partes genitales utriusque Jexus, in quibus plurima obfervanda, ab aliis animalibus peculiaria; et Trapbam quoque in defript. Jamaicae cit. Excell. Rajo obfervavit, Marem et foeminam Teftudinum per integrum menfem lunarem in complexu Venereo perfeverare; hinc Wormius foeminas mares valde reformidare fcribit, ob congreffum longiorem nempe, qui ipfis injucundus; Septima Ovarium exbibet et Tulmones, quos non in Thorace, fed in Ventre inferiore fub dia- 
phragmatefitos $\mathcal{F} 0$ h. Faber Lynceus tradidit, cui hypothef haec et aliae tabulae favere videntur, hinc ottava pulmones cum folliculo aethereo fift t ; Nona Scutum inferius, decima ejusdem Sceleton, quo clare innuitur, Teftudines Scuto fuo, ut vulgus putat, exire non poffe, quod oculis jam expofuit Lacbmund Dec.I. Ann.IV. et V. Obferv. CLXXXIII. p+240. Claudit tandem Tab. Decima cum variis Teftudinum fcutis, e quibus coloribus et magnitudine differentibus varia et elegantia conficiunt opera, quae cum iis certant, quae ex Achate elaborantur. De ovis Teftudinum varii Auctores varia. Fo\%. Ott. L.B. de Helnig in Infula Cera Auftrali-Orientali, faepius 300 , et 400 . in foveam arenaceam deponi a Teftudine refert, folo calore folis fub Arena, absque ulla alia incubatione excludenda ; cum tempus advenerit exclufionis, pullos recenter exclufos adventantes e mari parentes devorare afferit, fi vera funt, quae narrat. Dec. II. Ann IX. et X. Obferv. CXCIV. $\$ .27$. De modo Teftudines in dorfo refupinatas capiendi Rupifort. Hift. Nat. Antill. Pomet. dans l'Hiftoire generale des Drogues, Second.Part Livr.I. chap. 36. pag. 36. tres modos recenfet. Conf. etiam $M$ MU. MIofcard. Libr. III. pag. 218.

Teftudinem SEP1A excipit, quae nomen obtinuit ex atramento, veluti putrida quadam fanie, Graeci ontrødóve vocant, qua abundat, vel ob ońtrıor, quod, uti poltea dicemus, in dorfo gerit, fic fentiente Excell. Charltono de differ et nominibus Animal. et ppec. de Pifcib.pag. 50. Refertur in claflem mollium pifcium, et optime cum Icone Sepiae pronae Salviani convenit, in hac noftra Tabula expreffa figura. Proprium. huic pifci eft, ( praeter fiftulam inter caput et alvum prominentem, quod atramenti copia luxuriet, et vel ideo quam in caeteris reperiatur majori, ) quod vitam litoralem traducat, et nihil aliud, quo fibi auxilietur, habeat, cum Polypis etbrachia et mutatio coloris inferviat: unde fit ut atramentum illud; frve cruorem fuum atrum per Aquam effundat, cum fe peti animadvertit, et pifcatoribus iter veluti praefepiat; a quo nigro liquore Germanis Slact= Fifd) ober Dinten= Sifd nominatur, a molliufcula autem ftructura Suttcl = Sifd). Hoc fepiae atramentum Sinenfes cum Brodio oryzae vel alterius leguminis infpiffant et formant, et in univerfum orbem fub nomine atramenti Chinenfis trans: mittunt; tefte Excell. Hermann. de Mlater. Medica. Habet et praeter atramentum Sepia, in dorfo óńt ov robuftum et latum, inter fpinam et os mediam prae fe ferens naturam, fubftantiam nempe teftaceam candidam, levem, utrinque tumidam, parte fuperna duriufculam, inferna fungofam molleculam leviter afperam friabilem, faporis aliquantum falini et fubacris, odoris nullius, in officinis Os fepiae dictam, Licet afpect u plane horridus fit hic Pifcis, in culinam tamen et cibos recipitur, non ab Italis tantum mare mediterraneum accolentibus, fed et a Gallis, tefte Pomet dans l'Hiftoire gener, des Drogves; hinc Boufluetus de Aquatil. nat. canit: 

Sepia dura quidem eft, fed fi femel efca coquatur, in fomacho et venis et jecore optime alit.

Apud Veteres quoque in efu ut ufu fuiffe, fufe probat, et ex omni antiquitate derivat laboriofifimus Aldrovandus, de mollibus, cruftaceis et Teftaccis Lib. I. cap. 4. pag. 59. Etiam ova Sepide in ficcum ejecta, a quibusdam edi cocta in fartagine, fribit Rondeletius. Singularis ovorum Sepiae ffructura, de qua modo laudatus Boufluetus canit:

Ora edit baccis myrti forma efficieque, Qualis vinifera in vite racemus ineft.

De interna Sepiae ftructura Conful, Excell. Redi nell offervazioni in. torno agli animali viventi che fi trovano negli animali viventi. p. 16 g. feqq. Edit. Florent. in quarto.

\section{TAB. XVII.}

$\mathrm{P}$

RISTIS five SERRA PISCIS, Anglis The Sarb-Fifch, inter cartilagineos longos edentulos a Cl. Rajo in opere Willugbejano de. Pifcibus Libr. III. SeCt. I. cap. I4 P.m.6I. a Cl. Wormio in Mufeo non ad Galeos fed cetos refertur, et licet cum Cetaceis nullam habeat corporis fimilitudinem, ob molem et magnitudinem tamen faepe Cetacels. Cutim habet rudem et inftar Zygaenae cutis afperam, cineracei in dorfo coloris, in ventre candicantis. Caput Cordis figuram habet, compreffum nec craflum; in hujus medietate, paulo tamen verfus anteriora, in quolibet latere oculus, et poft quemlibet digiti fere intervallo fir irculum, per quod Aquam evomit, (quae foramina Excell. Rajus meatus auditorios effe credit,) et fub his in inferiore tamen parte oris fiifuram, ut in Zygaena fere transverfam labiis inflar limae acutis fine dentibus. Inextremo autem capitis verfus Serram in inferiori parte duo funt fpiracula fubftantiae interius inftar branchiarum, quibus fine dubio ferratum roftrum regit, nam has inter branchias ferra oritur. Caput igitur in longum et angufum, planum et firmum roftrum porrigitur, dequo mox pluribus, Pinnas pifcis habet VII. videlicet duas adlatera, paulo infra branchiarum fpiracula, poft has in lateribusiterum duas, fupra has in dorfo unam, deinde in extremitate corporis fere in dorfo itidem talem, et pro cauda feptimam. Corpus fubteres eft, anguftum verfus pofteriora. Pifcis, quem Auctor nofter habet et exhibet, vix emediocribus eft. Aft major fuit, e quo

SERRA PR ISTIS improprie Gladius, cujus figura quoque a Beslero noftro hac et eadem producitur Tabula; gladius enim Pifcis Xyphiae eft, Serra Priftis. Porrigitur, uti modo diximus, Caput Priftis 
in longum planum et anguftum hoc roftrum, utrinque multis dentibus five offeis firmisque ac rectis fpinis ex adverfo fitis ferrae inftar munitum; numero fecundum Illuftr. Rajum incerto, in aliis enim XXV. in aliis XXVI. in aliis XXVIII. utrinque cernuntur.In noftra Serra viginti fex numerantur fpinae, in Serrula vero, quae pifci adhuc agglutinata, viginti. Longitudinem quod attinet, binas ultra ulnas adaequat, unde Pifcis magnitudo facile aeftimari poterit. Per longitudinem porofi offis, duas habet cavitates, quae juxta extremitatem coalefcunt, nec in apice hiant. Vid. Cl. Jacob.Muf. Reg. Danic. Set.1II. p. 15. Plura de Prifti ejusque Serra fcire qui defiderat, evolvat Cluf. Exot. Libr.VI, cap. Ig. p. 135 . feqq. Mufeum Worm. Libr. III. cap. XV. p. 288. Pif. Hift. Nat. Brafil. Libr. III. p. 54. fub nomine Aragvagva. Rochefort l'Hiftoir. naturell.des Antilles.p. 1 g0. Mufeum Gottdorf. Olear.p.38. Muf. Calceolar. Sect. I p. 8 2.du Hamel Hift.Scient. Acad. Reg. pag. 7 0. pluresque alios.

PISCEM STVRIO NEM optime aeri incifum et delineatum effe, teftis et Cenfor eft omni exceptione major, Illuftr. Grem in Muf. Soc. Reg. qui ad Salvianioptimam expreffionem noftram pariter accedere refert : (e pecially that of SALVIANVS with is curious figure. The like in BESLER.) Corporis figura longa eft, fecundum Schoenfeld. in Ichtbyol. five Nomenclat. Animal marin. fuviat. et lacuftr. Holjat. et Excell. Charlton. in Onomaft. Zoic. trianguli feu prifma. tis fere figura, fecundum Illuftr. Rajum in Willugbejano de Pifcibus opere, Pentagona, quinque fcilicet fquamarum offearum ordinibus in quinque angulos tributa. Squamae fuperioris ordinis in medio dorfo, caeteris majores altius affurgunt. Harum numerus certus et definitus non eft; in aliis enim pifcibus XI. in aliis XII. in aliis tredecim obfervavit Rajus. Ordo hic usque ad pinnam dorfin, (quam unicam hic pifcis habet, non longe a cauda) nec ulterius extenditur. Ordines laterales a capite incipientes ad ipfam usque caud $\mathrm{m}$ procurrunt, triginta aut XXXI. alteruter fpinis compofiti. Ordines inferiores, qui planum ventris lateraliter terminant, a priori pinnarum pari inchoati, ad fecundum par definunt; conftantque finguli XI. XII. vel XIII. fquamis. Squamae omnium ordinum in univerlum omnes fpinam habent in faftigio brevem, yalidam, retrorfum incurvatam. Praeter hos V. ordines fquamas duntaxat binas habet infra anum in medio Ventre. Caput pro mole corporis exiguum, ut et oculi iridibusargenteis. Os in prona parte rotundum, femper hians, absque dentibus, magis ad fugendum quam mam fticandum accommodatum, ante quod propendent appendices carnofae quatuor. Mangopuzxóręo roftro longiori, quo more fuis terram fodit, unde Sturionis forte nomen illi impofitum credit folertiffimus Gesnerus, quibus fteren und ftoren/caenum aut vadum aquae fodere et commovere fignificat; quae nominis deductio certe melior videtur illa maximi Salmafii, Criticorum facile principis, dum Sturionis nomen 
exiltimat a Thurfione Pifce, disq frguévas deductum. Olaus Wormilus dictum putat a corporis proceritate, quia Stur vel Steer magnum in lingua Dunica denotat; hocque jam olim acutifimo fof. Scaligero; illuftriore Literarum quam Veronenfi Principatu, fuboluit, qui Gotbicum vocabulum Sturionem pronuntiavit: a Sturionis. Latino nomine Gallorum Efturgeon, et Anglorum Sturgeon indubie defcendit. Haud mi nus inter fe pugnant Auctores de Acipenferis nomine, quae collecta vi$\mathrm{d}$ bis apud Illuftr. Rajum in Willugbejano Opere, pag. 241. Gignunt equidem Maria hunc pifcem, maxima tamen fluvii dant incrementa:teAte enim Schoenfeld. in Icbtbyolog. p. 9. nifi utriusque Aquae dulcis et falfae beneficio fruatur viciffim libere, aegre incrementum fumit, ut in junioribus ex mari in vivaria et lacus translatis experientia docet. PiIcis imprimis nobilis, pinguedine flava abundans, palato A piciorum

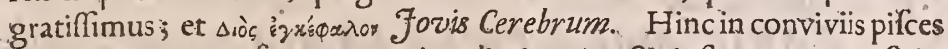
bos coronatos per fervos coronis redimitos, junctis inftrumentis muficis, appofuere, quafi quadam non delitiarum, fed numinis pompa, ut Athenaeusloquitur Deipnof. L. VII. c. is. Unde Ovidius in Halievt. Tuque peregrinis Acipener nobilis undis: et Martialis Libr.13.

Ad palatinas Acipenfera mittitomenfas, Ambrofias ornent munera rara dapes.

Plutrima ad delitias Pifcis hujus facientia collegit Cl. Elsholz. et Dodtiff. Bebrens in Diaetet. Sed unde digreflus fum, eo revertor: Pinnae huic pifci fubalbidae; quarum binae ad branchias, totidem ad ventrem fitae funt. A capite per dorfum ad caudam usque funis feu servins digiti craffitie excurrit, integrum roborans pifcem et firmans; coqui dum maetant, funem extrahere folent. Cauda qualis Galeorum, cui claffi ac. cenletur, bifida quidem fed adeo, ut fuperius cornu, una cum ipfo corpore tenuato, ultra inferius longe procurrat. Color Pifcis in fuperna patte fordide olivaceus, aut ex cacfio nigricans, in prona argenteus; media infuper fquamarum pars albet. Internarum partium fructuram five Anaromen Yifcis hujus, in Cadomenfi Academia factam, et a Reverendiffimo Abrincenfium Epifcopo Huetio Academiae Scientiarum Regiae Parifinde miffam, recenfet in Academiae illius Hiftoria $C l$. du Hamel Libr 1. Sed. V. cap. $1 V$. Ova pifcis hujus Sale condita, et in maffam coacta, Caveare vocant Itali, forte a Mofcovico nomine, Ikari, deduEto, ut Cl. Oleario in Itinere Perf. pag. 204. placuit. Julits Alexan. drinus, non imi fubfellii Medicus, Libr. de tuend. valetudine Caviaro Véterum garum effe credidit, ideo refutatus a $\mathrm{Cl}$. Nonno de re cibar. Libr. III. cap. 14. p.m, 4:16. Saponem viridem plane colore et fubltantia refert haec maffa, quae quamplurimis in delitiis habetur, viresque ejus medicae praedicantur variae. Sic Reverendiff. Epifcopus Jovins de Pifc. Rom. refert, Summum Pontificem Jutium fecundum hoc magma- 
te appetitum plane proftratum reftituiffe. Nonnulli aphrodifiacas illecebras in hoc coagulo quaerunt. Condiendi modus e Platina a Ges. nero refertur, reperiturque ejus differentia, quippe quem Itali $C a v i a r o$ negro vocant, ex ovis Sturionis, caviaro rofjo in Vrbe Capha ad Tanaim fluvium fita, e carpionum oris conficitur, quem Judaei expetunt, quippe lege Judaica Sturio Pifcis ipfis cibus vetitus. Aequale Caviaro condimentum Botargadictun (quod $\Omega \dot{\alpha}$ rós axa five ova fálità proprie effe Cl. Nonnus credit;) e capitonis five Mugilis, Provinciae Incolis Mujou dicti, ovis quoque confectum. De quo Ponet l' Hiftoire generale des Drogues. P.II. Livr. I. Chap. 44 de modo pifces Sturiones in Volga fluvio capiendi Strausfius in Itiner. p. 112.qui aliquot pifcium horum centenas, per diei unius fpatium obtineri retulit, modo ve. ra funt, quàe nariàt.

\section{C. $A N I S M A R I N V S$ five $L A M I A$ fequitur. Refertur} 'Pifcis hic inter Cartilagineos longos, dentatos f́pinis deftitutos et Galeorum omnium maximus, ut currui impofitus vix a duobus equis vehi poffit. Rondeletius vidit 1000, librarum pondere, imo Gillius 4000 . Librarum pondere captum fuifle annotavit; hinc Rondeletius in Santonico litore 'captùm vidit, cujus os et Gula tanta erant vaftitate, ut hominem etiam obefum commode potuiffet càpere: Vnde in quodam lorica. tus homo repertus, tefte Excell. Charltono in Onomaft. Zoic: five different. et Nomin. Animal.Claff. de Pelag. Cartil. p. m.7. Hinc Theologorum nonnulli o pinantur, nec fane praeter rationes praegnantes, Jonae Prophetae deglutitorem fuiffe Lämiam. Vid Illuftr. Rajus in oper. Willugbejan. dePifcibus Libr:III. Sect I. cap.I. p. 48. Quam fententiam tamen contra Cl. Najum et Paullinum deftruere conatur, Lamiae fubftituendo Balaenam, S.A. Pfeiffer in differt. Anno 1697. Lubecae imprefJ. 'Tam amplum et valtüm os, ampliffımum etiam latiffimumque caput requirit. Os autem non in roftro, fed ut aliis camibus fupina parte; ejus fciflura maxima eft, et in qualibet maxilla dentes durifimi. Dorfum breve et ad caeteras muftelas comparatum, latiffimum. Laterum et tergoris pinnas longe quam in quovis fui genere majores habet. Binae earum haud procul a cauda, una fuperior, altera inferior, ad branchias binae, ad podicem aliae binae, alia rurfus in medio fere dorfo. Cauda fi reliqui corporis magnitudinem fpectes, minus craffa fpiffaque, duabus conftans pinnis. Podex inter fupinas pinnas latet. Cute afpera integitur, in qua vafa funt obfervatu digniffima, exiftunt enim fontes unctuofi hu. moris Pifcium fuperficiem oblinentis, qui tumor aeque neceflarius eft ad pifcium in Aqua motum faciliorem reddendum, ac neceflarium eft naves mare fulcaturas axungia et pinguibus aliis obducere. Oculi pifci huic funt maximi rotundi, quorum mufculi, qui furfum deorfam, dextrorfum finiltrorfum movent, manifefte confjiciuntur, Plura qui de ejus externa internaque ftructura noffe cupit, adeat Illufir. Rajum in 


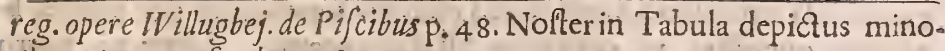
ribus vix accènfendus, uti et

MANDIBVLA Jeu RIETVS potius CANIS MART.

$N I$, quem Auctor aeri imprimicuravit, optime nifi magnitudinem excipias, cum illo in Múfo Regio Danico a Cl: efacobaeo expreflo convenicns. Scatct autem maxilla rictus quaelibet dentium númerofa ferie, utplurimum feno ordine difpofiti funt dentes durifimi, et acutifimi tri. anguli figura utrinque ferrati. Qui in priori ordine funt, extra prominent, et in anteriorem partem vergunt, lecundi ordinis recti futit, tertii, quarti, quinti et fexti in os recurvi, maxima ex parte in utracyue maxilla carne molli fungofaque contecti fecundum Excéllènt. Räjum. Quid quod Excell. Charltonils ex acutillimo Stenonionotat, in inferiori pifc is mandibula tredecim dentium ordines oblervári. Quaelibet maxilla uitplurimum $>2$. comprehendere debet dentes, quae fummal in utraque 144. dentium; led numerus omnino incertus eft, quippe pro aetate pificis variat, et obfervatum, novos quotannis dentes huic pifcium generi; quamdiu vivunt, fuccrefcere. Accuratiflme haec omnia rimatus eft Keverendifl. Titiopolitanus Epilcopus Steno in examine Capitis Carchariae pifcis, Nyologiae ejus aninexo; quam Anatomen parirer $\mathrm{Cl}$. Blafius Anatom. Animal. p. $2 \sigma_{3}$. intulit. Credit modo laudatus Steno, Gloffopetras vulgo dietas e terrae erutas gremio, revera nón lapides, réd majores Carchariae canis dentes olim lepultos efle; qua de re alibi. Confer ad hunc Pifcem, quae Cl. Rupifortius in Hiftor natur. Antill. Int jul. de pifce, Requiem dicto, habet p.191. Mul. Olear.p. 32 et 36 .

$C A P V T$ DELPHINI potius PHOCAENAE eft, (differentiam quippe exhibuit in opere $W$ illugbejan diligentifjinus Rajus) carne omni integumentisque caffum, rictu dentibus horride armató.

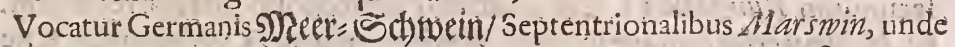
aliarum gentium denominationes detortae. Captus talis Pifcis Apen. radae in Hollatia Anno 166 . Iongitudinis 13. craflitiei 7 ulnarum, tefte Cl. Oleario in Mufeo Gottdorff. ab Excell. Majore examini Anatomico fubjectus; quod Ephem. Nat. Curiol.Dec. I. Ann.III. Oblerv. XX. infertum, et a Cl. Blafio pariter Anatom, Animal.illatum. In vertice cernere licet fpiraculuni illud femilunare five hydragogum, quod omnium accuratiflime defcripfit Excell. Major; fub cuite gyrolus quidam plexu's velit Labyrinthus eft, rugofus duplex, unus fuperior nigricans, alteri candido fuperincumbens. Hinc ftylo adacto diftincti duo ductus, quos hydragogos ab ufu vocare licet, manifefto deprehenduntur, profunde per cranium adipfam palati tunicam pertingentes, et interpofito fepto oflèo, cujus apex eft inflar criftae Galli, craffities vero pennae Anferinae, ab invicem difcreti, perque ductus iftos vel fiftulas Phocaena aquam ore hauftam potenter et tanquam eSiphone ejicit, ficut Phyleter et Balaena per duplicem prominentem tubulum. Annotat infuper lll. Rajus, fiftulam fumma parte, antequam in duo foramina narium aemula dividitur, 
glandulofa carne intus cingi, quae a plurimis foraminulis ceu papillis thquorem quendam in cavitatem fiftulae excernit. Convenit porro cranium noftrum cum illo, ab Excell. Majore delineato. Dentesadeo pulchra ferie difpofiti fint, ut inter fpatiolaillorum excipiantur dentes maxillae oppofitae, acuti omnes, parvi licet, et quod mirum obfcure mobilcs. Wormius \s o.numerat; Bartbolinus 92. Major et Rajus 96. totidem quoque in maxillis Capitis Tabulae noftrae mumerantur. Plura qui dePifce hoc legere defiderat, praeterIchthyographos, et hactenus a nobis citatos Auctores, conful. Scboenfeld. in Ichtbyolog. et Nomenclat. Animal.marin. Holjat.p. 77. Jacobaeum in Muf.Reg. Danic. Wormium in Mufeo aliosque, inprimis Anatomen Pbocaenae Ty Jonis; et fi quis fabulis fimilia amat, adeat Ariftotelem, Plinium, Aelianum, Agellium aliosque veteres, qui plurima de Amore Delphinorum erga homines et Muficam annotarunt.

\section{TAB. XVIII.}

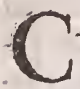
ANCER hic MOLVCCANVS, quem pronumet fupinum, nitidiffime delineatum exbibet Auctor nofter, a Cl. Wormio in Mufeo Libr. III. cap. V. inter cruftata rotunda refertur, quia, fi caudam acutam exceperis, totum ejus corpus ad rotunditatem accedat. Americanis vocatur Signok, Malajenfibus Balancas, Javanis Aiteme, five Mimi. Joh. de Laët in defcript. Ind. Occident. 1.2.c.rg. Ara. neum marinum; lolertif. Rumphits in de Amboinifche Raritei-Xam. mer Libr. I. Sect. 21.p. 21. Cancrum perverfum nominat. Cl. Clufio, qui primus ejus notitiam dedifle videtur, Cancer Noluccanus audit, eo quod circa Infulas Moluccanas copiofe capiatur; quanvis et alibi, imprimis fecundum Rumphium I. c. in ManadoPromontorio Celebes reperiarur. Et Helfigroeriae quoque in mari Danico ejus generis vivus captus, tefte C. Wormio: ubi tamen notandum, quod eodem tempore quinque naves Belgicae ex India Orientali reduces appulerint, ubi haud levis fulpicio orta, annon quisquiliis et algis navibus adhaerentibus implicatum, hucque delatum fuerit animalculum. Ent autem cruftatuan, duabus cruftis duris defuper tedun, quarum anterior patellae infisr convexa admodum craffa duplicata, circa frontem orbicularis et elegantiffime conformata, qua alteri conjungitur, femilunae inmodam excifa, anteriori latere tubercalis quibusdari et aticubi brevibss ex obtufis aculeis difin"Ais ordinibus afperatur. Pofterior crufta priori minor efi, Rbombiformis et utrinque dentata for aminuls quibusdam, pulchro ordine variegata. Cauda crufacea oblonga et longitudine quidem corpus longe excedens, trigona, et a fui medio ad cufpidem usque aculers velutiferrat et ajpera, atque in fine fpiculi infar acuta, qua fi quem imprudentcm $P_{i}$ fcatorem laeferit, einon minorem, quam Scorpius álorem infert; hinc vere de illo Cl.Bontius Hiftor. Nar, er Med. Ind. Lib. V, cap. 3 1. canit: 



\section{Quisquis candati fenffti tela Paguri,}

Difce meo exemplo mor fus vitare dolofos

Dente Leonino, quos aula volubilis infert

A tergo, et pejus retinet fors cauda venenum.

Concava parte plura crura habet inftar Cancri, et quidem primo octo breviora, de in bina oblongiora, et alia rurfum bina breviufcula, officulo obtufo veluti remigio inftructa, quibus natare creditur. Duas praeterea circa os exiguas admodum chelas, quibus mandit; fub polteriore crufta veficulae aliquot fibi invicem fuperpofitae, quae haud fecus inflantur ac tanarum buccae folent. Clufius in defcriptione hujus Cancri, notante Illuftr. Grenv in Muf.Societ. Reg.craffum erravit errorem, quod partem anteriorem cum longo aculeo elfe dixerit, cum fit polterior. In litoribus marinis paludofis degunt, femper ferme bini, mas nempe et foemina, cum vero mas femper foemella minor, illius dorfo infidens undque circumfertur. Plurima ova continet, oculis non obvia, modum tamen ea detegendi Cl.Rumphiusl. alleg. demonftrat. Praeter citatos jam Auctures vid. Oleatr. Mluf.Gottdorf. Tab.28. p. 50. Ephem. Nat. Cutriof. Dec.I. Ann.II. Obferv. I02. Sachf. Gammarol. cap.6.p.113. Jacobaei Muf. Danic. SeIt. III.p. 17. Nulla tàmen figura Auctoris noftri ferme comparanda, (licet a Fonflono Oledrioque ex Besleriano Alufeo indubie mutuofumpta videarur:) hinc 1lluftr. Grew l. c. Fcribit: The beft figure bereof is given by Besler, wobo alone Shews the Eyes; yet not fo clarly, as could berwished. Cancri Moluccani fragmentum foffile et lapideum delineavit et defcripfit Excell. Scheuchzer Specim. Lithograph. Helv. cur. p.65.jeq.

CANCER ANONYMIVS RONDELETII nafcitur in mari et marinis ftagnis, eoque frequentius in Gallia Narbonenfi vefcuntur. Caret nomine, hinc Rondeletius Anonymum vocavit, et in genere ab Incolis Cancre appellatur. Brachia habet non admodum magna, pedes longos in acutum definentes, cornicula duo. Super Carbones affatur, vel elixus et crufta fpoliatus in fartagine frigitur, et hecticis imprimis commendatur, optimusque eft, cum ova habet. Vires ejus medicas cecinit Bouffuetus de Aquatil.nat. P. I.P.m.23I.

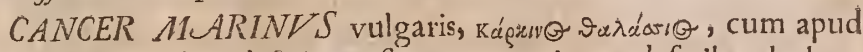
omnes Ichthyographos defcriptus fit, non ero in eo defcribendo longior. Optime aeri incifum et quoad omnes partes explicatum dedit Cl. Rumpbius in de Amboinifche Rariteiten Kammer 7. Hooftdeel p. m. io. Eorum apud Venetos innumerus numerus, et Granceoli vocantur ac molechae; cum igitur plebecula Veneta iis faepius vefatur, Mangiamoleche vocantur, ficut Mediolanenfes Mangiabofeche Ralbaunen= Echludier/ Neapolitani Mangiabrocolli- Robl= Stefier/ referente 
hoc Cl. Sachfio in Gammarol. p. 110 , Elsholz in Diaet. Libr IV.c.6.S. 2.pag. 238 .

CANCER HER ACLEOTICVS RONDELETII maximus e $\mathrm{Pa}$ gurorum genere, cruribus brevibus, forcipibus admodum validis, ab illuItri Vrbe Ponti Heraclea ita dictus, vocatur etiam Gallus marinus, quia ejus brachia in criftae morem tornata funt, fic fentiente Sachfio in Gammarol. p. I 10. Defcribitur a Bellonio et Rondeletio: fed defiderat immortalis gloriae Aldrovandis, quod pofterior in fua defcriptione nullam fecerit mentionem tuberculorum, quorum plurima confpiciuntur per dorfum, colore fere miniaceo; neuter autem eorum, cornuum intra oculos, exiguo a fe diftantium fpatio, et ex plurimis articulis feu internodiis conftantium, meminerir. Demollib. et cruftac. teft. et Zooph. L. II. cap. XIX.pag. 188. De cjus VJu in medicina et cibis BoufJ. de aqu. Nat. pag. 225 .

\section{TAB. XIX.}

(Nter univalvia non turbinata agmen et principatum ducit $N A V T 1$ $L V S$, a verbo Graeco nomen trahens, quo pilcis, et nauta fimul defignatur; carinamigitur fimul et Nautam e Polyporum prolapia $A u$. Zor nofter exhibet, utrumque folum Nautilum nempe et Pompilum. Cl. Rumphius illum eo modo, uti in marivelificat et remigat, ad vivum de. linearicuravit, et poftmodum Ephem. Nat. Curiof. Dec. II. Ann.VII. obf.IV. communicavit, cum antea Carinam Nautili elegantiffimam, ab Aquila marina, e mari cum Polypo ereptam, ejusque unguibus Polypo tantum affixis iterum folutam, et a Pifcatoribus littoris Amboinici repertam, Magnif. Febrio Acad. Nat. Curiof. Praefidi fecundo, dono dediffet; vid.Dec.II. Ann.IV. obferv. 109.p. 2 lo. Optimus naturae interpres Plinius l. 9. c. 29. tam apte, tam concinne, Pifcis hujus naturam expreffit, quam fi ipfe in ejus carina habitaflet: Inter praecipua miracula eft, qui vocatur Nautilos, ab aliis Pompilos; fupinus in fumma aequo. rum pervenit, ita Je paulatim fubrigens, ut emiffa omni perfftulam Aqua, velut exoneratus fentina, facile naviget, poftea duo prima brachia reflectens, membranam inter illa mirae tenuitatis extendit, quavelificante in aura caeteris fubremigans brachiis, media cauda, ut gubernaculofe regit. Haclenus Plinitus, et paulo poft: Itavadit alto, liburnicarum ludens imagine, et fl quid pavoris interveniat, bauftafe mergens aqua; quae omnia veriffima et convenientiffima effe, avtoptac in Indiis Cl. Rumphius modo laudatus, et Cl. Bontius in Hift. Natur. et Medic. Ind. Libr. $V$. cap. XXVII. teftantur, et quidem polterior damno fuo edo. Gus fcribit; nam dum talem Pifciculum in maricaptum, imprudentius manibus contrectaffet, tantus ardor manzum inva fit, tanquam fi aqua ferventi fuffufa effet: unde Pifcem bunc Nautili incolam Holotburiorum generi accenfet. Non autem in Mari folum Indico velificat, fed et in Adria- 

Adriatico, ubi illum inter fepiàs prope littorales fcopulos Pifcatores depre. hendunt, illic enim frequenter pafcitur; hinc Italis Polpo mofcardino, aut mofcarolo vocatur. Nauta vilo, carinam quoque infpiciamus. ConItat autem illa ex tefta puriffima, argenti aut margaritarum Orientalium inftar pellucida, ac limpidiffmis-ntriis artificiofiffme contexta, fubtilifima infuper ac folio papyraceo fimilis, adeoque valde fragilis, hinc $\mathrm{Cl}$. Rumphio Nautilus tenuis, Amboinenfibus Roema gerita vocatur. Na. viculam exprimir tribus compactam partibus, nempe lateribus binis, et carina. Vid. fufus hune Nautilum defcribentem Rumplium in AIuJ. Amboinenf. Libr. II. Art. III.p.63. R. P. Buonammum in Recreat. Oculi et mentis P. II. Claff. I. n. I3. Incomparabilem Lifterum in regia Conchyliorum Hiftoria Libr. IV. Seit. IV. de Polypis tefaceis p. 5+9. feqq. diligentif. Pettiver in Icon. et nomin. Aquatil. Animal, Amboin. Tab. X.Fig. I. Cl.Gottivald, in Muf.Tab.V. Capf. I 5. n. 433. et paffimalios plurimos.

Sequitur alia NAVTILI INDICI crudi fpecies, quem fubnomine Indico Bia papeda, Nautilicraffe five majoris Cl. Rumphius in Muf. Amboin. et Rupifort.in Antillar Inful. defcript.c.19. Art. 4.p. 223. fub nomine Burgaudefripfit. Incola naurili hujus a praecedente differt, et licet a $\mathrm{Cl}$. Rumphio Polypodum profapiae accenfeatur, mirum in modum tamen differt, ceu ex figura Tab.X $\cup$ II. Lit.B. expreffa pater. Excell. Liflerus in Hift. Conchilior, Libr.IV.Sed.IV.f. 553 . Vermiculum exiguum album nautiloidem, algae fere adhaeren $\mathrm{em}$, oculis expóiuit. Margaritarum conchis fimillimus eft Nautilus hie craflus, hinc concham vocarunt Margaritiferam, non quidem ex foecunditate, qua margaritas producat, ut falfo cum aliis mulris credidit Bouffuctus de Aquitil. nat. pag. 49. Sed Margaritifera dicitura Colore, quo margaritis alfimilatur. Porcellanam Galli nominant, quia tefte Bonann. Recreat. Ocul, et ment. ex ejus tefta aliarumque cochlearum ab Indis confici fama eft; hine a Gallis paffim Coquille de Pourcelaine vel grofje coquille de nacre de Perle dicitur. Pocula ab Indis exinde parantur, nec in Europa infrequens, fic enim Boufluetus l.c.

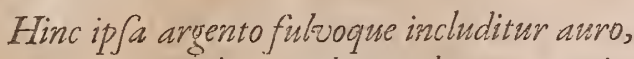 Fiuntque binc oculis pocula grata meis.}

His Vafibus et Nautilo confectisu, murrhina antiquorum Vafa comparat Aldrovandus, indeque murrbinum nautilum vocat. Pars externit induiturtunica quafi offea, caftaneo maculata colore, haec ab Indis imaginibus infculptis exornatur, quas Auctor nofter fub titulo $N A V T I-$ LI SCVLPTVRIS 1NDICIS CONSPICVI ob oculos pariter ponit: exfatque elegantiffimum Nautili tale poculum fculpturis fulgidum, nitide et affabre effictum in Mufeo Conchyliorum Cl. Goitroaldi paginauh tima. Interior Nautili Pars unionum apparentiam, five Gemmae opali 
variam, ad varias luminis reflexiones exhibet. Interna fabrica in trigin. ta ac plures concamerationes dividitur, ut ex figura Rumphiana Tab. $X V I I$. Lit.C. elucet. Ex una in aliam pro lubitu animalculum transmeare putarunt aliqui, per fiphunculum quendam, quo in omnibus aditus patet, ut in anguftiorem femper, et magis intimam ftationem fecedens, pericula tutius evitare queat. Verum quia foramen illud vix fubulae exili aditum concedit, et animal in latiori parte Teftae, ut offibus caro conjungitur; hoc minime credendum opinatur Rev. P. Bonannus l. c. qui infuper addit, ftructuram hanc ad motum infervire, ut animal facilius in aqua fupernatare poffet.

CONCHA ECHIN AT A CRVD A, quam hacTabula Auctor conipiciendam praebet, videtur effe cochlea maris mediterranei, ditta a Ron. deletio eclinophora, et Tuberculis, quibus I pinae frequenter gibbulofae intumefcunt, et proportione fervata diminuuntur, candida colore, fed rara. V.R. P. Bonann. P. Il. clall. 3. n. 18.

CONCHA MARINA INDICA POLITA dicitur a P.Bonanno Perlata, non ex margaritis ab illa productis, fed a margaritarum nitore, quo fulget decorticata cute lapidea et rudi. Fa fcia colore puniceoafperfa cingitur, qua infignis pulchritudinis notailli augetur.

\section{TAB. XX.}

Appicito, variis repleta eftcocblea rugis, et latum Jimma in parte for amen habet.

$\mathrm{H}$ Is ab Auctore delineatam COCHLEAM RVGATAMI et VMBILICATAM innuit Bouffuetus de Aquat. Nat. Haec falfo tertia Nautili fpecies effe traditur, cum nullus unquam hac in conchaviderit Pompilum; qui minor eft, quam ur tantam concham fe. cum trahat, cujus etiam ftructura a facili natatione aliena eft ob transverfas rugas, cum in animantibus marinis hoc diligentiffime caverit natura, ne quideffet, quod natationi moram aut impedimentum afferret, annotante hoc magno Aldrovando de Teftac. L. III. cap. 34. pag. 390. Obtinuit autem a rugis nomen, quibus tota Cochleae tefta per. transverfum ducta eft, ita elatis, ut et ftriata dici poffit. Colore intus eft albo, foris flavefcente, valde fragili. Turbinis claviculae in acumen non definunt. Foramen valde apertum et longum. Annon Buccinum magnum ampullaceum tenue, roftro leviter finuofo profunde fulcatum Excell. Lifteri? Hift. Conchyl.Tab.898. in Gottmaldiano MIu. Jeo Capf.IX.Tab.1, n, 1. 2.

MIVREX ACVLEATA MIARMOREA Auctoridicta elt Murex marmoreus Rondeletii, interque murices primatum ducere videtur, optimeque convenit cum Illuftr. Lifteri Buccino bilingui gravi, labro et columella Jubcrocea, acutis muricibus borrido, chavicula denfe ftriata; non

tamen 


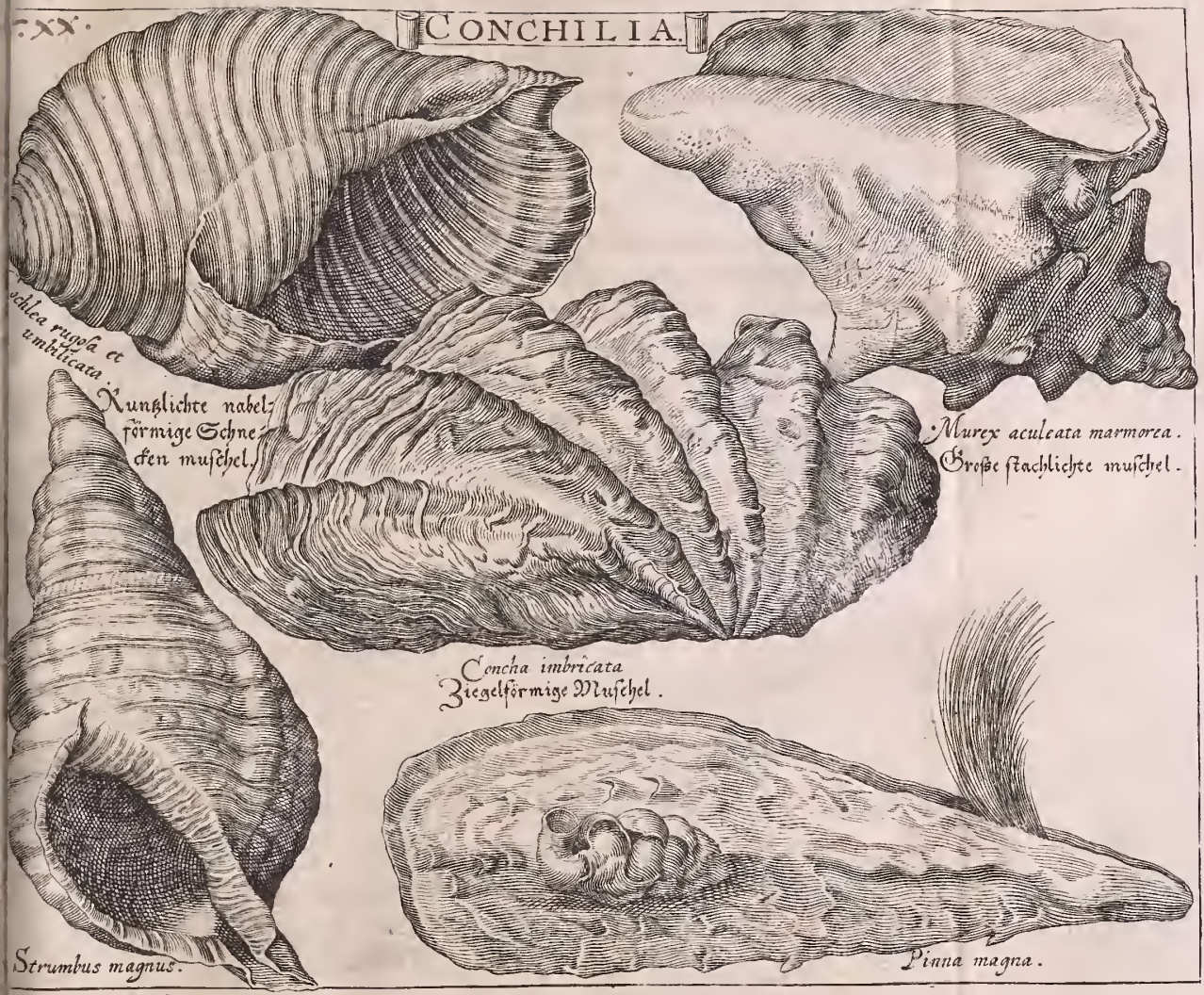


$=-1,1=1.1+20$

$+1$
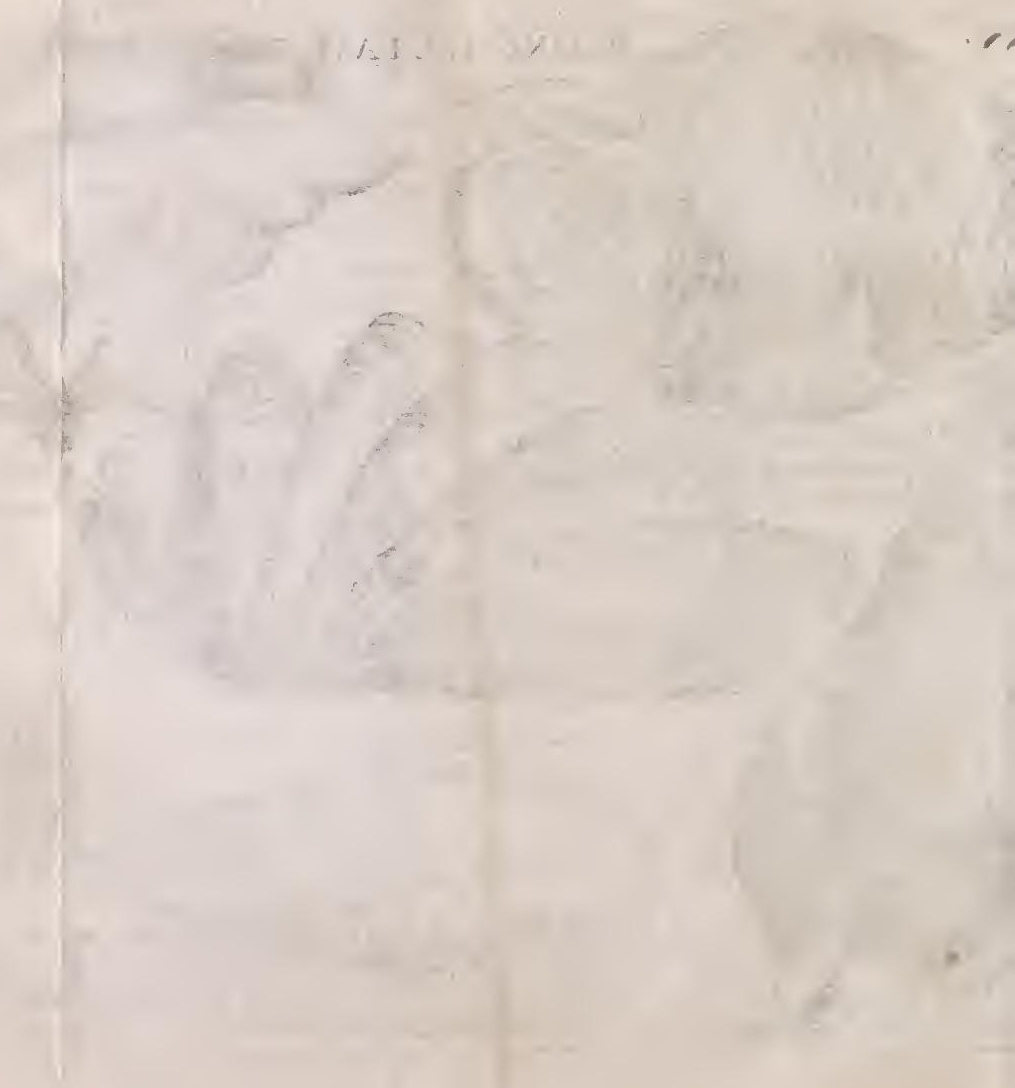
tamen apte convenit cum murice orthocentro Aldrovandi, ut infpicientibus facile patet. Obtinuit autem nomen Muricis ob figuram: fignificantưr enim hac voce faxorum afpera, unde Poëtarum Princeps Maro:

Conoufae cautes, et acuto in Murice remi

Obnixicrepuere.

Eadem pariter voce exprimitur bellica clava ferreis horrida aculeis, cujus erat Barbaris praecipue frequentiflimus ufus, truculento marte cum holtibus dimicaturis. Marmoreus infuper dicitur, quia tefta admodum craffa tuberculisque horrida et afpera, ideoque aculeatae nomine infignitus. Parte interna ex albo purpurafcit, figura inter buccina et conchylium media. Vfum medicum Muricis epigrammate complexus efr Boufuetus de Aquatil.natur.p. 35 .

CONCH. AE IMBRICATAE figura non quadrat ad Rondeletianam, feà potius Iridracbnae Aldrovandi, pedalis quippe longitudinis; tefla imbricata undata, ad undarum fefe attollentium fimilitud nem diftinra, eo loso quo fibi invicem connectuntur. Singulae duos digitos per Eransverfum craffae; intus candicant et glabrae funt. Imbres externe ádeo mirifice difpofiti, ut difficillime fermone exprimas, oculis vero ulurpes jucundius. Convenit optime cum concha maxina imbricata Ind. Orient. Illuftr. Lifter. n. 385.

STRO MLBVS MIAGNVS ad buccina et turbinatorum genus in anfractum intortum pertinet, quod ore quidem lato, mucrone autem acuto clauditur, juxta O ridii illud:

\section{Cava buccina fumitur illi \\ Tortilis in latum, quae turbine crefcit ab imo.}

Quamobrem fonum edunt, fi voce inflantur, et Tritonum ori admo. tas Pictores et Poëtae exhibent, quos inter $\mathrm{Na}$ So Neptunum defcribers canit:

\section{Caeruleum 'T ritonavocat, conchaque fonanti \\ Infir are jubet, fuctusque et flumina figno \\ Jam revocare dato.}

Imo ab antiquis Romanis loco Tubarum fuiffe adhibitas, affirmat $V i r$ gilius:

\section{Buccina jam prifcos cogebat ad arma Quirites.}

Dicitur autem Strombus, quia 5 gom $\beta \omega d \tilde{\omega} y$ nomine intelliguntur, quae in longum turbinem definunt, et in anfractus contorta. Defcriptio Strombi jgitur magni Auldoris optime convenitcum Bonaninana; novem enim anfractibus producitur proportione fervata diminutis, illique primi orbis longitudine commenfurantur. Circa orbium commiffiras veluticapillorum tricae circumvolvuntur, et fingulis cormin labrum 
quoddam annectitur, quo veluti diftinctus Cortex indicatur. In parte interiori e carneo colore albefcit, exteriorem verö femicirculares maculae albae, rufae et caltaneae invicem alternatae condecorant. Labrum, quod reflexum orbi propinquo adjacet, minutiffimis crenulis corrugatur, quod vero expanfum, oris aperturam amplificat, undofis finubus crifpatur. Invenitur in mari Europae adjacente, fed coloribus dilutis picta labrisque crenatis ac tuberofis. De Vfu in cibis et Medicina fule Aldrowandus de Teftac. L. III. cap. 6. feqq.

PINNA IIAGNA concha elt, e duabus compofita teltis, et a mytulorum figura, magnitudine excepta, non multum differt. A b inferiori et ftrictiori parte in amplam latitudinem extenditur, illic arciffime clauduntur teftae, hic facile diducuntur. Exteriorem faciem terreae glebae fimilem habet multoque luto maculatam: hinc nonnulli crediderunt, nomen Pinnae ex Graeco tivis, quae vox fordes denotat, provenire. Tubuli vermiculares et Balani faepius parti pinnarum exterioriadnafcuntur, uti ex figura noftrae pinnac apparet. Inferior pinnae facies rubida five helva cum nitore, pars vero acuminata, ubi animal ad. haeret, margaritarum vulgarium aut aeris aemulatur colorem. V'ariur". a variis concha haec nomen obtinuit. Apud veteres Graccos vocabatus

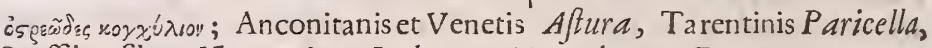
Maffilienfibus Nacre, aliis Nacharone, Neapolitanis Perna,

$$
\text { a forma Pernae, quam gerit, affimili. }
$$

Adnafcuntur huic Pinnae fila vel lineum capillamentum, in figura quoque noftra expreffum, unde Genuenfes pinnam lanam, et lanam pinnam nominant. An byflo veterum analoga haec materia, pluribus dif putat Aldrovandus de teftaceis p. 540. feqq.

\section{TAB. XXI.}

DRoftant hacin Tabula fub Fig. 1.2.3.4. et sta. non naturae quidem nova opera, fed Artis. $L A K V A E$ enim funt e variis Conchyliorum teftis concinnatae, ad oculos aeque oblectandos, ac animum ad Creatoris optimi fapientiflimique laudes tam varia naturae miracula, in viliffrmis naturae rebus effingentis, alliciendum. Leves funt tenuesque hae teftaceae Larvae, nec comparandae iis, quas fumme Rev. Bonannus Recreationi mentis et oculi Claff. III. n, 407. coronidis loco adjunxit. Et hae tamen non accedunt iis, quae in Regia Crypta Verjailliana fpectantur, in qua fignum Solis fculptrix manus fimulavit, apud Thetidem orbe peragrato diverfantis, additis e Mufivo opere ornamentis, quorum materiem undarum foecunditas in Conchyliis fubminiltravit.

Fig. VI. MVREX EX APPENDICIBVS QVINOVE, inftar brachiorum extenfis, et circa labrum additis, a Graecis $P$ cntedady his dictus. Strigis crifpatus elegantifimis albi, brunni et ad fanguineum ac- 

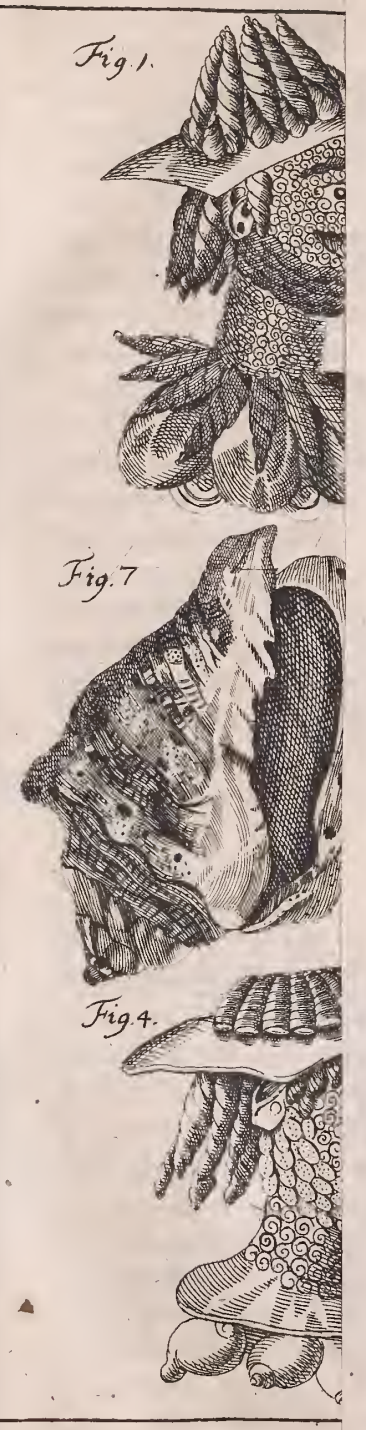


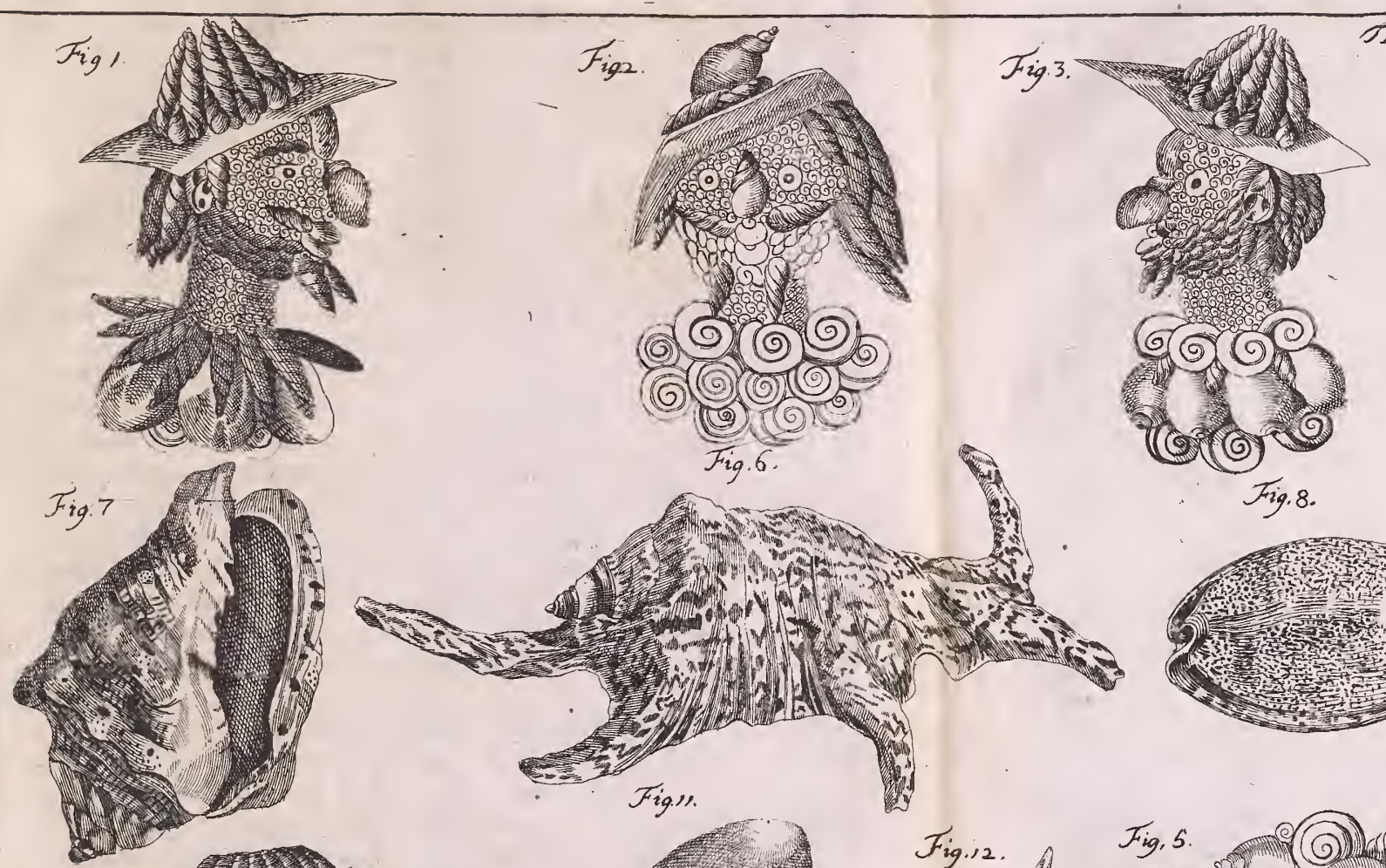

$\sigma_{A B} X X_{I p, 74}$

Fig.4.
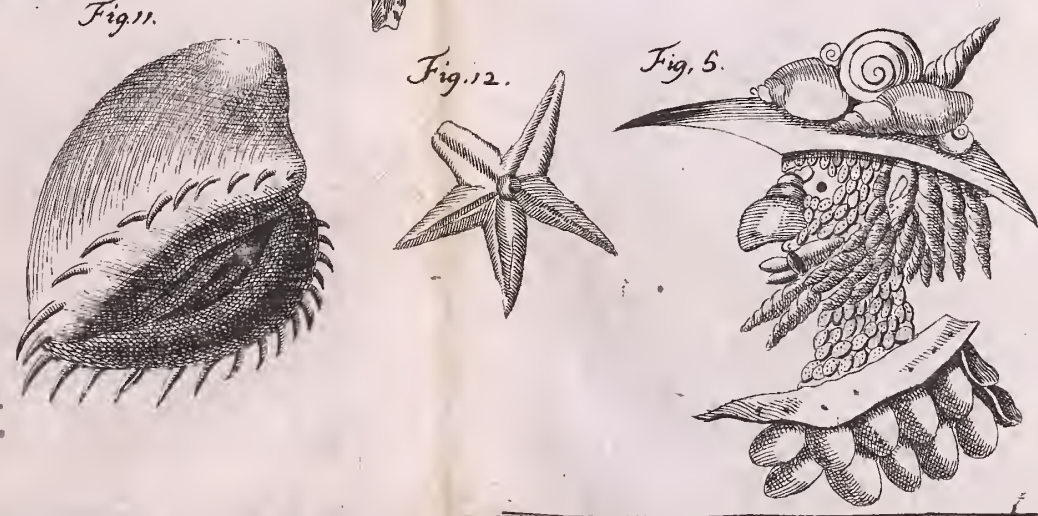

cedentis eft coloris, mire maculis variegatis ludens ; oris aperturam minutifimis incifuris rugatam habens, maxime infuper expolitus; intus croceus color in albedinem fe diffundit. Eftque murex hic Purpura Pentedactylus Bellonii, cujus Figura optime exhibetur ab Excell. Liflero in elegantiffima Conchyl. Hiftorian. $3>0$. et in Excell. Gottwald. AIuf. Conchyl. Tab. IV. Capl. VII. n, 141. b. diligentifimus Pettiver in Aquatil. Animal. Amboin. Icon. et nom. Tab. XIV.n. 3.

Fig. VII. BVCCINVM MIVSICV $M$ eft craflum, clavicula muricata infructum in Infulis Jamaica, Barbados et Corafjao obvium, ab Excell. Liflero Hift. Conchyl.Libr.IV. Seet-XI.c. 2.n.80 s. delineatum et a P.R.P.'Bonann.inCl, 3.n. 296. defcriptum. Vocantur Mufica Buccina, quodmuficis notis lineisque Natura fignaverit, ne forte Marinae Nymphae figuratis defraudarentur cantilenis, Neptunusque Fovis non invideret delitiis, aut fi conmento non affentiris, ut jpectantium faltem oculis fuis numeris abfolutam Harmoniam efficer ent, ut elegantifimejocatur R. P. Bonannus. Colores jucundius oculis ufurpantur, quam calamo referuntur: funtenim lineae aureo fulgore notabiles, notulae fanguineae, puncta e flavo rubefcentia, tefta autem fubjęta vel vinofa vel onychina. Has conchas Muficas omnium optime delineatas reperies in Excell. Gottroald. Milu. Conchyl. Tab. III. capf. VI. n. I I7. I I 8. I I Cl. Rochefort dans l: Hilloire naturelle des Isles Antilles Chap. I 9. Art. $X I$. concham Muficam exhibet, Coquillage couvert des Notes de Mufique dictam, illa tamen non buccinis, fed conchis Venereis, fi figura vera eft, accenfenda.

Fig. VIII. CONCHA HAEC VENEREA eft literaria dicta a Cl. Rumphio Ephem. Nat.Curiof. Dec.II. Ann. V. obf. CXII. communicata Arabica; qui eam poftmodum Mufeo Amboinico Libr.II. Art. $X X I 1 I$. n. I1. lit. M1. pariter intulit, defcripfit eam quoque Lifterus in Hift. Conchyl.Cl.V. ponderofa longiufcula etanguftior ventre fubplano albicante, lateribus crebris maculis nigricantibusque mediocribus diftinctis dorfo velut characteribus quibusdam depicto. Fig. IX. et X. Cr. LINDRI lunt, in quibus tamen patentiores et magis expreffi Arabici characteres. Eorum plurimos depictos habet Muleum Gottwald. Tab.III. Capf.V. et Tab. II. capr.XXVI.

Fig. XI. e numero rarifimarum Concharum VVLVAMI MARINAMl exhibet; et figura oculis fubjecta nominis rationem exprimit, ut ulteriori explicationi non indigeat; aculeis inftar pubis horrida. Defcripfit et depinxit illam Cl. Rumphius in Mufeo Amboin. Tab. XLVIII. Fig. s. et ante illum Olearius in Muf. Gottdorfiano Tab. XXIX. Fig. IV.

Fig. XII. a Cl.M.R. Beslero his verbis delcribitur : Stella Marina elegans, cocbleam in medietate veluti gemmam annulo inclufam complestens. 


\section{TAB. XXII.}

$\mathrm{M}$

A rina STELLA praecedentis Tabulae ad alias MARINAS nos ducit, MAFOREM nempe et MINOREM. Referuntur ab Aldroviando in Zóophytorürn claffem; ab aliis ad Infecta Aquatilia apoda, multas incifuras in radiis habentia. Graecis ásìe, Sylvãtico fidus marinum vocatur. Ràdii quinque in multiś particulis, tanquam e vertebris componintur, ut in aqua mobiles exiftant; cavi praeterea funt hi radii ac in méditallio os conftituurnt, quo alimentum attractum confcitur, et per omnes partes difpergitur, Colore vergunt hae ftellae ad cihereum.

Quae fequitur AIARINA STELLA TREDECIAI RADIO$R V M$, optime defcribitur a Cl.Clüfo Exot. Libr.VI.c. 20. p. I 44. licet Figura longe melius ab Auctore noftro expreffa. Eft autem haec Stella ex actileatarum genere, fatis amplo corporis orbe, non valde longis tamen radiis'cońtans; qui tredecim numerô funt, illiäure omnes di. redi ñonfintuoli, aèquáliter longi prona parte, quüinis aculeorum ordinibus praediti, tribus medium occupantibus, duobus alis latera, fic ut fingula latera decem aculei pectinatim 'muniant, coloris rubelcentis; fupina pars flavefčit, "et vertebras illas, e quibus finguli radí componuntur, mantiffefte offendit. Decem radiis ftella thárina defcribitur ab $1 /$ l

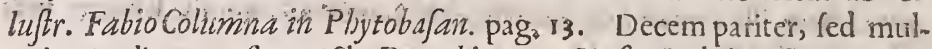
tiplici radioruin flexu $C l$. Rumpbius in $M 1 u$. Amboin. TAB. $X V$. Lit. F.

SOLEN FOEMIINA haec ab Auctore delineata multiplici exprimitur nơmine, gutorum Plinius meminit. Solen five $A V L O S$, five $D O N A X$ five $O N Y^{\prime} X$, five DACTY $L V S$; et quidem Solen dicitur a

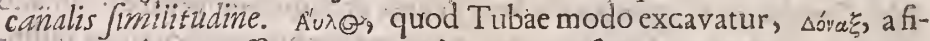
gura arundinis craffae ac cavae ad amnes crefcentis, quae dónzy et $\mathrm{Cy}$ pria arundo nominatur. 'ôvu vero i.e. ab extremis tenuitate et figura unguibus fimilli. Dactylüs, emente Plinii pariter ab humanorum digitorum fimilitudine. A Venetis vocatur Cappa longa, a Bononienfibus Pefce canella, aliis Italis Cannolichio, Gallis Couteaul, quod cultri manubrivin referat. Ex quilbis denominationibus omnibus figura Solenis lig̨uét. Vivit ut Tellinà fub arena; tefta feprem ad minimimum digitos longa, vix unum lata; huic fummacuticula. Vid. R. P. Bonannus p. I06. quod noctu luceat, Bouffuetus affirmat de A quat. nat.

Qúä SPONGI AE FOE MIN AE nomine delineatam exhibet, ego potiüs FAY AGINECH five Menikneav Ariftotelis, aut Alcyonium fecinduin Diofcoridis crederem; quae mafla quaedam eit ex innumeris conltans pelliculis five vefricis, iis fimilibus, quae e Pifis excorticantur, dum coquuntur, invicem unitis et fpongiae inflar concretis, vacuis, coloris ex albo flavefcentis, pugni quandoque magnitudine, quandoque major, 


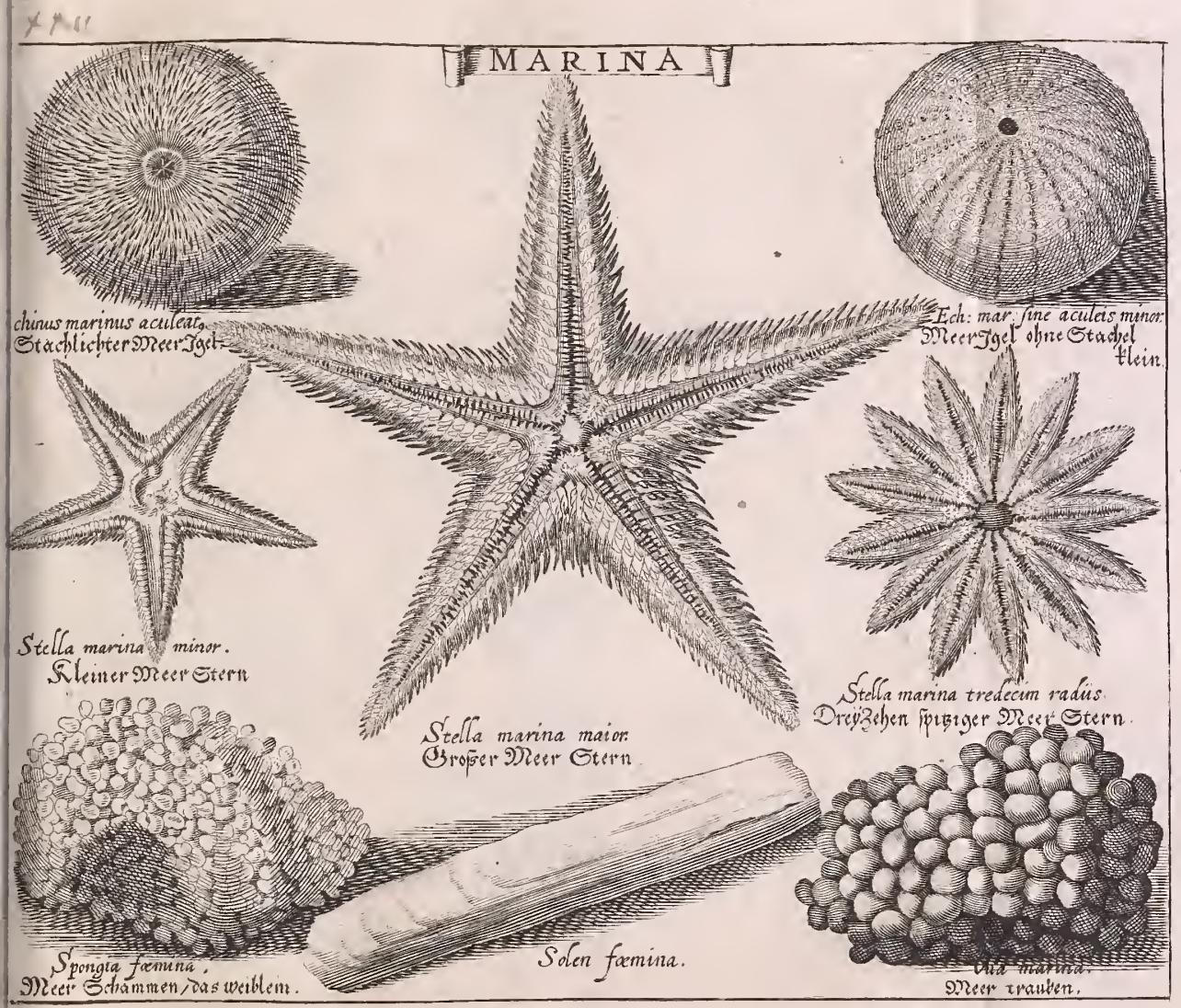





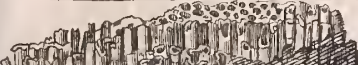

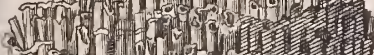
rifor 1 .

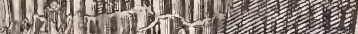

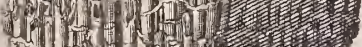
InI

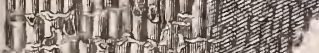

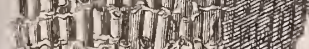
10 는 Pot का

Allyonum maris rubri.
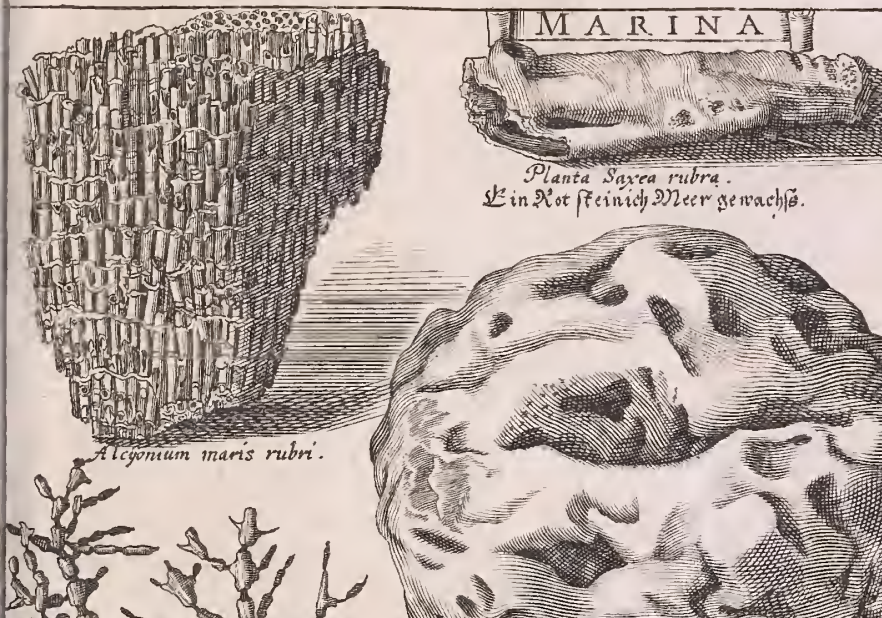

Hippuris saxea.
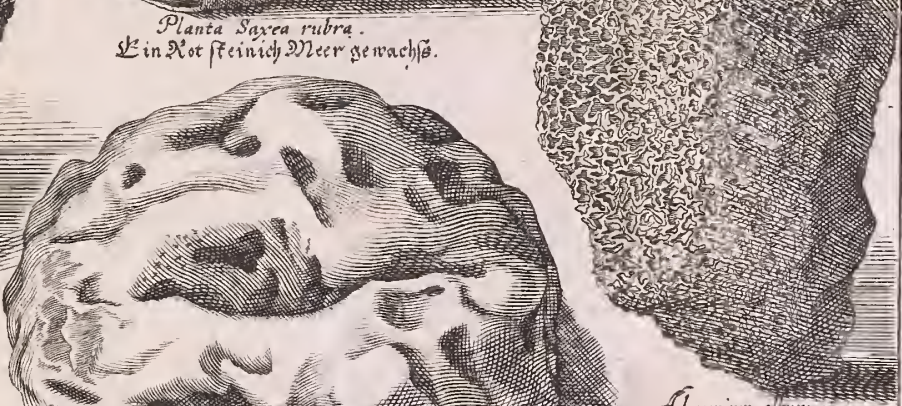

Alcroniun allum Dest Eshoum .
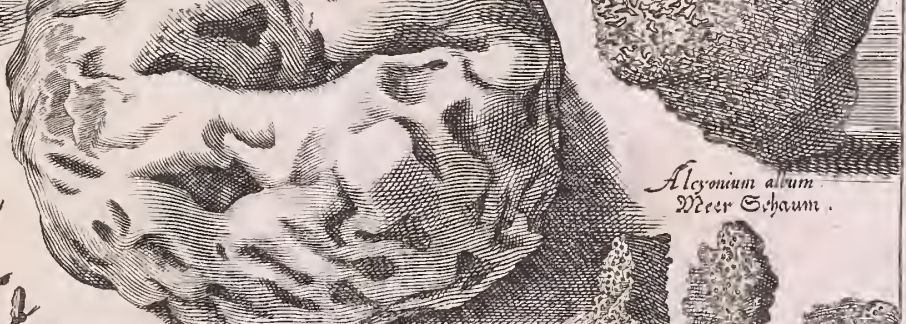

tilcyonï alex species.

2. $3(3-5)$ $a^{3}$ is

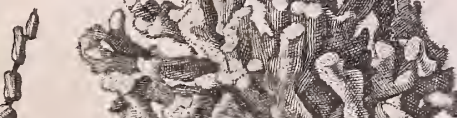

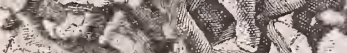

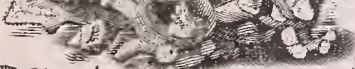



major, quandoque minor, cujus genefis, e mente Ariftotelis, fequenti contingit modo. Purpurae, mytuli, buccina, aliaque ejus generis oftracoderma, emittunt lentorem quendam, five humorem mucofum, yelut e feminis natura, femen vero eorum nullum eft. Exillo, purpuris verno tempore congregatis, veluti favus ex putaminibus cicerum co. Etorum alborum, inter fe cohaerentibus coagmentatur, quam alii pro maris Ipuma, alii falfo pro fpongia oftentare folent; indeque pariter factum, ut Auctor nofter fpongiam foeminam crediderit. Vid. plura in Muf. Worm. pag. 236 . et apud Aldrovand. de Tefac. Libr. III. pag. 300.

Et $V V A$ quoque $M A R I N A$ favaginis fpecies effe videtur, alii proovis Rajae pifcis ovario exemptis, et peculiari modo arefaetis venditant; quorum jam Tab. XV. e Bouffueto facta mentio. Nulla enim uvae marinae Rondelet ii cum noltra hac fimilitudo.

\section{TAB. XXIII.}

$\mathrm{O}$

Ccafione fpongiae faeminae praecedenti delineatae Tabula, quam Alcyonium fecundum Diofcoridis elle diximus, Auctor copiam nobis facit ALCYONII MARIS RVBRI, quod a Cl. Legato quoque Spongia corallina vel Coralloides Jpongiofa nominatur, illudque

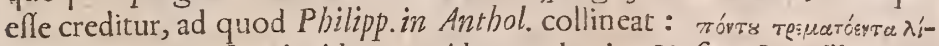
Qov: Ponti pertufum lapidem. Aldrovandns in Mufeo Metallico pag. 291. vocat $P$ Jeudo.Corallium rubrum Calamites. Excell. Welfchius Auctori noftro dicam fcribit, quod nullo antiquitatis teftmonio et leviffimo colorisargumento Alcyonium maris rubri nominet, cum potius fit Tubularia Coralloides pulcherrima, et pro Tubularia purpurea, five Alcyonio Milefio Ferr. Imperat. haberi pollit. Cum autem concretum hoc femper promaritimo habeatur, miro tamen calu in Pago Svevico Sontheim, Heilbronnae urbi vicino, pugni mediocris magnitudine miro cafu, lapidiquadrato mufcofo adhaerens repertum, ac ad Virum rariffimae Eruditionis in Fiftoria naturali Job. Matth. Fabrum delatum, quiillud Anat. Botanolog. Pilaemarinae p. 202. inferuit et delineari juffit. Vid. quoque Clarifl, Rajus Hift. Plant. T.I. Libr. 2. c. 2.p. m. 64. Excell, Tournefortius Inltit. Rei Herb.p. 575. Muf. Calceolar. p. 22. Muf.Worm.p.2.37. quod corpus purpureum tamen differre videtur.

ALCYONIV $I I$ ALBV $M$ Auctoris, prima impreffio aut deli. neatio Madreporae creditur R.P. Boccone, dans les Recherch. et obferv. naturell. Epift. XV1.pag. I 39. qui Beslerinoftri Mufeum citat, et Alcyo. nium tuberofum Ferr. Imperati effecredit. Eft autem fubftantia marina, porofa, fungo fimilis, levis, intus afpera pumicem referens, alba tamen, acris faporis, odoris expers, uti alia Alcyonia, quae e mariortum habent, cujus Aquae cum falfae fint, ex ejus f puma, cum tenuillimis for- 
dibus permifta, accedente fucco lapidefcente, in varias figuras concre. frant. Confer. de Alcyonio Excell. Langii Hift. Lapid. p.72.73. ALCYONII ALIA SPECIES videtur effe Lapis fungites cerebriformis Excell. Raji.

PLANTAAI HIRSVTAM FORMA CORALLIORVMI credo Escharam Coralliodem a Clufio Exot.Libr.VI. c. g. defcriptam, folidam totam, candidam et in varios ramulos creberrimis foraminulis di. finctos divifam, valde eleganticonfpectu. Vel potius Porum cervinum Ferr. Imp. Hift. nat. Libr. 27. p.630. Edit. Venet. nov. Cl. Olearius in..Mufeo Gottdorf. matricem Coralliorum credit; vel Fruticem coralloidem, quiomni ex parte refert hirfutum cornu cervinum, quod lanugine obducitur adhuc novellum. Worm. in Aluf.p. 233.

PLANTA SAXEA ALBA et RV'BRA, non colore tantum;' fed fructura maxime differunt. Plantam Saxeam rubram quodattinet, colore eft rubri pallidioris, fubftantia et figura externa cfteolithis non abfimilis, durioritamen, faporis aliquantulum acris, odoris nullius. Planta faxea alba cum in fequentibus Tabulis quoque occurat, illic differendi locus fupererit. Vid. Tab. XXVI. Fig. IV.

Sola reftat HIPPVRIS SAXEA; equiletum hoc eft in multos graciles ramos divifum, ac frequentibus diftinctum nodis et articulis, linguli articuliftriati, ac veluti canaliculati, ad fingula vero genicula five nodos graciliores, fufci fplendentis tamen coloris, ut etiam finguliarticuli fufco aliquo glutine connexi videantur. Interior pars lignofa, quemadmodum ex abruptis quibusdam articulis confpicere licet; minime autem Clufiana figura, quam habet Exot. Libr. VI. cap. 8. cum Auctoris noftri convenit, illa vero quae in Olearii Mufeo Gottdorffiano' repertu datur, e Besleriana Tabula, ut plures aliae indubie mutuo fumpta videtur. De Planta hac faxea vid. Illuftr. Raj. Hif, Plant. Libr. 11. Sect.II. cap, 6. p.68. et fub nomine Calbahar littoreum in Append. Milf. Alufeor.p. 111 .

\section{TAB. XXIV.}

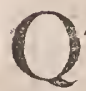

$\checkmark$ ERCVS MARINA THEOP.HR ASTI Auctoris plurimum differt ab ilia, quam Clufius Exotic. Lib. VI. cap. 4.p. 12 1. et poftea in Cur. pofterioribus P.90. exhibuit; aptius autem convenit defriptio 1ll. Sloane Catal. Plant. Inful. Jamaic. p. 3. quod fit Corallina Fru. ticofa bumilior et craffior, ramis quaqua verfum expanfis, fuperficie tuber. culata, quae in littoribus omnibus Infulae Jamaicae inter alia maris purgamenta frequentifime invenitur.

PLANTA RETIFOR.AIIS MIAXIMIA illa ipfa eft, quae ab Inful. Antill. Scriptoribus Rupifortio et R. P. du Tertre, PENNACHES DE MER vocatur, Anglis Sea-Feather. C. B. in P. dicitur Corallina cortice reticulato maculofo purpurafcente inftar virgulti lignola, 


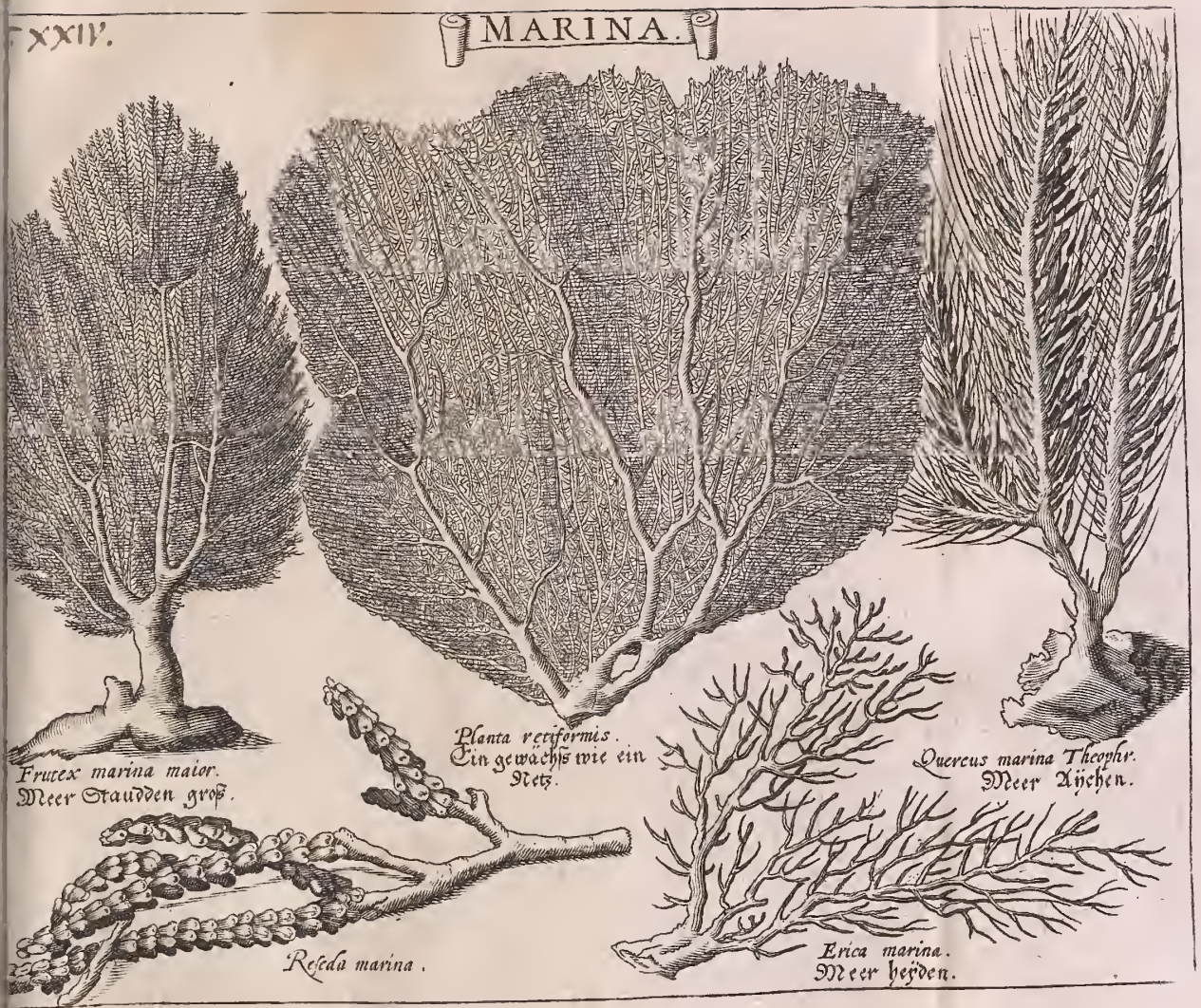


. 
et prorfus tamen plana, in frequentes ramos eosque etiam planos, $/ \mathrm{par} f a_{\text {, }}$ ex quibus in longitudinem exeunt multi nerviretis inftar fere contexti, adeo firmi, ut ex aereo filo conflati videantur, lumini tamen appofiti glutinis fubftantiam verius referunt. In AIuf. Reg. Soc. Anglic. P.II. Sea.V.cap. 1.p. 245 . ab Excell. Gren vocatur: Frutex maximus reticulatus five Flabellum marinum maximum, a great fee Fan. Scarabell in verfione Italica Muf. Settal, et Terzag. in Lat. MIuf. Septal. Mefficanan Coralloidemvocant, qua mulieres in Mexico pro ventilabro utuntur, tam affabre a natura edito, ut videatur filo ferreo contextum; varias vensilabri hujus fpecies promunt. Talem $\mathrm{P}$ lantam quoque retiformem, quąPuellae Sinenfes in decoquenda herba Thee focum excitar e folent, expreffam videbis in immortaliopere Biblioth. Vindobon. Sacratiffimi et Invidiffimi Monarchae noftriabilluftr. Lamb. edit. Tom. five Libr. Vill. Comment. p.659. et in Cl. Neffelii Catal. Biblioth.Cae.. Manufcript. Part. VII.pag. 163. Confer, A1uf. Calceol. p. 16. Annon Akarbabar Kipas Rumphiz; In Append. Aluf. Alufeorum p. 109. 110.

FRVTEX MARINVS MATOR optime defcriptus exftat apud Cluf.Exot.L.VI. cap 2. p. I20. durus prorfus et lignofus atque valde planus flabelli inftar in ternos aut quaternos craffuiculos ramos divifus, a quibus innumeri alii minores producuntur, qui deinde in ali-. os iterum minufculos dirimuntur, in longum et latum le difpergentes tam miro ordine, ut fimul quodammodo coalefcant, vacuaque tantun quaedam fpacia relinquant, cribri aut reticuli foramina imitantes. Integer Frutex nigro purpurafcente colore nitente eft obductus. Sed falfuginofae materiae, qualis Cluftus meminit, uti in Wormiano, fic in nofro quoque nullum veftigium. Nautae Corallium appellant; fed ad Palmae marinae Theophrafto defcriptae genus aliquod referendum cenler Bauhini Epitomator Chabraeus. Rupifortio in Antill. Hiftor. c. 19. Art. 1 3. p. 234 .vocatur Arbre de mer, pieturaque plane Auctoris noftrifimillima, Ill. Sloane Catal. Plant. Inful. Famaic. Fcribit, in profundis maris Jamaicenfis fcopulis et rebus folidioribus innalci copiole, unde frequenter in vicinum littus ejicitur. Vid. Excell. Raj.T.1. Hift. Plant.p. 6\% cui in paucis a praecedente Planta retiformi differrevidetur.

Plantamarina RESEDAE nomine, ut optime Wormits notavit, in maximam quandoque excrefcit magnitudinem. Planta plana eft, ut marinae pleraeque, nullos ramos nifi ad latera transmittens, interior fubftantia lignofa, albicans obducitur cortice duro, nigro fplendente et: ad naturam Corallii nigri accedente, qui rurfum falfa et alba materie obducitur, efformata in modum valculorum rugoforum, quae femina matura Plantae Refedae continent, ex albo cinerea minora paulo et infma parte utplurimum ipfis ramulis connexa, vacua, fragilia et quae digitis attrita facile in pulverem folvuntur, faporis falfr. Vid. Cluf. Exot. Lib. VI. cap. VI. Excell. Raj. T. I. Hift. Plant. Libr. II. Sef. II. cap. V. pag. 68. 
ERICA MIARIN.A a Clufio Exot. Libr. VI. cap. s. p.m. I2 2. defcripta; videtur effe Corallina fruticofa elatior ramis quaquaverfum expanfis teretibus, Anglis Sea-Feather five P inus marina; affurgit Itatim baec maris foboles ab infimo in frequentes ramos, atque illi denuo in minores alios dividuntur; interdum fimul coalefcunt, ut in plerisque Plantis in mari nafcentibus evenire folet: tenui tegitur cortice, terrefrisque eft coloris. Totus porrofrutex planaforma excre cit, ramique tanquam quibusdam tuberculis obfiti funt. Totaplanta lignofa et dura, atque lapidi aut fcopulo innata videtur, falfi faporis, tanquam Oceani nata. Hanc marinam Plantam fub nomine Acarbabar rutti rulti defcriptam invenies in Muf.Muf. Append.p. 110.

\section{TAB. XXV.}

$\mathrm{T}$

Oties jam concretionum Corallinarum $f_{a}$ cta mentio, ut opus fit ad ipla progredi CORALIA. Maxima de Corallio, an vegetabilium vel mineralium regnofitinferendum, inter Hiftoriae naturalis fcriptores nata lis et controverfia, quorum rationes ex utraque parte non contemnendas attulit Excell. Ettmüllerus in elegantiffima de Coralliorum Tinctura difputatione, tandemque rite penfitatis omnibus concludit, Coralium (derivatur quippe Graecis a voce rógn puella et à $\lambda_{s}$ mare, quafipuellan five maris filiam dicas) efle lapidem in fruticis peciem concretum. Hinc Auctor quoque nofter Corallia (ut vulgo feribitur) er productiones Coraloides ad lapidea concretarefert, cum per extrapofitionem feu additionem partisad partem, non vero per fucci nutritii intus fufceptionem crefcant et augeantur, ut hoc vir ingeniofffimus et rei herbariae callentiffimus Rev. P. Paul. Boccone äurónтm faepius obfervayit, et ex ejus obfervationibus Gallice infriptis: Recherches et obfervationsnaturelles touchantle Corail Esc. palam fit. Confentientem hac in hypothefi habet Medicum Avenionenfem Gvifonium, qui in literis ad P. Bocconem datis nullum prorfus Coralii genus Plantam effe afferit, aft purum putum minerale et multo Sale ac pauca terra potifimum compofitum. Exiftimat quidem variorum Salium cum Terra aliisque mixtionis principiis arietantium occur fu atque praecipitatione tam nobile mixtumemergere, non fecus ac fanigeratam illam incrementi tantum non extemporanei Chymicorum arborem metallicam, quae Mercurii et Lunae capellatae in Aqua flygia prius diffolutorum ef Aquae communi dein innatantium fubfidentis atquenexu per appofitionem partis ad partem accrefcit. Haec Gvifonius, fed accuratiorem genefin oopáraro Ettmüllerus exhibet, generari nempe credit Coralia, e fucco quodam minerali, falino nitrofo, pinguedine et vifcofit ate quadam fulphurea impraegnato, quae per fubterraneum ignem per poros fundi maris erumpit, aft ubi attigerit marinas Aquas, protinus tum frigore tum congelante earum faljedine fubfidet, primaque fundamenta agit futurae concretionis, 


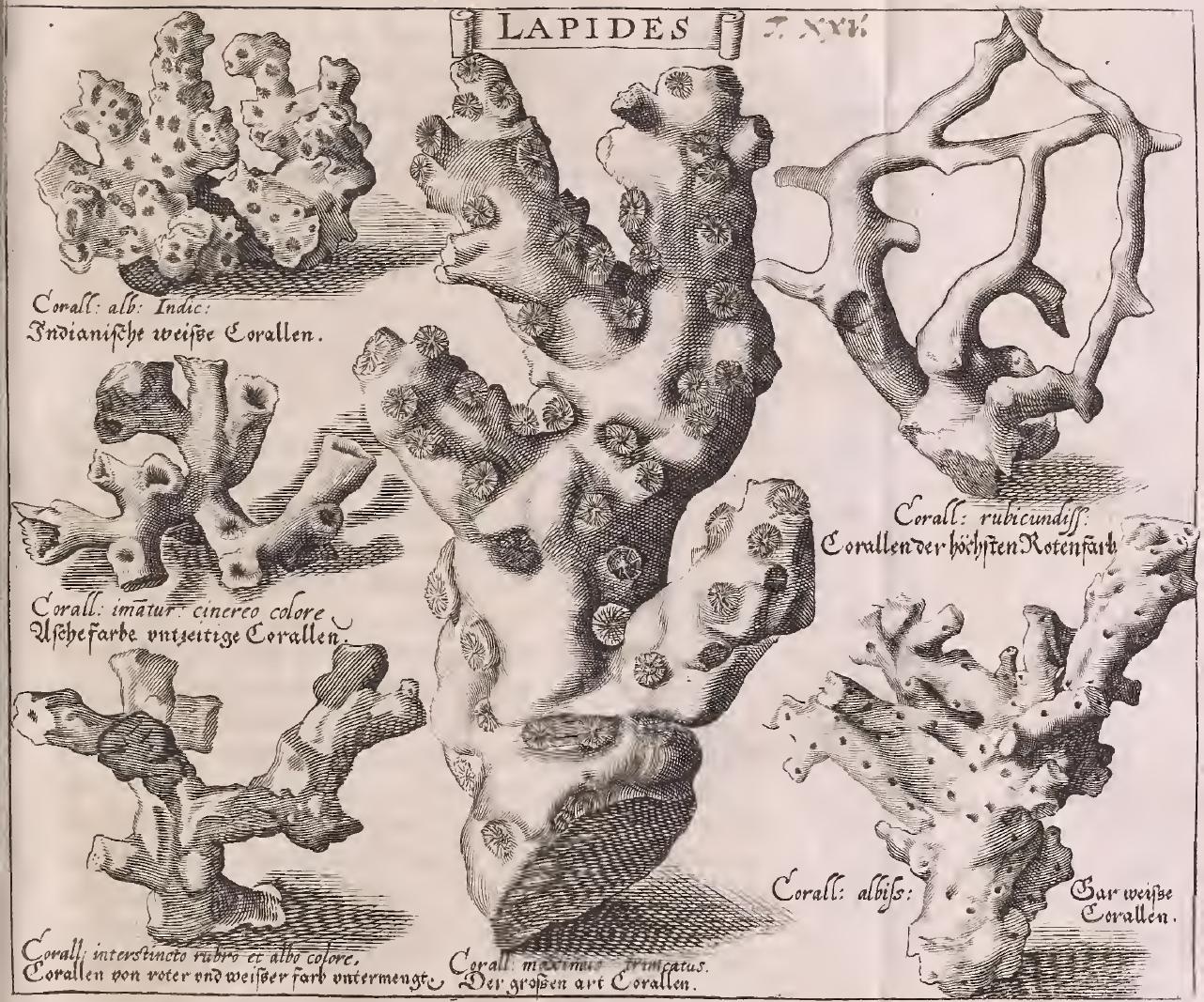




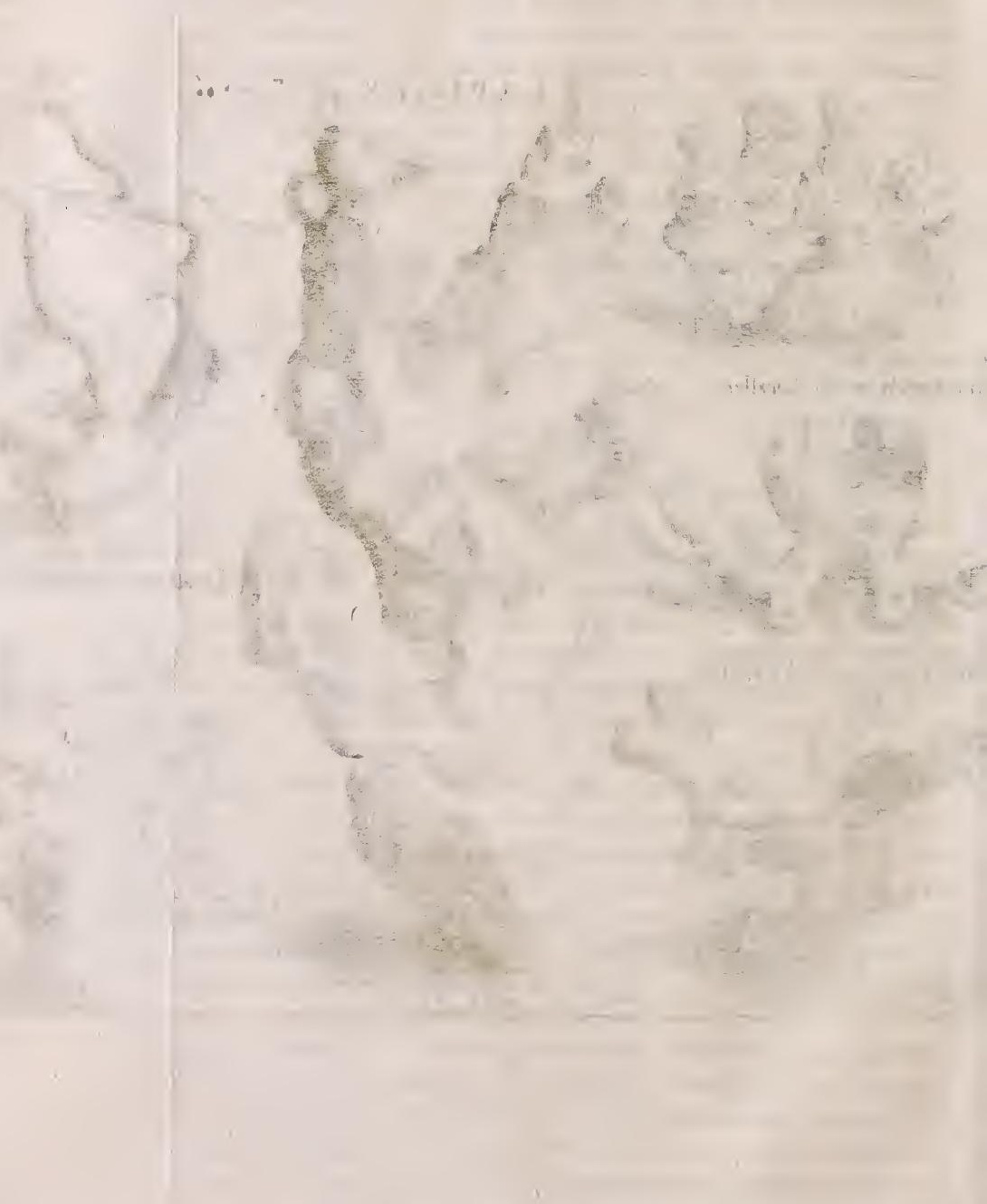


exallabente veroet expirante continuo novo fucco, coagulata iffa mate. riafenfim diffenditur, fenfimque in altum elevatur, quae novo novoque corpufculorum fulphureo-falinorum affluxu non tantum conden/atitr, Jedulterius quoque a/cendendo, ob copiam futcciturgens binc inde in ramos erumpit, qui ex novo appulfo fucco primo quidem verrucul as qua'fi promunt, quas recens falinus liquor ulterius extendendo, in furculo. rum e ramulis enatorum peciem expellit. Quod fiabundantia nimia diffendendo arbufculam disrumpat, vel e ramuli extremitate exfudet, cxfilllans liquor Jpermatis naturam affumit, ficque novam Coralii prepaginem fundat, et quamcunque rem attigerit, tanquam fertile folum of culando, novo fuperingefto permate in arbufculi fpeciem fimiliter extollitur. Eodem ergo modo celebratur haec Coraliort:m genefis,' quo caeterae fatium efflorefeentiae contingunt, vel quomodo enati funt filices, aliique lapides, qui ramulis infignes et fruticum fpeciem gerentes reperiuntur, quales le vidiffe ad Albim prope oftium Tangrae, memorat Encelius de remetall. 1. 3. c. 3. Quae antiquitas olim tradidit, ac fi Corallitim molle et fub undisherba fuerit, aft in lapidem,

\section{Quo primum contigit auras, iempore durefcat;}

Experientia nunc falfi convincit, ad oculum quippe diligentiffimus $P$. Boccone, qui Coraliorum Pifcationi in canali, Calibriam a Sicilia dift:nguente, interfuit, in literis ad Alexandrum Narchetti.Pifanum Matbematicum exaratis demonftravit, non minus fub undis quam jupra undas durum et lapideum efje, cortice duntaxat molliet mujcofo (qui tamen facile deraditur) integi. Obfervavit praetcrea vir ingeniofiffimus, quod excipiendae fint ramorum fummicates fubrotundae, quae infla. tae funt et tenerae, fuccumque lacteum parva licet quantitate fundant, lactucae aut 1 ithymali yuodammodo fimilitudine, Extremitates hae five faftis; tumida grandiora non funt Ribefia aut Berberis baccis, neque apud hiftoriae naturalis friptores defcripta aut depicta reperiuntur, qquandoquidem in Coralio ex Aquis extrahendo non fatis diligentes et eduti fuere. Ipfe enim obfervando didicit, Corallium retibus implicitum teneras fuas extremitates, ad abrumpendum proniffimas, plerumque amittere. Item P. Boccone cruftam tatraream Corallium integen. tem, in rubro Coralio rubram effe, in alboalbam annotavit, quin et fub crufta exteriore plures rugas feu fulcos ad extremitates praedictas termi. natas cerni, ubi cellulae quaedam obfervantur. In extremitatum autem circuitu clariffime dilcernuntur complures pori feu foramina exigua fiellata, quae in omnibus aliis partibus ad pedem usque habentur. Pororum nomine intelligit notas quasdam in 7. aut 8. fiffuras divifas, quae omnes fimul feellam efformant, nudo etiam oculo absque micro. fopio conf́piciendam, quas ramorum productioni infervire credit. Extremitates rotundas fupradidas curiofus examinans, et unguibus 
rumpens, plerasque omnes invenit in fex cellulas diftinchas, humore quodam albo et pingui repletas, fapo:e acri cum aliqua adfritione ad Piperis et Caftaneaé faporem accedente, qui in recens e mari extracto Coralio manifefte fentitur, in exficcato evanefcit, adfrictione tantum refidua. Succus, quem diximus, talfeus intra fex circiter horas, poltquam Coralium e mari extractum eft, ficcelicit, et colorem mutat. Ilte ipfe fuccus lacteus five Coraliorum fpermaticus per eorum Canalicu. los extrufus, qualequale etiam corpus contactu ferit, illis adnafcitur, hine rupibus non tantum et faxis agglutinata Coralia, fed a Pifcatoribus extrahuntur, offa, lateres, tabulae ligneae, ferramenta a liaque coraliis confecta. Sic fagacifimus naturae forutator Kircherus rupis integrae partem in Mufei rarioribus obfervavit, e profundo maris extractam, totam coraliis obfitam, cui varia Conchyliorum adtnatafunt; in hac rupe partim e concava Conchyliorum parte, etalicrum convexa, partim vero ex ipfa foliditate faxea erumpunt coralia, Vid, ejus mund. fu'bterr. L.g. SeC. 3.c. G. et Muf. P. II. c. VIII. Sic A1. Dux Hetruriae Pifis in Gazophylacio habet cranium bumanum, equo Caraiina planta excreviffe ppetatur. Sic in eminentiffimi Cardinalıs Barbarini Gazophylacio Coralium, tandem in Myricae affinem Plantain defmens invenitur; quin e Delpbini duroCorio Coralia propullularunt. Sed tempus elt, ut vela contráhendồ a Coralii Pifcatione et genefi ad Auctoris noftri tabulam reditum paremus, Siltit hic primo CORALLIVAI RVBICV N.DISSI$M V M$, intenfioris nempe rubedinis qualis cocci, figura autem eft arborea multis ramistortuofis, qui rurfus in alios minores divaricantur. Citat hunc noltrum Auctorem in recenfione rubicundiffimi hujus Coralii Excell. Turnefort. Infitt. Rei Herb. Claff. XVH. Gen. V. pag. 572. nec figura nultum a noftra abludit, nifi quod difci fgulini limbo adnatum fit, quod in Mufeo fuo affervat modo laudacus Furnefortius.

CORALIV II ALBISSIATV M quod rubicundifimo fubjungit, non eft verum Coralium album, quippeilluda rubro non nifi colore d.ffert, duritie fuperat et carius venditur. Hocautem Auctoris noftri eft Coralium album majus officinarum oculat um $F$. B. cet primo fatimintuitu patet; illud elegantifime quoque depictum reperies in AIufeo Gottmaldiano Tab. de Corall. IH. Fig.IV.

CORALIl MAXIAIVS TRVNCVS videtur effe Coralio affi nis Portus megnus $\mathcal{F}$. B. five ALAdreporamaximaraborea Turnefortii, et Paromagno Imper at. Exhiber quoque hoc Coralium porefum ex mari Tabraca a latumP. Buonanni in Mufeo.Kircher.Claff. VIII.n.4. Truncus enim circaradicem craffitudine fere eft brachii humani. Aft cun Co-

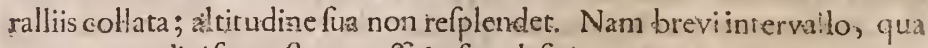
truncorum divifura eft, a crafintie fua deficir atque minuitur; neque enim alte anturgit. Terminatur in germina craflitudine digirali. Cir ca truncos:folidus eft inftar Coralii, at ultimi ramiadmodum porofi funt 


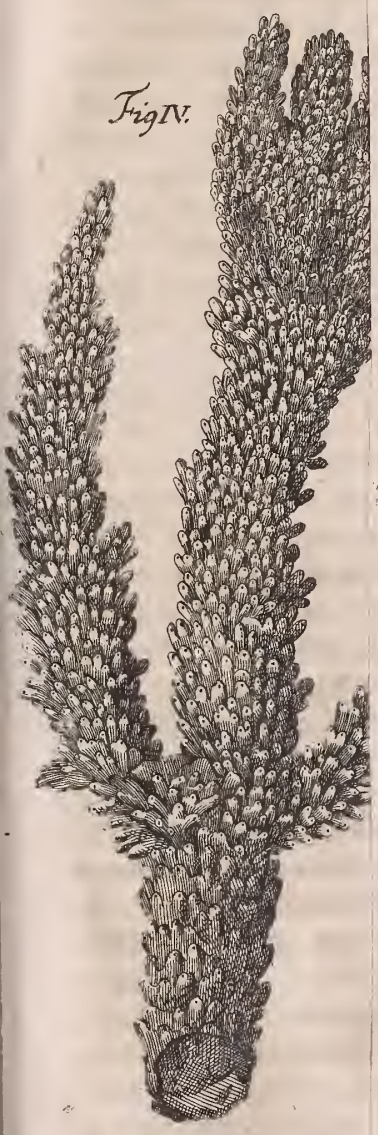





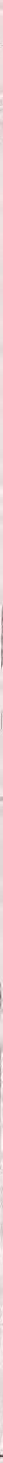




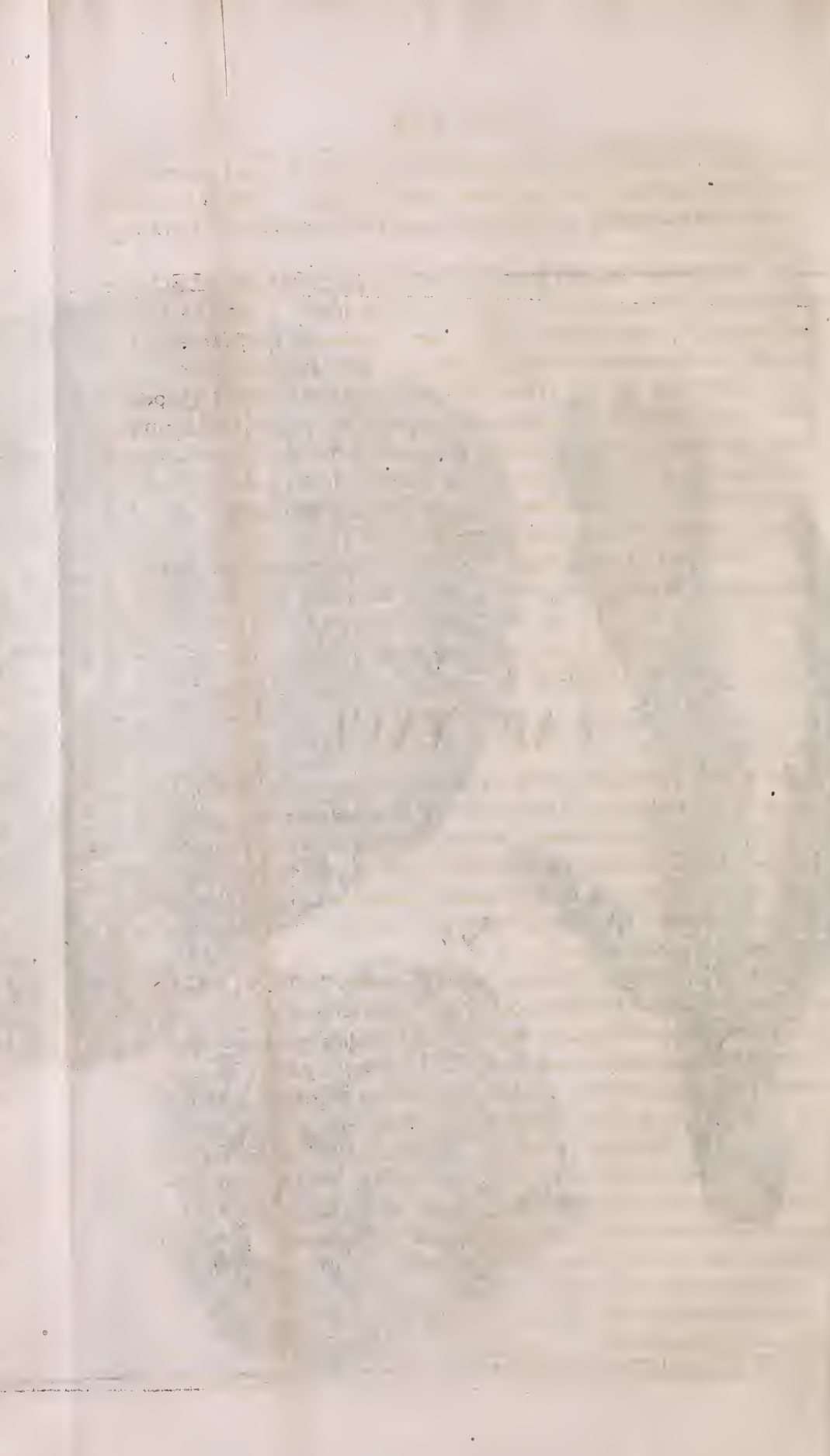


et fragiles. Color ei albus, fuperficies rugofa et ftellata, caeterasque obtinet conditione, poris in genere tribui folitas. Annon Coralium verruco izm maximum indefeffinaturae myfae Gesneri de Fig. lapid.pag. I32. 133 .

CORALIV MI INTERDISTINCTO RVBRO ET ALBO CO. LORE non ubique occurrit et rarioris commatis. Hinc a Cl. Turne-, fortio quoque, citato Auttore noftro, inter Coraliorum fpecies recenfetur. Vocatur ab Aldrovando in M1ufeo Metall. p. 287. Erythrolevcon.

CORALIV M IAMAATVRVA CINEREO COLORE potius Poris quam Coraliis accenlendum, foraminibus quippe ftelliformibus hinc inde obvium, colore quoque a Coraliis differens, quoad color em. cinereum convenit cum Lithophy to cinereo rugofo J. B. Exhibuit tamen Coralium cinereum ramofum et monoclonon unico longo caule $\mathrm{Cl}$. Rumphius Ephem. Nat. Curiof. Dec. II. Ann. III. p.77.78.

CORALIV $M$ quoque INDICV $M$ ob poros, quos continet copiofiores, Mladrepor ae potius quam Coralii progenies Qui veterum placitis de Coraliisdelect atur, adeat Ganfii Hiftoriam Coraliorum.Kirchmaieri diff. de Coraliis A.1665. Witteb. et Linffii Jen. 1675. de Coralio juxtadudum Ptiniihabitam.

\section{TAB. XXVI.}

Fig. I. TOcatur ab D.M.R. Beslero in Gazophylacio Alaffa Coralloides albicans porofa, maris fluduationem egregie repraefent. tans; eftque revera Aftroires undulatus major politis, quem Pl. Rev. Pater Boccone dans les Recherches et obfervations naturelles luettr. YVII P. J4I. defcripfit, quemque Mercatus in Theatr. Metal. lic Nanufcripto Lapidem Lunbricalem vocat. An Batu Parudan Append. Muf. Mufeorum p. 16.

Fig. II. Elt fecundum nofirum Auttorem PLACENT A CORAL LOIDES ALBICANS SINV OSA, et fi accuratius infpiciatur, erit quoque Lapis aftroites undularus majornondzm politus modo laudati Boccone, qui Fafciculumr rariorum Baflii Besteri noftri notat, quod Aftroi. tem undulatum nominet quidem, fed neque depirgat, neque defcribat, vid. loc. cit p. 144. Olear.Muf.Tab.34. N. 1.

Fig. III. Vocatur FY NGVS LAP1DOSYS ab Auctorenoftro, et cft revera elegantifimusille Fungis, quem e Nilo et mari Indico ad Cel. Clufium detulit Mercator Amitelodamenfis, Exot.Libr. VI.cap. 10. p. 12 5. et licet magnitudine a Clufiano differat, eft tamen pariter faxeus et candicans fuperna parte ab umbilico ad circumferentiam, multis profundis ftriis oblique quodammodo excurrentibus ornatus; convenit quoque in reliquis cum Clufiano Fungite, ut nullum fuperfit dubium, unum efle eundemque. Fungum binc Alcyonits potius accenfendum putat P. Butonanni in Mufeo Kircheriano: nam etfi fungifiguramimita. 
tur, fructura tamen differt, tham rimulae five friae, quae a Centro ad circumferentiam in fungis funt, femper in parte inferiori humüm refpicutint, e qua enafcuntur; in hoc autem partem fuperiorem exornant. Clail. Vili. n. 22. Ejus quoque Icon in Nafeo Otear. Tab.37. n. 2 , in Gottioaldiano Mufeo Iab. I. Capf. I. omnium accuratifime depi* Etus eft. - \& ar :

Figl IV. Defcribitur a Beslero: Truncus elegans Jubftantiae lapideae, Fruticem Corallii albi reprae/entans, minuitifimis puintis et poro fitatibus foatens, conum in fummitate triplicem producens. Nifi me tamen fallunt ominia, videtur effe Arbufcula Coralloides Pifoñis Fijt. Bra. fil.natur. et medic. Libr: IV. cap. 68. Curang Bonga Append. Mufa Miif. p. IIs. et non multum differt a Planta Saxea Abrotoneide Clufii, cujus jam timentio injecta. Cerutiss in Alufeo Calceolariano elegantifime et defcripfit et figuram dedit. Excell. Gottraldus in MInfeo Tab. III, Corall. Fig. 2, et 3. hánc Plantàm áccuratiflima quoque delineatione expreflit. Vid. pariter Excẹll. Langidin Hiflor. Jap. Figur, p. 57. et Muf. - 110 card.libr.1I.p.1.8\%.

\section{TAB. XXVII.}

$\mathrm{N}$

Ondum productionum Coralloidum finis, dolendum enim quam. maxime, omnem in his Tabulis Lapidum deeffe ordinem, nullum felectum, ut methodus illa accuratiflima, quam viri in ftudio hoc ingeniofiffimi, Aldròdidus, Lifterus, Luydius, Scheuchzerus, Langius, Beieris aliogucue nobis' exhibuere, obfervari minime queat. Occurrit hac in Tabülx, puit Beslerit noitri mortem certe exarata, CORALLINA MARINA, non illa quidem officinarum, five Mufcus matiomus, vel

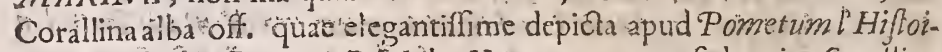
re generale des Drogues P. I. Libr. V. c 1 8.p. 1052 . Fed potius Corallina fitulofa fragilis $\mathcal{G} . \mathscr{B}$. quae numerofos progignit cauliculos, cinereo filo craffiori pares, fuperficie crifpa, feinmum faccharo conditorum, circlelaribus zonis denfis praecineta, fragilis admodum er levi d gitorum attritu in arenam folubilis, fapore fatuo. Annon Corallina Hitpitrioides $\mathrm{Cl}$. Welfebii Hecitoft. I. obr. XVII.

LAPIS CORALOIDES ALBVS viderureffe Corallium album fragile ramufcillis aequalibus contignis dumofin Alorif. Hij. Oxon.P. 3. p. 656. Set. Is.

FVNGVS TIARINVS LAPIDEVS is ipfe Fungus Niloticus, et quidem altera ejers pars, cui pediculus brevis et crailitilculus adhaeret, qui a fopulo aut perra abruptus videtur; ; de qquo fingo in Tab. pracied. Fig. 3.

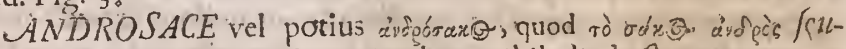
tum viri praefentet. Plantula marina haec nihil aliurd oft, quam congeries fungulorum cumfuis Pileolis visl foutulis bumore Coralino in miri Juper 


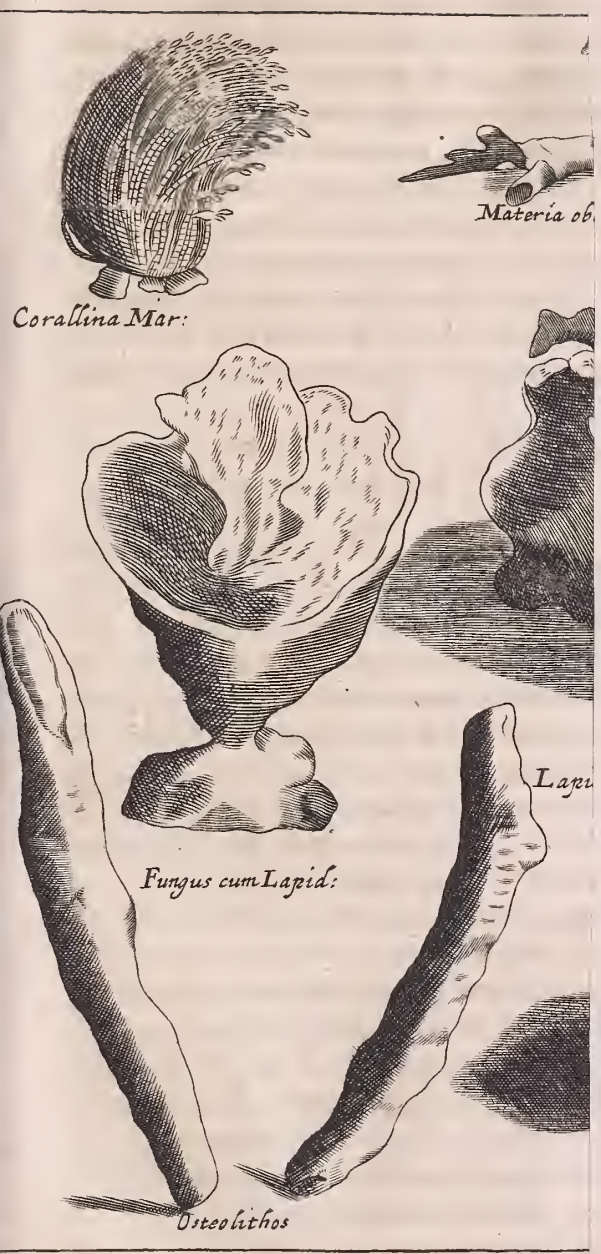





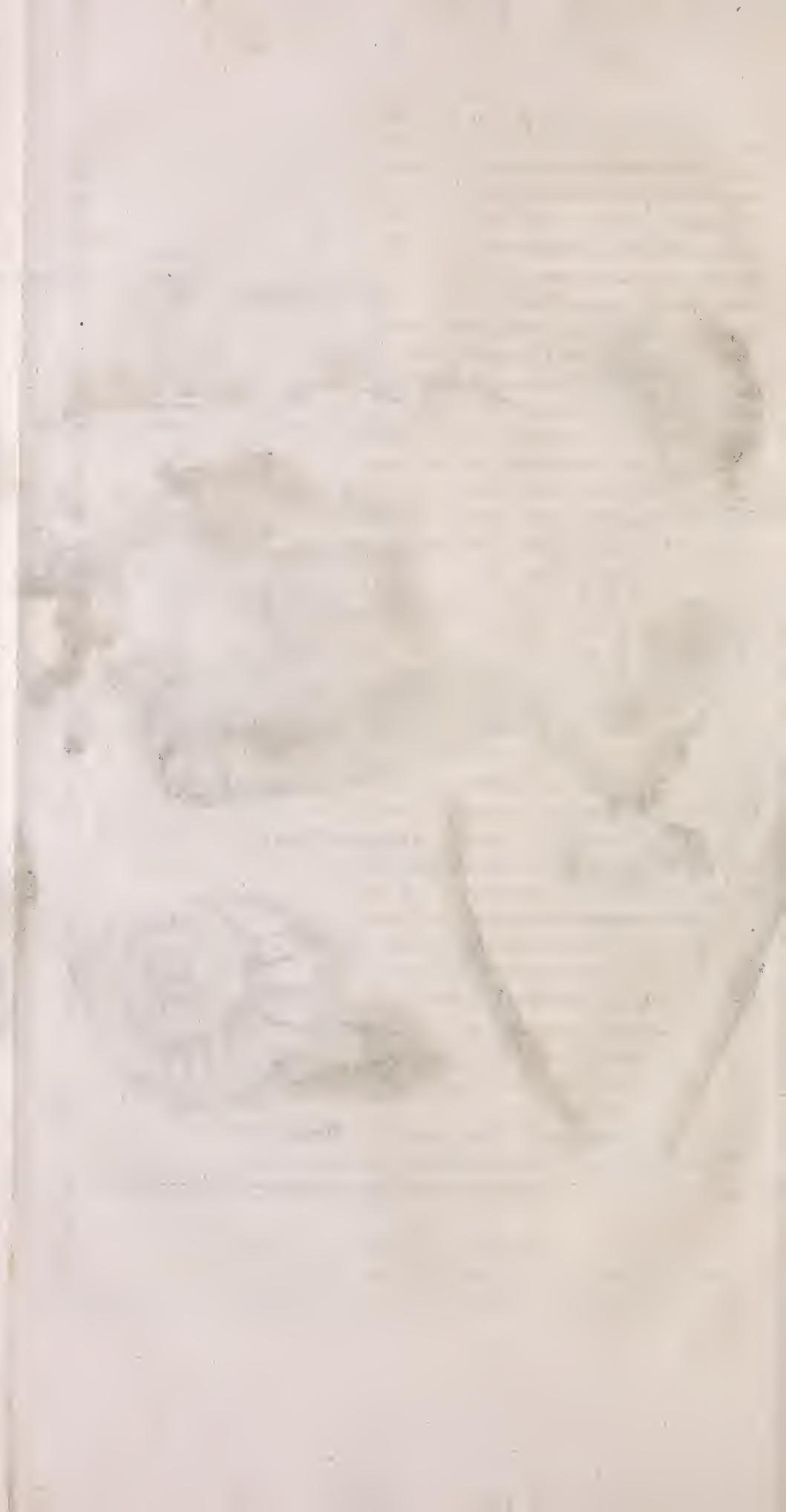


Juperpetram, concham, (ut in noftra hac tabula) et alias res induratorum. Lobelius in Adverf.Stirp.p. 165. optime defcripfit, et Cotyle don marinum vocat. Ipli videcur effe genere plantarum earum, quas parafiticas feftive quis dixerit, propterea quia non nifi aliena quadravefcuntur, cibo et difco; aliis, uti modo diximus, rebus innatae; HaecLobelius, qui plurima adhuc circa loca, ubi capiuntur, habet lectu non indigna. Cl. Wormius credit hanc plantulam marinam, illam iplam efle Fungimappam ab indefelfo naturae forutatore $M$. Aur. Severino in EpiAtola ad Joh. Simonema Gratia defcriptam, fed aliter plane fentiet, qui lapidem Fungimappam exhibentem, in!pexerit: ftipites enim efiliculo vegetationi fubfrato affurgentes, unica Mappa teguntur omnes, cum in Androface, unusquisque Funguli pedicellus pileolo fuo tegatur, uti ex Figura, EpiftolaeSeverini praefixa, patet. Nec ex lapide Lyncurio. five Fungifero prodeuntes funguli funt, de quibus in Epiftola ad Cl. Alich. Rupert. Beslerum fufus egit, quem modo Laudavimus, Tarfigena Severinus, quos fungos efculentos cum fubftrato lapide aeri incidi curavit Illultr. Academ. Nat. Curiof. Praefes Tertius, immortalis gloriae Volkammerus, Dec.II. Ann. III. obferv.1 16. Talem lapidem (quâlem Carol. Avantius eruditiff. in Coenam Bapt. Fier. Not. p. 47. nomine FungiLyncuriidefcripfir) cernere mihi licuit in horto inftructilfmo, Hesperid. Noriberg. Auctoris nobiliff. J. C. Volkammeri.

MIATERIA OBCRVSTATA V ARIA IN FONTE POETARVAI FRANCOFVRTI AD ODERAAI. Notorium eft, plurimos fontes ex illo faxi calcarii genere, quod cognatum eft gyplo, falire, et ubi erumpunt, ochra quadam, et vario colore cuncta inficere, ac lapidem gignere ftalactiten, figura extus varia, ac zonis intus et cruftis ob coloris atque ftructurae convenientiam et pulchritudinem, oculos pariter et animum pafcentibus diftinctum. Fontem autem Pö̈tarum Francofurti ad Oderam effe illum, quem Thurneiffer. Libr. VII. de Aqu, mineral. et metall. p. 304. memorat, videntur probare incruftata cochlea et ligni fruftulum ab Auctore noftro delineatum; Sic cnim modo citarus Thurneiferus in lingua vernacula : 23 ir wollen Deffen/ fo auffer

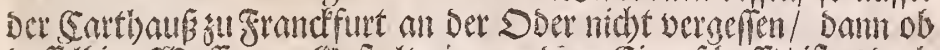

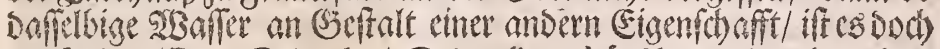

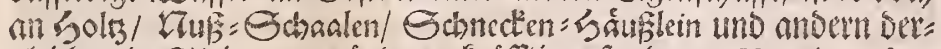
gleichen in Stein su berandern/ fraffitig erfunben. Hoc de eodem confirmat fonte Excell. Becmannus de Memorand. Francof. ct quidem brevi urb. Fr ancof. defcript.c.3.p.m. 34. qui infuper addit, eum plures adhuc circa urbem hanc fontes incruftandi vi praeditos detexiffe, plurimaque ibidem reperiri.

OSTEOCOLLA tradit; quae cum Auctor in Tabula noftra quoque exhibeat, illa, quae laudatiflimus vir Editori Ador. Pbilofoph. Anno 1668. Menf. Septembr. n. 4. communicavit, breviter excerpendu duxi : Ofteocolla nempe crefcere in folo arenofo, fed non fa- 
bulofo, nunquam in terra pingui argillofave terra. Non dequalis craf. fitiei funt rami inflar plantarum crefcentium fupra terrae fuperficiem; ad duplam hominis alititudinem radicatur radicesque frequentius direEtae ad perpendiculum, rarius per latera diffundit ramufculos. Locus ubi Ofteocollacrejcunt, inter fubflavam arenam albicans neque pinguior arena apparet, vocata ab iis, quorum opera in eo invefligando utuntur, Flos hujus fubftantiae. Ofteocollum ftatim erutum molle efl, fria. bile tamen magis quam duttile; nam Jemihoram vel paulo amplius foli expofitum, illam acquirit duritiem, qua venale in officinis proftat. Species Margae videtur, cujus ingens in vicinia Ofteocolli copia. Callfa divifionis in tot ramos a radicibus, fubter terra fe paffim diffundentibus, provenire autumat; inde eft, quod per Ofteocollum femper por. rigatur media linecu obfcura, quae indubie radicis pars; addit alia quoque, quae attentionem merentur, a nobis brevitatis amore praetermittenda. Plura enim de re ubique obvia dicere non licet, Ejusdem commatis videntur

OSTEOLITHI, vel potius Holoftei dicendi, cum non differant ferme ab Olteocollo, nifi quod nulla cavitate fint praediti, fed toti repleti materia friabili ; imo reperit quoque Excell. Becmanmus l.c. Ofteocollon penitus non cavum, ubi obfervavit, illud non adhaefiffe circum craffae radici, quin potius femet collegiffe circum complures fibrastenues, unde etiam ejusmodi Ofteocollon adeptum fuerat poros per totam longitudinem, fed non cavitatem, prout alterum Oftéocollon cavum. Olteocollo fimiles vel certe non multum diftant Coni Norici, de quibus immortalis Welfchius Hecatoft.I. p. 86 , forte Geodes figura oblonga pecie flercoris canini. de quo vid. Excell. Beierus in Oryttogr. Nor. p. 33.

HOPLITES CVM LAPIDE eft cornu Ammonis matrici adhaerens, quod cum ferrea fit armatura, Hoplites vocatur, de quo lapide cum Tab. 34. agere decreverimus, hic calamo filentium imponimus.

FVNGVS CVM LAPIDE videtur concretumillud effe, guod fub fpongiae elegantis nomine defcripfit Exot. Libr. VI. cap.XI. Cl.Clufius, inhaeret enim non minus ac ille lapidi fuo duriffimo nigroque. Fungus five lapidea fpongia vel floris exprimit imaginem vel infundibulum, nam cavus eft, in infima, qua faxo inhaeret, parte valde anguftus. Confer $\mathrm{Cl}$. Wormium Muf.p. 237. Eft et fungi lapidei fpecies Szjamur taxis dicta Javanis, Malayis autem Tfiandaman Karang, five fungus lapideus infundibiliformis, tuberi regio innafcens, ufu medico pollens, de quo Herbertde Jäger in Epift.III.ad Rumphium et Excell. Valent. Mul.Muf. T. II. p. 96. De Lapide Filtro Vid Excell. Valentini in Differt. pecul. Gieflae A,1702. habita. 


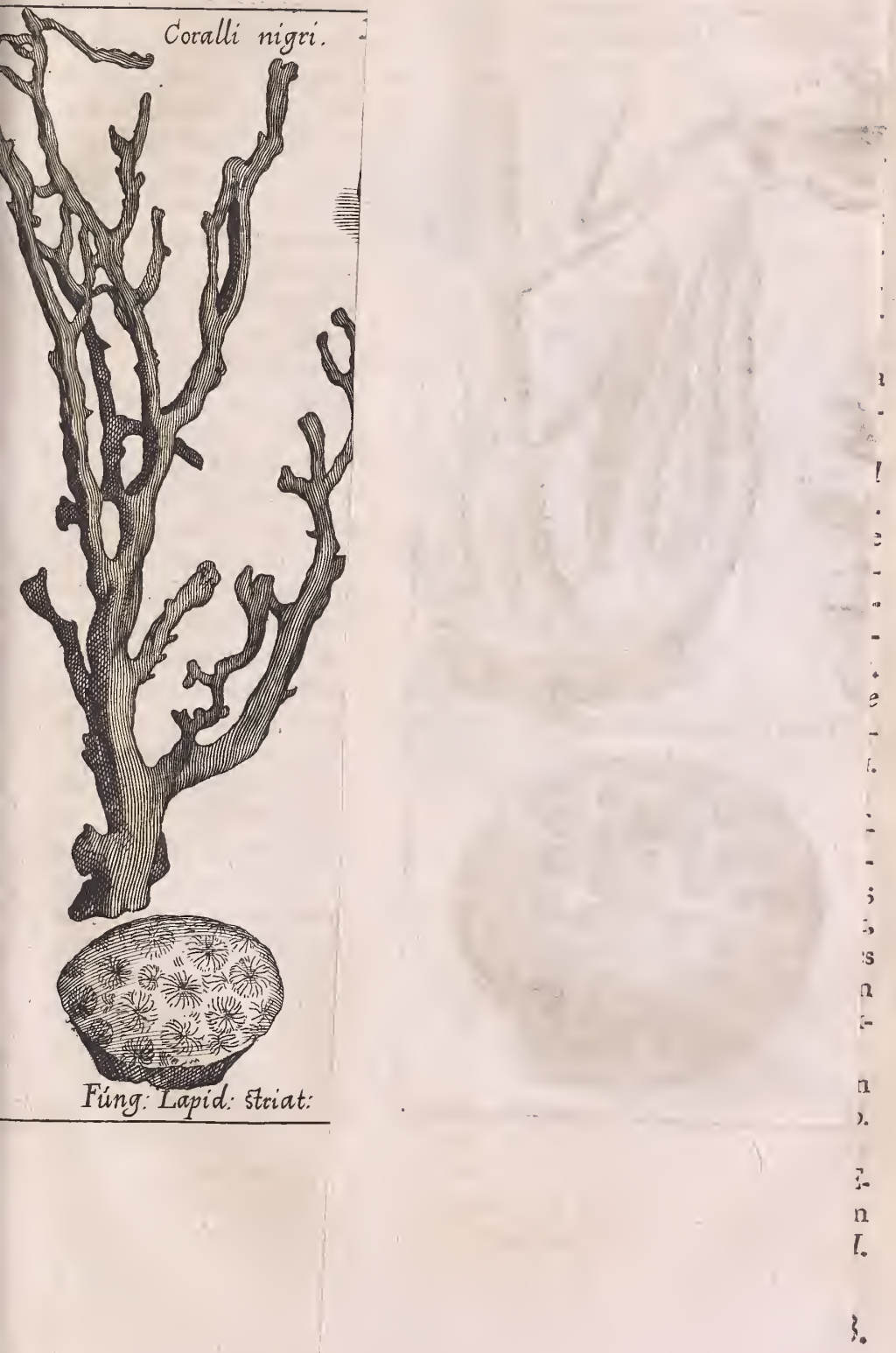





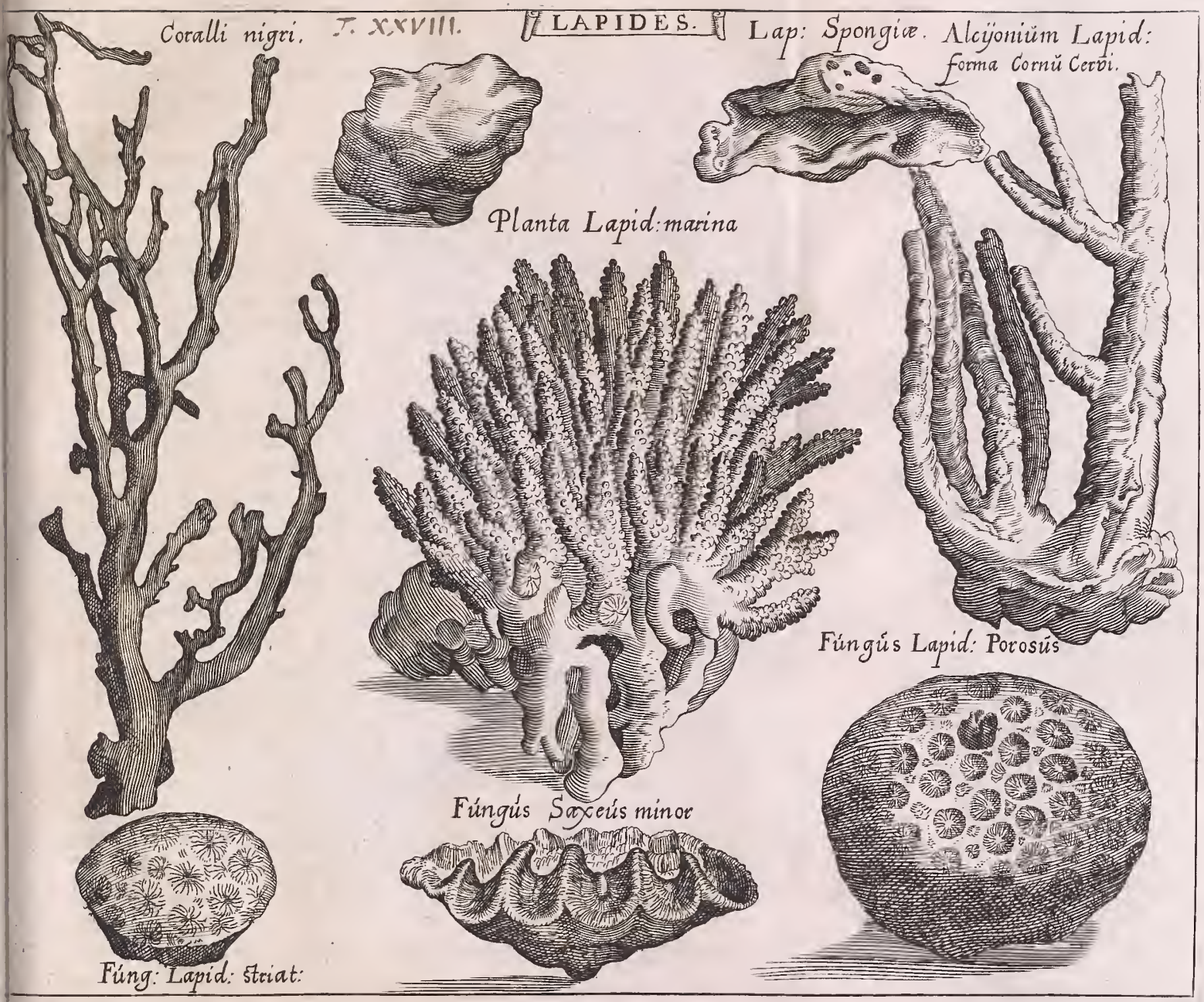




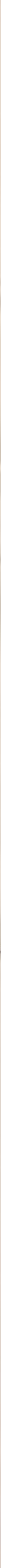




\section{TAB. XXVIII.}

TAbula haec poft tot Coralia et coralloides productiones tandem CORALIV MI NIGRV M profert, cujus Tab. XXV. ubi variae Coraliorum fpecies recenfitae et delineatae, mentio injicienda fuiffet, fed dolendum poft Besleri fata incifis Lapidum Tabulis nullum plane ordinem ineffe. Et quidem Coralliumnigrum in Tabula noftra delineatum, quod concernit, neque Coralium nigrum verum eft, quod a corallio rubro non nifi colore differt, pretiique rubro majoris, neque Antipathes five Pfeudo-Corallium nigrum, neque unum exillis nigriCo.. rallii, five Acarbabar Poborlpeciebus, in Appendic. Mul. Mul. p. 107. feqq. defcriptum, fed artificiale quid, nec nomine nec defcriptione, nedum delineatione dignum.

PLANTA LAPIDEA MARINA jam Tab. XXVI. defcripta eft Carang Bonga Append. Mluf. Muf. p. 1i s. five Planta Saxea Abro. tanoides Clufii.

ALCYONIVM LAPIDEVMI FORMA CORNV CERVI maxime convenit cumillo, a Cl Clufio Exot. Libr. VI. cap XII.pag. I 26. defcripto, nifi quod cranii loco, cui cornua Cervina lapidea adhaefille videbantur, in noftro lapis confpicitur; in ranos caeterum inftar Clufiani fparlum, inferna parte denlo corpore et craffo fpongiolo tamen fa. poris falf. Videtur efle Planta tophaceamarina fimile al Corallo bianco con alcune groffi rami tuberofi, rotondi, inequali e firiati $E c$. EC. Eftremita di lei pedale forma, una bafe rotonda e tuberofa come nelle Corne de cervi, con le quali parimente quelta Pianta ba qualque fimilitudine difigura Vid. Cl. Legatonel Muf. Coppian, Libr. 2. cap. 24. p. 13 r. Conful. Jll. Rajus Hiff. Plant. T.I. Libr.II.c. I 3. P. 82.

FVNGVS SAXEVS MINOR MIARTNVS, qui compreffus floris formam quodammodo exprimit, exacte cum Clufiana defcriptione, quoad longitudinem, latitudinem et altitudinem convenit; ftriae, quae externa parte a pediculo ad circumferentiam excurrunt, non funt valde conlpicuae, quae autem in parte interna profundiores et magis confpicuae, fimul etiam in medio coëuntes, quemadmodum et figura aeri incifa accuratius multo, quam in Clufiano fchemate, exprefla.

FVNGVS L APIDEVS POROSVS ad Aftroites referendus, in Muf. pariter Olearii Gottdorfiano depictus. Sed cum de Afroitibus Tab. XXXVI. agere decreverimus, abftinendum nobis toc loco.

SPONGIA IN LAPIDEANI SVBSTANTIAN CONCRE. $T A$, lapis eft cavus oris inaequalibus finuofis in partem internam reflexis. Spongites varios produxit Excell. Welfchius Hecatoft. I. pag. 30. 


\section{TAB. XXIX.}

Q Vae Auctor nofter hac Tabula exhibet, proletaria oppido funt, ideoque illis non diutius immorari animus, cum paffim non tantum in omnibus officinis Pharmacevticis proftent, fed et reliquis artis falutaris et Hiftoriac naturalis paene ignaris nota fint. Et $H A E M A$. TITE $M$ quod concernit, cum ex ejus minera ferrum excoquatur, et Magnes, (extra controverfiam martialis profapiae) per calcinationemin haematitem convertatur, imo magnetis inftar, licet non adeo potenter, ferrum trahat, omnino ad martialia referri debet; quamvis de Saturno quoque participet, hinc in fodinis, e quibus fannum et plumbum album excoquitur, neben Den Brbitter=Ssangen/ und unter Denfelben/Albino tefte reperitur, ac ex artefacto Haematite, capite nempe mortuo florum, ex limatura ferri plumbo et Sale ammoniaco fublimatorum, et vi emetica Saccharo Saturnianaloga patet. Quem Auctor nofter Haematitem vocat, verae metallicae eft fubftantiae, inftar ligni petrefacti, vel Antimonii, ftrias vel fibras oblongas habens, et acuum inftar acutas, colore faturaterubro, nulla admifta forde aut venis intermediis. Stupendae foepius molis eft, ut fruftum Centum et $X$ Librarum ponderis apud folertiffimum DN. Dietericum intucri licuerit. Poft Aldrovandum in Muf. Metallico, Caefum de mineralibus, Bö̈tum a Boot de Gemm. et lap, aliosque conful. imprimis Praefidem Academ. Nat. Curiof. primum et Fundatorem Baujchium in fchediafm. de Haematite.

Quem SPVRIV $M$ nominat HAEMATITEM AuAor SCHI$S T V$ Selt, quicum facile in longas rectasqve laminas atro- rubentes findi poteft, Schifus Germ, fotwarset unt fdiefritbter $B$ lut = Etcin nominatur, de quo lapide peculiari Differt. differuit modo laudatus Excell. Baufchius.

Succedit Haematiti MAGNES martialis pariter profapiae, inque haematitem per calcinationem redigendus, qui ob mirabilem virturem, inter reliqua lapidum genera facile palmam obtinet, unde vaftis voluminibus confuribendis occafionem praebuit, quos inter friptores primus de co nugari defit Gilbertus Anglus, qui Harveo tefte, experimentis de Magnete fadis quinquaginta nummorum millia confump/it; quem poltea lecuti Cabaeus, Zuccbius, Grandamicus, et in diffufo opere folertifimus Kircberus, ac Leotaudus in Magnetologia, in qua, fi titulo fides, exponitur nova de magneticis Pbilofophia. Illuftrifl. Baco de Verulamio inter pofthuma de Niagnete quoque inquifitionem reliquit, inter Belgas celeberrimus Navarchus Laur. Real, et ante annosaliquot mole quidem exiguum, fed fi experimentorum et hypothefum felectum fpe. Etes, utilifimum de Magnete edidit librum Exc. Zningerus; nec contemnendus liber Callice infcriptus: Traité de l'Ainant par Mr. $D^{* * *}$ quodopufculum Germanice verfum, inlertum Tom. III. MLuf. MIuf. Ex. 


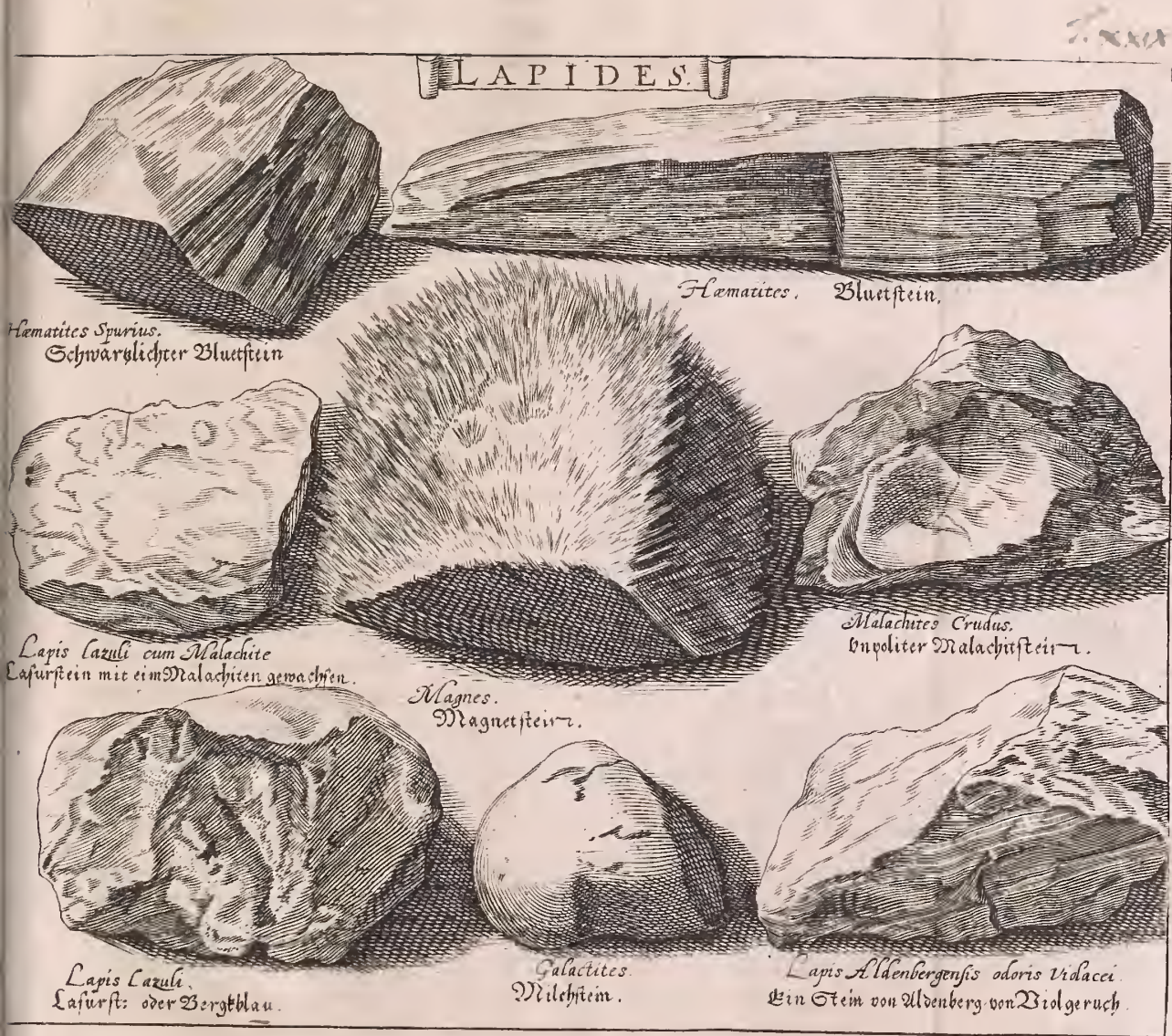



cell. Valentini. Expofuere lapidis hujus efficaciam differtationibus Academicis. J. C. Ludekus Wirteb. 1634; Salzmann. Argert. 1648;

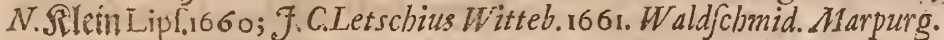
I683. imprimis Cl: F. F. Spenerus de Magnete errores variorum detexit in differt. Babira Lip r. I 688. Quis igitur nobis vitio vertet, fi poft tot volumina jam con/cripta, fileamus de Magnete.

MALACHITES CRVDVS ad Jafpidis vel Prafi fpecies referendus, lapis viridis et opacus inftar foliorum Malvae, unde Graecum no* men fluxit, albas hábet venas nofter, maculisque inficitur nigricantibus, et ut e Scheda affixa apparet,Auetori noftro e Sylva Hercynia miflus; minime ideoque cum Orientalibus comparandus. Licet inter Gemmas ób afpétum noñ admodum gratum huic lapidi nullus locus, ab officinis tamen pharnacevticis minime excludendus, modo vera forent, quae de. illocecinit Marbodaeus:
Infantum cunas virtute fra malachites
Protegit, etcafus abigit quoscunque finiftros,
Ne teneris membrispars poffit iniqua nocere.

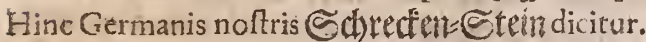

LAPIS LAZVLI CVM MIALACHITE, quem Auctor exhibet, videtur effe tertium genus Malachitae Anfelm, Boëtiia Boot, cuico. lor caeruleus diftincte intermixtus.

$L A P I S L A Z V L I$ vel potius $L A Z Y R I$, Árabice enim Azur" vocatur et Germ. Safue:Ctem/ videtur efic Plinii Sapphirus, quippe haec ei opaca gemma aureis punct:s collucens, id quod in Lapidem noftrum quadrat, qui Lapis eft durus, colore florum Cyani caerulco, pun. ctulis auteis ac flammulis exornatus; Has aureas micas nonnulli verum credidere aurum, crijus extractionem propofuere Kircher. in Mundo Jubterr. T.11. Libr.111. Sect.IV.cap;3. et Libr. X11. Set. V. P. 111.cap.4. Propof. 12. Excell. Langius Lipf de Mat. Mled. p. 316 . ideoque lapidis hujus differentia orta, nempe in ig nem immiffione, ubi in Orientali f́in. tillulae illac aureae pulchriores redduntur, in Germanico fiveignobilio. ri evanefcere dicuntur. Strobelbergertus tamen de Confect. Alkerminunquam tale quid fe deprehendiffe ingenue faflits eft, fed omnes, qui ignis perfenfere vim, feititillas illas non aureas, fed marcafitae potius flores, amifife. Aft Strobelbergero Pharmacopa eorum nonnulli contradicunt, inque Tranfylvano et Hungarico lapide LaLuli revera Auri miculas exiftere et remanere ftatuunt, penes quos fidesfit; hancque rationem fübelfe credo, quod Confectionem Alkermes, feu cordiale, uti vocant, ins grediatur cun emetica tamen vis, (quam ex acrariis metallifodinis, ubi effoditur, contrahit) ac purrgans manifefte in illo deprehendatur, et co= lore Matrem, in cujus finu natus, prodat.Confer. Excell.Pechlin. de Purg. c. 22. et Ephem. Nat. Curiof. Dec. 11. Ann.V.obferv. 37. Scbol. et de Vi eleitrica Lapidis hujus Dec, I. Ann.VI.etVII. obferv. 218. Differt. pe- 
culiari hunc Lapidem examini fubjecit Argentoratenfium quondam Aefculapius Sebizius, imprefia Argent. An. 1668.

Quem Auctor nofter GALACTTTEN exhibuit, Germ. 9) (illd): Sithin nominatur, eo quod lacteum fuccum, cineritii licet coloris fit, emirtat, dulcisque exiftat, ad Lac Lunae five Agaricusn mineralem referendus, quem cum elegantifima difputatione Kilonii Anno $1667 . \mathrm{im}$ prefla lucipublicae cxpofuerit Maximus Major, Purpurae laciniam affucre non audeo. Vid. quoque Lachmund. Oryctogr. Hildes. p. 18.

LAPIS ALDENBERGENSIS ODOR:S VIOLACEI; five Tolithos Scbrenkfeldii; nec enim omni odore deftituuntur lapides, odorenque alii gratum fundunt, alii ingratum, telte Anf. Bö̈tio de Gemm.et Lapid. L. 1. cap.6. pag. 21. Sic Mofchi odorem Kabet lapis Marienbergius, qui in vena divi Fabiani et Sebaftianirepertu datur. Serpilli odorem habet Thuringius, qui prope Beuchlingam invenitur. Mufti odorem Zebticius Ophites. Vinum olet Echites apud Solinum. Ingratum odorem cornu ulti habet Enofteus. Sulphuris odore gaudent filices illi, ex quibus ignis elicitur. Non igitur mirum, et noftro Aldenbergico inefle odorem violaceum, licet Bö̈tio fufpitio orta, hujusmodiodorem a mufco quodam eluteoviridi lapidiadhaerente, provenifle, quo detracto, lapidem nullum amplius odorem fparfiffe, quod ex Agricola et Schrenkfeldio de Silef. Folfil.p. 3 82. haufit Bö̈tius. Afferto tamen huic Experientia contradicit; nec in noftra ulli mufci adhaerentis veltigia. Candidiflimus Gesmerus refert, ipfum a Georgio Fabricio jam olim Lapidem odoris violacei accepiffe. Et Kentmannus Geodem illum Aldenbergicum cinereum violam olentem Germ. Riolen ober Benliden = Stein / inter lapides odoratos recenfet: in

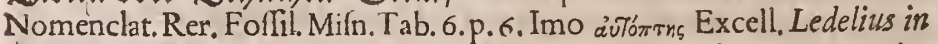
Mifcell. Acad. N.C. lapidem absque mufco vidiffe, odoremque violaceum in illo deprehendiffe ingenue fatetur; fic in cornubus A mmonis ditionis Scaphufinae odorem hunc violaceum quoque expertus eft Excelt. Wagner. in Hilt. Nat. Helvet. Sect. 6. Art. I. Vid. Dec. II. Ann. VIII. obferv. 2 9. p. 8 1. ubi inprimis Scholion Magnif. Acad. N.C. Praefidis Dn. Scbroeckii, legi meretur.

\section{TAB. XXX.}

$\mathrm{N}$ E actum agere videar $B$. L, monendum duxi, hanc Tabulam to. tam Excell. Baufchium ab Audore noftro mutuo fumfiffe, iploque honorifice nominato, Schediafmati de LAPIDE AETITE confcripto, non tantum intuliffe, fed et quod caput reieft, fingulos, ratione contentorum, loci natalis, figurae, coloris, fuperficiei, magnitudinis, conffftentiae, odoris, faporis et virium defcripfiffe, ut nil paene nobis reliquum, nifi quod Beslerum noftrum notet, illum $B E L E M N I T E M$ GERAIANICF M FLVVIATILEM, Germ. Den SeUtiden 2(oler: 


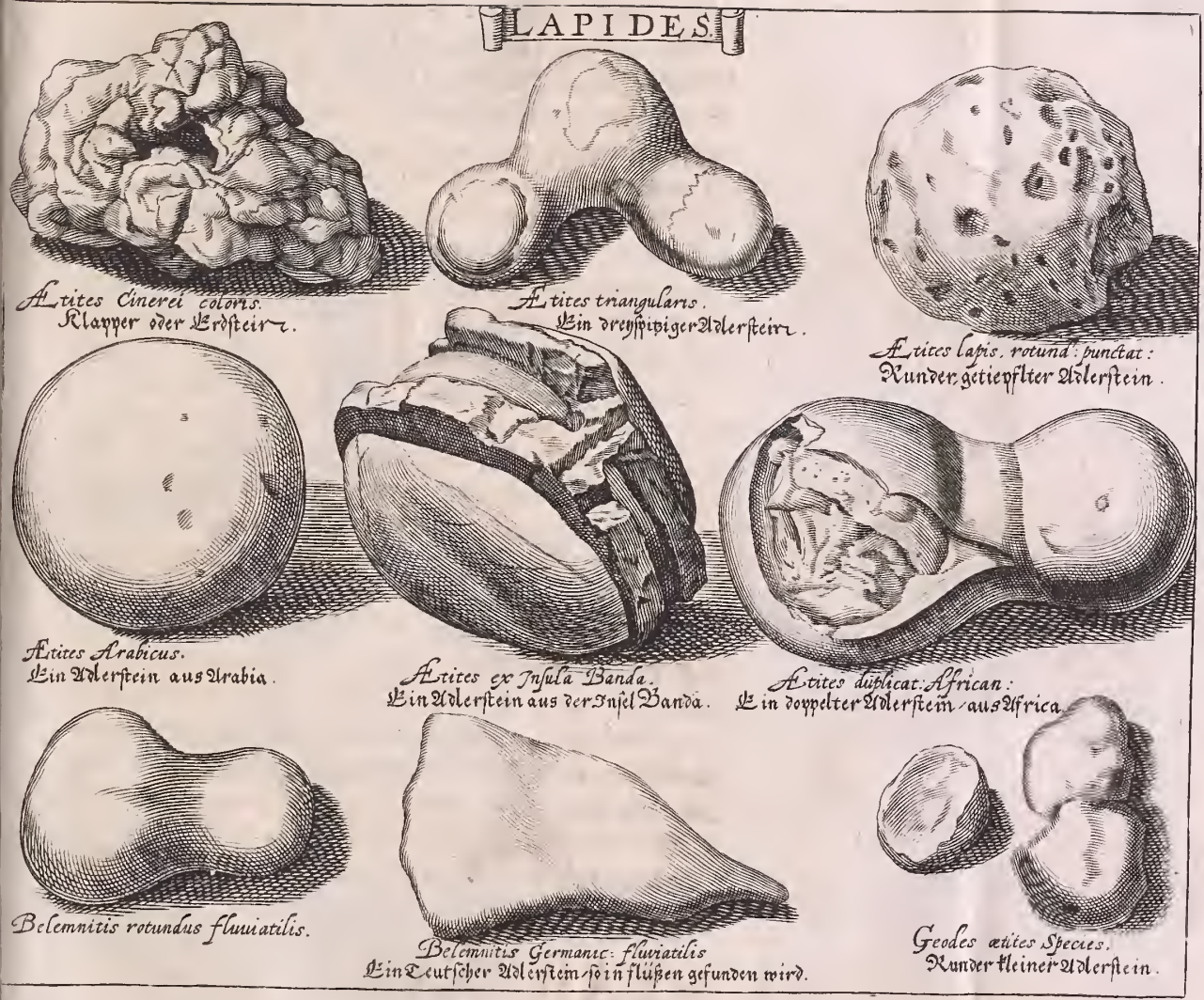




Etein/ /o in fluffen gefunden wirb / et BELEMNITEM ROTVNDVAI FLVVIATILEA1, minus recle belemnites vocaffe, cum belemnites diverfi fint, quod a nobis occafione dactylorum:daeorum ind gitatum. Forte hic lapis Auctoris noftri minus recte denominatus, $\mathbf{E m}$ bydros erit, Aètitis species, quod loco Callimi five lapilli inclufi, aquam contineat, quae intus in eo veluti in ovis liquor, fluctuat; hunc Tapbizfium Plinius vocat; ut fic tres Aëtitis fpecies ab Auldore noftro recer:fitae fuerint; Aetites proprie fic dictus filice vel callimo praegnans, quales fex priores; poftea BELENINITES improprie ab Auliore nc:Atro vocati, potius Enhydri five Taphiufii, et denique GEODES, qui callimi loco terram vel arenam continent. Non autem terra tantum vel Arena, et Ochra item ac cinnabarina terra et bolo rubro repientur, fed putamine quaque ex ferro et Ochra inveftiuntur Aëtites; id quod Aëtite Clivenji probat Excell. Menzelins Pater Ephem. Nat, Curiof.Dec. II. Ann. 6. obf. 46. qui pariter Aetitem filiceum rar:flimum Ejusd. Ann.obferv. 1. pofteaobjerv. IIl. Conchitem Aëtitoidem defcripfit. Excell. Welchius. Hecatoft. 1. p. 53. Aëtiten nucis mo/chatae figurae exhibuit. Vires lapidum horum in praecavendo abortu et partu facilitando, a plurimis Medicis, imprimis frftiviffimo Ammanno, mire labeGactatas reftituere nititur Excell. Albrecbt Eph. N.C. Dec. 11. Ann. IX. $o b f$.70.p.36. Recenfentur Aettites ab Excell. Bajero in Oryctograph. Noric. optime inter eos lapides figuratos, quitales funt Lufu naturae fio gurarum matbensaticarum rotundarum.

\section{TAB. XXXI.}

$\mathrm{D}$

ENTES MAXILLARES LATIDEI nonadmodum rari, plane fimiles habet in Muf. Metall. Aldrorandus pag. 828. Tab.VI. Fig. I. Major. in Mernorial. A. Ser. III.de Foffil. Littor.Kilion. Dentem molarem lapideum vel hominis vel bruti cujuspiam animalis fe poffidere, proxime penes mare, procul a venis metalli et montibus ab iplo repertum teflatur. Odontoides varii recenfentur a Gesnzero de Figur. lapid. et Excell. Langinus quoque odontopetr.zs molares noftris plane non diffimiles exhibet in Hiffor. Lap. Fig. Quod de maxillaribus, illiud pariter de ALIIS DENTIBTS LAPIDEIS, in ima Tabulae hujus parte ab - Audore noftro delineatis, dictum eflo. De maxilla Querfurtenfi $L a-$ pidea Cl. Buttneri Rudera dituviiteffes p. 222 . de dentibus Gigantum confer. Difert. Cl. Hofmanni Jen. Anno 1670. babita de Gigantum offibus c. 2. Solu. 2 .

Vix ovum ovo fimilius ac ConVS PICEA LAPIDEA Strobiliti, five pineumn frülum aemulanti Lapidi apud 11 . Aldrovandum in ,Mufeo Whetallico. p. 829. delineato et defcripto.

TRVNCVS LIGNI E VALLE FOACHIMICA IN LAPIDEM CONverfus inque fodinis, ut Infcriptio oftendit, ibidem Anno 1557 . d.17. 
Febr. repertus et ex aliquot mille orgyiarum profunditate extractus, $t$ dn: tae eft duritiei, ut fi polatur, Jaspidem et colore et duritie a emuletur; qualem pyri truncum lapideum hic loci in aedibus Gencrofiffmae cujusdam faniliae videri mihi contigit, huic quoad omnia fimilem, cujus fuftulum ab artifice artis hujus gnaro politum, inlignibus incidendis Jaspidis inftar optime inferviit. Vid. Excell. Bajer. Oryttogr. p. 52. Caetèrum Lithoxylorum Hiftoria a plurimis illuftrata, imprimis ab Exc. $V_{a-}$ lentini in Mujei Mufeorum P. II.cap.4. P.25. ut his aliquid addere fupervacaneum. Imoin agro noltro Noricoultra duodecim ligni petrefadipecies collegit et defcripfit Excell. Beierus in Orydograph. Noric. p. 51, feq. de Ligno foffili eruditiffmum Tract. edidit Francifeus Stellutus, quem Excell. Major cum notis denuo editurum promifit.

In Cenfüm hunc pertinet $L_{I G N V M} F_{A G I} L_{A P I D E V M}$, quod oxybten nominare lubet, cum Oxyam Graccorum Botanici Fagum credant, aho lapideo aemulum productum, de quo Pontanus in Mleteor.

\section{videas lapidefere Sarni}

Caeruleo jub fonte alnum filicisque maniplos.

de Phegithe vid. Excell. Beier.oryttograph. p. 52 .

CARO et OSSA LAPIDEA. Maflam hanc informem, carnem oflibus agglutinatam et petrificatam exhibentem dijudicare, afpicienti=" bus haud difficile erit, quibus addere licebit Pernas integras, non procul ab urbe Roth regiminis Sereniflimi Principis Brandenburgici-Onoltsbacenfis verfus Palatinatum fuperiorem, repertu dari, in lapideam fub. ftantiam converfis fale infperfis, fumoque induratis Weftphalicis non abfimiles. De Carne lapidefcente vid. Cl Buttneri Rudera diluvii teltes p. I 40. de Petalunculo laudat. Beier, Oryctogr. Nor, p. 47.

LAPIS FULMINIS five CERAVNIAS ad Qucrcum arborem diffractus eft, idquod Auclor nofter cum Gesnero, Kentmanno; Boëtio a Boot, Aldrovando aliisque credit, cum fulminis fupendi effectus aliam plane maffam fulmineis inefle telis fat fatis evincant. Vid. Exc. Charl ton. Inquif. Anatom prim. qua Anatomen pueri caelo tadi inftituit. Cl. Major diflert. de Fulmine tadis. Kilion. 1673. cap. 2. $\int .9 .10$. Nec Europaei tantum hanc de Fulminis telis fententiam fovent, fuperant eos hac in re, qui Indias Orientales incolunt. Vid. quae de Ceraunia $\int p a$ thula metallica ex Indiis Ephemeridibus Nat.Curiof. Dec. II. Ann.IV. Oblerv. CX. et Dec.11. Ann.VIII. obferv. III. communicavit folertiffmus Rumphius, et poltea pluribus auxit in Muf. Amb. Libr. III. cap. VIII. et IX. et de Chryjocolla cum Fulmine coelo delapfa nobilif, Balduinus in Venere Aurea Dec. I Ann. VIII. App. annexa. Confer, Elegantif, diff. Hoechftetterorum de Lapide fulminari Altorff. babitam Anno. I701. et Fob. Gottfr. Laue differt de Telo fulmineo Lipl. 1706. 

PSEVDOCORONA ANGVINA, Agyrtarum delufionibus accenfen$\mathrm{dd}$, quibus vulgus credulum decipere confueverunt, quippe nibil aliud funt, quam dentes molares porcellorum, fubftantiae candidae, fuperficiei inaequalis, acutis eminentiis feu apicibus pulchre exasperatae, inferiori parterotundae, it a ut obid elegantis coronae formam prae Je ferant, et a Circulatoribus pro P/eudocoronis ferpentum candidorum Scllangen: Sironlein/ divendantur; de quibus pluribus egit $\mathrm{Cl}$. Wagnerus Dec. II. Ann.V.obferv. 106.pag. 2 II. et dilucidiora adhuc promit Magnific. Nat. Curiof. Prae es Schroekius in Scholio annexo, et eruditifimus Welfchius Hecatofl.I.obferv. 27. qui Draconites five opheoftaphanifcosfititios e maxillis aprorum fe collegiffe, et decuffis quibusdam eminentiis łaevigatos, limaque expolitos, ad lubitum efformavit.Vid. quoque $M u$. Soc. Reg. cui fraus fuboluit. Hinc double tooth or grinder, dentes molares duplices vocavit.

\section{TAB. XXXII.}

TAbula haec ICHTYITES varios fiftit, quorum plurimos Exc. Scheuchzerus in exafciatiffimo Schediasmate, Pifcium querelae et vindiciaeinf cripto, et Tiguri Anno 1708 .impreflo, recenfuit; et quidem FIGVRAMI LVCII PISCIS in MARMORE AGRI EPIS. COPALIS EI'STETTENSIS expreffam, quod attinet, hujus pariter laudatiffimus Dn. Scheuchzerus citato, Beslero noftro, meminit l. c.p. 4. ubi Lucium quoque ex Oeningenfi Lapidicina protractum exhibet, qui non fuperficiali ut Audoris noftri Lucii fimilitudine gaudet, fed to: tius Pifcis fubftantiam oculis exponit, ceu indubius antediluvianus teflis.

Lapides binos ISLEBIANOS E MANSFELDICO Comitatu Tabula haecpromit, in quorum primo MVSTELAE PISCIS effigies in Lapide fiffili nigro aeris divite, aureis ftriis a pyrite malfulisafperfis et intermixtis. Producitpariter hos, citato Auctore noftro, Excell. Scheuchzerus 1. c. absque tamen fchemate.

ALTER ISLEBIANVS LAPIS PISCEM SQVAMOSA EXHIBET CVTE, illaque ex parte detracta, interior carnis ftructura apparet. Exc. Scheuchzerus, qui fimilem aeri incidi curavit e truttarum genere, Pifeem effe autumat, non tamen abfolute eo illum referre aufus fuit, propter ventralium pinnarum abfentiam. Cl. Rumphius in $\mathrm{Mu}$. feo Amboinico quoque Tabula LIX. Lit. B. Lapidis hujus figuram, uti et Ill. Rajus in libell. de Mlundi primordio, mutatione et interitu $p_{.} 189$. exhibuit. Vid. Exc. Alberti in Difp. Lipf. 1675. habita, de Figuris variarum rerum in Lapidibus et peciatim foffilibus Comitatus. MANS. FELDICI habita : et Nobiliff. Mylius in Memorab. Saxon. Subterr. Rel. I. Lungershaufen de Imitam. Nat. S.4. 
FVNDVLVS fequitur in marmore agri Ey/fättenfis expreffus, hunc cum Pifciculo in fifjli lapide candido e Mufeo Vallijneriano fomparandum putat, tuties jam laudatus Exc. Scheuchzerus. l.c. p. 12. Conf. C1. Jungium de mineralibus Sched. i s.p.6. qui Aultorem noftrum citat.

Omnes hactentis recenfitos Iclstbyolitbos pene luperar in Marmore Eyfäitenfi expreffus GAMMARVS FLVVIATILIS, indubie e Solenhofenfi Lapidicina defumptus, quippe non fuperficialiter ut reliqui lapidi impreflis, fed totum cruftaceum putamen, quo totus veluti eataphractatus integitur, oftendit, curn ejus cauda five potius collo, quinque rabellis, et quinque pinnis cum hirfutis extremitatibus, pedibus articulatis, chelis five forcipibus denticulatis, capite, fronte, oculis, cornubus et appendicibus hirfutis; nec tamen hujus egregii Gammarolitbi ac Besleriani, qui illum continet Mufei mentio, neque in Exc. Sachfii Gammarologia, nec in annexa pariter maximi Majoris eruditifjw ma Dijfert. de Cancris et Jerpentibus petrefactis. Mijcellanea Beroli. nenfia lapidem Ilmenavienfem cancrifiguram in finu ferentem, delinearunt, cum noftro tamen vix comparandum. Aft fatis de his Icbtbyolithis lslebienfibus et Eyftätrenfibus; qui plura praeter allegatos jam Auctores fcire defiderat, adeat Dn. Mylium in Alemorabil. Saxcon. Subterr. Exc.Valentin.Muf. Muf. T.Il.cap.7.pag. 37 Exc.Spener.in Mijcell. Berolinenf. p.roo. Quae inter viros in Hiftoria naturali fummos DN. Woodroard et Luuyd Anglos, et Helvetios DN. Scheuchzerum et Langium, circa generationem horum lapidum lites ortac, notac funt ex eorum friptis publicae luciexpofitis, quas tandem componereftudebit feculi neftri Oraculum, Illuftr. Leibnizius, in Differtatione, utinam mox proditura! de antiquisfimis Hiftoride vefigins in ipfius naturae monumentis. Huc quoque fpectat Cl. Buttneri fcriptun, cui Titulus: Ruderà Diluvii tefies imprefl. Lipf. i 710.

\section{TAB. XXYIII.}

C Ammarolithum praecedente Tabula defcriptum; excipiat $F A G V$. 1 RVS LAPIDEVS, qui medium Tabulae hujus occupat, et plurimos fibi fimiles in variis Muleis oflendit. Sic optime convenit cum Paguro lapideo, parte fupina exprefo, apud folertiflimum $G e f-$ nerum noftrum de Figur. lapid. p. I67. apud laboriofiffmum Aldrovan. dum in Mluf. Metallic. p. 461. in Alufeo Veronenfi Calceolarii p. 47s. in Mufeo Neapolitano Ferrant. Imper. in Tigurino tefte Cl. Wagnero Hift. .Natur. Helv.p. :31. In Mufeo Societ. Reg. D. Nebem. Grew. p. 25 s.ubi figura noftra Besleriana citatur. Paguri quoquenon Gammari lapideifiguram hubent Cancri petrefadti Sinenfes, quos Lufitani Petro de Kameron vocant, et in Ephem. Natur. Curiof.Dec.11. Ann.obj. CXLVIII. expofuit Cl Grimmizs. Nec ab hic diverfi ab ampliffimo Rumphio iu Mufeo Amboinenfi Lib.II cap. 8 s. defcripti Paguri lapidei, a.M. Nlartinio in Sinenfi Atlan- 

. A1

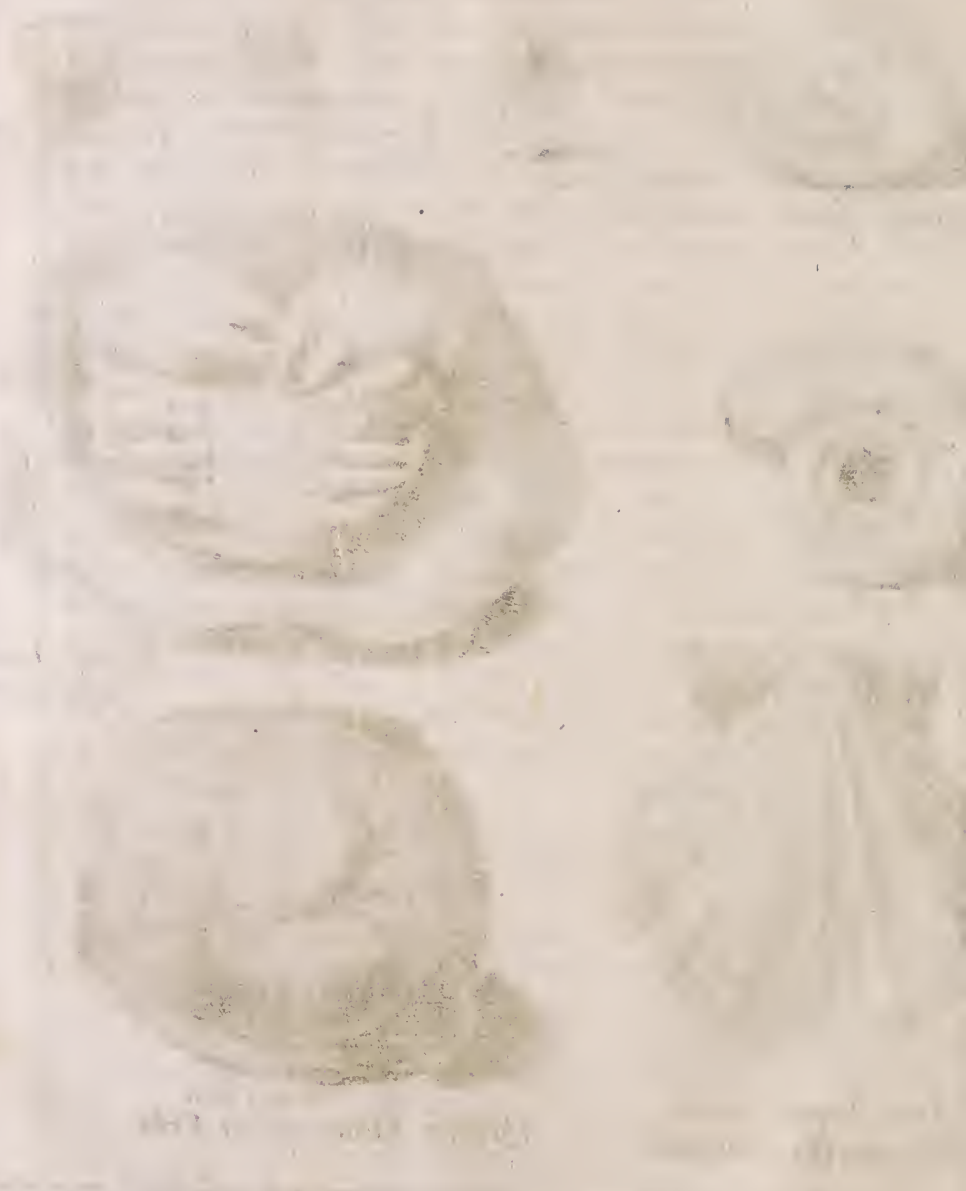


Atlante primitus defcripti, a Lufitanis Crangejo de Pedradicti, quorum virtutes medicae fufe ibidem recenfentur. Quibus addeExc. Scheuch. zerum in Pifc.Querel. et vind. p. 29.

CANCR $M$ MINOREM MARINVM referenslapisad can. criformes quoque lapides referendus, ct quidem inter illos, qui Animalia integra continent. Quadratautem figura in lapide expreffa optime in Cancrum anonymum Rondeletii. An is fitcarcinolithos, cujus fub nomine: Lapis Cancer marinus meminit Stephanus Antiochenus interpres Ibn Abbrs, cui dicam exinde fcripfit o $\pi \alpha^{\prime} v$ Welfcbius, afferere pro certo non audemus.

CONCHA LEVISLAPIDEA referai poteft ad Conchitem laevem aequilaterum fubrotundum mediocrem fubcinereum ventre. craffiore.

CONCHITES DVPLICATVS et concha ftriata, pertinent ad Conchites valvis aequalibus aequilateros ftriatos fubrotundos, quo et-. iam conchula ftriata, quae non nifimole differt, referridebet. Maxima conchitarum harum ubique multitudo. De Querfurtenfibus confer. $\mathrm{Cl}$. Buttneri rudera diluvii Teflesp. 263.

PECTEN LAPID. GVTT AT, ad pedinites refertur, quia figura concham cui peetinis nomen a Rondeletio impolitum, exacte repraefentat, exutroque verticis latere apophyfes vel aures prodeunt, in noftro quoque lapide conlpicuae; plures equidem apud Auctores. pectinites repertu dantur, praecipue apud diligentiflimum Aldrovandum Muf. Metall: quorum nullus tamen noftro comparari poterit, hinc $a b$ Auctore noftro recte guttatus exprimitur.

PECTVNCVLIS LAPIDEVS Auctoris eft pectunculites par: vus capillaribus friis donatus, qui cuctoritate Excell. Lifferi fic dicitur, quod auriculis deftituitur; et Cl. Scheuchzerus infuper annotavit, femper reperiri eos bivalves, propter valvarum inaequalitatem ano. mios, et aliquando circellis quibusdam veluti fafciatos; nofter hic armatura ferrea infuper veftitus.

PECTVNCVLV S FERREOLVS pertinet ad Conchitem laevem, minimum ab Excell. Lang. Hiforia Lap. p. 138. defcriptum, nif quod armatura ferrea adinftar praecedentis inftructus fit. Similem habetExc, Baier. Orydogr.p. 75.

CORNV AMMONIS FERREV MI, non equidem eft, et conftat e ferro fufo, fed fub infolita minerae ferreae-figura fe offert, fimile illi cornu Ammonis ferreo, quod cum matrice fua depingi curavit Cl.Wagner. Ephem. Nat. curiof. Dec.11. Ann.V11I.obf. CXLIX.p.32I. feq. Plura de Ammonis cornubus Vid. Tab. XXXIV.

COCHLEA LAPIDEA Cocblites eft, five Lapis ad cochlearum quandam inaginem figuratus, turbinatus, h.c. una velut Tefta in conum procedente donatus, intortus five anfractuofus, ethoc ipfoad cornua Ammonis quoque accedens. 


\section{TAB. XXXIV.}

4 Lucet prae reliquis in Tabula hac contentis, MARMOR CVM FRVTICIBV S, HERBVLIS ET ARANEA, optime expreffis, ut penicillo nil pingi aptius, nil fingi poffit. Pertinet igitur Lapis hic ad Dentrites, vel potius eft Dendrites Arachnoides. Quod autemad Dendrites attinet, cum nunquam fatis laudandus Exc. Scheuchzerus eos acutiffimo examini fubjecerit, eorumque genefin, ut ab omnibus capi poffit,clare et perfpicue exprefferit, optimoque parenti, pro ea, quaeillos in tercedit arctilfima animorum conjunctio, infcripferit in $D i \iint_{\text {ert }}$ at. Ep $i$ iftolica Appendic. Ann.V.et VI.Dec.1II. Ephem.Nat. Curiof. affixa, nil fupereft, quod Dendriti $i$ Auctoris noftri addere poffem; nifi quod Vir modo Laudatiffimus in Herbario Diluviano (cujus pariter pars citata Dendritarum differtatio eft) Tab. VIII. Fig.VIII. et ultima, elegantiffimum Dendritem in lapide fifflili marmoreo candido, e Lapidicina Solenhofenfi exhibuerit, noftro fi araneam exceperis fimillimum. Cum autem, cui Dendritarum fpeciei et Plantae accenfendus; dicere muffet vir ingeniofiffimus, quis a judicii mei tenuitate crifin expectet?

Aliquot in Mufeo Metallico CHEIRITES five Chirites. Lapides nempe, qui HOMINIS MANVM IMPRESSAM GERVNT, fuppe. ditavit indefeflus Naturae fcrutator Aldrovandus, e materia alba et gyplea, qui cum Auctoris noftri Lapide colore cinereo, cui forma manus impreffa, minime conveniunt, Lapis enim nofter fatis durus, coloris ut jam innuimus, minime albicantis fed cinerei, digitique jufto ordineet longitudine rite difpofiti, cum aliquibus obfcuris licet unguium rudimentis. Elegantifimum quoque et noftro fere fimilern Chiritem, prope Arcem Blankenftein effoflum, et ab Illuiftriffimo Comite. Hazfel-

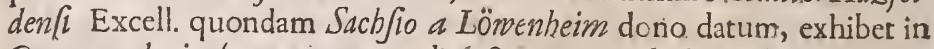
Gammarologia Jua pag. 159. adjuncto pariter Cbiritis Schemate.

Lapis, qui vocatur CORNV 'AMMIONIS. AVREI.COLORIS ad Chryfammonites feu potius 'Anrimóchbryfos rèfertur ab Excell. Ambrofino in Muf. Metall. Aldrovandi et a Cl. Reiskio in Exercit. Hift.

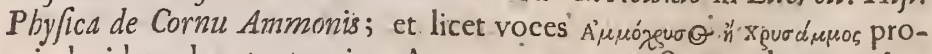
prie lapidem denotent, qui ex Arena aurea compactus, colorem refert aureum, ac refolutus in pulverès, fcriptiturae poftea confpergendae, aut ficcandis literis infervit; cum Ambröfinus tamen cornua Ammonis coloris aurei hac voce pariter defignet et figuris exprimat, applaudente illi pariter Reiskio, et noftrum quoque Ammonis cornu aureum Cbryfammonitem vocabimus; aurea praeterea vel Orichalcea potius armatura, ad Hoplites referendum. Plura quide Cornuum Ammonis differentia et ftructura legere er fcire cupit, adeat Exc. Baierum in Orydogr. Nor . p. 59 .leq. qui prae aliis hos lapides in ordinem redegit. 
$-8$

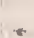

.

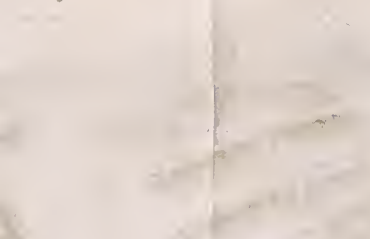

'?

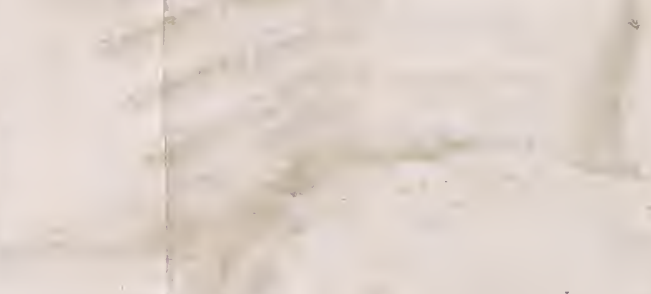

.
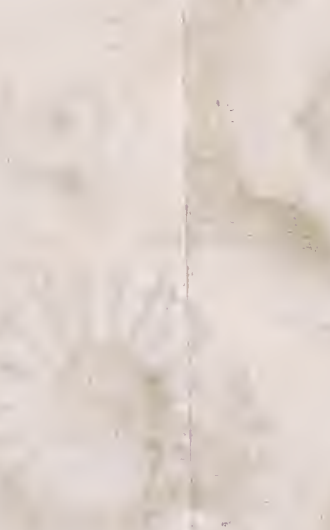

. 
LAPIS AMMONIS CVAI FERREA ARMATVRA, nil aliudquam Hoplites. Vocant enim metallici armaturam, quod ferri politi, autaeris, aut auri, (ut praecedenti lapide,) fimilitudinem gerat, vel ut Ferdinandus Imperatus Italice hoc exprimit : Veftite di color

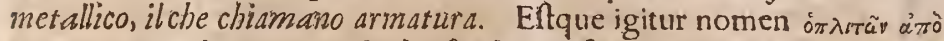

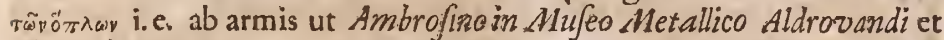
Cl. Reiskio I. c. placuit. Solertiffimus Agricola Libr. de ort. Jubterr. annotat: Cornua Ammonis quae plerumque annatura ferripoliti colo. rem referente obducuntur, fucco Aluminis infelta aurei fieri coloris; patet inde quomodo in Tab. noltra praecedens Ammonis Cornu ab hoc differat lapide. Crederem hoc Ammonis Cornu ferreae armaturae Au. Etoris noltri, cum Lifferiano de Cochlitis Angliae P. I. Tit.III. p. 207.defcripto, comparari poffe, quippe Ammonis Cornu Ipina in Ambitu eminente, ftriis lateralibus, ex toto orbem extimum trajicientibus limatura ferrea.

LAPIS INSIGNITYS FORAIA SERPENTIS commode inter Ammonis Cornua referri pollet, quia tamen laevis et nodis tuberculisque caret, lerpenti affimilatur, et ab Ambrofino in AIu N Metallico Aldrovandino OPHIOMORPHI ГES vocatur. Gesnerus huc quoque collineat cum Lapide noltro haud abfimili de Fig. Lap.cap. XV.p. 167. Lapidis Serpentis in fpiram convoluti effigie, ita ut caput in circumferentia pronineat, extremo vero cauda pro Centro fit. Hujus generis lapidum infinitum poene numerum repertu dari in Angliae oppido quodam Keysham vocato, quinto lapide a Briftolia Vrbe diftante et alibi puriter teltis eft $\mathrm{Fxc}$ Charltonus de different.et nomin. Fo/fil.

LAPIS MVLTIS SERPENTIBVS CONGLOMERATIS infignis, ophites dici meretur, et exillis eft, quos nonnulli $P$ ifcium vifcera crediderunt, humore aliquo lapidefcente indurata. Annon ad Vermes Melitenfes petrefactos Wormii referri poffet? illis dijudicandum relin. quo, qui acutius in hoc Ptud:o cernunt. Memorat Exc: Baufchins Diff.

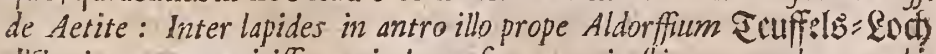
dicto, inventos extitiffe, qui plures ferpentes in firam revolutos exhi. buerint; de Tubulis vermicularibus vid. Excell. Baier. Orylagr. pag. 72. Spongites tubulis ferpentiformibus conftratos exhibet Exc. Wellchius de Vena Medinenfi p. 93 .

CONCHAE IN LAPIDEM CONVERSAE Conchites funt, qui paffin in agro noftro effodiuntur, et ubique proftant; tefte Excell. Beier.Orydogr.p. 73. innumerus tamen corum numerus in Alzeyenfibus montibus inferioris Palatinatus, quos ideo Conchiferos nominavit Exc. Geyerus in differt. de montibus conchiferis Alzeyenfibus. His Auctoris noftri fimillimos conchites, reperi in monte vico Zürndorffen $\_$vicino, ab arce veteri diruto 2 Ilte $\mathfrak{B e f f e l l ~ d i d t o , ~ c l a d e ~ S u e c o r u m ~}$ funefto, cum dileatfimo Patri aegrum in vicinia vifitanti, comes exifterem. 


\section{TAB. XXXV.}

Abulae initium promit PISOLITHVAI Germ. noftris Erbfen= Strin/dictum, cum Pifa optime exhibeat, hinc Gefnero Orotias quod e multis ceu pifis ceu ervis conftet praeduris, fuis quaeque inclufis leculis, e quibus levi negotio extrahuntur, quae dentibus fratagi nequeunt, colore fufco; non abludunt ab hoc Pifolitho Pifa fic diata Carolina, e guttis Aquarum Thermarum rotundis feu fphacricis in lapidem ejusdem figurae coagmentatum. Extra Matricem pifa haec lapidea in agris reperiuntur Bethlehemiticis ex Monconny/ii relatione T. I. p. 313. confer, de his lithojpreis fic enim Graece vòcari polfe credit Calceolar. in AIuf.p. 410 , Worm. Aluf.p. 52 . Ambrof. Aluf. Metall. Ald. P.5 12. Exc. Major in AAemorial de Foffil. Littor. Kilonienf. obferv. III. f. 8. Boetius a Boot de Gemmis et Lapidibus Libr. II. cap. 239.p. 424. qui hunc lapidem:Bezoar minerale appellari credit, fquamis enim feu cuticulis conftat ut Bezoar, deinde fubjacens cutis fplendet, color etiam fmilis, aurpatio plus rufefcit.

Forláneadem cum Boëtio mens Auttori noftro, qui $B E Z O A R$ MINERALE pifolithis fubjungir. Meminit hujus ceu arte elaborati Pietrad'Aventure dicti, Gl. Wormius in Alufeo, fed coloris et confiltentiae acfubftantiae ratione quae ipf vitred quali eft, plane a noftro 13 zodr minerali differt; accedit potius ad Bezoar minerale, quod $P$. - Paulus Boccone vir in Hiftorid naturali certe eruditifmus, dans le Recherches et obferv. naturell. Lettr. 22 p.225. feqq. deforipfit, et Bo!o Arthenae albae gucad guthum et confiltentian perfimilem pronuntiat, $\mathrm{et}$ ni color obftaret Bezoar minerale Serapionis et Rbafis efle credit, quod tamen citrini coloris, friabilis, nulliusque faporis eft; forfan exillo poculailla et vafa Bezoardica fabricantur coloris viridefcentis fulphurei, guae in curioforum mufeis affervantur, et qualia citat hoc loco, et poftea nell offervazioni ove fe contengono materie Aledico. Pbifiche et di Bo. tanica. Bonon. 1684 impreffs aeri incidi curavit. Non autem Bezoardici Siculi hulapides, matricibolaris fubfantiae inclufi, rotundi funt piforum -inftar, quod Boetius voluit, fed figurae parim oblongae partim compreffae,ceu ex figura tabulae noftrae ubi vacua exemptorum lapidum loca facile confpiciuntur, patet ; lapides autem ipfi omniumoptime apud laudatum Boccone in obfervationihus. Gallice et Italice foriptis delineati. De Viribus nil addo, quas fufe recenfet, plurimisque teftimoniis confirmat; quibus fi fides Lapidibus pretiofis Bezoardicis e regno animali vix amiplius opus effet; buic lapidinon multum difimilem citato Auctore noAtro exhibet. Cl. Baufchius de Aetite p. 27.

Succedic Pijolitbo et Bezoardicis mineralibus lapidibus, AHECONITES Germanice Der Piogen=Etein dictus, quod ovis pifcium fimilis fit, vel quod Graecum vocabulum. Aleconites vult, feminibus papave. 


\section{IL A P I DE SII}

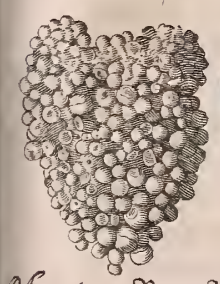

Meconites. Rogenftein.

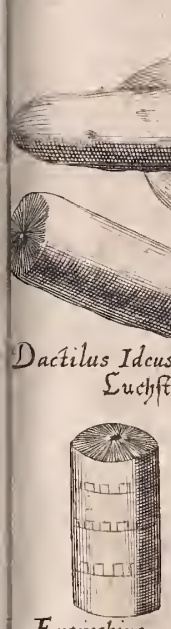

Entrochiu:

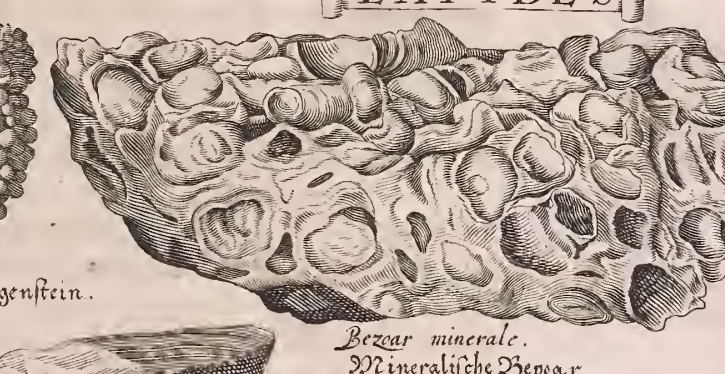

Bezear minerale.

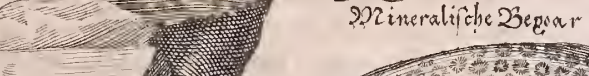

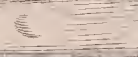
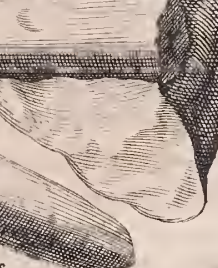

uchftein

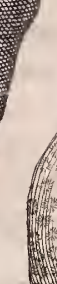

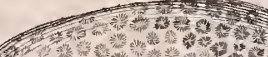

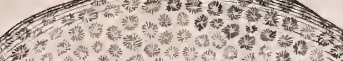

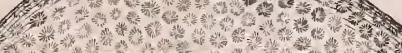

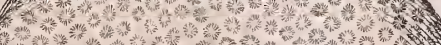

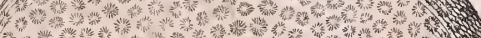

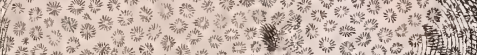
W W. W

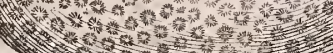

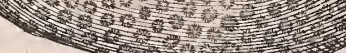

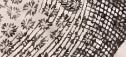
s.

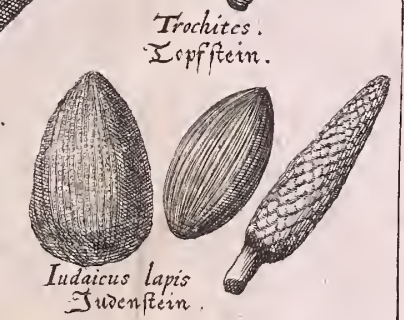


saceis, vel arenulis compactis, unde Hammites minor dicitur, fub Hamm mitis majoris enim vocula Pifolithum exprimit Gesnerus et Bö̈tius. Friabilis interdum hic lapis, ut facili modo in arenulas five granula, e quibus conftat refolvi polfit, non tamen omnis Hammites hujus raturae, fed faepius ita confufus et in folidam duramque maflam coagmentatus, ut filicem non figuratum primo afpectu referat, tefte Exc. SCHEVCHZERO in Specim. litbograph. Helvet. curiof. p. 4. et poltea in two

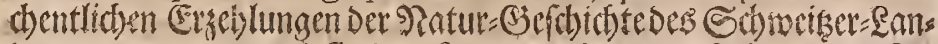
De5. n. 27. p. 106. Autoris noftri Meconites inter friabiles recenfendus ex ovulorum fubluteorum congerie in maflam facile refolvendam coagmentatus, hinc forte exillorum genere, qui in agro noftro et quidem inter Secmbutg et Sulģberg repertu dantur, quorum meminit Excell. Bajerus in Opuxrozea es Norica cap.7.p. 67. Cl. Lachmund OryElogr. Hildesh.Sect. III. cap. XIV. qui nefcio qua de caula Ammonitem vocat. Vid. quoqueoptimum Parentem noftum de Meconite in Méconopacgnio.p. 24.

DACTYLI ID AEI fequuntur, id nominis adepti, quod in Ida monte olim repertifuerint, et digitum repraefentent. Belemnites au-

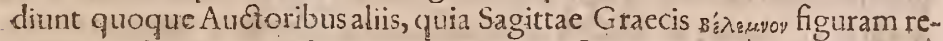
ferre creduntur, quod nomen Auctor nofter aliis lapidum figuris ta. men atribuit; Germanis quoque noltris a fagittae fimilitudine Sllpen: Sobs / incubi Sagittae, (huic enim morbo mederiolim crediderunt) er Shly. Gotil/ nominantur: Sunt autem uti ex Auctoris figura pater, lapidesteretes, oblongi, in apicem obtufum definentes variis colo. Ti: us, quandoque vacui, quandoque filicibus turgidi; extitit quoque in Mufeo Excell. M1ajoris, qui alium minorem dactylum continebat. Omnes pene extrinfecus linea vei crena per longitudinem inferipti, intus - vero fi transverfim frangantur figuram fellulae radiorum plurium ferenstes. Ques Auttor nolter habet femipellucidi funt, dantur tamen ali\& as ct pellucidi et opaci. Dactylorum unus frufto majori filicis inhaeret, er quafi impactus, qualem quoque $C$. Major recenler, quipene ducentos varii coloris et molis poffedic, interque illos marchafita coloris aurei obductos, five armatura aurea, exInfula Helgolandia allatos. Tot licet poffederit, nullus tamen ab illo in his lapidibus odor notatus, quem tamen infer trinae felium vel Lyncis, hinc Sudb) Stetin Germanice dicti, de fe fundere veteres putarunt; nec vis electrica five paleas trahendi in illis ab Excell. Majore deprehenfa, qui omnium optime hos defcripfit lapides. Memorial. Anat.Obf. Tert. de Fo/fil quibusd. Littor. Kilonienf. 5. is . Reqq. Confer. quoque Muf. Worm. p. $>0$. Bellon. obferv. Libr.I. cap. 25.p. 21, Gesner. de Lapid. p. 91. 6. Lachmund. Ory\&. Hildesh. p. 2 q. Ambrof. Muf. Metall. p. 620 feqq. Orydogr. Nor. Excell. Bajeri.p. 34.Muf. Mufeorum P. II. p. 13. Muf. Olear. p. 6, Kentman. pag. 34. Ephem. Nat. Curiof,Dec. I. Ann. IX, et X.pag. 225 , et 
infinitosalios, impr. Exc. Scheuchzerus, qui fingularem de lapidibus iftis differtationem promifit, fpecim. Lithograph. Helv.p. 26.

ASTROITES 1 NDIC $V$ S, lapidum quos tabula haec habet elegantiffimus. Dicam fcribit Auctoribus fedulus Gesneris, quod Aftroitem vocent, a Graeco àspoy, fidus vel ftella, unde melius aftrites ternis Jyllabis, vel Aftrios potius dicendus; Germ. Stern= Stcin/ quod p!ures in illoftellae conlpicuae. Lapis eft opacus, quo ipfo ab Aftroite gemma diftinguitur, moderatedurus, colore cinereo fufco nigricante, eximiae magnitudinis, quippe ad humani capitis magnitudinem illum faepius excrefcere refert $\mathrm{Cl}$.Worm. in Altt. $\mathrm{p}$. 68. Aceto impofitus hinc inde moveri dicitur, acfi vivus effet, hocque procedere ajunt ab aceto per poros lapidis fe infínuante, et aèrèm illis inclufum premente, qui exitum dum molitur lapidem tradit acmovet. Hoc experimento innixus P Kircherus, Telluidinèm arte factam quafi viventem feque avtomatis inftar moventem huiclapidi impolitam vult in Arte Magnet. fedopus eft ut melior fit experimenti fucceflus, quañn Cl.Oleario àccidit qui levem admodum motum in pluribus plàte nullum obfervavit, in Aluy. Gottdorff.p. 65. Ferunt illum incubicullo "fufpenfüm, araneos aliaque animalia venenata abigere, quod experientia edoctus? frims falfum deprehendit; ejusdem veritatis, quod geftanti victoriam conciliare credatur hine Germanis Siegs Stein/ quam fabulam falfe exagitat Exc. Vabent. in MIuf. Muf.P.II. p. 13. Vires huic lapidi plurès alfignantur, fed ejusdem veritatis funt, ac Marfilii Ficini affertum, quui lapidem hunc Draconitem dictum cenfet, quodex Draconis cápite eximatur. Vid. Boetius a Boot. L. II, 145. feqq. Elegantifimum Aftroitem reperit optimus $P$ arens ad Regnefi et $P$ egneli confiéntiam, "marmoreac duritrei, ab Exc. Baiero in Oryliggr. Noric. p.42. defcript.

Succedit in Tabula ASTROITES VNDVLATVS et STELLATVS. Quatioor enim Aftroitum generaftatuit Boëtius a Boot, unum qui exacte formatas ittellas refert, qualis eft quein modo defcripfimus et hic ftellatus, qui a priori nonnifi magnitudine et figura differt; alterum quod undárum et vermium gỳros referat, undulatus indedictus; de reliquis duobus quorum unum genus rofas, alterum, quod confufe et obIcurie maculas potius, quain praedictas figuras oftendere creditur, cum ab Auctore noftro non exhibeantur, filentio qunque practerimus. Confer. de his Aftroitibus Exc. Scheachzerum in Lithogr. Helu curtiof. p. 36. feqq. et $\mathcal{R} \cdot P$. Boccone, obfervat. Naturell. cujus tamen Aftroites undulatus et tubularis majoribus ftellis maxime a noltratibus differt, et alio lo co a nobis explicandus. Aftroites hos lapides Afterias nominat Excell, Wellchius Hecatoft. I. p. 16.

Aftroitibus five potius Afriis jungimus ASTERIAM veram fflilem, q̧ui lapis e mente Bootii potius nomen ftellaris meretur, quam praecedentes, conftant autem ex teffellis plufculis utplurimum novem ad decem tranverfim fibimet arcte incumbentibus, ita concinne junctis 
et aptatis, üt nullus artifex melius jungere potuilfer, feparari autem facile a fe poffunt; hinc Afteros $\int p h r a g i s$ Gelnerovocantur. Sunt autem teflellae iftae, ut e figura ab Aultore noftro exprefla pater, planae, utcunque angulofae, fuperne ac inferne infculptae veluti ftellulis quinque radiorum. Conf. de his Baubin. in Baln. Bollenf. c. I. p. 3 I. Lachmund. Oryctogr. Hildes. imprimis Exc. Majorem Memorial. obf. 111. \$.13. de Foff. Litt. Kilion. Worm. Muf. p.69. Exc. Welfchius rariores Afterias entrocho fimiles exhibet Hecatolt. I. p. 16. De Alteria Gemma differt. confcriplit Hentfchelius Witteb. 1602.

-t ENTROCHI figura Germanice SiáDet" = Stcín lequitur, et proprie eft trochitarum plurimarum conjunctio, conjunguntur autem invicem fuprapofiti tam eleganter, ut arte videatur conjunctio facta. Nam radii unius, alterius ftriis inferuntur, quemadmodum in commiffuris craniihumani videre licet, interdum viginti hoc modo committuntur. Trochitas autem leparatos quod attinet, obtinuere nomen, quia rotae aut Horologii in horas divifi figuram refert; pars ejus rotunda laevis eft, utraque vero plana habet modiolum, a quo ut in rotisfieri folet, $\mathrm{ra}$ dii eminentes ad extimam orbis partem ita procedunt, ut inter illos frrae fiant, Quod fi trochitae in Entrocho fibi fuper impofitae fint longiores, Entrochicolumnares, five ut Imperatus exprimit Italice Colonnette, dicuntur. Exc. Scheuchzerus in Spec.Lithogr. Helv.p. 2. Afteriam columnarem Entrocho fimilem exhibet. Germ. dicitur quoque Spangen=Stcin/ cujus nominisEtymon rimatur Exc. Valent.Muf.Muf. I.II.p.I7.e confultiflimi VV inkelmanniChronica Hafjaca, quippe arci Spangenberg, a multitudine lapidum inibi reperibilium; ab his lapidibus nomen datum fuiffe credit, quodet olim jam Bö̈tius a Boot, meminit in Lap. et Gem. Hiftor. Libr. II. C. 127.

Quem TROCHITEM Au\&tor nolter nominat, nihil minus quam Trochites eft, et Germanicum nomen adjunctum fatisexplicat, nil aliud effe nifi Tofum five Tophum, lapidem nempe afperum, facile in arenam refolubilem. Vid. Gesnerus de Fig. lap. p. 33.

Superfunt in Tabula adhuc explicandi $7 V D$ DICI LAPIDES, qui cum Trochitis magnam cognationem habere dicuntur. Variis infigniuntur nominibus, et quidem Fudaici, quod olim utplurimum in Syria et Judaea reperiebantur: a Plinio Encroës vocatur, quod Vrinam Aluere faciat, et Tecolithos, quod calculum refolvat. Vt nomine variat, fic etfigura, ut ex Tabula noftra patet; qui inftar glandis et balani eft, Phoenicités, qui inftar nuclei Olivae, Pyrenes, qui inflar fpinae echini marini, a quibusdam ecbinites appellatur. Sunt autem omnes cinerei exterius fere coloris, oblongiufculi ftriis multis et inaequalibus a bafi in apicem dotati, ac fi arte tornefacti effent. Meminit hujus lapidis jam Aëtius Amidenus Obfequii Comes Libr. 2. Tetrabibl.cap. 19. et adcalculum renum efficacem pronuntiat. Aliqui diftinguunt fexum, et minores foeminas, majores mafculos arbitrantur, illos veficae lapidem 
fundere, hos lapides Renum expellere judicant. Hinc Poëta de illis :

\section{Salve Arabum mare, Tecolithum mortalibus aegris}

Largitum ad morbos nobile praefidium.

Confer Petr. And. Matthiol, in Diofcorid. Libr. V. cap. V. Gefner. de Figur. Lapid.p. 128. Boetium a Boot p. 40 3. feq. Cae alp. de Metall. Lib. 2. c. 4 5. Ambrof. Muf. Metall. Aldrovand. p. 71r. Hift. Nat. Ferr. Imper.p. 576.Muf. Worm. p. 69. Lapides Judaicos ferreos exhibent Ephem. Nat.Curiof. Dec. II. Ann. VIII. Obferv. 149, p+322. Exc. Beier. OryAtogr.Nor. p. 44.

\section{TAB. XXXVI.}

CEMINA ANISI ET FOENICVLI LAPIDE INCRVSTATA, S funt illa elegans Staladites fpecies, quae Tivali in Italiae agro Romano repertu datur; cumque inaequalis ac variae figurae, tam exaete femina faccharo obducta ac incruftata refert, ut iis fallere multos li. ceat ; quocirca et nomen hoc apud Italos obtinuit, ut Confetti de Tivoli vocent. Subftantia eft non usque adeo dura, et ex ea optimam calcem conficiunt accolae aedificiis idoneam. Lapidea haec feminum Anifi et Foeniculi confectio defcribitur pariter in Muf Societ. Reg. Angl. P. III. c.V.p. 296. fub nomine Small Tibuline Sugar-Plum, additque Exc. Nebem. Grem: Besler figures feveral of the fe under the Name of petrify'd Anife feeds, Fenil feeds Ec. Erc. Vid. quoque Muf. Worm. p. s2.et Exc. $V$ alent.Muf. Mufeorum P.II. p. 1. Cl, Behrens in Hercyn. curiof. pag. 19. ubi cryptam parvam, lapidea hac confectione refertam, in antro Baumanniano recenfet.

COCHLEA CYLINDROIDES in lapidem converfa, ef Coch. lites cylindroides five pyramidalis Excell. Langiiin Hiftor. Lap. Figur.p. II 2. qui figura fua praefert Cochleam Cylindroidem Rondeletii, e qua nomen quoque habet. Haec a figura cylindro proxima cylindroides vocatur vel etiam pyramidalis, quia pyri modo turbinata eft. Os proxime a bafi, feu a fpiris, vel in fe convolutis, vel parum productis incipit, et usquead alteram extremitatem extenditur, quae a potiori in acumen definit, et frequentiusin figuram conoalicuiaut pyramidi fimilem.

Quos FRVCTVS PINEAE LAPIDEOS recenfet Auctor, melius conveniunt, quam quos $\mathrm{Tab}$. fequenti fub nomine $N$ uclei pinei delineavit, quosque melius radiolo cucumerino III. Luydii convenire credimus.

FRVCTVS CVBEB ARV M LAPIDEI funt quoque falagmitae Bellariis fimiles, majores Exc. Langii Hiftor. Lap. p. 31 . et nalcunsur ut ftalactites ex Aqua non adeo depurata, in parva fubrotunda cor- 
Cochlea Cylendroid.in

Lapid: conbers.

$$
\begin{gathered}
\text { Confect: sem: Anisiet } \\
\text { Lap. inctustat.. } \\
3
\end{gathered}
$$
Rhabarbarum in Lapid:

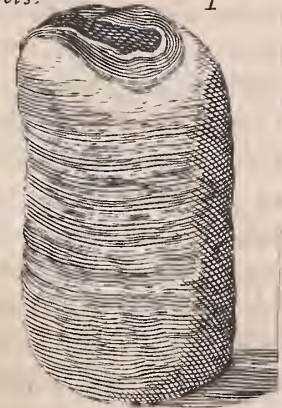





$$
\text { , }
$$

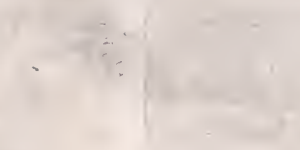

$1=$
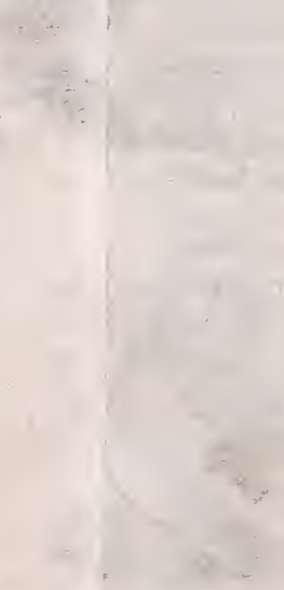
pora, femina facchaio albiflimo obducla non inepte mentientia, concrefcente, et inter illa pariter, quae vulgo Confetti di Tivoli dicuntur, uti modo innuimus, recenfenda, eruntque fructus hi cubebarum lapideiftalagmites beliaria fubrotunda afpera referens. In Mufeo Societatis Regiae Angl. p. 296. vocatur: a Great Tibuline Jugar Plum. Dantur quoque cubebaeferreae. Ephem. Nat.Curiof. Dec. II. Ann. VIII.

AMTGDALA IN LAPIDEM CONVERSA ad lapides belAaria mentientes referenda, et Amygdaloides dicendi. Nobilifi. Mylius in Memorabilibus Saxon. fubterr. Relat. V. plura de his amygdaliformibus lapidibus in faxis non procul Zwiccavia et pago $23 i l d$ at repertis refert, horumque hiftoriame Boetio a Boot et Gesnero illuftrat. Confer. quoque Excell. Valentini, qui in A1uf. Mufeor. Part.11. p. ro. felapidem Amygdaloidem, illis qui cinnamomo obducuntur, et Bintntets S)anveln dicuntur, per omnia fimilem poffidere fcribit. In Muf.Societat. Regiae Angl. p. 266. vocantur petrified Almonds, et Beslerus nolter citatur.

LAPIS CRINATVS Pyritae fpecies et quidem illa, cujus Gefnerus meminit de Fig, lapid. cap. XII. p. 1406. pilos referentis, aut ßos gúxž h. e. cirrhos, cincinnos vel plexos mulierum crines.

EXVVIAE SERPENTIS LAPIDEAE a Aufei Regii Anglicani Excellentillimo Autore, citato Beslero noftro, fifuldri Alcyonio, Gve Ferrant. Imperativermibus marinis petrefadis, Iralice Vermi marini impetriti accenfentur.

RHABARB ARV $M L A P I D E V M$ illud nomen non nifi colore Rhabarbari meretur, cum fructura plurimum a radice illa Sinenf, in officinis noftris pharmacevticis ufitata, differat.

LAPIS IIARGARITIFER, conchites eft margaritifer ab Am brofino in Alu. Metall. Aldrovand. defcriptus. Quamplurima frufa horum lapidum nobise Montibus Alzeyenfibus ab Excell. Geyero de1criptis afferuntur, et juftae magnitudinis funt cum Beriberi Indorum five concba margaritifera ab llluît. Liftero in Exercit. . Anatom. 3. Con. chyl. bivalv. Tab. IX. depicta, et in regio opere Hiftor, Concbyl. n. 22 . 222 .repetita.

PIS.A MAFORA LAPIDEA funt Pifa Thermarum Caro. linarum, quaePifis magnitudine, et forma fimilia. Stein: Srbfen dicta a Kentmann. in Catalog. Rer. foffil. Tit. VI. \$. 24. p. 38. Mufeum Regium Anglicum quoque memorat, et noftris fimilia pronuntiat ; apparet in nonnnullis armatura quoque ferrea. Vid, Ephem, Nat. Curioj. Dec.II. Ann.VII1. obferv. CXL1X. Plura non addo, cum horum piforum injecta mentio, ubide Pifolitbis. Tab. praecedenti.

SEMIINA LVPINI LAPIDEA nihil aliud funt, quam Sta. lagmites bellaria laevia majora referentes Excell. Langii in Hift. lapid. quorum jam aliquoties hac in Tabula facta mentio, et his Tabulam claudimus, quibus initium factum. 


\section{TAB. XXXVII.}

Diores quatuor lapides fructus exhibent in lapideam duritiem concretos. Sic e $M Y^{\prime} R O B A L A N O R V M$ genere unus comparet, cui vix fimilem in Mufeis quis reperiet; ficut et PIPER LONGVM $\angle A P I D E V M$, vegetabile exacte referens. OLIV A et NVCLEVS PINI LAPIDEVS, antiqui Lapidibis Judaicis annumerarunt, five ad balanites et glandarios, fed minus recte et exacte, ceu tabula praecedenti innuimus. LAPIDEAM OLIVANI quod concernit, affimilari poterit commode illi lapidi, quem Excell. Beyerus Orydogr. Noric. p. 45. exhibet, vel Pyrenae in Muf. Worm. p. 09. In Muf. Societ. Reg. P. III. cap. 2. p. 267. haec leguntur: Besler troo or three Stones Somew. hat like this, which becalls Petrify'd Olives.

NVCLEVM PINI LAPIDEVM adradiolumcucumerinum Luydii reducendum modo diximus, qui infuper apice acuminato fingularis elt, quales nondum Cl. Langio in Hiftor. Lap. figur. viff.

LAPIS STELLA MARINA INSIGNITVS e rarioribus Mufeorum eft. Exhibet quidem Ambrofinus in Mlufeo Metallico Aldrovandi Echinitem forma Stellari pulcherrimum, cuin noftro tamen non comparandum, in illo enim anguli plane obtufi, cum in noftro fint acutifi. $\mathrm{mi}$; Stellae marinae peromnia fimilis eft, nifi quod radii inaequales, inferiores enim fuperioribus breviores.

HI'STEROLITHOS fpadicei coloris, potius Lithocardites nominandus, cum Hyfterolithos proprie lapidem denotet, qui pudendum muliebre figura fua repraefentat, a quo nofter plane diverlus. Convenit melius cum Bucardite n. 2.ab Aldrovando M1uf. Aletallic. p.479. delineato, vel cum Bucardite Excell. Langii in Hift. Lap. Fig. Helvet. Tab: $X L$. n. 4. Excell. Baier Orydogr. p. 76.

HYSTEROPETRA fubalba major ad Bucardites potius referenda quam ad Hyfterolithon, differt tamen a reliquis Bucarditis interna concavitate, et concharum valvis convexis; quoad colorem convenit cum Bucardite Wormii in Mufeo p.81. Cor utrumque, non tamen exacte referens, In Mufeo Reg. Societat. Angl. Bucardites quoque noIt:r refertur, additurque: Figur'd by Besler with the name of Hifterapetra.

AMIMONIS CORNV PRRITI adhaerens, quale illud a B $d u$. bino in Balneo Bollenfi Libr.IV. p.15.16. defcriptum.

LAPIS NIGRICANS ROTVNDVS ALBIS MACVLIS. Nifi omni. me fallunt, crederem hunc effe $V A R I O L A T V A I$ fufe ab Ambrofino in Mul. Netall. Aldrovandi L ibr.IV.p. 882. feqq. defcriptum; vel $V$ ariolitem Lucernenfium nigrum variolis feu puftulis al-

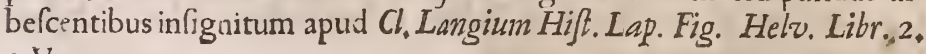
c. V.pag. 40. 
Mýrobalanus Lapid:

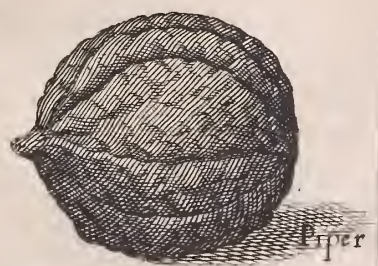

$\mathrm{H}$ usteralithis minor Spadicei Col:

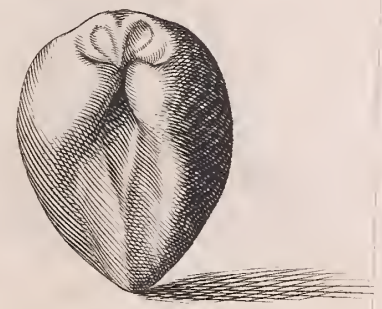

Lapis Nigricans rotund: alb maculis

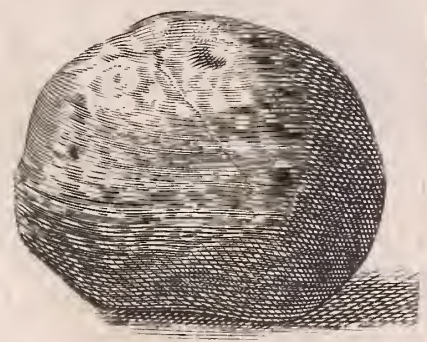



5. $x+2018$

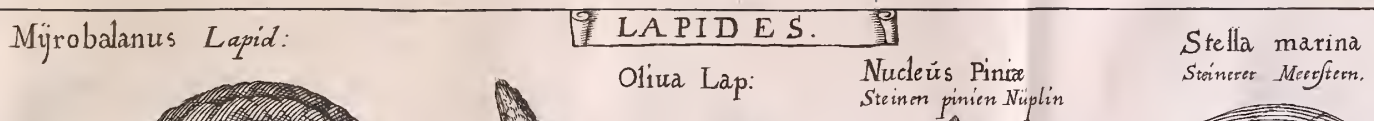

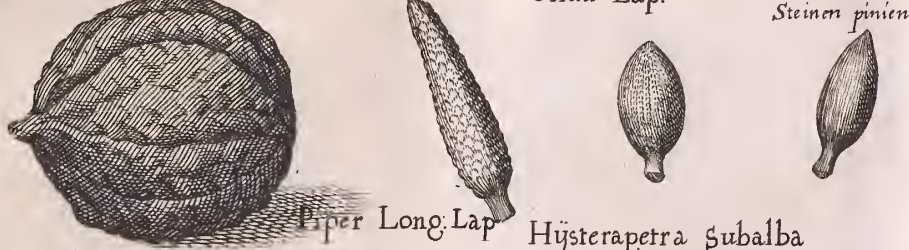

Hüsteralithis minor Spadicei Col:

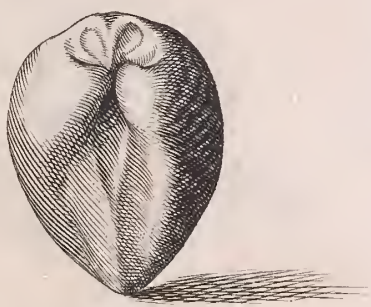

Lapis Nigricans rotund: alb maculis

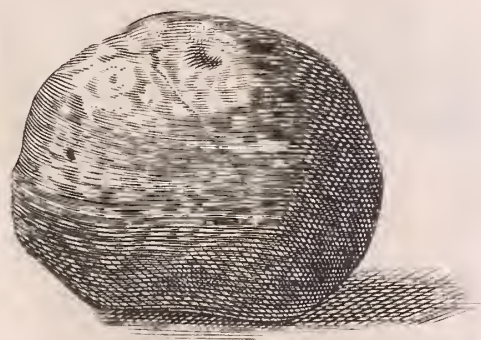

maior.

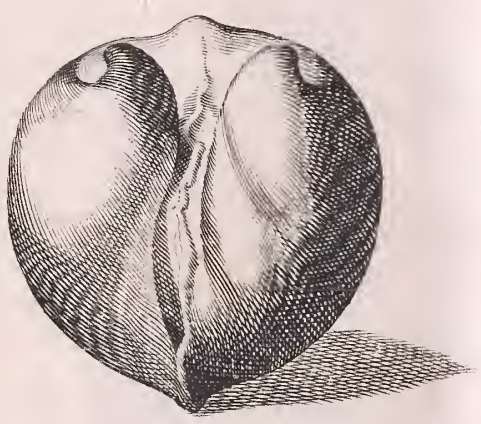

Oculus: Vitúlimǔs

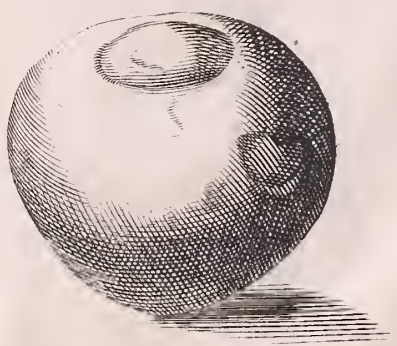

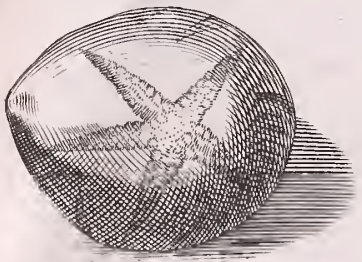

Amonis Cornŭ adharens püriti

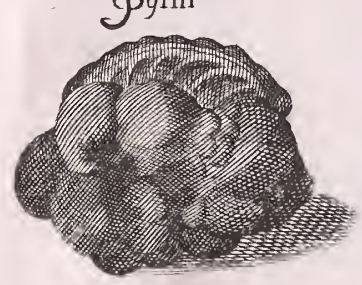

Lapis: Vermiculat us

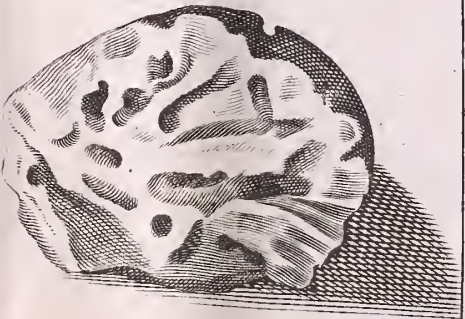




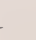
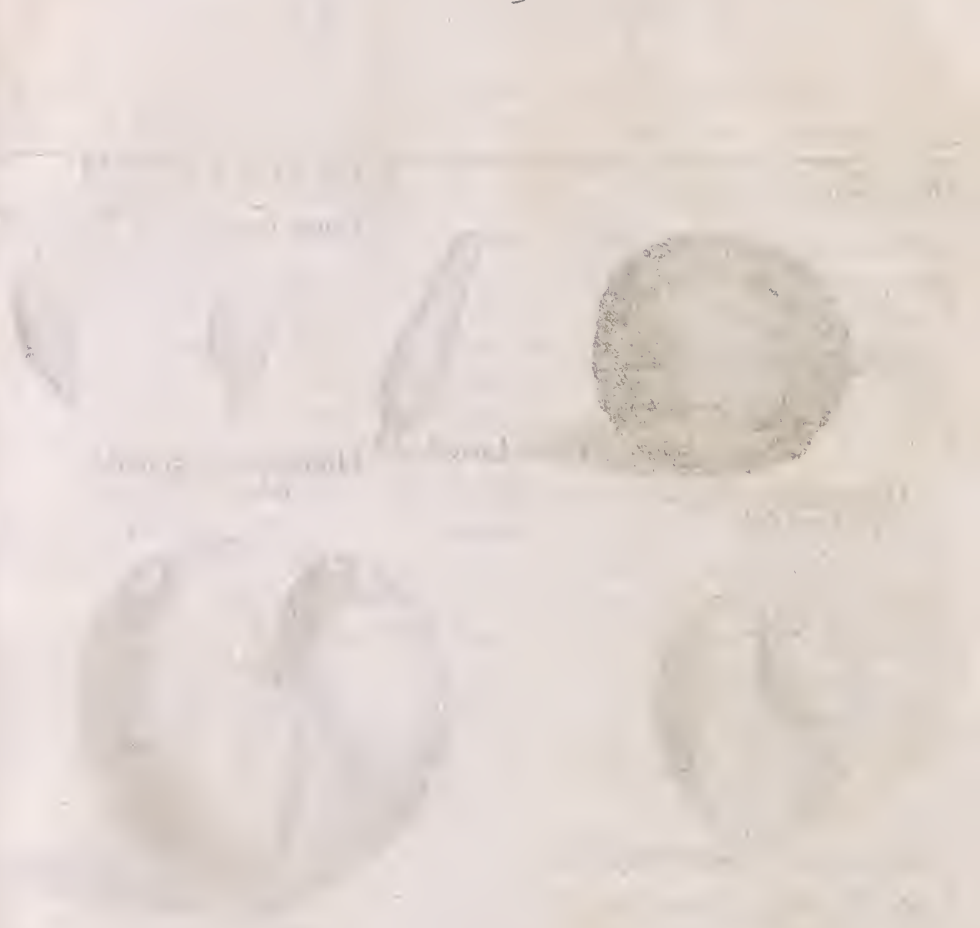
Lap: Vndülatús cum silice

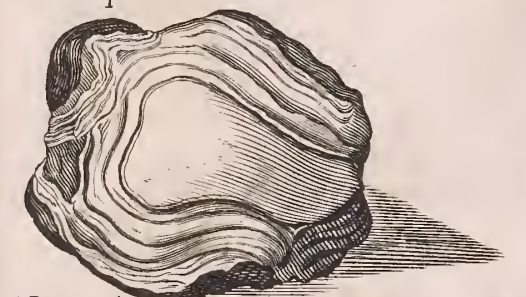

Marmor in quo $\rightleftharpoons$ Crux

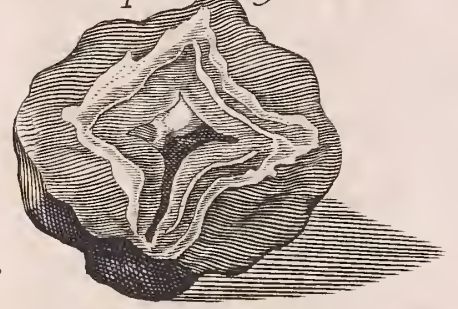

Lap:Herbipolens formazinziberis

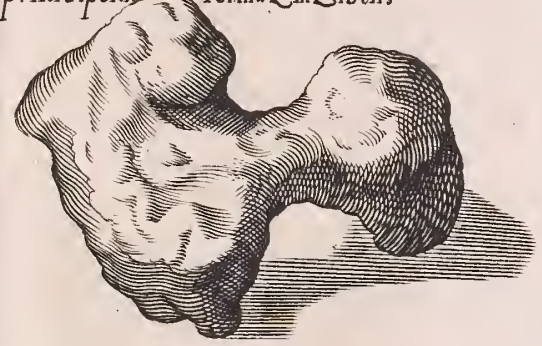

LAPIDES L $5 \times x \times$ III.
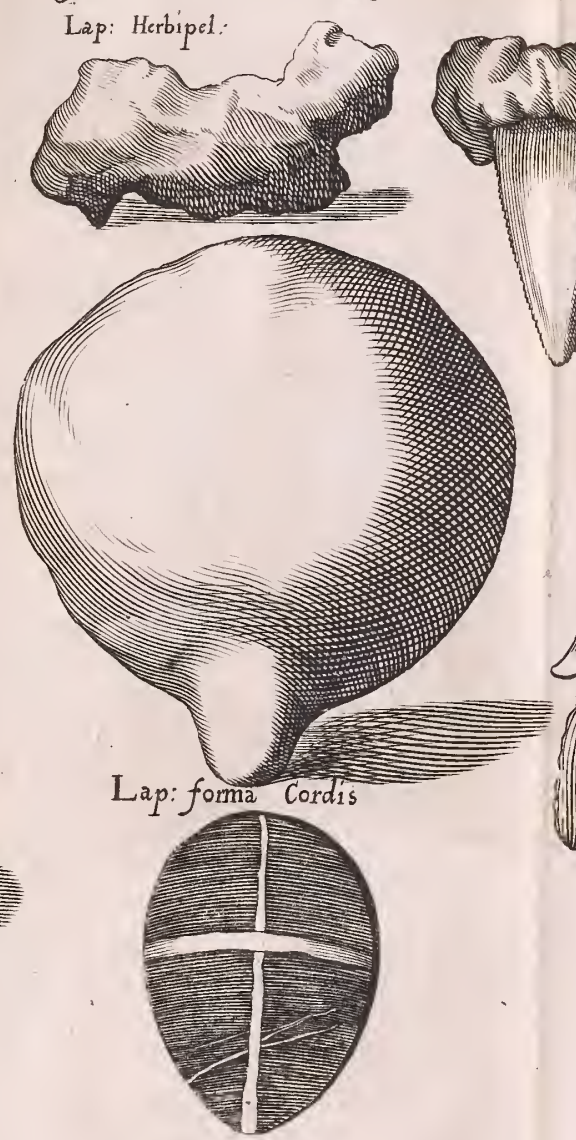

Lap: Lideús in quio
Glolsopet ra species
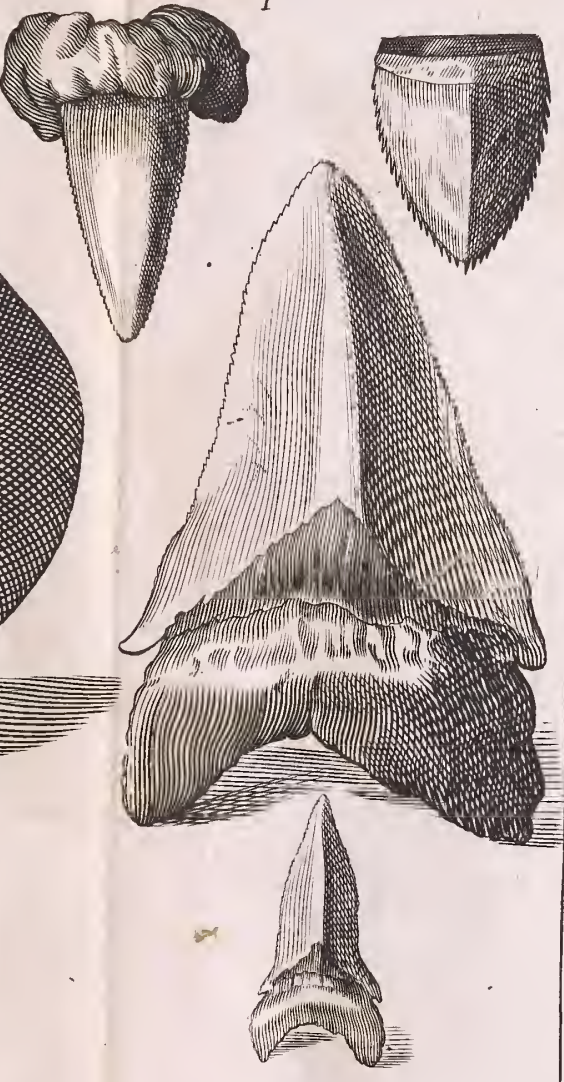
II.

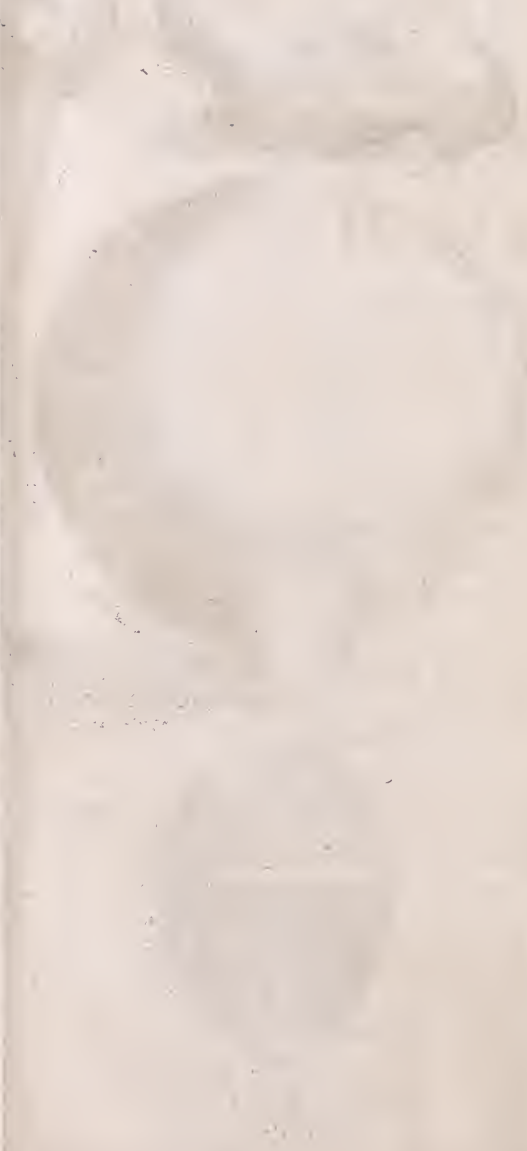

117 
OCVLVS VITVLINVS videtur effe Levcophthalmus five potius Lycophthalmos 1 liniia Gesnero de Fig. Lap. p. 144. et 1 s6. defcriptus, colorem enim habet rutilum, et in medio nigricante, gryleo et albicante cingitur. Vid, Erasm. Stell.in libell. de Gemm. P.IV. cap. G.

LAPIS VERAICVL ATVS Aultoris noltri, nullain plane fimilitudinem et convenientiam habet cum lapidibus vermiculatis, abA uctoribus Lithographicis defcriptis; nihil enim illi commune cum tubulatis vermicularibus $C$. Langii; fed lapis eft filic eae quodammodo fubltan tiae, cavitates intus exhibens, nidis, in quibus vermes exclufi, non abfimiles. Si conjecturae locus, forte terra eft, in qua Vermes Melitenjes perrefati, de quibus Wormius in AIufeo Libr. I. Sect. II. cap.13.p. go.vel filici Moeskirchenfi verminofo analogus, cujus meminit Exc. Welfchius Hecatoft. I. oblerv. 48.

\section{TAB. XXXVIII.}

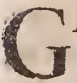

LOSSOPETRAS variae magnitudin's exhibet Autor, quos aptins ad Odontopetras referri et nominari credit Excell. Langius Hif. Lap. Fig. Helv. L.III. c. so p. 49, Multum differunt a Linguis Picae avis et ferpentum, quae non triquetrae, fed teretes et bifidae, planeque ab his Gloffopetris abludunt; hinc odontopetres has Exc. Luydius divi. dit in irrcifores ct molares; per incifores intelligit dentes magis acuminatos, et eos Ichthyodontes cuf́pitatos appellat: per molares vero magis obtufos, et eos 1clychyodontes Scutellatos nominat. Ex nomine Icbthyodon. tum apparet, ab Exc. Luydio, ut et ab.aliis plurimis, lapides hos pro dentibus Canis. Carchariae et Liamiae Pifis haberi; id quod $\pi i \xi$ vò $\lambda d d^{\prime} \xi$ defendit ingeniofiffimus Stenonius in. Anat. Capitis Carchariae Pifcis; quam opinionem deftruere conatur Cl. Reiskius in Differt. de Gloffopetris Lïneburgenfibus. Variant autem Odontopetrae magnitudine figu* raque, prout etiam pifces diverfis dentibus muniuntur; nec minus coloris differentia. Monftrolas et rariffimas in Lib. Joh. Laet de Gemm. er Lapid. viderelicet. : Nec in Italia folum, ubi Lamiarum copia, fed et in Germaniae noftrae Provinciis paffim proveniunt, ut non opus fit ad Alelitekfes tantum recurrere. Sic de Alzeyenfibus et Flonsheimenfib. Geye. rus, de Nlansfeldicis Alberti, de Luneburgèrfibus Reinkius; de Querfurtenfibus Buttnerus; de Helveticis Langius, de Holfaticis Major, de alis alii piffim. VTum Aedicum e pluribus breviter contraxit Cl. Lam gus Confer. prae aliis pluritnis Exc. Scbeuchzerus in Pifcium quierel, ef vindic.p. 17.18. feqq.

LAYIS FORMA CORDIS five Cardikes thinime ad Bucardites referri poteft. Vid. Muf. Fern. Imperati, qui primus eum defcripfit; nec convenit cum filice Bucardite Aldrovandi, nêc cum filice cardite Scbeucbzerim Specin. lithogr. Helvet. in quo ventriculibini cordis, eo* 
rumcjue figura fatis apeedifcrimina nur ; fed filiceus lapis, aliud quid potius quam Cor referens.

LAPIS LYDIVS, IN QVO CRVX ALBA. Stavrolithos five crucifer lapis, a crucigeris lapidibus, qui viginti milliaribus a Fano divi Jacobi Compoftellac dicto eruuntur, et ab Ambrof mo in Nufeo Metall. Aldrovandi defcribuntur, multum diftans, cum erim (1) omnes hi lapides per transverfum fecti, figuram cordis oftendant, (2)

- lapides molles fint; nofter hic Stavrolithos e genere lydiorum duritiei extremae eft, cui crux tantum in fuperficie impreffa, coloris albicantis in lapidenigro, Quoad duritiem melius conveniret cum Silice Stavrophoro ab codem Ambrofin. Muf. Aletall. Aldrovand. p.735. n. 2. deferipto. An illis lapidibus nofter hic fimilis? qui in regno Chilen $f \mathrm{i}$ in exiguo flumine, Flaragvete ab incolis dicto, prope oppidum de Petegvelea inveniuntur, figno crucis fignati. Figura equidem irregularis eft, red ubi crux vifitur, ovalis; formatur ea per interfectionem rectangularem diametri majoris et minoris, atque fanguinis inftar rubet. Vid. Journal des obferv. Phyfiqu. Matbem. et Botaniqv. du.R. P. Louis Feuille, quibus continenturObfervationes Phyficae et Botanicae ac Mathematicae, juffu Regis Galliarum in America Meridionali ẹt Iñdia Orientali ab An. 1707.usque ad An.1712, factae.

MARMOR, IN QVO 'CRVX, convenit quodammodo cum filice Stavrophoro ab Ambrofino defcripto, qui expreffam quoque a natura crucem ferebat, et marmoris inftar radiabat. Coloris tantum ra. tione differt, cum Aldrovandinus filex viridi et obf curo colore infignitus cum cruce coloris herbacei, cum in noftro lapis albefcat, et crucem includat quoad infernam partemnigram, quoad fupernam cineream.

LAPIDES HERBIPOLENSES, quorum unus figuram Zingiberis, alter Stalactiten repraefentat, filiceae funt duritiei, naturaeque lufits non adeo admirandi.

LAPIS VNDVLATVS CVM SILICE nil aliud effe videtur, quam fpecies Oftracitis Silicei undati rugofi a Cl. Langio in Hiftoria Lu. pidum Helvet. Lib. 6. cap. 10. p. 1 s o, defcripti. Vid. Lacbmund.Orydogr. Hildes beim. c. II. p. 32.

\section{TAB. XXXIX.}

$\mathrm{C}$

Yontinet utplurimum Lapides e regno Animali defumptos. Et quidem quos Auctor LAPIDES ASELLORVM MAJORES nominat, apte conveniunt cum Lapidibus Corvuli et Vmbrae Pifcis, aCl. Ambrofino in Muf. Aldrovand. Metallic. p. 796. defcriptis et depictis; funt enim gibbofi juxta partem exteriorem, habentesque tuberculum in medio cum appendice. Hos Lapillos fub nomine Lapiduan Manati Amfterodamo miffos accepit folertiflimus Pharmacopaeus Dietericus, in fubftantia cerebri repertos, ideoque plane differentes a lapide 


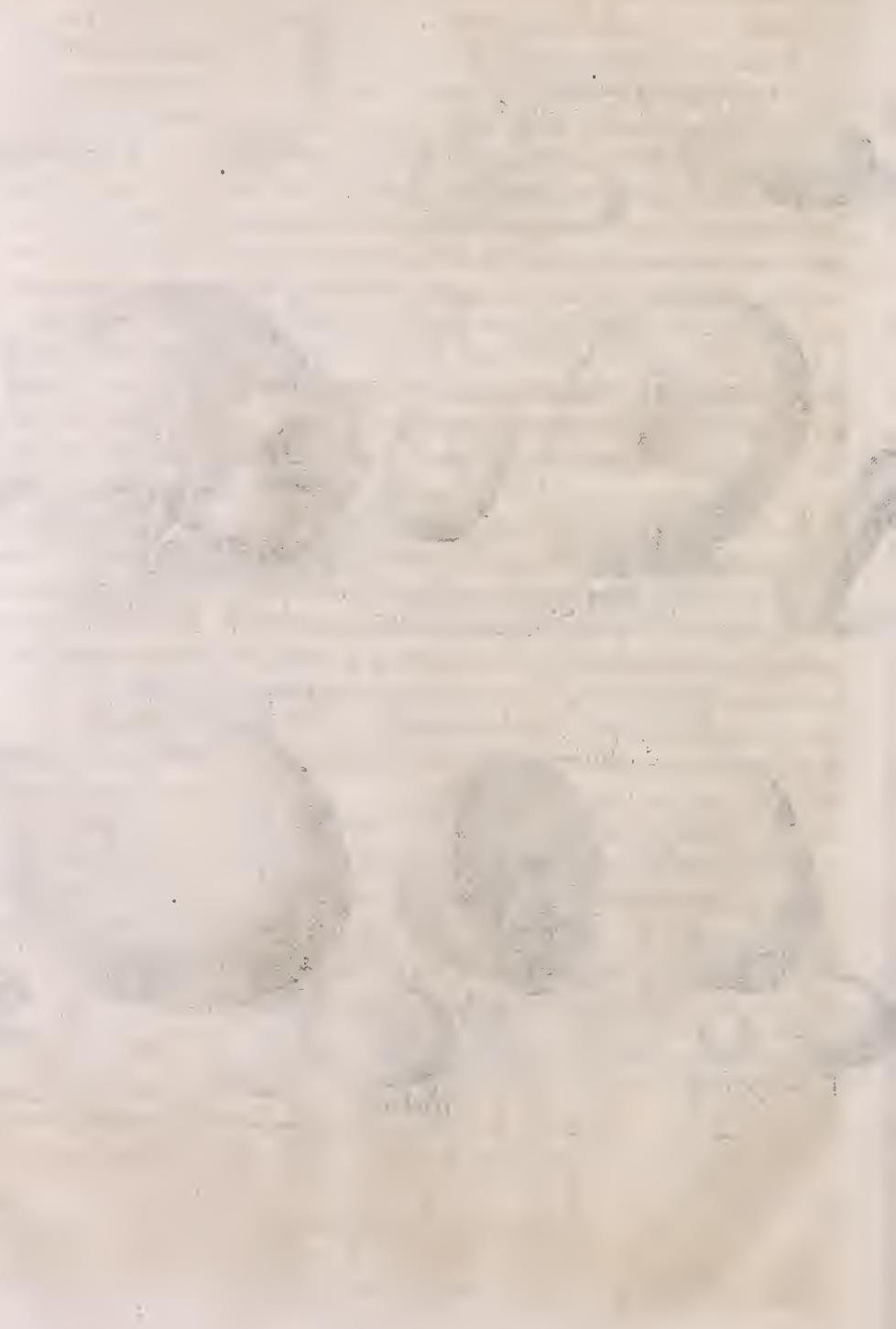
iflo Mlanati, five offe ad Auditum fpectante, quod hoc fub nomine in Muleis et officinis Pharmacevticis proftat. Quod Lapidum iftorum effcaciam concernit, vulgo dictum lapidem Manati fi non luperare, aequare certe vifi funt optimo Parenti, qui aliquoties eos feliciffimo cum fucceffu in coërcendis Sanguinis fluxibus exhibuit. Tales quoque lapides in Afellis majoribus, vulgo Cabelian dictis, repertos fuiffe, nullum dubium, cum Exc. Welfchius fcripferit Hecatoft. 1. obf. 28. Nullum bucusque Pifcium genus in ejus manus veniffe, in quo, fi copia daretur, difcerpto ca: pite praeter ofjum lapides etiam lapillos verosnon repererit.

LAPIDES ASELLORVM MINORVM funt lapilli Pifcis marisBalthici Accolis Dorfch dicti, candidi, oblongi, incurvi, laeves, fed in limbo utrinque pulcerrime crenati, circa bafin Cerebri obvii, tefte Excell. Major. in Memorial. Anat.objerv. V. de Animal. Littor. Kilon. \$. 7. Minimi autem lapilli funt Percae pilcis in Officinis Pharmacevticis notiffimi.

LAPIS E FELLE TAVRI e majoribus eft, qui extrahuntur, nec cumillis convenit in Mufeo Aldrovandino ab Ambrofin. L. IV. p. 750. delineatis, quibus ut plurimum in veficula fellis humani reperti fimiliores, quos adumbravit in Lithogenej. five de Microcofmi membr. pe. trefact.cap.X. p. 2I. F. G. Schenkius a Grafenberg. Sylvaticus lapidem hunc Majatium interpretatur. Quae Bellonius hoc de lapide annotavit, illum apud Turcas maximo haberi in pretio, ac Arabice Hazaczi ab Avicenna vocari et commendari, ac ab Judaeis Orientalibus morboregio obnoxiis ceupraelentiffimum remedium exhiberi, experientia quoque apud nos confirmat. Vid, prae aliis plurimis, qui lapidis hujus me. minere, folertifimus Wel/chius Hecatoft.I. p. 116.

De LAPIOIBVS BEZOAR poft Cl. Sylvaticum, Baubinum et Deufingium, qui tractatibus integris, et Rolfinkium ac Cl, $\mathrm{Vefti}$, qui differtationibus Academicis peculiaribuss, et hic quidem Erfurti Anno 17.07. ille Jenae.1675. Luci publicae expofuere, cui Laur. Catelani quoque libellus e Gallica in Germanicam Linguam translatus addipoteft, nil nobis fupereft, quam ut rem omnibus notam breviufcule delineemus: $L a$ piden Bezodr Orientalem effe fubltantiam lapideam foris fplendidam, glabram, quafi laevigatam, coloris foris arro virentis, interdum dilutius virentis pallefcentis, intus obfcure cinerei; forma modo rotunda, modo oblonga, tereti, vel ovali, magnitudinis variae, compacta e plurimis la. mellis inftar caeparum fibi invicem incumbentibus, oftendens in meditul. lio cavitatem notabilem continentem paleas; pilos, fibrillas aliaque fimilia, nata in facculo peculiari ventriculi Gazellae Indicae cornibus rectis nigris longiffimis prope caput annulatis, Tab. X. a nobis defcriptis, odoris nullius evidentis,

LAPIDES BEZOARDICI OCCIDENTALES funt fubftantia lapidea Orientalibus fragilior et laxior, foris fcabra et minus laevigata, coloris modo ex viridi nigricantis, modo cinerei, inftar caeparum pariDd 2 
ter tunicata, forma u: plurimum rotunda, interdum quoque, uti e fgur Autoris patet, ovali ct oblongiufuld, nagnitudine varia, res heteroge. neas in meditulio continens, nata in facculo peculiari, oprime ab avtopta Ponet l'Hiftoire gener. des Drogizes delcripto, ventriculi Animalis Bezoardicioccidentalis Ficuniras five Toraguas Acoftae, Teuthlama came Hemardez, Guguacu Pifoni Marggravioque dict. Quamvis Exc. Hermannotefte, hoc proprium in India Occidentali, quod vix anitnal reperiatur, in quo non generentur Lapilli tales, omnesque hoc nomine ad nos deferantur. Sic Cl. Rumphius palmam inter Bezoardicos la. pides tribuit illis, quie fimiis Borneae majoribus colliguntur, Culiga Kaka dictris. Lufitanis Pedra vel Culiga de Buzio. Vid. ejus Muf. Amboin. L ibr. II. Art. LV. Horum Lapidum jam ante Rumphium defcripticnem dedit Magnific. Nat. Curiof. Praefes Volkammer. Ephem. Nat. Curiof. Dec. II. Ann.II. obferv.189.p. 420. Cum merx haes plurimis mangoniis exponatur, cautelis opus, quas optime expofuit Exc. $V$ alent. Muf.SIufeorum Tom.I.p. 426 .

LAPIS TVBERONVM vel potius TIBVRONVM five Canis Carchariac aut Lamiae Auctoris nofri plane diffimilis illi, ab Ambrofino in Muf. Aletall.Aldrov. Lib.IV. c. 58.p.797.exhibito. Quoad Cubnantiam hic nofter non diffimilis Lapidi Manati, quem eundem cum Tiburonum lapide cenfuit olim diligentiffimus Clufius, vid. Worm. in Muf. sap. VIII. p. 58. ideo refutatus ab Exc. Stablio Differt. de Lap. Mlanati,

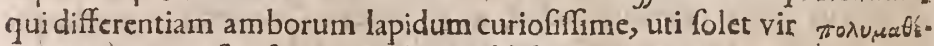
sara. , rimatus eit, ufusque medicos addidit.

$\therefore \quad$ SCOLOPENDRITES et ECHINITES non nifimagnitudine differunt; Et quidem Scolopendrites Auctoris convenit cum ecbinit filiceo faftigiato Excell. Lifteri de Cochl. Angl. p. 219. Meminit hujus lapidis illuift. Grem in Muf. Societ. Reg. Anglic. P. III. p. 260. Besler flgures a fmall Conick Helmet by the name of Ecbinites: a greatone, by that of Scolopendrites.

ECHINITES quod concernit, funt illifecundum Exc. Beierum. c Clafle univalvium teftaceorum belicibus carentium, figurae utplurimum fubrotundae, quosilluftr. Luydius appofite nuncupat fibulares, propter formam glomerulo veftiario (cin Snopff) accedentem, dividunturque in papillofos et Juturis aut fulcis lineisve ornatos, quibus Aucto. ris noftri accenlendi.

OVVM ANGIINVM, ad Brontiam five Ombriam a nonnullis relatum, eft Echinites pariter orbiculatus deprellus filiceus, ab Excell. Lifterop. 2 c. deficriptus. Ovum hoc anguinum Nobilifl. Luydio Lithophy!. Britann. p.100. vocatur echinites maximus laticlavius. Rarifimi hilapides in Britannia integri inveniuntur, at fragmenta fatis elegantiacirca Oxonium faepius occurrunt. De V fu medico hujus lapidis varia Olear. in Auf.Gottdorff. p. 32 . feq q. Qui victoriam fibiex hoc lapide pollicen- 
tur. Enfis capulo conjungi curant. Rufticae Danae contra incantationem vafis lacteis apponunt.

BATRACHO1DES vel Crapodini vulgo dici lapides, quorum capitibus contineri multis perfuafum. Auctor nofter duas Ipecies exhibet, a Gesnero quoque de Figur. Lap. Cap. XIII. pag. 16 r.b. defcriptas. Rotundus intus cavus, foris convexus, coloris albefcentis ad fubcine.reum tendentis; alter major et oblongior; addit Gesnerus lapidem poAeriorem et rariorem vocari quoque Ophitem, Gd) langen=-Stcinobel groffen Fitotell= Stein. Aldrovando dicitur Batrachites Orientalis figurae ovalis er oblongae, quem in Mufeo Metallico, noltro plane fimilem delineat, MIuf. Metall. Libr. IV .cap.60.p.814. Citatur Audtoris noltrifigura in Aiu. Societ. Reg. pag. 200. Besler figures tbis, with the Name. of Batrachoides. Plura de hoc lapide in Cl. Libavii fingularibus. P.IV. et quidem Batrach.L.II.cap.23, et Exc. Paullini in Bufone: Sect. III. cap. 3, p. 20. \{eqq. Baldneus in defcript. or ae Malabar. Coromandelet Ceylon. p, I62.

CHELITONII LAPIDES ab Autore noltro delineati, plane differunt a lapide Chelidonio Cl. Wormii, qui lapillus eft perexiguus, magnitudine feminis Lini, fed figurae hemifphaericae, coloris obfcure lutei fplendentis parte convexa et rotund ore, purpureo et nigricante parte feffili; hunc in ventriculis hirundinum inveniri fama fert. Ad normam $W$ ormiani pariter delineat Exc. Langius Hift. figur. Lap. Helv. Libr.V.cap.V. P. I I s. Tab. L. Nulla plane lapidum fimilitudo cum noftris, nifi cum Aldrovando diftınguere velis inter lapides Chelidonios fofiles et animales. Lucem majorem praebet Excell. Welfchius Hecatoft. I. pag. 74. qui hac in re conlulendus. Cl. Sacb. Gammarol. pag. 306.

CARPIONV II five Cyprinorum LAP1S, proprie non lapis, fed triquetra cartilago coloris Lubfavi mollis, nec caeteris hactenus delcriptis duritie refpondens; modo laudatus Welfchius ofla lapidefcentia pronuntiat, qua fpina capiti connectitur acetabulo impofita, adeoque dentis vertebralis in homine fimilitudinem gerentis, Genuinos vero lapillos geminos exiguos planos albosque cuivis in cerebro cyprinorum inquirenti obvios fieri, lcribit Hecatoft. 1. n, 28. De viribus medicis hujus lapidis Vid.Worm.in Muf.Exc. Sachf. Gammarol.p. 307.

ALECTORIVS LAPIS fimilis ferme Calceolariano, quem a J.B. Portaceu donum accepit, licet non fatis accurate triangularis exiftat; nec conftat, an in ingluvie, an in lecore repertus fit. Marbodaei verfus de hoc lapide recitat Ambrofinus in Muf. Metall. Aldrovand. L APIDEM E STO AIACHO GALLINAE profilice devorato et in ftomacho polito habemus.

LAPIDES EX CANCRIS melius vocantur, quam oculi cancrorum, funt enim proprie lapilli cruftacei, duri albicantes glabri oricula. ri, diverfae magnitudinis, una parte comprefi et finuati, altera convexi, 
nati utrinque unus, in ventriculo Aftaci fluviatilis, laporis et odoris nulli * us evidentis. Licet omnibus noti fint hi lapilli, non tamen omnibus corum eft ortus. Vtplurimum Menfe Junio et Julio languere et aegro tare nicipiunt hi aftaci, cumque non nutriantur, exanimantur fere, et in corum ventriculo tunc reperitur materia quaedam lactea, quaequae fenfim poft aliquot dies concrefcit in lapillos, qui deinde fenfim iterum confumuntur, et ut probabile eft, in reftaurationem cedunt, exuvias enim tum reponunt et refumunt; haec Excell. Hermanmus. Fufusifta ex Viri incomparabilis Wepferi obfervatione explicat, diligentiffrmus Sachfius in Gammarolog. qui omnia, quae de lapillis his dici poflunt, congeflit.

\section{TAB. XL.}

CVm Tabula XXVII. occafione Androfaces LAPIDIS FVNGIFE- $R I$ et Funginappae injecta fuerit mentio, immortalisque Gloriae Severinus, Epiftolam de Lapide Fungifero nomini Celeb. Mich. Ruperti Besleri inforiplerit, quam Cl. Carolis Avantius, Baptiftae Fierae Coenae notis illuftratae adjunxit, liberque hic inter rariffimos nunc effe coeperit, confultum duximus rariora hujus epiftolae, relicta luculenta Severini de Tuberum natura et generatione digreffione, excerpere, aliisque ad lapidem fungiferum lpectantibus, ex aliis A uctoribus fupplere. Tam oppido obfcuram, tamque retrufam naturam nactus eft lapis, quem vulgo fungiferum appellant, ut ne etiam nomen unum apud omnes retinuerit, aut ad unum tantum genus rclatus fue. rit. Aliis nempe volentibus, Lyncurium, aliis Elearum aliis TuberFungarium. Anveteres hujusmodi Fungorum cognitionem ullam habuerint, non facilc erit determinare. Theophraftus quidem Hift. Plant. 1.4. c. s. in

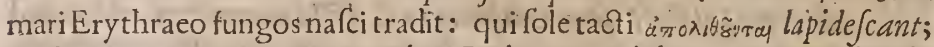
quales et nos quoque in rarioribus Beslerianis exhibuimus. At elapide fungos prodire, non dum fe legiffe meminit $\mathrm{Cl}$. Avantius. Quod enim fcribit Hermolaus Barbarus, Coroll: 698. effe ubi Plinius hoc innuerit, modo laudatus Avantius certe in auctore illo, quem non perfunctorie fe legiffe profitetur, nihil tale obfervafie fcribit. Mlatthaeus Sylvati: cus equidem in $P$ andectis cap 447. Evacis mentionem injicit, qui hujus lapidis Lyneis, meminife fertur, fed hunc Evacem, Arabum Regem Neroni familiarem, legitimum fcripti Auctorem fuiffe, eruditiomnes dubitant. Quid verofi de his loquatur Arifeas apud Athenaeum? mú-

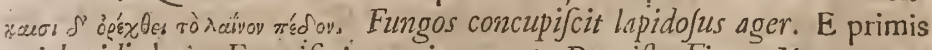
qui lapidis hujus Fungiferi meminere, crit Baptifta Fiera Mantuanus, in Caena. De Mlatthaco Sylvatico Pandectario modo diximus, ut et de Hermolao Barbaro. Meminit pariter hujus lapidis Andr. Caefalpinus de Metall.c. 2 5. Julius Caef. Scaliger in Cardan, de Subuil. Exerc. 87. Petr. Andr. Mlattbiol. Comment. 7 s. I. 4. in Diofc, Vlftad. lib.de fenfib.c. 33. J. B. PortaVillae lib. I0.et Phytognom. I. 6. c. 26. Ferdinand. Imperatus 
$\mathcal{F}_{\text {ig.VI. }}$
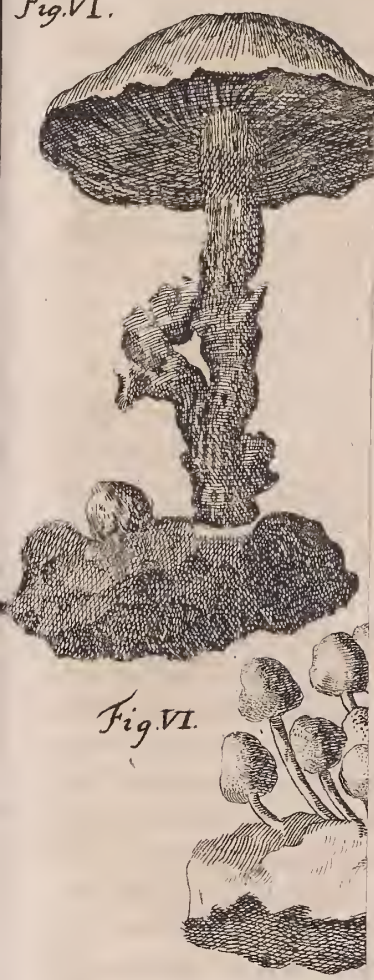

\section{Fig.III}

r

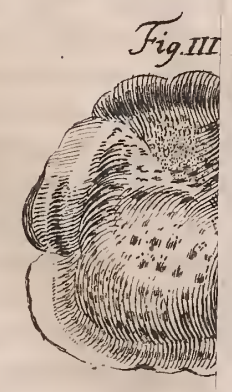



$\widetilde{J A B X L}_{\text {. }}$

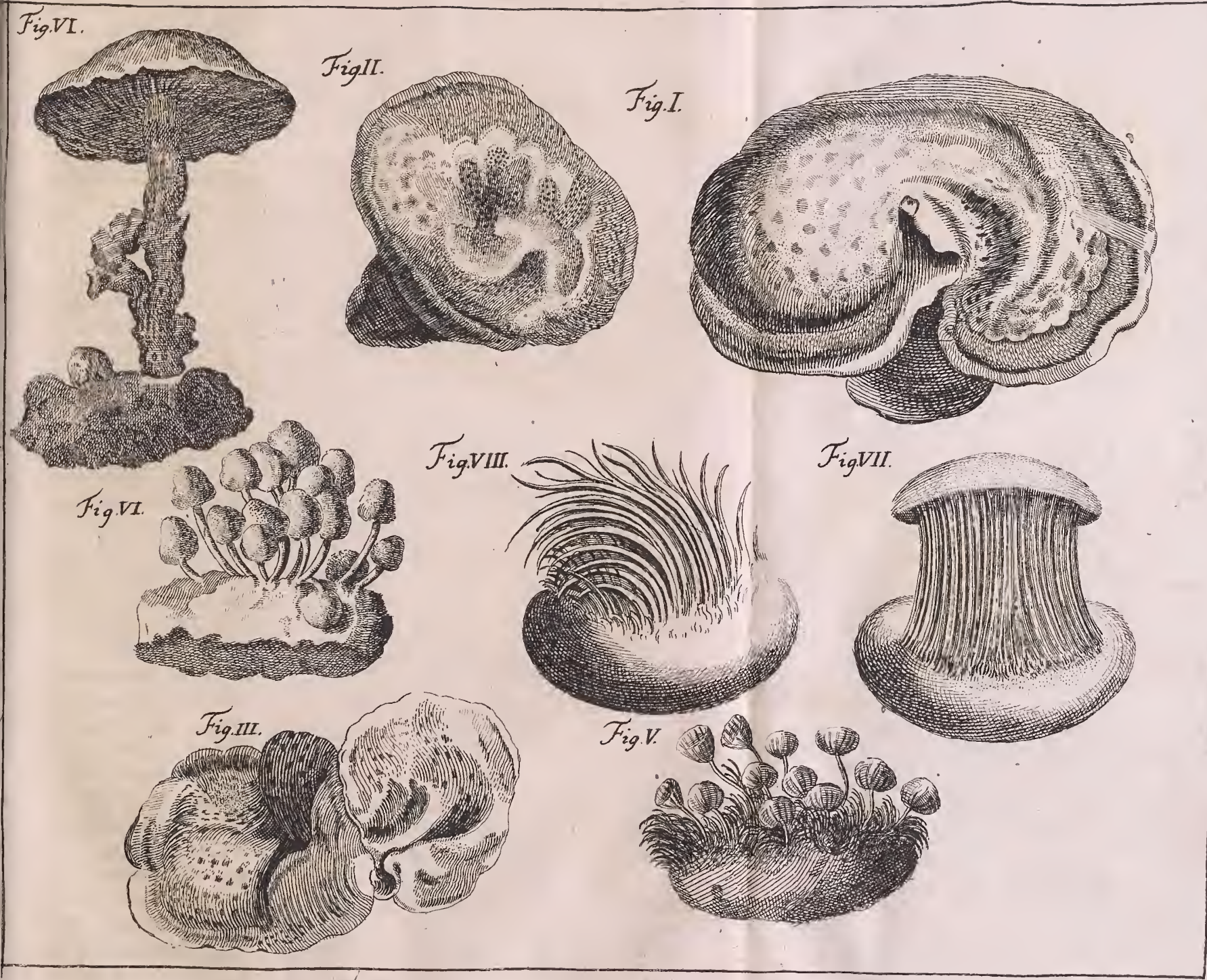



cap. V.et VI. Clufius Tradt. de Fungis, Sterrebekk, Theatr. Fumgor. fufiusque his de fungis corumque natura et generatione fe tractaturum promi. fit Cl. Avantius in Paraleipomenis Botanicis. Effe autem lapidem Fungiferum, de quo nobis fermo, legitimumL yncurium, fi modo unquam in rerum natura exftitit, minime probari ullis poteft argumentis; quis enim tefte Severino et Avantio fibi perfuaferit, e Lyncis animalis non valde magnilotio, lapides centum et interdum plurium librarum excrefcere; quibus adde hujusmodi lapides effodi pluribus Regni Neapolitani Tractibus, in quibus nullos nafciLynces apud omnes in confeffo eft. Si quidigitur in hifce vulgi ineptiis conjicere licet, exiftimat toties laudatus Avantilus, id nominis Lapidi factum effe, quod optimae notae effodianturad Collem Pardi, ditionis Procerum Columnenfium, unde celebratifimae Anticoli aquae derivantur; atque ex natali loco primum Lapides collis Pardiappellatos fuiffe; inde vero fciolum quempiam ex Pardo Lyncem, et ex Lynce demum Lyncuriz nomen ineptifime effinxilfe; vel quia fungi ex eo prodeuntes, crebris illis, quibus funt fparfi, maculis, maculati tergora Lyncis quodammodo referre videantur. Eft autem Lapis bic ex Avantii defcriptione, qui Tobia Aldino illum dono accepit, magnitudine bubuli capitis, cujus etiam figuram non inconcinne referre dicitur, (quamvis figura variet, nec enim ille, quem Excell. Volkamerus e Neapolitano obtinuit Regno, hujus figurae,) Juperficie appera, rugofa, rimis nonnullis bislca; colore partim inten/e nigro, partim dilutiore, et adcinereum vergente; Jubfantia porofa, pumici non abfimili, longe vero ponderofiori; quae et filicis fruftula quandoqve inferta babet, ut connatum efje videatur, argumento quidem non levi, lapides iftos $e$ lento ac glutinofo terrae fucco, et adjacens quidlibet invifcante coalefcere. Hic pingui terra modice tedus, et tepida fubinde confperfus, Fungos fert fuaviffmos. Illorum generationem aut fi mavis productionem, latius e Severino defcribimus; Portio, inquit, fungiferi triplex: İna quae fub Terra, radix et fibrae colore pullo. Secunda pedunculus alboluteus. Tertia Fungi umbella. Radix propemodum arborefcentem proceffum refert i.e indivaricatum: fcifflis eft et geniculata, ut Zinziberis Penae, Iridis Sylveftris Matthioli, Ec Ec. Radicis extimae fibraefunt veluti capillus, tenuisfmae ac varie implicatae crippaeque, quales ad ungvem fipitis Oryzae funt paleae minutae. Fungi germen primum et fipes, fiplenis fuis numeris adoleverit, digitali usque longitudine attollitur: infino pediculo nixus, quomagis terrae propinquat, gradatim tenuiore. Cui Fungoprimum erumpenti Veficula major eft gemmae vitis magnitudine, aut paulo majore; quae digitis compreffa reddit bumorem aquae fpecie, faporis aciduli guftu. Eft autem Fungus facie, qua coelum jpectat, umbilicata, et levi: inferiori vero conit. nentiferie diftinda, pundulis quam creberrimis et alveolis minutiffmis: Jungimus Severinianae defcriptioni Avantianam: Fungi figurae modo rotundae, modo ovatae, Jaepe etiam inaequali labro, variisque ac finuo. 
fis anfractibus bumanas auriculas aemulant ibus Vid. Fig. I. II. et III.Colore interdum flavo, (exalbo flavefcentes erant in Horto Volkameriano prognati Vid. Floram Noribergenfem.p. I 78.) interdum dilute purpureo, (e mper verocrebris padiceis, vel at rorubentibus maculis apper $i$; quae prius quam objole cant, non parvam ip $\sqrt{5}$ elegant iam conculiant. Illud quog, admiratione non vacat, quod f capus, qui ab evulfo fungo Lapidi adhaeret, Jenfim induretur, ac eandem cum Lapide foldditatem et fubftantiam acquirat; ita ut fungus lapidem et matricem fuam, ue aic Fiera in coena alere, et alimentum, quod acceptt, ip $\sqrt{2}$ quodammodo rependere videatur. His non concentus $\mathrm{Cl}$. Severinus Analy/in quoque Hermeticam hujus Fungi, opera Nobilitr. Fojepbi Donzellii Neapolitani, et Magnifici quondam Academiae Naistae-Curioforum Tertii PracfidisBeatisfimi Volkameri, quem amiciffimum vocat, inftiruic. Extracta Aqua farua Ipiritus er oleum ad L. Quajaci per recortam pulfi fa-, porem et odorem maxime accedens, cinis e quo Sal valde acre excractum. Spiricum vulnerarium optimum deprehendir Severinus, ur ejus ope folius ex umbone, qui ad folliculi lufum cubico inducicur, per vim illifo vulnus inferiore labro cransfoflum quatridui fpatio curaric. Fungiaurem arefacti pulvifculun audiveric Medico cui. dam in Calabris uficarum, Plevrutidis es Nephritidis remedio, quod abfeeflum aut macure diflolvit, auc fuppuratum jam disrumpic acpurgat. Cumque elui paricer gracum, verum eric medicamentum alimentofum. Hactenus ex Avantioer Severimo Fungiferi Lapidis defcriptionem dedimus, differc tamén ab illa maxime quem modo laudatus Excell Volkamerus Ephem. Dec. II, Ann. III. exhibuir Fig. IV. a robis paricer exprelfum, er dum Neapoli apud Cl. Severinum ftudiis Chirurgicis incumberet ipfi, una cum alis a Generofif: Equite Cafliano a P'ureo, et Marco Schipano Severino communicatis, quae fungiferi Lapidis Species Fig. V. VI. et VII. exhibencur, ur exinde clare parear, diverfiffimas dari lapidum horum fungeas excretiones. Sequicur Lapides Fungiferos Fig. VIII. ec IX. FVNGIMAPP A ab Excell. Severt. no Epiftola ad Jobannem Simonem a Gratia defcripra. Eftque bic Lapis Coticula parva ovi unfermi longitudine, fed eodem complanatior. Si perconteris de magnitudine cotw, unciolas tres examinata pendit. Ecujus diametro circumquaque furgat Seges capillamenti, recti, digitipollicis infantis longitud.ne, colore candedisimo, rigentibus fetis, quae cußpidulae extremae, fiquidem obtutu diligenti et acrifpectantur, acetabula ct cotyledones referunt exzliffimos; vifa eft baec babitsdo tota barbam canam referre; quibus tamen pilis infiructisfima Cos plurima parte deglabrata; leu quidem extremo fqualore colla: $/ 2 \mathrm{~s}$, Jeu frequenti manuum attrectatione detriment.x pasfis. Cacterum baec fila dentibus attrita gufitum linguae falfum excitavere, terreumgue ecbini marini psculorum Jen/um ftridefcentem reddidere. Quadelapji parte capili facies Cotis aperior et bifpidior, ut cogno, ceret quis inde relicta veftigia decrfforum pilorum. Indicavit autem Si. mon a Graesa Severno, fylvelienes Saxo mulcos ac cenuifimos quafi capillos, fummis fuis a picibus tenus communiobductos umbella, et convexa propemedum fun-. gea pacella; quamobcaufamdubius, an fungiferum, an Hcrbiferum lapidem vocarec. Qua caeteroquin umbella non comperta, credidic facile Severinus longin.' quioris agicatione vecturae decultam, Hac igitur particula, quam non vidic fuppofica, licenti in renova vocabulo Fungimappam vocare aufus: quod fungca foboles mappa quadam inducta fuperne contegatur. Credic autem Fungirappae procreationem in Saxo convenire cum his, quae relatafunt de Coralliis er ftirpibus, quae in ftaruis lapideis concrevere. Fxhiber aurem Figura VIII. Fungimappam cum /uterftite T mbella, ubi AA. Siliculus fubfratus vegetanti locus. BB. Itipites . ailurgenies. C C. Mappa fuperdata. Fig. IX. Fungimappam difcaffa umbella fittis, er quidem D D. Siliculum vegerationi fubftratum. $\mathrm{E}$. ftipices liua mappa orbacos ac propterea reclinaros. 


\section{F $\mathrm{L} O \mathrm{R} A$}

MALABAR I C A S I. V E

\section{HORTI MALAABARICI}

$$
C A T A L O G \cup S
$$

Exhibens

Omnium ejufdem Plantarum nomina, que é variis, tum veteribus tum recentieribus Botanicis collegit, or in ordinein Alpbabeticum dige fort.

\section{CASPARUS COMMELIN, Med. Doctor,}

Et Horti Medici Amfelodamenfis Botanicus.

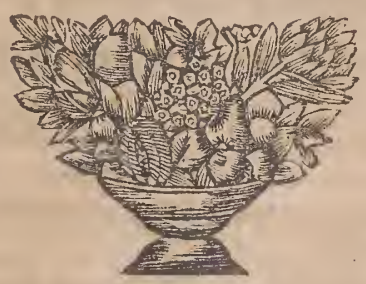

LUGDUNI BATAVORUM,

Apud FREDERICUM HAARINGH, Bibliopolam.

M. DC. XCVI. 


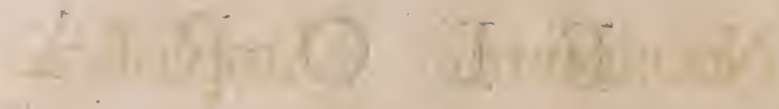

(5)

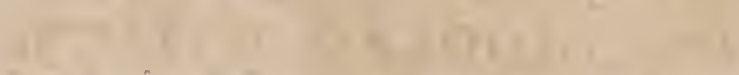

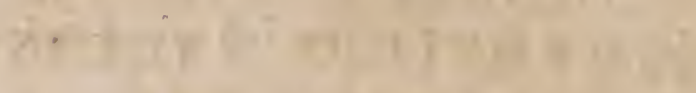

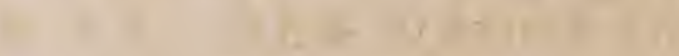

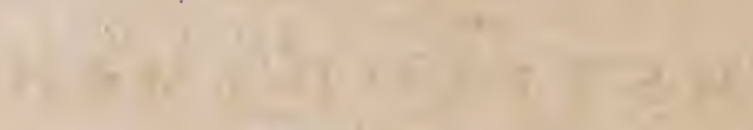

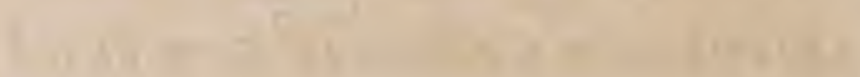

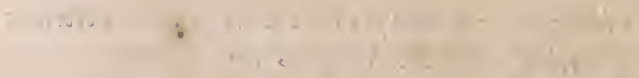

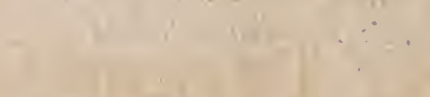

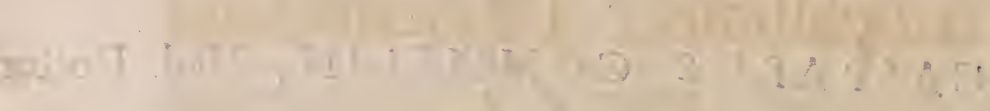

$:$

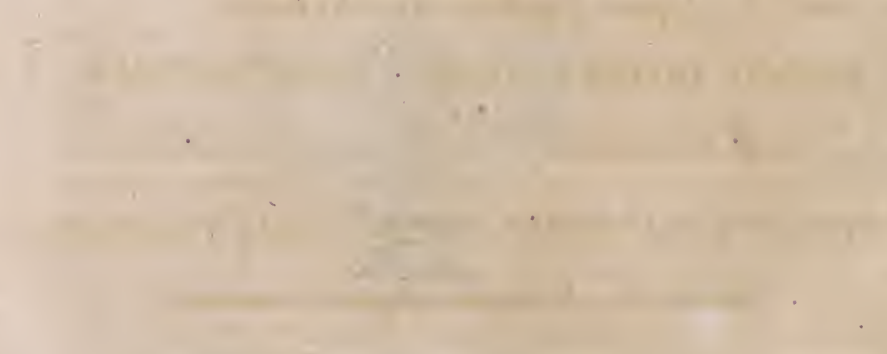

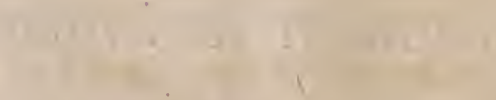

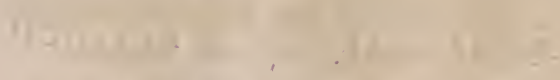




\title{
Nobilisfimis, Amplisfimis,
}

\section{Prudentisfimis}

\author{
$V \quad I \quad R \quad I \quad S$
}

Dno. JOANNI HUDDE,

Dno. NICOLAO WITSEN, f: V. D.

Dno. CORNELIO VALKENIER,

Dno. THEODORO BAS, 7. V. D.

A M S T E L O D A M E N I S REIPUBLICAE CONSULIBUS, E SENATORIBUS.

NEC NON

\section{Ampliflimis , Prudentiflimis}

$$
\begin{array}{llllll}
V & I & R & I & S
\end{array}
$$

Dno. FRANCISCO de VROEDE, F.V.D.

\section{Scabino Præfidi \& Senatori.}

Dno. JOANNI HUYDEKOOPER VAN MARSEVEEN, J.V.D.

Exfcabino.

HORTI MEDICI AMSTELODAMENSIS PRCEFECTIS.

Dominis fuis, \& Patronis perpetuum venerandis.

FLORAM HANC WALABARICAM $E a$, qua decet, reverentia

D. D. D.

CASPARUS COMMELIN. 


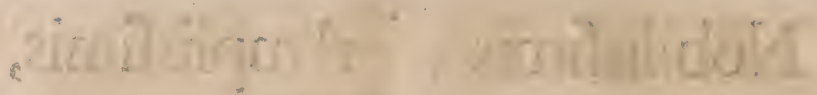
achilbrulise

$$
\text { 18. } 102 \quad 1=1
$$

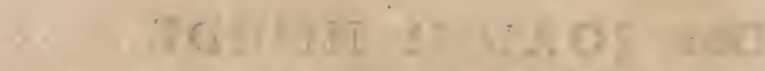

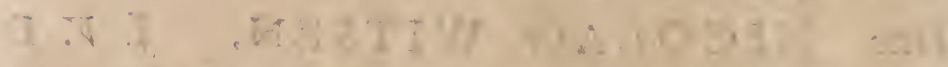

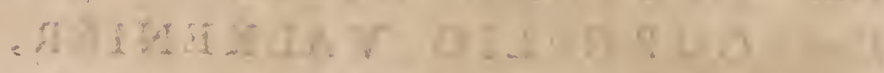

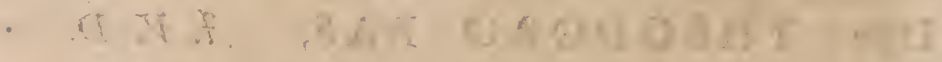

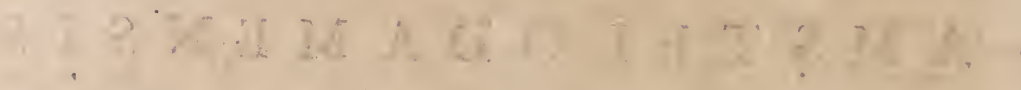

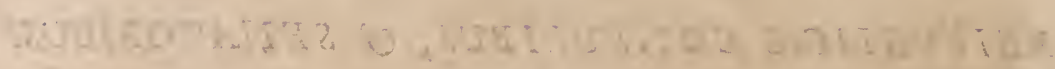

$$
\because 6 \text { is } 9801 \text { ? }
$$

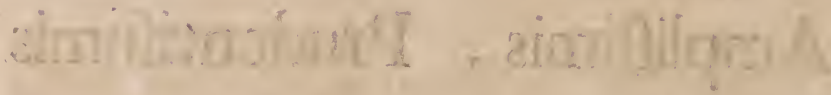

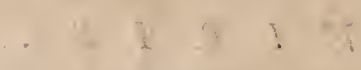

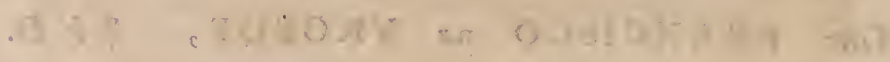

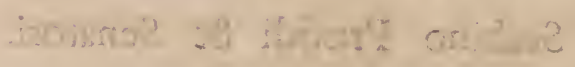

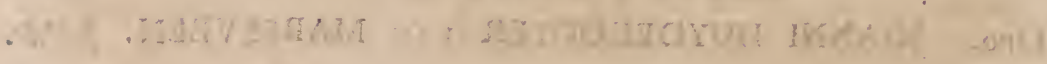

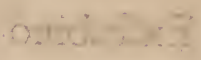

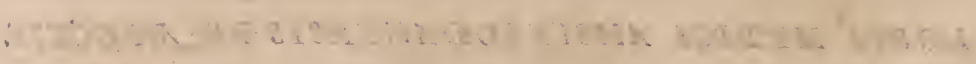

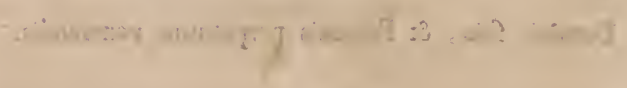

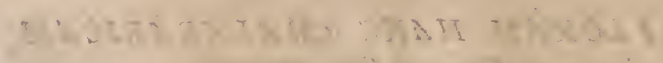

$$
+, \ldots, \cdots: ?, 2
$$

$\therefore \quad .5$

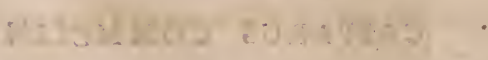




\section{LECTORI BENEVOLO}

$S$.

7 Rodierunt ante aliquot annos duodecim vafti iffius Operis Hort MALABAR ICI titulo infigniti tomi, quos fummá diligentia in ipjo Regno Malabarico collegit Nobiliffimus \& Generofifimus Dominus Henricus van Reede tot Drakenftein. Toparcha in Mydrecht \&c. \& c. Ac orbi publicos fecit, quorum primuin notis \& commentariis illuftravit clariffimus EG expertiffimus vir Arnoldus Seyen Med. Dottor, Med. \& Boranices in Academiä Lugduno-Batava (dum viveret) Profeffor celeberrimus, quomortuo, reliquos undecim tomos notis E commentariis illuffravit Patruus, Joannes Commelin Amftelodamenfis Reipublicx (dum viveret) Senator, Hortique Medici Prefectus; in quo Horto Malabarica multe planta reperiuntur, quaruin tum veteres, tum recentiones rei berbarie forptores mentionem facientes, illas ipfas aliis nominibus, E Sapifsime convenientioribus (relictis nominibus barbaris $\mathcal{F}^{2}$ ab indigenis ufitatis, qua tamen nonnulli fervarunt) ab ipfis plantarum partibus pracipuis E' conftantifsimis, boc eft, frutificatione defumptis, infignire voluerunt, quales funt in re herbaria verfatifsimi viri C. Clufius, G. ab Horto, C. a Cofta, G. Pifo, J. Bontius, G. Marggravius, uterque Bauhinus, A. Seyen, J. Breynius, P: Hermannus, J. Kajus, J: Commelin, L: Plukenetius, P: Turnefort, S: a Dale, aliique bene multi, quorum omnium finitâ bac prefatione feries exbibebitur: quarum omnium plantarum tum a veteribus tum recentioribus rei herbaria foriptoribus defcripiarum, EO Horto Malabarico contentarum nomina collecta, e er in ordinem alphabeticum difpofita tibi, Lector Benevole, nuncexbibeo, additâ tomi, Libri, É pagina tum citati auctoris, tum ipsuss Horti Malabarici indigitatione continua a nec omifsis tum Malabarenfibus, tum Bramannis, tum Lufitanis, tum Batavis (in Malabaria babitantibus nimirum) tum aliis gentibus uftatis nominibus, adeo, ut quigque plantam fibi propofitam invenire posfit, qualecumque ejus nomen noverit, nam barbaris dumtaxat nomibus Sapisfime, tum ex utrâque Indià, tum aliis telluris plagis in Europam vel advehuntur femina, vel planta, EF ab auctoribus defcri- 
buntur, quod prefertim boc jeculo ob plantarum ante non vifarum copiam accidere botanicorum nemo nefcit; quo enim feculo magis boc ipfofloruit res berbaria, quam, fiprateriti temporis recordemur, Eo á fine prateriti feculi in bunc ip fum diem detectas plantas in memoriam revocemus, quâ copiâ veteribus ignotarum ditatam bocce die non videmus? ex quâ copiäillud utilitatis, boc commodireful tavit, quod fimplicia medicamenta plurima detecta fint, quorum nobis antea, ob brevißimas E obfcuras, multorum fimplicium apud veteres defcriptiones, prater folum nomen, Ev virtutum cognitionem aliqualem innotuit nibil, exempli Loco fint Lignum colubrinum, Nux vomica, Amomum, Gutta gamba, Coftus aliaque Simplicia, que accurate Satis defcripta atque delineata exbibet Hortus Malabaricus, quorum omnium fimplicium accuratam babere cognitionem cum deceat Medicum, quibus plantis cum ditatum fit fudium botanicum, E Medicis \& Botanophylis Horti Malabarici Lecturam fummopere neceffariam nullus dubito. Hac funt L. B. qua prafari volui, the interim fruere noftro Labore, E Vale.

Dabam Amftelodami ipfis Kalendis Decembris. M. DC. XCVI. 


\section{PR在CIPUORUM NOMINUM \\ A B B R E V I A T O R U M \\ D I L U C I D A T I O NES.}

Alp: de Pl: CAg:

B: Pin:

S B:Theat: Bot:

B: Mattb:

Belg:

Boccon: Ic: D. D:

Bont:

Bram: $1.7:$
Breyn: Cent:
Bresn: P: $\mathrm{J}$.

- Breyvi: PP: 2. Eivit?

C: H: Beaum:

C: H: Beaumont: $M:$ :St

Ceylon: Eే Zeyl.

Cingalens:

Clus:.APp:-

Chus: Cur: p:

Chus exot:

Chus: $H$ :

Clus: in Garz:

Colum: in not: ad Hern:

Comnel: Cat:

Commel: in not:

C: a Coft:

Cunci Refp: Hebr:

Dale Pharm:

\section{Dod:}

Ferrar: Flor: Cult:

G: ab Horto

Herm: Cat:

Hern. Herb: v. Ceyl:

Herm: in Ep: ad: d: Syen Herm: Mus: Zeyl:

Hernand:

H: Lugd:

H: Reg: Par: Cat:

$\mathcal{F}: B: \mathcal{T}: L:$

Linfchot: itinerar:
A Lpinus de Planris Ægyptiacis.

Calparus Bauhinus in Pinace.

Ejuftem Theatrum Botanicum.

Ejufdem editio Matthioli.

Belgx.?

Pauli Bocconis Icones \& Defcriptiones rariorum plantarum Sicilix.

Jacobi Bontii Hiftoria naturalis \& medica Irida Orientalis cứm cómmentatió Pifonis.

Bramannes.

Jacobi Breynii exoticarum flantarum centuria prima.

Prodromus fafcucali rariorum plantarum Primus ejuldem.

Ejufdem Prodromus Secundus.

Horti Beaumontani exoticarum plantarum C̣atalogus.

Ejus Catalogus Manufcriptus:

Ceylonenfes, \& Zeylonenfes.

Cingalenfes.

Caroltis Clufius in Appendice Hiftorix rariarum planta-

rum.

Ejurdem Curæ pofteriores.

Ejufdem exoticorum Hiftoria.

Ejufdem Hiftoria rariorum plantarum.

Ejufdem Notæ in Garziam ab Horto.

Fabii Columnæ annotationes in Hernandi Volumen.

Joannes Commelin Catalogus Horti Medici Amftelodamenfis.

Idem in notis ad Hortum Malabaricum.

Chriftophori â Cofta Aromatum Hiftoria

Cunæi Refpublica Hebræorum.

Samuelis â Dale Pharmacologia, feu Manuductio in rem Medicam.

Remberti Dodonæi Kruydboek.

Joannis Baptiftæ Ferrarii Florâ, feu Florum cultura.

Garziæ ab Horto Aromatum Hiftoria.

Pauli Hermanni Horti Academici Lugduno Batavi Catalogus.

Hermannus in Herbario vivo Ceylanico, quem ex infula Zeylon ad Patruum miferat Hermannus.

Hermannus in Epiftola ad Dominum Syen.

Hermanni Mufrum Zeylanicum.

Francifci Hernandes nova Plantarum, Animalium, Mineralium Mexicanarum Hiftoria.

Hiftoria Generalis Plantarum Lugduni.

Horti Regii Parifienfis Catalogus, feu Schola Botanica,

Hiftoria plantarum univerfalis Joannis Bauhini Tomus $x, 2,3$. Liber.

Jan Huygen van Linfchotens Voyagien. 
Lob: Obferv:

Lob: advers:

Mal:

Malaccens:

Margg:

Matth: in Diosc:

Mifc: Cur: DD: A:

Munt:

Nieubov: Itimer:

Nieubov: Legat.

Par. Bat.P.

Parkins. Theat.

Pijon.

Pifon. Mant. Ar.

Pluken. P.T.

Raji H:

Rivin: introd:

Syen in not:

Stap: in Theop:

Sterbeck. Catric.

Turnef, El. Bot.

Vefling. ObS.

Zanon. H. B.

Zeyl.
Lobelius in Obfervationibus,

Lobelius in adverfariis.

Malabarenfes.

Malaccenfes.

Georgii Marggravii Hiftoria rerum naturalium.

Andraas Matthiolus in Diofcoridem.

Mifcellanea curiofa Medico Phyfica Academix naturæ cu: rioforum Decas, Annus

Abraham Muntingh naukeurige befchryvinge der aardgewaffen

Nieuhovii Reys befchryvingh.

Nieuhovii Legatio ad magnum Tartariæ Chamum.

Pauli Hermanni Paradifi Batavi Prodromus.

Joannis Parkinfonii Theatrum Botanicum.

Guilielmi Pifonis Hiftoria de Indix utriufque re naturali \& medica.

Ejufdem Mantiffa aromatica.

Leonardi Plukenetii Phytographia, five Stirpium illuftrio* rum ac minus cognitarum Icones, Pars, Tabula.

Joannis Raji Hiftoria plantarum.

Rivini introductio in rem Herbariam.

Arnoldus Seyen in notis ad Hortum Malabaricum.

Joannis Bodxi a Stapel Commentaria in Theophraftrum.

Francifci Sterbeek Citri cultura.

Pitton Turnefort, Elemens de Botanique.

Joannis Vef̣lingii obfervationes de Plantis \&ggyptiaciso

Hiftoria Botanica Jacobi Zanoni.

Zeylonenfes, 


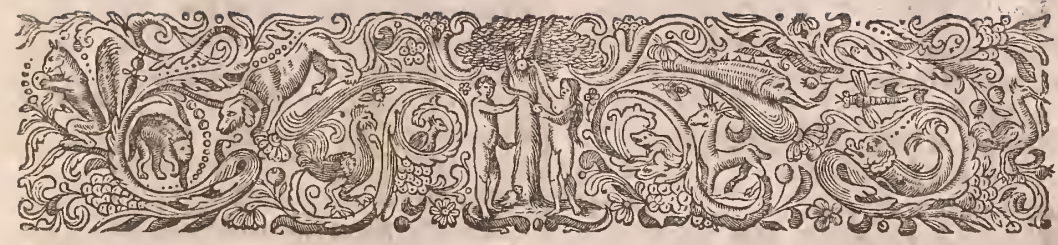

\section{F I O R A \\ MALABARICA.}

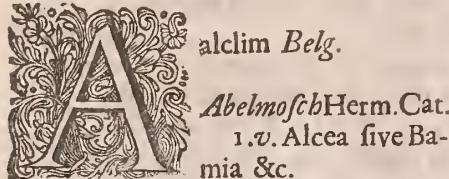

Abrus Alp. de Plant. ÆEg. 76.v. Phafeolus alatus \&c.

Abuli Bram

Abutilon Indicum J. B. T. 2. L:xxiii 959. Althxa \&c.

Abutilon Indicum quinque ad fingulos flores thecis Raji H. 1880 v. Althra \&c.

Acacia gloriofa Lentifci folits Spinofaflore Spicato Luteo, filiqua magna muricata Pluken. Pi.T. 2. f. II. v. Crifta Pavonis \&c.

Acacia Malabarica altera fpinis carens Commel. in not. Arbor Indica filiquofa flore tetrapetalo ftellato, filiquis bipalmaribus planis. Raji H. I766 Waga Mal. Sigi Bram. Favas do Lafaro Lufot. Melshouwen Bolg.

A cacia Malabarica flore globofo, filiquis latis Commel. in not. Acacia Malabarica globofa Intfia dicta Raji H. 1739 . Acacia Malabarica fulcata floribus globofis albis $P$ ar. Bat.P. 304. Tehoaxis foliis acacix fimilibus Herm. +09. Intfia Mal. Cocoefa Bram. Spinhos dos morcilhos, vel Spinhodos mauros Lufit. Wond-doorn Belg. an Aca-
8- 55 cia Javanica fulcata caule \& folio. rum coftis Spinofis C. H. Beaum. 2? Acacia Maderafpatana Spinofa pinnis veluti Lunulatis acutioribus Myrtiamulis, nervo pinnularum ad unum Larus vergente, filiqua lata. Pluken P. 3.T. cxxij.f. 2? Mimofa arborea Javanenfis Spinofa tenuiffmis pinnis, fliqua Lata pergrandi, fpadicea Breyn P. 2. 73?

Acacia tinctoria Herm. v. Crifta pavonis \& $\mathrm{c}$.

Acacie cognataplanta J. B. T.r. Lxii. 433 v. Siliquofa Indica \&c.

Acara-Patsjotti. Mal. vide Baccifera Indica \&c.

$2-35$ Acatsja-Valli. Mal. vide Cufcutæ fpecies \&c.

Acetofa Indica Bont. I I3. V. Alcea Indica \&c.

Acorus verus five Calamus aromati$6-3$ $6-11$ $5-15$ $7-83$ $6-75$ cus Afiaticus, radice tenuiore Herm.Cat. 9. Calamus Aromati6-9 cus G. ab Horto zoo Capicatinga, aliis Jacarecatinga, Jeu Acori fpePifon 241. Vazabu हु Vazumbo Ceylon: Va-Embu Mal. Bembi Bram.

Acua Bram. v. Zerumber.

I $1-99$

$1 \mathrm{I}-\mathrm{I}_{3}$

Adaca-Manjen. Mal. v. Planta Indica \&c. $: 0-85$ Ada-kodien. Mal. v. A pocynum \&c. 9-9 Adaly Bram. v. Ranunculi aftinis \& $c_{1} 10-93$ 
AdamaramMal. $\tau$. Anygdala Indica

\&c.
Adamboe Mal. v. Convolvulus \&c. $\quad$ I 1 - I 15 Adamboe E Cadelipoea Mal:v. Alcea Indica \&c.

Adderboonen Belg. $v$. Clematis arborea jndica \&c:

Adel-Odagam Mal.

Adbatoda Zeylanenfium Mus: Zeyl: Herm: Cat: App: 642.v. Frutex indicus

Adbatosia flore minore Turnef: El: Bot: I 44.v. Frutex indicus \&c. Adbatoda flore Labio fuperiori angufijfimo Es ad pofteriora reclinaro. Turnef: El: Bot: I 44. ข. Frutex indicus \&c.

Adolia Bram: $v$. vitis Idææ fpecies \&c.

Adoulatti Bram: $v$. Baccifera fpinofi \&c.

Adulafo Bran.

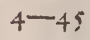

$6-47$

$9-8 I$

$$
2-33
$$

$2-33$

ZEfchinomene mitisfecunda, vel potius Herba cafta Zeylanica, filiquis latis compreflis minoribus. Breyn: Cent: 47. Raji H: 98r.NitiTodda-Vaddi Mal Lauri Bram.

Agaty Mal: Agafto Bram: $v$. Sesban Affinis \&c.

Ageru Bram: v. Heliotropium Indicum \&c.

Abate vel Aie de Panucbo. Herm: $348.454 \cdot v \cdot$ Pomifera indica \&c.

$3-2 I$

Ain-Pariti Mal: v. Alcea indica \&c. 6-73 Ajomato Bram: $v$. Frutex indicus baccifer \&c.

$5-79$

Ala-Candalu Bran: v. Candela indica \&c.

Alady Bram: v. Curcuma \&c. Alangi Mal: v. Baccifera indica \&c. A lce a Javanica aborefcens, Flore pleno rubicundo Breyn: Cent: 121 . Schem-Paretti Mal.

Alcea five Bannia Mufchata Egyptiaca Alpini \& Veflingii Breyn $P$. 1, 2. AEgyptiaca villofa $B$. Pin: 317. Althaa Egyptiaca mofchata, abelmofch dicta. Morif. H: 533 . Ketmia Egyptiaca femine Mofchato Turnet: El: Bot: 83 , Bamia Mo fchata officinarum. Dale Pharm. 342. Belmofchus regyptia Hono- rio Bello. テ: $B: T_{2}$ : L.xxiii 960. belmofch, vulgo Herm Cat: 25. Quigombo prior, five Alcea Mufchata Pifon. 2 10. Cattu-Gaturi. Mal: Bonda-Calo Bram.

Alcea arborefcens Japonica, pampineis foliis fub afperis, Flore mutabili, five colorem mutante Breyn: $B .2$. 10. Alcea Candaharenís arborea, pampineis foliis, flore mutabili Breyn: Cent. 122 . Alceis arborea rofea finenfis Commel Cat: 12. R ofa finenfis Ferrar:Cult:47\%. Althæa rborea rofea finenfis flore multiplici Herm: Catt: 22. Malva rofea arborea indica fimplici \& dupliciflore'Parkins:T beat:300. Murmtingh 192. Ketmia Sinenfis, fruciu rotundo Turnef: El: Bot: 84 . HinaPareti Mal: Madjani Bram: Rofa de china Lafit: Sineetfche Roofeboom Bely:

Alcea arborea Indica maxima, po$6-69$ puli folio, flore majore flavefcente Breyn: $P$ : 2.10. Alcea Malabarienfis abutili folio, flore majore, ex albo flavefcente Syen in Not: Raj: H. 1069. Althæa arborea indica populi folio, flore ephemero Herm: Cat: 22. Ketnia indica populi folio, fructu Orbiculato compreffo. Turnef: El: Bot: 84 . Bupariti CMal: Valli-Cari-Poefi Bram: Surighaghas vel arbor Solis Zeylon:

Alcea arborea Indica, Tilix folio craffiore, flore minore flavefcente Breyn: P: 2. 10. Alcea Malabarenfis, abutili folio, flore minore, ex albo flavefcente exterius fubafpero Syen in not: Raji H: 1070. Alchaa arbor indica, Tilix folio , flore ephemero Herm: Cat: App: 644. Ketmia indica tilia folio Tur nef: El: Bot: $8_{4}$ Pariti feu Tali-Pariti: Mal: Cari-capufi Bram:

Alcea jndica arborea pericarpio carnofo in plura Loculamenta partito Raji. H: 1902 . Alcea indica arborefcens Laurifolio Prima, /ive Alcea indica arborefcens foliis Laurinis fubafperis, Polyanthos Minor , flore purpureo hexapetalo, petalis rotundioribus, \& Latioribus fructu minore caudato Breyn: 'P.2. Ix. Althæa ærborea indica floribus violaceo purpureis
$I-5 X$

$1-53$ 
fpicatis Par: Bat. P. 307. A damboe \&5 Cadelipoea Mal. Soculari Bram. Catupinaca da Serra Lus it, Baakroofen Belg.

Alcea Indica arborea elatior peticarpio carnofo fubafpero Raji $H$. $\mathbf{I} 902$. Alcea indica arborefcens Laurifolio Secunda, Sive Alcea indica arborefcens, foliis Laurinis Lanuginofis \& Hirfutis, flore purpureo hexapetalo, petalis anguftioribus, Fructu Majore. Breyn. P. 2. 11. Katou-Adamboe, \& Katou-Kadelipoea Mal. DavaSotulari Bram. Catupinaca Brava Lufit. Wilde Baakroofen Belg:

Alcea indica camabino folio, acetofe fapore quibufdam Dale Pharm 343 v. CannabiSimilis exotica \&c. 10 - 19 Alcea Indica fruticofa flore coccineo, petalis crifpis RajiH: 1900. Rofa Batavico-Indica inodora feu Malva frutefceus Bont: 141. Ain Pariti Mal: Defura \& Kaprafila Bram: Futa do Sapato Macho Lis lt: Enckelde Schoenroos Belg: 6-73

Alcea Indica Spinofa magno flore ex albido Flavefcente Commel: in-not: Alcea acerofa Indica Spinofa, foliis profunde Laciniatis, flore fubluteo amplo Breyn: $\boldsymbol{P}:$ 2. 9. Althra Indica Sfinofa acctor fapore, flore flavo pendente Par: Bat: $\mathcal{P}: 308$. Acetofa Indica Bont: 113 Narinam-Poulli. Mal: Ambetti Bram: Fula Gafinhota Lufit: Krabben doorn Belg:

Alcea Malabarica folio vitis, flore ninore, rofaceo colore, fructu Lappaceo, femine roftrato Commel. in not. Uren Mal. Tupu Kadu Bram.

Alcea Malabarenfis pentapisylla, flore minore ex albo Flavefcente, femine tomentofo Syen in nor. $v$. Xylon Malabaricum \&c.

$A l_{c}$ Bram. v. Zingiber \&c.

Algodamo Lufit. $v$. Goffipium

Algodamo do Mato Lufit: $v$. Goffipium \&c.

Alkekengi fructu parvo verticillato.

Turnef: El: Bot: I 26. v. Solanum Somniferum \&c.

Alkekengi Mexicanum Cdlumn. in not. ad Hern: 296. $v$. folanum \&o. 4-I 3 Aloe Vulgaris $B, \mathcal{P}$ in.296. हु $V$ ariorum.vera vulgaris Muntingh. 309. kadanaku, vel Catevala Mal. Cumari Bram.

Aloe affinis Indica fupra arbores crefII -7 cens Commel. in not. Kansjiram-maravara Mal.fonon Bram. 12-17

Alcra Lufit: $v$. baccifera indica \&c. $\quad j-109$

Alofna de Batao Lufit. v. Matricaria \&e.

Alpam $10-87$

Alpam Bram.

Alfine Myriophylli folio, flore carneo Commel. innot. Araka-Puda Mal. Mefi Bram.

Alfine fpuria, $\int e u$ Veronica indica, flore cæruleo, chamædri folio.

4-47 Commel. innot. Tsjeria-manga- $\mathrm{Na}$ ri. Mal. Annili Bram.

Alfine affinis planta indica, flore can- $9-\times 65$ dido Commel. in not. Muriguti; Mal.Gae-Maril. Bram.

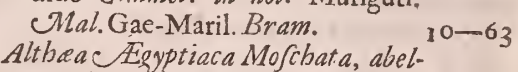
mofch dicta Morif: $\mathrm{H}: 533$ v. Alcea:

Althæa Americana betonicæ folio, flore Luteo Commel. in not. KatuUren Mal:

Alt be a americana frutefcens, $M e$ 10-107 locbice foliis anguftioribus Pluken: P: 2 T: LXXIV. 8. $v$. Sideritis folio \&c.

Alibea arborca lindica foribus vio. laceo Purpureis picatis Par: Bat. P. 307.v. Alcea

Althe a arborea Indica, populifolio, flore epbemero. Herm: Cat: $22 . v$. Alcea

Altba a arbor indica, Tilice folio, fore eppemero. Herm. Car. App: 644. $v$. Alcea

Alt bea arborea rofea sinenfis flore multiplici Herm: Cat: 22. v. Alcea

Althea Indica Spinofa acetofe fapore, flore flavopendente. Par: Bat: P. 308. v. Alcea

$1-55$ Althra Indica vitis folio flore am$4-45$ $2-71$

$6-5^{1}$
$2-33$

$10-39$

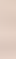


Althea Theophrafti fimilis $B: \mathcal{P}$ in: 316 Abutilon Indicum $\mathcal{F}: B: \mathcal{T}: 2$. $L$ : xxiii 959 . Abutilo Indico $\mathrm{Ca}$ mirarii fimle, fi non idem $R a j i H$ : 1880. Beloere Mal: Ta paucodo Bram: Fruita gargantilha Lufit: Lobhalfen Belg:

Althææ fpecies Commel: in not: Nelavaga Mal:

Amali Bram: v. Chryfanthemum \&c:

Amarantho affinis Commel: in not: Belutta-Adeca-Manjen Mal. an Amaranthoides humile maderafpatanumcap itulis candicantibus, folio molli 'Puken: $P$ : $3 . T$ : Cxxxiy. $f: x$ ?

Amarantho affinis Commel: $2 n$ not: Tfieria-belutta - Adeka - Manjen. Mal:

Amarantho affinis , feu Amaranthoi des major indica ocymoidis folio, \& facic , flore globofo Purpureo Breyn: P: 2. 13. Amarantho Affinis Indix Orientalis, floribus glomeratis, ocymoidis folio Breyn: Cent: 109. Amaranthoides Indicum monofpermum foliis ocymaftri, capitulis purpureis $\mathcal{P}$ ar: Bat: $\mathcal{P}: 309$. Gnaphalio affinis ocymaftrifolio, flore expurpureo Violaceo Herm: Cat: 294. Wadapu Mal: Goudo Bram: I0-37 Amargoleira Lufit: $v$. Azadirachta Indica \&c.

Amargofeir a macbo Lufit: v. Azadirachta Indica \&c.

Ambadeki Bram: v. Nux Myriftica \&x:

Ambal.tm Mal:v. Mangre affinis \&c: Amba-Paja Mal: v. Pepo arborefcens \&c:

Ambetti Bram: $v$. Alcea Indica \&c: Ambetti Bran: v. Jambos \&c:

Ambetti Bram: v. Solani affinis \&c: Ambel Mal: v. Nymphaa \&c.

Ambo-Kely Bram: Ambo Bram: $v$. Manga Indica \&: Ambrofia malabarica, artenifix folio odoratifrumo, floribus flavis Commel: innot: Katu-T fiette-Pu. Mal: $10-89$ Ameli Bram: v. Bacci fera indica \&c. $s-65$ Amelpodi mal. Amelpo Bram. v. Arbor Indica \&rc. $5-101$ Ameri Mal: $v$. Coluta Indica \&c. $\quad x-10$ I
Ammaco Lufit: $v$. Pruni fera \&c.

Ammacomacho Lufit: v. Prunifera

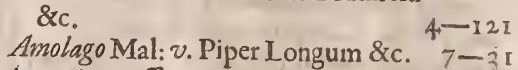
Amonium officinarum Dale $\mathrm{P}$ barm: 363: Amomum racemofum $B$ : Pin: 4I 3 Amomum novum cardamomi vulgaris facie, five indicus racemus $7: B: T: 2 . L: x v$. 195 fructus quintus è Walachria Ch:exot: L: 2. 49. Elettari primum Mal: Elu Bram:

Ampana Mal: v. Palma \&c:

Amvallis Bram: v. Bilimbi Altera \&c:

Amvetti Mal: v. Arbor Indica \& $3-57$

Amuli Bram:

$5-107$

$12-71$

10-75 Amuli Bram: $v$. Alfine Spuria \&c: $9-165$

Amygdala indica Nieubov:Itin:Ada. maram vel Saros Mal: Jibe Bram. Pinha Lufit: Katappers Belg:

A mygdalæ affinis Indica, fructu umbilicato, nucleo nudo, cortice pulvinato trifido tecto Raji H: 1428. Panoc Mal: Doepoe Bram: Arbore enfenza Lufit: Harsboom Belg:

Amygdalam referens fructus birfortus J: B: T: I. L. I1. 183.v. Manga indica \&c.

\section{$4-5$}

$4-x$

Anacardium B: Pin: 5 I1. E variorum Arbor Indicafructu conoide, cortice pulvinato nucleum unicum, nullo officulo tectum, claudente Raji H: 1566 . Oepata, Jew Upata Mal: Kandalu Es Oepali Bram: Salgueira Lufut: Zoutboom Belg:

Anacardium occidentale Cajous dictum officulo reni Leporis figura Herm: Cat: 36. Anacardii alia fpecies $B: P$ in: 5 I 2. Pomifera feu potius Punifera indica nuce reniformi fummo pomo innafcente, Cajous dicta Raj: H:1649. Arbor a caju, vulgo Caju. Pifon. Mant. Arm. 193. Kapa-mava, Seu Katjavomaram. Mal. Kasjo Bram Cajous F: B. T: 1. L: iii: 336 . Lufit E Belgis

Ana-Coluppa. Mal:v. Ranunculiaffinis \&c.

Ana-Dalaqui Bram: v. Arbor Indi-

Anagyris indica Leguminofa filiquis $10-93$ toro/is Par. Bat. P: 311 . Phafeolus arbor \&c. 


\section{$M \quad A \quad L A$ B A $R$ i C A.}

Ananas Acoft.284. Linfch. leg: 72. F: B: T: 3. L: XXV.95. Bram: Lufit: Pijon. 1 95. Cynara Indica feu Ananas fructus Bont: 149 . Nana Brafilienfibus Marggr: 33 . Pinea Indica Hifpanis $\mathcal{F}: B: \mathcal{T}$. I. $L: i x .264$. Matzatli feu pinea Indica Hernand. $; 11$. Carduus Brafilianus foliis aloes $B$. Pin. 384 . Kapa-Thakka. Mal.

P. 3 i2. Anona Indica fructu co. noide viridi fquimis veluti aculeato. Pluken. P. 3.T.CXXXV.f.2. Pomifera Indica fructu conoide fquamofo, viridi. Raji H. i 650 . Ate vel Ahate de panucho Hern. 348 . \& 454. Atamaram \& Maniljaca Mal. Atoa, Manil-panofou, \& Jona-jaca Bram. Atas \& Ato-

Ananas Sylveftris, folio aloes, fructu cupreffino $\mathcal{F}: B: T: 3 . L: X X V$ : Carduus Brafilianus Sylveftris $B$. Pin: 384 . Ananas Sylveftris $C: a$ Coft: Nana Brava Margg: 33 : Frutex indicus fructu aggregato conoide Kaida dictus Raji H.1 442 . Kaida Matl. Bendaki Bram:

Ana-mullu Mal.

Anantaly-maravara. Mal. $\%$ Or-

Anonis iflatica frite fens floribus Luteis amplis Turncf. E1. Bot. 326.v. Genifta.

Ansjeli Mal. $v$. Caftanea \&c. $\quad 3-25$

Anvali Bram. v. Myrobalánus Emblica.

Apacaro Bram. v. Frutex Indicus $8 \rightarrow 73$ \&c.

Apana Bram. v. Siliquofa Indica chis \&c.

Ana-parua Mal.

Ana-Scborigenam. Mal. v. Urtica Malabarica \&c.

Ana-Scovadi. Mal.

Ana-Scbunda Mal. $v$. Solanum Indicum \&c.

Anavinga Mal. v. Baccifeca Indica \&c.

Ancboa Hernand. I69. v. Zingiber. \&c.

$12-15$

$7-75$

Ape-Diruyven Belg. v. Vitis fylvertris ¿ेc.

$2-77$

$10-13$

Apioficorodon, jeu arbor americana tripbylla allii odore poma ferens Pluken. P. 3.T. CXXXVI. f. $\%$. $2-65$ v. Pomifera Indica \&c.

Apocynum crectim majus Latifolium indicum, flore concavo amplo, carneo, fuavepurpurafcente Breyn. P. 2. 5 . A pocynum $\mathrm{La}_{-}$ tifolium xgyptiacum, incanum,

Andena-Motha-P anna Bram. v. Palma vinifera \&c.

Andi-Malleri Mal. v. inirabilis peruviana \&c.

$11-27$

Angelina Acoft. 276.v. Caftanea.

$\begin{array}{ll}\text { Angelina Acott. 276. } v \text {. Caftanea. } & 3-25 \\ \text { Angeli-Maravara Mal.v. Orchis: } & 12-1\end{array}$

Aryolam Mal. v. Baccifera Indica \&c.

Anil five Nil Indorum color. J. B. T. 2. L: XXII. 945. v. Colutea Herbacea \&c.

Anona Indica fructu parvo violaceo

Herm. Cat. App.645. anona Indica pomo cæruleo $P$ ar. Bat. $P$. 3 I2. anona Indica anguftifolia, fructu creruleo, cortice fquamato glabro Pluken. $P$ : 3. T: $C X X X I V$. $f:$ 4. Pyro fimilis fructus alter in nova Hifpania B.Pin.439. Guanabanus Oviedi, fructu fquamato 7.B. T.1. L.1.1 I 4. Quautzapot, feu Anona Hernand. 90. AnonaMaram , \& Parangi-Jaca Mal. Tsjina-Ponofou Bram.Anona L $L$ -

Ant.
Anona Indica pomo viridi $P$ ar: Bat.
$3-9$

10- 149

$4-39$

I-IO: erectuin, floribus fpicatis, maximis, pallide violaceis, filiquis folliculatis rugofis Herm. cat. 53 . Apocynum xgyptiacum Lactefcens, filiqua Afclepiadis $B$. Pin. 303. Apocynum Syriacum Munt. 346. Apocynum agyptiacum floribus umbellatis Turnef: $E l$ : Bot: 78. Apocynum rectum Americanum majus five Latifolium Pare kins: theat: 386 . Beidel Ssar Vefling: 0b5: 28. Beidelfar Alpini five Apocynum Sýriacum $7: B: T$. 2. cum, five paleftinum, \& forte æggyptiacum Chus: H: L: V: 177. Waraghala Zeyl: Ericu. Mal:Roey Bram:

Apocynum indicum floribus parvis, $2-53$ flavefcentibus umbellatim difpo. fitis, filiquis nigricantibus, oblonge friatis Commel: in not:Kakakodi. Mal: Kiti Bram:

$3-23$ Apocynum indicum, folio oblongo, glabro, flore exalbo flavefcente. $L: X V$. 136 . A pocynum five Syria- 
Commel: in not: Kudici-kodi. Mal: Duda-Valli Bram:

A pocynum indicum Latifolium, flore rubefcente, interius candido, filiquis longis, anguftis, venis in longitudinem Striatis Commel: in not: Kametti - Valli Mal: UluValli Bram:

Apocynum indicum maximum, folio amplo, rotundo, flore candido, filiquis longis Commel: in not: Belutta-kaka-kodi. CMal:

Apocynum indicum Scandens Latifolium, flore viridi diluro, filiquis oblongis cufpidatis Commel: in not: Katu-Pal-Valli. Mal:

Apocynum majus Syriacum, caule viridi, flore exalbido $H$ : Reg: $\mathcal{T}$ ar: Cat: I 39. Bel-Ericu CMal: DaviRoey-Bram:

A pocynum malabaricum arborefcens, Limonii folio, flore ex flavo rubefcente, filiquis maximis. Commel: in not: Nelem-Pala Mal: Utago-Culo Bram:

Apocynum malabaricum folio cordis humani forma, flore viridi diluto, umbellatim difpofito, filiquis oblongis, Latis, obtufis Commel: in not: Watra-kaka-kodi Mal:

Apocynum malabaricum fcandens Latifolium, flore rubefcente, filiquis Longifimis \& anguftiffimis Commel: in not: Pal-valli Bram:

Apocynum fcandens, flore variegato filiquis Ericu fimilibus. Commel: in not: Ada-Kodren Mal:

Apocyni repentis fpecies Commel: in not: Niota-Niodem-Valli Mal: Zira-Puti-Valli Bram:

A pocyni Species Commel: in not: Wallia-Pal-Valli Mal:

Apocyni fimilis planta fcandens, \& Succo Limpido turgens Commel: in wot: Nansjera-Patsja Cital: Dadu-Valli Bram:

Appél Mal: $v$. Arbor malabarica baccifera \&c.

Appel.doorn. Belg: v. baccifera Indica \& ic.

Araca-gilacu Pifon 153.v. Guajaya rubra

Araca-Patsjotti Mal: $v$. baccifera

Indica \&c.
Araca-Puda Mal: v. Alfina. $\quad$ ro- 59

Arachus indicus feu africanus Per- kins: Theat: $107 \mathrm{r} .0$. Phafeolus. Arana-Panna Mal:

Arbor Acaju, vulgo Caju Pifon mant: A. 193. v. Anacardium.

Arbor americana tripbylla numerofis ftaminulis purpureis apicibuspreditis floris umbilicum occupantibus Pluken: P: 3. T: CXLVII. f. 6. v. Pomifera Indica \& 8 c.

Arbor amcricana trifolinta pomifera feminibus reniformibus C: $\mathrm{H}$ : H'caum: 10. $v$. Pomifera Indica \&c:

Arbor baccifera Indica racemofa, tetrapetalo flore, fructu rotundo monopyreno Raji $H$ : 1595 . Kasjavo-maram CMal: Sarani Bram: Palnis Lufit: Lieverboom Belg: 5-37 Arbor baccifera Indica fructu culpidato monopyreno Raji H. 1596. Mala-Poenna Mal: Nalal-Suri Bram. Saritos Lufat. Bronsboom Belg.

Arbor baccifera Indica racemofa. Acinis oblongis monopyrenis, flore tetrapetaloide Raji H: I 596 . Kari-vetti Mal. Pada-daliqui Bram. Querillas Lufit. Hartenhaver Belg.

Arbor Baccifera malabarica, folio pinnato floribus umbellat is, fimplici officulo, cumpluribus usucleis Raji H. 1558. v. Vitcx.

Arbor Baccifera malabaricatrifolia, fimplici officulo cum plaribus mucleis Kaji H. I557. v. Vitex.

Arbor baccifera malabarica officulo fructus trifpermo Raji. H. $1557^{\circ}$ Parili Mal: Parilofí Bram. arvore bitanha Lufit: Speen-beffen Belg:

Arbor baccifera racemofa, fructu corticofo, dipyrenq Raji H. г 606 . Nyalel Mal: Laffa Brum. Maquinha Lufit. Werlingen Belg. an. Sambucus Indica Bont. 108 ?

Arbor baccifera racemofa, vitis floribus, acinis oblongis compreffis monopyrenis Raji H. 15,7. Calefiam Mal. Mourmouratarum Bram. Bainhero Lufat. twee-beffen Belg.

3-33 Arbor Caffiam folutivam ferens. Bont. 101. v. Caffia fiftula.

Arbor exotica Lentifci folis B. Pin. 399. ข. Balanus Myrepfica.
$4-111$

$5-3$

$5-I$

$s-5$

$4-37$

$4-67$

I -37 $6-x_{9}$ Arbor 


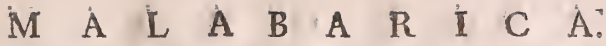

Arbor exotica Spinofa foliis lentifci

B. Pin. 399. v. Crifta pavonis. 2-35 Arbor fabifera I." Boa T sinkking dicta. Bont. 135. v. Coral Arbor.

Arbor farinifera Clus. exot. 5. $v$. palma

Arbor flore tetrapetalo adorato,

fructu nullo Raji $H$. I786. Tonditeregam $\mathrm{Mal}$. Tondi-karavatti Bram. Folhas da rafpa macho Lufit. Groot Ryfblad Belg.

Arbor Indica cocculos officinarum ferens Breyn. P. 2. 19 Coccula officinarum $B$. Pin. 5 I. Cocci Orientales 7. B. I. 1. L. iii. 348 . Cuculo lndiano \& Galuzza di Levante Italis. Natjatam Mal. Garundo-Pala Bram. Fruita matta peire Lufit. Water-quaad Belg. . 7 - 1 Arbor Indica que gummi gotte finndit fructu acido, Sulcato, aureo, mali magnitudine Herm: in Ep. ad D. Syen v. Cambogium.

Arbor: Indice fructu conoide, cortice pulvinatonncleum unicum nullo oficula tectum claudente Raji $\mathrm{H}$. I566. $v$. Anacardium.

Arbor Indica fructi aggregato globofo Katu-Tsjaka dicta Raji $H$. I 441. Katou-T sjaka Mal. DavoPonoffou Bram. Jaqua falfa Lufit: Morgen-fterren Belg.

Arbor Indica fructu aggregato conoide Cada-Pilava dicta Raji $H$. 442. Arbor Conifera Macandou Javanenfum Bont. 97. Confolida Indica arborea ejufdem CadaPilava Mal. Macada-Pila Bram:

Arbor Indica fructu rotundo, cortice molli nucleum glandi fimitem continente Raji H. I664. Courondi Mal: Courdi Bram. Afotas Lufit. Grieten Belg.

Arbor Indica mali medice amplioribus foliz madera (patana Pluken. P. 3. T. CXLVII. f. 3. v. Prunifera.

Arbor Indica floribus f́picatis, Seminibus parvis in vafculis Siccis $R a j i$ H. 1712. Amvetti, feu VettiTalu. Mat. Anadalaqui Bram. Querilhas macho Lufir. Harshaver Manneken Belg.

Arbor Indica Siliquofa, flore pentapetalo Siliquis in fpiram contortis Lanuginofts Raji H. I 746: Katou- conna Mal. Tambido-Rato, \& Colladi Bram. Favas Orelheiras Lufut. Oorhangers Belg. an Ava. ramo-Temo Pifon: 168?

$6-2 \pi$

Arbor Indica Siliquofa, floribus Racemofis, pentapetalis, filiquis foliaceis, ad fingulos flores ternis. Raji H. 175 . Pongelion, five perimaram Mal. Saralu Bram. Favas de tres humas Lufit. Drieboom Belg. 6-27

Arbor Indica foliis alatis, flore \& fructu vidua Raji H. 1786. Benkalefiam Mal. Mourmoura Bram. Arvore da Folha parida Lufit. Loof-Appel Belg:

Arbor Indica foliis adverfis, flore flavefcente retrapetaloide adorato, fructu nondum comperto $R a j i H$. 1786. Asjogam Mal. E Bram. Caffibori Bram. Fula do diabolo Lufit. Tover-bloemen Belg. : 5-I17

Arbor Indica Spinofa flore \& fruciu vidua $R a j i$ H. I 78 7. Taliir-kara Mal. Talir-Gali Bram. Efpinho capado Lufit. Queendoorn Belg.

Arbor indica foliis alatis flore \& fructu vidua Ben-Moenia dicta Raji H. 1787 . Ben-Moenia Mal. Naravolo Bram. Pao da verge Lufit. Draakwortel Belg. $5-i \sin$

Arbor Indica đँrapr (c) floribus umbellatis, tetrapetalis RajiH: 1787 . Amel-podi Mal. Amelpo Brän. Raiz da Cobra Lufit. Slangewortel Belg.

Arbor Indica a'x<pлro, floribus adoratis pentapetalis, petalo uno $\mathrm{Lu}$ teo, reliquis candidifimis $R a j i H$ : 1788. Sida-Pou, \& Pufpajano. Mal. Demendz, \& Dixadoufti Bram. Don George Lafit: Sinken Belg:

Arbor Indica mali aur antice foliis obtufioribus è Maderaspatan Pluken: P. 3. T.CXIII. f. 2. v. Baccifera Indica.

Arbor Indica fraxino fimilis Olea $4 \div 7 \pi$ $5-75$ fructu B. Pin. 416. v. Azadirahta Indica \&c.

Arbor Indica fraxino fimilis altera, flore albo, fructu rotundo nigro Commel. in not. v. Azadirahta Indica \&c.

5-107 Arbor Indica flore maximo, cui multæ innafcuntur Siliquæ $R a j i H$. 1707. malus rofea malabarica. Commel. in not. Syalita Mat: Ka-

B 2
$5-105$

$6-109$ $5-15$

$4=-10 \%$

$4-109$ 
rinbala-Pala Bram: Fruita Eftrelada Lufit: Roosappel Belg: Arbor Indica Siliquofa, flore tetrapetaloftellato, filiquis bipalmaribus planis Raji H. I 766.v. Acacia malabarica \&c.

Arbor Kokos, Indis Coqueira Nieuhov. itin. 10I.v. Palma.

Arbor Lanigera, five Golfampinus Plinii Bont. 105. v. Goffipium. Arbor Lanigera Spinofa malabarica. Commel. in not. v. Goflipium. Arbor Maderajpatana Galactoxyli Americani folior am amula Pluken. P. 3. T. CXLIII. f. 4 . $v$. Ficus Malabarica.

Arbor malabarica Lactefcens fimbriato flore, fructu circa cuficidem reflexo Syen in not. Curutu-Pala Mal: Cudo Bram. an Arbor Javanica perfica foliis 'Plaken.P. 3.T. CXLIII. f. 6.

Arbor malabarica Lactefcens, Fafmini flore odor ato, Siliquis oblongis Syen in not. $v$. Nerium. Arbor malabarica pentapbyllos lactefcens Siliquis Anguftis Longiffimis. Syen in not. v. Nerium.

Arbor malabarica acacie folits, fructurotundo, Semine triangulo Syen in not. $v$. Myrobalanus Emblica.

Arbor malabarica, flore vario, filiqua nuciformi Raji H. I766. KarinNioti Mal: Locandi Bram: Fruita Saneta Lufit: Kroon-nooten Belg: Arbormalabarica baccifera, cortice albicante, glomerato flore Syen in not. Tinda-Parua C Mal.

Arbor malabarica baccifera flore parvo umbellato, odoro Syen in not. Arbor baccifera malabarica flore umbellato odoro monopyreno, Tetragonia Indica Raji H. 1598. Appel, feu Nalla Appella Mal. Caro-Nervoloe Bram:

Arbor malabarienfum fructu LentisciB. Pin. 399. v. Pavate.

Arbor mangifera Bont. 95. $v$. Manga Indica.

Arbor Melonifera Bont. 96. v. Pepo arborefcens.

Arbor orientalis baccifer a laurifoliis crajlis veno/is, per Siccitatem atronitentibus, quafi vernice tinctis, polypyrena Pluken. P. 3.T.CXL. fig. 2. v. Frutex indicus baccifer \&c. 3-3y $\begin{gathered}\text { Arbor platani folio fructu peponis } \\ \text { magnitudine eduli Bauh. Pin. 431. }\end{gathered}$ v. Pepo arborefcens.

Arbor prunifera malabarica pentapbylloides, fructucalyci injidente.

6-9 Commel. in not. $v$. Prunus.

Arbor racemofa malabarica fructu triquetro Syen in not. Canfchi Mal: Schivanni Bram:

3-59 Arbor Sancti Thomx, five Affitra Jacobi Zannonii Breyn.P.2.19.Siliqua Silveftris rotundifolia Indica B.Pin. $4 \mathrm{O}_{2}$. Arbor Siliquofa malabarica, foliis bifidis, florepurpurafcente ftriato Syen in not. Cho3-85 vanna-mandaru Mal. Iambidomandaru Bram.

Arbor Siliquo a malabarica cordato folio fructu maximo, oblongo, plano, femine membranaceo Syen in not. $v$. Clematis.

Arbor Siliquofa malabarica, folio majore mucronato, fructu maximo,oblongo, plano, Semine mem$1-85$ branaceo Syen in not. $v$. Clematis. Arbor Siliquofa trifolia Indica, flore papilionaceo, Siliqua grandi, pilofa, unicam intus fabam continente Raji H. 1721.Plafo Mal. Palafu Bram. Favas de Engenho Lufit: Ratten-hauwen Belg:

Arbor Siliquofa flore papilionaceo, fabis longis \&s latis, phana parte fibi invicem incumbentzbus. Kaji $\mathrm{H}$. 1733.v. Crifta pavoniz.

6-31 Arbor Siliqnofa malabarica, foliis bifidis majoribus, flore intenfius purpurafcente ftriato Syen in not.

1-87 Chovanna-mandaru Mal.

Arbor Siliquofa malabarica foliis bifi$1-76$

$x-80$

$I-8 I$ dis minoribus, flore ex albo flavefcente Striato Syen in not. Flos divi Thoma vulgo Commel. Cat. 34. Canfchena-Pou Mal. Cantfanu Bram.

I-99 Arbor Siliquofa malabarica, foliis $1-63$ bifidis, flore purpurafcentefiriato 5-Iy Syen in not. $v$. Arbor fancti Thomæ.

4- I Arbor Siliquofa malabarica foliis bifidis minoribus, flore candido ftriato. Syen in not. Thomæa arbor Siliquofa, foliis bifidis, minor flore candido $P$ ar. Bat. $P$. 380 . Velutta-mandaru Mal: Davo-mandaru Bram:

Arbor Siliquora malabarica pluribus 


\section{A $\quad$ L}

ad fingulos flores Lobis Raji $H$. 1754. Nux malabarica fulcata, mufcilaginofa fabacea Syen in not. Cavalam Mal. Bencaro Bram. Arbor Siliquofa Indica, filiquis Lon. gis contortis in quatuor cellulas per longun divifis Raji $\mathrm{H}$. $\mathrm{x}>64$. v. Clematis.

Arbor Spinofa indica filiquis villofis monofpermis Bankaretti dicta Raji H. 1744 . v. Crifta pavonis.

Arbor trifolia Indica J: B: $\mathrm{T}: 2$. L:XVII. 368. v. Phafeolus arbor.

Arbor triftis myrto fimilis $B: P_{i n}$ : 469. arbor triftis variorum. Manjapumcram Mal: Pariaticu Braw:

Arbor triftis de die altera Commel: in not: $v$. Jafminum.

Arbufcula Corallii Ferr: Flor: Cult: I 80. v. Coral arbor. $6-\mathrm{x} 3$

Areca five Faufel Cl:in not:ad Garz: 188: $v$. Palma

Arecafive Avellane indice verficoloris gemus oblongum Parkins th: I $643: v$. Nux myriftica.

Areca-Ambel Mal:

Arecagolu Bram: v: Ficus.

Are-A $A$ Mal: v: Ficus.

Aria-Bepou Mal: v: Azadirahta.

Aria-Veela Mal:

Arinbo Lufit: v: Baccifera indica \&c.

Arifarum indicum aquaticum, cum piftillo rubro, pediculo globulo adhrrente: Commel: in not: NirTsjembu Mal:

Arifarum indicum petraum bumile piftillo rubro adberente, Granis purpurafcentibus Commel: in not: $v$ : Arum.

Ariftolochia clematitis indica, flore albicante fructu majore Commel: in not: flurealbicante Turnef: El: Bot: 132. Arifolochia clematis indica adorata Par: Bat: P.inter Add: Sacfanda Zeylan: Careloc-vegon Mal: Sapoeffi Bram: Aterlufi Lafit Kokerlingen Belg: an Volubilis Gangetica Sapore acri \& aromatica, Seu Ariftolochia clematitis Gangetica foliis in caulem abeuntibus radice adoratiffma Phken: Pi: T: LXIX: 5 ?

Ariftolochix fpecies Commel: in not: Kari-valli Mab: Gointi Bram:Popinhodo parare Lufit: Karlingen Belg:

一

$9-41$
Armatoria das igrezias, fen, $P$ alma d'igrefia Lufit: $v$. Palma.

Arola Lufit: $v$. Baccifera Indica \&c. 5-4ir

Arola Benacboza Lufit v. Baccifcra

Indica \&c.

Arola menor Lufit: $\because$. Baccifera Indica \&c.

$6-53$

Arolada Scrra Lufit:

Arpuli Bram: v. Serra.

$s-47$

6-35 Arty Bram: v. Methonica Malabarorum.

Arum humile Arifarum dictum latifolium ceylanicum, piftillo Longifino miniato colore Commel: Cat.36.Arifarum indicum petræum humile, piftillo rubro adhærente, granulis purpurafcentibus Commel: in not. Nelen fchena $\mathrm{Mal}$.

Arum malabaricum minus polyphyllum radice globofa Commel. in not. Katu-Schena Mal.

Arum maximum ceylanicum, ra$11-4 t$ dice craffa, longa, rotunda, geniculata, colocafii folio Commel: Cat. 37. Arum paluftre malabaricum, folio nimphrze radice arundinacea Commel: in not. Weli-ila $\mathrm{Mal}$.

Arum minus ceylanicum fagittarix II -43 folio Par: Bat: $\mathcal{P} .315$. Nelenfchena $\mathrm{Mal}$.

Arum polyphillum Dracunculus \& II -39 Serpentaria dictum ceylanicum, caule glabro viridi diluto maculis albicantibus notato, majus \& elatius Commel: Cat: 3 8. Arum polyphyllum, dracontium \& Serpentaria dictum folio ramofo pxoniæ in ftar caule Levi Zeylanicum Par: Bat: P. 3 I 5. Serpentaria polyphylla indica, caule maculato Levi Breyn. P. 2. 90. Schena Mal.

Arum polyphyllum Dracunculus \& Serpentaria dictum ceylanicum, caule afpero cum maculis viridi fufcis, \& viridi dilutis albicantibus pulcre notato majus \& elatius Commel: Cat: 38 . A rum polyphyllum Dracuntium \& Serpentaria dictum folio ramofo pxonix inftar caule afpero ceylanicum $P$ ar: Bat: P. 315 . Serpentaria polyphylla indica caule maculato afpero Breyn:P.2.90. Mulen-fchena Mal. 
Ari fpecies Commel: in not. KarinPola Mal.

Arundo indica maxima arborea cortice Spinofo Hermanni Syen in not. Arundo mambu Pifon: mantis $A$ : x86. Arundo arbor, in qua humor Lacteus gignitur, qui tabaxir Avicennx \& Arabibus dictur $B$. Pin. 18. Tabaxir G. ab borto 164 . $G$ 'a Cofta 259 . Tabaxir lute Mambu arbor F:B:T: 1. L:VIII. 222. Canna ingens Mambu vel Bambu dicta P arkins: Theat: 1630 . Bambu \& Bamboes Nieubov. leg. P. 5. 9r. Ily Mal. Vafi Bram.

Arundo indica Bambu fpecies fecunda Raji H. 13 16. Beelha Mal. Zivo Bram. Bambu d'eferiver Lufit: Pylriet Belg.

Arundo indica Bambu fpecies tertia Raji H. 1316 . Nola-Ily Mal. Vafinola Bram. Bambu-Gorri Lif it. Pypriet Belg.

Arundo indica Latifolia B: Pin: 19. f:B:T:2. L:XVIII. 48 9. Arundo indica florida, Cannacorus quorundam Lob:Obf: 29. Advers: 28. Cannacorus Latifolius vulgaris Turnef: El. 3.295. Canna indica Latifolia Humilior, Hore faturatius rubente Herm: Cat. 2 I 3. Canna indica $V$ arıorum. Langeas Stap: in Theopb:334. Mecru Marg: 4. Katu - Bala Mal. Rana-Queri Bram.

Arundinis indica volubilis fpecies Commel: in not. Panambu-Valli Mal. Silona Bram. Ratao falfo Lufit. Wilde Rotting Belg.

Arvore Bitanba Lufit: v. arbor haccifera.

Arvore contra das ery/ipelas Lufit. v. Pavate arbor

Arvore da folls $\Psi$ arida macho Lufit: $v$. forbus fpuria.

Arvore da fulba parida Lufit: $v$. arbor indica \&c.

Arcxore da Piemento falfo Lufit: $v$.

Baccifera indica \& $\mathrm{x}$.

Arvore de rafpa Lufit $v$. Ficus.

Arvore ac rafpa major Lufit. Ficus.

Arvore de rays Lufit. v. Ficus.

Arxore de rays Linfchot. itiner. 82. $v$. Ficus.

Arvore de rays Ladro Lufit. v. Ficus.

$5-119$

$x-25$

Alowatou Bram: v. Ficus malabarica.

Afparagus aculeatus maximus farmentofus Zeylanicus Herm: Cat: 63. Hatawariia Zeylon: Schada. veli-kelangu Mal. Safara-mullu Bram:

Afphodeli indici affinis floribus hexapetalis, fpicatis Commel: in not: Katu-kapel, Jeu Cademaco Mal. I I-83

Aftragalus indicus fpicatus, filiquis copiofis deorfum fpectantibus non falcatis, feu polylobos Herm: Herb. v. Ceyl: Katu-Tagera Mal. pilæghas Zingal:

Ainmaram Mal: v. Anona.

Atas Lufit: v. Anona.

Ate vel Abate de panucho Herm. 348. 4,5. $v$. Anona.

$11-85$ Ateg-Cudo Brann:v. Nerium.

Aterhifi Lufit. v. Ariftolochia.

Atoa Bram: v. Anona.

Atocira Lufit: $v$. Anona.

$3-2 I$

$3-21$ $-85$

$10-x 9$

$4-33$

$6-41$

$5-93$

$5-117$

$4-103$

Atti-meer-alou Mal.v. Ficus $\quad 3-21$

Atti-alu Mal v Ficus.

Atroyatl Herm: $1-4.3$

5-5 Atzoyatl Herm: 1 70. v. Mirabilis peruviana.

$10-149$

Avanacoe \&5 Catavanacu Mal:v.Ricinus.

Avara-apacaro Bram:

Avaramo-Temo Pifon: 168. v. Arbor $5-38$

Indica \&c.

4-49 Avellana indica C: â Coft: 268, v. 6-2

3-79 Palma. $1-9$

Avellane indice genus oblongum

3-81 Clus: in Garz: 189.v. Nux My-

3-71 riftica.

Avenka Mal.

Avond-Bley Belg. v. Balfamina Cucumerina,
$3-21$

$\mathrm{I}-85$

$8-49$

$3-2$ I

21
-75

49
$3-73$

$4-69$

$3-7$

$3-75$
$4-9$
$12-72$

$8-35$ 
Azadirahta indica, foliis fraxini, five non ramofis, majoribus, flore minore albo Breyn: $\mathcal{P}: 2$. 2 I. Azadarach indica foliis non deciduis officulo polypyreno $\mathbb{P a r}$ : Bat: $P: 3$ I6. Azedarach floribus albis femper virens Herm: Cat: App: 652 . Olea malabarica Nimbo dicta, fructuracemofo oblongo Raji H. 1545. Olea malabarica fraxineo folio è Maderafpatan Pluken. 'P. 3.T. CCLVII.1. Arbor indica fraxino fimilis, olex fructu. $B: P$ in: 4 ; 6 . Nimbo folio \& fructu oler F: $B:$ T: $1 . L: v i .27$. Nimbo C: â Coft: 281, Garz: ab Hort 226. Aria-Bepou Mal. Nimbou Bram. Amargofeira Lufit. Galbeffen Belg.

Azadirachta indica foliis fraxini, five $4-107$ non ramofis minoribus, flore parvo albo Breyn. P. 2.21. Olea malabarica Nimbo dicta fructu racemufo rotundo RajiH. 1545. Arbor intica frasino fimilis altera, flore albo, fructu rotundo nigro, feu Nimbo ảltera Commel: in not. Kari-Bepou Mal: Karabou Bram. Amargofeira macho Luf $u t$. RondeGalberfen Belg.

Azeitones do malavar Lnfit. v. Olea. 4-5I

Baakroofen Belg. v. Alcea.

Baala-P aleti Mal: $v$. Frutex baccifer \&c.

Baava-P aleti Mal. v. Frutex indicus baccifer \&rc.

Babofa quinado Lufit: v. Sedi fpecies.

Babouli Bram: $v$. Baccifera indica.

Babouli-Canti Bram: v. Frutex indicus baccifer \&c.

Baccifera indica umbellata, fructu Umbilicato, ftriato monopyreno Raji H: 14 , 8. Kandol Zannoni Kare-kandel, velKandeque Mal: Kandelo Bram: Arvore da pao Salgado Luift. Kandeke, Runboom Belg:

Baccifera indica fructu umbilicato, $4-45$ $2-1$ $5-31$ $7-7$ $5-69$ $5-77$ racemofo, candido, monopyreno, rotundo Raji H: 1498. Beluttakameli, feu Bem-Niavel, feu Poutsja Mal:Davi-Bedoefi Bram: Fruita-Cauri Lufot. Dwergen-Ap-
Baccifera indica umbellata, fructu umbilicato nigro, of ticulo intus unico Raji H: 1499. Niara Mal: Bedoufi Bram. Gibique \& Grao do gato Lufit. Stramboom, of Katers ballen Belg.

Baccifera indica racemofa, fructu umbilicato rorundo monopyreno Raji H: I 500: Mail-Ombi CMal. Ona \& Jammana Bram: Saloins Lufit: Warsboom Belg.

Baceifera indica racemofa, florum ftaminulis binis, acinis monopyrenis. Raji H: 1597. MallamToddali Mal. Chori-Bori Bram: 'Tarilla d'agoa LuJit. Nanen pluymen Belg:

Baccifera indica trifolia, racemofa, acinis umbilicatis tricoecis $R$ aji $H$. 150 I Tsjerou-Theka Mal. DoudaSailo Bram: Teka Crifpa Lufit. Netel Teka Belg.

Baccifora indica fructu cufpidato, mononyrcno, calyce refiduo excepto Raji H. 1770. Bafaal Mal. Vilengi Bram. Fruita Pedrica L $/ f t$. Swyn-beffen Bels.

Baccifera indica fructu oblongo, calyci infidente monopyreno, officulo compreffo RajiH. I 57 i. KákaNiara Mal Nilbedoufi Bram. Fruita Gibique preto Liv fit. Swart Stramboom Belg.

Baccifera indica fructu calyculato, fubrotundo, culpidato, quadripartito, tetrapyreno. Raji H: 1572 . Acara-Patsjotti $M a l$. Tiło Sameno Bram: Salao femea Lufft: Lerick Wyfken Belg. an Arbor indica mali aurantix foliis obtufioribus é Maderafpatam $P$ luken: $P$. 3. T: CXLII. 2 ?

Baccifera indica trifolia, fructurotundo monopyreno, pediculo longo Raji $H$. i 593 . Molago-maram Mal. Mirifato Bram: Arvore da piemento falfo Lufit: Wilde Peperboom Beig:

Baccifera indica floribus racemofis, fructu plano rotundo, dipyreno Raji H: ı 606. Kanden-kara Mal. Pouli-gali Bram. Efpinho malinho Lufit: Strom.doorn Belg. 5-71

Baccifera indica floribus spicatis, fructu umbilicato tricocco lacic acerrimo manante Raji H. 1496.

C 2 
ข. Tithymalus.

Baccifera indica, fructu glabro tribus Loculis terna Semina continente Raji H. I+96. Ponnagam Mal. BenifTa Bram. Arola Lufft. Himpen Belg.

Baccifera indica fructu Lanuginofo, cum officulo tribus loculis terna Semina continente Raji H: 1496. Tsjerou - Ponnagam Mal. DavoBeniffa Bram: Arola menor Lufit: Roode Himpen Belg.

Baccifera indica fructu tetrafpermo, in foliorum alis feffili $R a j i H$ : 1623 . Corni feu Sorbi fpecies Bont. 103. Scherunam-Cottam Mal.

Baccifera indica baccis oblongis in umbellæ formam difpofitis Raji H. : 634 . Liguftri fpecies Commel: in not: Poutaletsje Mal. Barfoti Bram: Ilata Lufit. Waakblad Belg. an Poutaletsje malabaricie fimilis arbufcula maderafpatenfis Pluken. P. I. T: LIV.f. I?

Baccifera indica fructu umbilicato rotundo cerafi magnitudine dicocco Raji $\mathrm{H}$ : 14.97 . Angolam, feu Alangi Mal. Angolam Bram. Efpinho Sancto Lujit. Keyfers Vreught Belg.

Baccifera indica flofculis ad foliorum exortum confertis, fructu dicocco Raji H. 1497. Tsjerou-kara Mal. Canti \& Bidani-Gali Bram. Efpinho Salfedo Luftt. Bitterdoorn Belg. an Lycium bifnagaricum acuminatis minus durioribus foliis \& aculeis ex opfofito binis Phiken. P: 2. T: XCVII. f. 3 ?

Baccifera indica flofculis umbellatis, baccis umbilicat is dicoccis $R a j i H$. 149\%. Bruxaneli CMal. Sarpalo Bram: Arinho Lnfit. Drielingh Belg.

Baccifera indica fructu umbilicato racemofo monopyreno Raji $H$. 1498. Patsjotti Mal. Sameno Bram. Olheira Lufit. Oogappelen Belg: an Cambay, feu Myrtus americana Sylveftris Pifon: 178 ? s- 9

Baccifera indica umbellata flore pallido pentapetalo, raro fructus ferens Raji H. 1635. RamenaPou-maram Mal. Brampou Bram: Eftrela d'alva Lis $I t$ : Morgen-fterren Belg:

Baccifera indica flore compofito $R a j i$
Baccifera indica, floribus fpicatis $4-9 I$ fructu rotundo, nigricante, polyfpermo Raji H. 1494. Ben-Kara Mal. Gali , feu Babouli Bram. Efpinho d'urfo Lufit. Appel-doorn Belg.

Baccifera indica fructu cum quadripartito in vertice umbilico quadricapfulari Raji H. 1495 . Pee-Ponnagam Mal. Soubeniffa Bram. Arola penachozo Lufit: PluymHimpen Belg.

Baccifera indica ad foliorum alas florida, fructu umbilicato \& caliculato tricocco Raji H: I49s.
$5-109$ 
Katapa Mal. Kari Bram: Arvore Santenella Lu/it. Waakhout Belg. $5-93$

Baccifera indica foribus ad foliorum exortus, fructu fulcato decapyreno Raji H. 1632. v. Solanum.

Baccifera indica, fructu rotundo atro purpureo, pentacocco Raji H. 1933. Vetadagou Mal:Polti Bram. Nani Lufit. Craambeffen Belg.

Baccifera indica floribus umbellatis, fructu rotunlo tricocco Raji $H$. I6I s. Karetta-Amelpodi CMal. Ameli Bram: Raiz da cobra Lufit: Slangewortel $B$ Belg.

Baccifera indica fructu rotundo, cufpidato, cerafi maguitudine, polypyreno Raji $H: 1932$. Anavinga Mal. Talana Bram. Bringiala falfa d'arbore Lufit. Granaat-pruymen Belg:

Baccifera malabarica, flotibus fpicatis, dipetalis, fructu monopyreno Raji $H$ : Is95. Watta-Tali Mal. Comati Bram. Folhas da minta L" flt. Loogboom Belg.

Baccifera malabarica, fructu umbilicato, pruniformi, unico intus nucleo Raji H: r 499. PerinNiara feu Inalel Mal. Madanaka Bram: Grao do gato Luftit. Katersballen Bels.

Baccifera malabarica racemiofa, tripetala, fructu oblongo tricocco, calyce exccpto Raji $H$. 1571 . Tsjerou - Poeam Mal. Patarola Bram. Nillha Lufit. Quel-beffen Belg.

Baccifera malabarica fructu oblongo tetracocco, calyculato Raji $\boldsymbol{H}$. 1 57 . Niir-Notfril Mal. Negunda ES Ciritamari Bram. Nochil Luffit: Water Kuys boom Belg.

Baccifera racemofa acinis oblongis, polypyrenis arecæ Raji $H:{ }_{1} 633$. Ben-Theka, Mal. kafailo Bram. Theca-macho Lufit, Wit Theka Betg:

Baccifera Spinofa indica racemofa, acinis globofis, gemino in fingulis nucleo Raji H: I 606. Wadouka Mal. Adoulatti Bram: Banhoeira Lufit: Smeer-Appel Belg. 4-97

Badera-multa Bram.

Badukka Mal: v. Capparis arborefcens.
Babel.scbulli Mal: v. Genifta.

Babel-T sjulli Mal. v. Digitalis affinis.

Baja-Sajo Bram:

Bajo Bram. v. Caffia fiftula.

Bambero Lufit. v. Arbor baccifera \&c.

Bala Braris.

Bala Mal: v. Ficoides.

Balam-Pulli Mal: $v$. Tamarindus $1-17$

Belam-Pulhi Mal:

Balanus myrepfica, filiqua triangulari, femine minore alato Breyn: P. 2. 22. Nux been zeylanica, $f_{1-}$ liqua triangula, feminibus alatis Herm: Cat: $A p p: 69$ 2. Arbor exotica Lentifci foliis $B: P i n: 399$. Boa Keloor ten Rheyne. Moringa C: a Coft: 278. Ferrar: Flor: 385 . Lufft: Moringa Lentifci folio fructu magno angulofo, in quo femina erui $F: B: T: 1 . L: X I I$. 435. Katu - Myringha Zeylanenfium Herm: Mhus: Zeyl: Mouringou, vel Muringo Mal. Maifingou Bram.

Balia-Mucca-Piri Mal: v.Balfami-

na cucumerina
Ballel Mal. $v$. Convoloulus. il

Balfamina cucumerina ceylanica fructu flavefcente Commel: Cat: 47. Momordica five Charantia indiæ oriental is, fructu aurantia majore oblongo, Seminibus albis. Breyn: P: 2. 73 . Momordica ceylanica, fructu pyriformi majore ex flavo rubente, feminibus albis C: H: Beaum: 30. Momordica zeylanica, pampinea fronde, fructu longiore Turnef: El: Bot: $86 . \mathrm{Cu}-$ cumis puniceus indicus major $\mathcal{P}$ ar: Bat: $P$ : 329. Pandi-Pavel Mal: Valli-caretti Bram. Folhas margofeira cum fruita grando, \& Maragofa Lufit. Groot bier-blad Belg:

Balfamina cucumerina flore candido mufcofo, fructu glabro Commel: in not: Scheru-Padavalam Mal: kleyn Kalpert Belg:

Balfamina cucumerina foliis integris fructu aculeato Commel: in not: Erina-Pavel Mal: Pavali Bram. TindaliSpinofa Lu/ut. Doorn-mitfen Belg.

Balfamina cucumerina, folio amplo, flore candido, fructu glabro ex flavo rubefcente Commel: in not;
$9-169$

$8-51$

$x-37$

$4-67$

$12-85$

$\mathrm{I}-17$
$\mathrm{I}-39$

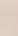

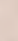




\section{F L}

Padavalam Mal: Pouli Bram:Sa-

bino Lufit. Kalpert Belg.

Balfamina cumerina fructu viridi ftriis albis Commel: in not: Tota-Piri Mal:

Balfamina cucumerina indica folio integro, fructu variegato Commel: in not: Cucumerina punicea Lob. Obf. 369 . Cucumeraria $7: B: T$ : 2. $L: X V I .25$ r. 'rotundifolia repeus feu mas $B:$ Pin: $306, \mathrm{Cu}-$ cumis puniceus Cordi Moris: $H$. $\mathcal{P}: 2.33$. Momordica vulgaris Turnef: El: Bot: 86. Balia-MuccaPiri Mal. Carinti Bram: Tindalica Lufit. Milten Belg.

Balfamina cucumerina malabarica fructu minore, oblongo, rotundo, glabro Commel: Cat: 47. Momordica minor indiæ orientalis bryoniæ facie, frẹctuglabro, molli, uvæ crifpre magnitudine \& effigie, fuave purpurafcente, Lineis niveis ftriato Brein: P: 2. 74: Bryonia zeylanica foliis profunde Laciniatis Herm: Cat: 97. Nehoemeka Mal. Kavandali Rram Nhola Lufit. Slitten Belg. an Convolvulo fimilis bryonix albx folis villofis ex india orientali $P$ hoken: $P: \mathbf{r}$. $\mathcal{T}: X^{V} \cdot 3$ ?

Balfamina cucumerina pinacea, glabra, maculis albis notata Commel: in not: Covel Mal. Tenduli Bram: Tindeli comprido Lufit: Milten Belg:

Balfamina cucumerina punicea glabra, maculis albis notata Commel: in not: Mucca-Piri Mal. Deva-Teva Sini Bram: an Cucumis bryanoides bifnagarica, fructu parvo, florum calice muricato Phken: P: 1. T: $X X V I$. 4?

Balfamina cucumerina punicea ceylanica major Commel: Cat: 47. Momordica zeylanica, pampinea fronde, fructu brevioie Turnef: $E$ l: Bot: 86. Cucumis puniceus zeylanicus Maragofa Lufitanis Herm: Cat: 204. Cucumis indicus minor Par: Bat: Prod: 329. Cucumis malabaricus fructu ex flavo rubente minor. Commel: in not: Pavel Mlal. Carati Bram.

Balfamina cumerina radice tuberofa Commel: in not: Bem-Pavel Mal. Dadula-Papali Bram: Tapadeira
Balfaminæ fæminæ ffecies varix $\left\{\begin{array}{c}84 \\ 91 \\ 93 \\ 95 \\ 99 \\ 101\end{array}\right.$

Bambu \& Bamboes Nieuhov. Leg:

P. 5. 91. $v$. Arundo indica. $\quad \mathrm{I}-25$

Bambu d'efcriver \& Bambu gorri

Lufit: $v$. Arundo indica. $5-119$

Bamia mofçata officinarum Dale

Pharm 34.2. v. Alcea. 2-7 r

8-2 I Banana, Banantes Munting. 26. $v$. ficoides.

$I-17$

Bananiera Pifon 154. v. Ficoides. 1-17

Bangada-Valli Bram:v. Convolvu-

lus.

$x 1-1$ I 7

Bangue cannabi fimilis J: B: T: 3 .

$\mathrm{L}: \mathrm{XXX}$. 449. $v$. Cannabi fimilis.

$10-119$

Banboeira Lufit: $v$. baccifera fpinofa \&c.

Ban-Karetti Mal: v. Crifta pavonis.

$4-97$

$6-35$

Bara-Mareca Mal. $\quad 8-85$

Barba caftilhamo Lufit. $\quad 7-87$

Bare-Mogari Lufit: v. Jafminum. 6-97

Barfoti Bram: v. baccifera indica \&c.

Bafo 4-117

Bafact Mal: v. baccifera indica \&c. $5-23$

Bafaala-Poulou-Maravara Mal. $\quad 12-53$

Bafella Mal: v. Solamun.

$7-45$

Bafil Bram:

$7-95$

Baftao de jogi Lu/it: $17 \quad 8-57$

Baft aard mogori Belg: $v$. Jafminum. 6-95

Baftaard Runboom Belg. $\quad .6-67$

Batatas occidentalis india, \&f in bame orientalis Lifitanorum Parkins: Theat. I383.v. Convolvu. $8-25$ lus.

Bat atis affinis Igname, five Inbame J: B: I: 2. L:XIX. 793. v.Ricaphora.

Batti-Schorizenam Mal. v. Urtica $\quad 7-97$

Bedel-hout Belg.

$2-75$

$8-57$

Bedel-jioeren Belg. $v$." Jambos. $\quad 4-15$

Bedouf Bram: $\quad 5-99$

Bedoufi Bram: v baccifera indica \&c. $5-53$

Beenel Mal. v. Frutex baccifer \&c. $5-7$

Becra-kaida Mal. $7 \quad 1_{2}-100$

Beesha Mal. v. Arundo indica. 5-II 9

Beetklim Belg: v. Solanum. $\quad 7-49$

Bela-Pola Mal:v. Gladiolus. $\quad$ I $\pi-69$ 


\section{A L A B A $\quad$ R I $\quad$ C A.}

Bela-Schora Mal. v. Pepo. $\quad$ 8- I Ben-Kara Mal: v. baccifera indica

Belam-Canda-Scbular-Mani Mal: $v$.

Gladioli affinis.

$11-73$

Bel-Ericu Mal: v. Apocynum. $\quad 2-56$

Bel-Aciamboe Mal: v. Convolvalus.

Beli-Caraga Mal:

Beli-Tsjira Mal.

$11-119$

$12-87$

$9-165$

Belilla Mal. v. Frutex indicus \&c.

Bella-Modagam Mal: v. Prunifera indica \&c.

Bellam-Patsja Mal:

Belmojchus Agyptia Honorio Bellio J: Bauh:T:2.L: XXIII. 96.v. Alcea.

Bel-Nagueri-Bram: $v$ baccifera indica \&c.

Beloere Mal. v. Althæa.

Belou Bram: v. Cucurbitifera trifolia.

Belutta-Adeka-Manjen Mal. v. Amarantho affinis.

- Behutta-Amelpodi Mal.v. Frutex in. dicus ár $x$ p $\pi$ (c) \&c.

Belutta Areli Mal: v. Nerium

Belusta-Kameli Mal. v. baccifera' indica \&c.

Behtta-Kaka-Kodi Mal. v. Apocynum.

Belutta-Modela-Muccu Mal.v. Lyfimachia.

Belurta-Onapu Mal.

$10-159$

Belutta-Pola-Taly Mal. v.Lilium. Ix-75

Belutta-Tsjampakam Mal:v. Caftanea.

Belurta-Tsjori-Valli CMal.

Bembr Bram: v. Acorus.

Bem-Curini Mal. $v$. Frutex indicus fpicatus \&c.

Bem-Nofi Mal: $v$. Vitex.

Bem-Schetti Mal: v. Jafminum. $\quad 2-19$

Bem-Tamara Mal. v. Nimphax affinis.

Bem-Pavel Mal. v. Balfamina.

Bena-Patsja Mal. v. Heliotropium.

Bencaro Bram: v. Arbor filiquofa. \&c.

Ben-Daki Bram: v. Ananas.

Ben-Darli Bram: v. Frutex baccifer. \&c.

Ben-Darly Bram: v. Selago.

Ben-Darly Bram:

Ben-Darfi Bram:

Ben-Derli Bram:

Ben-Kadali Mal. v. baccifera indica $\& c$. \&x.

Ben-Kalefarn $\mathrm{Mal}$ - 59 \&c.

Ben-Moenia Mal. v. Arbor indica \&c.

Ben-Niavel Mal. $v$. baccifera indica \&c.

Ben-Pala Mal. v. Tithymali fpc-

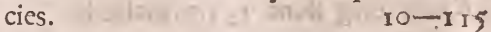

Ben-Theca Mal: $v$. baccifera race- mofa \&c:

Ben-Tiru-Tali Mal. v. Convolvulus. - $\quad$ II Ben-T́s jappo Bram.v.Zedoaria. I I $\mathbf{I}$ Bengiri Mal. $v$. Ricini indici fpe- cies.

Beniffa Bram: v. baccifera indica is \&x.

Ber indica fructujujubino $\mathrm{J}: \mathrm{B}: \mathrm{T}: \mathbf{x}$.

L.VI. 44. $v$. Jujuba indica. $4-85$ Bergh Craam-befJen Belg. v. Vitis Idææ fpecies.

Bergh Heyl-wortel Belg: v. Panella minor.

Bergh Himpen Belg:

Bergh Mugori Belg: v. Jafminum.

Berberis indica aurantix folio Commel: in sot: Noeli-Tali Mal: Beftram Bram: Cordocira Lufit. $5-6 x$

$6-95$
$3-63$

$7-19$

I $1=99$

$2-33$

$2-15$ Vlas-hout Belg.

Beftram Bram: v. Berberis.

Beta baccifera aizoides rotundifolia Zeylanica Breyn: P: 2. 23. v. Solanum.

Betæ folio malabarica, femine lap-

$4-115$

$4-115$

$7-45$ paceo Commel: in not: Wellia- Codiveli Mal: Citia - Cuvadi Bram:

Betre five Tembul B.Pin:410 Be ${ }^{10-I_{7}}$ tle officinarum Dale Pharm. 406. Bettele five Betre Linfchot: itiner: 84 . E Varior: Beetla-Codi Mal. Beetla Bram \& Lufitan:

$1 \mathrm{x}-6 \mathrm{x}$

$8-35$

ro -95

$1-80$

$2-1$ $5-91$

$12-97$

$12-52$

$7-53$

$7-75$

Biborala Lufit. $v$. Prunus indica. $\quad 4-23$

Bidani-Gali Bram: v. baccifera indica \&c.

Bidziam Hitem Malaccens v. Sefa $5-73$

mum.
Bidziam Poeteb Malaccens, v Sef2num. $\quad 9-105$

Bignonia arbor indica foliis cordatis

Turnef: El: Bot: 133.v. Clematis.

$1 \rightarrow 77$

4-89 Bignonia arbor indica foliis oblongis

$\mathrm{D}_{2}$

Turnef: 
Turnef: El: Bot: $133 . v$. Clementis.

Bilala-mado Lufit. v. Palma.

Bitimbi Mal. v. malus indica.

Bilimbi altera minor Commel. innot.

Neli-Pouli Mal. Amvallis Bram.

Cheramela Lufut. Suercnoop Belg.

Bilenfchera Mal.

Biling-Bing Bont. 133.v. malus indica.

Bipali Bram. v. Piper Longum.

Bipalou Bram.v. Ficus.

Bintamburu Zeylon: v. Convolvulus.

Biti-Maram-Maravara Mal. $v$. Orchis.

Biti $M a$ ?

Bitolo Bram.

$3-57$

$8=9$

$3-55$

$7-27$

$1-47$

I- 15

$3-55$

Brampou Bram. v. Baccifera indica

\&c. 4-125

Bredo-Tali Lufit. v. Solanum. $\quad 7-45$

Bringarafi Bram. v. Chryfanthemi

Ipecies.

Baccifera indica \&c. 4-rox

Bronsboom Belg. v. Arbor baccife-

ra \&.

Bruxaneli Mal. v. Baccifera indica $5-17$ \&c.

$1-$ I 7

Bryonia zeylanica foliis profunde ${ }^{5-83}$ laciniatis Herm. Cat. 95. v. Bal-

$\mathrm{I}_{2}-7$

$5-115$

$5-115$

Bladdrager Belg.

Blattaria indica urticæ folio pilofo, flore amplo miniato Commel: in not. Sjafmin Mal.

Blutti Jeu Katou T'sjambou Mal.v. Jambos.

Slimbur. $3-43$

Blimbynen Belg. $v$. malus indica. 3-55

Blitum bacciferum Ceylanicum, folanum tinctorum Ceylanicum Hermanni C. H: Beaumont. M. S. 169ז. v. Solanum.

Boa keloor ten Rheyne $v$. Balanus Myrepfica.

$12-13$

IO-I

famina cucumerina.

Bryonir Levis fpecies malabarienfis

Commel: in not. Pada-Valli aut Pada kelengu $\mathcal{M}$ Mal. Pada.Valli Eึ Mutsjega Pada Bram. Raiz de Camera Lufit: Stoelwortel Belg. an Convolvuli in ftar volubilis é cormandel, umbilicatis foliis craffis, acuminatis villofa $\mathcal{P}$ luken: $\mathcal{P}$ : 1. T: $X X I V .6$ ?

Bugloffum ecbioides indicunn convolvuli carulei minoris folio Breyn. in Mifellan: cur. A.04.\&5.14.6. v. Euphrafix affinis.

Bujar-Anvali Bram: v. Vitis idxr 9-87 affinis.

6-Ig Bui-Cuivali Bram. v. Flos paffionis

Bobara Lufit. v. Colocynthis. Bobara d'agao Lufit.v. Pepo. Bobara-branca Lufit. v. Pepo: Bobara Guinea Lufit. v: Pepo: Bocalo Bram:

$8-9$ fpurius.

$8-5$ Bui-Tolaffi Bram:

8- 1 Bula Mal. $8-37$

$8-3$

Bula.Vanga Bram. ข. Frutex indicus \&c.

Bula.Vanga Bram: v. Lyfimachia

Bupariti Mal v. alcea.

9-109

$2-\sigma_{3}$

$10-61$

$12-51$

$10-183$

$6-; 3$

Butta-Gageri Bram. v. Genifta. $9-53$

Butumbo Bram $v$. Euphrafia affinis.

Caacbira Pifon: 198. v: Colutea indica:

- 1 Caca-Mulhu Mal. v. Solanifolio maw $9-87$

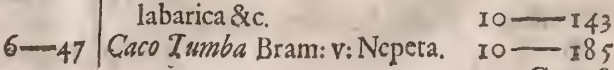

Caara - Veela Mal: v. Pentaphyllum:

$2-35$

$4-73$

$\mathrm{I}-75$

4-85 labarica \&c $10-1+3$

5-8 I Caca-Palam Mal:v. Colocyuthis. $8-7$

I2-3 I Caca-Taly Bram: v. Solanifolio ma-

$1-10 x$

$9-43$

Bonda-Calo Bram. v. Alcea.

Boriti Bram. v. Frutex baccifer \&c.

Bofaya Bram.

Bovatti \&ீ Padri Bram. v. Clematis. 


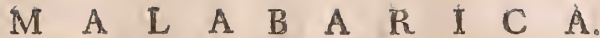

Cacoefa Bram: v. Acacia:

Cada-Pilava Mal: Cada-Pila Bram: v. Arbor indica \& ce.

Cada.Valli Bram:

Cadelari Mal, $v$. Verbena.

Cadel-Avanacu Mal: v. Ricinus:

Cadelipoea Mal: v. Alcea.

Cadenaco Mal: $v$. Afphodeli affinis \&.c.

Caela - Dolo Bram. v. Hedera terreltris.

Cajan arbor indica foliis trifolii bituminof, filiquis orobi Breyn P: I. 20. v. Phafeolus arbor.

Cajenneam Mal. v. Chryfanthemi Species.

$1-97$

$7-21$

$10-155$

$2-61$

$4-45$

I I -83

$\mathrm{s}-\mathrm{rO} 3$

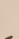

$6-23$

$10-81$

Caipa-Scbora Mal: v. Colocynthis 8-9 Capa-I sjambon Mal: v. Jambos.

Caitu Bram.v. Laurifolia malabarica \&c'

Caikotten-Pala Mal: $v$. Veronicx fimilis \&x.

$10-65$

Cajous Lufit \& Bslg: v. Anacardium. 3-65

Calabafen Beig: v. Colocynthis 8-9

Calageri Bram v. Serratula indica. 2-39

Calamus aromaticus G. ab Horto 200, $v$. A corus Verus.

Calefiam Mal. $v$. Arbor baccifera racemofa \&c.

Cali-Apocaro Bram: v. Punifera.

Cali-Apocaro Bram: v. Frutex indicus baccifer \&c.

Cali. Apocaro Bram: v. Frutex indicus baccifer \&c.

Cali-Valli Bram: v. Convolvulus. I I -113

Calo-Dotiro Bram: v. Stramonia.

Camaru Pifon: $149 . v$. Sulanum. Io-I 4 เ

Cambay, feu Myrtus americana Sylveftris Pifon: $s^{2} / 8 . v$. Baccifera indica \&c.

Cambogium officinarum, Gutta Gamba, \& Gutta Jemou Dale Pharm: 443. Carcapuli variorum. Carcapuli malo aureo æmulo $B$ : Pin:437 arbor indica, qux gummi guttæ fundit, fructu acido, fulcato, mali magnitudine, Carcapuli a Cofta, Ghoraka Cingalenfibus dicta Hermanni Syen in not. Coddam-Pulli feu Ota-Pulli Mal: Da. rambo Bram:

Cammetti Mal: v. 'Tithymalus:

Camotes Hifpanorum B: Pin: 9r. v. Convolvulus:

Canango Bram: v: Convolvulus:

Canavali Bram: v. Phafeolus:

Candela arbor foliis in pediculo ter-

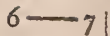

nis, fructu anguftiore Raji $H$ : I 7 \%. Kani-Candel, feu Kanil Kandel Mal:Savo-Candalo Bram: Salgeira fativo Lufit: Tamme Runboom Belg: an Mangle arbor pyrifolia falfis \& uliginofis Locis proveniens. fructu oblongo, te. reti, fummis ramis radicola $P h b$ ken: $P$ : 3. T: $C C I V: 3$ ?

Candela indica fructu longiore \& craffiore flore tetrapetalo Raji $H$ : 1770: Pee-Kandel Mal: Ala candalo Bram.Salgeira mainatoLufit: Wilde Runboom Belg:

Candela indica humilior flore exalbido pentapetalo, fructu majore Raji H: 1770 . Tsjerou-Kandel Mal: Maha-Candalo Bram: Salgeira major Lufit: Water Runboom Belg:

Candela indica floribus pentapetalis odoratiffimis, fructu minore incurvo Raji H: 1770 :Pou-Kandel Mal. Siri-Cançalo Bram. Salgeira Fermea Litlat: Kleyne Runboom Belg. an Mangle alba coriaria, folio denfiufculo, fubrotundo, glabro, fructu forma chariophylli aromati majore Pluken:P: 3.T:CCIV.4? 6-65 Candel Mal: Candalo Bram: v. Frutex indicus \&c. Canella Malabarica Es Jaranenfe B. Pin: 409.v. Caffia malabarica. $1-107$ Canclla Sylveftris malabarica Raji $H, 1562$. Canella five Cinamomum vulgare craffiore cortice $7: B: \mathcal{T}: I$. LIV:45 I: Canella arbor Sylveftris Munting 120: Tamalapatrum five Folium B: Pin: 409: Malabatrum \& Folium indum $f: B: T: 1: L: I V$ : 430: Katou-Karua Mal: Davo-Bahena \& Tiqui Bram: Canella do mato Lufit: Wilde Cameel Belg: 5- $105^{\circ}$

Caniram Mal.v Solanum. $\quad x-67$

Canna indica Arborea Zann: v. My- robalanus.

Canra indica Varios: $1-69$

Canna ingens Manibu vel Bambu ditta

Perkins Theat. I630. v. Arundo. I-25

Connacorus Latifolius vnlgaris Turnef: El: Bot: $295 . v$. Arundo. $\quad x \leq-85$

Cannæ feu A rundinis indicæ affinis.; flore globofo Commel: in nor: Narukila CMal. Polo Bram:

Cannabi fimilis exotitica $B$ : Pin:

$8-83$ 330. Bangue $G:$ ab Hort: 233. C: a Cofta 290. Bangue Par. 
kins T beat: 1624 . Bangue cannabi fimile $7: B: T: 3 . L X X X .440$. Alcea indica cannabino folio acetofa fapore quibufdam Dale Pharm: $3+3$. Kalengi Cantsjava Mal. Bangi Bram. Frmina: 10-1 19 Eadem Mas. Tsjeru-Cantsjava Mal. Tsjada Bangi Bram.

Canfchena Pou Mal. v. Arbor Siliquofa \&x.

Cant chi Mal. v. Arbor racemofa \&c.

Cansjam-Cora Mal: v. Perfolıtæaffinis:

$10-103$

Cante-Mogaro Bram: v: Verbena: 10-1 57

Canti Bram: v: Baccifera indica \& c: $5-73$

Cantfanu Bram: v: Arbor Siliquofa \&c:

Capicattinga, aliis jacarecatinga, Seu Acori Species Pifon: 141. v. Acorus.

Capo-Molago Mal, v. Piper.

Capraria Curafavica Par. Bar, P. 319. v. Gratolx affinis.

Capura-Catari Mal. v. Planta bifoliata \&c.

Capparis arborefrens in tica Badukka dicta flore tetrapetalo Raji $H$. 1630. Badukka CMal. Ranamandaru Bram. Tabal. Lufit. Quetblom Belg

Capparis arborefcens indica flore tetrapetla Solda dicta Raji H. 1630. Solda Mal. Siri-Pada Bram. Tula do mano Lufat. Dodoren Belg.

$1 \div 63$

$1-63$

$1=76$ II

$x \mathrm{x}-99$

$2-109$

$10-105$

$1 I-8 I$

\begin{abstract}
An be bine cappares, fint illa ip fe non fpizofa Es arabice, frudu ous magnitudine, Scmine piperis inftar, an earzndem fpecies, quarum mentionem facit obfervationum juarum L. 2. C.60. Bellonius, guse ritur.
\end{abstract}

Capufs Bram: v. Xylon malabaricum.

Cara Pifon: 93. Cara Brafilienfibus, Inbame de S.Thome, Congenfibus Qiiquoaquicongo. Margg. 29. $v$. Ricophora.

Cara-Canir am Mal: v. Crotalaria. 9-109

Cara-Pullu Bram: v. Lyfimachia. 2-97

Cara-Scbulli Mal. v. Frutex indicùs.

Cara.Nofi Mal: v. Vitex.

Carabalo Bram:

Carabou Bram: v. Azadirachta. 4-10,

Carambola Bram: ES Lufit: $v$. malus indica.

Carambu Mal. v. Lyfimachia.
1 Carandi Bram:

Carando Bram:

Caranf/l Bram: v. Crifta pavonis.

Carapu Bram: v. Smilacis afperæ Ipecies.

Carati Mal: $v$. Balfamina cucume= rina.

Caravatti Bram: v. Ficus.

Caravatti-Valli Bram: v. Convolvulus.

Carcapuli variorum v. Cambogium. $\begin{array}{ll}3-83 \\ \mathrm{I}-4 \mathrm{I}\end{array}$

Cardiaca Afiatica nepetz folio, floribus brevibus, purpurreis, pallidis Commel: in not: Cardiaca ame- ricana annua nepetæ folio, floribus brevibus, phaniceis, villofis Herm: Cat: 1 17.Leonurus annuus americanus, Nepetæfolio, flore phaniceo minore Breyn: P: 2.62 . Tsjadaen Mal. Tsjalo Bram: 10-I79

Cardamomum minus Bont: 126. Bodai â Stapel in Theoph: 1014. Cardamomum fimpliciter in off. cinis dictum B: Pin: 41 4. Cardamomum cum filiquis five thecis brevibus F: $B: T: 2 . L: X V .205$. Cardamomum minus vulgare Chis: in Gars: 187 . Elettari 2. Malab. Elu Bram.

Carduus Brafilianus foliis aloes $B$ : Pin: 384 . v. Ananas.

Carduus Brafilianus Sylveftris $B$ : Pin: $38+v$. Ananas,

Car-Ehu Mal. v. Sefamum.

Carloe-Vegon Mal: v. Ariftolochia 9-107

Caremotti Mal. v. Ricini fpecies. $4^{-105}$

Caretti Mal. v. Crifta Favonis. 2-35

Cari-Capu/l Bram: v. Alcea. $\quad 1-53$

Cari-Villandi Mal.v. Smilax afpera. $7-59$

Carilba Lufit. v. Vitex. $\quad 5-1$

Carilba de Serra Lufit.v. Vitex. $\quad 5 \rightarrow 3$

Carinz-Curini Mal. v. Frutex indicus fpicatus.

Carim-Gola $\mathrm{CMal}_{\text {. }}$

Carim-Pana Mal v. PaIma.

$2-31$

I 1 - , 1

$1-11$

Carm-Tumba Mal. v. Nepeta. Io-185

Carinti Bram. v. Balfamina Cucumerina.

Caro Bram. v. Solanum.

$8-1.5$

Caro-Crodi Bram.

$1-67$

$7-87$

Caro-Nervoloe Bram. v. Arbormalabarica baccifera \& $x$.

Carotha-Tali Bram.

$1-99$

$7-89$

Caro-Tilu Bram; v. Solanum. 9-107

Carua Mal: v. Caffia malabarica. I 107

\begin{tabular}{r|r}
$3-51$ & Caryophyllus Spurius malabaricus \\
$2-95$ & fore huteo minore Commel: in not:
\end{tabular} 


\section{$\begin{array}{llllllllll}M & A & L & A & B & A & R & I & C & A\end{array}$}

v. Lyfimachia.

Caryophylhus Jpurius malabarien/is flore Luteo Commel: in nor: $v$. Lyfimachia.

Caffia Fiftula alexandrina $B: P$ in: 403. Caffia purgatrix $\mathcal{F}: B: T: 1$. $L: X I I .416$. Arbor Caffiant Solutivam ferens Bont. Ior. Caffia fittula vulgaris flore Luteo Breyn: $P: 2.26$. Quauhayohuatlis fecunda , feu Carfia fiftularis Herm: 87. Conna CMal. Bajo Bram.

Caffia malabarica Herm: Cat: 1 . 0. Arbor canellifera malabarica, cortice ignobiliore, cujus folium malabatrum officinarum Breyn: P: 2. 18. Caffia vulgaris calihachas dicta Pifon: Mant: Aroin: 165. Cinamomum \& canella malavarica \& Javanenfe $B ; \mathcal{P}$ in: 409 . Caffia Lignea officinarum Dale Pharm: 429. Carua \& Bahema Mal. Tiqui Bram.

Caffibori Bram; v. Arbor indica ixc.

Caftanea malabarica Angelina dicta Raji $H_{1.1}{ }^{8}$ 4. Angelina C: a Coffa 276. an Angelina arbor $B$ : $P$ ins: 449. Ansjeli Mal: Pata-Ponoffou Bram: angeli Luftt: anjeli Belg:

Caftanca indica florida $R$ aji $H$ : 1680 . Caftanea indica rofea Auct: $H: M$ : Belutta-Tsampakam Mal: Nagatampo Bram: Moroius rofado Lu/itt. Caftani-roofen Belg.

Caftoeri-Mogarı Bram. v. Jafminum. 6-97

Caffuri - Camalla Bram. v. Nimphra.

Catecbu officinarum Dale: Pharm: $v$. Palma.

Catevala Mal. v. Aloes.

Cat-Ambalam CMal.

Catbukarobiti Cingal: v. Melampyro cognata.

Catri-Couda Mal.

Cat $\{$-Piring Indor. $v$. Jafminum. $6-89$

Cattu-Carambiu Mal. v. Lyfimachia.. 2-97

Cattu-Gafuri Mal. v. Alcea.

Cattu-Molago Mal:

Cattu-Ficinna Mal. v. Cucumis.

Cattu-Schiragam Mal. v. Serratula. $2-39$

Cattu-Tirpali Mal. v. Piper Longum.

Cattu-Tirtava Mal.

$18-53$

$1 \rightarrow 9$

II -7

$x-93$

9-77

$2-133$

$2-7 \mathrm{r}$

$7-25$

$8-13$

$2-39$

Cattu-Valli Mal.

Catu-Baramareca Mal. v. Phafeolus.
$7-27$

$10-17 \mathrm{I}$

$11-127$

$8-87$
Catu-Paeru Mal. v. Phafeolus. minum.

Catu-Tsjandi Mal. v. Phafeolus. $\quad 8-83$

Catulama Bram: v. Vitex Sylveftris:

Catulli-Pola Mal, $v$ Narciffus. $\quad 7$ I $^{13}$

Catupinaca Brava Lufit. v. Alcea 4-47

Catupinaca da Serra Lufit. v. Al-

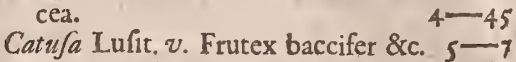

Cavalam Mal. v. Arbor Siliquofa \&c. I-89

Cavandely Bram. v. Colocynthis. 8-7

Caunga Mal. v. Palma.

Cerafus umbellata pavonina foribus coccineis Hermanni $v$. Jafminum.

Cerberi-Valli Bram. v. Clematis. 7-17

Cerberi-Valli Bram.

$7-19$

Cbamecaffie affinis tetraphylla, $\sqrt{6}$ liquis tenuifimis, femine tereti, apicibus obtufis, quafi abjciffis, Jua longitudine fecundum longitudinem filique pofito. Breyn. P: 2.

Chamecaffia anguffifolia indica Breyn. P: z. 29. v. Senna.

Chamrecriftx pavonis affinis indica, caffix folio, filiquis compreffis latiffimis propendentibus, floribus ampliffimis in fummo ramo. rum fpicatis Breyn: $\mathcal{P}: 2.30$. Siliquofa malabarica flore pentapetalo, filiquis longis, planis, diapluragmatis femina fecludentibus interceptis $R$ aji $H$. 1 746. WelliaTagera, vecWellia-Ponnam-Tagera, vel Wellia-Ponnavire Mal. Sarpouli Bram. Tagera Lufit. Fula de Coupang indis Groot Glidhout Belg.

Champacam Mal: Champo Bram. $v$. Uvrifera arbor \&c.

$2-\mathrm{IO}_{3}$

$2=1$ OI

Cheramela Lufit. $v$. Bilimbi.

Cheru Chunda Mal. v. Solanum. 2-67

Cheru Mal. v. Prunifera malabarica \&ce.

Cbineefche Prumen Belg. $v$. Pru- ${ }^{4-19}$

Chori-Bori Bram: v. Baccifera indi-

Chovanna-Mandaru Mal. v. Arbor Sancti Thome.

Chovama-Mandaru Mal. v. Arbor filiquofa malabarica \&c.

E 2
6-I7

$1-3 \mathrm{x}$

$4-53$

$4-83$

$1-57$

I- 59

Chry- 
Chryfanthemum indicum, urtica folio, flore Luteo, petalis bifidis Commel: in not: Vallia-MangaNari Mal: Amali Bram:

Chryfanthemi fett Bellidis majoris fpecies Commel: in uot: Cajenncam Mal. Maco Bram:

Chryfanthemi ́eu Bellidis majoris fpecies Commel: in not: Péé-Cajenneam Mal: Bringarafi Bram. 10-83 Chunda Mal: v. Solanum.

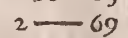

Chylli indie orientalis, Jeu Zingiber femina Hernand: 169 . v. Zingiber.

Cinamomum Eैं canella Malavarica Eg . Favanen/is B: Pin: 409. v. Caffia malabarica.

Cinamomum vulgare craffiore cortice J: B: T:1. L:IV. 45 I.v. Canella Sylvefris.

Circa-Davetha Lufit: v. Siliquofa malabarica \&c.

Cirita-Mari Bram: $v$. Baccifera ma-

labarica \&ic.
Ciffus chamarbodendros, Seu Ledum orientale pentaneirros, foliis brevioribus, ferrugineas molli $\mathrm{La}$ wugine villofis Pluken: $\mathrm{P}: 3 . \mathrm{T}$ : CLXI. 2? v. Baccifera indica \&c.

Cifus humilis indicus ciceris folio, flore Luteo Comnel: in not: Kurundoti $\mathrm{Mal}$. Tupucadi $\mathrm{Bram}: 10-35$

Ciffus indicus quinque nervis, folio birfuto \& fcabro, floribus roffis amplis, captululis fericeis villofis, puppa nigrarefertis major , Cingalenflibus Malabotbyiadictus Herm: Herb: v. Ceyl: v. Baccifera indica \&c.

Ciffus pulpifer indicus Herman: v. Baccifera indica \& $c$. .

Cifti indici Jpecies quarta Commel: in not: $v$. Baccifera indica \&c.

Cit-Ambel Mal. v. Nymphxa.

Cit-Amerdu Mal.
Cit-Naqueri Bram: v. Baccifera indica \&c.

Cit.OEti Bram: v. Cornus.

Cit - Rana-Nimba Bram: v. Malus Limonia.

Cita-Mataki Bram: v. Frutex indicus \&c. $4 \longrightarrow 9 \mathrm{I}$ $4-87$ Citavanace Mal: $v$. Ricinus. Citia-cuvadi Bram: v. Betx folio \&ic. $10-117$

\section{R A}

Claver-Appelkens Belg: v. Malus Limonia.

Cleeff pruymen Belg. v. Sebeftena domeftica.

Clematis arborea indica juglandis folio, flore Luteo fpicato minimo, filiquis longis, angultis, quadratis, atque retortis, feminibus fubftantia Lignofa obductis Breyn 'P: 2. 34. Siliquofa flore pentapetalo, filiquis longis, anguftis, quadratis, intortis Raji H: 1750 . Padri Mal. Bovatti Bram: Favas da Cobre Lufit. Adderboonen Belg. an Padri Malabaricæ fimilis arbor é Maderafpatan Pluken: $P$ : I.T: LIII. 2 ?

Clematis arborea indica juglandis fo. lio, longiffimis floribus, filiquis teretibus, longifimis, contortis, femine fubftantia lignea fungofa inclufo Breyn: Prod.2. 34 . Arbor filiquofa indica filiquis longis, contortis, in quatuor cellulas per longum divifis Raji H. 17 G4.NiirPongelion Mal. Singi Bram: Cornos dos diabos Lufat. Bokshoorn Belg.

Clematis arborea malabarica maxima fatida, juglandis folio, pinnis longioribus, flore albicante amplo fatido, filiquis compreffis Latiffimis Breyn: $P: 2.34$. Arbor filiquofa malabarica, folio majore mucronato, fructu maximo, oblongo, plano, femine membranaceo Syen in not. Bignonia arbor indica foliis oblongis Turnef. El. Bot. 13 3.Pajaneli Mal.

Clematis arborea malabarica maxima, juglandis folio, pinnis ro. tundioribus, flore albicante ampliffimo fatido, filiqua compreffo latiffima Breyz. P. 2.34. Dignonia arbor indica foliis cordatis Turnef. El. Bot. 133 . Arbor Siliquofa maJabarica, cordato folio, fructu maximo, oblongo, plano, femine membranaceo Syer in not. Palega-Pajaneli Mal. Davandicu Bram.

Clematis triphylla arborefcens é Maderafpatan Phiken. P. 3.T. CLXIII. 1. Tsjou-valli Mal. Cerberi - valli Bram. Uras d'afiofare Lufit. Plat Pimperlingh Belg. 


\section{$\begin{array}{llllllllll}M & A & L & A & B & A & P & I & C & A\end{array}$}

Clematis indica perfica foliis, fruĖu periclymeni B: Pin. 301 .v. Solanum.

Cliche falfa Lufit. v. Crifta pavonis 6-35

Climmende Rÿfboom Belg: $v$. Convolvulus.

Clitorius flos albus Herm: Cat. $16_{2}$. v. Phafeolo affinis \&c.

Coccule officinarum B: Pin: $5 \mathrm{r}$. $v$. Arbor indica cocculos officinarum ferens.

Codaga-Pala Mal. v. Nerium.

Codagen Mal.

Codda-Panna Mal. v. Palma.

$7-1$

I0-91

Coddam-Pulli Mal. v. Cambogium. $1-4$

Codigi Bram. v. Pulmonaria.

Codivi-vaffi Bram:

() -127

$10-47$

Codi-Avanacu $\mathcal{M}_{a} l$. Boin Erando Bram: an Lathyris fruticefcens fructu in foliorum alis cchinato Raji H. 1,10?

Coduco-Ambabo Bram:

Coduvo-NaniBran. v. Malus Limonia.

Coifa Bram.

Coipa Bram: $v$. Perficariæ folio \&c. IU-2

Colaffo Bram: v. Genifta.

Colcbicum ceylanicum flore viole, odore Ef colore ephemero Par: Bat: P: 304.v. Zedoaria.

$2-63$

$1-93$

$4-29$

$\mathrm{I}-2 \mathrm{I}$
$2-87$

Colini 4 II 17

Colinil Mal: v. Polygala indica. $\quad I-\mathrm{IO}_{3}$

Colladi Bram: $v$. Arbor indica Siliquofa \&c.

Colletta-Veetla Mal. v. Melampyro cognata \& c.

Colocynthis oblongo $B$ : Pin: 313 . Parkins: T beat. 160. cucurbita afpero folio amara, grandis, oblonga, viridis $\mathcal{F}: B: T: 2 . L: X V I$. 229. Caca-Palam Mal. Cavandely Bram. Fruita Quifoute Lulut. Swalm-appel Belg.

Colocynthis pyriformis, feu Pepo amarus $B$ : 'Pint: 313 . Cucurbita afpero folio, amara, turbinata, flava, candicantibus lineis in fcripta, parva $\%: B: \mathcal{T}$. 2. L: $X V I$. 229. Caipa-Schora Mal. Culivo Dudi Bram: Bobora Lufit: Calabaffen Belg.

Coluppa Mal. v. Perficarix folio \&c.

$6-2 I$

$9-77$

Colutea indica herbacea, ex qua Indigo Herm: Cat. 168. Sesban aniliferum indicum, coronillx foliis, vel Indigo indica Breyn: P:
2. 91. Nil, Anil, five indigo indica CMoris: HI: 202. Anil. five Nil indorum color. $F: B: T$ : 2. L: XXII. 945. Polygala indica Frutefcens Hermanni Raji $H$. 928. Ifatis indica, foliis rorifmarini glafto affinis $B$ : $P$ in: 113. Phafeolus A ninericanus. vel Brafiliausus fextus eju/dem 242 . indigo folio cordato, five indigofera coluteoides Muntingh. 229. Nil, Jive Anil, Glaftum indicum Parkins: Theat: 614 . Indicum officinarum Dale Pharm. 32.3. Caachira prima Pifon: 198. Herva de Anil Lufitanis Margg: 47. Xiuhquilit Pitzahac, feu Anir tenuifolia Hern: 10s. Awary Cingalens: Ameri CMal. Nely Bram: $1-10 I$

Colutea filiquofa malabarienfis Commel: in not: Siliquofa malabarica filiquis Spithamxis, anguftiffimis, contortis Raji H: 1735 . Kedangu Mal. Kenanga Bram: Fruita d'dgaroa Lajut. Spinnckoppen Belg. 6-49 Comati Bram:v Arbor malabarica \&c. $5-63$ Commodu Bram: v. Nymphax affinis \&c.

Comody Bram. $11-55$ Comody Bram: v. Lyfimachia. $\quad 2-99$ Commetti Bram: $\quad 7-67$ Comna Mal: v. Caffia fiftula. $\quad 1-37$

Congas Ceylan: v. Saponaria arbor. $4-43$ Confolida indica arborea Bont. 97. v. Arbor indica \&c.

Convolvulus aquaticus folio longiore, floribus candidis Conmel: in not: Ballel Mal. Takafivalli Bram. I I - IO7

Convolvulus exoricus antuus, foliis myriophylli, feu millefolii aquatici, Hore fanguineo Moris: $H: 2$. 20. Convolvulus tenuifolius, $\sqrt{\text { ive }}$ pennatus americanus Parkins: Theat: 170. Convolvulus elegains tenuifolius five indicus pennatu's Munting. 505. Jafminum millefnliifolio B: Pin: 398. Quamoclit, five Jafminum americanum Chus: Cur: $p$ : 9. Quamoclit five convol-: vulus tenuifolius $F: B: \mathcal{T}: 2 . L$ : $X^{2}$. 177. Tsjuria-Caranti. Mal: \& Bram.

Convolvulus indicus arborefcens fructu pruni amulo Raji.H: $530 \mathrm{Val}$ li-Teregam Mal: Caravatti-Valli Bram. Arvore da rafpa pregirofo Lufit. Climmende Ryvboom Belg. 
an Uvifera arbor americana convolvulacea, fructu punctato, Barbadenfibus chequer-grape, ideft, Uva teffulata, nuncupatur $P$ luken: $\mathcal{P}$ : 3. T: CCXXXVII.4?

Convolvulus indicus, radice tuberofa eduli, cortice rubro, Batatas dictus Par: Bat: Prod. 32 . Convolv ulus indicus Batatas distus Raji H. 728. Convolvulus indicus orientalis inlıame feu Batatas, Sifarum peruvianorum, feu Battata Hifpanorum Mor. H. 2. I 1 . Batatas, Camotes Hiffanorum Chus:Hift: L:IV.78.B:Pin.91.\& Variorum Jecica Pifon: 294. Kappa-kelengu Mal. Cananga Bram: Batatas Lufit. Batratcs Belg.

Corrvolvulus indicus minor, alfine folio, flore rubicundo purpureo Commel: in not: Viftum Clandi Mal.

Convolvulus indicus minor folio angulofo, flore ex albo flavefcente Commel in not. Sendera - Clandi Mal.

Convolvulus malabaricus, flore amplo, viridi diluto Commel: in not: Munda-Valli Mal.

Convolvulus malabaricus, floribus ex albo purpurafcentibus Commel: in not: Convolvulus maderafparanus purpureus, violæ martiæ foliis, floribus plurimis fimul junctis Pluken: P: $3 . T$ : CLXVI. 5 . Tiru-Tali Mal.

Convolvulus malabaricus folio longiori , flore candido. Commel: in not. Pen-Tiru-Tali Mal.

Convolvulus malabaricus, angufto folio, flore variegaio Commel: in not. Tala-Neli Mal. Cali-Valli, velRain-Mamorad Bram.

Convolvulus malabaricus flore maximo purpurafcente Commel. in not. Adamboe Mal.

Convolvulus malabaricus folio rotundiore craffo, flore candido Commel. in not. Bel - Adamboe Mal. Bangado-Valli Bram:

Convolvulus maritimus Zeylanicus, folio craffo, cordiformi Herm. Cat. 17 5. Bintamburu Zeylon. Pefcapræ Lufit. Schovanna-Adamboe Mal.Bangada-Valli Bram: an Convolvulus maritimus feu Soldanella é Maderafpatan, folio in fummitate finuato Pluken. $P i . \mathcal{T}$ : $X X I V .4$ ? $11-117$

Convolvulus maximus malabarienfis, folio villofo floribus purpu. rafcentibus Commel. in not. Samu. dra-Tsjogam Mal. \& Bram. I 1-125

Convolvulus Zeylanicus villofus pentaphyllus \& heptaphyllus minor, Pes Tigrinus dictus Herm.Cat. 184. Convolvulus indicus Pes Tigrinus dictus minor \& hirfutus $\mathcal{P}$ ar. Bat P.326. Convolvulus hepraphyllus indicus villofus Breyn.P: I. 3 3. Ë Mifc. cur: D: 1. $A: 4$. Es 5. 145. Pulli-Schovadi Mal. Arty Bram:

$11=12 \mathrm{I}$

Convolvuli affinis malabarica, floribus pilofis, variegatis Commel. in not. Katru-Kelengu Mal. 11-10s

Convolvulo fmilis Bryonia alb e foliis villofis ex India orientali Pluken. P. 1. T. XXV. 3. v. Balfamina Cucumerina.

Convolvuli inftar volubilis è Corman. del, umbilicatis foliis, craljis, acuminatis, villofa Pluken. P.r. T. XXIV. 6. $\%$. Bryoniz Levis speeies.

I- $\mathrm{IO}_{3}$ Convolvulus brafilianus Inbame de $S$. Thome dittus Commel, in not. v. Ricophora.

Conyza indica teucrii folio, flore flavo odorato Cummel. in r.ot.Man-. ja-Adeka-Manjen $M$ ul.

Conyza malabarica lamii folio, flore purpureo Commel. in not. NariPatfia Mal. Vafini Bram,an Eupatoria conyzoides maderafpara. na, foliis glabris, fummo caule ramofior Phiken. P: 3. T: CLXXVII.2?

Conyzx affinis malabarica, aquilegiæ folio, flore purpureo Commel. in not. Puam. Curundala Mal. 10-12\%

Coral arbor fpinofa orientalis, fru. ctu intenfius rubente $\mathcal{P}$ ar. Bat. $P$. 327. Arbor Coral filiquofa $\mathcal{F} . B$. T. x. L: $X I I .426$. filiqua Sylveftris fpinofa arbor indica $B: P$ in: 402. Arbufcula corallii Ferrarii Flor. Cult. 380 . Arbor fabifera prima, Boa Tsink kingh dicta Bont. 135. Erabu Zeyloz: Mouricou, Muricu \& Morico C Mal. Pangiro Bram. Folhas da trinidade Liufit. Slackhout, Washout, Elephants Boom Belg: 
Corallinum Lignum Par: Bat: P. 328 . v. Siliquofa indica \& $\mathrm{c}$.

Cordoeira Lufit. $v$. Berberis.

Cordoeira Lufit. v. Ficus.

thæ cattariæ affinis.

6-39 Covalam Mal. v. Cucurbitifera tri-

Cor-indum ampliore folio fructu majore Turn: El. Bot. 342. Halica. cabum peregrinum multis, five Cor-Indum if: $B: T: 2$. $L: \mathrm{X} V$. 173. Pifum cordatum, Cor indum. Halicacabum peregrinum Lob. ObJ.5.16. Pifum veficarium fructu nigro, alba macula nototo B: Pin. 343 . Ulimia Mal: PiruDukka Bram: Fruita Bolfa china Lufit. Timpen Belg.

Corinti.PanelMal. Corinti Bram.v. Frutex indicus baccifer \&c.

Cormos dos diabos Lufit. v. Clematis.

Cornus malabarica, folio cufpidato, 4-115 folia.

$3-87$ CovelMal.v. Balfamina CucumeriConpajada-Gon coniBram: v. Siliquofa flore umbellato \&c.

Couradi Mal. v. Frutex baccifer \&c.

Courdi Bram: $v$. Arbor indica \&c. $4-103$ Courondi Mal. v. Arbor indica \&c.

Craam-Beffen Belg. v. Baccifera indica \&c.

Craye-Beffen Belg. $v$. Baccifera indica \&c.

Crica da velha pequena Lu/it.

officulo tomento obfito Syen in not: Schageri-Cottam Mal. Safali Bram.

Crica da velha Trapadeira Lufit.

Crifta panonis coronillæfolio prima, five floribus fpicatis ampliffimis ex aureo \& coccinco variegatis, filiqua pifi Breyn: $P: 2.37$. Frutex pavoninus, five $\mathrm{Crifta}$ pavonis Breyn. Cent. 37. Erythroxylum indicum minus fpinofum colutex foliis, filiquis anguftioribus, flore ex luteo \& rubro eleganter Raji H. $153^{-}$-Tsjerou-Ponna Mal. Cit-Octi Bram. Ponnaca-Pequena Lufit. Kleyne geele gom appelen Belg. Kina Herm. Herb. v. Ceyl.

Corni Seu Sorbi Jpecies Bont. 103. v. Baccifera indica \&c.

Corofinam Mal. \& Bram.

Coroliera Bram. v. Sedum.

Corotba Bram. v: Pomifera indica \&c.

Corou-Moulii Mal.v. Frutex indicus baccifer \&c.

Coftus officinarum Dale Pharm. variegato $P$ ar: $B a t: P: 333$. Poinciana flore pulcherrimo Turkef. El. Bot. 492. Monarakudimbiia

9-1 33 Zeylon: Tsjetti-Mandaru Mal.

9-129 T sjettia Bram: Foula de pavan Lulfit. Paeuwe Staerten Belg.

4-i I

Crifta pavonis coronillafolio fecun$\mathrm{da}$, five tinctoria indica, flore

$5-77$ Luteo racemofo minore, filiqua larifima glabra, lignum rubrum 366. Coftus, Arabicus Diof coridis: Iridem redolens: Amarus officinarum, feu Helenium \& Comagenium Diofcoridis: Dulcis officinarum Centaurio magno cognatus B: Pin. 36. 37. ejufdem in Thearr: Bot: 6,0 671. Helenii facie officinarum: Dulcis officinarum Centaurio magno cognatus j: B:T: 2. L: $X I X .751$. Arabicus Diofcoridis Mattb. in Diofc. 39. Cofti quioddam genus Zinzibri radici fimile Clus. in Garz. 206. Coftus indicus Clufii Parkins. Theat. 1582. Tsjana-Kua Mal: Ponvo Bram:

$I I \longrightarrow 15$

Cottarn Mal. v. Baccifera indica \&c.

Cottam Mal. v. Nepetæ feu Men-
$2-23$
Sappan dictum, ferens Breyn: $P$ : 2.37. Erythroxylum, feu lignum rubrum indicum fpinofifimum, coluteæ foliis, floribus luteis, $\mathrm{f}_{1}$ liquis maximis $P$ ar. Bat. $P: 33 z$ : Santalum octavum, five ligno brafiliano fimile B: Pin: 93. Lobus cortice membranaceo, atro tumido Ejufdem 404. Lobus membranaceus niger, \&5 niger primus tumidus Chus: exot. 71 : Acacia tinctoria Hermanni. Tsjapangam Mal.Pao de fapan Lujit. Rafphout, Sapanhour Belg. an Ibirabitanga, feu lignum rubrum $P$; fon: 164 ?

Crifta pavonis coronillæfolio quarta, five Senfitiva; five Crifta pavonis minor indica fpinofiffima, fo$F_{2}$
$5-59$

$4-87$

$7-47$

$7-49$

\author{
49
}

$6-1$

$6-3$

liis 
liis coronilla fimilibus, flore Luteo amplo ad foliorumalas, filigua lata parva lanuginofa Breyn. P. 2. 37. Mimofa malabarica, flore pentapetalo, filiquis lanuginofis Raji H: 1 740. Kal-ToddaValli CMal. Lafari Bram. Erua mimofa Lilit Liefblad Belg.

Crifta pavonis glycyrrhiza folio $\mathrm{mi}$ nor, repens, fpinofiffima, flore luteo fpicato minimo, filiqualatiffima echinata, femine rotundo cinerco, lineis circularibus cincto, majore Breyn. P. 2. 38. Acacia gloriofa Lentifci foliis fpinofa, flore fpicato lutco, filiqua magna muricata Phiken: P: 1. T: 1 1. 2. inimboy Brafilianorum, frutex fpinofus fpicatus platilobis echinoidibus glycyrrhize folis Breyn: P: 1. 4.0. Lobus énuróngs Chis: exot: 70. Arbor cxotica fpinofa folis Lentifci B: Pin: 399. Lobus ¿̇urwódns cum pifo duro cinereicoloris F: B: T: I. L: XII. +3\%. Lobus echinatus fructu cæfio foliis longioribus $P$ ar: Bat: $\tau^{\prime}: 34^{8}$. Inimboy Pinfon. 205. Margg: 12. Bonduch Indorum. Caretti CMal. Tiringocfi Bram:

Crifta pavonis glycyrrhiza folio maxima indica, flore fubluteo minimo fpicato, filiquis anguftislongiffimis, ubi femina occultantur, protuberantibus, femine orbiculato compreffo fanguineo Breyz: $P: 2$. 38. Phafeolus alatus arboreus, fructu orbiculato, compreffo, coccineo Herm. Cat. 495. Arbor filiquofa indica, flote fpicato pentapetalo, filiquis longis, nodofis, fabis coccineis $R a j i H$. I 7 2. Miandithya feu Mara Ferm. Mus. Z $\%$ l. Mandsjadi-Mal. Gunfii \&ु) Goefii Bram. Mangalins Lufit. Manjelyns vel Weegh-boom Belg.

Crifta pavonis monof́permos prima, five Arbor vefpcrtilionis juglandis folio minore fpinofiffima, flore viridiluteo ad foliosum"alas, fenine \& filiqua villofa Breyn: $P$ : 2. 39. Arbor fpinofa indica filiquis villofis nonofpermis, Bankaretti, dikta $R a j i H:$ I 44 . Bankaretti CMal. Dou-Tiringouffi Bram: Cliche falfa, vel Silva- da-prajamacho Lujit. Praatjens Belg.

Crifta pavonis monofpermos fecun$\mathrm{da}$, five Arbor vefpertilionis indica, Lentifci folio, fpinofiffma, flore racemofo Luteo parvo odorato, filiqua \& femine glabro Breyn. P: 2. 39. Siliquofa indica, flore papilionaceo, filiquis latis monofpermis Raji H. 745 . Kaka-Mullu, vel Kaka-Moulou Mal: Ticanto Bram. Graon de veado Lufit: Schulpdoorn Belg.

Crifta payonis monof permos tertia, five Arbor velpcrtilionis maxima indica, juglandis fulio majore, floribus fpicatis, albicantibus, odoratis, filiquaa non nihil falcata, femine renali latifimo Breyn. $P$ : 2. 39. Arbor filiquofa flore papilionaceo, fabis longis \& latis, plana parte fibi invicem incumbentibus Raji H: 1733 . Pongam Sen Minari Mal. Caranfi Bram: Favas de chapa Lufit. Mansboonen Belg.

Crocus indicus, arabibus Curcum, officinis noftris radix curcume, dictus Bont: 1 r6. v. Curcuma radice longa.

Croefelingen Belg. v. Flos paffionis fpurius \& $x$.

Croeften Belg: Methonica malabarorum \&c.

Crotalaria afiatica, floribus huteis, folio fingulari, cordiformi Herm: Cat: 200, v. Genifta.

Crotalaria malabarica Sylveftris, foliis fingularibus majoribus, floribus luteis Commel: in not: $v$. Genifta.

Crotalarie afiatica frutefcens trifolia fortbus huteis amplis Herm: Cat: 1 96. v. Genifta.

Crotalaria Bengbalenfis foliis genifia fubbirfutis Par. Bat P: 329. $v$. Genifta.

Crotalaria afiatica folio Ingulari verrucofo, floribus caruleis Herm: Cat: I 98. v. Genifta.

Crotalaria fpecies Commel. in not. Cara - Caniram Mal. Boin - Caro Bram:

Cruculo indiano E̊ galuzza di levante Italis $v$. Arbor indica cocculos officinarum ferens. 
Cucumis fativus malabarienfis, fructu mucronato Commel. Cat. ro5. Mullen-Belleri Mal. Tava-Tini Bram. Pepinho do mato Lufit.

Cucumis Sylveftris malabaricus fructu firiato amaro Commel: int not: Picinna Cital. Goufaly Bram: Patolas Lulat. Traken Belg: an Cucumis indicus ftriatus operculo donatus , corticofo putamine tectus Pluken: P: 3.T: $C L X X I I$. s?

Cucumeris, JPu Colocynthidis Sylveitris fpecies Commel: in not: Cartu-Picinna Mal.Matri-Gonfali Bram. Fruita cofa Lufit. KorsAppel Belg.

- Cucumis Bryanoides bifnagarica, fructu parvo, florum calyce muricato Pluken:P:I.XXVI.4.v.Bal= famina cucumerina.

Cucurnis malabaricus fructu ex flavo rubente minor Commel: in not. v. Balfamina cucumerina.

Cucumis punicezls Cordi Mor. Hift. 2. 33.v. Balfamina Cucumerina.

Cucumis prniceus indicus fruEtumajore, ex flavo rubente Commel: in not. v. Balfamina cucumerina.

Cucurbita afperofolio amara, grandis, oblonga, viridis J: B: T:2. L: XVI. 229. v. Colocynthis.

Cucurbita afpero folio amara, turbinata, flava, candicantibus lineis in fripta, parva J.B.T.2. L.XVI.229.v: Colocynthis.

Cucurbita folits apperis, five Zucchaflore hiteo J: B: T: 2.L:XVI. 218. v. Pepo.

Cucurbita aspera folio non firso fruElu maximo albo, Seffili J: B: T: 2. L: XVI. $221 . v$. Pepo.

Cucurbita major rotunda, flore luteo, folio afpero B: Pin: 3 I2. v. Pepo. Cucurbitifera trifolia indica, fructus pulpâ cydonii amula Raji $H$. 1665. Pluken: P: 3. T: CLXX. 5. Cydonia exotica $B$ : Pin: 455 . Cydonia bengalenfis $G$ : ab Hurto 223. Covan Mal. Belou Bram: Marmeleira Lufit. Slymappel Belg. an Malum cydonium indicum Bont. 98?

Cudo Bram: v. Arbor malabarica. lactefcens \&c.

Cudu-pariti Mal: v. Xylon malabaricum.

Culi-Tamara Mal. v. Sagitta indica.

Culivo-Dudi Bram: v. Colocynthis. 8-9

Cumari Bram: $v$. Aloes vulgaris. $\quad 11-7$

Cumbulam Mal. v. Pepo. 8-5

Cumbulu Mal. v. Nux malabarica. $\quad I-75$

Cumudi Bram: v. Nimphæa: I I -57

Cunto Bram: $v$. Frutex indicus baccifer \&c.

Cupameni Mal. v. Mercurialis 5-29

Cupa-Veela Mal: v. Sinapiftrum.

Cappi Mal. v. Frutex indicus \&c. $\quad 2-37$

Curcuma radice rotunda Commel: in not: \& Par: Bat: P: 330. ManjaKua Mal. Davi-Kua Bram. Raiz do Zafrao Lust:

S-15 Curcuma radice longa Herm: Cat: I 1 - I9 208. officinarum Commel. Cat.107. foliis longioribus \& anguftioribus Breyn. P. 2. 40. Curcuma, five Terra merita officinarum radice crocea 7. B. T. 2. LXIX. 746. Cyperi genus ex India Mattb: 8-19 Fufc: B: Pin: 37. Curcuma Ejufdem Theat: Bot. 679. Cype8-2 I rus indicus Diofcoridis B. Matth. 27. Crocus indicus, Arabibus Curcum, officinis noftris radix 8-17 Curcumæ dictus Bont.116. Manjella-Kua Mal. Alady Bram. Kaha Zeylonens

$8 \rightarrow 7$ Curiga-Tali CMal.

Curinil vel Curiginil Mal.

Curini (forte) prima ppecies Pluken.

I I -2 I I

$7-49$

$7-47$

P: 3. T: CLXXI. 4? v. Frutex indicus \&c.

Curutu-Pala Mal. v: Arbor malabarica lactefcens \&c.

8- 1 Cufcuta fpecies fupra arbores \& plantas nafcens Commel: in not. AcatsjaValli Mal. Medicatali Bram:Ra-

8-3 mos dafevi Lufit. Meer-vleghtwortel Belg. an Cufcuta baccifera

8-1 Barbadenfium â maritimis Pluketr: $P:$ 3. T: CLXXII:2?

Cuvaly Bram: v. Pepo

Cuvali Bram. v. Flos paffionis $\mathrm{fpu}-$ rius

Cydonia exotica B. Pin. 435.v.

Cucurbitifera trifolia indica \&c.

Cynara indica, Sen Ananas Bont. 145. v. Ananas.

Cyperns indicus Diofcoridis B. Matth.

$2-3 I$

$1-83$

$3-37$

$1-83$ 27. v. Curcuma.

II 2 I 
Dacalo.Cante-Mogero Bram: v. Veronicæ fimilis.

Dacalo - Nanditu Bram: v. Jafminum.

Dacalo-Tandalo Bram:

Dacoli-Gajeri Bram: v. Genifta.

Dacouli-Naqueri Bram: v. Baccifera indica \&c.

Dacula-Bonda-Calo Bram: v. Althæa.

Dadu-Valli Bram: v. A pocynum.

Dadul-Paja Bram:v. Pepo arborefcens \&c.

Dadula-P apali Bram: $v$. Balfamina cucumerina.

Dadumari Bram.

Dadumari Bram: v. Gramen.

Dala-Vallu Brans:

Damapana Bram: v. Mimofx fpecies.

Damitaffi Mal. v. Saponaria Arbor.

Danti Bram: $v$. Ricinus indicus.

Darambo Bram: v. Cambogium.

Darpu Bram:

Dafameno Bram. v. Frutex baccifer malabaricus.

Datura indica foliis malabatri Breyn: Cent: $119 \cdot v$. Baccifera indica \&c.

Dature malabarice Hummatu dicte prima Jpecies Raji H: 749. v. Stramonia.

Dature malabaric e Jecunda fpecies Raji H: 749. v: Stramonia.

Dature malabarice tertia Species Raji H. 750 . v. Stramonia.

Dava-Sailo Bram: v. Prunifera indica \&c.

Dava-Karandi Bram:

Dava-Sotulari Bram: $v$. Alcea.

Davandicu Bram: v. Clematis.

Davi-Bedoefi Bram: v. Baccifera in-

dica \&c.
Davi-Padacali Bram:v. Jafminum. $2-39$

Davi-Rinti Bram: $v$. Vitex.

Davi-Roey Bram: v. Apocynum.

Davi-Roma-Caro Bram:

Davi-Sinfori-Touda Bram.

Davim-Pala Bram:

Davo-Babena Eુ Tiqui Bram: $v$. Canella.

Davo-Beniffa Bram: v. Baccifera indica \&c.

Davo Caro Bram: v. Solanum.

$4-93$

$6-79$

$9-2$ I

$8-35$

$9-\mathbf{3} 5$

$9-\mathbf{3} 39$

$8-55$

9-7I

$4-43$

$10-15 \mathrm{I}$

I -4 I

$12-107$

5 -I I

$7-65$

4-47

$1-77$
Davo-Mandaru Bram: v. Arbor filiquofa malabarica. $\quad 1-6 !$

Davo-Miri Bram.

2-107 Davo-Poejo Bram: v. Frutex indicus

10-59 fpicatus \&c.

6-47 Davo-Tiloe Bram: y. Sefamum 2-33

I - 2 I

$4-87$

Derpu Bram:

Defura Bram: v. Alcea.

Deva-Teva Sini Bram: 6-73

9-105

na cucnmerina.

Dewenda Bram: 8-25 $\alpha^{\prime \prime} x \alpha \operatorname{sp}(0)$ \&c.

$6-109$

Digitalis affinis malabarica, folio pilofo Commel: in not: Valli-UpuDali Mal.

Digitalis affinis indica, Blattarix folio, flore rubicundo Commel: in not: Bahel-Tsjulli Mal.

Digitalis orientalis fefamum dict ${ }^{9-169}$ Turnef: El: Bot: I $35 . v$. Sefamum.

$9-105$

Dino Bram: v. Frutex baccifer \&c. $2-43$

Dixadoufti Bram: v. Arbor indica

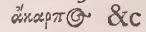

$6-109$

Dodini Bram: v. Veronicx fumilis

$\begin{array}{cc}\text { \&c. } & 10-65 \\ \text { Dodoren Belg: } v \text {. Capparis. } & 6-103\end{array}$

Doepoe Bram: v. Amygdalæ affinis. $4-33$

Dolari Bram: v. Solanum. $\quad 2-69$

Donsboom Belg: $v$. Goffipium. 3 $\quad 3-59$

Don-George Lufit: $v$. Arbor indica àxaprto \& \&.

Doornkerfen Belg: $v$ Jujuba 6-icg

Doornmillen Belg: v. Jujuba. 4-85

4-59 Doornmilfen Belg: v. Balfamina cu-

cumerina.

$8-23$

Doti-Mogari Bram: v. Jafminum. $\quad 6-89$

Dotiro Bram: v. Stramonia. $\quad 2-47$

Dovadeke-Goli Bram: v. Ficus. 3-69

Douda-Sailo Bram: v. Baccifera in-

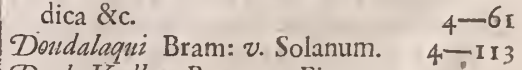

Doulo-Vadbou Bram: v. Ficus. $\quad 3-73$

Dou-Cerberi-Valli Bram: v. Hedera trifolia.

Dou-Parvatti Bram.

Dou - Tiringous Bm. 7-73

$7-7$ Dou - Tiringous $\sqrt{2}$ Bram v. Crifta $\mathrm{Pa}$. vonis.

$6-35$

Draakwortel Belg: $v$. Arbor indica \&c.

5-43 Drieboom Belg: $v$. Arbor indica fi-

$7 \rightarrow 9$ liquofa \&c. 


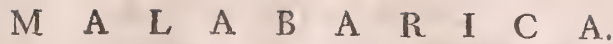

Drielingh Belg: $v$. Arbor indica \&c.

Erando Bram: v. Ricinus.

5-83 Ericu Mal. v. A pocynum.

$2-57$

Erima.Pavel Mal, v. Balfamina cucumerina.

Dudaim Cunæi Refp: Hcbr: P:2.490. v. Ficoides.

Duda-Valli Bram:v. Apocynum.

Dulcamaræ fpecies Commel. in not. Valli-Kara Mal. Fruita do Cao Lufit: Hondsbeffen Belg.

Dullert Be Jjen Belg: v. Prunifera malabarica \&c.

Dulle Boom Belg: v. Prunus:

Durba Bram:

Duymkruyd Belg.

I-I7 Erima-Tali Mal.

9-13 Erua-Bendita Lulit.

Erua d'empige Pifon: 238. v. Gramen.

7-35 Erua-Mimosa Lufit. v. Crifta pavonis.

4-x 9 Eryngium Ceylanicum febrifugum

4-4I floribus Luteis Herm: Herb: v.

12-87 Ceyl: $v$. Melampyro cognata. $\quad 9-77$

7-53 Erytbroxylum indicum mimus spinofurn, colute foliis, filiquis angufioribus, flore ex huteo 6 rubro

Drwaaldoorn Belg: v. Siliquofa indica \&c.

Dwergh-Appelen Belg: $v$. Baccifera indica \&c. eleganter variegato Par. Bat. P. 332. $v$. Crifta pavonis.

5-39 Erytbroxylum fen Ligun rubrum indicum pinofum, cohitea foliis,

Eborno \& Titi Bram:

$4-45$

Ecapani Bram:

Ecbolium Rivin: introd: P: I. v. Frutex indicus fpicatus \&rc.

Ecapatli altera Hernand: $>6 . v$. Senna Orientalis.

I0-9I

$2-33$ floribus Luteis, filiquis maximis Par: Bat: P: 333. v. Crifta pavonis.

Espinbo capado Lufit: $v$. Arbor indica \&c.

2-IOI Espinbo dos Bugios Lufit: v. Frutex indicus baccifer \&c.

Ela-Calli Mal: v: Euphorbio \& Tithymalo media affinis \&c.

EJpinbo do Ladro Lufit: $v$. Frutex baccifer \&c.

Ela-Pola Mal: v. Gladioli affinis \&c:

Elaticanto Bram: v: Prunus.

Elengi Mal. v. Prunus.

Elettadi-Maravara $\mathrm{Mal}$.

$\mathrm{I} \mathrm{I}-7 \mathrm{I}$

$4-4 I$
$I-33$

$12-41$

Elettari Mal. v. Amonum, \& Cardamomum.

Eliphantsboom Belg. v. Coral Arbor.

Elu Bram. v. Amomum \& Cardamomum.

Enckeide Schoenroos Belg: v. Al-

thra.
Eneadi-Kourengo Mal: v. Selago. Ene-Pael Mal.

Entada Mal.

$\mathrm{II} \rightarrow 9$

$6-13$

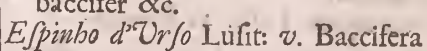
indica \&c.

Espinbo Malinbo Lufit: $v$. Baccifera indica \&c.

Efpimbo Salfedo Lufit: $v$. Baccifera indica \&c.

Efpinbo Sancto Lufit: v. Baccifera indica \&c.

Ejpirbo Sancto bravo Lufit: v. Prunifera indica \&c.

I 1 - 9 Eftrela d'alva Bram: v. Baccifera indica \&c.

6-73 Eupatoria conyzoides odorata, folio crenato, molli, fubinc ano Pluken:

Ephemerum malabaricum flore tripetaloide Commel. in not. Nir-pulli Mal. an Ephemerum phalangoides maderafpatanum minimum fecundum caulem quafi ex utriculis floridum Pluken. P. 3.T. $C L X X I V .3$ ?

Erabudu Zeylan: v. Coral Arbor. 6-13.

P: 2. T. T. LXXXVIII. 2. $v$. Serratula.

Eupatoria conyzoides maderafpatana, foliis glabris, fummo caule rannofior Pluken: P: 3. T:

CLXXVII. 2. v. Conyza? IO-I 23

Euphorbium indicum opuntia facie, caule geniculato triangulari Breyn. P. 2. 44 . Euphorbium verum Commel. in not. Verum antiquorum Raji H. 878. Tithymalus indicus fpinofus \& angulofus lacte turgens

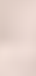

$$
\text { G } 2
$$

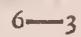

$5-75$

$5-77$

$5-81$

$5-69$

$5-71$

$5-73$

4- 39

$4-55$

$4-125$

$2-39$ 
acri C. H. Beaum. 4r. SchadidaCalli Mal. Pada-Nivuli Bram. $2-8 \mathrm{I}$

Euphorbium fecundum hactenus ignotum Commel.in not. Euphorbio \& Tithymalo media affinis aizoides indica arborefcens, nerii folio Breyn. P. 2. 45. Tithymalus ceylanicus fpinofus arborefcens Par. Bat. P. $3^{81}$. Ela- Calli Mal. Nivuli Bram.

Euphrafix affinis indica echioides Herm. Cat. 668. Gratiolx affinis echioides zeylanica major Breyn. P. 2. 34. Bugloffum echioides indicum convolvuli cærulei minoris folio Breyn. in Mifcellan. Cur. $A .{ }^{\circ}$. हु 5. 146. Ly fimachix virginianæ accedens planta Commel. in not. Kawatuwa Zeylon. PéeTumba Mal: Butumbo Bram.

Ey-Keylen Belg.

Bram.

Ficoides, feu Ficus indica, longifsmo latifimoque folio, fructu longiffimo, Mufa Serapionis dicta Herm. Cat. 256. Ficus exotica cruciata Sterbeek Citri cull: 6 i. Mufa, Banana, Banantes, Ficus indica Muntingb 26. Pacoeira, Bananiera $P_{2}$ fon. 154 . Pacocra, Banana Margg. 137. Palma humilis longis latifque foliis $B . P$ in. so\%. Arbor foliis ampliffimis, fructu cucumeris forma. Ejujdem Ficus indica fructu racemofo, folio oblongo ejufdem 508. Mufa Serapionis Lob Obf639. Mufa arbor f: B: T: 1.L: 1. r 49. Ficus indica Linfchottani ejufdem I $_{5}$. Mauz, Mufa Alp. de Plant. EEg. 80. Dudaim Cunei Reb. Hebr. 490.

7-67 Bala Mal. Kely Bram.

\section{Faba purgatrix latiffima ex infula} D. Thome B. Pin: 338 v. Phafcolus.

Favas d'aya Lufit.

Favas de Bramane Lufit. v. Phafeolo affinis.

Favas caringejo Lufit. v. Phafeolus.

Favas de chapa Lufit. v. Crifta pavonis.

Favas de cobre Lufit. v. Clematis arborea.

Favas cofeira Lufic. v. Phafeolus.

Favas cufeir a Lufit. v: Phafeolus:

Favas cufeira pequeno Lufit:v. Phafeolus:

Favas de engenbo Lufit: v. Arbor filiquofa trifolia \&c:

Favas de lafaro Lufit: v: Acacia:

Favas orelbeiras Lufit: v: Arbor indica filiquofa \&c:

Favas dos paros Lufit: v: PhafeoIus

Favas dos paros fativo $L u f$ t .

Favas de tres bumas Lufit: v. Arbor indica filiquofa \&c.

Favas turquefca $L u f i t$.

Faufel, five Areca palma foliis J: B: T: I. L: $3 \cdot 3^{89}$.v. Palma.

L.I. 145 Nieubov: Legat: P. 5 . I00. Ficus indica foliis mali cotonei fimilibus, fructu ficubus fimili in Goa B. Pin. 457 . Arbore de 8-89 Raiz Lin/chott.itiner. 82. KatouAlou Mal.Doulo-Vadhou Bram: 8-69 Rayfeira vidriado Lufit. Glas Vygeboom Belg an Ficus arbor ame8-79 ricana, arbuti foliis, non Serrata, fructu pifi magnitudine funiculisé ramis ad terram dimiffis prolifera Pluken:P: 3.T:CLXXVIII.4?

$8-6_{3}$ exeuntibus, eique accrefcentibus

8-6r augens Raji H. $143^{8}$ Atti-MeerAlou Mal. Rouka-Paray Bram:

8-67 Arvore da Rayz ladrao Lufit. Wortelvygh Belg.

6-29 Eadem fecunda Raji $H$. I 438. Handir-Alou Mal. Vodou Bram: Figos do Buzio Lufit. Krayvygh 6-2 1 Belg.

Ficus malabarenfis folio craffiufculo

majori, fructu gemino, intenfe rubente Syen in not. Per-Alu Mal. Vadhou Bram.

$6-27$ Ficus malabarenfis, folio oblongo, $8-73$ acuminato, fructu vulgari æmulo Syen in not. Atty-Alu Mal. Roem$x-9$ badoe Bram:

Ficus malabarenfis folio cufpidato, fructu rotundo, parvo, gemino Syen in not. Are-Alu Mal.Bipalou Bram.

Ferrum equinum majus malabarien$\mathrm{fe}$, filiquis in fummitate Commel. in not. Neli - Tali CMal. Nabali 
Ficus malabarenfis, folio denfiufculo, nirente, fructu parvo, rotundo, coronato Syen in not: IttyAlu Mal. Areca-Golu Bram:

Ficus malabarica folio \& fructu minoreCommel. in not: Tsjerou-MeerAlou Mal. Paray Brars:Arvore de Rays Lufit. Wortelboom Belg:

Ficus malabarica, folio mali cotonei, fructu exiguo, plano rotundo, fanguineo Commel. in not. Itty-Arealou Mal. Dovadeke - Goli Bram. Arvore da Rays minor Lufit: Kleyn Wortel-Vygen Belg.

Ficus malabarica, foliis afperis, fruEtu rotundo Lanuginofo majore Raji H: I 43 5. Perin-Teregam Mal. Meri-Caravatti Bram.Arvore da rafpa major Lufit. Groote Ryv-boom Belg.

Ficus malabarica, foliis rigidis, fructu rotundo, lanuginofo flavefcente, cerafi magnitudine Commel. in not. Teregam, feu Teregamaram CMal. Caravatti Bram: Arvore da rafpa Lufit. Ryv-boom Belg.

Ficus malabarica femel in annisfructifera,fructu minimo, Tsjakela di-. cta Raji H: 1435 . Tsjakela Mal. Ran-Vodou Bram:Cordoeira Lus fit:Heupboom Belg.an Ficus americana, latiori folio venofo ex $\mathrm{Cu}$ racao Phiken.P:3.T:CLXXVIII. I?

Ficus malabarica, fructu ribefii forma \& magnitudine Tsjela dista Raji H: 1435. Tsjela Mal: Afovatou Bram. Morfegeiro Lafut: Vleedermuyfen-boom Belg.an Arbor maderafpatana Galactoxyli americani foliorum æmula Pluken: P: 3. T: CXLIII. 4?

Ficuum Specie fructus peruvianus $\mathrm{B}$. Pin: $457 . v$. Pepo arborefcens Figos de buzio Lufit: $v$. Ficus Filfel \& Fufel Avicen v. Palma

Flagellum S.Thome vulgo v. Sela-

Flos divi Thome vulgo Commel: Cat: 34. v. Arbor Siliquofa malaca \&c.

Flos indicus Champana dictus Bont. 140. $v$. Uvifera arbor \&c.

Flos paffionis fpurius malabaricus quinquifido folio primus, five

fpinofus fructu rotundo Breyn: $P$ : 2. 48. Modecca fructu majori, flore ex albo flavefcente $P$ ar. Bat. P. 354. Modecca Mal. Bui-Cuivali Bram. Narola Lufit. Croefelingen Belg.

Flos pafionis fpurius malabaricus $3-7 \mathrm{I}$ quinquifido folio, fructu rotundo fecundus Breyn.P. 2.48. Modecca fructu majori, flore ex albo viridante Par. Bat. T. 354 . PalModecca Mal.

Flos paffionis fpurius malabaricus quinquifido folio, fructu vario, tertius Breyn. P. 2. 4 9. Modecca fructu minoriflore pallide virente Par. Bat. P. 355. Motta-Modecca Mal.

Flos paftionis fpurius malabaricus, folio integro, fructu rotundo Breyn. P. 2. 49. Orela-Modecca Mal. Kroefeling h Belg.

Flos paftionis fpurius malabaricus, flore majore, fructu minore Commel. in not. Pal-Modecca Mal. Cuvali Bram.

II IOI $3-79$

Fockii Fockii Bont. I 2 3. v. Solanum.

Folhas aredilha $L n \int i t$.

Folhas da cároa Lufit.

Folhas dacbina Lufit. $v$. Periclyme-

no fimenfi variegato fimilis. $6-\mathrm{II} 3$

Folhas da Lanca Lufit.

Folhas da Minta Lufit. $v$. Baccifera malabarica \&c.

Folhas da Pao Lufit.

Folbas darafpa Macho Lufit.v. Arbor flore tetrapetalo \&c.

Folhas da trinidade Lufit. v. Arbor Coral

Follhas de dente Lufit.

3-85 Folbas do Pitao Lufit.v.Valerianella curaffavica

$10-47$

$7-91$

$8-5 x$ 
Fructus exoticus quartus a Gareto acceptus Clus. exot. 40. v. Manga indica

Fructus peregrinus cum granis nucis vomica fimilibus $\mathrm{J}: \mathrm{B}: \mathrm{T}: 1$. L: III. 341 .v. Solanum arborefcens

Fructus quintus è Walacbria Clus: exot. 49. v. Amomum

Fruita bandoliera Lufit.

Fruita baretto Lufit: v. Frutex malabaricus

Fruita bareto Lufit. v. Althæa

Fruita barruga $L u f i t$.

Fruita bolfa Lufit. v. Malus indica

Fruita bolfa china Lufit. v. Cor in. dum

Fruita burrufa penachofo Lufit.

Fruita cata Lufit. v. Cucumis

Fruita cauri Lufit, v. Baccifera indica \&c.

Fruita cauri do Mato Lufit.

Fruit a cont fii Lufit: v. Phafeolus alatus \& $\mathrm{c}$.

Fruita d'agaroa Lufit: v. Colutea filiquora

Fruita da gralha Lufit. v. Baccifera indica \&c.

Fruita da gralha branca Lufit. v. Baccifera indica \&c.

Fruita da gralba do mato Lufit. v. Baccifera indica \&c.

Fruita da grallsa pequeno Lufit. v. Baccifera indica \&c.

Fruita da grude Lufit. v. Pomifera indica \&c.

Fruita d'entrude Lufit. v. Sebeftena. domeftica

Fruita do cao Lufit. v. Dulcamaræ fpecies \&c.

Fruita eftrelada Lufit: v. Arbor indica \&c.

Fruitagargantilha Lufit: v. Althæa.

Fruita gibique preto Lufit: v. Baccifera indica \&c.

Fruita gradiuba Lufit: v. Pavate arbor \&c.

Fruit a gundra Lufit: v. Siliquofa flore umbellato \&x.

Fruita macanda Lufot.

Fruita manilba Lufit: v* Prunus.

Fruita pardao da Serra Lufit.

Fruita pardao Trapadeira Lufit.

Fruita pardao pequeno Lufit.

Fruita patao Lufit. v. Rhamni fpecies \&c.

Fruita pedrica Lufit: v. Baccifera

L $\quad$ R A

indica \&c.

Fruita penacho Lufit $\quad 5-23$

$4^{-1}$ Fruita Qufoute Lufit: v. Colocynthis.

Fruita fancta Lufit: v. Arbor malabarica \&c.

Fruita tanao Lufit.

11-9 Fruita tirilba Lufit:v. Siliquofa in-

8-9I dica \&c.

Frutex baccifer indicus fpinofus, tri-

$6-3 \mathrm{I}$

$7-53$

$6-51$

5-103 folius, floribus fpicatis, fructu

6-79 planorotundo, tricocco Raji H:

7-69 1612. Kaka-Toddaly Mal.Boriti Bram: Efpinho do Ladro Lufit.

4-65 Praatkens Belg. an Kaka-Toddaly malabarica ex oris Cormandel $8-53$

$7-7 \mathrm{r}$ Pluken. P: 2. T: $X C V .5$ ? pentapetalis ramis inhrerentibus, fructu tetrapyreno Raji $H:{ }_{1} G_{24}$. Perim-Patsjotti CMal. Dafameno me Lerick Belg:

8-7I Frutex baccifer malabaricus, fructu $5-11$ plano-rotundo, pilofo, tetrapy6-49 reno Raji H: 1624. Pai-Paroca,
feu Couradi Mal. Bendarli Bram: 4-87 Garfilha Lufft. Nierplaymen Belg. an Pai-Parocx, feu couradi fimi-

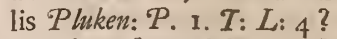

Frutex baccifer malabaricus floribus umbellatis, pentapetalis, fructu nigricante, poly permo Raji $H$ : 1635. Naligu Mal. Dino Bram. Frutex bacciter fructu ad fingulos 3-45 flores multiplici Raji H. I636. 3-45 flores multiplici Raji H. I636.

Frutex baccifer calyce excepto fulcato, trypyreno Raji H: 1572 . Katou-Patsjotti \& Tsjotti Mal.

3-39 Samenotti Bram. Salao Lufit. Lerick Belg.

Frutex baccifer malabaricus, flori5-55 $\begin{aligned} & \text { bus umbellatis, fimplici officulo } \\ & \text { tetrafpermo Raji.H: I } 557 \text {. Beenel }\end{aligned}$ Mal. Mana Bram: Catufa Lufit: Papekoppen Belg.

6-37 Frutex baccifer malabaricus, officu-

7- 5 I lo fragili, cunt fex intus nuclcis

4-53 Raji H: I558. Perin-Nirouri, feu 7-5 Ma-Nirouri, \&ु Mapana-Poja

7- 7 Mal. Poja Bram: Fruita da trini-

7- 3 dade Lusfit: Maagdelynen Belg. 5-87 Frutex baccifer malabaricus, fructu calyculato, rotundo, monopyreno,Myftax dietus Raji H: 1570. 
Modera-Canni Mal.

Frutex baccifer malabaricus, floribus pentapetalis, binis, una bacca. nigra in calyce felliformiter expanfo Raji H. I s71. Peragu Mal. Saikilo Bram:

Frutex baccifer malabaricus, fructu calyculato, tetracocco, umbellato Raji H. 1572 . Tsjocatti Mal. Valermani Mal. Foula Paolifta Lufit: Sottebollen Belg:

Frutex baccifer malabaricus, fru¿tu calyculato, ratnido, rubro, poly/permo Raji H. I 573. v. Jafminum.

Frutex indicus $\alpha^{\prime} x \alpha \beta \pi \sigma \sigma$, foliis binis adverfis, floribus pentapetalis, candidis, unguibus Luteis Raji H: $77^{8} 7$. Belutta-Amelpodi Mal: Sa - Ameli Bram: Marani Lufit: Groot Liever Belg:

Frutex indicus baccifer, Vitis id $x x$ fecundx Clufii foliis Breyn: Cent: S. Niruri CMal: Pane-Poi Bram: an Vitis idax fimilis Frutex africanus $\mathcal{P}$ ar: Bat: $\mathcal{P}: 325$ ? Vitis idæx fpecies maderafpatana, $\mathrm{Ni}$ ruri forte malabarienfibus dicta Pluken: $P:$ r. T: $L X I X .3$ ?

Frutex indicus baccifer hexapetalos, fructu rotundo monopyreno nigro Raji H: 1594 . Tsjerou-Panel, \& Baala-Paleti Mal: A pacaro Bram: Klcyn Heylwortel Belg.

Frutex indicus baccifer flore hexapetalo, fructu rotundo, racemofo monopyreno Raji H: I 594 . Corinti-Panel Mal: Corinti, \& Apocaro Bram: Pao Coftus do mato Lufit: Heylwortel Belg.

Frutex indicus baccifer fructu racemofo cufpidato, ribium fimili, monopyreno Raji H: I596. Tsje- $_{5}$ ram-Cottam Mal. Pattara-Panni Bram: Ramifoli Lu/lt. Lysbeffen Belg:

Frutex indicus baccifer fructu rotundo, polypyreno Raji H. ${ }^{16} 34$. Corou-Moelli MAal. BabouliCanti, \& Obadali Bram. Efpinhos dos bugios Lufit. Wafdoorn Belg.

Frutex indicus baccifer, floribus umbellatis, fructu tetracocco Raji $H: 1624$. Sondari, \& Kaka-Ponna Mal. Ajomato Bram. Tiloins Lufit. Maarboom Belg:
$2-29$

Frutex indicus baccifer, floribus ramofis, fructu oblongo, tetrafy. reno Raji H. 1625 . Perin-Panel Mal. Cali-Apocaro, EG Cunto Bram. Pao Coftus Lufit: Groot Heylwortel Belg. ant Arbor orientalis baccifera lauri foliis, craffis, \& venofis per ficcitatem atro nitentibus, quafi vernice tinctis, polypyrena Pluken: $P: 3 . T: C X L$. 2? 5-29

Frutex indicus baccifer fructu oblongo polyfpermo Raji H: 14.93 . Belilla Mal. Stravadi Bram:

Frutex indicus baccifer floribus umbellatis fructu rotundo, polyfpermo Raji H. I 494. Cupi Mal. Cita-Mataki Bram:

Frutex indicus baccifer, floribus verticillatis, fructu monopyreno $R a j i$ H. 1500 . Nedum-Schetti, Jeu $6-83 \quad$ Pua-Schetti Mal. Puula-Padacali Bram.

Frutex indicus baccifer fructucalyculato monopyreno, Negundo dicta Raji H. 1575. v. Vitex trifolia

Frutex indicus flore dipetalo, capfula oblonga, binis cellulis bina femina continente $R_{a j i} H:{ }_{17} 6_{5}$. Katou-Pulcolli Mal. Rana-Dadumari Bram: Arvore enfitho Lufit. Koelblad Belg.

Frutex indicus flore dipetalo labiato, filiqua geminata aculeata $R a j i$ H: I 767 . Nir-Schulli Mal.BulaVanga Bram.

Frutex indicus flore papilionaceo fanguineo, foliis pinnatis, fructuriduus Raji H: I733. v. Periclymenum.

$5-27$ Frutex indicus fructu é Styli apice egreffo, fextuplici funiculo in fpiram convoluto conftante Raji $H$. 1765 . Helicteres arbor indix orientalis, filiqua varicofa, \& funiculi in modum contortu plicata Pluken: P: 3. T: $C C X L V$. 2. Ifora-Murri Mal. Tannini Bram: Pao de chanco Lufit. Schroefboonen Bilg. 6-55

Frutex indicus fructu aggregato conoide Kaida dictus Raji $H_{\text {: }} \mathbf{r}_{\mathbf{4}+2}$. $\checkmark$ Ananas.

5-77 Frutex malabaricus flore pentapetalo ftellaco, fructu pentagono, \& pentacocco Raji H: I 7 1 1. Poeatsjetti Mal. Gara Bram. Fruita Baretto Lufit. Papckappen Belg, 5-103 5-79 Frutex malabaricus trifoliatus, flore $\mathrm{H}_{2}$

penta- 
pentapetalo candidiffimo; fructu triangulo Commel. in not. Nela. regam $\mathrm{Mal}$.

Frutexparonimus, five Criftaparo. mis Breyn: Cent: 61. v. Crifta pavonis

Frutex indicus pentapetalos gemina bacca, calyce excepta Raji H: 1607. Tsjovanna-Amelpodi $\mathrm{Mal}$. Matavi-Aloos Bram: Talona Lufit. Nog Liever Belg.

Frutex indicus ramis demiffis radices agentibus fe multiplicans, fructu oblongo, terete, corticofo Raji $H$ : 1769 . Candel Mal. Candala Bram: Pao Salgado Malho Lufit. Runboom हु Kandele Belg.

Frutex indicus fpicatus, floribus galeatis, vafculo bivalvi dicocco Raji H: 1709 . Adhatoda floris labio fuperiori anguftifimo \& ad pofteriora reclinato Turnef: El. Bot: I 44. Carim-Curini Mal. Poefoo Bram:

Frutex indicus fpicatus florum pediculis brevioribus Raji H. I7og. Adhatoda flore minori Turnef. El. Bot. 144. Bem-Curini Mal. DavoPoefoo Bram. an Adhatoda zeylancnfium Mus: Zeyl: Herm. Cat. in App. 64.2? Ecbolium Rivin introd. P. 1? Curini (forte) prima fpecies Pluker. P. 3. T. CLXXI. 4?

Frutex indicus fpinofus foliis agrifolii filiqua geminata bivalvi $R a j i$ H. 1766. Paina-Schulli Mal.

Frutex indicus 1pinofus capparis for$\mathrm{ma}$, filiqua bivalvi brevi Raji $H$. 1755. Cara-Schulli Mal. RanaGondu Bram.

Fruticulus capfularis bexapetalos, foliis brevioribus, fubrotundis E denfins fipatis Pluken: $\mathrm{P}: 3 . \mathrm{T}$ : CLXXXIII. 4. v. Vitis idær affinis \&c.

Ioiem brevioribus foli,s Ef anguftis Pluken: P. 3. T. CLXXXIII. 5. v. Viris idæx affinis \&c.

Fula Bordao, Senc Arvore trifte de die Lufit: $v$. Jafminum.

Fula de S. Antonio Lufit. v. Syringa.

Fula de Coupang Indis v. Chamxcriftx payonis affinis \&c.

Fula da Naira Lufit.

$6-8 \mathrm{r}$

$2-93$
Fula da Mel Lufit.

Fula do diabolo Lufir. v. Arbor indica \&c.

Fula do MaoLufit: $v$. Capparis

$5-117$

Fula Gafiubota Lufit: $v$. Alcea $\quad 6 \longrightarrow 75$

6-I Fula Leitica Lufit.

7- 103

Fula Meftica alba Lufit: v. Nerium indicum

Fula Meftica incarnaia Lufit: v. Nerium indicum

$9-3$

9- $\mathrm{r}$

Futa Morifca Lufit: v. Periclymcnum

Futa do Sapato macloo Lufit:v. Alcea.

$6-57 \mid$ Gae-Maril Bram: $v$. Afme affinis \&c.

$10-\sigma_{3}$

Gagana Bram:

$12-59$

Gageri Bram: v. Genifta

$9-49$

Gafero Bram: v. Genifta

$9-5$ I

Gajapala Zeyl: v. Ricinus

$2-6 x$

Galbeffen Belg: v. Azadirachta 4-107

2-3I Galege affinis malabarica arborefcens, filiquis majoribus articulatis Syen in not: $v$. Sesban affinis \&c.

Galege affinis fopbera dicta B: Pin. 352. v. Senna orientalis $2-10 \mathrm{I}$

Gali Bram: v. Baccifera indica \&c. $5-69$ Gali-Doufa Bram: v. Olea Sylve-

Gandarli Bram: v. Schrophularia $10-167$

Gangila Congenfibus Margg: 21 . v. Sefamum

Gangoli \& Oulaffani Bram:

$9-105$

Gara Bram: v. Frutex malabaricus \&c.

Gara-Dudi Bram: v. Pepo

$7-43$

Garail Bram: Gairo Belg: \& Lufit: v. Phafeolus.

Garilba Lufit: $v$. Frutex baccifer malabaricus \& c.

Garundo-Pala Bram: v. Arborindica cocculos officinarum ferens.

Geele Gom-appels Belg. v. Prunifera Seu Nucifera \&c.

Gelleminum vel Fafminum catalonicum multiplex Parkins: Theat. 1464. v. Jafminum

Gelfeminum ar abicum $A$ Ipin de plant: Eg. 72. v. Jafminum.

$7-1$

Genifta indica alni folio, floribus caruleis, filiquis bullatis Commel. in not. Geniftella major indica, alnifolio, flore caruleo fpicaro 
M A. L

Breyn: $P$ : 2. 50. Crotalaria afiatica folio fingulari verrucofo, floribus cæruleis Herm: Cat. 198. Pee-Tandale-Cotti Mal. ButtaGageri Bram.

Genifta malabarica, folio fingulari, floribus Luteis, filiquis bullatis Commel: in not. Geniftella indica falicis folio glabro, obtufo, cordiformi, flore Luteo minori Breyn. P. z. 50 . Crotalaria afiatica, floribus Lureis, folio fingulari cor: diformi Herm: Cat. 200. TandaleCotti Mal.Schama-Cufpi Bram: $9-45$

Genifta malabarica, folio fingulari, oblongo, flore flavo dilutiore, filiquis bullaris Cummel: in not: Crotalaria malabarica Sylveftris, foliis fingularibus, majoribus, floribus Luteis Ejuld: in not. Crotalaria Benghalenfis foliis geniftre fublirfutis Par: Bat: Prod: 329. Pluken: P: 3. T: CLXIX. 5 . Katou-Tandale-Cotti CMal. Dacoli-Gageri Bram.

Genifta malabaria pentaphylloides, flore amplo, aureo, flavefcente, filiquis bullatis Commel: in not. Wellia-Tandale-Cotti Mal. Gagaro Bram.

Genifta fpinofa indica verticillata, flore purpurco carulco, feu fpartium fpinofum filiqua gemınata Raji H. 173 1. Bahel-Schulli Mal. Colaffo Bram:

Genifta trifolia malabatica, floribus Lutéis amplis, filiquis bullatis Commel: in not. Crotalaria afiatica frutefcens trifolia floribus Luteis amplis Herm: Cat: 196. Anonis afiacica frutefcens, floribus Luteis amplis Turnef. El. Bot. 326 . Ononis natrix dixta frutefcens zeylanica, labusni folio flore Luteo fpicato amplo Breyn: P. 2. 78 . Laburnum zeylanicum, floribus ex Luteo \& rubro variegatis, $f_{1}-$ liquis bullatis Brcyn: $\mathbb{P}_{\text {: }}$ I. 40. Nellia-Tandale-Cotti Mal.Gageri Bramı

Genifte tinctorice Jpecies Commel: in not. $v$. Lotus tenuifolius.

Genam Bram:

Gentianellæ fpecies Commel: in not: Tsjanga-Pufpam CMal. \& Bram: an Gentiana maderafpatenfis, foliis afclepiadis caule ramofo $P$ :

$2-87$ $7-37$
A $B \quad A \quad R \quad I \quad C \quad A$.

P. 2. T: XC. 6?

Getri.Madi Bram: v. Baccifera indica \&c.

Gibique Eं Grao do gato Lufit. v. Baccifera indica \&c.

Gin-Colla Cingal:

Girgilim Luyftanis Margg: 21, v. Sefamum

Giri-Koliniane Brom: $v$ Zingiber $1 \mathrm{-10}$

Giri-Majo Bram: $\psi$. Ricini indici fpecics \&c:

Gtriy Bram: v. Orchis $4-105$ $12-5$

Gladiolus indicus paluftris latifolius, flore albicance Commel. in not. Bela-Pola $\mathrm{Mal}$.

I $1-6.9$

Gladioli affinis latifolia, flore campanulato Commel. in not. Ela-Pola Mal.

Gladioli affinis malabarica, flore flavo, maculis rubris imperfo Commel. in not. Belam-Canda-SchularMani Mal.

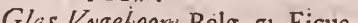
$9-47$

Glaux indica portulacx folio, flore majore diluto cxrulco, albicante colore Commel. in not. Brami $\mathrm{Mal}$.

Glycyrrb:za indica filiquis \& feminibus pifa coccineis bilo nigro notatis Par Bat, P: 337: v. Phafeolus alatus

Glycyrrbiza, vel(fi mavis) Gíycyrrbiza affinis arborefcens americana, foribus ex Luteo Eั rubro vartegatis, folio acuminato, flitqua latifima Breyn. P. 2. 53. Siliquofa indica \&c.

$I I-71$

$3-7 \frac{1}{3}$

$10-27$

$8 \rightarrow 18$

Gocarni Bram; v. Phafeolo affinis \&c.

Godoe-Ambado Bram v. Mangx affinis

Goejaves हु Goejaves Appelen Belg. v. Guajava alba \& rubra.

3 I

$8-59$

$6-39$

Gointi Bram. v. Ariftolochia 8-si

Gola-Conao Bram. v. Lilionarciffus

Goli Bram. v. Portulaca

9-69 Gontua Bram.v. Melampyro cogna-

Gorallo Bram.

Goffipium arboreum caule fipinofo $B$. Pin. 43 O. Arbor Lanigera fpinofa malabarica Commel. in not. Moul- 
Elavou Mal. Valli-Sanvari Bram. Algodano do mato Lufit. Woldoorn $B e l g$. an Lanigera arbor fpinofa Guineenfis falicis foliis digitatis $C$ : H: Beaum: 26?

Goffipium arboreum orientale, foliis falicis digitatis latioribus Herm: Cat: 294 Goffipium indicum falicis folio, fructu quinque capfulari Raji H. 1899. Golfipium Jeu Xylon arbor orientalis, feu digitatis foliis levibus, fructu quinque capfulari alba \& nitente lanugine farcto Pliken. $P$ : $3 . T$ : CLXXXVIII.4. Goffipium javanenfe, falicis folio $B$ : Pin: 430 . Lanigera arbor peregrina Clus: exot. 1 2. F.B. T. 1. L: III. 347. Arbor lanigera, five Goffampinus Plinii Bont: 105 . Panja-Panjala Mal. Sangori Bram. Algodano Lufit. Kapock Malaccis Dousboom Belg.

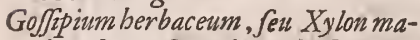
derafpatense, rubicundo flore pen tapbylleum Pluken: P: 3. T: CLXXXVIII. 3.v. Xylon malabaricum \&c.

Gotting a Bram: v. Prunus.

Goufaly Bram: v. Cucumis.

Grabofa Lufit.

Grabofa rotunda Lu/it.

Grabofa ovado Lufit.

Grabofa \&ै Fruita Barrugo Lu/ıt.

Gramen dactylon Ægyptiacum $B$ : Pin: 7. ejuld. Theat. Botan. 10. Parkins. Th. I 179. Gramen crucis Nejem el falib $A l p$. de $P l$. CEg. I 2 1. j: B: T: 2. L: XVIII. 460. Cruciatum Bont: $148 . \mathrm{Ka}$ vara-Pullu $\mathrm{Mal}$.

Gramen dactylon Fgyptiacum Park. Theat. I 1 79. Gramen ftellatum Egyptium Vefling: Obf: 52 . Kouda-Pullu Mal. Tana Bram.

Gramen florens capitulo fquamofo Raji H. 1;18. Jupicai Brafilienfibus, Erua d'empige Lufitanis Pifon. 23 8. Kotsjiletti-Pullu Mal. Dadumari Bram.

Granate malus zeylanica pino fa Par. Bat. P: 338. v. Malus Limonia. Granaat pruymen Belg: $v$. Baccifera indica \&c.

Grana tiglia \&ु lignum moluccenje officinarum Dale Pharm: $137 . v$.
Ricinus arbor.

Grao do boy Lufit. v. Phafeolus $8-83$

Grao do gato Lufit. v. Baccifera $\{53$

$3-6 r$

malabarica \& indica \&c.

Grao do pulia Lufit.

Graon de veado Lufit. v. Crifta pavonis

Graos da noffa Senhora Lufit: v. Phafeolus

Gratiolx affinis frutefcens americana foliis agerati, feu veronicæ erectx majoris Breyn: P. 2. 54. Capraria curaffavica $P$ ar. Bat. $P$. 319. Cabritten kruyd vulgo Tsjeru-Parua Mal.

Gratiole affinis echioides zeylanica major Breyn: P:2. 34.v. Euphrafiæ affinis \&c.

Grieten Belg: $v$ A rbor indica $\quad 9-87$

or indica \&c. 4-103 culg: Balfamina cucumerina

3-59 Groot Glidhout Belg: v. Chamæcriftx pavonis affinis indica \&c. 6-17

Groot Hertftong Belg: v. Prunifera indica \&c.

Groot Heylwortel Belg: v. Frutex

$\mathbf{x}-55$ indicus baccifer \&c.

$4=I 2$ I

$5-29$

4-23 Groot 7afmin Belg: v. Jafminum 6-97

8-r3 Groot klimmend Hondepint Belg. $\quad 7-49$

Groot Liever Belg: $v$. Frutex indicus ärap $\pi$ (G) \&c.

Groot Maagden kruyd Belg.

$7-67$ Groot Rüfblad Belg. $v$. Arbor flore tetrapetalo \&c.

Groote R̈̈fboom Belg. $v$. Ficus

Groot Wilde Panna Belg.

Groot Wortel vaeren Belg.

Grove-Sada-Pali Bram: v. Jambos Sylveftris \&c.

$7-69$

$4-123$

$3-8 \mathrm{I}$

$12-35$

$12-25$

$4-15$

Guajava alba dulcis fructu longiori Herm. Cat. 30 5. Guajabo pomifera indica pomis longiufculis $B$ : Pin. 43 7. Guajaba Pifon: $1530^{\circ}$ Guajava Clus: in Append: CCLIV. Guajava indica fructu mali facie F: B: T: 1. L: 1 . 108 . Xalxochotl, feu pomum arenofum fecundum Hernand: 84 . Pyra indica feu granatenfia vulgo. Pela $\mathscr{E}$ Pelouka Mal: Pera Bram. Guajavas \& Peera Lufat. Goejaves Belg.

$3-32$

Guajava rubra acida fructu rotun- diori Herm: Cat: 305 . Guajabo pomifera indica pomis rotundis $B$. 
Pin. 437. Araca-Guacu Pifon: 152. Xalxochotl feu Pomum arenofum prinum Hernand: 84 . Malakka-Pela, \& Tsjiria-Pelouka Mal. Pera Bram: Pera de Malakka Luft. Goejaves appel Belg.

Guajava tertia fpecies Commel:in not: Pelou \& Katou - Pela Mal. Pelo varta Bram: Pera brava Lusit. Wilde Goejaves Belg.

Guard Olhos Lufit. v. Tithymalus

Guanabanus Oviedi, fructu Squamato J:B:T: I. L: I. I 4 4. v. Anona.

Guilo Bram: v. Phafeolus

Gundo Bram: v. Amarantho affinis \&c.

Gunfii \& Gonfii Bram:v. Crifta Pavonis

Gutta Gamba, Gutta Germandra, Gutta Femou Dale Pharm: 484 . v. Cambogium officinarum

Gutte Gambe Ipeciem Lacrymam fnndens arbor Commel: in not:v. Prunifera, feu Nucifera \&c.

Haanballen Belg: $v$. Malus indica \&c.

Halicacabum peregrinum multis five Cor-Indum J: B:T: 2. L: XV. 173. $v$. Cor-Indum.

Halicacabum Jeuc Alkekengi Arabibus dictum Bont: I 4 9. $v$, Solanum

Handir-Alou Bram: $v$. Ficus.

Harlaer Be'lg;

Harlaer Manneken Belg.

Har sboom Belg: $v$. Amygdalæ affinis \&c.

Harshaver Manneken Belg: v. Arbor indica \&c.

Hartenbaver Belg: $v$. Arbor baccifera indica \&c.

Haftey - Gafisrculi Bram: v. Urtica.

Hafti : Canto Bram:

Hatawariia Zeyl: v. Afparagus 10-19

Hedera trifolia baccifera malabaren. fis Commel: in not: Kareta-TsjoriValli Mal: Dou-Cerberi-Valli Bram: Uvas de Boy Lufit. Wild Pimperlingen Belg.

Hederæ terreftris fpecies Commel: in not: Kakapu Mal: Caela-Dolo Bram:
$3-33$

$3-35$

$5-89$

$3-23$

$8-61$ $10-73$

$6-25$

$1-4 \mathrm{I}$

4-79

$4-49$

$8-53$

$10-139$

$3-77$

$7-41$

$7-43$

$4-33$

$5-107$ 4-III

$2-77$

$8-73$

(10)

$9-103$
Helay Bram: v. Jaca minor

Helicteres arbor indice orientalis $\sqrt{6}$ liqua varicofa, Ef funzuli in modum contortu complicata Pluken: P: 3. T: CCXLV. 2. P. Fratex indicus

Heliotropium indicum, latiore \& ro$6-55$ tundiore folio Commel: in veot: $\mathrm{Be}$ na-Patsja Mal. Ageru Brapn: ro-95

Herba vivi foliis polypodii 4 : $P$ it: 360 Viva C: a Cofta H: Lugd: T: 2. 688. Totta vari, oforfi mimofa Zanon $H$ : $B$ : Todda-Vaddi Mal. Lacheri Bram. an Herba Viva anguftifolia Zeylanica Breyn: P: 2.55 ?

Herniariæ fpecies Commel: in not: Scheru-Bula Mal. an Herniaria africana major Parkins: Theat. 447.

Heupboom Belg: $v$. Ficus

Heylboonen Belg: v. Phafeolus $8-75$

Heylpeeren Belg: v. Prunus 4-23

Heylwortel Belg: $v$. Frutex indicus baccifer \&c.

$5-27$

Himpblad Belg.

$7-109$

Himpen Belg: $v$. Baccifera indica $5-4 I$

Hina-Pareti Mal: v. Alcea arborefcens Japonica \&c.

$6-69$

Hoefblad Belg: v. Siliquofa indica \&c.

Honde Pinten Belg: v. Siliquofa malabarica \&c.

Hondsbeffen Belg: $v$. Dulc-amaræ fpecies \&c.

Hondstongh Belg: $v$. Pomifera indica \&c.

Hondswortel Belg: $v$. Ricophora. $\quad 4-x 19$

Hoxocoquomaclit Clus. Cur. Poft. III. v. Senna Orientalis.

$2-10 I$

Hummatu Mal. v. Stramonia. $2-47$

Jaca arbor $7: B: T:$ I. L: $T$. I I 5 . $G$ : ab Horto $227 . C: a$ Cofta $28 \mathrm{x}$. Palma fructu aculeato ex arboris: trunco prodeunte $B:$ P in. $5 \mathrm{Ir}$. Tsjaka-Maram, \&5 Pilau Mal. Ponoffou Bram: Jaqueira Lufot. Soortfaeken Belg.

Jaca minor Sylveftris malabarica $3-17$ Commel. in not. Tatai-iba Pifon: 163 . Ponga Mal. Helay Bram. Mafao Spinofa Lufit. Boom Cliffen Belg.

I 2 
Facea \& Serratule affinis, capitulis Baccharidis, Trachelii foliis Zeylanica Breyn: P. 1. 39. v. Serratula indica

Jacobrex fpecies Commel, in not. Nelam-Pata Mal:

Falappa vera Muntingh 266.v. Mirabilis peruviana \&c.

Fambos G. ab Horto 233. v. Prunus

Fambos Acofte J: B: T: r. L:I. 116. $v$. Prunus

Jambos Sylveftris Auct. Hort. M. Blatti, \& Katou Tsjambou Mal. Ambetti Bram: Jambou de mato Lufit: Sterrebollen Belg.

Jambos Sylveftris malabarica Samftravadi dictus Raji $H$ : 1479 . Samftravadi \& Caipa-Tsjambou Mal. Sada-Bali Bram. Rofairo de Jambu Lufit. Wilde Jamboefen Belg.

Jambos Sylveftris Samftravadi dictus alter Kaji H. r 480 . Tsjeria-SamAtravadi CMal. Gove-Sada - Pali Bram: Rofaira brava Laffit. Bedel. fnoeren Belg.

Jambos Sylveftris montana Raji $H$. 1480. Malla - Katou - Tsjambou Mal. Malambetti Bram: Janbou dos bugios Lulfit. Sivynen Jamboefen Belg.

Jammana Brani: $v$. Baccifera indica \&c.

Fanipaba Pifon: 13 8. v. Pomifera indica \&c.

Fapalu Bram: v. Ricinus arbor

J aqua falsa Lufic. v. Arbor indica \&c.

Faq eira Lufit: v. Jaca Arbor Fafll Bram: $v$. Rhamni fpecies Jafminum arborefcens indicum, flore tetrapetalo umbellato phreniCæo, foliis Laurinis lacioribus Breyn: Prod.2.58. Jalminum indicum Laurifoltum, inodorum, umbellatum, floribus coccineis Par: Bat. P. 342. Jafminum zeylanicum flore pavonino Herm: Cerafus umbellata pavonina floribus coccineis Ejufdem Ratambala Ceylon:Phiken P. I.T.LIX. 2. Frutex baccifer malabaricus, fructu calyculato, rotundo, rubro, polypyreno Raii H: 1573 . Schetti Mal. Pada Cali Bram.

Jafminum indicum myrti lauræx fo-

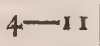

$4-15$

$3-43$

$4-17$

$5-51$

$3-45$

$2-6 \mathrm{I}$

$3-29$

$3-17$

$7-33$

Jafminum indicum flore polypetalo exalbido, fructu minori Raji $H$. 1601. Jafninum indicum Latifolium fructu gemino Turnef. El. Bot. 470 . Tsjiregam-Mulla Mal. Caftoeri-Mogari Bram: Bare-Mo. gari Lulft. Groot Jafmin Belg.

Jafminum humilius magno flore $B$ : Pin: 398. Hilpanicum flore majo. re externe rubente $\mathcal{F}: B: T: 2, L$ : $X V$. IOI. Catalonicum fimplex Parkins: Theat. 1464 . Candiflorum majus Gerard: Pitsjegans. Mulla Mal. Sai Bram: Jafmin LNfit. \& Belg.

$\mathrm{Jafminnm}$ indicum flore polypetalo, candido oris rufefcentibus $\mathrm{Raji} \mathrm{H}$ : 1602. Jafminum indicum angunti-

nicum multiplex Parkinfoni Raje aurantii foliis bullatis, \& verrucofis flore pleno C. H. Beaum. 25. ternis $B: B a l:$ P. 379 . KuddaMulla Mal. Doti-Mogari Bram. fen Belg. an Jafminum indicum mali aurantix foliis flore albo pleno amplifimo Breyn: 2. 59 ? Catfi Jafminum indicum mali aurantix foliis, flore albo pleno minore Breyn: Beaum: 25. Jafminum arabicum fivc Syringa arabica Chus. Cur.p. bum $\mathcal{F}: B: T: 2 . L: X V .10 z$. Sambach Arabum, five Gelfemi72. Syringa arabica folis aurantii mali B: 'Pin: 398 . foliis binis, Nalld-Mulla Mal. Mogari Bram: Mogari flores mali aurex floribus odoratiores B.Pin. 470 ? Mogari 4. \& 5.143 ? Mogari flores odore florum mali aureæ $\mathcal{F}: B . \mathcal{T}$. $x$. $6-87$ Tsjeni-Mulla Mal: Mamogari
Bram. Lufit. Belg. $6-8 s$
afininum vel Gelieminum catalo-

liis, flore albo Breyn. T. 2. 59 . ratiffimo Raji $H: 1601$. Jafmini arabici pecies Commel. in not: 
folium fructu gemino Turnef. El. Bot. 470 . Catu-Pitsjegam-Mulla Mal: Nara-Sai Bram: Jafmin do Mato Lufit. Wilde Jafmin Belg.

$\mathrm{Jafminum}$ indicum flore polypetalo, candidiffimo, fructu majore Raji $H$. I 602. Jafminum indicum Latifolium monoccon Turnef: El. Bit. 47 I. Katu-Tsjiregam-Mulla Mal. Saio Bram: Mogaro da Serra Lufit. Bergh Mogori Belg.

Jafminum indicum flore pentapetalo, candidiffimo, fructu TsjeramMulla Raji H: I 602. Jafminum indicum Latifolium, fructu biventri Turnef: El: Bot. 470. KatuMulla Mal. Vifa-Mogari C Nal. Mogari falfo Lufft. Baftaard Mogari Belg.

Jafminum indicum bacciferum flore albo majore noctu olente; feu Arbor triftis de die altera Commel. in not: Rava-Pou Mal. Marotani Bram: Fula bordao, feu arvore trifte de dia Lat it. Nachtbloemen Belg.

Jafminum indicum Laurifolium inodorum umbellatum, floribus albicantibus, \& Schettialbum Phlken. P. 2. T: CIX. 2. Bem-Schetti Mal. Davi-Padacali Bram.

Jafminum malabaricum foliis mali aurantii, flore niveo odoratiffimo Commel in not. Nandi-Ervatam Mal. Dacalo-Nanditu Bram.

fafminum millefolii folio B: Pin. 398. v. Convolvulus

Fafminum mexicanum, five flosmexicamus multis $\mathrm{J}: \mathrm{B}: \mathrm{T}: 2 . \mathrm{L}: \mathrm{XX}$. 81:4. v. Mirabilis peruviana. Io-I 49

Jata Bram:

Ibirabitanga, five Lignum rubrum Pifon: $164 . v$. Crifta pavonis.

Idou-Moulli Mal: v. Prunus.

Fcfuiten-Mutfen: Belg. v. Althæa.

fetica Pifon: 254 . Conolvilus. $7-79$

Igname five Inbame Lufitanorum

Clus: Hift: L: IV: 78. v. Ricophora.

fibe Bram: $v$. Amygdala.

$9-93$

$2-19$

$7-97$
Yferhout Belg.

Yllamatlantli Hernand: $4.43 . v$. Solanum.

$2-65$

Ilata Lufit: v. Baccifera indica \&c. 4-117

Ily Mal. v. Arundo.

Ily-Mullu Mal.

$1-25$

$12-143$

Inaia-Guacuiba, vulgo cocos Pifon: 130. v. Palma $I-I$

Inalel Mal. v. Baccifera malabarica

\&c.

Indicum officinarum Dale Pharm:

323. v. Colutea I-101

Indigo indiga Morifon. $v$. Colutea $\mathrm{I}-10 \mathrm{I}$

Indigospuria Raji H. I 734.v. Polygala

$\mathrm{I}-\mathrm{IO}_{3}$

Indigofera coluteoides Muntingh. 229. v. Colutea. $\mathbf{I}-\mathbf{1 0}$

6-99 Indigofera rotundifolis Muntingh 228. v. Polygala $\quad 1 \longrightarrow \mathrm{IO}$

Inbame de cao Lufit. v. Ricophora

$8-97$

Inbame five Igzame Lufitanorum

Clus. Hift. L. IV: 7 8. v: Ricophora

Inbame orientalis Lufitanorum E Batatas accidentalis indice Parkins: Theat: $1323 \cdot v$. Convolvulus

Inimboy Pifon: 205. Margg: 12. v.

Crifta pavonis

Infchi Mal: v. Zingiber

Intfia Mal: v. Acacia

$2-35$

$11-23$

$6-7$

Fona-Faca Bram: $v$. Anona indica \&c.

$3-2 I$

Ira Mal.

$12-103$

Ira feu Balari Mal.

$12-105$

$9-145$

Iripa Mal:Firipou Bram: v. Malus indica

Iris Latifolia tuberofa, Zingiber

$4-65$ dicta, flore albo Mor. Hift. v. Zingiber

$11-23$

Ifatis indica, foliis rorifmarini, glafto affinis B: Pin: $113^{\circ}$. v. Colutea indica

Ifora-Murri Mal: v. Frutex indicus \&c.

$I-I$ or

$6-55$

Itty-Alu Mal: v: Ficns

Itty-Arealou Mal. v. Ficus $\mathrm{K}$
$1-45$

$3-69$

Itty- 
Itty-Canni Mal: vo Periclymetium indicum

Jujuba indica rotundifolia fpinofa, foliis majoribus fubeus Lanuginofis \& incanis Breyn: P: 2.60. Ziziphus indica argentea tota cliariophylli aromatici flore Herm: Herb. v. Ceyl: Jujuba indica $B: P$ : 446. Malus maluccenfis non nihil fpinofa Ejufd: 433. Arbor cujus fuccus exftillans gummi Lacca Dale Pharm: 446. Ber E̋ Bor, $C:$ a Coft: 287 . Ber indica fructu jujubino $\mathcal{7}: B: T:$ 1. L: VI. 44. Perin-Toddali Mal. Bori Bram: Tarilla \& Mancanas de la india Lufit. Doornkérfen Belg:

Funipappeeywe Brafilianorum Clus: Exot: I 0. v. Pomifera indica \&c.

Fupicai Pifon: $238 . v$. Gramen

Furipeba famina Pifon: 1 1 8. v. Solamum

Furipeba Mas Pifon: I 1 3. v. Solanum

Futay five Tamarindus Pifon: 157. Tamarindus

Kada-Kandel Mal.

Kadali Mal: $v$. Baccifera indica \&ic.

Kadanaku Mal: $v$. Aloes Vulgaris $4-87$ Kadebou Bram: v. Polypodium

Kaden-Pullu Mal.

Kaba Zeylon: $v$. Curcuma

Kaida Mal: v. Ananas

Kaida-Taddi Mal.

Kaida.Tsjerria Mal.

Kaipa-Tsjira Mal.

Kairoli Bram: v. Phafeolus

Kaka-Kodi Mal: v. A pocynum

Kaka.Mullu छூ Kaka-Moullou Mal: $v$. Crifta pavonis

Kaka-Niara Mal: v. Baccifera indica \&c.

Kaka-Ponna Mal: v. Frutex indicus baccifer \&c.

Kaka-Pu Mal: $v$. Hedera terreftris

Kaka-Toddaly Mal: v. Frutex baccifer \&c.

Kaka-Toddali malabarica ex oris Cormandel Pluken: P: 2, T:XCV. 5. v. Frutex baccifer \& . Kaku-Valli Mal: v. Phafeolus

$5-8 \mathrm{x}$

$5-81$
Kalengi - Cantsjava Mal: v. Cannabi

Kalpert Belg. v. Ballamina cucumerina

Kal-Panna-Maravara Mal.

al-Todd-Valli Mal: $v$. Crifta pa-

vonis 6-15

Kal-Tsjerou-Panel Mal. v. Panclla minor

Kal.Vetadagou Mal: $v$. Vitis idæx fpecies

Kalu-Polapen Mal: $v$ Sedum $5-6 r$

Kalo - Aduluffo Bram: v. Perficaria

Kannetti-Valli Mal: v. Apocynum 9-23

Kandalu Bram: v. Anacardium 4-95

Kandelo Bram: Kandeke Belg: v. Baccifera indica \&c.

Kondele Belg: \&c.

Kanden-Kara Mal: $v$. Baccifera indica \&c.

dica \&c.
Kanneli.Itti-Kanni $M a l .7$ I

Kansjiram-Maravara Mal: v. Aloe affinis

Kapa - Mnava Mal. v. Anacardium

Kapa-Tsjakka Mal, v. Ananas.

$12-17$

$6-57$

Kapock Malaccis v. Goffipium

Kappa-Kelengu Mal: v. Convolvu-

$3-59$

lus

Kaprafila Bram: v. Alcea.

$7-95$

$6-73$

Kara-CAngolam Mal: v. Prunifera indica \&ic.

Kara-T sjira Mal: v: Portulaca 10-7

12-89 Karabou Bram: v. Azadirachta 4- 109

I I-2 I Kare-Kandel vel Kandeque Mal: v:

2-I Baccifera indica \&e. $\quad 5-25$

2-3 Karendi Bram. $7-69$

2 -7 Kareta-T sjori-Valli Mal,v.Hedera $7-85$

Io -4.7 Karetela Bram: v. Palma $3-x$

$8-63$ Karetta-Amelpodi Mal:v. Baccifera

9- 1 I indica \&c. $5-65$

Kari Bram: v. Baccifera indica \&c. $5-93$

Kari-Bepou Mal: v. Azadirachta 4-109

Karii-Kandel Mal: v. Candela ar-

bor

Kariil Mal: v. Prunus pentaphyllos $4-75$

Kari-Kara Mal: จ. Malus indica \&c.

Karin-Bala-Pala Mal. v. Arbor indica \&c.

Cioti Mal. v Arbormalabarica

Karin-Pola Mal:

$6-3 \mathrm{I}$

Karin-Tagera Mal

$11-45$

$8-63$ Karinta-Kali Mal.v.Violx folio \&c. 10--4r

Kari. 
Kari-Vetti Mal: v. Arbor baccifera indica \&c.

Kari-Valli Mal: v. Ariftolochia

Kari-Weli-Panna-Maravara Mal. I2-35

Karlingen Belg: v. Ariftolochia.

Karodi Bram: v. Ricophora

Kafailo Bram: v. Baccifera racemofa \&c.

Kasjan Mal.

Kasjavo-Maram Mal.v.Anacardium 3-65

Kasjavo-Maram Mal.v. Arbor baccifera indica \&c.

Kasjo Bram: v. Anacarditum

Kafouri Mal: v. Palma

Katapa Mal: v. Baccifera indica \&c.

Katapinake Cingalens: v. Baccifera indica \&c.

Katappes Belg: v. Amydala

Kater'sballen Belg: v. Baccifera malabarica \&c.

Katbukarobiti Cingalen: v. Melampyro cognata \&c.

Katou-Adasnboe Mal: v. Alcca

Katou-Alou Mal: v. Ficus

Katou=Belutta-Amelpodi $M$ al.

Katou-Cadelipoea Mal: v. Alcea

Katou-Conna Mal: v. Arbor indica filiquofa \&c.

Krtort-Indel Mal: v. Palma

Katou-In/cbi-Kua Mal.v.Zingiber $11-27$

Katou-Kadali Mal: v. Baccifera indica \&c.

Katou-Kalefram Mal: v. Sorbus

Katou-Karua Mal: v. Canclla

Katou-Kayda-Maravara Mal.

Katou-Mail-Elavou Mal: v. Vitex

Katou-Naregam Mal: v. Malus Limonia \&c:

Katou-Nirouri Mal:

Katou - Pat sjotti \& Isjotti Mal: v. frutex baccifer \&c.

Katou-Pela Mal:v. Guajava

Katou-Ponnam-Maravara $\mathrm{Mal}$.

Katou-Pulcolli Mal: v. Frutex indicus \&c.

Katou-Tandale-Cotti Mal: v. Genifta \&c:

Katou - Theca Mal: v. Prunifera indica \&c.

Katou-Theca-Maravara Mal.

Kasou-Tsjaka Mal: v. Arbor indica \&c.

Katou - Tsjambou Mal: v. Jambos Sylveftris \&c.

Katou-Tsjerou Mal: v. Prunifera malabarica \&c.

$5-105$

$12-51$

$5-3$

$5-\mathrm{r} 3$
Katou-Tsjolam Mal.

$12-113$

Katsji-Kelengu Mal: v. Ricophora 7-7I

Katsjou-Panel Mal: $v$. Panel Sylve-

8-5 I Katfula - Kelengu Mal: v. Planta

7-97 bifolia \&c. II $-8 \mathrm{I}$

Kattu-Kelangu C Mal. $\quad 7-7$ I

Kattu-Kelengu Mal.v.Convolvulus i i- -105

Kattu-Tagera Mal: v. Aftragalus 9-5s

Kattu-Tirtava Mal. $\quad$ ro- I 7 I

Kattu-Tumba Mal: v. Nepeta $\quad$ I $0 \cdots 18_{3}$

$5-37$ Katu-Bala Mal:v.Arundo indica I I -85

3-65 Katu-Beloeren Mal: v. Althæa 6-79

3-I 5 Katu-Kapel Mal: v. Afphodeli affinis \&c.

Katu - Kara - Walli Mal. v. Rhamni

$4-S_{7}$ fpecies \&c.

4 -5 Katu-Karivi Mal:

553 Katu-Katfiil Mal.

Katu-Kurka Mal:v. Nepeta

\{ 57

Katu-Mailofina Mal.

Katu-Mulla Mal:v. Jafminum $6-99$

9-77 Katu-Muringha Zeylanenfum Herm:

4-47 Mus: Zeyl:v. Balanus Myrepfica 6-i9

3-73 Katu-Nuren-Kelengu Mal. $7-65$

5-66 Katu - Pal - Valli CMal.v. Apocy-

4-47 num 9-17

Katu-Pee-Tsjanga-Pufpam Mal. 9-I I 3

6-2 I Katt-Schena Mal: v. Arum 1 I-4I

3-Is Karu-Tali Mal. 9-157

Katu-Tsjeregain-Mulla Mal: v. Jafminum.

4-91 Katu-Tsjetti- $P_{u}$ Mal: Ambro-

4-69 fia ro-89

Katu-Tsjurel Mal.

Katu-Viftina-Clandi Mal.

Katu-Ulinu Mal.

Katu-Uren Mal:v. Althæa

$6-95$

4-29 Kavandali Bram: v. Balfamina cu-

6-85 cumerina 8-37

Kavara-Pullu Mal: v. Gramen $12-13$ I

3-35 Kedangu Mal: v: Colutea Siliquo-

$12-55$ fa.

Kely Bram: v. Ficoides

6-i Keli Bram:

Kenanga Bram: v. Colutea Siliquo.

$12-123$

9-1 19

$8-95$

$-107$

$8-37$

fa

Kennapa Bram:

Keriti Bram:

Kerpa Mal.

Kerswortel Bely.

3-29 Ketmia Asyptiaca Semine Mofchato Turnef. El.Bot. $83 . v$. Alcea 2-7I

$3-43$ Ketria indica populi folio, fructu orbiculato compreffo Turnef: El:

$4 \rightarrow$ Ig Bor. 84. v. Alcea

$\mathrm{K}_{2}$

$I-5 I$

Ket- 
40 F L $\quad$ L R $\quad \Lambda$

Ketsnia indica tilia folio Turnef: El: Bot: $84 . v$. Alcea

Ketmia funchis, fructu rotundo Turnef: El: Bot: $84 . v$. Alcea

Keylen Belg.

Keylen met ronde Wratten Belg:

Keyfer's Vrengbt Belg: v. Baccifera indica \&c.

$1-53$

$6-69$

$7-63$

$7-65$

$4-39$

$10-113$

Kilcola-Tsjerti Mal.

Kina Herm: Herb: v. Ceyl: v. Cornus

Kirganeli Mal: v. Vițis Idææ affinis \&c:

Kiti Bram: v. Apocynum

I $0-29$

$9-11$

Kleyn. Climmende Kraen - oogh Belg:

Kleyne geele Gomappels Belg: v. Cornus

Kleyne Heylwortel Belg: v: Frutex indicus baccifer \&c:

Kleyne Hondepint Belg:

Kleyn Kalpert Belg: v. Ballamina cicumerina \&c.

Kleyn Kraan-oogh Belg.

Kleyn Maagdekruyd Beig: v. Phafeolus

Kleyne Runboom Belg: v. Candela indica

Kleyne Worteluygen Belg: v. Ficus $3-69$

Knevelklim Belg:

$7-7$

$4-8 \mathrm{I}$

$5-31$

$7-47$

$8-31$

$7\{3$

$7\{5$

$8-67$

$6-8 \mathrm{~s}$

$7-87$

Kodatjeri Mal: $v$. Portulacæ foliis \&x.

Kodda-Pail Mal: v. Sedum

Kodi-Pullu Mab.

hocywortel Belg:

Koelblad. Belg: v. Frutex indicus \&cc.

Kokerlingen Belg: v. Ariftolochia

Kolinyane Bram: v. Zingiber

$9-131$

$11-63$

$12-107$

$7-81$

Kolly - Tsjerou - Mau - Maravara Mal.

Kol-Puliu Mal.

Kondam-Pallu Mal.

Konni Mal: v. Phafcolus

Kors Appel Belg: v. Cucumis

Kotsjiletti-Pullu Mal: v. Gramen

Kouda-Pullu Mal: v. Gramen

$6-41$

$11-27$

?

$12-13$

$12-119$

c. -57

$8-78$

8 - I5

9-139

$12-0.5$

Kraanoog Belg: ข. Solanum

Krabbendoorn Belg: v. Alcea
Krayvygh Belg: $v$. Ficus

Kreefthout Belg.

Krimpboonen Belg: v. Phafeolus $8-87$

Krocfelingh Belg: v. Flos paffionis fpurius

Kroonblad Belg:

Kroomooren Bclg: $v$. Arbor malabarica \&c.

$8-45$

$8-5$ I

$6-31$

Kua Mal: v. Zerumbet

Kudda-Mutha Mal: ve Jafminum

Kuda-Mulla Mal: v, Jafminum 6-89

Kudici-Kodi Mal. v. Apocynum 2-I3

Kudici-Valli Mal:

Kudira-Pullu Mal.

Kuka Bram:

$12-115$

$11-49$ Teylon: v. Mercuriais

$10-16 \mathbf{r}$

$12-115$

I $1-49$

$10-35$

Kurka MaL

Kurundoti Mal: v. Ciftus

Laburnum zeylanicum, floribus ex Luteo Ë rubrovariegatis, filiquis bullatis Breyn: P: r. 40. v. Genifta

Lacheri Bram: v. Herba viva

Lada Pifon: Mantis A. 492. ข. Piper

per
Lange Peper Belg: v. Piper $\quad 7-23$

Langoos Stap: in Theoph: 334. Arundo

Lanigera arbor peregrina J: B: $T$ : I. L:III. $347 \cdot v$. Gofipium

I $1-85$

$9-49$

$9-33$

Lanigera arbor jinofa guineenfis Salicis foliis dig it at is C:H:Bearm: 26. v. Goffipium

Laffa Bram: v. Arbor baccifera ra-

cemofa \&c.
Lajari Bram: $v$. Crifta pavonis $\quad 6-37$

Latbyris frutefcens fruElu in foliorum alis ecbinato Raji $\mathrm{H}:$ I 710. v. Codi-A vanacu

$3-59$

$3-61$

$4-37$
$6--15$

$2-63$

$9-35$

Lauri Bram: $v$. Efchinomene
Laurifolia malabarica, fructu ofleo, nucleos continente Syen in not: Marotti Mal: Caitu Bram.

$\mathrm{r}-65$

Lens phafeoloides maxima indica, caffir foliis, femine maximocordiformi Breyn: P: 2. 63 . v. Phafeolus

Leonurus annuns americanus Nepete folio, flore phaniceo minore

I-67 Breyn: P: 2. G3. v. Cardiaca I0-175

Lerick Belg: $v$. Frutex baccifer \&c. $5-1$

Lerick Wijfken Belg:v. Baccifera indica \&c.

$5-15$ 
Liefblad Belg: v. Crifta pavonis 6-1s fpecies Commel: in not. Manneli Lieverboom Belg: v. Arbor bacci-

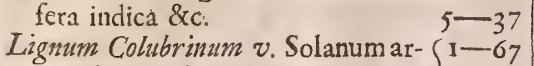
Mal. Tippoli Bram: borefcens indicum

Lupulo vulgari fimilis india orientalis, floribus in fpicam ex origine foliorum prodeuntem difpofitis

Lignum moluccenfe C: a Coft: 276 . Pluken: P: 3. T: CCI. 5. v. Ur$\&$ Variorum $v$. Ricinus tica

Liguftri Jpecies Commel: in not: $v$. Baccifera indica \& 8 .

$2-61$

$4-\mathrm{II}_{7}$

Lilium zeylanicum Juperbum vulgo Pluken: in App: I. T: CXVI. 3. $v$. Methonica

Lilio-Narciffus maximus Commel. in not. Sjovanna-Pala - Taly C Mal. Gola-Condo Bram.

Lilii Ceylanici umbelliferi \& bulbiferi confpecies Commel, in not. Belutta-Pola-Taly Mal:

Limao Caraodo Lufit: $v$. Malus Limonia

Limao da Folba crufado Lufit: $v$. Malus Limonia

Limro do Mato Lufit. v. Malus Limonia

Limao pimentofa Lufit: v. Malus Limonia

Lobbalsen Belg: v. Althæă

Lobus cortice membranaceo atro, tumïdo B: Pin; 404. v. Crifta pavonis

Lobus crafus ex infula S. Thome Clus: exot: L: III: 65. $v$. Phafeolus

Lobus "̌zuvoóns Clus: exot: 70. v. Crifta pavonis

Lobns membranaceus niger, Seuniger primus tumidus Clus: exot: $7 \mathrm{I}$. $v$. Crifta pavonis

Lobus peregrimus cartilagineus phafeolo ex puniceonigro tanquam annulo cincto J: B: T: 2. L: XVII. 273. v. Phafeolus

Locandi Bram: v. Arbor malabarica \&c.

Loebeffen Belg: $v$. Prunus chinenfis

Looghboom Belg: $v$. Baccifera malabarica \&c.

Loopbeffen Belg: $v$. Frutex trifoliata

Lotus Egyptia Alp. de Plant. Ëg. I03. $v$. Nimphra

$7-107$

Lycium indicum ppinis quaternis ad fingulorim foliorum exortum $\mathrm{C}$ : H: Beaum: 2 8. v. Melampyro cognata

Lycium bifnagaricum, acuminatis minus durioribus folits \& aculeis ex oppolito binis Pluken: P: 2. T: XCVII. 3.v.Baccifera indica \&c.

Lymappel Belg: $v$. Pomifera indica \&c.

$1-75$

Lysbeffen Belg: $v$. Frutex indicus baccifer \&c.

Lyfimachia indica not papppofa, flore Luteo minimo, filiguis charyophylium aromaticum æmulantibus Herm:Cat. 396. Caryophyllus purius malabaricus flore $\mathrm{Lu}$ tco minore Commel. in not. Carambu Mal. Bula-Vanga Bram: 2-95

$5-67$

$6-77$ Lyfimachia indica Lutea corniculata non pappofa, caule altiffimo, flore adorato Commel. Cat: 214. Lyfimachia indica non pappofa Lutea, flore fructuque majore caryophylloide $R a j i H$. I 5 lo. Caryophyllus fpurius malabaricus flore Luteo Commel. in not. CattuCarambu Mal, Cara - Pullu Bram.

Lyfimachia indica non pappofa re$2-97$ pens, flore pentapetalo, fructu caryopliylloide $R a j i ~ H: 15$ IO. Nir * Carambu Mal. Comody Bram: Lyfimachia indica falicis oblongo folio, flore albe fpicato Commel. in not. Belutta-Modela-Muccu Mal. Sifori Bram. an Perficaria maderafpatana Longiore folio hirfuto Pluken. P. 3. T. CCX. 7? 10-159 Lysimacbice Virgimane accedens planta Commel: in not: $v$. Euphrafix affinis

$$
9-87
$$

$5-1$ Magden blom Belg.v.Phafeolo aftinis 8-69 Maag'den kruyt Belg. v. Phafeolus 8-6I Maagden lot Belg. v. Periclymenum 6-I 11 Maagden lynen Belg. $v$. Frutex baccifer \&c.

Maanboonen Belg. filiqua fingulari glabra $P$ lukent: $P$. 3. T: C CI. 2. Geniftx tinctoriæ $x+51$ 


\section{2}

Maa-Panaa Bram:

Maarboom Belg: v. Frutex indicus baccifer \&cc.

Macada-Pila Bram: v. Arborindica \&c.

Macadapola Bram.

Macande Belg:

Macandou Javanenfium v. Arborindica \&c.

Maco Bram: v. Chryfanthemi fpecies

Macuca Gangoli Bram:

Madanaca Bran: v. Baccifera malabarica \&ic.

Maderam-Pulli Mal: $v$. Tamarindus

Madi Bram: v. Palma

Madjain Bram: v. Alcea

Mado Bram: v. Palma $\mathrm{ra}$ indica \& $\mathrm{c}$.

Maba-Candalo Bran: v. Candela indica \&c.

Mail-Anjcbi Mal. v. Rhamnus

Mail-Elou Mal: v. Vitex

Mail-Ombi Mal: v. Baccifera indica \&c.

Maifingon Bram: v. Balanus Myrepfica

Malabatbrum \&5 Folium indum J:

B: T: I. L: I V. 45 I. v. Canel-

Mal-Naregam Mal. v. Malus Limonia

Mala-Elengi Mal: v. Baccifcra indica \&c.

Male-Iiifchi-Kua Mal: v. Zingiber:-

Mala infana Dodon: 751 v. Solanum

Mala-Poinna Mal. v. Arbor Bacci-

fera indica \&c.
Malacca-Scbambu Mal: v. Prunus malabarica

Malacka-Pela Mal: v. Guajava ru-

Malaki-Caramboli Mal: v: $\mathrm{Ma}^{3}$ lus

Malambetti Bram: v. Jambos

Malam-Todda-Vaddi Mal.

Malaz-Kua Mal. v.Zedoaria

Malla-Katou-Tsjambon Mal: v. Jambos

Mallam-Toddali Mal: v. Baccifera indica \&c.

Mallam-Tsjulli Mal. $4-83$

Malleamot be Mal:y Pavare \& $9-163$ $1-97$ $7-5 \mathrm{r}$ $7-5 \mathrm{I}$ $I-97$ $10-8 \mathrm{x}$ $7-41$ $5-57$ $\mathrm{I}-39$ I -9 $6-69$ $I-1$ $9-91$ $6-63$ $1-73$ $5-1$ $S-5 I$ $6-19$ $-105$ $4-27$ $-109$ $1-29$ - I 47 $-17$ $-27$ $3-33$ $3-55$ $4-17$ 4) 37 $1 \div 17$$$
-17
$$

2-35 Malua cbinenfis rofea arborefcens $5-79$ 3

3

Munting 192 . v. Alcea 6

Malva frutejcens Bont: I 4 I. V. A1cea

Malum Cydonium indicum Bont: 98. v. Cucurbitifera trifolia

Malus granata zeylanica aculeata

Plukenet: P: 2. T: XCVIII. 6. v. Malus Limonia

Malus indica fructu pentagono $\mathrm{Bi}-$ $4-29$ limbidicta Raji H: I 4.49. Billing Bing Bont: 13 3. Bilimbi Cnal. Malaki-Caramboli Bram: Bilingbinos Lalfit. Blim bynen Belg. $3-5.5$

Malus indica pomo àngulofo Carambolas dicta Raji H. r419. Carambolas Parkins: Theat. 1637.C: a Coft: 286. J: B: T: r. L: I. I 7 . Bont: 10z. Mala Goenfra fructu octangulari pomi vulgaris magnitudine $B$ : Pin: 433 . TamaraTonga Mal: Carambola Bram: \& Luifit. Vyfloeken Belg. $\quad 3-5$ I

Malus indica pomo corticofo juglandipari, monopyreno Raji H: 1663. Karin-Kara Mal. Tamagali Bram: Narilha Lufit. Haanballen Belg.

Malus indica pomo cucurbitæformi, monopyreno Raji $H .1675$. Iripa Mal. Iripou Bram: Fruita Bolfa Lufit. Tafnoten Belg: an Fructus exoticus 1ecundus Chas: Exotic. 52?

Malus Limonia indica fructu pufillo Raji H: 1658. Tsjerou-KatouNaregam Mal: Citt-Rana-Nimba Bram: Limains da folha crufado Lufit. Claver Appelkens Belg. Malus Limonia indica floribus umbellatis fructu parvo Raje $H$ : 1658. Mouli-Ila, feu Moul-Elavou Mal:Tipali \& Agadani Bram: Limao Pimentofa Lufit. Peper Limoenen Belg. an "Zanthoxylum americanum, fou Hercules arbor aculeata major juglandis folits al. ternis parum finuofis Pliken: $P$ : 3.T: CCXXXIX. 6? 5-67

Malus Limonia malabarica fructu umbilicato Raji H: I463. Granata malus zeylanica fpinofa $P$ ar. Bat.. P. 33 8. Katou-Nagegam Mal:Rana-Nimba \& Coduvo-Nani Bram: Limao Coraodo Lafit: Wilde Limoenen Belg. an Malus granata zeylanica aculeata Pluk: 


\section{A $\quad L \quad A \quad B \quad A \quad R \quad I \quad C \quad A$.}

P: 2. T: XCVIII. 6?

Malus Limonia pumila fylveftris zeylanica Hermanni. Mal-Naregam, feu Mara-Maram Mal. Nani \& Rana-Nimba Bram: Limao do mato Lufit. Wilde Citroenen Belg.

Mahis malabarica folio Es fructu amaricante, semine compreffo plano Syen in not: $v$. Solanum

Malus maluccenfis nomibil spinofa, E. jujuba indica B: Pin: $433 . v$. Jujuba

Malus rojea malabarica Commel: in not: v: Arbor indica \&c.

Mamoera famina Clus: Cur: Port: 79. v. Pepo arborefcens

Mamoera Mas Clus: Cur: Poft: 80. v. Pepo arborefecens

Aamogar i Bram: Lufit: \&્ Belg. $v$. Jafininum

Maria Bram: r: Frutex baccifer \&c.

Mana Bram. v. Sedi fpecies \&c.

Manam-Podam Mal.

Mandaru-Valli Mal.

Mandatbiia Herm: Mus: Zeyl: $v$. Crifta pavonis

Mandjadi Mal. v. Crifta pavonis

Manerick Belg: v. Siliquora indica \&c.

Manga Sylveftris lactefcens venenata, Jaimini flore \& odore $P . B$. (Prod. 35 r. Manga fructu venenato, officulo cordiformi, nucleo gemino Raji $H$. I s 2 . Mangas 1 fruftu venenato $B$ : $\mathcal{P} i n .440$. Perficá fimilis anguftifolia, offe cordis humani figurâ, binos nucleos continente Syen in not. Mangas. Bravos C. a Coft. 284 . Odallam Mal. Uro Bram.

Manga indica fructu magno reniformi Ragi $H$. 1550. Mangas domeftica 'Par: Bat: $\mathcal{P}: 35 \mathrm{r}$. Perfic fimilis putamine villofo $B: P$ in: 440. Amygdalam referens fructus hirfutus $\mathcal{F}$. B. T. r. L. II. I 83 . Amba five Mangas Ejujd: 173. E Variorum. Fructus exoticus quartus â Gareto acceptus Chus. exot. 40. Arbor Mangifera Bont. 95. Mao fel Mau Mal. Amba Bram. Manga Jeu Mangeira Luffit. Mange Belg.

Manga affinis, flore parvo Stellato, nucleo majori offeo Syen in not.
4-29| Ambalam Mal. Godoc-Ambado Bram.

Manga-Nari Mal- Veronica I-9.

Mangaratia Pifon: $227 . v$. Zingiber

Mange Bcig. v. Manga

Mangelinos Lufit. v. Crifta payonis

I $1-23$

$4-27$

Mangeira Lufit: $v$ Manga

I -67 Mangle arbor pyrifolia jalfis \&o Vl; ginofis locis in america proveniens, fructu oblongo tereti, fummis ra= mis radicoja Pluken: $\mathrm{P}: 3$, $\mathrm{T}$ :

CCIV. 3. v. Candela arbor \&c. 6--59

$4-48$

$3-39$

Mangle arbor coriaria, folio denfifus cuio, fubrotundo, glabro, fru-

$1-23$ ETu forma chariopbylli aromatici majore Pluken: P: 3. T: CCIV.

$I-2 I$ 3. $v$. Candela indica \&c.

Mania-Adeca-Manjen Mal. v. Conyza

Manja-Kurini CMal.

$5-7$

Manja - Pumeram Mal: $v$. Arbor triftis \&c.

Manja-Kua Mal: v. Curcuma II-I9

Manjella-Kua Mal. v. Curcuma Ix-2I

Manirouri Mal: $v$. Frutex baccifer \&c

6 - is

$6-25$

Manil-Gale Bram: v. Prunus chi-

$\begin{array}{cc}\text { nenfis } & 4-53 \\ 6 \text {-5I Manil-7aka Mal: } v \text {. Anona } & 3-21\end{array}$

Maniil-Kara Mal:v. Prunus chinenfis

Manil-Ponoffou Bram: v. Anona $4-53$

Man-Onapu Mal.

Man-Todea-Vaddi Mal. v. Mimofa malabarica

Manneli Mal: $9-39$

Mans-Boonen Belg:

Mans-Boonen Belg: v. Crifta pavo-

Mans Druyven Belg: v. Vitis Syl$1-72$ veftris

Mao Mal: v. Manga

Maparia-Poja Mal: v. Frutex baccifer \&c.

Maquinba Lufit: $v$. Arbor baccifera $5-85$

\&c. $\quad 4-37$

Maragofá Lufit: v. Balfamina cucumerina

Marani Lufic: v. Frutex indicus

Anaps G \&c.
Maravaras, Tsjembo Mal.
I2-I

Marchato Lufit. 7-109

Mareta-Mali Chal. ' I I-129

4---I Maretta-Mala-Maravara Mal $12-57$

Marmelgira Lufic: $v$. Cucurbitifera trifolia \&c.

L 2 
Maroi Bram:

Marotani Bram: v. Jafminum

$7-6$ I Mercurialis zcylanica tricoccos cum

Marotti Mal: $v$. Laurifolia malaba-

4-99 acetabulis, Kupamenia Zcylonenrica \&c.

Mafao Spinofa Lufit: v. Jaca minor

Mafara Bram:

$\mathrm{I}-65$

$4-73$

$10-165$

Maferafefade Bram: v. Mercurialis

Matavi-Aloos Bram: v. Frutex indicus \&c.

Matricaria indica, latiore folio, flore pleno Commel. in not. TsjettiPu Mal. Sevanti Bram: Alofna de Botao Lufit.

Madsjadada Bram: $v$. Sideritidis folio \&c.

Matti-Gonfali Bram: v. Cucumis Matzatli, Seu Pinea indica Hexnand: 3 II. $v$. Ananas

Mau Mal: $v$. Manga indica

Manz, MuJa Alp: de Plant: 王g: 8o. v. Ficoides

Mau-Maravara Mal.

$10-161$

$6-81$

$0-87$

$9-\mathrm{I} 4 \mathrm{I}$

$8-15$

I 1 - I

$4 .-1$

$1-17$

$12-47$

Mede-Canni Bram: v. Periclymenum

Medica Tali Bram: v. Cufcutrefpecies \&c.

Meerboonen Belg.

Meerlingb: Belg:v. PericlymenoSinenfi variegato fimilis \&c.

Meer vleclstWortel Belg: v. Cufcutæ fpecies \&c.

Meeru Margg: 4. $v$. Arundo

Melamfyro cognata maderafpatana fpinis horrida Plikenet: $P: 2 . \mathcal{T}$. CXIX. 5. Eryngium ceylanicum febrifugum floribus Lureis Herm. Herb. v. Ceyl. Kathu - Karohiti Cingal.Collctta-Veetla Mal.Gontua Brarn: an Lycium indicum fjinis quaternis ad fingulorum foliorum exortum C. Beanm. 28?

Melilotus indica humilis erecta, floribus exiguis, odoratis, albis, pericardiis majoribus fpicatim denfius ftiparis Phuben: $P: x, T$ : XL V. 5. Meliloto vulgari flore albo accedens, fi non eadem Commel. in not. Suendadi - Pullu Mal.

Mella.Pana-Kelengu Mal. Melongena C: B: Matth: $760 . v$. Solanum

Melsbouroen Belg: v. Acacia Mendoni Mal: v. Methonica $7-83$

$7-107$ fibus Herm. Cat. App. 686 . Urticre folio, flore albicante fpicato, cui paffim thecula bicornea infidet, foliis in fummitate caulom ambientibus Commel. in not. Cupameni Mal. Maferafefade Bram.

Meri-Caravatti Bram: v. Ficus $3-8$ r

Mefi Bram: v. Alfina 10-39

Methonica malabarorum Herm. Cat. App. 688. Nienghala Zeylonens. Lilium zeylanicum fuperbum vulgo Pliken: P. 2. T. $C X V I .3$. Mendoni Mal. Arty Bram: Raiz d'Empofe Lufit. Croelteen Belg. 7--rof

Mety Bram: v. Rhamnus

$1-73$

Milten Belg: v. Balfamina cucumerina

Mimofa arborea favanenfis, tenuiffimis pinnis, fliquấ latâ, pergrandi, Spadicea Breyn: P.2. 73. v. Acacia

Mimofa malabaricaflore pentap:t $n$ lo, filiquis Lanuginojis Raji H.

1740. v. Crifta pavonis

Mimofa malabarica, foliis pilofis, non finofa minor, flore Papilionaceo Lureo, filiquis anguftis, articulatis Commel. in not. ManTodda-Vaddi Mal.

Mimofr fpecies Commel. in not. Tsjo - Vanna - Manneli Mal.Damapana Bram.

Minari Jeu Pongam Mal. v. Crifta pavonis

Min-Angani Mal. v. Sideritidis folio \&c.

Mirabilis peruviana flore flavo Herm. Cat. 42 8. โூ V ariorum Jafminum mexicanum, five flos mexicanus multis $7 . B . T$. 2. L. $X X .814$. Solanum mexiocanum flore Luteo B. Pin. 168. Jalappa Vera, vel Mirabilis peruviana flore Luteo Munting. 266.Atzoyatl Hernand. 170. Andi-Malleri Mal:

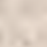

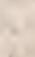

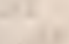$$
\text { 170. Andi Malleri Mal. } 149
$$

Eadem flore exalbido, \& purpureo

$9-75$
Variorum
Miri Bram.

Mirifato Bram. v. Baccifera indica

$10-47$ \&c. $5-49$

$6-9$
Miriffo Bram. v. Piper $\quad 5-49$ 


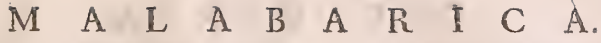

Modagam Mal: v. Pomifera indica \&c.

Modecca Mal: v. Flos paffionisfpurius \&c

Modira-Canni Mal: v. Frutcx malabaricus \& c.

Modira-Caniram Mal:v. Solanum

Modira-Valli Mal.

Moella Bram: v. Siliquofa indica \&c.

Moemoe Bram: v. Sorbus fpuria

Moetoe Mal: v. Solanum veficarium

Mogari Bram: \& Belg: v: Jafminum Mogari falfo Lufit: v. Jafminum

Mogaro da Serra Lufit: v. Jafminum

Moggori Roofen Belg: v. Jafminum

Mogori fores mali aurea foribus odoratiores B: Pin. 470 . v. Jafminum

Molago-Codi Mal. v. Piper Molago-Mallam Mal: v. Baccifera indica \&c.

Molanga Pifon: Mant: A. 8o. v. Piper

Momordica ceylanica fructu pyrifor. mi majore ex flavo rubente, Scminibus albis C: H. Beaum: 30. v. Balfamina cucumerina

Momordica minor indice orientalis, Bryonia facie, fructu glabro, molli, wve crijpa magnitudine \& effigie, fiuve purturafcente, $\mathrm{Li}$ neisniveis ftriato Breyn: $\mathrm{P}: 2.74$. ₹. Balfamina cucumerina

Momordica, S. Cbarantia india orientalis, fructu autrantio majore, oblongo, feminibus albis Breyn: p. 2. 73 . v. Balfamina cucumerina

Momordica zeylanica, pampineâ fronde, fructulongiore Turn: El: Bot: 86.v. Balfamina cucumerina

Eadem fructubreviore Turn: El: Bot.

86. v. Balfamina cucumerina

Momordica vulgaris Turn: El: Bot: 86. v. Balfamina cucumerina

Monarakuaimbiia five Cauda pavonis zeylonenjibus Herm: Cat: 192. v. Crifta pavonis

Moorenkappen Belg: v. Solanum Morgenferren Belg: $v$. Arbor indica \&x.

CNorgerferren - Belg: v. Baccifera indica \&c. $4-125$

4-119 Moringa Lentifci folio, fruetu magno angulofo, in quo femina erui J: B: T: ^. L: XII. 435 . v. Balanus myrepfica 6-I9

Morico Es Mouricou Mal: v. Coral

\begin{tabular}{l|ll}
$2-29$ & arbor & $6-13$ \\
$8-47$ & Moroins rofado Lufit: v. Caftanea & $3-63$
\end{tabular}

\begin{tabular}{l|ll}
$2-29$ & arbor & $6-13$ \\
$8-47$ & Moroins rofado Lufit: v. Caftanea & $3-63$
\end{tabular}

7-87 Morfegeiro Lufit: v. Ficus $3-85$

Motta-Modecca Mal: v. Flos parfio-

$6-11$ nis fpurius $8-43$

4-69 Motta-Pullu CMal. 12-27

Mottenga Mal.

Moul-Elavou Mal: v. Goffipium 3-6r

Moul-Ila E̋ Moul-Elavou Mal: v• Malus Limonia

Moullava Mal. v. Siliquofa indica \&c.

Mouricon Mal: v. Coral arbor 6-13

Mouringou, Muringo, \& Maifngou Mal. v. Balanus Myrepfica 6-19

Mourmoura Bram; v. Arbor indica

6-87 \&c. 4-7I

7-23. Mourmouratarum Bram: v. Arbor Baccifera \&c.

$4-67$

$5-49$

$7-23$

Mucca-Piri Mal.v. Balfamina cucu-

merina $S-25$

Mucuna Brafilienfum Margg: I9. v. Phafeolus

$8-17$

Mudela-Nila.Humatu Mal: v. Stramonia

Muel-Schevey Mal. v. Planta indica \&c.

Mugi Bram: v. Phafeolus

Mulen-Belleri Mal: v. Cucumis

Mulen-Pullu Mal.

Mulen-Scbena Mal. v. Arum

Mund Bram: v. Planta indica

$10-135$

$2-5 x$

$8-63$

Munda-Kalli Mal:ve Convolvulus 10-85

Mu-Kelengu Mal: v. Ricophora $8-97$

Mumicks Keylen Belg.

Muricu Mal: v. Coral arbor

$7-69$

Muriguti Mal: v. Alfine affinis

Muringo Mal: v. Balanus myrepfiridace Breyn. $\mathcal{P}$. I. 42. M ca

Mufa arbor J: B: T: I. L: I. 149. v. Ficoides.

Mufta Bram:

$12-97$

Myrobalanus emblica officinarum Dale Pharm: 444. Myrobala. nus emblica foliis fecuridaca Breyn: $P$ 2. 74. Myrobalano Emblicx affinis, foliis fecu-

$6-19$

I- 17

(1)

$4-I^{2} 3$

$3-29$ 


\section{$4^{6}$}

Myrobalani Emblicx $B: P$ in. 445 . Emblica in fegmentis nucleum habentes angulofx F. B.T. $1 . L$. $I I .20 \mathrm{G}$. Canna indica arborea Zann. Arbor acacix foliis malabarica, fructu rotundo, femine triangulo Syen in not: Nili-Canaram CMal Anvali Bram.

Myrtus americana Sylveftris Pifon: 178. $v$. Baccifera indica \&c.

Myxa pyriformis officulo trifpermo Raji H. 1556 'Tsjem-Tani Mal. Tanis-Mory Bram: Myxon EF Sebeften Dod: 1262. v. Sebeftena domeftica

Nacht bloemen Bclg: v. Jafininum Naetklim Bels.

Naga-Dante Mal: $v$. Ricinus

Naga-Mu-Valli Mal.

Naga-Pu Mal.

Naga-Valli Mal.

Nagam Mal: v. Siliquofa flore umbellato \&c.

Nagatampo Bram: v. Caftanea indica

Nain-Canna CMal.

Nai-Corana Mal: v. Phafeolus

Nala-Tirtava CMal.

Nalabi Bram. v. Ferrum equinum 10-169 Nalal-Suri Bram: v. Arbor baccifera \&c.

Nalla-Apella Mal: v. Arbor malabarica baccifera \&c.

Nalla-Mullla Mal: $v$. Jafminum

Naligu Mal: v! Frutex baccifer \&c.

Namidou Bram: $v$. Prunifera indica \&c.

Nana Brafilienfibus Margg: 33. v. Ananas

Nana Brava Margg: 33.v. Ananas

Nandi-Ervatam Mal.v.Syringa \& Jafminum

Nani Bram: $v$. Malus Limonia

Nani Lufit: $v$. Baccifera indica \&c.

Nani da Serra Lufit: $v$. Vitis idæx fpecies

Nanfcbera-Canfcbabu Mal. v. Ve-

ronica
Nansjera -Patfia Mal. v. Apocynum

Naqueri Brath: v. Baccifera indica

$2\}$

$4-27$
O R A

Nara-Maram Mal: v. Malus Limo-

nia
Nara-Sai Bram: v. Jafminum $\quad 4-27$

Nara-Valu Bram:

Naravolo Bram: $v$, Arbor indica 9-147 \&c.

Nari-Patsja Mal: $v$. Conyza $\quad \begin{array}{r}5-11.3 \\ 10-123\end{array}$

I-69 Narciffus zeylanicus, flore albo hexagono odorato, Lunana zeylonnenfibus Herm: Cat. 69 3. CatulliPola Mal.:

I I -79

Narilba Lufit. v. Malus indica \&c. $4-49$

Narinam-Poulli Mal. v. Alcea $6-75$

Narla-Gondo Bram.

Narola Lufit. $v$. Flos paffionis fpurius \&c.

Narrephimmen Bclg. v. Baccifera

4-99 indica \&c. 4-33

8-91 Naru-Kila Mal: v. Cannx affinis

$10-151$ \&c.

$8-57$ Naru Nundi Mal.

10-1 I 1 Narum-Panel Mal: $v$. Frutex bac-

$8-\$ 5$ cifer \&c.

cifer \&c. $2-11$

$6-37$

Nati-Schambu Mal: v. Prunus
Natjatam Mal.v. Arbor indica cocculos officinarum feren

3-63 Nazano Bram:

8-6I Nedel-Ambel Mal: v. Nimphrxaffnis \&c.

Nedum - Schetti Mal. v. Frutex indicus baccifer \&c.

Negunda \&5 Cirita mari Bram: $v$. Baccifera malabarica \&c.

Negundo mas variorum v. Vitex

Negundo femina variorum $v$. Vitex

$11-67$

$10-67$

$x-55$

$2-2 I$

$4-97$

$2-15$

$2-43$ Neboemeka Mal: v. Balfamina cucu- ${ }^{2-13}$ merina $\quad 8-37$

$4-55$ Nela-Naregam Mal: $v$. Frutex malabaricus \&c.

I I-I Nela-Tsjiria Mal: $v$. Sedifolio \&c. Io-6 I

Nela-Vaga Mal: $v$. Althææ fpecies \&c.

$10-\Upsilon 37$

S 105 Nelam-Mari Mal: v. Planta bifo-

(107 lia \&c.

$9-16 \mathrm{r}$

Nelam-Parenda Mal.

Nelam-Pata Mal: $v$. Jacobæa fpecies \&c.

$5-59$ Nelam-Pullu Mal: v. Phalangii affinis \&c.

$9-\mathbf{1} 17$

$10-97$

5-61 Nelem-Pala Mal: v. Apocynum $\quad \begin{array}{cr}\text { nis \&c. } & -37 \\ 9-5\end{array}$

Nelen-Tsjunda Mal: v. Solanum $x$ I -145

9-2I Nelenfchena Mal. v. Arum $\left\{\begin{array}{l}33 \\ 39\end{array}\right.$

4-57 Neli-Pouli Mal: $v$. Bilimbi altera $3-57$ 


\section{A L A B A}

Neli-Tali Mal: $v$. Ferrum equinum 9-3 I Nelipu Mal:v.Planta aquatica \&c. 9- 137 Nella-Panna-Maravara Mal.

Nellia-Tandale-Cotti Mal: v. Genifta

Nely Bram: v. Colutea

Nepeta indica rotundiore folio Commel. in not. Katu-Kurka Mal.Saikilo Bram:

Nepeta indica Sideritidis folio, floribus fpicatis Commel: in not. Tumba Mal.

Nepeta indica Sylveftris, flore purpureo fpicato Commel: in not. Kattu-Tumba Mal. Boin-Tulafi Bram:

Nepeta malabarica folio Latiore flore cxruleo exalbido Commel: in not. Carim-Tumba Mal. CacoTumba Bram:

Nepetæ feu Menthæ cattariæ affinis indica, candido flore Cornmel: ine not: Cottam Mal:

Neriam Pulli Mal.

Nerium indicum anguftifolium floribus odoratis fimplicibus Herm: Cat: 448 . Nerium indicum anguftifolium flore incarnato odorato fimplici Par: Bat. P: 35 6. Belutta-Areli Mal. Fula meltica alba Lufit.

Nerium indicum latifolium floribus plenis odoratis Herm: Cat: 449. Nerium indicum flore rubefcente pleno Breyn: P: 2. $7^{6}$. Nerium indicum latifolium flore rubro \& aliquando variegato odorato pleno 'Par. Bat. P. 356 . TsjovannaAreli Mal: Fula meftica incarnata Lujui.

Nerium Lactefcens malabaricum, chamæcerafi alpinæ, five mali au= rantiæ foliis rugofis, flore albo odorato, filiquis propendentibus longis Breyn: 'P: 2. 76. Arbor malabarica Lactefcens, Jafmini flore udorato, filiquis oblongis Syen iu not. Codaga-Pala Mal. Attego-Cudo Bram:

Ncrium Lactefcens malabaricum maximum pentaphyllum polyanthemum, flore minimo, racemofo, odorato, Viridi albicante, filiquis propendentibus 'longiffimis Breyn. P: 2. 77. Arbor malaba. rica pentaphyllos Lactefcens fili. quis auguftis longiflimis Syen in

$9-49$ not: Pala Mal. Santenu Bram. $\quad 1-8 \mathrm{I}$ Netel-TekaBelg: $v$. Baccifera indica \&c.

Neya Bram: v. Ricophora

1-10I Nhandu Margg: 75. $v$. Piper 7-3 I

N'bola Lufit: v. Balfamina cucume rina

$8-37$

Niara Mal: $v$. Baccifera indica \&c. $5-5 \hat{3}$

Niccol Cingal:

Nienghala zeylonenf fum Herm: Mus:

Zeyl: $v$. Methonica $\quad$ 7-107

Nierpluymen Belg: $v$. Frutex indicus baccifer \&c.

Niir-Notfiil Mal: v. Baccifcra malabarica \&c.

Niir.Pongelion Mal: v. Clematis $6-53$

Niirvala Mal: $v$. Pomifera indica \&c.

Nila-Barudena Mal: v. Solanum ro- 447

Nila-Humatu Mal: v. Stramonia $\quad 2-49$

Nila-Pulhu Bram: v. Phalangii affnis $\quad 10-37$

Nilbedoufi Bram: $v$. Baccifera indica \&c.

Nilba Lufit: $v$. Baccifera malabarica \&c.

5-III d inferno Lufit: $v$. Ricini indici fpecies

9-3 Nilicamaram Mal: $v$. Myrobalanus $\quad I-69$

Nil Anil five Indigo indica Moris. H: 202. $v$. Colutea 1-IOI

Nilfive Indigo spuria Raji H: I 734 . v. Polygala $\mathrm{I}-\mathrm{IO} 3$

Nimbo C: â Coft: 2 \& 1. v. Azadirachta

Nimbo altera Commel, in not:v. Aza -107

9-I dirachta 4-ro9

Nimbou Bram:v. Azadirachta 4-107

Niota-Niodem-Valli Mal: v. Apocynum

Nir-Carambn Mal. $\mathrm{T}$. $9-27$

Nir-Cottam-Pala Mal: v. Tithymalus

$2-99$

Nir-Mulli Mal.

Nir-Pullari Mal.

9-67

Nir-Scbulli Mal: v. Frutex indicus

\&c. 2-89

Nir-T sjembu Mal: v. Arifarum I I -33

Nir-Valli-Pullu Mal: $\quad$ IO-23

Nir-Pulla Mal. IO- 53

Niruri Mal: $v$ Frutex indicus baccifer \&c.

Niruri Mal. 
Niruren Mal.

Niti-Panna Mal:

10-ro9| not: Ambel Mal. Saluca Brant.

Niti-Todda-' addi Mal: v. Efchi-

nomenes
Nivuli Bram: v. Euphorbio \& ' Tithymalo media affinis \&c.

$3-7$ an Nymphaa alba major Egyptiaca, five lotus AEgyptia $\mathcal{P}$ arkius. Theat. $125 \mathrm{~s}$ ? Lotus ÆEgyptia Nuphar vocara Alp: de Plant: Egg: 10\}? Nymphia feu Nufar IEgyptium Vefling: Obferv. 42? 8I-5I

Nocbil Lufit: v. Baccifera malabarica \&c.

Noeli-Tali Mal: v. Berberis

Noel-Valli Mal: $v$. Siliquofa indica \&c.

Nogliever Belg: v. Frutex indicus pentapetalos \&c.

Nola-Ily Mal: v. Arundo

Nootjes kraak my niet Relg: $\nabla$. Ricini indici fpecics

Noz de Molucco falfo Lufic: v. Nux Myriftica

Notenga Mal. v. Perficaria

$9-35$

$2-83$

Nuren Kelengu Mal:

Nux Been zeylanica, filiqua triangula, Jeminibus alatis Herm: Cat: App: 692. v. Balanus Myrepfica

Nux Faufel, Seu Pinang Bont: go.

Nymphæa malabarica minor, folio Serrato Commel. in not. Cit-Ambel Mal.Cafturi-Camalla Bram: I I 53 Nymphra indica minima, flore flavo Cummel. in not. TsjerouCit-Ambel CMal. Cumudi Bram.

Nymphræ minoris affinis indica, flore albo pilofo Commel, in not. Nedel-Ambel Mal. Commodu. Bram: \begin{tabular}{r|r} 
4-9 & Nymphxa affinis malabarica, flore \\
amplo, rofaceo, albicante colore
\end{tabular} Commel: in not. Tamara Mal.

7-67 Nymphæx affinis malabarica, fo. $\begin{aligned} & \text { Pada-Maetu Bram. } \\ & \text { N9 }\end{aligned}$ lio \& flore amplo, colore candido Commel. in not. Bcm-Tamara Mal.

$$
11-61
$$

$6-19$ v. Palma

Nux Malabarica fulcata, muscilagnofa fabacea Syen in not: v. Arbor Siliquofa \&c.

Nux malabarica unctuofa, flore cuculiaro Syen in not: Cumbulu Mal. Bon-Varo Bram:

Nux Myriftica major fpuria malabarica Raji H: 1524 . Nux indica oblonga, intrinfecus fimilis nuci mofcatx F: B: T: I. L:III. 499 . A vellanæ indicx genus oblongum Clus: in Garz. 189. Palma, cujus fructus oblongus faufel fimilis $B$ : Pin: 5 10. Arecx, five Avellan $x$ indicx verficoloris genus oblongum Parkins. Theat. 1643. Panam-Palka Mal. Ambadeki, Eु Palka Bram: Noz de Molucco falfo Lufit. Wilde Mannekens Nooten Belg:

$1-9$

$x-89$

$$
x \rightarrow 75
$$

Obadali Bram: v. Frutex indicus baccifer \&c.

Odalam Mal: v. Manga

Odeca-Aloen Bram: v. Sagitta indi- $\mathbf{I}-\mathbf{7 1}$ $\mathrm{ca}$

I $I-95$

Oepata Mal: Oepoli Bram: v. Anzcardium

Oet. Bram: v. Prunifera, feu Nucifera \&c.

Ogoranim Bram:

Olas d'agoa $L u f i t$ :

Olea Sylveftris malabarica, fructu dulci Raji H: 1546. Perin-Kara Mal. Gali-Doufa Bram: Azeitones do malavar Lufit. Wilde O-

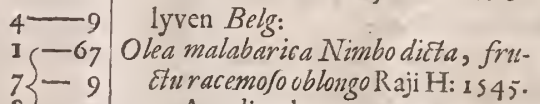
\begin{tabular}{l|l}
$4-9$ & lyven Belg: \\
$7\{-9$ & Olea malabarica Nimbo dicta, fru- \\
-9 & Etu racemojo oblongo Raji H: 1545.
\end{tabular} $8\left\{\begin{array}{r}-9 \\ 8\end{array}\right.$

Nux Vomica

v. Azadirachta

Eadem fructu racemojo rotundo Raji

H: I 545 . v. Azadirachta

Otee affinis pyrifolio malabarica, flore odorifero ftellato Syen in not:
Nyalel Mal: v. Arbor racemofa Nymphæa indica, flore candido, folio in ambitu ferrato Commel: in v. Prunus 
Olbeira Lufit: $v$. Baccifera indica \&c

Ona Bram: v. Baccifera indica Onapu Mal:

Onobrychis maderaspatana diphyllos minor faliculis birfutis Pluken. P. 3. T: CCXLVI. 6. v. Planta indica \&c.

Ononis natrix dicta frute (cens zeylanica, laburni folio, fore luteo, Spicato, amplo Breyn: P. 2. 78. v. Genifta

Oogappeler Belg: v. Baccifera indica \&c.

Oorblad Belg:

Oorbangers Belg: $v$. Arbor indica Siliquofa \&c.

Orbicularis fructus peregrinus pri. mus Clus: exot: 29. v. Solanum

Orchis abortiva aizoides malabarienfis, flore odoratiffimo variegato, intus aviculam reprefentante Commel: in not. Angeli-Maravara Mal.Ponoffou-Kely Bram:

Orchis abortiva aizoides malabarienfis altera, flore odorato, fanguineo colore, intus aviculam purpuream referente Commel: in not. Biti-Maram-Maravara Mal.Giriy Bram:

Orchis abortiva aizoides malabarienfis, foliis obtufis, flore aureo odorato Commel. ix not. Ponnampou - Maravara Mal. SovannaPoufpa Bram:

Orchis abortiva aizoides latifolia malabarica, clitoride, flore Luteo, pilofo Commel. in not. AmantalyMaravara Mal.

Orela-Modecca Mal: v. Flos paffionis fpurius

Ota-Pulli Mal: v. Cambogium Ottel-Ambel Mal. $v$. Sagitta indica

Oulaffani Bram:

Oulaffo Bram.

Ourinti Bram: $v$. Saponaria arbor

Ouro Bram: $v$. Tithymalus

Oxyacanthe affinis malabarica Syen in not: $v$. Rhamnus

Paapekappen Belg: $v$. Frutex malabaricus \&c. $\quad 5-103$

Paapekoppen Belg: $v$. Frutex baccifer \&c.

Pauwe Staarten Belg. v. Crifta pavonis $5-7$

Pada-Cali Bram: v. Jafminum $\quad 2-17$ Pada-Dalaqui Bram: v. Arbor baccifera indica \&c.

Pada-Kelangu Mal: 2 - I I I . Bryonix Levis fpecies \&c.

Pada-Mactu Bram: v. Nymphæx affinis

$7-93$

Pada-Nivuli Bram: $v$. Euphorbium 2-8I

Pada-Valli Bram: $v$. Bryonix Levis fpecies \&c.

Pada-Vara Mal.

Padavalam Mal: v. Balfamina cucumerina

$7-93$

$7-51$

Padri Mal. v. Clematis :6-47

Padri malabarica fimilis arbor $\grave{e}$ Maderaßpatan Pluken: P. I. T. LIII. f. I. $v$. Clematis

ano Mal. $v$. Amygdalx affinis \&c.

Paeru Mal: $v$. Phafeolus

Pabiora Bram: v. Siliquofa indica \&c.

$6-51$

Pajaneli Mal: v: Clematis $\quad I-79$

Pai-Paroea Mal: $v$. Frutex baccifer \&c.

Paina-Schull 5 - 91

Paina-Scbulli Mal: v. Frutex indicus fpinofus \&c.

Pal-Modecca Mal: v Flos paffio ${ }^{2-93}$ nis fpurius \&c.

Pal-Valli Mal: $v$ Apocynum

Pala Mal: $v$. Nerium I I -8 I

Palafu Bram: $v$. Arbor filiquofa trifolia \&c.

Palega-Pajaneli Mal: $v$. Clematis $\quad \mathbf{x} \longrightarrow 7$

Palins Lufit: $v$. Arbor baccifera indica \&c.

Palka Bram: v. Nux myriftica

Palay Bram;

Palma coccifera complicato folio, fructu minore Syen in not. Palma coccifera, folio plicatili, flabelli formi , famina Raji $H$. 1366. Carim-Pana CMal. Talatamado Bram. Paimeira brava $\mathrm{f} x$. mina $L u / a t$. 
Palma indica coccigera angulofa $B$ : Pin: 508. Palma indica nucifera 7: B: T; 1. L. III. 375. Palma five Nux indica vulgaris cocos ferens Parkins. Theat. 1596 . Palma major coccifera C. H. Beaum: 33. Inaia Guacuiba, vulgo Cocos Pifon: 130. Palma Bahei Coyolli dicta Hernand: 75. Polghaha Zeylon: Tenga Mal. Mado Bram:

Palma indica folio bicompofito fructu racemofo Raji H: 1365 . Palmx dactyliferx fecies Syen in not. Schunda-Panna Mal: Birala-mado Luflit:

Palma arecifera nucleo verficolori nuci mofcatæ fimili $P$ ar. Bat. $P$. 361. Palma, cujus fructus leffilis Faufel dictus B. Pin. 5 10. Areca, five Faufel Chus, in Garz. 188. Avellana indica C. â Coft. 268. Faufel five Areca Palmæ foliis 7 . B. T. I. L. III.389. Nux Faufel feu Pynangh Bont: 9 o. Palma, cujus fuccus infpiffatus Terra Japonica feu Catechu officinarum Dale Pharm: 386. Caunga Mal. Madi Bram: Puwakghaha Zeylon:

Palma indica caudice in annulos protuberantes diftincto, fructu pruniformi Raji H: 1360 . Palma Japonica fpinofis pediculis polypodii folio Par. Bat. P. 361 . Palma vinifera Belgarum Breyn. $P$. I. 43. Palma farinifera Japonica Soteefou Japonenfibus Breyn: $P$. 2. 81. Palma prunifera Japonica Herm. Cat:472. Pailmam referens arbor farinifera $B$. Pin, 508 . Arbor farinifera Clus: exot. 5. Tod. da-Canna, feu Mouta-Panna Mal. Audexa-Motha-Panna Bram: Armatorias das igrezias, $\mathbf{S}$, Palma d'igrefia $L u l i t$.

Palma malabarica, flofculis ftellatis, fructu longo Squamato Syen in not. Palma coccifera folio flabelli formi mas Raji H: 1366 . Ampana CMal: Palmeira brave macho Lufit.

Palma montana malabarica, folio magno, complicato, acuto, flore albo racemofo, fructu rotundo Conzmel: in nor: Palma montana, folio plicatili flabelliformi maximo, femel tantum frugifera $R a j i$
H: I367. Codda-Panna Mal:Karetela Bram: Talagas \& Talagaia Cingalens: Arvore dos Sombreinos Liufit.

Palma Sylveftris malabarica, folio acuto, fructu puni facie Commel: in not: Katou-Indel Mal: Kafouri Bram: Tamara do mato Luffit. Wilde Dadelboom Belg:

Palma Humilis longis latisgue foliis B: Pin: 507 . v. Ficoides

Palma , cujus fructus oblongus Fan fel fimilis B: Pin: 5 I 0. v. Nux Myriftica

x-Is Palma fructu aculeato ex arboris $3-1$ trunco prodeunte B: Pin: s $11 . v$.

Palmeira brava famina ES macho Lufit: v. Palma

Pana-Poi Bram:

Panam-Palka Mal: v. Nux Myriftica \&.

Panambu-Valli Mal. v. Arundo indica

Pandi-Avanacu Mal: v. Ricinus

Pandi-Pavel Mal:v. Balfamina cucumerina

Panel Mal: v. Prunifera racemofa \&c. Sylveftris Auct. H. M. 2-9

Panel Sylveftris AuEt. H. M. Katsjou-Panel Mal. Pee-A pacaro Bram: $\mathbf{P}_{20}$ Coftus bravo Luefit. Wilde Heylwortel Belg.

Panella minor foliis minoribus aromaticis Raji H: 1594. Kaltsjerou-Panel Mal. Avara-Apacaro Bram: Pao Coftus da Serra menor Lufit: Bergh - Heylwortel Belg:

Pane-Poi Bram: $\nabla$. Frutex indicus baccifer \& 8 .

Panepojoe Bram:

Pangiro Bram: $y$. Coral Arot $5-87$ $3-9$ Pnja, Panjala Mal: v. Goffipium $3-59$

Panitsjika-Maram Mal: v. Pomifera indica \&c. ra indica \&c. Polypodium

Panna-Mara-Maravata $\mathrm{Mal}$. $\quad \mathrm{I}_{2}-29$

Panna-Valli Mal. $\quad$ I $_{2}-\mathrm{G}_{3}$

Panui-Valli \& Noel-Valli Mal. v. Siliquofa indica \&c.

Panover-Tsjerua CMal.

Pao-Coffus Lufit: v. Frutex indicus baccifer \&c.
$3-17$ $\left\{\begin{array}{l}\text { It } \\ 13\end{array}\right.$ $0-53$ 4-9 $7-99$ $2-60$ $8 \rightarrow 17$ $5-35$ $5-33$ $5-45$ $-87$ $2-23$
$2-29$
$2-63$ $6-39$ I $1-65$ $5-29$ 


\section{$\begin{array}{lllllllllllllllll}M & A & L & A & B & A & R & I & C & A\end{array}$}

Pas Cofuts Bravo Lufit: v. Pand Sylveftris

Pao Cafus da Serra mar $5-35$ Panella minor \&c.

$P_{a o}$ Coffus do mato Lufit: v. Frutex

indicus baccifer \&c.
Pao da Cobra Lufit: v. Solanum $\quad 5-27$
$8-47$

Pao da verse Lufit: v. Arbor intica \&c.

$P$ ao de Chanco Lufit:.v. Frutex indicus \& \&c.

$\mathcal{P}_{a 0}$ de Sapan Lufit: v. Crifta pavonis

Pao de Solor Lufit: v. Solanum

Pao do Pilao Lufit.

Pao Salgado macho Lufit: v. Frutex indicus \&c.

Papaja ortentalis mas fent Sterilis Commel: Cat: 26 r. v. Pepo atborefcens

Papaya maram Mal: v. Pepo arborelcens

Para-Panna-Maravara Mal.

Parangi-faca Mal: v. Anona $\quad 3-23$

Parangiato Bram: v. Periclymenum

Paray Bram: v. Ficus

Pariatacu Bram: v. Arbor triftis \&c.

Parili Mal: Pariloffi Bram: v. Arbor baccifera \&c.

Pariti Mal: v. Alcea

Parpadagam Mal: v: Spergula

Parparam Mal:

Parua - Kelangu Mal: v. Plantagini

finilis \&c.
Pata. Ponofjow Bram: v. Caftanea $\begin{array}{rl}I & 2-31 \\ 2-25\end{array}$

Pato Mal: v. Arbor filiquofa trifólia \&c.

Patarolo Bram: v. Baccifera malabarica \&c.

Patisjivi-Maravara Mal: v. Phyllitidi affinis \&c.

Patolas Lufit: v. Cucumis

Patsjotti Mal: $\vee$. Baccifera indica - \&x.

Pattara-Ponni Bram: v. Frutex indicus baccifer \&c.

Pattates Belg: v. Convolvulus

Pavali Bram: $\mathrm{v}$. Balfamina cucimerina

Pavate arbor foliis mali aurex $7: B$ : T:2. $L: X V$. I02. Pavate \& Vafaveli Bram. É Cassaximis. C.ä Coft: 266. Arbor malabarenfium fruetu Lentifci $B$. P in. 399. Pavetra \& Malleanothe Mal: Cita-Mataqui

-II 3

$6-55$

6-3

$8-47$ $5-115$

$6-57$ $I-2 I$

$x-23$

I2-3I

6-III

$3-71$

$1-35$

$1-53$

$10-6 y$

$9-29$

$2-25$

6-29

$12-21$
Bram: Arvore contra das eryfipelas, Fruita gradinha Luffit: Scheelkoorn Belg: rina

$$
8=19
$$

Pce-Ambalam Mal:

Pee-Amerdu Mal:

Pee-Apacaro Bram: v. Panel Sylveftris

$5-5$

$P$

Pee-Cajenneam Mal: v Chry $5-35$

mi f pecies \&c.

Pee-Coipa \&c.

10-133

Pee-Cupameni Mal: v. Urticæ folio

\&c. $10-163$

Pee do Morto Lufit: v. Pomifera in-

dica \&c. $\quad 3-49$

Pee-Kandel Mal: v. Candela indica \&c. $\quad$ 6-6I

Pee-Inota-Inodien Mal; v. Solanum $10-14 \mathrm{I}$

Pee-Mottenga $\mathrm{Mal}$. $\quad$ 12-99

Pee-Ponnag am Mal: v. Baccifera indica \&c.

Pee-Tandale-Cotti Mal: v. Genifta indica \&c.

$5-47$

Pee-Tardavel $M a l$.

Pee-Tsjanga-Pufpam Mal: $\quad 9-115$

Pee-Tsjerou-Ponnagam Mal.' 5-45

Pee-Trumbo Mal: v. Euphrafia affinis \&c.

Pee-Ula Mal.

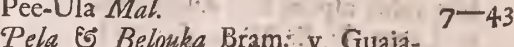

$3-31$

Pelou Mal: Pelouarta Bram: v. Guajava

$3-35$

Penaar Bram: Penar-Valli $\mathrm{Mal}$.

$8 \int 0^{1}$

Penacho-Macho Lufit.

5-II Pena Bram:

Penshout Belg:

$7-43$

$12-77$

$7-61$

Pentaphyllum filiquofum malabarienfe Commel. in not. Caara-Veela Mal: Veela \&5 Teloni Bram:- $\quad 9-43$

Peper Belg: v. Piper 7-23

Peper het Mannekeu Belg: $\forall$. Pi.

5-2I per

7-95 Peper Limoenen Belg: v. malus Lìmonia

$8-23 \mid$ Pepinbo do mato Lufit. v. Cacumis $8-67$

Pepo arborefcens \& papaya orientalis Column. in not. ad Hernand. 870. Papaja Hern. 99. Eु Bram. Arbor flatani folio, fructu peponis magnitudine eduli $B$. P in. $43 \mathrm{r}$. Fichum fpecies fructus $\mathrm{N}_{2}$

peruanus 
peruanus Ejufd: 457. Arbor melonifera Bont: 96. Papaye Pcruan!s F: $B: \mathcal{T}:$ 1. L: I. $147 . \mathrm{Ma}-$ moera famina $\mathrm{Cl}$. Cur. poft. 79. Marg. I 03 . Pinoguani Fæmina Pifon: I 5 9. Papaya - Maram CMal.

Pepo arborefcems mas, feu Srerilis 'Par. Bat.' 'Prod. 362. Papaja orientalis mas feu Sterilis Commel. Cat. 26r. Mamoera mas $\mathrm{Cl}$. Cur: poft. 80. Marg: 103. Ambapaja Mal. Dadul-Paja Bram: Pinoguacu mas $P$ ifon: 159.

Pcpo compreffus major $B: \mathcal{P}$ in: 3 I I. Pepe maximus compreffus indicus Lob. Obf. 365 . advers. 286 . Pepo rotundus major Dod: 1041. Cucurbita afpera, folio non fiffo, fructu maximo, albo feffili $7 . B$. T. 2. L: $X V I .22$ I. Schakeri-Schora Mal. Folita-Cali-Dadi Bram: Bobara Guinea Lufit. Pepoenen Belg.

Pepo oblongus B: Pin: 3 r. $\mathrm{I}$ Major Dod: 1040 . Oblongus Vulgatiffimus Lob. Obf. 365 . advers: 286. Cumbulam Mal. Cuvaly Bram: Bobara d'agoa Lufit: Waterpepoenen Belg:

Pepo vulgaris Raji $H: 639$. Cucurbita foliis afperis five Zuccha flore Luteo $7: B: T:$ 2. $L: X V I$. 2 I 8 . Cucurbita major rotunda flore Luteo, folo afpero $B . P$ in. 3 I2. Cucurbita five Zuccha omnium maxima Lob. Obf. 366. advers: 287 . Bela-Schora CMal. Gara-Dudi Bran: Babora-Branca Lufit: Witte Pepoenen Belg.

Pera Bram: $v$. Guajava

Pera brava Lufit: $v$. Guajava

Pera de Malacca Lufit: v. Guajava

Peragu Mal: v. Frutex baccifer \&c.

Peralu Mal: $v$. Ficus

Perfoliatæ affinis indica Lychnidis æmula , flore viridi diluto Commel: in not: Cansjan-Cora Mal. 10-103

Periclymenum finenfe variegatum, flore fanguineo amplo Breyn: $\mathcal{P}$ : 2. 82. Frutex indicus, flore papilionaceo fanguineo, foliis pinnatis, fructu viduus $R a j i$ H.1733.

\section{R A}

Tsjude-Maram Mal. Parangiato \& Porvatri-Pou Bram: Folhas du cobra bibora Lufit: Maagden Lot Belg: an Periclymenum ceylanicum herbaceum, foliis variegatis, diverficoloribus maculis ornatis Par Bat: P: 363 .

$6-I I I$

Periclymenum indicum flore $\mathrm{fla}$ vefcente Turnef: El: Bot: 48 x. Itty - Canni CMal. Mede - Canni Bram: Fula morifca Lufit: Prickhout Belg: an Periclymenum herbaceum rectum virginiarum $P$ luk: T. 2. T. CIV. 2 ? Periclymenum furrectum perficæ foliis maderafpatanum Pluken: P. 3. T: CCXII. 5?

Periclymeno Sinenfi variegato fimilis frutex longo angufto folio variegato, Sinicus Breyn: $P: 2,82$. Tsjere-Maram Mal: Quelaftro Bram: Folhas da china Livit: Meerlingh Belg: $\quad 6-113$

8-3 Periera dos aizabos Lufit: v. Pru-

nus
Perimaram Mal: v. Arbor indica filiquofa \&c.

Perim-Kaku-Valli Mal: $v$. Phafeolus $4-4 x$ $6-27$

Perim-Tolafs Mal: v. Scrophularia

Perin-Courigil Mal: $v$. Siliquofa indica \&c.

Perin-Kaida.Taddi Mal.

Perin-Kara Mal: $v$. Olea

Perin Niar M-5I

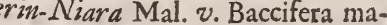
labarica \&c.

Perin-Nirouri Mal: v. Frutex bacci- $5-57$ fer \&c.

$3^{1}$ Perin-Panel Mal: $v$. Frutex indicus baccifer \&c.

Perin-Patsjotti Mal: $v$. Frutex baccifer \&c.

Perin-Toddali Mal: v. Jujuba $4-85$

Perin-Teregam Mal: v. Ficus

Perin-Tsjurel Mal.

2-41 Perficaria malabarica, flore galeato

$5-85$

$8-59$

$9-147$

$10-167$

$6-43$

$2-5$

$5-29$

$5-11$

$3-8 \mathrm{r}$

I-49 \& Labiato monofpermos Commel. in not. Vada-Kodi Mal. KaloAduluffo Bram:

$9-79$ Pare faceo colore, fructu pilofo Commel. in not. Tilo-Onapu Jeu Notenga Mal. Tilo Braw:

Perficaria maderafpatana, Longio$9-101$ re folio birfuto Pluken: $\mathrm{P} .3 . \mathrm{T}$ : 
CCX. 7. v. Lyfimachia ro-159 teo, filiqua angufta, parva, hif-

Perficarix folio repens malabarica, flore globofo albefcente Commel. in not. Coluppa Mal. Coipa Bram.

Perfice fimilis anguftifolia, offe pida Breyn: $P:$ 2. 82. Putsja-Paeru Mal: Mugi Bram: Favas cufeira pequeno Lufit: Kleyn Maagdekruyd Belg.

Phafeolus alatus major, fructu coccordis bumani figura, binos nucleos continente Syen in not. cineo, macula nigra notato Commel. in not: Phafeolus alatus voluv. Manga

Perfice fimilis put amine villogo $\mathrm{B}$ : Pin: 4.40. $v$. Manga

Perfici ofjiculo fructus malarcen is B: Pin: 4.4r. v. Prunus

Pes Capre Lufit: $v$. Convolvulus

Pevetti Mal: v. Solanum

Peylkruyd Belg:

$1-71$

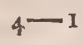
$1-27$ $x x-1 \times 7$ 4 - I I 3 $7-10 I$

Phalangii virginiani fpecies Commel: in not: Tali-Pullu Mal:

Phalangio affinis indica, flore $\mathrm{cæ}$ ruleo pallido Commel. in not: Nelam-Pullu Mal: Nila-Pullu Bram: $10-37$

Phafeolus indicus filiqua majore pungente Commel. in not: Lobus peregrinus cartilagineus Chus: exot. 66. Lobus peregrinus cartilagincus phafeolo ex puniceo nigro tanquam annulo cincto 7 : B: T: 2. L: XVII. 273. KakuValli Mal. Kairoli Bram: Fava Cofeira Lufit. Grood Maagdenkruyd Belg: an Phafeolus americanus frutefcens foliis glabris, Lobis pluribus, villofis, pungentibus, fructu orbiculari plas no, hilo nigro, tanquam annulo, totum fere ambiente Plltken: $P$ : 3. T: CCXIII. 2? Phafeolus brafilianus frutefcens, Lobis villofis, pungentibus, maximis Par: Bat: $\mathcal{P}:{ }_{3} \sigma_{3}$ ? Mucuna Margg: 19?

Phafeolus maritimus purgans, radice vivaci, foliis craffis, fubrotundis, bifnagaricus Phken: P: I.T: LI. 2. Catu-Tsjandi Mal:Canavali Bram: Grao do boy Luftt: Uyleboonen Bely:

Phafcolus indicus maritimus perennis ; foliis craflis, fubrotundis, minor Par: Bat: $P$ : 364 . CatuBaramaieca Mal.Ranavalu Bram: Favas dos paros Lalitit. Krimpboonen Belg:

phaf́colus indicus hirfutus, florelum

$9-123$ bilis \& major Indix orientalis fructu coccineo, hilo nigro notato Pluken: P: 3. T: CCXIV. 5. Glycyrrhiza indica filiquis \& Seminibus pifi coccineis, hilo nigro notato Par: Bat: P.3 37. Phafeolus ruber Abrus vocatus $A l p$. de plant. AEg: 76. Pifum indicum minus coccineum B: Pin: 343 . Arachus indicus feu africanus Park Theat: 107 I. Phafeolus indicus ruber fecundus Bont: 136. Pifum americanum coccineum, aliis Abrus 7 : B:T: 2. L: XVII. 263. Anjacock Surinam. Konni Mal.Ratena-Gundi Brams: Fruita Contfii Lufur. Ronde Weeghboom Belg.

Phafeolus arbor indica incana filiquis torofis Kayan dicta Herm. Cat. in App. 694. Cajan arbor indica foliis trifolii bituminofi, filiquis orobi Breyn. P. 1. 20. Phafeolus incanus erectus filiquis torofis $P$ luk. P. 3.T.CCXIII. 3. Anagyris indica Leguminofa filiquis torofis Par: Bat.P: 3 11. Thora.Paerou. Mal. Thori, Tantarega Bram: Quitfierrii Lufit. \& Belg: an Arbor trifolia indica $F: B: T: 2, L$. XVII. 368 ?

Phafeolus zurrattenfis filiqua hirfuta Coulage dicta Raji H. 887. Phafeolus filiqua hirfuta Parkins: Theat: 1056 . Phafeolus utriufque indix, Lobis villofis pungentibus minor Par: Bat.P.365. Nai-Corana CMal. Guilo Bram: Favas Cufeira Luflit. Maagdekruyd Belg: 8-6

Phafeolus alatus indicus fructu fufco orbiculato maximo, Lobis Latiffimis \& Longiffimis Herm. Cat. 494. Lens phafeloides maxima. indica, caffre foliis, femine maximo cordiformi Breyn. P. 2.63. Pufwel zeylon. Pèrin-Kaku-Valli Mal. Garail Bram. Gairo Lufit. \& Belg. an Phafeolus novi orbis, five faba purgatrix latiffima cordis figura F.B.T. 2, L. XVII.276? Faba 
purgatrix latiffima ex infula $D$ :

Thomx B: Pin. 338 ? Lobus eraf-

fus ex infula Sancti Thomx Chus: exotic. 65?

Plaafeolus indicus trifoliatus minor flore creruleo, fructu minore Commel. in not. Paeru Mal. Sanvali Bram: Graos da noffa Senhora Lufit. Heylboonen Belg.

Phafeolus indicus trifoliatus Sylveftris, flore purpurafcente, fructu majore Commel. in not. Catu-Paeru Mal.Rana-Sanvali Bram: Favas Caringejo Lufit. Qualboonen Belg: 8-79

Phafeolo affinis, glycyrrhizæ germanicx foliis, orientalis; flore albo Par. Bat. P. 365 . Clitorius flos albus Herm. Cat. I 62. Schanga-Cufpi Mal. Gocarni Bram: Favas de Bramanx Lufit: Smaltkruyd en Maagdenblom Belg.

Pbafeolus alatus arboreus, fructu or biculato, compre $\int 0$, coccineo Hcrm: Cat: 495 . v, Crifta pavonis \&c. 6-25 Pbajeolus americanus vel brafiliamus Sextus B: Pin: 34 2. v. Cotea I-101 Phyllitidi affinis indica, foliis ari Commel. in not. Patisjivi - Mara-

Piper longum anguftifimum ex Florida $B: F_{i n:} 412$. Piper ex Florida $7 . B . T .2 . L: X V, 187$. P. per frutex americanus fpica longa gracili Pluken: P. 3. CCV. 2. Planta peregrina Chus: exot. 84 . Nhandu feu Piper caudatum $M$ arg. 7 5. Eु 'Pifon: 197. Analago Mal. Miriflo Bram: Pimento macho Lufit. Peper het Manneken Belg. 7-3x

Piper rotundum nigrum $B$. Pin. 411 . Nigrum $\mathcal{F}: B: T:$ 2. L: $X V$. I $\delta$ I. छ઼ $V$ ariorum. Rotundum Hernand. 1,3. Lada, \& Molanga, five Piper aromaticum mas $\mathcal{P}$ iforr. Mant. A: 492. Molago - Codi CMal. Miri Bram: Pimenta Lu/at. Peper Belg:

Piperi fonilis fructus Striatus mas vara Mal.Sorina-Sjiba Bram:

Picinna Mal: $ซ$. Cucumis Pilaghas Cingalens: v. Aftragalus Pilau Mal. v Jaca Pimenta Lufit. v. Piper Pimenta longa Lufit. $v$. Piper Pirmento macbo Lufit. $v$. Piper Pimento do Mato Lufit.

Pimperlingh Bely.

Pimpilim Pifon: Mant. A. 182.v. Piper

Pinba Lufic. $v$. Amygdala indica Pinea indica feu MatzatliHernand: 311.v. Ananas

Pinoguacu Mas Pifon: x 59.v. Pepo arborefcens

Pinoguacu famina Pifon. 159. v. Pepo arborefcens

Pino Pifon. 2 ;5. v. Urtica

Pinus indica nucleo purgante B. Pin. 492. $v$. Ricinus

I. $2-2$ I

$8-13$

9-5s

$3-17$

7-23

7-27

$7-31$

$7-25$

$7\left\{\begin{array}{l}15 \\ 19\end{array}\right.$

$7-27$

$4-5$ $I-21$ $x-23$

$2-75$ $2-6 I$

Piper indicum filiqua flava vel aurea, figura Latiore $B:$ Pin: 102. Vallia-Capo-Molago Mal. PoitaCali-Medi Bram:

Piper indicum filiqua flava vel au-
B. Pin: 4 I2. $v$. Vitex trifolia 2-I5

Idem femina B: Pin. 4I2. v. Vitex trifolia

Piripu Mal.

Piru-Dukka Bram: v. Cor-Indum

Pifcobo Bram:

Pifum cordatum Lob: Obf. $516 . v$. Cor-Indum

Pifum indicum minus coccineum B. Pin: 343.v. Phafeolus

Pijum vefucarium fructu nigro alba macula not ato B. Pin. 343.v. CorIndum.

Pitsjegam - Mulla Mal, v, Jafminum

Pitta-Gafurculi Bram: v. Urtica

Pitra-Gafurculi Bram:

Plañta aquatica aphyllos repens, flore caruleo difformi Commel: is not. Nelipu CMal.

Planta bifolia humirepa, arifolio, flofculis aureis, villofis, articulatis Herm: Herb. v. Zeyl: NelamMari Mal. Singari Bram. an Onobrychis maderafpatana diphyllos minor, filiculis hirfutis 'Plaken. P. 3. I: CCXLVI 6? 9-16: 


\section{$\begin{array}{llllllllll} & \text { A } & \text { L } & \text { A } & \text { B } & \text { A } & R & \text { I } & C & \text { A. }\end{array}$}

Planta bifolia, radice tuberosâ, flore tripetalo difformi malabaricnfis Commel. in not. Katsjula-Kelengu Mal. Capura-Catari Bram:

Planta indica alato caule, folio crenato, pilofo \& vifcofo, flore glomerato purpureo Commel. in not. Adaca - Manjen CMal. Mundi Bram:

Planta indica erucx folio caulcm ambiente, flore pilofo Commel. in not. Mucl-Schevey Mal. Udiram-Panum Bram: an Sonchus Levis maderafpatanus Pluken.P. 3. T. CCXXVII. 3? 10-135

Plantaperegrona Clus: exot: $24 . v$. Piper

Plantagini affinis indica Commel.in not. Parua-Kelanga $\mathrm{Mal}$.

$7-31$ Plajo Mal. v. Arbor Siliquora \&r.

Plat Pimperlingh Belg: $v$. Clematis

Pluymkeylen Belg.

$1 I-3 I$

$6-29$

$7-17$

$7-71$

Pockbout Belg: $v$. Similacis afperæ fpecies \&c.

Podava-Kelengu Mal: $v$. Ricophora

Poeatsjetti Mal:v. Frutex malabaricus \& $\mathrm{C}$.

Poerinfiz Mal: v. Saponaria arbor

Poefoo Bram; v. Frutex indicus fpicatus \&c.

Poja Bram: v. Frutex baccifer \&c.

Puinciana fore pulcberrimo'Turnef: El: Bot: 4.92. \%. Crifta pavonis

Poira-Cali-Medi Bram: v. Piper

Pola-Tsjira Mal: v. Sideritidis folio \&c.

Polghaba Zeylon: v. Palma

Polita-Cali-Dadi Bram: v. Pepo

Polo Bram: v. Cannæ affinis \&c.

Polti Bram: $v$. Baccifera indica \&c.

Polygala indica minor filiquis recurvis Syen in not. Indigo folio rotundo, five Indigofera rotundifolia Mantingh 228. Nil five indigo fpuria Raji H. 1734. Colinil Mal. Schera-Punca Bram:

Polygala indic a frute/cens Hermanni Raji H. 926. $v$. Colutea

Polypodium indicum foliis latiffimis Conzmel: in not: Panna-Kelengu-Maravara CMal. Kadehou

6- I $9-6 j$ $9-153$ $\mathrm{I}-\mathrm{IO}_{1}$
Bram: Wortel Vaaren Belg. an Polypodium indicum Pifon. Mant. Ar. Iys?

$12-23$

Pomifera indica trifolia fructu pruniformi caudato Raji $\mathrm{H}$ : 1644 . Tapia Brafilienfium fimilis Commel: in not. Niirvala Mal. Ranabelou \&6 Pretonou Bram: Peedo Morto Lu/ut: Bombeenen Belg: an Tapia Pifon: I 40 ? Arbor amcricana trifoliata pomifera, feminibus reniformibus Cat: Beanm: 10 ? Apiofcorodon, feu Arbor Americana triphylla, allii odore, poma ferens $\mathscr{P}$. 3.T: $C X X X V I I$. 7? Arbor americana triphylla, numerofis ftaminulis purpureis apicibus preditis floris umbilicum occupantibus, Plukenet. 3. $T$. CXLVII. 6?

Pomifera indica flore rhododendri, fructu pyriformi Raji H. ז644. Modagam Mal. Corotha Bram: Anmaco Lufit. Hondstongh Belg.

Pomifera indica tinctoria Janipaba $4-119$ dista Raji H. 1666 . Janipaba Pifon: 138 . Pomo fimilis brafiliana $B:$ P 4.43 .. Junipappeeywa Brafiliancrum Chis. exot. 10. Junipappeeywa Brafilianorum nucum folis, five Genipato $\%: B$ : T. I. L. III. 653 Panirsjika-Maram Nial Tembiri Brain: Fruita da grude Lifit. Lym-Appel Belg.

Pcomifer a fou potius Prunifera indica, mice reniformi furmo pomo innafcente, Cajous dicta Raji H. 16 $+9 . v$. Anacardium Pomifer a indica fructu conoide, fqua$8-3$ Anona

II-67 Pomum arenofum fen Xalxocbotl v. Guajava

Pomum de Hiericbo melongenis con$3=-45$ gener J: B: T: 3.L.XXXIV.619. v. Solanum

Pomum finofum J: B: T: 3. L: XXXIV. 624. v. Stramonia 5 Pon-Kely Bram:

Ponampon-Maravara Mal: v. Or. chis.

Ponga Mal: v. Jaca

Pongam Mal: Crifta pavonis

Pongati Mal.

O 2
$2-69$

$2-47$

$12-55$

I $2-7$

$4-73$

$6-5$

$1 \mathrm{I}-47$ 
Pongelion Mal: $v$. Arbor indica filiquofa \&c.

Pongolam Mal.

Ponna, feu Ponna-Maram Mal: Ponnaka Lufit: v. Prunifera feu Nucifera \&c.

Ponnagam Mal: v. Baccifera indica \&c.

Ponnaka-Pequena Lufit: v: Cornus

Ponnam-Tagera Mal: v. Senna

Ponolfou Bram: v. Jaca

Ponoffor-Kely Bram: v. Orchis

$6-27$

$7-111$

Ponvo Bram: v. Coftus officinarum $11-15$

Popinbo do patare Lufit: v. Ariftolochia

Portigall-Nivuli Bram: v. Tithymalus

Portulaca Sylveftris Commel. in not: Kara Tsjira Mal. Gali Bram:

Portulacæ foliis fimilis planta, flore albo galeato, \& Labiato, femine oblongo, rotundo, ruffo, fufco colore Commel, in not: Kodatsjeri CMal: Zenca - t'sjada Bram: num

Para-Pullu Mal

Pou-Kandel Mal: v. Candela

Pouli Bram: v.Balfamina cucumeri-

Pouli Gali Bram: v. Baccifcra indica \&c.

Poutaletsje Mal: v. Baccifera indica \&c.

Poutsja Mal: $ซ$. Baccifera indica \&c.

Praatjes Belg: v. Crifta pavonis Praetkens Belg: $v$. Frutex baccifer \&c.

Prangwortel Belg: ca \&c.

Prickbout B Ig: v. Periclymenum Prunifera indica fructu umbilicato. fulcato, groffulariæ fimilis $R a j i$ $H$ : I 48 r. Takkada zeylanenfibus Herm. Cat. App. 652. Bella-Modegan (Mal: Tacorotha Bram: Ammaco - Macho Lufit. Groor Hertftongh Belg:

Prunifera indica fructu umbilicato racemofo, avellanæ magnitudine Raji H: 1482 , Katou-Theca Mal.
Porvattz-Pou Bram: v. Periclyme-

Pretonou Bram: $v$. Pomifera indi-
Dava - Sailo, \&] Vana - Papalou Bram: Theca brava Lufit: Wilde Teka Belg.

Prunifera indica arbor fructu umbilicato corticofo perfici fimili Raji $H:{ }_{4} 8$ 3. Kara-Angolam Mal: Namidou Braw: Efpinho Santo Bravo Lufut. Wilde Keyfers Vrught Belg:

Prunifera malabarica fructu racemofo parvo, acri, fucco tinctorio Raji H: I 5 47. Katou-Tsjerou, feu Cheru Mal. Rana-Bilo Bram: Uvas d'inferno Lufit: DullenPruymen Belg:

Prunifera veficaria fructu multiplici, officulo in fingulis quadrato $R a j i$ H. I 565 . Kiati, feu Quercus indica Bont: 107 . Theca Mal. Sailo Bram: Teca Lit fit: \& Belg:

Prunifera racemofa malabarica fructu cumpreffo, nucleo nudo Raji $H:$ is u. Panel Mal. Cali Apocaro Bram:

Prunifera feu Nucifera malabarica foliis Nimphræ, fructu rotundo, cortice pulvinato Raji $H$ : 1525 . Arbor fundens Lacrymam guttæ gambx fpeciem Commel: in not: Ponna, Jeu Ponna-Maram Mal. Oeti Bram: Ponnaca Lufit. Greele Gom Appels Belg. an Arbor indica mali modicx amplioribus foliis maderafpatana Plukenet.P. 3 . T. CXLVII. 3?

Prunifer a fructu racemofo, parvo, mucleo faponario Raji H. $1548 . v$. Saponaria Arbor

Prunus malabarica fructu umbilicato pyriformi Jambos dicta minor 6-35 Raji H. I 478 . Perfici officulo fructus malaccenfis ex candidorubefcens $B$. 'Pin. 441. Jambos 7 . $B$ T. 1. L. I. 116. छัV ariorum. Malacca-Schambu Mal. Tuphat indi Arab. Alma Turcus.

Prunus malabarica fructu umbilicato pyriformi Jambos dicta major Rajl H. 1578. Jambos Sylvatica fructu cerafi magnitudine, Walgambu Cingalcnfium, Hermani Commel. in not. Perfici officulo fructus malaccenfis rubens $B . P$ in. 441. Nati-Schambu Mal. Schambu Bram.

Prunus fructu umbilicato pyriformi fpinofa, racemofa $R$ aji $H$. I 480 . $x-2 \gamma$

$$
1
$$

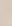


Idoum Moulli Mal: Elacanto Bram.

Periera dos diabos Lafft: Dulleboom Belg.

Prunus indica racemofa, fructu

4

Pypriet Belg: v. Arundo

Pyra indica, feu Granatenfia vulgo.

v. Guajava

Pyro fimilis frudtus alter in nova

Hippania B: Pin: 43 9. v. Ano-

Mal. Gottinga Bram: Biborala

Lufit: Heylpeeren Belg.

Prunus pentaphyllos malabarica, fructu calici infidente Raji $H$. I 564 . Arbor prunifera malabarica fentaphylloides, fructu calici infidente Commel: in not. Kariil Mal. Zalico Bram. Satirao Lufit.

Prunus malabarica, fructu calyculato Raji H. ${ }_{5} 6_{4}$. Olex affinis pyrifolio malabarica, flore odorifero ftellato Syen in not. Elengi Mal. Vavalli Bram:

Prunus chinenfis duplici in fructu officulo Raji H: I565. Maniil-Kara Mal. Manil-Gale Bram: Fruita manilha Lufit. Loebeffen of te Chineetfche Pruymen Belg: an Pruno fimilis fructus chinenfis B: Pin: 444?

Prunus malabarica, fructu racemofo calyce excepto Raji H. 1563. $v$. Sebeftena domeftica

\section{Pu-Pal-Valli $M a l$}

Pu-Tumba Mal.

Pu-Valli Mal.

Pua-Schetti Mal: v. Frutex indicus baccifer \&c.

Puam-Curundala Mal: $v$. Conyzx affinis \&c.

Puem-Peda Mal.

Pul-Colli Mal.

Pulli-Schovadi Mal: v. Convolvulus. na

$$
3-23
$$

Qualboonen Belg: v. Pliafeolus $8-79$

Wuamoclit five fafminum americanum Clus: Cur: p. 9. v. Convol. vulus

$1 \mathrm{I}-\mathrm{I}_{2} 3$

Quarena Bram: v. Sebeftena domeftica $4-77$ Q2uaubayobuatli fecunda . Hernand: 87. v. Caffia Fiftula $\quad 1-37$ 2)iabayobuatli tertia Hernand: 88 . v. Ricinus

I-33 Quaubmecapaltli Hernand: $290 . v$. Smilacis alperæ fpecies Quautzapotl Hernand: 90. v. Anon.

Queendoorn Belg: $v$. Arbor indica \&c. 5-75 2uelaftro Bram: $v$. Periclymenum 6-II 3 Q) itelbefren Belg: $v$. Baccifera malabarica \&c.

5 -III Quercus indica Bont: 107. v. Prunifera veficaria

Querilbas Lufit: $v$. Arbor baccifera indica \&c.

Querillas macbo Lufit: $v$. Arborin-

$10-127$

$12-71$

$9-135$

$4-57$

$4-$ III

I I I I I

Pulmonaria folio maculato fimilis indica, floribus tripetalis rofacæo faturis Commel. in not. Soneri-Ila Mal. Codigi Bram:

Punarnava Bram: v. Valerianella

Puppajano Mal: v. Arbor indica axкарт)

Pufwal Zeylon: v. Phafeolus

Putsja-Paeru Mal: v. Phafeolus

Punla-Padacali Bram: $v$. Frutex indicus baccifer \&c.

Puwakgbaba Zeylon: v. Palma

Pylriet Belg: v. Arundo

Pyzangh Bont: 9o. v. Palma

$9-127$

$7-105$

6-rog

$8-59$

$8-67$

2-2I

$3-9$

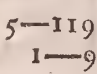
dica \&c.

2uetblon Belg: v. Capparis

Quigombo prior Pifon: 210. v. Al-

Quitflerrii Lufit: Eึ Belg: $v$. Pha-

feolus

Quylklim Belg: v. Sedi fpecies.

Raiz da Sollteira Lus/it.

Raiz da Boba Lufit: v. Smilacis afperæ fpecies

Raiz da Bolfa Lufit: v. Ricopho-

Raiz da Cobra Lufit: $v$ : Baccifera indica \&c.

Raiz da Cobra Lufit: v. Arbor indi-

$5-107$

$6-105$

$2-71$

$6-23$

$7-71$

$7-73$

$7-59$

$7-97$

$5-65$

ca $\alpha_{x \alpha \rho \pi}$ (G) \&c.

Raiz da Cobra Branca do Mato Lut-

fit.

Raiz da Moftarda Lufit.

$7-111$

Levis fpecies

Rais d' Empoff 7-93

Empoje Lufit: $v$. Methoni-

Raiz do Zafrao Lufit: v. Curcuma $\mathrm{II}-\mathrm{I} 9$ 
Ramena.Pou. Maram Mal: v. Baccifera indica \&zc.

Ramifoli Lufit: v. Frutex indicus baccifer \&c.

Ramos da Sevi Lufit: v. Cufcutæ fpecies \&c.

Rana - Bibo Bram: v. Prunifera malabarica \&c.

Rana-Dadumari Bram: v. Frutex indicus \& $\mathrm{cc}$.

Rana-Dadumari Bram:

Rasia-Derpu Bram:

R゙ana-Diacq Bram: v. Vitis Sylveftris fpecies \& $\mathrm{c}$.

Rana-Gondu Bram: v. Frutex indicus fpinofus \&c.

$4-125$

$5-21$

$$
7-83
$$

$4-19$

Rana-Nimba Bram: v. Malus Limonia

Rana-Mandaru Bram: v. Capparis

$6-4 \mathrm{I}$

$9-83$

$12-103$

$7-11$

$2-91$

27

$4\{20$

Rana-Queri Bram: v. Arundo

Rana-Sanvali Bram: v. Phafeolus

Rana-Tolaffi Bram:

Rana-Vali Bram:

Rana-Valu Bram: v. Phafeolus

Rana-Vete Bram:

Rana-Vodou Bram: v. Ficus

Ranabelou Bram: v. Pomifera indica \&x.

Raniquela Bram: v. Sinapiftrum

Ranunculo affinis planta indica, floribus purpureis Commel. in not. Ana-Coluppa Mal. Adaly Bram:

Rapum brafilianum Seu americanum alterum B. Pin. 9 o. v. Ricophora

Rasphout Belg. v. Crifta pavonis

Ratambala Ccylon: v. Jafminum

Rattenbauren Belg: v. Arbor indica trifolia \&x.

$6-105$

I $\mathrm{I}-85$

$8-79$

ro- 771

$7-51$

$8-87$

$12-123$

$3-87$

$3-49$

$9-6 \mathrm{I}$

Ratao falfo Lufit: v. Arundo

Ratena - Gundi Bram: v. Phafeolus

Rava-Pou Mal: v. Jafminum

Ranka-Paray Bram: v. Ficus

Raifcidra vidriado Lufit: v. Ficus

Rhamnus malabaricus fructu racemofo calýculato Raji $H$ : 1573 . Oxyacanthr affinis malabarica Syen in not. Mail-Anfchi Mal. Mety Bram:

$8-71$

4-99

$3-75$

$3-73$
tu-Kara-Walli Mal. Jafil, \& Sato-Val-Gali Bram: Fruita Patao Lufit: Salk Doorn Belg: Rhamnus an potius Lycium Fingrego Jamaifenfibus dictum Pluken. $P$.

2. T: $C V I I I .2$ ?

Ricinus Africanus maximus caule geniculato rutilante $H$. Reg. Par. Cat. 127. Avanacoe fen Citavanacu Mal. Erando Bram:

Ricinus indicus maximus caule ge$2-57$ niculato totus ruber Herm: Cat: 525. Ricinus vulgaris major $R a j i$ H: 17 10. Pandi-Avanacu Mal. Vallo-Erando Bram:

Ricinus arbor fructu glabro, grana tiglia officinis dicto Par: Bat: $P$. 370. Lignum Moluccenfe $C . \hat{a}$ Coft: 276 . Lignum moluccenfe foliis malvx, fructu avellanx minore, cortice molliore \& nigricante, Pavana incolis $B$ : $\mathcal{Y}$ in: 393. Pinus indica nucleo purgante Ejufd. 492. Pini nuclei moluccani five purgatorii $7: B: T: I, L$. III. 32 2. Lignum moluccenfe $\mathrm{Pa}$ vana dictum fructu avellanx ejusd. 342. Grana Tiglia \& Lignum moluccenfe officinarum Dale Pharm: 137. Quauhayohuatli tertia, feu femine arboris cucurbitinæ, nuclci pinus forma, purgante Hernand: 87. Gajapala Mal. CadelAvanacu Mal. Japalu Bram.

Ricinus Indicus femine fpadiceo Commet: in not: Naga dante $\mathrm{Mal}$. 7-97. Danti Bram: an Ricinus indicus 6-3 minor foliis Solani Breyn. Cent. I 18 ?

Ricini indici fpecies Raji H: 1896 .

$10-157$. Bengiri Seu Caremotti Mal. Girimafo Bram: Nilica d'inferno Lufat: Nootjes kraackt my niet Belg.

Ricophora indica five Inhame rubra, $4-105$ caule alato fcammoneifoliis nervofis conjugatis Par. Bat.P. 370 . Katfii-Kelengu $\mathrm{Mal}$.

Ricophora five Inhame malabarica fpinofa Bat: Par: TP. 371. Convolvulus Brafilianus Inhame de $S$. Thome dictus Commel. in not. Rapum brafilianum, five americanum alterum $B:$ Pin: 90 . Igname 


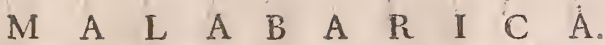

five Inhame Lufitanorum Clus: $H$. $L: I V .78$. Batatis affinis Igname five Inhame $7: B:$ T:2. L: $X I X$. 793, Cara Brafilienfi bus, Inhame de S. Thome, Congenfibus Quiquoaquicongo Margg: 29. Pifon: 93. Podava-Kelengu Mal. Karodi Bram: Raiz da bolza Lufit. Beurswortel Belg:

Ricophora five Inhame malabarica folio rotundo in acutum apicem abeunte Par: Bat. P: 371 . MulKelengu CMal. Neya Bram: Inhame de Cao Lufit. Hondswortel Belg:

\section{Roembadoe Bram: v. Ficus}

Rocy Bram: v. Apocynum

Roma-Valli-Caro Bram:

Ronde Galbeden Belg. v. Azadirachta

Ronde Weegbboom Belg: v. Phafeolus

Roode Himpen Belg: v. Baccifera indica \& $\mathrm{c}$.

Roos Appel Belg: v. Arbor indica \&x.

Rofa batavico indica inodora, fen Malva Frutescens Bont: 141. v. Alcea

Roja Sinenjis Ferrar: Cult: 479. v. Alcea

Rofa Mogori Lufit: v. Jafminum

Rofairo bravo Lufit: v. Jambos

RoSairo de Fambu Lufit: v. Jambos

Rottang Mal.

Roukalou Bram:

Roukakely Bram:

Rubia indica . Sylveftris, foliis Levioribus flore albicante Commel. in not: Schanganam-Pullu $\mathrm{Mal}$. 10-45

Rubix fimilis indica, flore albicante Commel. in not. Tsjeru-JongenaPullu Mal.

Rumboom Belg: v. Baccifera indica \&cc.

Rumboom Belg: v. Frutex indicus \&c.

Ryfloom Belg: v: Ficus

Sa-c Ameli Bram: v. Frutex indicus «'

$12-19$

I $2-43$

$5-25$
Sabao dos canarins Lufit: $v$. Saponaria arbor \&c.

Sabino Lufit: v. Balfamina Cucumerina

Sada-Bali Bram: v. Jambos

Sada-V aingani Bram: v. Solanum

Sagitta indica major, folio obtufo, floribus minoribus, albicantibus

7-97 Commel: in not. Culi-Tamara CMal.

Sagittæ affinis malabarienfis, latiffimo folio, floribus ex albo trifoliatis Commel: in not: Ottel-Am-

bel Mal. Adeca-Aloen Bram. 1 I-95

Sai Bram: $v$. Jafminum

Saikilo Bram: v. Frutex baccifer

$$
11-93
$$

$8-29$

4. -1 I

$2-65$$$
\text { (1) }
$$ \&c.
$2-4 \mathrm{I}$

I-43 Saikilo Bram: v. Nepeta 10-1 79

2- 33 Sailo Bram: v. Prunifera veficaria

7 -5 \&c. 4-57

Saio Bram: v. Jafminum $\quad 6-95$

4-109 Salao Lufit: v. Frutex baccifer \&c. 5-13

Salao d'orra Lufit: v. Frutex bacci-

8-7I fer \&c. 5- I I

Salao femea Lufit: v. Baccifera in-

Salken Belg.

$3-39$

Salgeira falfa Lufit:

Salgeira fermea Lufit: v: Candela indica \&c.

6-73 Salgeira mainato Lufit: v. Candela indica \&c.

6-69 Salgeira major Lufit: v. Candela in-

$6-89$ dica \&c.

4-1 I Salgeira Sativo Lufit. v. Candela

$4-15$

I2-I I I

Salgueira Lufit. v. Anacardium

Salique da Serra Luifit.

Salkdoorn Belg. $\vee$. Rhamni fpecies \&c.

Saloins Lufit. v. Baccifera indica \&c.

Salfa parilla officinarum Dale Pharm. 264.v. fmilacis afperx fpecies $8-6 s$

Saluca Bram. v. Nymphaa II $-5 x$

Sambach Arabum, five Gelfeminum arabicum Alpin. de Pl. $\mathbb{E g}$. 72 v. Jafminum

Samburus indica Bont. 108. v. Arbor baccifera racemofa \&c.

6-57 Sameno Bram. v. Baccifera indica \&c.

$5-15$

$8-89$

$6-67$

$6-6 s$

$6-6 x$

$6-63$

$6-59$

$4-95$

$7-79$

$7-33$

$5-5=$

$6-87$

$4-37$

Samenotti Bram. v. Frutex baccifer \&c.

Sammana Bram:

$5-13$

Samftravadi Mal. v. Jambos 4-II

6-83 Samudra - Tsjogan Mal. \& Bram 11-I25

$\mathrm{P}_{2}$

Sangori 
Sangrri Bram: v. Goffipium

Saniti Bram:

Santalim octavum, five Ligno brafiliano fimile B. Pin. 393. v. Crifta pavonis

Saintenu Bram•v. Nerium

Sanvali Bram.v. Phafeolus

Sapanbout Belg. v. Crifta pavonis.

Sapoeffi Bram. v. Ariftolochia

Saponaria arbor trifolia indica Herm. Cat. 53 6. Semine Lupini Par: Bat: P. 373. Prunifera fructu racemofo parvo, nucleo Saponario Raji H: $154^{8}$. Poerinfii \& Vercoepoelongi Mal. Ourinti \& $\mathrm{Da}$ mitafi Bram. Sabao dos canarins Lufit. Congas Zeyl. Seepnooten Belg.

Saralu Bram. v. Arbor indica filiquofa \&c.

Sarani Bram: v. Arbor baccifera indica \&c.

Saros Mal: v. Amygdalus indica

Saritos Lufit. $v$ Arbor baccifera indica \&c.

Sarpalo Bram: $v$. Baccifera indica

Sarpouli Bram: v. Chamacriftx pavonis affinis \&x.

Safali Bram: $v$. Cornus

Safara-Mullu Bram: v. Afparagus.

Satayo Bram:

Satilhas Lufit.v. Solanum

Satirao Lufit. v. Prunus

Sato-Val-Gali Bram: v. Rhamni fpecies \&c.

Savo-Candalo Bram: v. Candela Arbor

$7-33$

$6-59$

Scabiofa zeylanica, capitulis folio/is, femine amaro Lumbricos enecante Herm: $v$. Serratula

Schada-Vel-Kelangu Mal: v. Afparagus

Scbadida - Calli Mal: v. Euphorbium

Schageri-Cottam Mal: v. Cornus Schakeri-Scbora Mal. v. Pepo

Scbama-Pufpi Bram: v, Genifta

Schambu Bram: v. Prunus

Schanga-CufpiMal:v. Phafeolo affinis \&c.

Schanga-Cupi Bram: v. Veronica

Scbanganam - Pullu Mal: v. Rubia

Scbeelkoorz Belg: v. Pavate

$5-37$

$\mathrm{I}-\mathrm{I} 0 \mathrm{~S}$

$7-57$

$4-\mathrm{II}_{3}$

$8-3$

$9-45$

$1-29$
3-59 Scbem-Paretti Mal: v. Alcea $\quad 2-25$

9- 9 Schembra-Valli Mal. v. Vitis 7 - I I

Schena Mal: v. Arum $\quad \mathbf{I I}-35$

Scbera-Punca Bram: v. Polygala $\mathrm{x}-103$

Scheru-Bula Mal: v. Herniaria 10-57

Scheru-Cadelart Mal: v. Veronica

8-75 fimilis \&c. 10-IS7

6-3 Scheru-Katu-Valli-Caniram Mal:v.

8-49 Solanum 7-9

Scheru-Padavalam Mal.v. Balfami-

na Cucumerina $8-3 \mathrm{I}$

Scheru-Valli-Caniram Mal. $\quad 7-7$

Scberunam-Cottam Mal. v. Baccife-

ra indica \&c.

Scbetti Mal. v. Jafminum 2-17

Schetti album Pluken. P.2. T. CIX. 2. v. Jafminum

Schetti-Codiveli Mal:

2-19

$10-17$

$9-105$

Scbivanit Bram. v. Arbor racemofa \&c.

$1-76$

Schorigenam Mal. v. Urtica

$2-73$

4-5 Schovama-Adamboe Mal. v. Convolvulus $\quad 11-117$

5-I7 Schovanna-Modcla-Muccu Mal: $12-147$

$5-83 \mid$ Scbroefboonen Belg. v. Frutex indicus \&c.

6-1 7 Scbulpdoorn Belg. v. Crifta pavonis

$6-55$

Schunambu-Valli Mal.

$6-33$

$7-21$

Schunda-Panna Mal.v. Palma $\quad x-15$

Scbuyteboonen Belg. v. Siliquofa flore umbellato \&c.

Scrophularia indica radice fibrofa,

$6-37$ floribus cxruleo albicantibus Conmel. in not. Perin-Tolaffi, \&Tirtava Mal. Gandarli Bram: 10-I67

Sebeften officinarum Dale Pbarm. 424. Scbeften domeftica B.Pin. 446. Alpitl: de Pl. CEg. 30. Myxon \& Sebeften Dod: 1262. Prumus malabarica fructu raccmofo, calycc cxcepto Raji H. 1563 .

2-81 Vidimaram Mal. Quarena Bram: Fruita d'entrude Lu/ut. Clecfpruymen Belg.

Securidaca IEgyptiaca villofa Parkinfoni Raji H. gr 1. v: Senna z-Ior

Sedum indicum paluftre, foliis Latiffmis, crifpis, fluribus albicantibus, pilofis Commel: in wot: Kodda - Pail Mal. Zclo Bram:

$10-45$ Sedi minoris affinis folio pilofo, I I $-G_{3}$ 5-19 flore monopetalo difformi mala- 


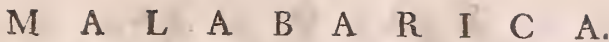

batica Commel. in not. Kalu-Polapen Mal. Corosjira Bram.

Sedi fpecies repens Commel: in not. Tsjangelam-Parenda Mal Mana Pram: Babofa quinado Lufit. Quylklim Belg.

Sedi folio indica, flore tetrapetalo, flavo colore Commel. in not. Nela-Tsjira Mal. Boin-Goli Bram.

Seeprooten Belg: $v$. Saponaria arbor

Selago indiæ orientatalis, five Ple. gmaria admirabilis zcylanica Breyn. Cent, 180. Flagellum S. Thomæ vulgo. Tana-PavelPaatsja - Maravara, vel EneadiKourengo Mal. Bendarly Bram. I 2-27

Sempen Alp. de P1. IEg. 98. $v$. Sefamum

Senna orientalis fruticofa Sophxra dicta Herm. Cat. 557. Chamæcaffia anguftifolia indica Breyn: P. 2. 29. Sophæra indix orientalis Breyn: P: I. 5 I. Galegx affinis Sophra dicta $B$ : Pin: 352 . Sophæra five Securidaca Ægyptiaca villofa. Parkinfoni Raji H. 9 I r. Sophæra Alp: de Pl. CEg. 83. F: B: T: I. $L: I X, 384$. Ecapatli altera Hernand. 7 6. Ponnam-Tangera, fezt Ponna-Virem Mal. Arpuly Bram: an Hoxocoquomaclit Chis: Cur. p. r11?

Senna fruria malabarica Raji $H$ : I\%43. Chamæcaffix affinis tetraphylla, filiquis tenuifimis, femimine tereti, apicibus obtufis quafi abfciffis , fua longitudine fecundum longitudinem filiquæ pofito Breyz. P. 2. 29. Tagera Mal.

Serpata-Valli Bram:

Serpent aria polypbylla indica, caule maculato, aspero Breyn. P. 2. 90. v. Arum

Eadem caule Levi Breyn: P. 2, 90. v. Arum

Serratula indica major Latifolia mollis Breyn. P. 2. 90. Jacex \& Serratulæ affinis, capitulis Baccharidis, Trachelii foliis zeylanica Breyn. P. I. 39. Scabiofa indica arborea Raji H. I 443 . Scabiofa zeylanica, capitulis foliofis, femine amaro lumbricus enccante Hermanni. Cattu-Schiragam $\mathrm{Mal}$. Calegeri Bram: an Eupatoria conyzoides odorato, folio crenato, molli , fubincano Pluken. P. 2. T. LXXXVII. 2? Serratula noveboracenfis, folio Leviter crenato, molli, fubincano Par. Bat. P. 375 ?

Sefamum B: Pin: 27. Eु Variorum. Sefamum fémine fufco Herm. Cat. 559. Sempren Alpin. de Pl. Eg. 98. Sefamum, Congenfibus Gangila , Lufitanis Girgilim Margg. 2 I. Digitalis orientalis fefamum dicta Turnef. El. Bot. 135 . Bidziam Poetech Malaccenfibus Schit - Elu Mal. Davo - Tiloe Bram:

Sefamum indicum, folio amplo 9-105 ferrato, flore majore, Semine nigricante Commel. in not. Bidziam-Hitem Malaccenfibus. CarElu Mal. Caro-Tilu Bram. an Sefamum alcerum foliis trifidis orientale, femine obfcuro Plik. P. 2. T. $C I X \cdot 4$ ?

Sesban aniliferum indicurn, coronilla foliis, vel indigo indica Breyn: P: 2, 9I. v. Colutea

Sesban affinis arbor indiæ orientalis Breyn. P. 1. 47. Galegx affinis malabarica arborefcens, filiquis majoribus, articulatis Syen in not. Agaty Mal. Agafto Bram:

Servanti Bram. v. Matricaria $19-87$

Siafmin Mal. $v$. Blattaria $10-\mathbf{r}$

Sida-Pou Mal. $v$. Arbor indica $\alpha^{\prime} x \alpha p \pi$ (G) \&c.

$2-\mathrm{IO}_{3}$ Sideritidis folio planta, caule pi6-109 lofo, capitulo globofo, flore monopetalo, quinque partito , candido Commel. in not. Min-Angani Mal. Matsjadada Bram:

Sideritidis folio infipido planta, flore pentapetalo, rofacei coloris, fructu rotundo in quinque partes divifo, femine triangulo Commel: in not: Tsjeru - Uren Mal. an Althæa americana frutefcens melochiæ fóliis anguftioribus Phkent. $P$. 2. T. XXIV. 8? $2-39$ 
Sideritidis folio indica paluftris, cayle fiftulofo, flore pentapetalo fubviridi, femine minutiffind ex albo rufefcente Commel. int not. Pola-Tsjira Mal.

Sigi Bram: v. Acacia

Siliqua Sylveftris rotundifolia indica B: Pin: 402. v. Arbor S. Thom \&c.

Siliqua Sylveftris spinofa arbor indica B: Pin: 402 . v, Coral ar. bor

Siliqua arabica, que Tamarindus B: Pin: 403. v. Tamarindus

Siliquofa indica, flore tetrapetalo, filiquis teretibus pulpa abfque Seminibus repletis $R a j i H:$ I 765 . Alpam Mal. Apana, 'E Pahiora Bram: Fruita Tirilha Lufat. Ma. nerik Belg:

Siliquofa indica flore papilionaceo Luteo, filiquis Lenibus tetra fpermis fere Raji H. I752. Moullava Mal: Moella Bram: Dwaaldoorn Belg. an Acaciæ cognata planta F: B: T: 1. L: XII. 433 ?

Siliquofa indica flore papilionaceo, filiquis planis, brevibus duo aut tria femina iftmis diftincta concinentibus Raji H. I 734 . NoeI. Valli, छึ Pannivalli Mal.Solori Bram: Folhas do porco Lafit. Hoefblad Belg: an Glycyrrhiza vel (fi mavis) Glycyrrhizæ affinis arborefcens americana, floribus ex Luteo \& rubro variegatis, folio acuminato, filiqua la. tiflima Breyn: P: 2. 53 ? Corallinum Lignum Par: Bat: $P: 328$ ? Pliken: P: 3. T: CLXIX. 1?

Siliquola indica flore papilionaceo. filiquis latis monofpermis Raji $\mathrm{H}$ : 1745. v. Crifta pavonis

Siliquofa malabarica pentapetala filiquis tomêntofis Raji $H: 1750$. Perin-Courigil Mal: Tali Bram: Circa-Davetha Lasfit: Hondepinten Belg:

Siliquofa malabarica filiquis fpitba meis, anguftiffimis, contortis Raji H. 1735. v: Colutea Siliquofamalabarica, flore pentapetalo, filiquis Longis, planis, diaploragmatis fermina fecludentibus interceptis Raji H: 1746 : v: Chamxcriftx pavonis affinis \&c:
Siliquofa flore umbellato pentapetalo, filiquis digitalibus, fpadiceis, monofpermis ad unum florem pluribus Raji $H: 1753 . \mathrm{Na}$ gam Cal. Coupajada-Gonconi Bram: Fruita gundra Lufit: Schuyteboonen Belg:

Siliquofa flore pentapetalo, fliquis $6-37$

I- 57 longis, anguftis, quadratis, in. tortis Raji H. I 7 o. v. Clematis

Silona Bram: v' Arundo

Silvada-Pajamacho Lufit: v Crif $7-99$

Sinapiftrum indicum diphyllum, fi. liquis ad alas ex uno pediculo binis Pluken.P. 2. T: CXIX. 7. Cupa-Veela Mal. Rani-Quela Bram:

8-5I Sincken Belg: $v$ Arbor 9-6s

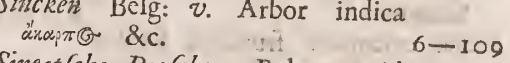

Sineetfche Roofeboom Belg: v. Alcea

Singari Bram: Planta bifolia $0-69$ G-I. Singi Bram: v. Clematis ... $\quad 9-16 \mathbf{r}$

Sinza Bram: v. Tamarindus $\quad 1--39$

$\begin{array}{ll}\text { Sinfarati Bram: } v \text {. Solanum } & 2-67\end{array}$

Siorallo Bram:

Sjovanna-Pola-Taly Mal, v. Lilio- $7-15$ Narciffus

Siri-Candalo Bram: $v$. Candel $\quad$ I -77

Siri-Pada Bram: 6-65

Sifori Bram: v. Lyfinachia. $\quad 10-159$

Slackbout Beig: $v$. Coral arbor $6-13$

Slangewortel Belg: $v$. Arbor indica

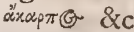

$6-39$

SlangerwortelBelg: $v$. Baccifera indi $5-10$ I ca \&c.

Slag Blom Belg.

$5-65$

$6-33$

Slitten Belg: $v$. Balfamina cucume $7-79$

Symappels Belg: v. Cucurbitifera trifolia \&ic.

Sinaltkruyd Belg: v. Phafeolo affinis \&c.

Smeerappel Belg: $v$. Baccifera fpinofa indica \&c.

Smilacis afperx fpecies Commel. in 12ot. Cari - Villandi Mal. Carapu. Bram: Raiz da boba Lrefit. Pock. hout Belg: an Salfa parilla officinarum Dale Pbarm: 264 ? 


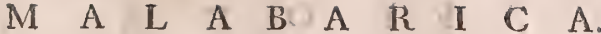

Quauhmecapaltli, feu zarza quarta Hernand: 290?

Smilthout Belg:

Smindelblad Bels.

\section{Sncep-Druyven Belg:}

$7-21$

Soladi-Tirtava Mal. $10-173$

Solanum arboreum indicum maximum, foliis Oenoplix , five $\mathrm{Na}$ pecx majoribus, fructu rotundo, duro, rubro, femine orbiculari compreffo maximis, nuces vomicas \& Lignum colubrinum officinarum ferens Breyn: $P: 2$. 92 . Malus malabarica folio \& fructu amaricante, femine compreffo, plano Syen in not: Nux vomica in officinis B: Pin: $5 \mathrm{I} \mathrm{r}$. Vomica major \& officinarum Par. Bat. P: 357 . Vomica vulgo officinarum, compreffa Hirfuta $7: B: T: x, L$. III. 339. Ligni Colubrini tertium genus in malabar vaftx arboris magnitudine B: Pin: 3or. Caniram Mal. Caro Bram.

Solanum arborefcens indicum, foliis Napecx majoribus magis mucronatis, fructu rotundo, duro, Spadiceo, nigrefcente, femine orbiculari compreffo maximis Breyn. P: 2.93. Nux vomica officinarum Vera, \& ipfifimum Lignum colubrinutu Commel. in not: Orbicularis fructus peregrinus primus Chis: exor. 29. Fructus orbicularis peregrinus, granis nucis vomicæ fimilibus $7: B: T: 1$. L: III. 342. Modira-Caniram CMal. Pao de Solor, vel Pao da cobra Lufit: Kraanoogh Belg:

Solanum arborefcens indicum, foliis Napecæ minoribus, fructu rotundo duro, \& femine orbiculari compreffo minoribus Breyn: P: 2.93. Nux vomica minor moluccana, Lignum colubrinum officinarum Par: Bat: P: 357 . Lignum colubrinum officinarum Dale Pharm: 48 s. Scheru-Katu-V alli-Caniram Chal. Davo - Caro Bram: Wild Climmend Kraanoogh Belg: an Clematis indica perficæ foliis, fructu periclymeni $B: P_{i n:} 301$. Solanum indicum pomiferum fpino- fum borraginis flore, fructu crocco Herm: Cat: 573 . Solanum fpinofum fructu rotundo. B: $P$ in: 167 . Pomum de Hiericho melongenis congener $\mathcal{F}: B: \mathcal{T}: 3 . L: X X X I V$. 619 Solanum f́pinofum malabarienfe tertium Commel. in not. Cbunda Mal. Dolari Bram: Idem candicans maxime tomentofum Herm: Cat: 573 . Solanum fpinofum maxime tomentofum Boccon: $I c$ : 65 D: 8 . Solanum fpinofum indicum borraginis flore Cat: H: Reg: Par: 142. Juripeba fanina Pifon: 18 I. Yllamatlantli Hernand: 443. Ana-Chunda Mal. Sada-Vaingani Bram:

Solanum indicum fpinofum fructu minimo, miniato, glabro $R a j i$ $H: 1876$. Solanum fruticofum indicum fructu rubro Turnef: $E l$ : Bot: 12 5. Juripeba mas Pifon: I 8 1: Cheru-Chunda Mal. Sinfarati Bram:

$2-69$

Solanum pomiferum fructu oblongo $B$ : Pin: 167. Solanum pomiferum fructu rotundo $7: B: T: 3 . L$ : $X X X I V .619$. Solanum indicum Forkii Fockii dictum Bont: 123. Mala infana Dod. 751 . Melongena $B$. Watth. 760 , Nila-Barudena Mal. Vaenna Bram: an Solanum pomiferum magno fructu ex albo \& atro purpurco nitente, foliis \& calyce fpinofis Pluken. P. 3. T. CCXXVI.3? I0-I 47 Solanum officinarum Dale $P$ harm: 270.Oficin: acinis puniceis $V$ ariorum. Hortenfe 7. B. T. 3. L. $X X X I V .61$ 3. Nelen-Tsjunda Mal.

Solanum fcandens malabaricum betæ folio Commel. Cat. 330 . Solanum peregrinum betæ folio Raji $H$ : I 876. Solano, an potius mirabili peruvianæ affinis tinctoria betæ folio, Cochin chinenfis flofculis puniceis mufcofis fpicatis, fructu intus cochleato Pluken. P. 1.T. LXIII. I. Blitum bacciferum zeylanicum, Solanum tinctorium Hermanni C. H. Beaum. $M$. S. Beta baccifera aizoides rotundifolia zeylanica Breyn. P. 2. 23. Bafella Mal. Wali Bram. BredoTali Lufit. Beetklim Belg: 


\section{F L O}

Solanum fomniferum verticillatum B. Pin. 166. Verticillatum F.B. T. 3. L. XXXIV. 6 10. Somniferum Chus: H: L: $v$. 8s. Alkekengi mexicanum Colum. in not. ad Hernand. 296. Alkekengi fructu parvo verticillato Turnef. El. Bot. I 26. Baccifera indica floribus ad foliorum exortus, fructu fulcato, decapyreno Raji H. 1632 . Pevetti Mal. Doudalaqui Brans: Satilhas Lufit. Mooren-kappen Belg.

Solanum veficarium indicum minimum Herm. Cat. 569 . Halicacabum feu Alkekengi Arabibus dictum Bont. I 49 . Inota-Inodien, fent Moe ioe Mal.Zera-Puti Bram. 10-I 39

Solanum veficarium americanum, caule quadrangulo, foliis ftramonix Herm: Cat. 569 . Tomatl, feu Planta acinofa Hernand: 295. Camaru, fell Solanum veficarium Pifon. I 49. Pee - Inota - Inodien Mal. Zera-Puti Bram:

Solano affinis malabarica, flore $\&$ baccis rubefcentibus Commel. in not. Tsjeria-Narinam-Puli CMal. Ambetti Bram:

Solanum mexiocanum, flore Luteo, ex albido, purpureo B: Pin: 168. v. Mirabilis peruviana

Solanum pomo spinofo rotundo, longo fore B. Pin: $\times 68$. v. Stramonia

Solanifolio malabarica, flore monopetalo, flavo diluto colore, fru\&tu quadrangulato Commel. in not. Caca-Mullu Mal. Caca - Taly Bram:

$10-143$

Solda Mal: $v$. Capparis arborefcens 6-103 Solori Bram: v. Siliquofa indica \&c.

Sonclus Levis mader aspatanus Pluk. P: 3. T: CCXXVII. 3. v. Planta indica \&c.

Sondari Mal: $v$. Frutex indicus baccifer \&c.

$5-79$

Soneri-Ila Mal: v. Pulmonaria 9-127

Sonou Bram: v. Aloes affinis \&rc. 12-17

Soort Jacken Belg: $v$. Jaca

Sophar a india urientalis Breyn: P: I. 51 . v. Senna

$3-17$

Sorbus fpuria malabarica Katu-Kalefiam dicta Raji H. 1643. Sorbus malabarica Commel. in not. Katou-Kalefiam Mal. Moemoe
R A

Bram: Arvore da Folha parida macho Lufit.

Sorbi Jpecies Bont: 103. $v$. Baccifera indica \&c.

Soteet fou Japonens: $v$. Palma

Sottebollen Belg. v. Frutex baccifer \&c.

Sotulari Bram: v. Alcea

Soubeniffa Bram: $v$. Baccifera indica \&c.

Soumalla Bram:

Souna-Sjiba Bram: $v$. Phyllitidi affinis \&c. $12-2 I$ Sovanna-Poufpa Bram: $v$. Orchis $12-7$

Sparlingh Belg.

Speenbefen Belg. $v$ 7-103 ra \&c.

Spergula indica major flore candido 5 Commel: in not. Parpadagam cMal.

Spinhos dos Morcilbos, vel splbinbodos manros Lufit: v. Acacia Spinnekoppen Belg: $v$. Colutea $10-69$ $5-95$
$4-45$
$s-45$
$2-4 x$
$2-21$
$12-7$ $5-95$
$4-45$
$s-45$
$2-4 x$
$2-21$
$12-7$ $5-95$
$4-45$
$s-45$
$2-4 x$
$2-21$
$12-7$ $5-95$
$4-45$
$5-45$
$2-4 x$
$2-21$
$12-7$ $2-23$ $3-9$ $-103$ $s-s$ $6 \rightarrow 7$ $6-49$

Sterrebollen Belg: $v$. Jambos

Stoelwortel Belg: $v$. Bryonix Levis fpecies \&c.

Stramboom Belg: $v$. Baccifera indica \&c.

Stramonia feu Datura pomo fpinofo $3-43$ $7-93$ 5-53 rotundo, longo flore Herm: Cat: 583. Stramonia multis dicta, five Pomum fpinofum $7: B: T: 3 . L$ : $X X X I V .624$. Stramonium fructu fpinofo rotundo, femine nigricante Turnef: El: Bot: 98. Dature malabaricx Hummatu dictx prima fpecies Raji $H$ : 749. Solanum Pomo fpinofo rotundo, longo flore $B$ : Pin: 168. Tlapatl Hernand: 278. Humatu Mal. Dotiro Bram.

$2-47$

Stramonia farida malabarica, femine paliido, pomo glabro, flore fimplici violaceo Herm: Cat. 584. Daturx malabaricæ fecunda fpecies Rajz H. 749. Nila-Humatu Mal. Calo-Dotiro Bram. $2-49$

Eadem flore duplici, triplicive Herm: Cat: 584 . Darurx malaba. rice tertia fpecies Raji $H .749$. Mudela-Nila-Humatu Mal. Vallo-Dotiro Bram.

Stramonia five Datura Cyfioides 
frutefceits Hirfuta major indi ca Breyn: P: 2. 97. v. Baccifera indica \&ic.

Stravadi Bram: $v$. Frutex indicus \&c.

Stromdoorn Belg: v. Baccifera indidica \&c,

Sucndadi - Pullu Mal. v. Melilotus

Suercroop Belg: v. Bilimbi altera

Surighaghas Zeylon: v. Alcea

Supuli Bram.

Swalm-e Appel Belg: v. Colocynthis

Swart Slangerwortel Belg: $v$. Baccifera indica \&c.

Swart Strumboom Belg: v. Baccifera indica

Sweïn Befen Belg: $v$. Baccifera indica \&c.

Swïnen Famboesen Belg: v. Jambos

Syringa malabarica lactefcens, flore niveo pleno odoratifimo Com mel: in not: Nandi-Ervatam Mal. Vallo-Nanditu Bram: Fula de $S$. Antonio $L u j f t$.

Syring a arabica fore pleno folizs ternis Par: Bat: P: 379. v. Jafminum Syringa arabica foliis mali aurant ii B: Pin: 398. v. Jafminum

Syalita Mal: $v$. Arbor indica \&c.

Tabal Lufit: $v$. Capparis

Tabaxir Variorum. v. Arundo

Tabeniffa Bram:

Tacarotha Bram: $v$. Prunifera indica \&c.

Tagadi Mal:

Tagera Mal: $v$. Senna puria \&c. $\begin{gathered}12-9 I \\ 2-103\end{gathered}$

Tagera Bram: v. Chamæcrifta pavonis

Tagera dimato Lufit:

Takafi-Valli Bram: $v$. Convolvulus I $1-107$

Takkada Ceylon: v. Prunifera indi-

ca \&rc. Palma

4-12I

Talana Bram: $v$ 3-

$\begin{array}{ll}\text { Talaffi Bram: } & 10-16 \text {, } \\ \text { Tala-Neli Mal: v. Convolvulus } & 1 \mathrm{I}-113\end{array}$

Talatamado Bram: $v$. Convolvulus $I-1 \mathrm{I}$

6-89

$6-87$

3-39

$1-25$

$5-4 s$
Tali Bram: $v$. Siliquofa malabarica Tali-Daukennapa Bram:

Tali-Pullu Mal: v. Phalangium

Tali-Pariti Mal: $v$. Alcea

Taliir-Kara Mal: Talir-Gali Bram: v. Arbor indica \&c.

Talona Lufit: $v$. Frutex indicus

Tahu-Dana Mal: $v$. Valerianella

Tamagali Bram: v. Malus

Tamalapatrum five Folium B: Pin: 4.09. v. Caffia

Tamara Mal: $v$. Nymphæx affinis \&c.

Tamara do Mato Lufit: v. Palma

Tamara-Tonga Mal: $v$. Malus

Tamarindus Herm: Cat $: 588$. \&ூ Variorum. Siliqua arabica, qux $T_{a}$ 。 marindus $B: F$ in: 403. Balam. Pulli, Jeu Maderam-Pulli Mal. Sinza Bram:

Tambido Bram:

Tambido Bajo Bram: v. Arbor indica 9-89

Tambido Citroco Bram:

Tambido-Mandaru $\mathrm{R}$ ram: v. Arbor Sancti Thomæ \&c.

Tambir i-Siufori-Touda Bram: 1-57

Tamme Crim-booncn Bcls: $\quad 12-147$

Tamme Lerick Belg: v. Frutex baccifer \&c.

cifer \&c.
Tamme Runboom Belg: v. Candẹla arbor \&c.

Tana Mal:

Tana Bram: $v$ Gramen Srlhan

Tana Bram:

Tanapocala $B$ ram:

Tana-Povel-Paatsja - Maravara Mal: v. Selago

Tandale-Cotti Mal: v. Genifta

$\times 2-95$

Tanis-Mory Bram: $v$. Myxa

Tamnini Bram: v. Frutex indicus \&c.

Tantarega Bram: 7 . Phafeolus

Tapadeira da Fula triffe do dio Lufit: v'Balfamina cucumerina $8-35$

Tapia Braflicen frum fimilis Commel: in not: $v$. Pomifera indica \&rc.

Tapucodo Bram: v. Althra

Tara-Candelo Bram:

Tardavel Mal:

Tarilla Lufit: $v$. Jujuba

Tarilla d'agoa Lufit: $v$. Baccifera indica \&c.

Tafnooten Belg: $v$. Malus

Tataiiba Pifon: 163 . v. Jaca 


\section{Tava-Timi Bram: v. Cucumis}

Teboax is foliis acacia fmilibus Hernand: 409. $v$. Acacia

Teka Lufit: \& Belg: v. Prunifera Veficaria \&c.

Teka-Crippa Lufit: $v$. Baccifera indica \&c.

Tembiri Bram: $v$. Pomifera indica \&x.

Tenga Mal.v. Palma

Touduli Bram: v. Balfamina Cucumerina

Tema Mal.

Teregam, Jeu Teregam-Maram Mal. v. Ficus

Tereta-Pullu Mal.

Terva Faponica Jeu Catechu officinarum Dale Pharm: 386. v. Palma

\section{Thali Bram:}

Thalia Maravara Mal.

Thalictro affinis indica, Alnifolio

Semine ftriato afpero Breyn: P: 2. 99. $v$. Valerianella

Theka Mal: v. Prunifera veficaria \&ic.

Theba Brava Lufit: v. Prunifera indica \&c.

Theka Macho Lufit: v. Baccifera racemofa \&c.

Theka Maravara Mal.

Therebinthns americana trifolia Lucida Par: Bat: P. 380 . v. Pomifera indica \&c.

Tholo Bram.

Tholafil Bram:

Thomea arbor filiquofa malabarica, foliis lifidis minor, flore candido Par: Bat: P: $380 . v$. Siliquofa malabarica \&c.

Thora-Paerou Mal: Thori Bram: $v$. Phafcolus

\section{Tjageri-Nuren Mal.}

Ticanto Bram: v. Crifta pavonis

Tilo Bram:

Tilo-Carandi Bram:

Tilo-Caro Bran:

Tilo-Onapu Mal: v. Perficaria Siliquofa
8-II, Tilo-Sameno Bram: v. Baccifera indica \&c.

Tiloni Bram:

Tiloins Lufit: $v$. Frutex indicus baccifer \&c.

Timpem Belg: $v$. Cor-indum

Tinda-P arva Mal: $v$. Arbor malabarica \&c.

$4-6 \mathrm{I}$

Tindalica Lufit: $v$. Balfamina cucumerina

3-45 Tindali-Comprido Lufit: $v$. Balfami-

$1-1$

$8-27$ $12-151$

$3-79$ $12-8 \mathrm{r}$

$I-9$

$\{7-47$

$\{12-9$

$12-9$

$7-105$

$4-57$

$4-59$

4-63

$12-43$

$3-49$

$12-39$

$12-49$ na cucunerina

Tindali-Spinofa Lufit: $v$, Balfamina cucumerina

Tipali Bram: $v$. Malus Limonia

Tippoli Bram: v. Lotus .

Tiqui Bram: v. Caffia malabarica

Tiri-Itti-Canni Mol.

Tiri-Panna Mal.

Tiringoefi Bram: v. Crifta pavonis

Tirtava Mal: $v$. Scrophularia

Tiru-Calli Mal: $v$. Tithymalus

Tiru-Tali Mal: $v$. Convolvulus, I $1-109$

Titi छ Eborno Bram:

Tithymalus arborcfcens Commel: in

$6-45$ not: Baccifera indica floribus fpicaris, fructu umbilicato tricocco, lacte acerrimo manante Raji $H$ : I 496. Cammetti Mal. Ouro Bram. Guard Olhos Lufit. Tygers Melkblom Belg:

Tithymalus malabaricus androf mi folio, flore rubro Commel in. not. Nir-Cottam-Pala Mal.

Tithymalus ramofiffimus frutefcens pene aphyllos Par: Bat: $P: 38$ r. Tithymalus indicus frutefeens Raji H: 17 I0. Tiru-Calli Mal.

Portigalli.Nivuli Bram. $2-85$
Tithymali fpecies Commel, in not:

10-10r

$5-67$

$9-69$

$1-107$

$2-35$

$0-167$

$2-85$

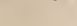

Titbymalus ceylanicus spinofus arbo.

$10-115$ refcens Par: Bar: P. $381 . v$. Euphorbio \& Tithymalo media affinis \&c.

Titbymahis indicus spinofius \&ु an$2--S_{3}$

$I-61$ $6-23$ $7-63$ $6-33$ $9\left\{\begin{array}{r}91 \\ 93 \\ 101\end{array}\right.$ $7-67$ $7-3$ gulofus ladie turgens acri Cat: $\mathrm{H}$ : Beaum: 4I.v. Euphorbium

$$
2-8 I
$$

Tlatlancuaye Hernand: I $26 . v$. $\mathrm{Pi}$ per

Todda-Panna Mal: v. Palma $3-9$ Todda-Vaddi Mal: v. Herba viva $\quad 9-33$ Tolaffi Bram: $\quad$ I $2-47$ TomatlHernand: $295 . v$. Solanum 10-I 4 I Tondi- 
Tondi-Teregam Mal: Tondi-Karcvatti Bram: V. Arbor flore tetrapetalo \&c.

Tooverbloemen Belg:v. Arbor indica \&c.

Torique $L u f(s t:$

Tota-Piri Mal: v. Balfamina cucumerina

$4-123$ $5-117$ $7-61$ $8-33$

Traken Belg. v. Cucumis Trapadeira de Ceo Lufit.

Trapadeira da Cobra Lufit.

Trafwortel Belg. v. Valerianella 7-ro5

Tsjadaen Mal. v. Cardiaca

Tsjada-Bangi Bram.v. Cannabi $\int_{1-}$ milis \&c.

10- 21

Tsjaka-Maram Mal.v.Jaca

Tsjakela Mal:v. Ficus

Tsjalo Bram: v. Cardiaca

Tsjama-Pullu Mal.

Tsjana-Kua Mal:v. Coftus

Tsjanga-Pufpam Mal: \& Bram: v. Gentianell fpecies \&c.

Isjangelam-Parenda Mal: v. Sedi fpecies \&c.

Tsja-Pangain Mal: v. Crifta pavonis

Tsjela Mal: v. Ficus

Tsjeli Mal.

Tsjem-Cumulu Mal.

Tsjem-Tani Mal:v. Myxon

T'sjeni Mulla Mal:v. Jafminum

Tsjeram-Cottam Mal: v. Frutex indicus baccifer \&cc.

Tsjere Maram Mal: v. Pcriclymenum

Tsjeria-Belutta-Adeca-Manjen Mal. v. Amarantho affinis \&c.

Tsjeria-Cametti-Valli Mal.

Tsjeria-Kuren-Pullu Mal.

Tsjeria-Manga-Nari Mal.

Tsyeria-Manga-Nari Mal.v. Alfine Ipuria

Tsjeria-Narinam-Pullu Mal: 9-165 - lani affinis \&c.

Tsjeria-Nirouri Mal.

Tsjeria-Onapu Mal.

Tsjeria-Pu-Pal-Valli Mal.

Tsjeria-Samftravadi Mal.v. Jambos

Tsjerou-Caniram, vel Tsjerou-Cansjeram Mal.

I $2\left\{\begin{array}{l}75 \\ 83\end{array}\right.$

II-IS

$6-1 \times 3$

I0-77 $8-81$ I $2-117$

$10-177$

9) -167

$5-87$

$9-93$

$7-\mathrm{IO}_{3}$
Tsjerou-Cit - Ambel Mal. v. Nymphra 11-57

Tsjerou-Kadali Mal: v. Baccifera indica \&c.

Tsjerou-Kandel Mal: $v$ Candela $4-93$

Tsjerou-Kanneli $\mathrm{Mal}$. $\quad$ 5-99

Tsjerou-Kara Mal: v. Baccifera indica \&c.

Tsjerou - Katou - Naregam Mal: v. Malus Limonia

$4-3 x$

Tsjou-Mau-Maravara Mal. $\quad{ }_{2}-1$ I

7-37 T'sjerou-Meer-Alou Mal: v. Ficus 3-7x

Isjerou-Panel Mal: v, Frutex indicus baccifer \&c.

Tsjerou-Poeam Mal: v. Baccifera malabarica \&c.

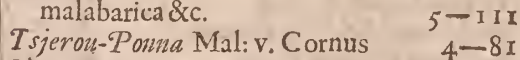

T'sjerou-Ponnagand Mal

Tsjerou-Ponnagan Mal: v. Baccifera indica \&c.

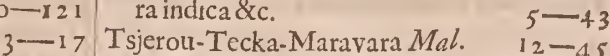

3-87 Tsjeron-Theca Mal: v. Baccifera $10-175$ indica \&c.

Tsjerou-Valli-Panna Mal.

Tsjeru-Cansjava Mal: v. Cannabi

$5-31$

fimilis \&c.

9-11 T Tsjeru-Fongenam-Pulh Mal:v.Ru-

bia fimilis \&c.

7-77 T sjeru-Katu-Valli-Ganiram Mal.v. Solanum

$6-3$ Tsjeru.Kirganeli Mal, v. Vitis idxx

$3-85$ affinis \&c.

I 2-I35 Tsjeru-Kotsjiletti-Pullu Mal. 10-3 I

I I 97 Tsjeru-Manncli Mal.

$4-2$; Isjeru-Parua Mal. v. Gratiolæ af-

$6-85$ finis \&c.

Tsjeru-Tahi-Dama Mal. v. Veroni-

5-21 ca fimilis \&c.

Tsjeru-Tardavel $\mathrm{Mal}$.

$10-49$

Tsjeru-Tsjurel $\mathrm{Mal}$.

$10-187$

Tsjeru-Vallel CMal.

Tsjeru-Vela Mal.

Tsjeru-Uren Mal. v. Sideritidis folio \&x.

Tsjetti-Mandaru Mal. v. Criftapavonis

Tsjetti-P $u$ Mal. v. Matricaria

TSjetti-Pullu Mal.

Tsjettia Bram. v. Crifta pavonis

Tsjina-P anofou Bram. v. Anona

Tsjina-Pelouka Mal.v. Guajava

$12-12 \mathrm{I}$

$10-55$

$9-63$

$9-143$

$3-33$

Tsjiregam-Mulla Mal.v. Jafminum 6-97

Tsjocatti Mal. v. Frutex baccifer

$4-$ Is \&c.

Tsjolap-Pullu Mal.

T's jori-V alli Mal. v. Clematis 
Tsjotti Mal: v. Frutex baccifer \&c.

Tsjovanna-Amelpodi Mal: v. Frutex indicus \&c.

Tsjovanna-Areli Mal: v. Nerium

Tsjovanna-Manneli Mal: $v$. Minofx fpecies \&c.

Tsjudan-Tsjeral Mal:

Tsyude-Mar am Mal: $v$. Periclymenum

Tsjuria-Cranti Mal: E Bram: $v$. Convolvulus

Tumba Mal: $v$. Nepeta

Tumba-Codiveli Mal:

Tupbat indi Arab: $v$. Prunus

Tupucadi Bram: v. Ciftus

Tupu-Kadu Bram: v. Alcea

Tweebeffen Belg: v. Arbor baccifera \&c.

Tygers Melkblom Belg: v. Tithymalus

Udidi Bram.

Vdiram-Fanum Bram: v. Planta indica \& $\mathrm{c}$.

Vallia-Manga-Nari Mal: v. Chry-

6-8 I fanthemum 10-79

9-1 Vallia-Pira-Pitica Mal. v. Vitis 7-13

Vallia-Tsjori-Valli CMal.

$7-15$

9-71 Vallo-Dotiro Bram: v. Stramonia 2-s

I2-71 Vallo-Nanditu Bram: $v$. Syringa 2-105

6-II Vana-Papalou Bram: v. Prunifera indica \& \&c.

Vanuala-Valli Bram:

Varai Bram:

$7-37$

I2-I5:

$4-59$

7-103

Io-1 I I Vafabu \& V a fumbo Zeylon: $v$. Aco-

ro-15 rus $\mathrm{C}$ (1)

1-27 a aveli Bram: Canarin. C. a Coft.

10-3

Vafimi Bram: v. Conyza

$V$ afinola Bram: $v$. Arundo

$V a-V$ alli Bram: $v$. Prunus

5-119

$1-33$

indica \&c.

$10-135$

Veetla-Caitu $\mathrm{Mal}$ :

Vada-Kodi Mal: v.Perficaria

Vadhout Bram: v. Ficus

Vaenva Bram: v. Solanum

Valermani Bram: $v$. Frutex baccifer \&c.

Valerianella curaffavica femine afpero Vifcofo $\mathcal{P}$ ar: Bat: $\mathcal{P}: 382$ : Thalictro affinis indica, alni folio, Semine Striato afpero Breyn: P: 2. 99. Talu-Dama Mal. Punarnava Bram: Folhas do Pitao Luffit: Trafiwortel Belg.

Velutta-Itti-Cinni CMal. $\quad$ IO -7

Velutta CMandaru Mal. v. Arbor Siliquofa malabarica \&c.

Velutta-Modela-Muccu Mal. 12-145

Verbena indica Bont. I 50 . Cadelari Mal. Cante-Mogaro Bram. $\quad 10-155$

Vercoepoelongi Mal. v. Saponaria ar-

Valli-Caniram Mal.

Valli-Carati Mal.v.Balfamina cucumerina

Valli-Cari-Capoefs Bram: v. Alcea

Valli-Itti-Konni Mal. cies \& $\mathrm{rc}$.

Valli-Modegam Mal.

Valli-Onapu $\mathrm{Mal}$

Valli-Panna Mal.

$1-51$

ro-s

$7-35$

$7-89$

$9-91$

$12-63$

Valli. Sanvari Bram: v. Goffipium 3-6I

Valli-Schorigenam $M a l$.

Valli-Teregam Mal: $v$. Convolvulus

Valli-Vpu-Dali Mal: v. Digitalis
$2-79$

$12-59$ bor

Veronica indica aquatica maxima odorata, teucrii foliis, flore purpurafcente Commel. in not.MangaNari Mal.

Veronica indica teucrii folioCommel. in not. Nanfchera-CanfchabuMal. Schanga-Cufpi Bram.

Veronica finilis malabarica, flore purpureo Commel. in not. TsjeruTalu-Dama Mal.

1.0-49

$4-43$

$0-11$$$
\text { ic }-99
$$

fimilis indica albicante flore Commel. in not. Caicotten. Pala Mal.Dodini Bram. 10-65

Veronic $\mathfrak{X}$ fimilis fpicata indica repens Commel. in not. Scheru-Cadelari Mal. Dacalo-Cante-Mo. garo Bram:

$V$ etadagou Mal. v. Baccifera indica 157 \&c.

9-85 Vete Bram. 


\section{$\begin{array}{llllllllll}M & A & L & A & B & A & R & I & C & A\end{array}$}

Vetti-Tali Mal. v. Arbor indica \&c.

Vidimaram Mal: v. Sebeften

Vilengi Bram. v. Baccifera indica \&c.

Violæ folio malabarica baccifera Commel. in not. Karinta - Kali Mal.

Vifa-MogariBram.v. Jafminum

Vitex maxima indica fructu carnofo , floribus majoribus \& denfioribus Breyn: $\mathcal{P}: 2.105$. Arbor baccifera malabarica, folio pinnato, floribus umbellaris, fimplici officulo cum pluribus nucleis Raji H. 1558. Katou-Mail-Elou Mal. Davi-Rinti Bram: Carilha deSerra Lufit. Wilde Loopbeffen Belg:

Vitex trifolia major indica, fructu carnofo, floribus minoribus \& rarioribus Breyn: $\mathcal{P}: 2.104 . \mathrm{Ar}-$ bor baccifera trifolia malabarica fimplici officulo cumpluribus nucleis Raji $H$. x 557 . Mail.Elu Mal. Davi-Rinti Bram: Carilha Lufit: Loopbeffen Balg:

Vitex trifolia minor indica Breyn: $\mathcal{P}:$ 2. 104. Frutex indicus baccifer, fructu calyculato monopyreno, Negundo dicta Raji $H$ : I 575. Negundo Arbor fæmina 7 : B. T. 2.L.XV. 189. G. ab Horto 26. C. $\hat{a}$ Coft. 280 . Piperi fimilis fructus ftriatus fæmina $B . \mathcal{P}$ in. 412. Cara-Nofi CMal. Negundo Bram.

$2-13$

Vitis trifolia minor indica Serrata Breyn: P: 2. 104. Negundo mas Variorum. Piperi fimilis fructus Striatus mas $B: P$ in. $4 \mathrm{I} 2$. BemNofi $\mathrm{Mal}$.

Vitex idæx affinis flore hexapetalo exalbicante Commel. in not. Kirganeli Mal. Bufan-Anvali Bram. an Fruticulus capfularis hexapetalos, foliis brevioribus, fubrotundis, \& denfius ftipatis Pluken. P. 3. T. CLXXXIII. 4 ?

$V$ itis idxæ affinis flore hexapetalo rubefcente Commel: in not: TsjeruKirganeli Mal. an Fruticulus capfularis hexapetalos, brevioribus foliis \& anguftis Pluken: $P: 3 . \mathcal{T}$. CLXXXIII. s?

Vitis idææ fpecies Commel: in not: Kal - Vetadagou Mal. Adolia \& aromatico Pluken: P: I. T. LXIX 5. v. Ariftolochia

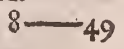

Upara-Sali Bram:

Upata Mal: v. Anacardium

Upu-Dali Mal.

$$
\begin{array}{r}
10-67 \\
4-95 \\
9-125
\end{array}
$$

Ura-Valli Bram:

Uren Mal: v. Alced.

$8-89$

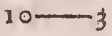

$I=7 I$

Uro Bram: v. Manga

Urtica brafilienfis $P$ ino indigenis dicta Raji H: 1 59. Pino Margg. 8. Batti-Schorigenam Mal. an Lupulo vulgari fimilis indix orientalis floribus in fpicam ex origine foliorum prodeuntem difpofitis Pluken: P: 3. T. CCI. 5 ? 2

Urtica frutefcens malabarica Scho. rigenam dicta $R a j i H$. 160 . Schorigenam CMal. Pitta-Gafurculi Bram:

Urtica malabarica tertia And-Scho-rigenam dicta Raji H. r6o. AnaSchorigenam Mal: Hafty-Gafüri culi Bram:

Urtica folio indica, flore tetrapetalo ramofo, capfula triquetri Commel: in not: Pee-Cuparneni $\mathrm{Mal}$. 
Irtice' folio, flore albicante spicato, cui palfim theca bicornea infidet, foliis in funmitate caulem ambientibus Commel: in not: $\mathrm{v}$. Mercurialis

\section{Vtago-Culo Bram: v. Apocynum}

Vvas d'aljofare Lufit: $\mathrm{v}$. Clema- tis

Uvas d'aljofare macho Lufit.

Uvas d'emfermos Lufit.

Uvas d'inferno Lufit: v. Prunifera malabarica \&c.

Vvas d'elephanti Lufit: v. Vitis Sylveftris fpecies \&rc.

Vvas de Boy Lufit: v. Hedera

Uvas de Tove Luffit:

Vvas dos bugios Lufit:v. Vitis Sylveftris fpecies \&c.

Uvifera arbor orientalis folio oblongo $P$ ar: Bat: $P$ : 385 . Champacam Mal. Champo Bram: an Flos indicus Champacca dictus Bont. I 40? Champe Flores indici B. Pin: 470 ? F: B: T: I. L: $I$. 107? Champa flus Boncii Raji H. 1811 .

Vvifera arbor americand convolvu. hacea, fructu punctato, Barbadenfibus Checquer-Grape, i.e. Vva teffulata, nuncup atur Pluken:P: 3 . T: CCXXXVII. 4.v. Convolvulus

Vyfhoeken Belg: v. Malus Uylleboonen Belg; v. Phafeolus

Waakblad Belg: v. Baccifera indica \&c.

Waakbout Belg: v. Baccifera indica \&cc.

Wadapu Mal: y. Amarantho affinis $5-93$ \&c.

Wadouka Mal: v. Baccifera fpinofa \&c.

Waga Mal. v. Acacia $10+73$ Waga Mal. v. Acacia
Walgambul Cingalenfium. v. Prunus $1-29$ Wali Bram: v. Solanum

Walingburu Zeylonens. v, Zerumbet

Wallia-Pal-Vallu Mal: v. Apocy- num

Waraghala Zeylonens. v. Apocynum

Warapoli Mal.

Wara-Pullu Mal.
$7-17$

$7-19$

$7-21$

4- I9

$7-13$

$7-85$

$-15$

- 1

$I-3 I$
$3-51$

$8-83$

Weegbboom Belg: v. Crifta paronis $6-25$
Weli-Ila Mal: v. Arum $11-43$
Werlia-Codiveli Mal: v. Betæ folio \&c.

Wellia-Cupameni $M a l$.

Wellia-Ponnam-Tagera, vel ellia-Ponnavire, vel $W$ ellia-Tagera

Mal: $v$. Chamæcriftx pavonis affnis \&c.

$10-171$

$10-165$

$5-77$

Washout Belg: v. Coral arbor 6-13

Water Kuysboom Belg: v. Baccifera

Water Quaad Belg: v. Arbor indica

cocculos officinarum ferens $\quad 7-1$

Wunboom Belg: v. Candela 6-63 num

$9-25$

$5-\sigma_{3}$

$7-61$

Wellia-Tandale-Cotti Mal.v.Genifta 9-5I

Wellia-Theka-Maravara Mal. 12--47

Welli - Panna - Kelengu - Maravara $\mathrm{Mal}$.

Werlingen Belg: $\mathrm{v}$. Arbor baccifera \&c.

$12-25$

Wild Glidhour Belg: $\quad 4-45$

WVild Heylwortel Belg: v. Panel $5-35$

Wild Keyfers Vreugbt Belg: v. Pru-..

Wild Klimmend Craanoogb Belg: $V_{0}{ }^{4-55}$

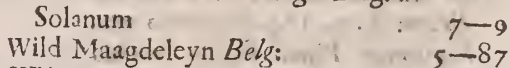

Wild Pimperlingh Belg. v. Hedera 7-85

Wilde Braakroojen Belg: v. Alcea 4-47

Wilde Caneel Bclg: v. Canella 5-105

Wilde Citroener Belg: v. Malus Li-

monia : $4-27$

Wilde Dadelboom Belg: v. Palma $3-15$

Wilde Diverghappelen Belg: $\quad 5 \div 99$

Wilde Goojares Belg: v. Guajava $3-35$

Wilde Jamboefon Belg: v. Jambos 4-11

Wilde fafmin Belg: v. Jafminum 16-93

Wilde Kraye beflen Belg: v. Baccifera indica \&c.

Wilde Limoenen Be $4-9$ monia

Wilde Loopbeffen Belg: v. Vitex $4-29$

Wilde Mamnekens nooteboom Belg:

v. Nux Myriftica 


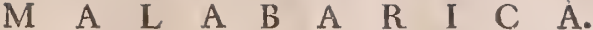

Wilde Olyven Belg: v. Olea

Wilde Peeperboom Belg: v. Baccifera indica \&c.

Wilde Rottingh Belg: v. Arundo

Wilde Runboom Belg: v. Candela indica \&c.

IVild. Theka Belg: v. Prunifera indica \&c.

Wilde Witte Slangewortel Belg:

Wind Wortel Belg:

Wit Theca Belg: v. Baccifera racemola \&c.

Witte Kraye beflen Belg: v. Baccifera indica \&c.

Witte Pcper Belg:

Witte Pepoenen Belg: v. Pepo

Woldoorn Belg: v. Goffipium

Wonddoorn Belg: $\nabla$. Acacia

Wortelboom Belg: v.. Ficus

Wortel Vaeren Belg: v.: Polypodium

Wortel Vygh Belg: v. Ficus.

Xalxochotl, feu Pomum arcnofium Primum \& Secundum Hernand:

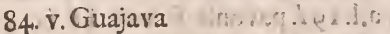
dis foliis alternis part

Zedoaria rotunda B:Pin. 36. RadiPluken: P: 3. T: CCXXXIX, 6. v. Malus Limonia

ce Lutea Breyn: P: 2. 105 . Colchicum zeylanicum flore Violæ, adore ephemero Par: Bat: P: 304, Malan-Kua Mal. Ben-T sjappo Bram:

Zelo Bram. v. Sedum

Zenca-Tsjada Bram.v. Portulace foliis \&c.

4-89 Zen-Camani Bram.

7-25 Zera-Puti Bram. v. Solanum Ve-

8- I ficarium

3-6! Zerumbet officinarum Dale Pharm.

6-7. - 366. Eे Variorum. Zingiber La-

$3 \rightarrow$ I tifolium Sylveftre Walinghuru Zeylonenfibus Herm. Cat. 636. Kua Mal: Acua Bram.

Zingiber Raji H. I. 314 . E Vario 'rim Zingiber famina $\mathcal{P}_{i j o n}$.Mant. A. 1.90. Mangatatia Pifon: 227 Chylli indiz orfentalis, feu Zingiber fæmina Hëriand. I 6 g. Infclii

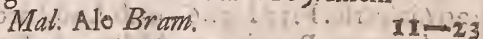

Zingiber Sylveftris Commel. in not. Zingiber mas (Pifon. Mant: $A$.

Xiubquilitl Pitzabac, Jeu Anir te muifolia Hernand: 10 8. v. Colutea

Xylon malabaricum Cudi-Pariti dictum Raji H: 1065 . Alcca malabarenfis pencaphylla, flore minore ex albo flavefcente, femine tomentofo Syen in not. CuduPariti CMal. Capuffi Bran: an Goffipium Herbaccum, S, Xylon maderafpatenfe, rubicundo flore, pentaphylleum Pluken: $\mathcal{P}: 3 . \mathcal{T}$ : CLXXXVIII. 3?

Yferhout Belg.

Zalico Bram: v. Prunus.

Lantboxy'hum americanum, feu berciles arbor aculeatamajor juglan-
11 - 17 $11-\sigma_{3}$

9-I 3 I

2-133

$\int_{0} 139$ $\{+4.1$
189 . Anchoa Hernand $160 . \mathrm{Ka}$ tou-Infchi-Kua Mal. Kolinyane "' 8 ild Bram.

Zingiber Montanus. Mala-InfchiKua Mal. Giri-Kolinyane Bram. I I -29 Zingiber Latifolium Sylveftre Walinghuru Zeylonenfibus Herm. Cat. 036. Zerumbet officinarum Dale Pharm. 366. Eீ Variorum. Kua Mal. Acua Bram.

I $1-27$

Zira-Puti-Valli Bram.v. Apocynum

Zivo Bram. v. Arundo

5-II9 $11-13$ riopby indica argentea tota chariopbylli aromatici flore Herm:

4-75 Herb. Viv. Zeyl. v. Jujuba $4-85$

Zoutboom Belg. v. Anacardium.

\section{F I N I S}




\section{Errata Corrigenda.}

Pag.1.a.lin.30.lege Hernand.b. 1. 23. l. radice P. 2.a.1. 32 l. Hernand.1. 43.l. Bamia.b. 1. 2.l. Abclmofch.1. 30. l.Ketmia.P.3.a.1.54.l. Column. b. 1.17. l.Amuli. P.4.a.1.33.l.Gundo, Bram:- 10--73. b.1.4.l.Amomum. 1.24, l. Raji Hift: 148 2. 1.42.l.prunifera.P:7.a.1. . . . odorato.b. 1. 17.l. odorato.1. 36.l.odoratis. P: 9.a.1. 3 l.mucilaginofa.I. 47 : $l$ odorata. $1.52 . l$. aromatico.1. 54 l.odoratiffima. b. 1.9 l.Senna.P. 10.a.1. 8 ldicitur. 1.49 \& 55 l.arvore. P. 1 I. b. 1. $26 l .1570$. P: 12 , b. 1.40l. ferruginea.1. 42 l. CLXI.1.54 l5. - -47.P: 1 3. a. 1.9.l. 1633. 1. 19.l. I632.P: I 3.b. 1.28. l. Convolvulus. P: 14.a.1.6 \& 55 l. Cucumerina. P: 1 5.a.l. $52 . l$. 32--27. P: 1 7 a.1.43.l.483.P: 18. a.1. 24 l.Gratiolx.b.l. 1.l.7-63. P: 19 a. I. 1 1. l. Hernand. 87 b.1.5.l.Vitis.1.43 l. uvifcra. P. 2 I 1.36 l. oblonga. P.23 a.1.19l, pavonis. P. 26 a. 1.6.l.9-47. P: 28 bl. 35 l. trunco.P: 31 a. 1.13 l. rotundo.P: $321.16 l$ alfine. 1.48 l. Gelfeminum. P: 33 b. 1. 20 l.infperfo. P: 37 1. 5 l.6--93.b. 1. 26 l.occidentalis. P: 41 a.1.23 l.Limao.b.1. 21 l. filiquis. 1.29 l.odorato: P:45 b.1.4 I l. Munnicks Keylen. P: 46 b.1. $3{ }_{3}$ l. 5 - -97.1. 54 l. 1 0-1 45. P: 48 a.1.27 l.mucilaginofa.P.49 b.1.40.l.6--29. P:52 a.1.16 l.Pepo.P: 54 a.1.2 l. Craffus.P: 57 . a.1.41 l. rofaceo.P: 58 b. 1. 40 l. J O-n 5 1.P: 61 b. 1. 3 l. odorata. 1. 26 l.9--107.P:62 a.1. 20.

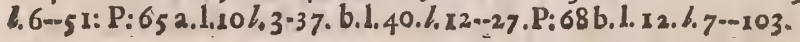




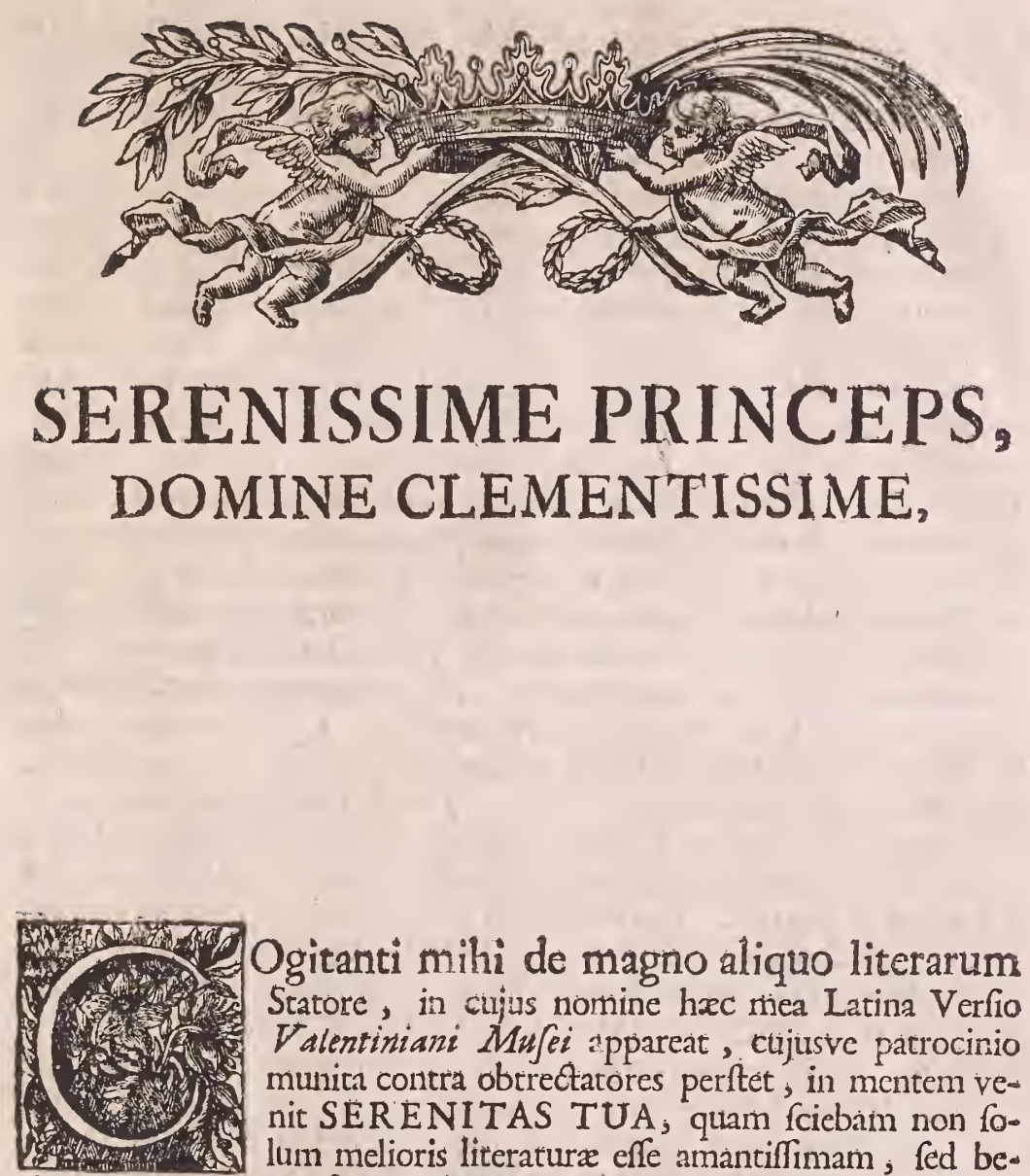

Ogitanti mihi de magno aliquo literarum Statore, in cujus nomine hæc riea Latina Verfo Valentiniani Mufei appareat, cujusve patrocinio munita contra obtrectatores perftet, in mentem venit SERENITAS TUA, quam fciebaim non folum melioris literaturæe effe amantiffimam, fed be. nigno quoque numine fovere Mufas, haturnque filios fufcipere ornandos. Nec enim prodire in lucem fine turela, fineque fpe patrociniti audebat. fcriptum, hac prefertim obtrectatorum foecunditate, neque venire in hominum manus geftiebat fine cenfurta, à tali tantoque peragenda, crjus cum auctoritate, tum judicii acumine fibi afferatur pondus. Qui autem ad utrumque valcat, tuendarum literartum 'TE majus extare ftudium velit, explorandis quoque Natura myfteriis TE maturius judicandi vinı actierit, fciebam neminem. Eftenim hoc SERENISSIMA DOMUI TUÆ gentilitium, fufcipere patrocinium Mufarum, ac confuetudinem in illo tuendo fervare. Non defatigabitur pofteritas, quin potius voluptatem capiet in pradicanda cum incredibili animi magnitudine, tum inexhauIta liberalitate, qua immortalis famæ Princeps I UD OVICUS V. Fidelis, Abavus Tuns, A. $160 \%$ d. 7. Oetobr. Academiam Giffenam, ab Se Ludovicianam dictam, condidit : qua GEORGIUS II. Proavus Tums, iftam ab divino Conditore eodemque Parente fuo, quod Marburgenfern anno quinto \& vigefino ab Se reftauratam, fovere Sibi deliberatum erat, prudenter fufperifam, anno 1650. de integro Giffam transferri, 
ferri, exulesque Mufas revocari curavit: qua divinus Avus T-uns LUDOVICUS VI. illan haud fecus atque pupillam amavit, amatamque fidei puritate juxta acfcientiarum cultura domi fervavit fplendidam, exteris æeftimatam. Quanta vero Sereniffimi Domini Parentis Tui cura extiterit, \& etiamnum extet tuendæ ornandxqueAcademix patrix, non neceffe eft, ut hic commemorem, cum unicúiqueconftet, ac exteri etiam zeftiment, admirenturque, quam magnis fumtibus Profeffores vocet, alat, iftorum numerum acftipendia augeat, \& quanta magnificentia fecularem Academir natalem, Jubilæum vocant, fecerit celebrari. Tantis genitus Parentibus SERENISSIME PRINCEPS! in id femper divinioris animi indole incubuifti, quo virturi fis fimillimus, i.e. quo fanctiffimis venerabilibusque Parentis, Avi, Majorumque veftigiis incedas. Quem ingeneratum TIBI vigorem omnibus doctrinæe ftudiis mira ingenii promtieudine perfecifti, itineribus quoque ac confuetudine fummorum Principum usque eo evexifti, ut æquales TE admirentur, ac potentiffima MagnæBritanniæ Regina, æeftimandis Tuis virtutibus adducta, gratiofiffima animi propenfione Sua in aula TE tractaverit: nunquam nifi honorificentiffime TE appellaverit : TEque abeuntem cum teftificatione Sux in TE voluntatis dimiferit ornatum. Quod numen Tuum, SERENISSIME PRINCEPS! ut fanctum mihi eft \& venerandum, ita Mufis meis velim effe propitium. Tentabit aditum hic prefens liber, quem pace Auctoris Latinitate donavi, quo præfixo nomine TUO, cum fibi apud exteros anctoritatem conciliet, tum me interpretem apud TE ponat in gratiam. Pro incredibili in literas literatosque amore veniam facies audacix, quâ Tibi, SERENISSIME PRINCEPS! hoc quantulumcunque munus fubmiffiffima animi pietate offero, huicque Verfioni mex SERENISSIMUM NOMEN TUUM fumo prafcribendum. Sufcipe igitur ac patrocinio TUO dignarc præfentern hunc. librum, ab fubjectiffimo TIBI cliente oblatum, in quo, ceu monumento ære perenniore, forfan $\& \approx$ nobiliore, pofteritas videat, legat, intelligat, Mufas noftras, SERENISSIMI DOMINI PARENTIS Tuaque gratia plus femel recreatas, aliquid ex fe promfiffe ad gloriam gentis TU $\bar{E}$; \& afferendam ab oblivione laudem, Domui Darmftadinæ propriam $\&$ peculiarem. Ego DEUM deprecor, ut TE, fecundum SERENISSIMUM DOMINUM PARENTEM, Principalis Familix decus, ab omni malo periculoque defendat: vita diuturna \& integra valetudine beet: fpem Principis,aliquando gloriofiffime recturi,de TE concitatam, fpatio vitæ omnique felicitate comprobet: ftirpem denique ac fuccef fionem per TE faciat firmari. . Sic vovet

\section{SERENITATI TUE}

Alsfeldix pridie Iduum Julii,

A. MDCCXV。

Subjedifinow fecures 


\section{$P R A F A T I O$.}

Quandoquidem verò liber hic ita comparatus fic, ut partim ob nimium, quo venit, pretium ab omnibus Philiatris minus coëmi, partim ob utriusque voluminis molem in excurfionibus Botanicis, quas Herbationes vocant, ruri per montes, fylvas \& campos absque moleftia circumportari non polfit ; hinc filio meo, natu majori, Chriftophoro Bernhardo Valentini, animum ad ftudium hocce applicanti, nuper autor fui, uc nucleum \& medullam quafi extrahendo quasvis Plantarum Claffes ex Autore fic in Tabulis difponeret, ut uno ftatim intuitu omnibus illarum generibus ( literis obliquis feu curfivis expreffis) ob oculos pofitis fpecies fubalternatæ (hinc inde quoque adjectx) eo facilius addifci $\&$ diftingui poflint. Ne verò fterilis fir comparata inde plantarum notitia, fuafi infuper, ut notas characterifticas, quêis univerfam Materiam Medicam diftinxic Celeberrimus $P$ aulus Herman$n i$ in Collegio MSC. à nultis in pretio habito, fimilibus in Tabulis diftingueret, ut fimul plantarum vires, à Simone Paulli in Quadripartito Botanico \& 7ob. Rajo in Hiftoria Plantarum longè elegantius quàm in Herbariis Theodori Tabernamontani, Pratthioli, Loniceri, Tragi, Lobelii, Pancovii, aliorumque traditas, addifcere $\&$ in futurum ufum medicum fibi firmiter imprimere valeret. Urroque inftituto hoc ex voto fuccedente, permifi tandem ut Preparationes Chymicas, à Turnefortio in Collegio publico olim traditas, cum annotationibus $\&$ atiologiis à me adjectis, fubjungendo panopliam quafi traderer, quâ medicamenta probatifima è fumplicibus, in Tabulis enumeraris, folidè \& racionabiliter præparari \& in Praxi demum feliciter ápplicari pollint ac debeant. Figure anea per adfcripta nomina feipfas explicabunt, exceptâ fortè majore in Tab. I. ubi Partes Florum fiftuntur in Flore Coronæ Imp. ita ut Num. I. 2.3.4.5.6. defignata petala alimentum capiant à pedunculo Num. 7. illudque intar vifcerum perficiendo fructui nafcenti Num. 8. fuppeditent : ineptis humoris partibus per famina feu vafa excretoria Num. 9. IO. I I. I 2. 13. I4. abeuntibus in apices feu receptacula 15. 16. 17. 18. 19. 20. quæ circumponuntur piftillo hic extra florem eminenti. Tandem calyx nihil aliud eft, quam bafis $\&$ nodus inferior florem firmans \& defendens quafi ab injuriis externis: neque aliud eft, quam productio exterioris tunicæ in germine. His obfervatis plantarum characteres corumque defcriptiones, cuilibet Claffi \& Sectioni ab Autore præmiff $x$, facile poterunt intelligi. Ut verò in plantis fpontè pullulantibus inquirendis $\&$ colligendis eò felicius progredi, earumque locum natalem \& florendi tempus accuratius obfervare poffint Botanophili, addimus pro coronide duplicem Tabulam, quarum altera è Laurembergio \& Simone Paulli formata, altera autem à Celeberrimo quondam Medico, Theophilo Kentmanno, confignata, \& Anno I609. Giffæ Hafforum correctius \& auctius edita eft : quæ utraque cum utilitate, tum raritate $L E C T O R I$ BENEVOLO fe facile commendabit, quem cum omnigena profperitatis apprecatione his optimè valere jubeo. Dab. Giffe Hefforum, die 20. April. A1.1715. 


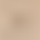

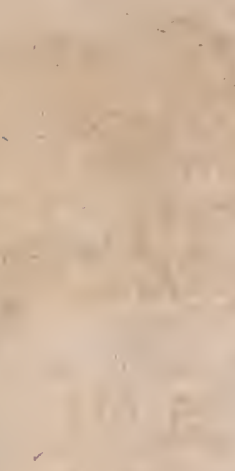

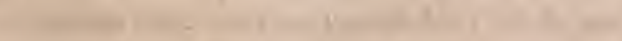

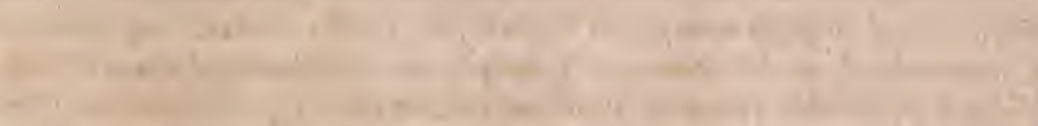

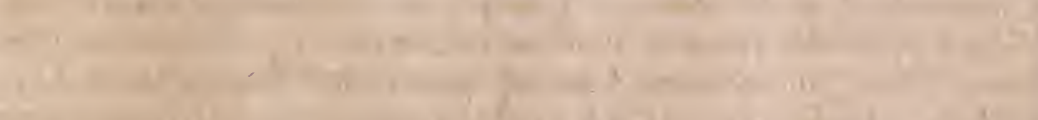

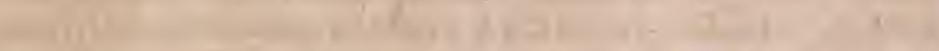
.

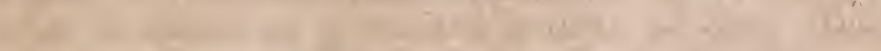

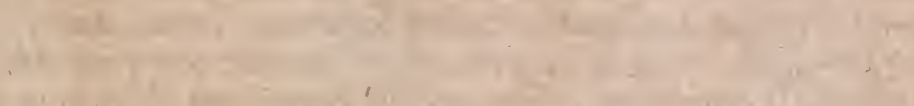

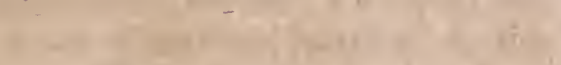




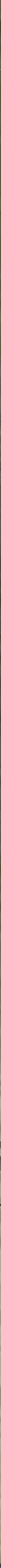


Fos Campaniformis. globostas:

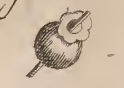

Fion Bclladono Campaniformis multi fiou

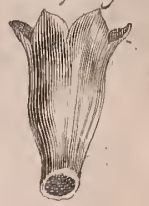

\section{Fiores Compositi.}

Flos Rajiatus.

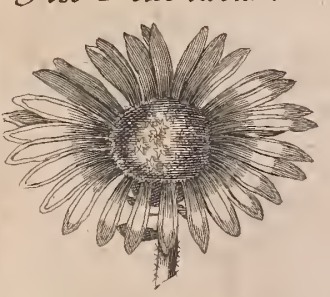

$$
\text { - Hos flosculosus. }
$$

- Frorter Anomati.

Flores Polypetali anomali.
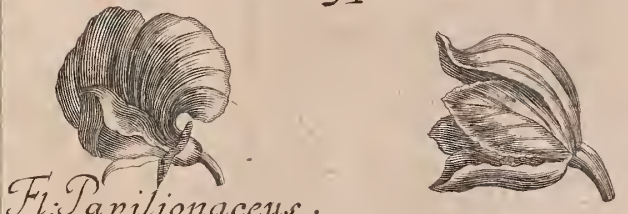

Flos Perfonatus.

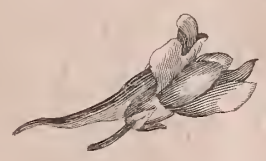

Flos femi losculofus.
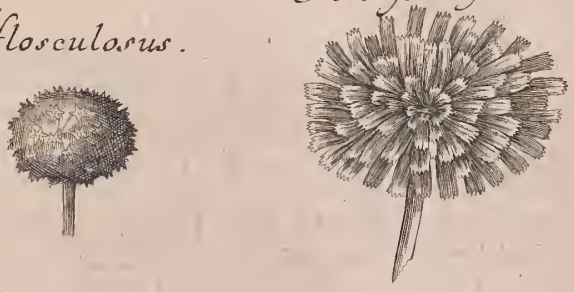

Flones Monopetali anomali.

pilionaceus.

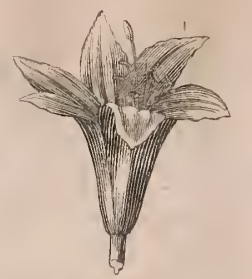

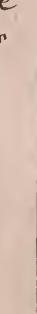




\section{HERBIS ET SUFFRUTICIBUS FLORE MONOPETALO ANOMALO.}

Sect. I.

Aurito vel cucullato.

2.

Tubulato in linguam definente.

3.

Utrinque patente.

Herbæ Flore Monopetalo, Anomalo, in

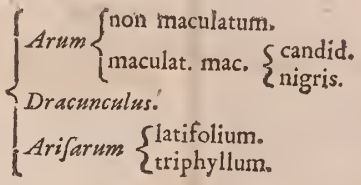

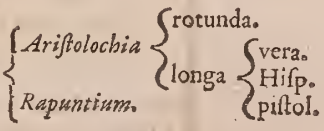

Pigignonia.

(Purpur.

$\left\{\right.$ Digitalis $\left\{\begin{array}{l}\text { Fl. candid. } \\ \text { Minim. Gratiola dicta, }\end{array}\right.$ Minor anguftif.

Pinguicula.

Scrophularia.

Antirrbinum \{ Vulg. maj.

Linaria.

Afarina.

pedicalaris $\left\{\begin{array}{l}\text { Purpur. vulg. } \\ \text { Lut. f. Crifta Gall. }\end{array}\right.$

Tubulato perfonato.

5.

In annuluñ defunente.

$$
\left\{\text { Acanthus } \left\{\begin{array}{l}
\text { Sativus feu Branca urfo } \\
\text { Sylveft. }
\end{array}\right.\right.
$$




\section{CLASSIS IV.}

$\mathrm{DE}$

HERBIS ET SUFFRUTICIBUS FLORE MO. NOPETALO LABIATO.

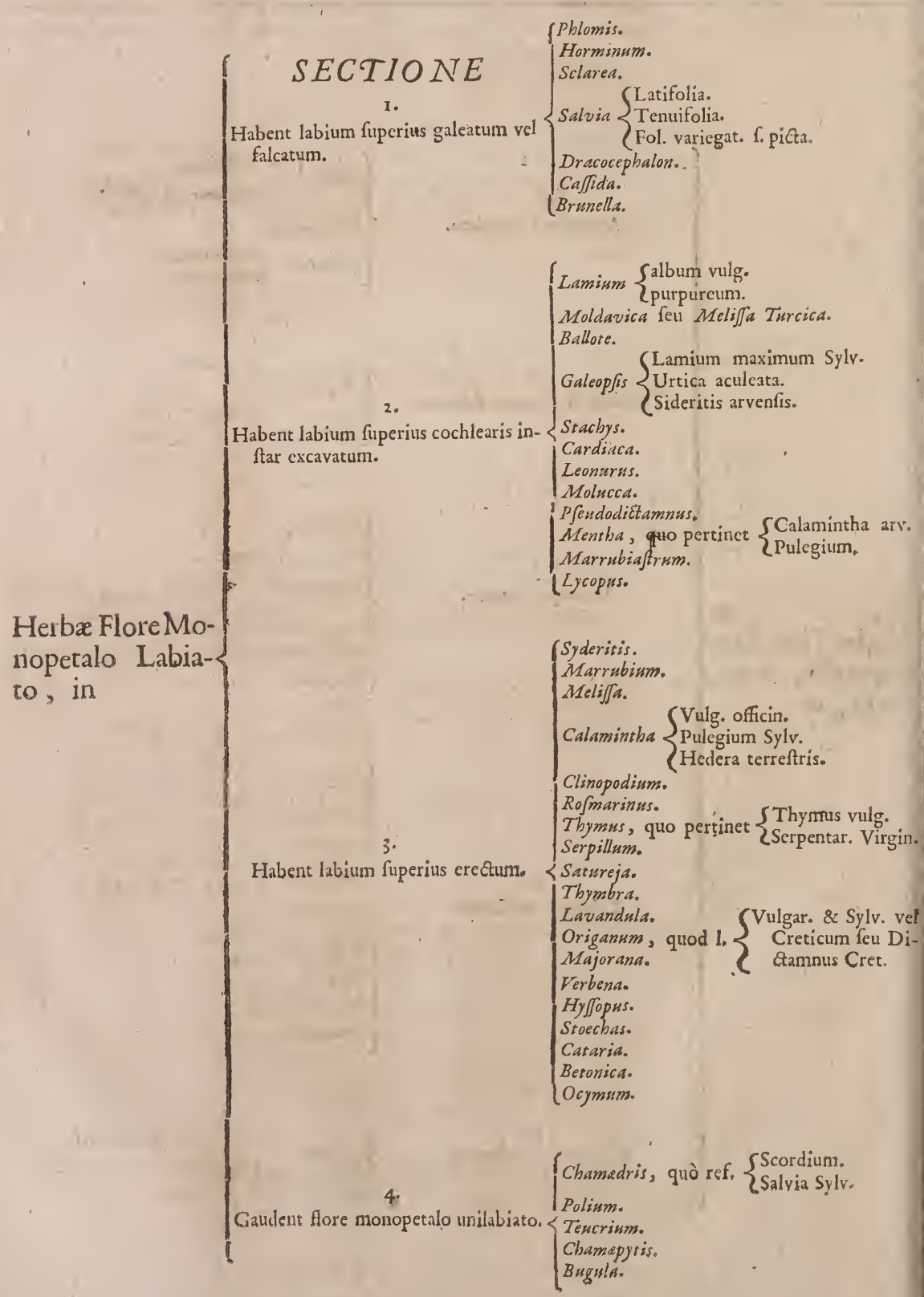




\section{CLASSIS V.}

$D E$

\section{HERBIS FLORE POLYPETALO CRU- \\ CIFORMI.}

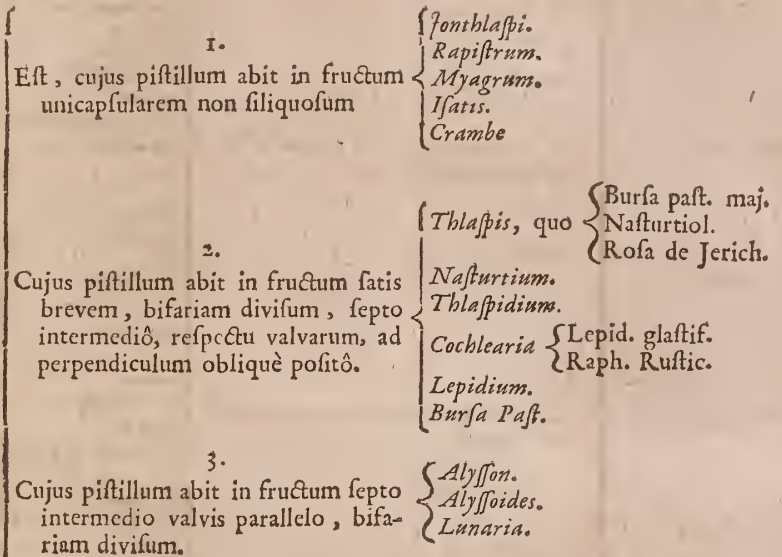

Herbæ Flore Polypetalo Cruciformi gaudentes IX. habent SeCtiones, quarum riam divifum.

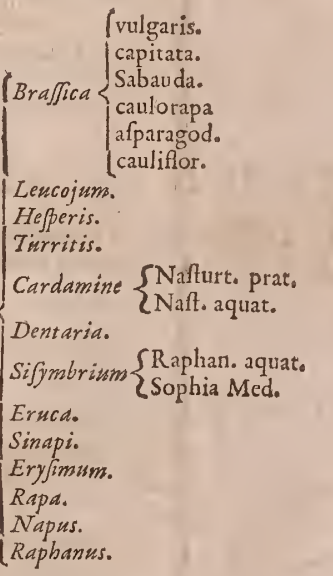

$$
\begin{aligned}
& \text { Dentaria. } \\
& \text { Sifymbritm }\left\{\begin{array}{l}
\text { Raphan. aquat。 } \\
\text { Sophia Med. }
\end{array}\right. \\
& \text { Eruca. } \\
& \text { Sinapi. } \\
& \text { Eryfimum. } \\
& \text { Rapa. } \\
& \text { Napus. } \\
& \text { Raphanus. }
\end{aligned}
$$

5.

Cujus piftillum abit in fructum filiquofum, bicapfularam.

Cujus piftillum abit in filiquam arti- $\{$ Raphanifrum. culofam. Hypecoon.

6. Cujus piftillum abit in filiquam uni- $\begin{aligned} & \text { Chelidoninm. } \\ & \text { capfularem. }\end{aligned}$
Sinapiftrum.
Epimedium. Epimedium.

7. Cujus piftillum abit in fruetum in ter-
na aut quaterna loculamenta divifum.

8.
$\begin{aligned} & \text { Cujus piftillum abit in plurima femi- } \\ & \text { na in capitulum collecta. }\end{aligned}$$\left\{\begin{array}{l}\text { Potamrogeton } \\ \text { Tribulus aquat, minoro } \\ \text { Millefol, aquat. }\end{array}\right.$ y.

Cujus piftillum abit in fructum mol- $\{$ Herba Pariso 


\section{HERBIS FLORE ROSACEO.}

Eft, cujus piftillum abit in fructum uni- $\{$ Amarambus. capfularem, bifariam transverfe hiefcen- $\{$ Portulaca. tem.

2.

Cujus piftillum alt calyx abeunt in fructum unicapfular $\mathrm{cm}$.

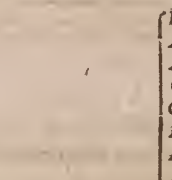

Propaver.

Argemoxe.

Anapodophyllon.

Opuntia.

Granzdilla.

Mursscujas

Mitella.

Alfine quó pertinet $\{$ Caryophyll, arvenl,

$\{$ Alfinnftrum. $\{$ Spergula.

Myofotis.

Ros Solis.

Parnaffia.

Kali.

Telephinum.

Holianthemsm.

Androjamum.

Herbx Flore Rofaceo IX. Genera habent, quorum

Cujus pifillum abit

CGeum.

Cujus pirtillum abit in fructum plerumque $\left\{\begin{array}{l}\text { Saxifragin, } \\ \text { Salicaria. }\end{array}\right.$

bicapfularem.

(Glaucium feu Papaz. Corricul.

Cujus piftillum abit in fructum multicapfu. larem. larem.

$\left\{\begin{array}{l}\text { Hypericum. } \\ \text { Afcyrum. } \\ \text { Pyrola. } \\ \text { Damafonium, } \\ \text { Ruta. } \\ \text { Harmala. } \\ \text { Nigella. } \\ \text { Fabago. } \\ \text { Corchorns. } \\ \text { Ciftus. } \\ \text { Nymphs. }\end{array}\right.$

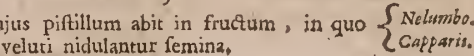

(Sedum.

Anxcamteros.

Ulmaria.

Barba Caprs.

Fagonia,

6.

funcago.

Cuius pifillum abit in fructum ex pluri- Geraniwm.

nis veluti capfulis compolitum,

Butomus.

Helleborus, fub quó Aconit. min,

Veratrum.

Populago.

Pannia.

Tribulus.

(Anemone.

Pul Jatilla.

Ranunculws.

7.

Filipendula.

Cujus piftillum abit in fructum ex plurimis feminibus in capitulum quoddam collectis compofitum.

\section{Caryophlllato}

Eragaris.

Pentaphyll.

Tormentill.

Pertaplaylodes.

8.
Cujus piftillum vel calyx abit in fructum
mollem. $\left\{\begin{array}{l}\text { Chrifophorinna. } \\ \text { I'byzolacca. } \\ \text { Aralia. } \\ \text { Aßparagss. }\end{array}\right.$

Cujus caly'x abit in fructum ficcum. $\left\{\begin{array}{l}\text { Cuminoides. } \\ \text { Circas. } \\ \text { Agrimonin. } \\ \text { Agrimonoides } \\ \text { Onagra. } \\ \text { Chamerion. }\end{array}\right.$ 


\section{HERBIS FLORE POLYPETALO ROSACEO} UMBELLATO.

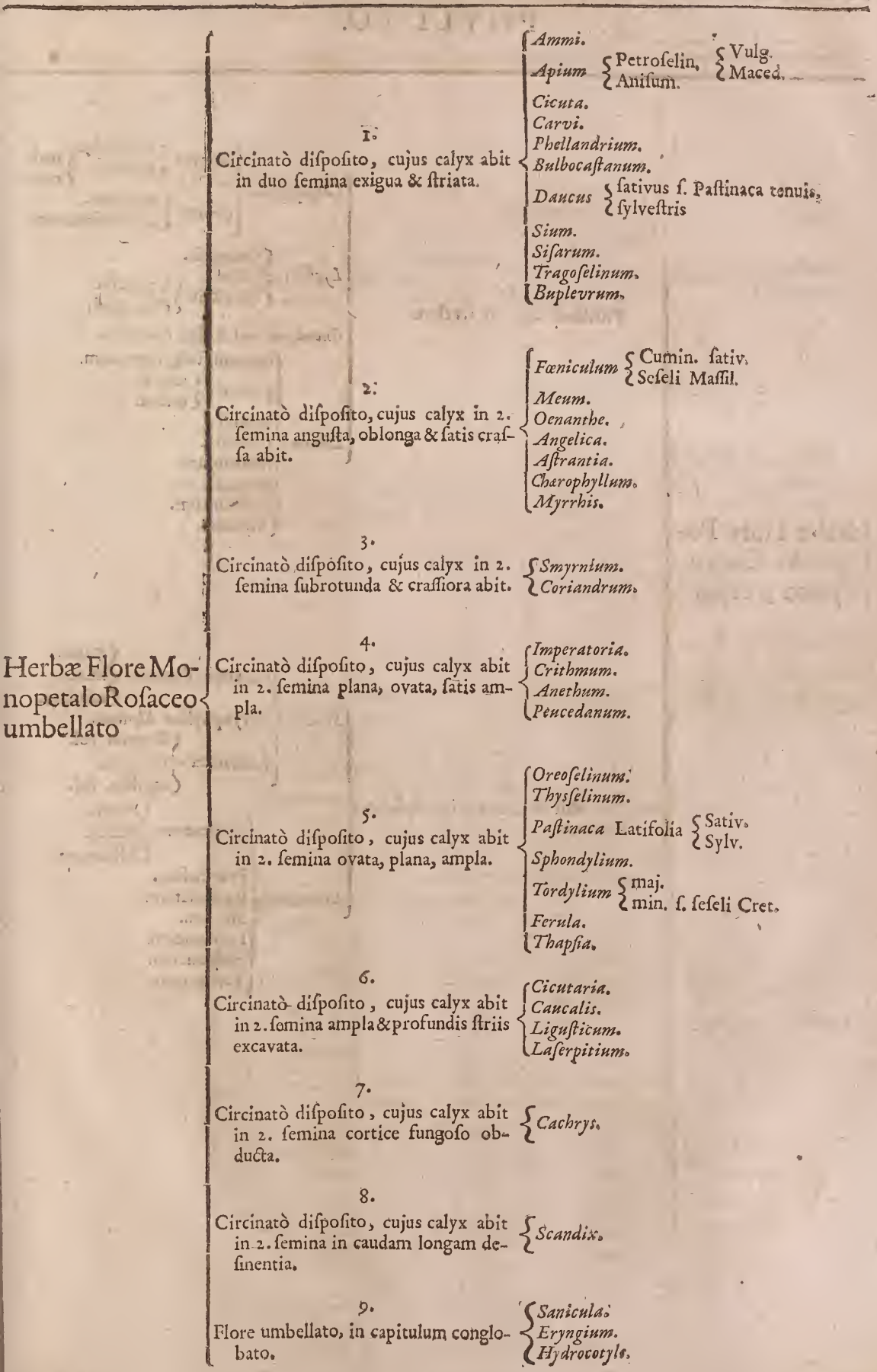




\section{HERBIS FLORE POLYPETALO CARYO.}

\section{PHYLLÆO.}

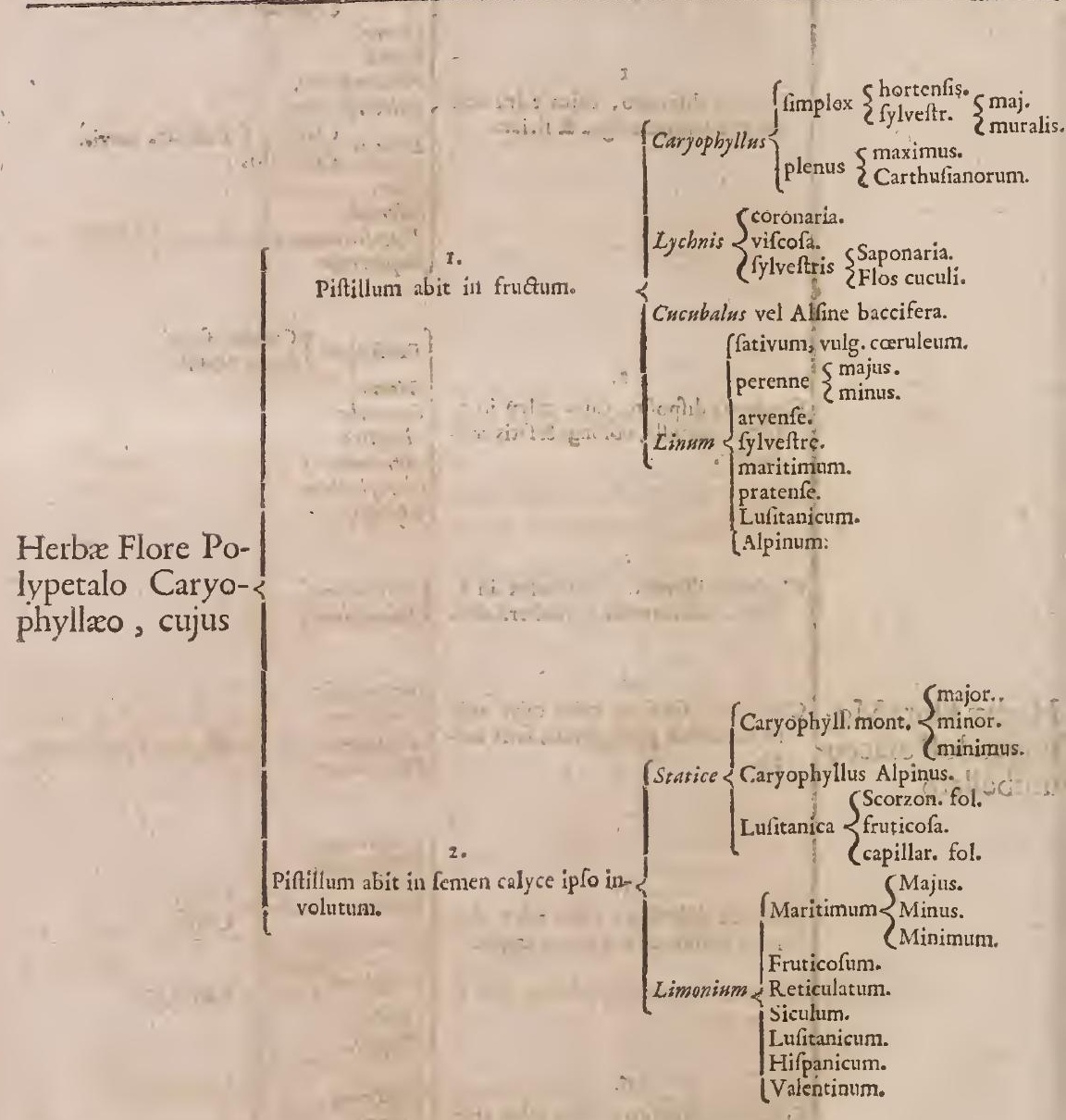

lypetalo Caryo-

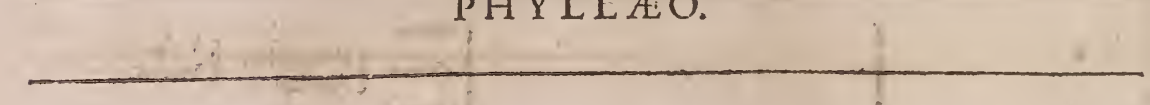




\section{- $)(0)(50$ \\ D E \\ HERBIS FLORE LILIACEO.}

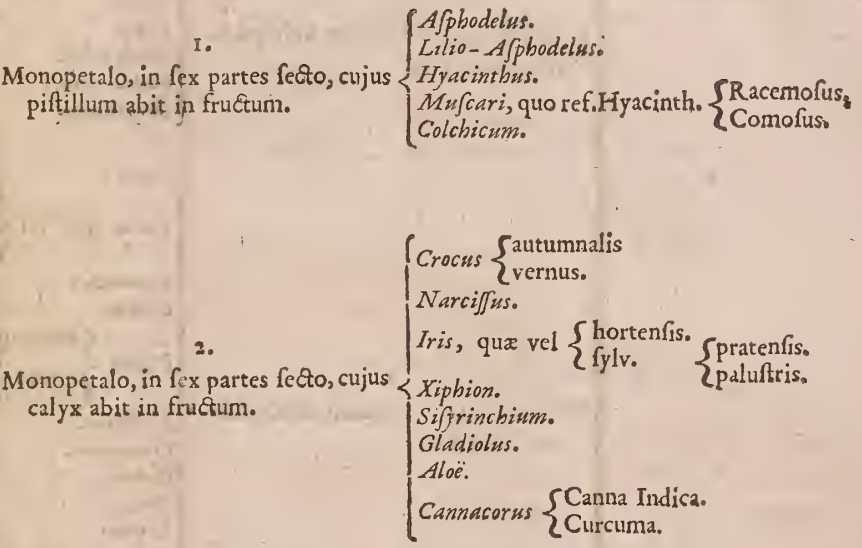

3.

Tripetalo.

Hexapetalo, cujus piftillum abit in fructum.
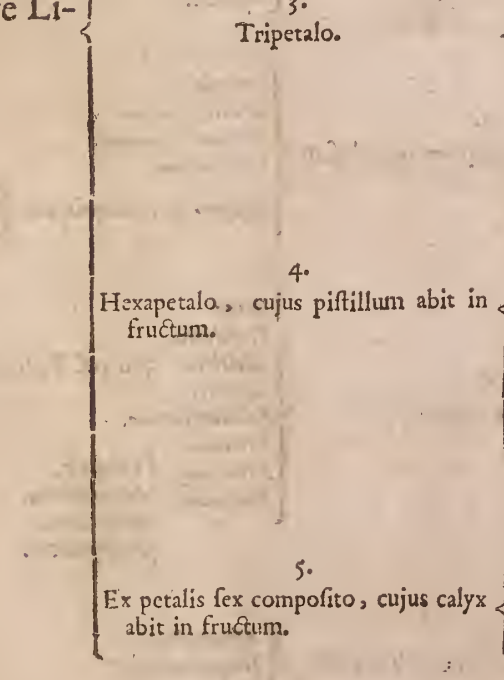

\{Ephemerum, f. Phalangium Virginianum.

PPhalangium.

Liliaftrum.

Lilium.

Lilio-Hyacinthus, f. Hyac. Ptellatus fol. Corona Imperialis. (\& rad. lil. Tulipa.

Fritillaria.

Dens Canis.

Ornithogalum.

Porrum. Sfativa Svulgaris.

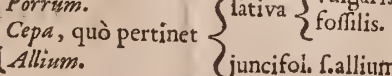




\section{CLASSIS X.}

$\mathrm{DE}$

HERBIS FLORE POLYPETALO; PAPI LIONACEO.

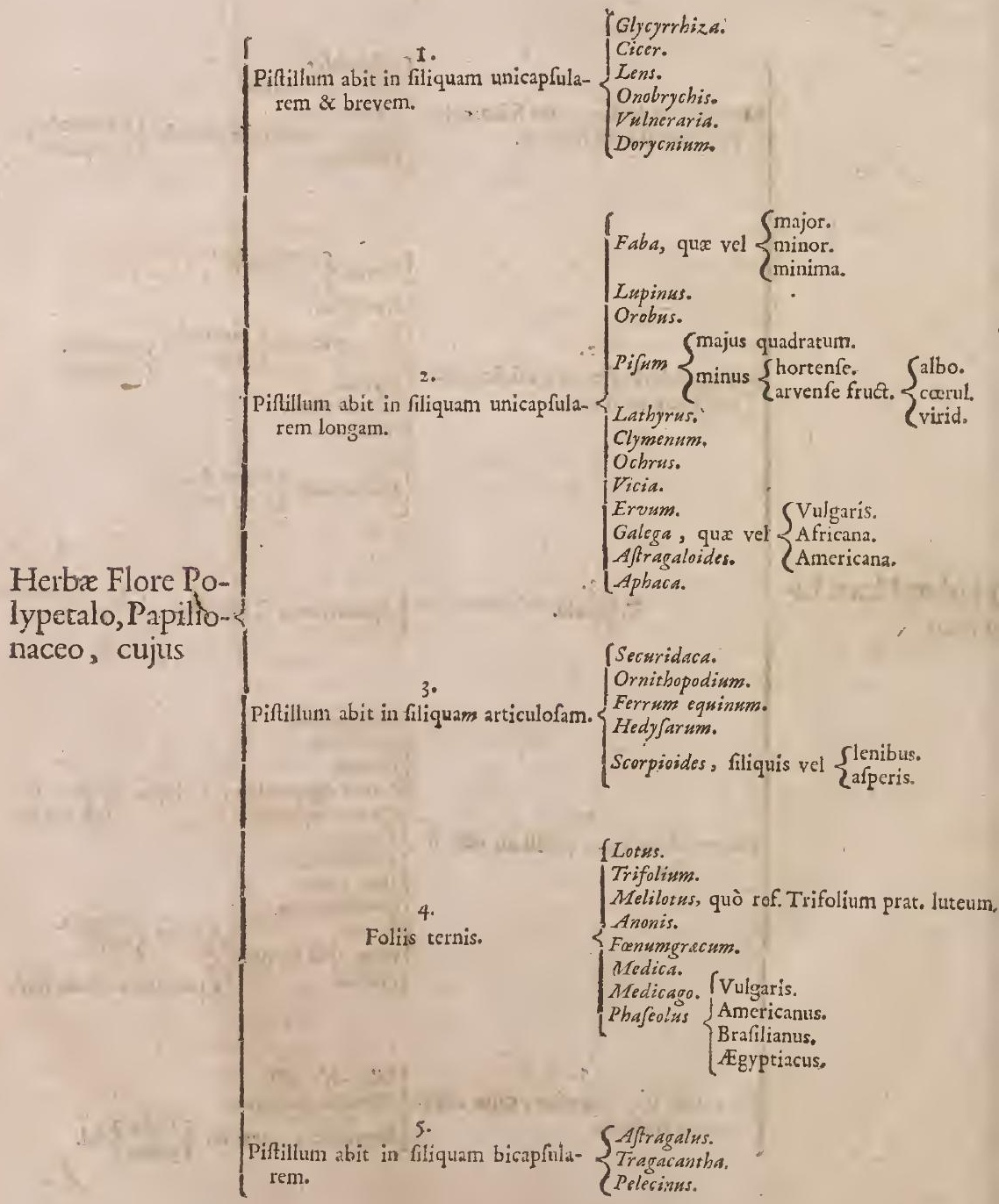




\section{CLASSIS XI.}

DE

\section{HERBIS FLORE POLYPETALO ANOMALO.}

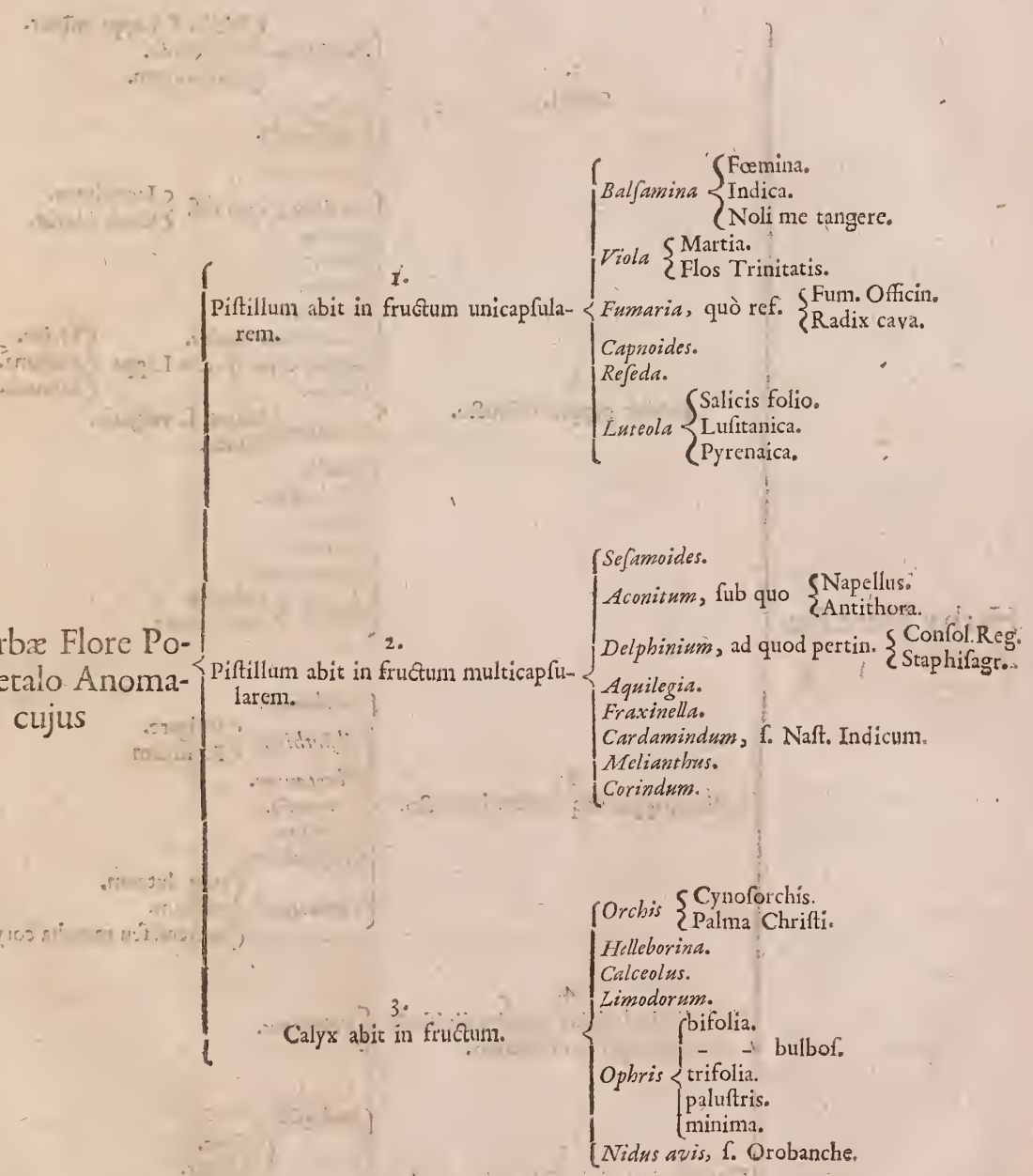




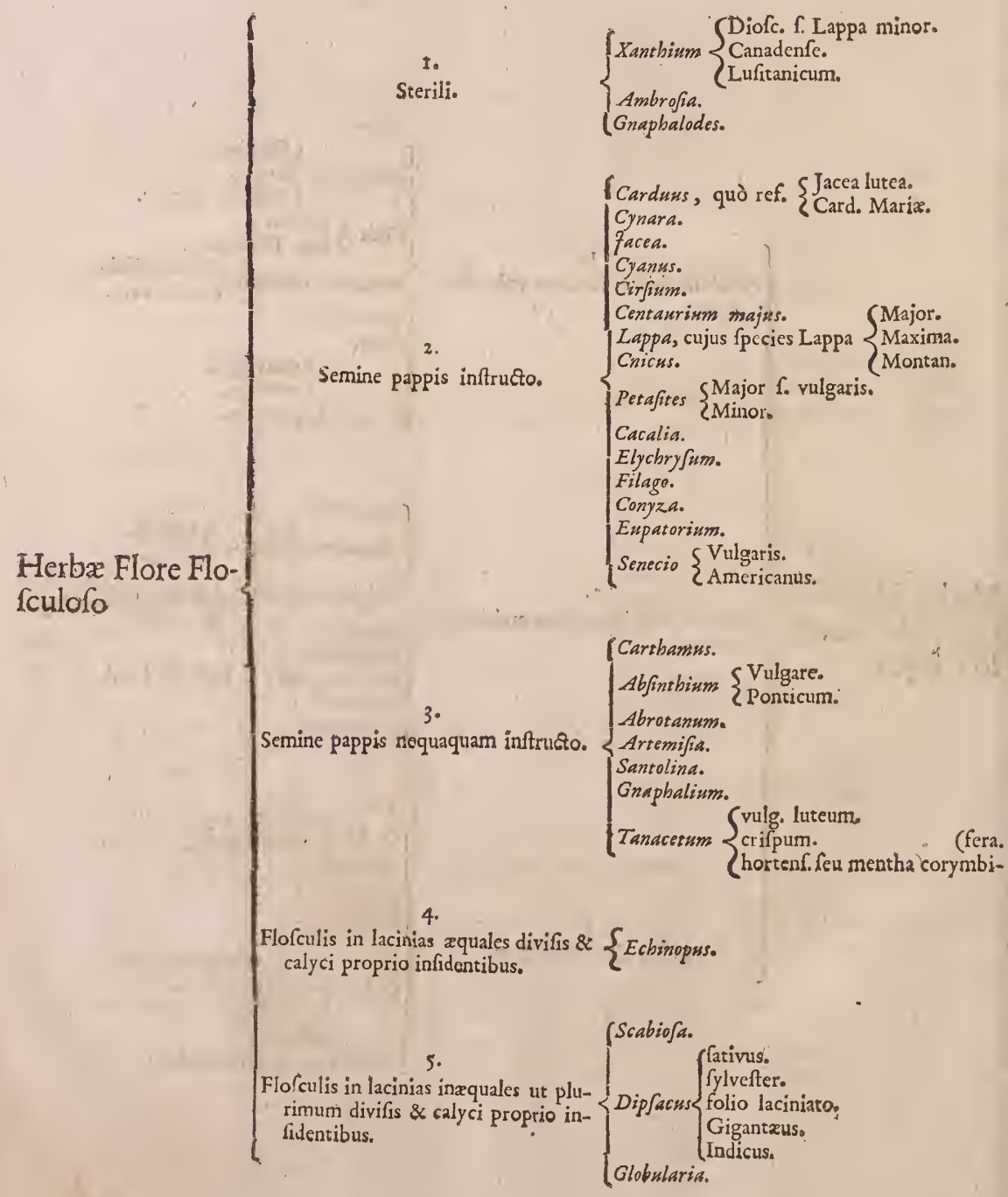




\section{CLASSIS XIII.}

DE

\section{HERBIS FLORE SEMI-FLOSCULOSO.}

Herbx Flore Semíni-Flofculofo
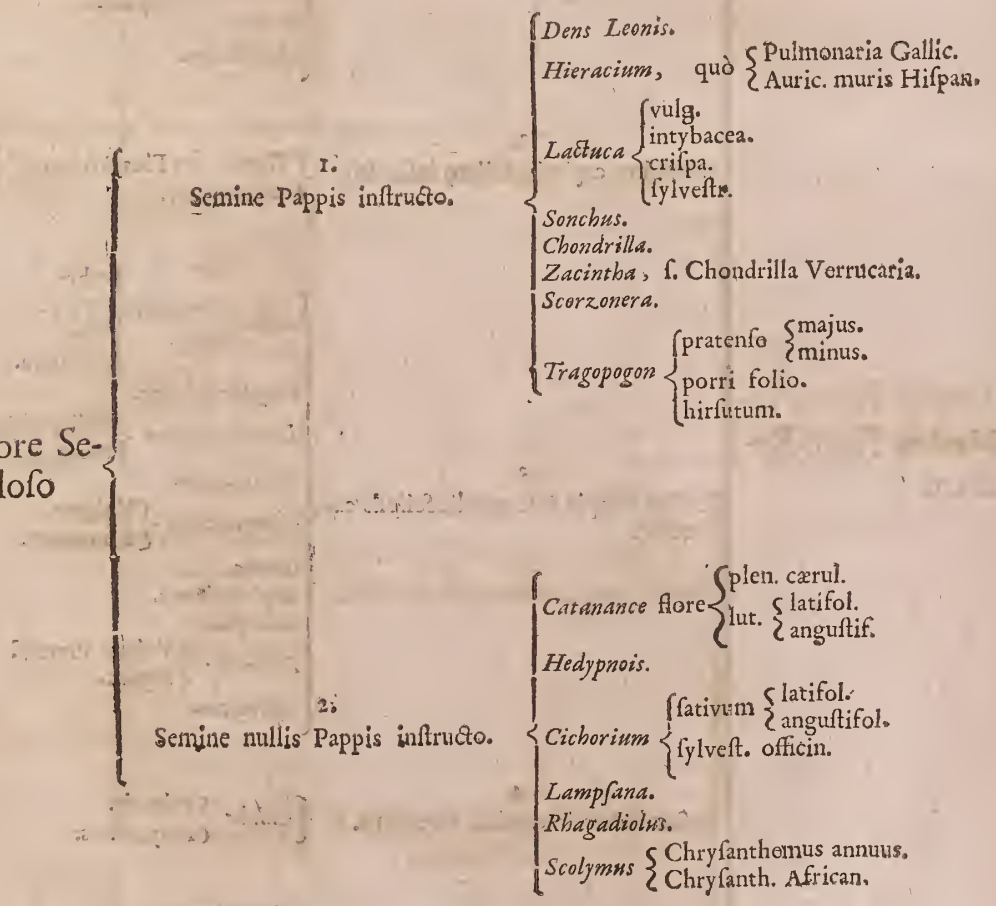


\section{GLASSIS XIV.}

$\mathrm{DE}$ HERBIS FLORE RADIATO.

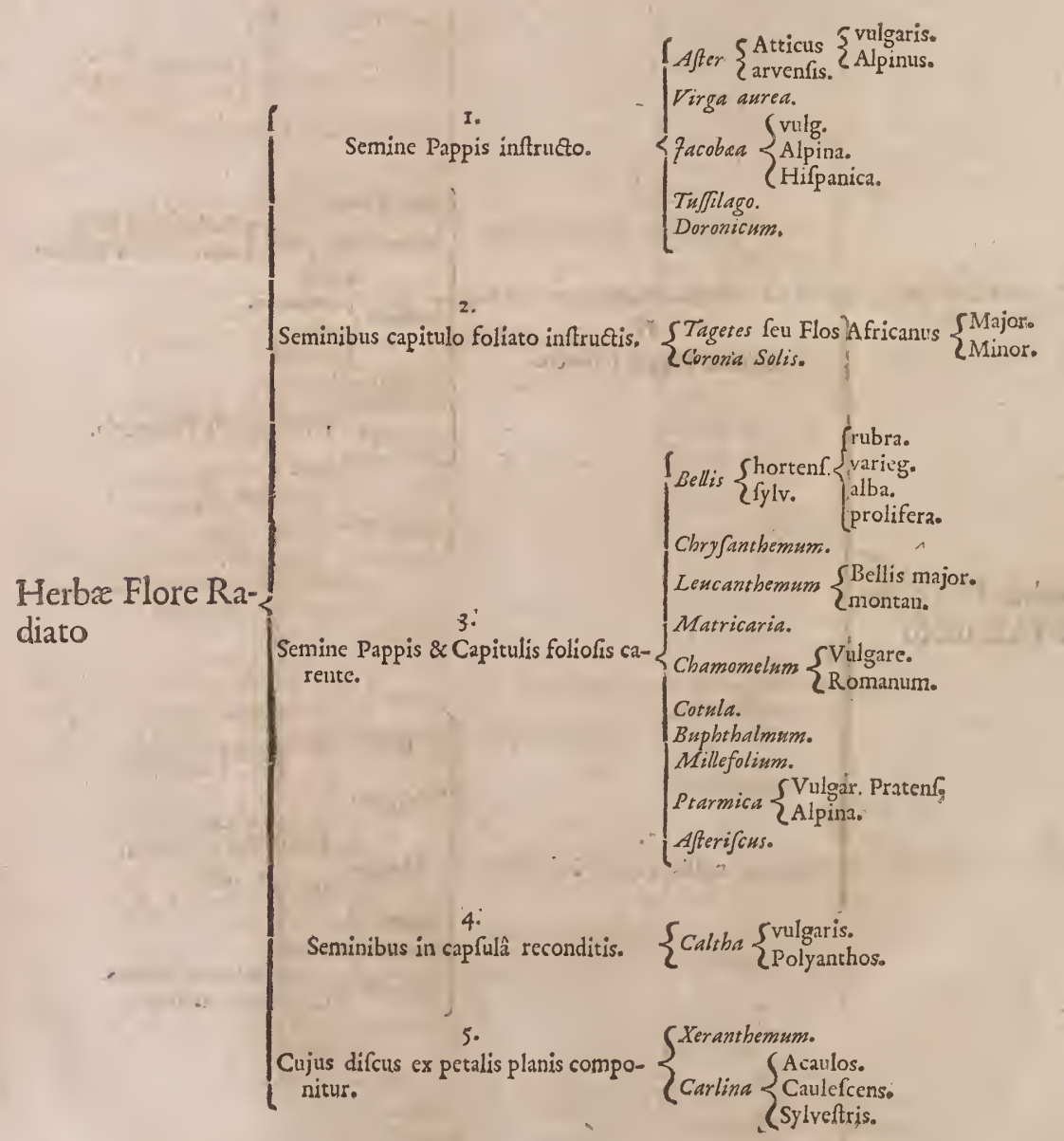




\section{CLASSIS XV.}

DE

\section{HERBIS FLORE APETALO . STAMINEO.}

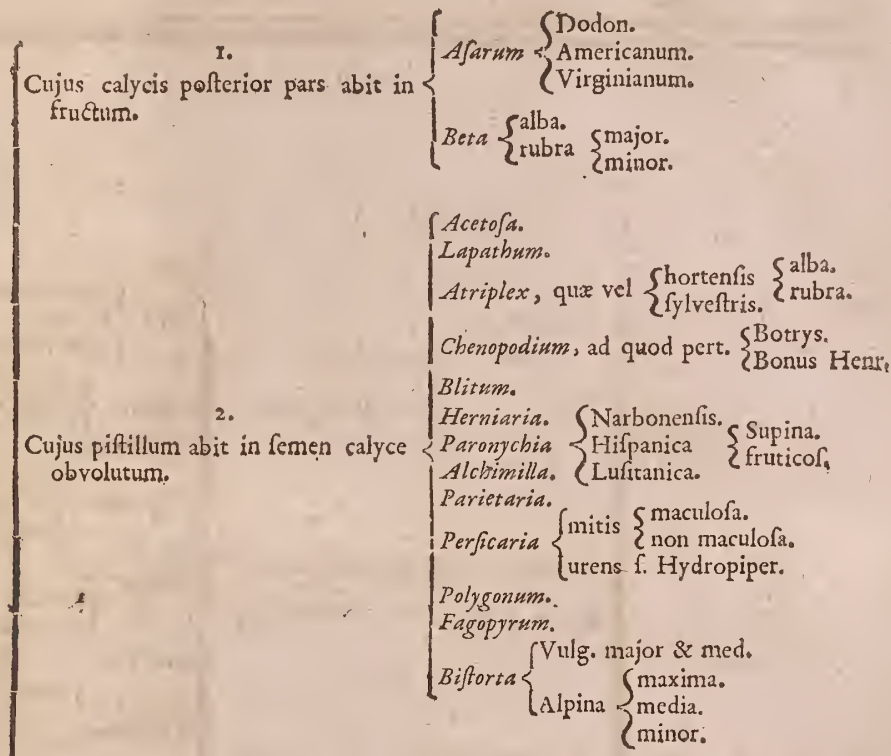

Herbæ Flore Apetalo f.Stamineo

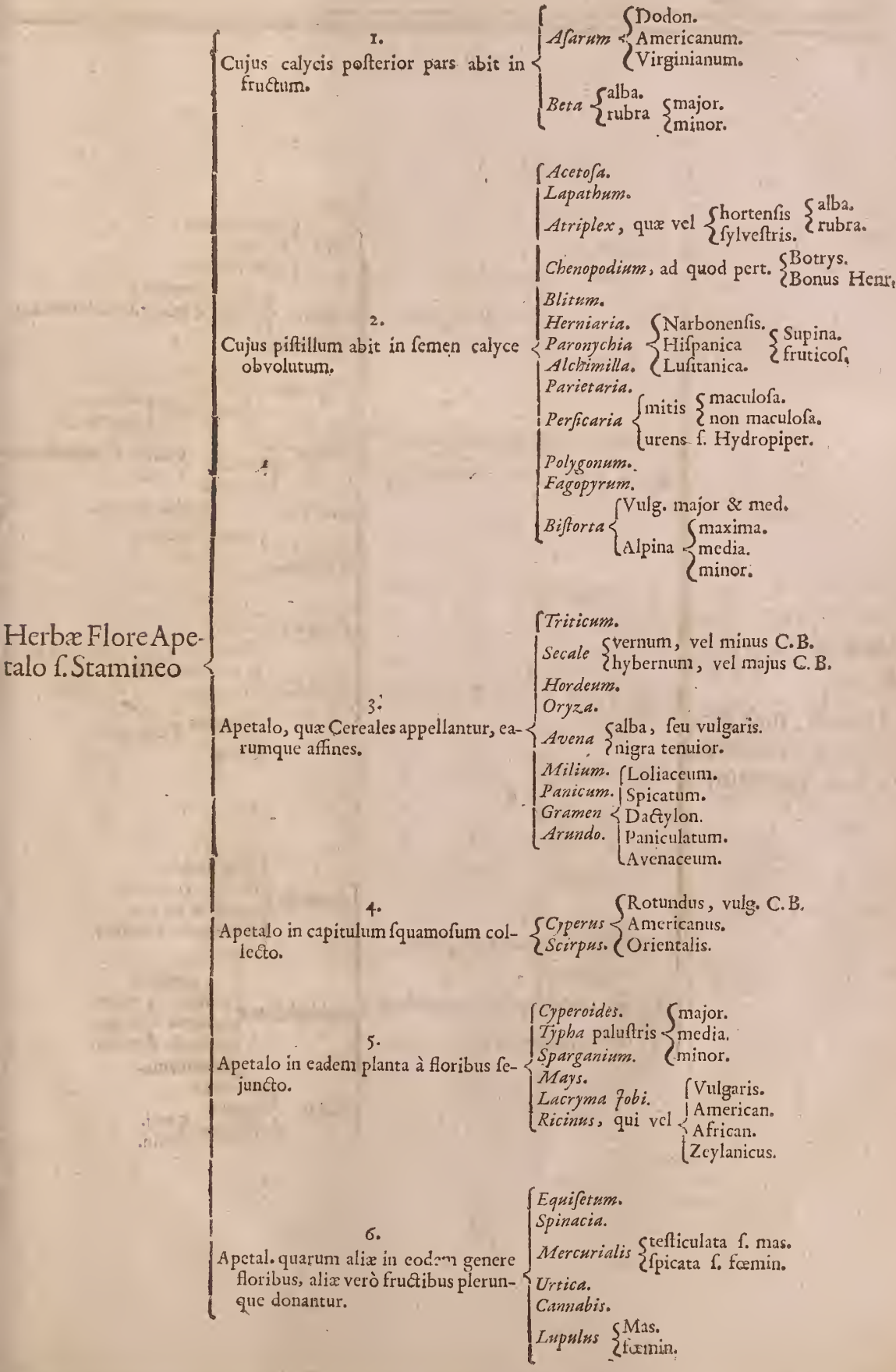


Herbx, qux Floribus carent, \& $\mathrm{fe}$ mine donantur.

I.

Quarum fructus foliis innafcuntur.

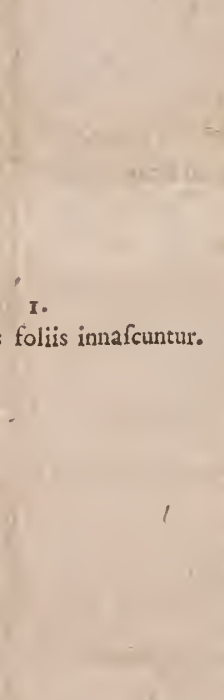

2.

Quarum femina foliis non innafcuntur.

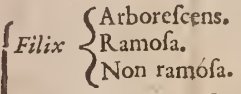

Lonchitis $\left\{\begin{array}{l}\text { afpera } \\ \text { glabra. }\end{array}\left\{\begin{array}{l}\text { major. } \\ \text { minor, }\end{array}\right.\right.$

Trichomanes.

Polypodium $\left\{\begin{array}{l}\text { vulgare. } \\ \text { minus. } \\ \text { majus fol. }\end{array}\right.$

Ruta muraria. 5 major $f$, adianth. alb

$\left\{\begin{array}{l}\text { Filicula }\left\{\begin{array}{l}\text { fontana } \\ \text { montana. }\end{array}\right. \\ \text { minor. }\end{array}\right.$

Adiantum feu Capillus Veneris. SOffic. Cetcrach.

Aplenium $\left\{\begin{array}{l}\text { ramofum. } \\ \text { villofum } \\ \text { cilfpum. }\end{array}\right.$

crifpum.

Lingua Cervina.

Lvulgaris.

. peregrina Cluf.

Hemionitis Lufitan.

maxima strifol,

tvaria.
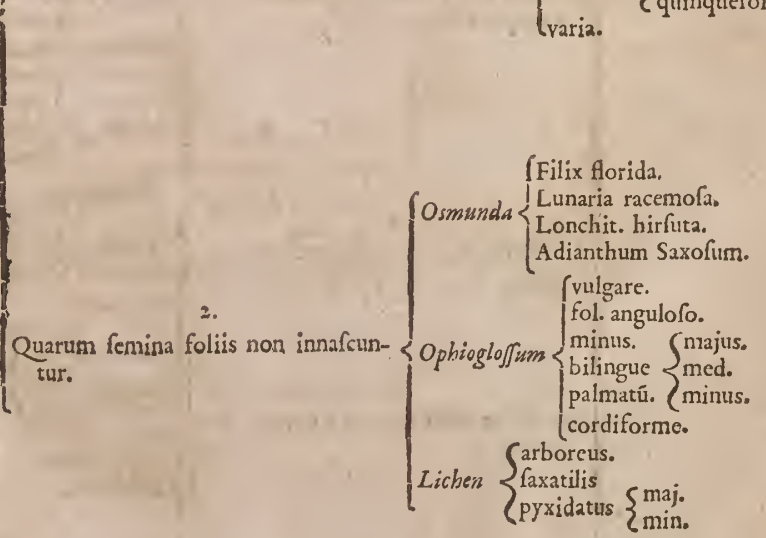


\section{CLASSIS XVII.}

$D E$

ARBORIBUS ET FRUTICIBUS FLORE APETALO.

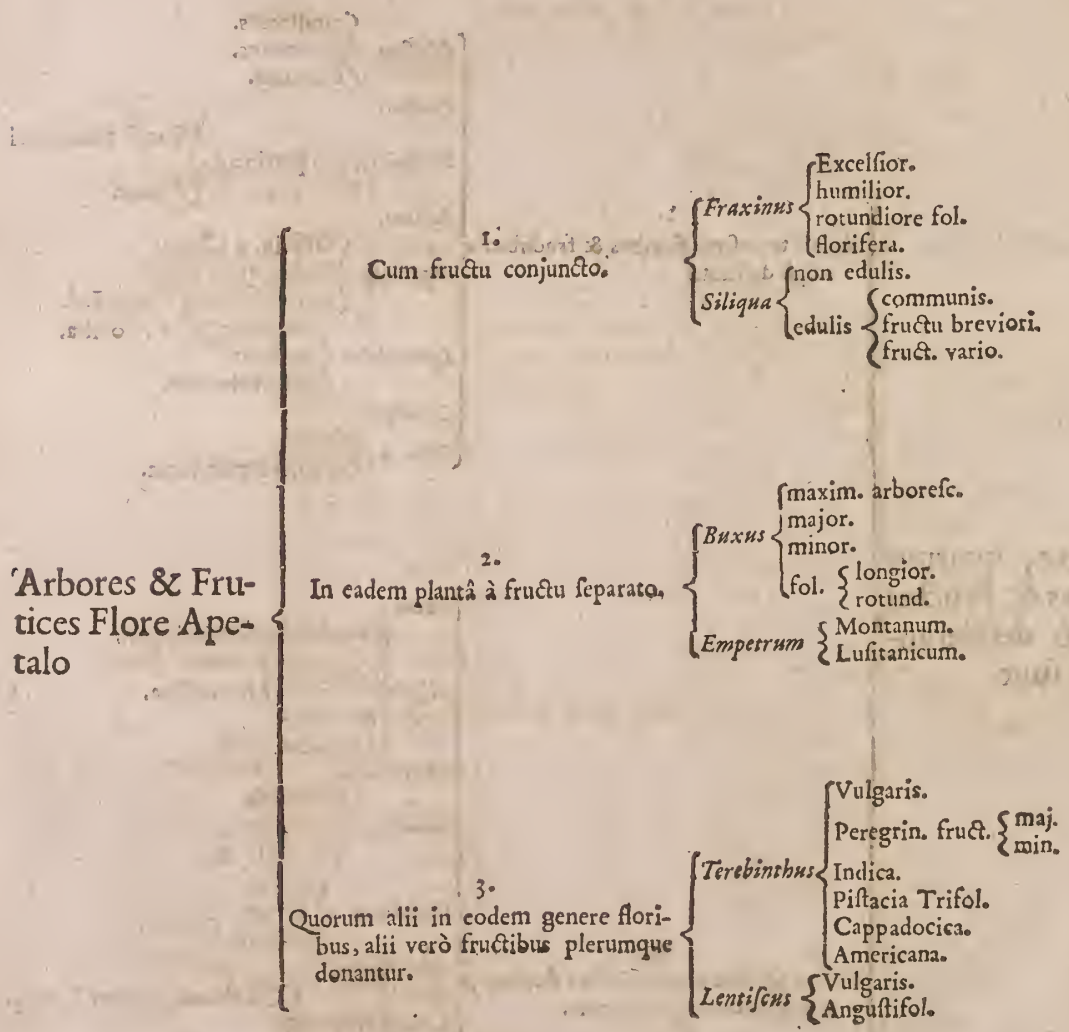




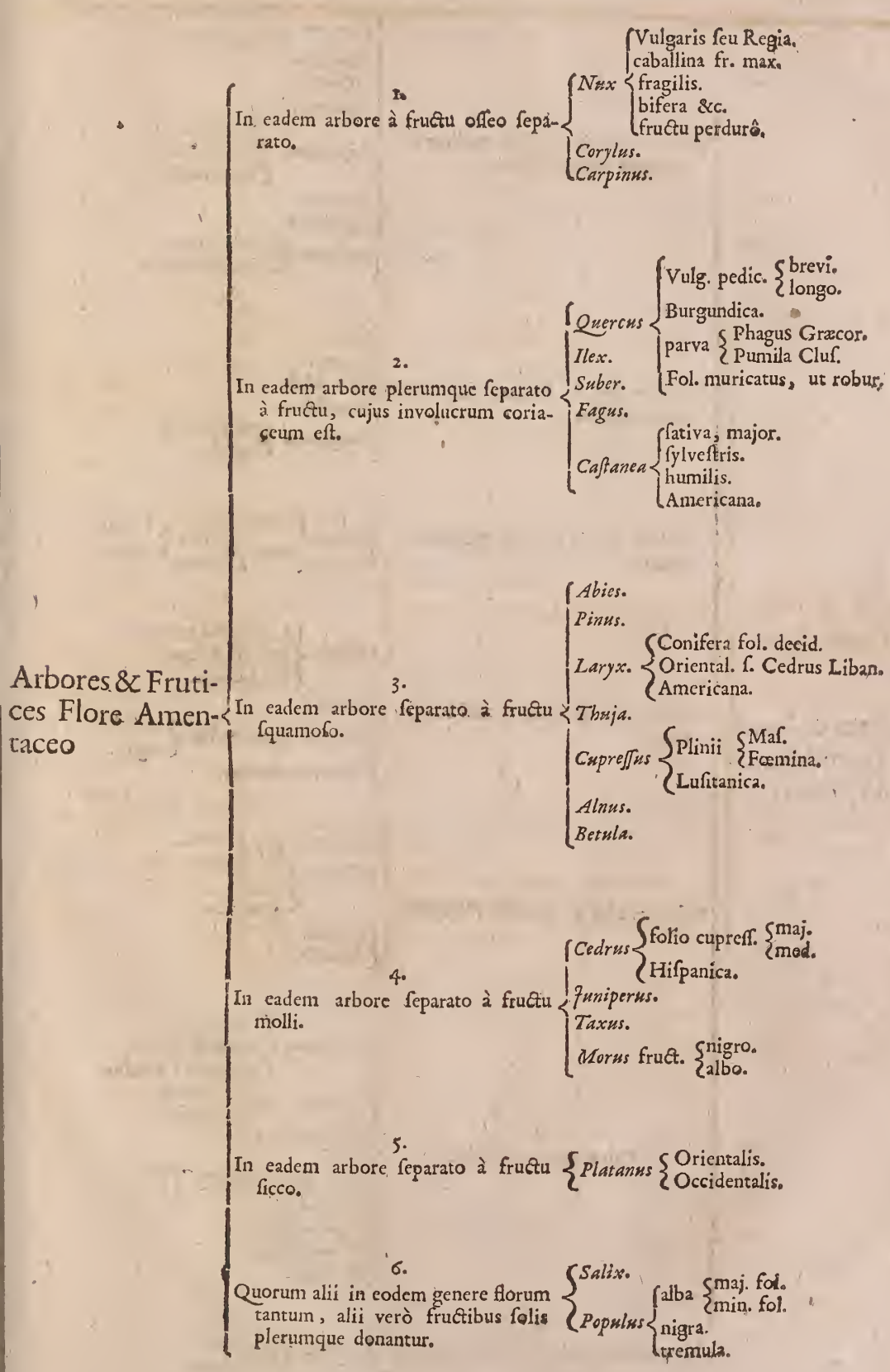




\section{ARBORIBUS ET FRUTICIBUS FLORE} MONOPET A LO.

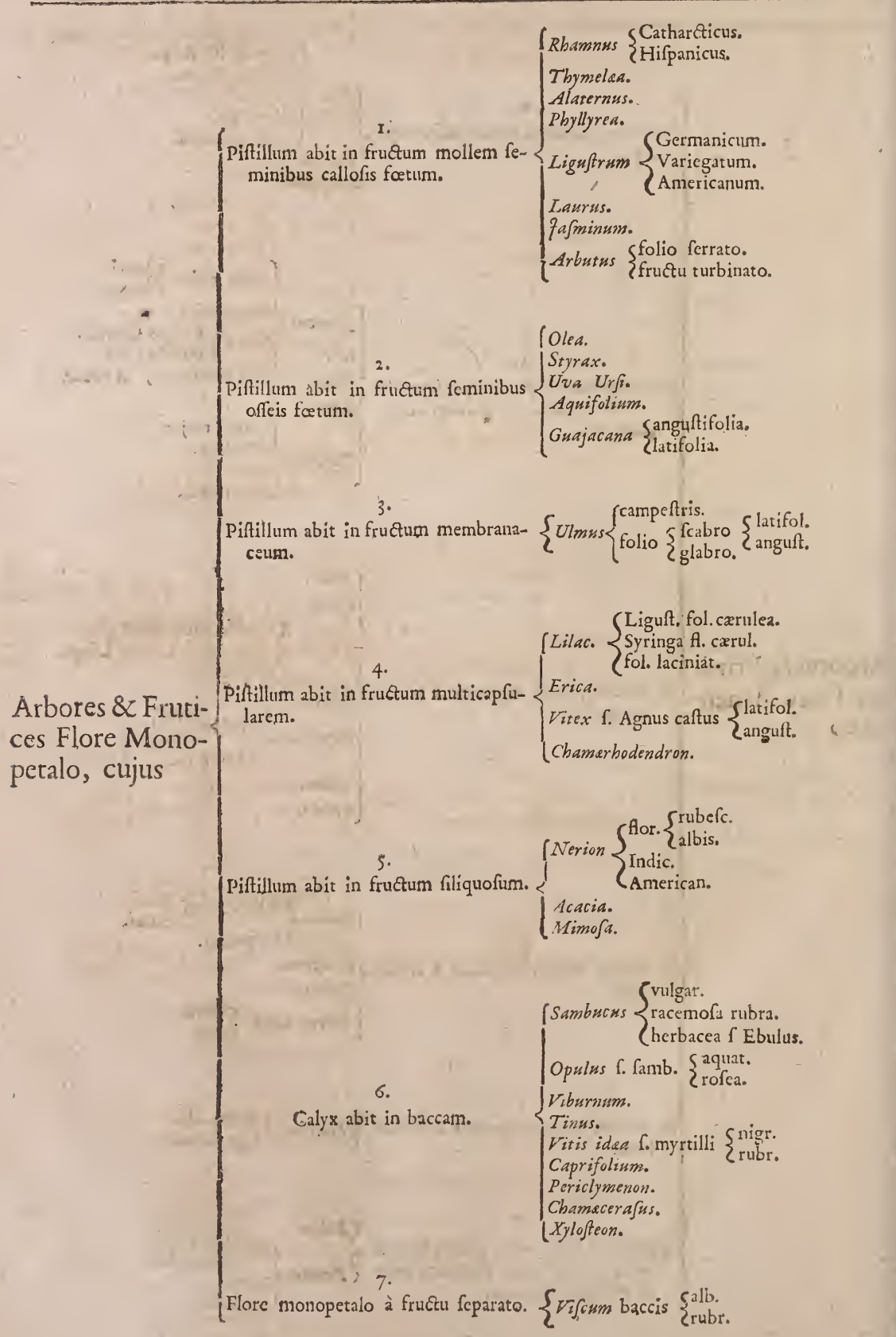




\section{ARBORIBUS ET FRUTICIBUS FLORE ROSACEO.}

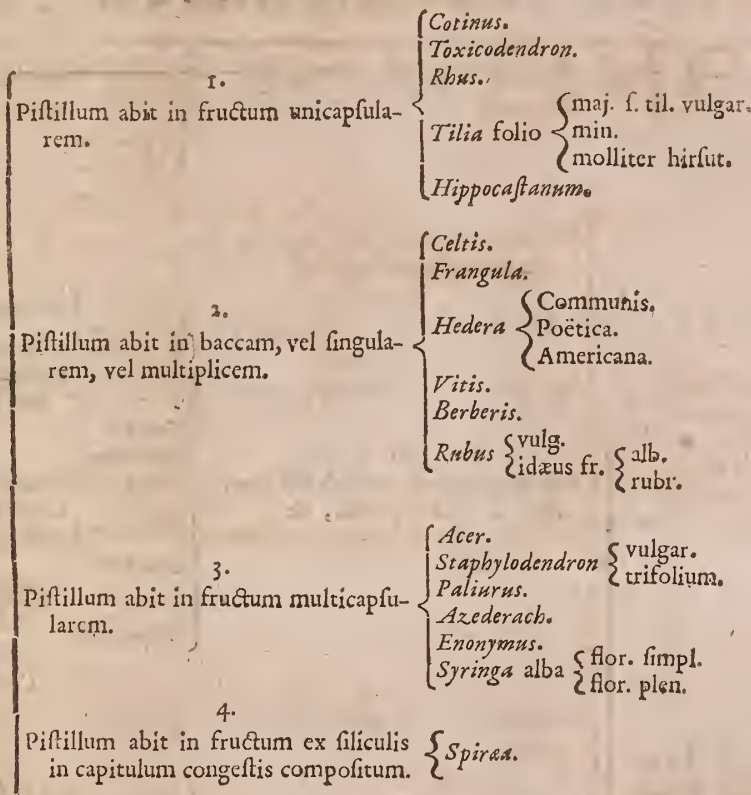

Arbores \& Frutices Flore Rofaceo, cujus

\section{5.}

Piftillum abit in filiquam.

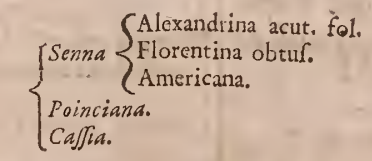
6.
fifillum abit in fructum carnofum,
feminibus callofis fœtum. $\left\{\begin{array}{l}\text { Aurantium }\left\{\begin{array}{l}\text { vulg. }\left\{\begin{array}{l}\text { dulc. } \\ \text { fycr. }\end{array}\right. \\ \text { Citreumetr. } \\ \text { Limon. }\end{array}\right. \\ \text { foxtiferum. } \\ \text { Sinenfe. }\end{array}\right.$

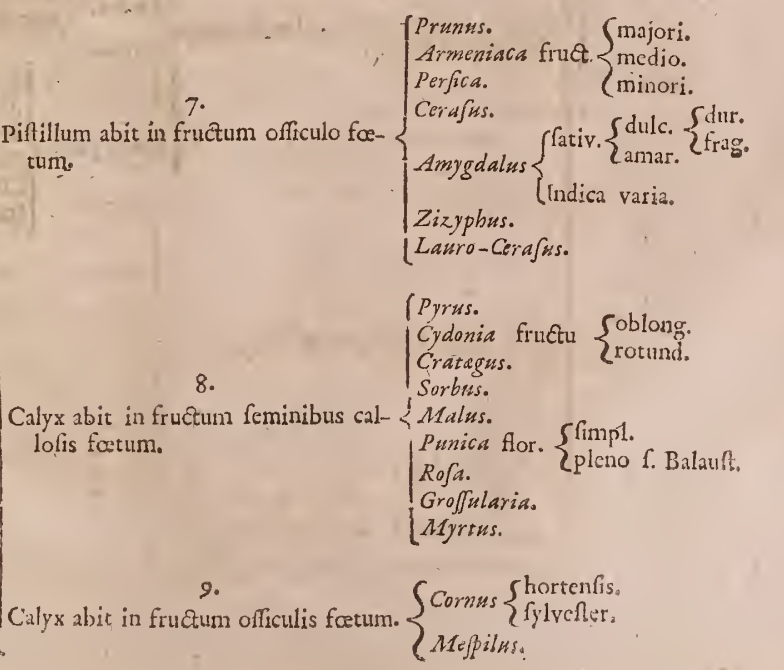




\section{CLASSIS XXII.}

ARBORIBUS ET FRUTICIBUS FLORE PAPILIONACEO.

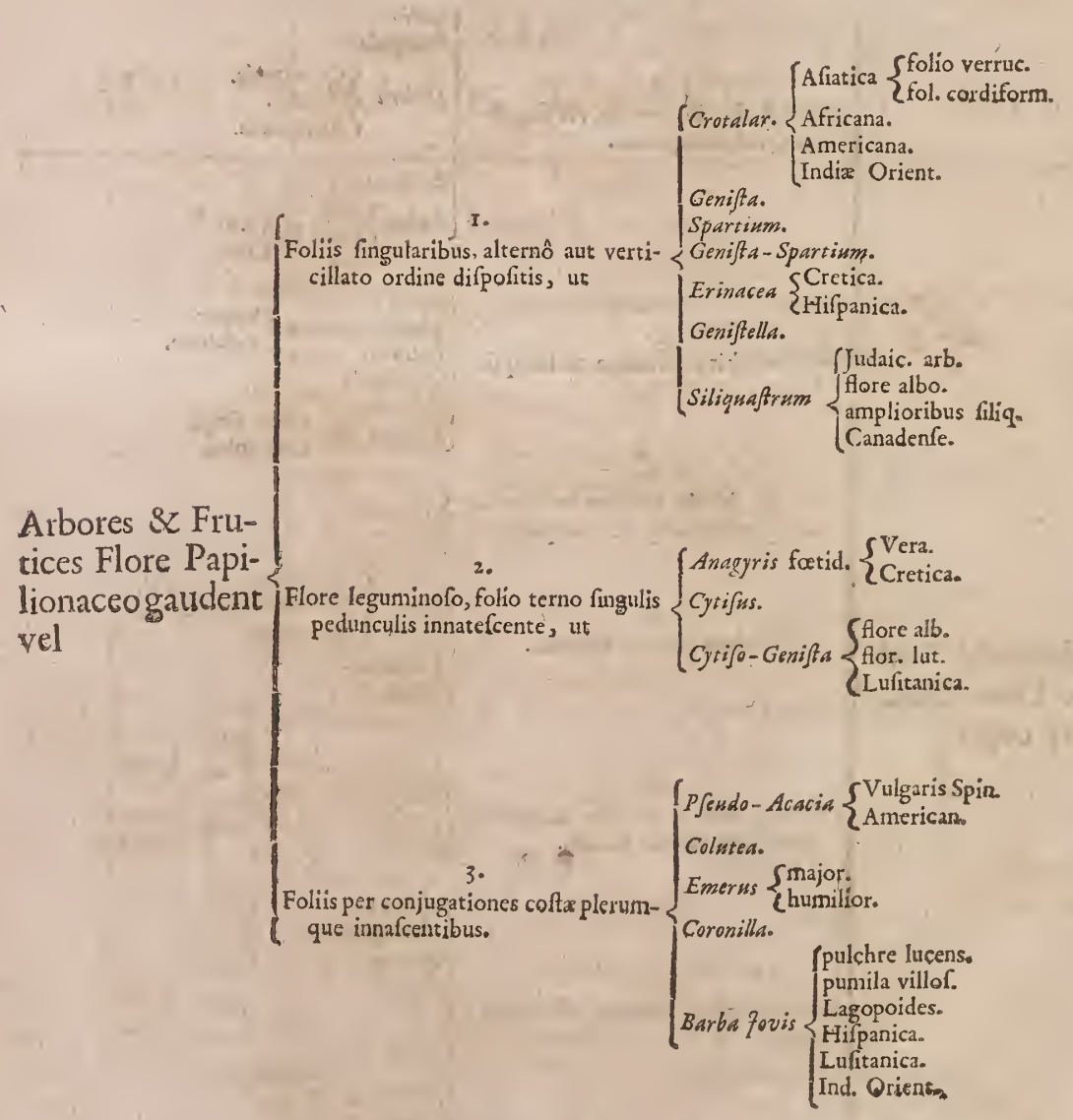




\section{CLASSIS III. \\ $D E H E R B I S$.}

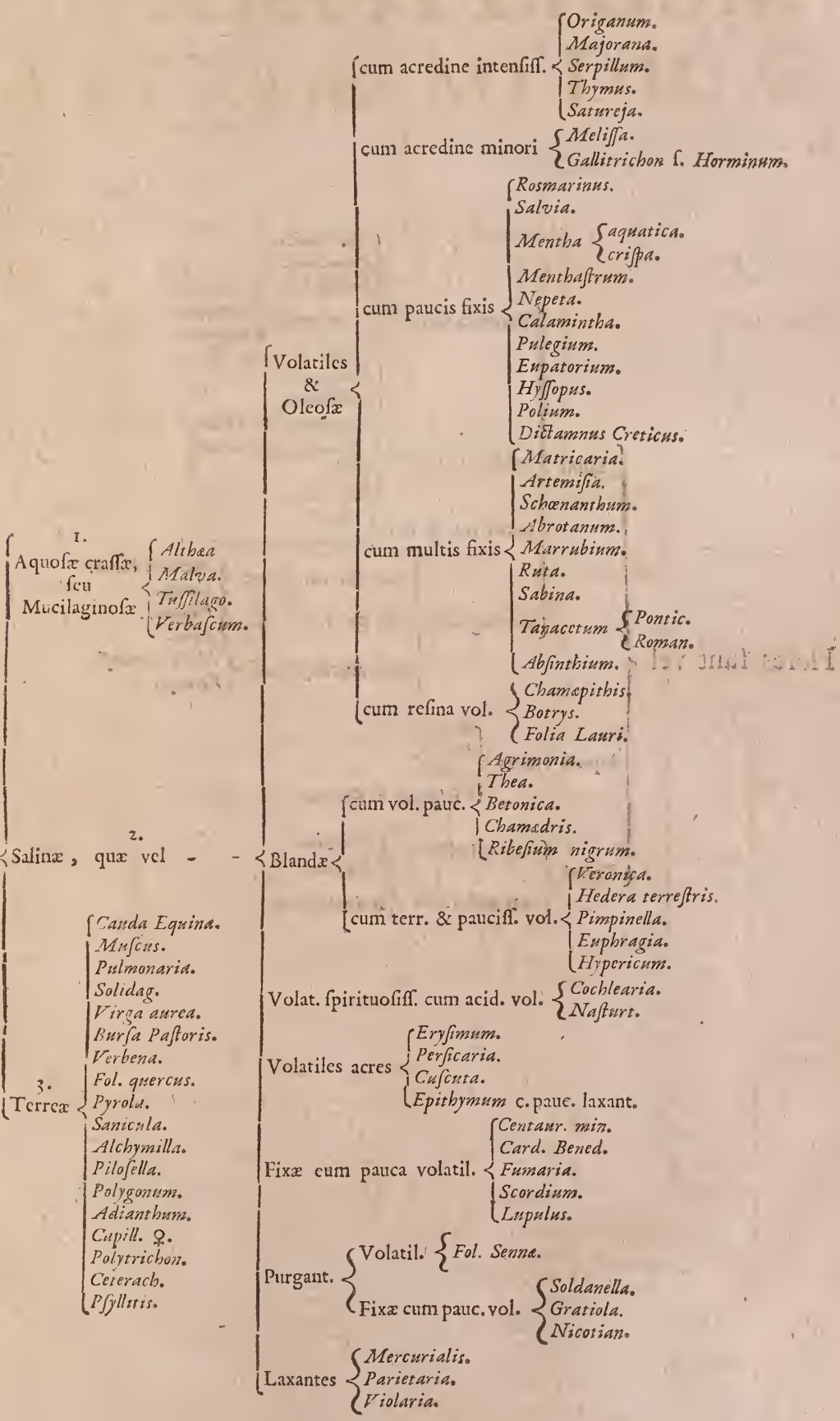




\section{CLASSIS I V. \\ $D E, F L O R I B U S$.}

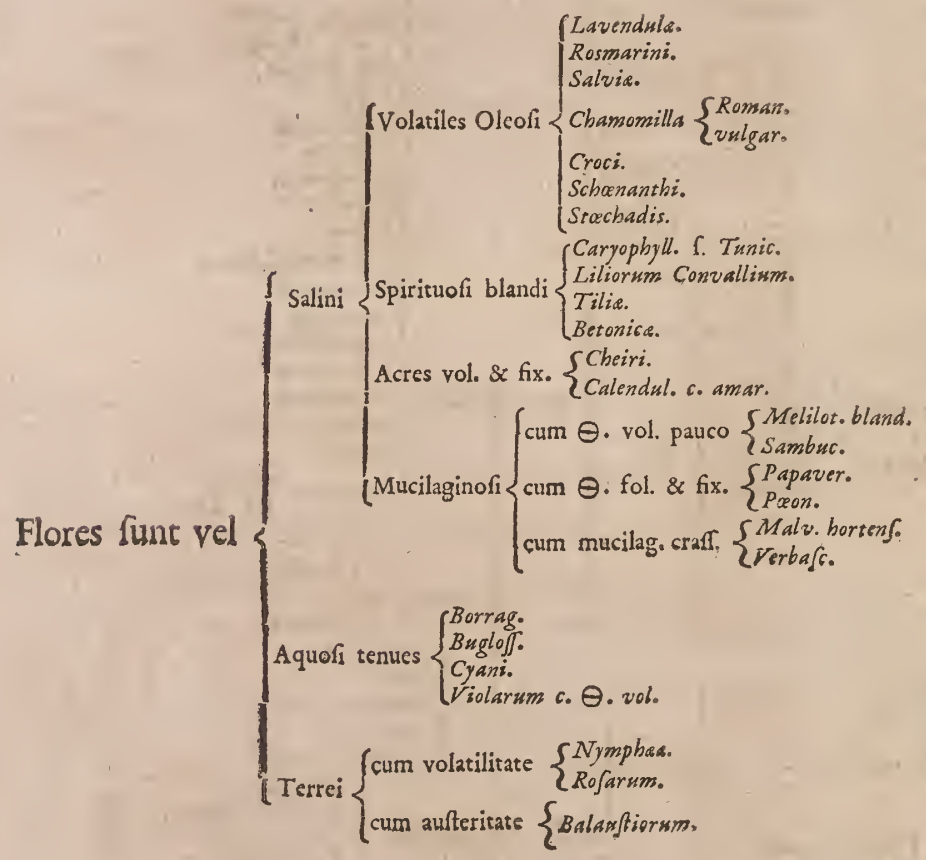




\section{DE FRUCTIBUS ET SEMINIBUS.}

Fructus \&xSemina funt vel

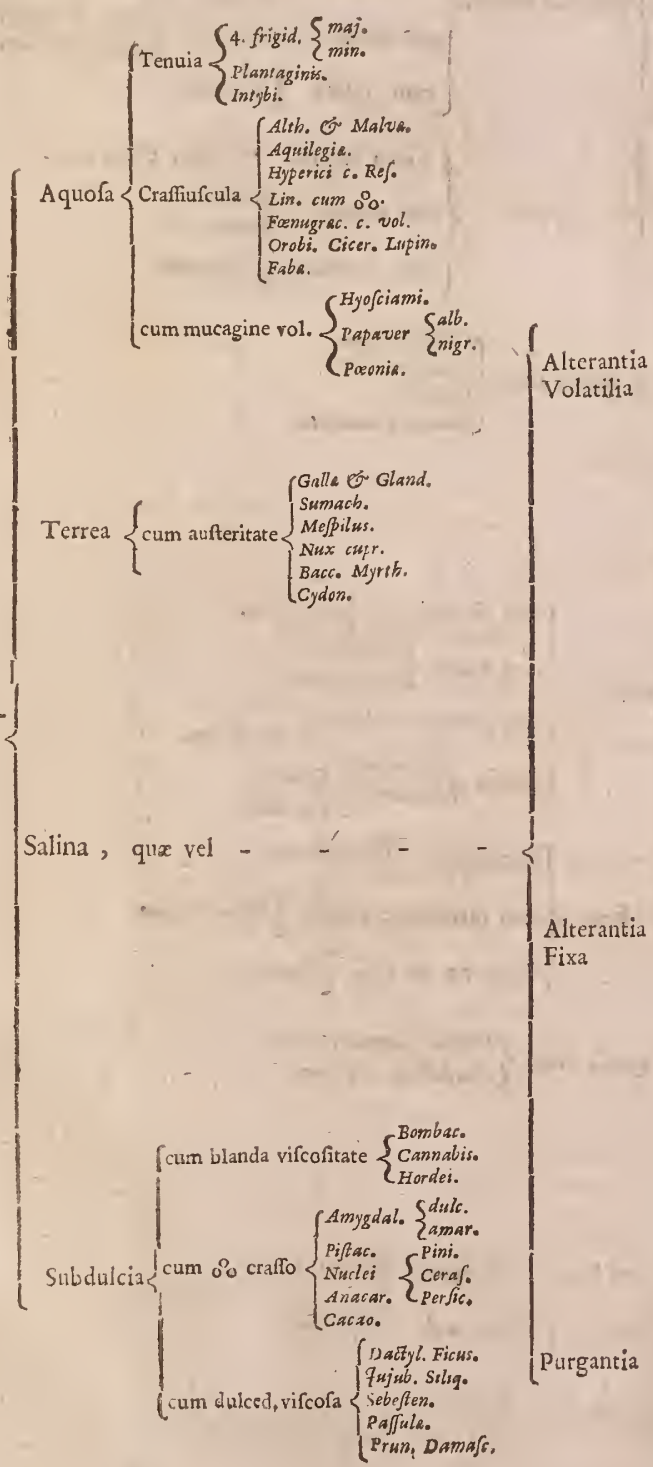

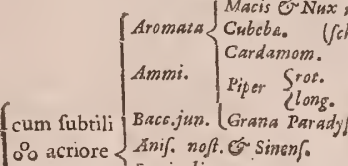

Eaniculi.

Leviftici.

Anethi.

Carvi for Sumini

Bace. Lauri.

Carpobalfami.

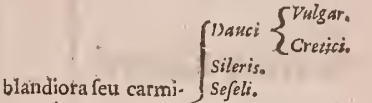

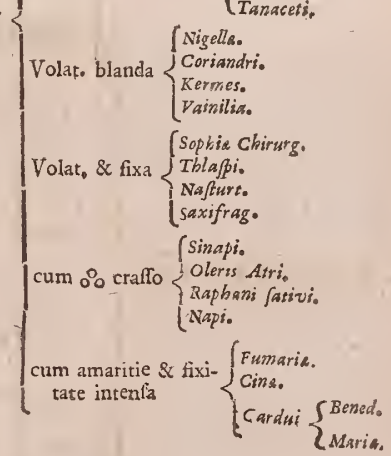

\section{Cusm lentore $\{$ Bardane.

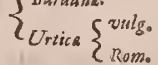

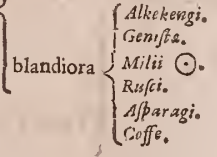

frolat. $\left\{\begin{array}{l}\text { Mezereum. } \\ \text { Pfillii. } \\ \text { Staphifagr. }\end{array}\right.$

vol. \& fix.c. amaritie $\left\{\begin{array}{l}\text { Colocynth. } \\ \text { Nux Vom. }\end{array}\right.$ cum io craft, $\left\{\begin{array}{l}\text { Granatill. } \\ \text { Catap. } \\ \text { Balan, myr. }\end{array}\right.$ blanda $\left\{\begin{array}{l}\text { Atripl. } \\ \text { Sarn.buc. } \\ \text { Cnici. }\end{array}\right.$ blanda $\left\{\begin{array}{l}\text { Cnicio. } \\ \text { Myrobal. }\end{array}\right.$ cum aciditate $\{$ Tamarind。 cum dulci vifcofit. $\{$ Galia fif. 


\section{CLASSIS VI.}

\section{DE CORTICIBUS, LIGNIS \& FUNGIS.}
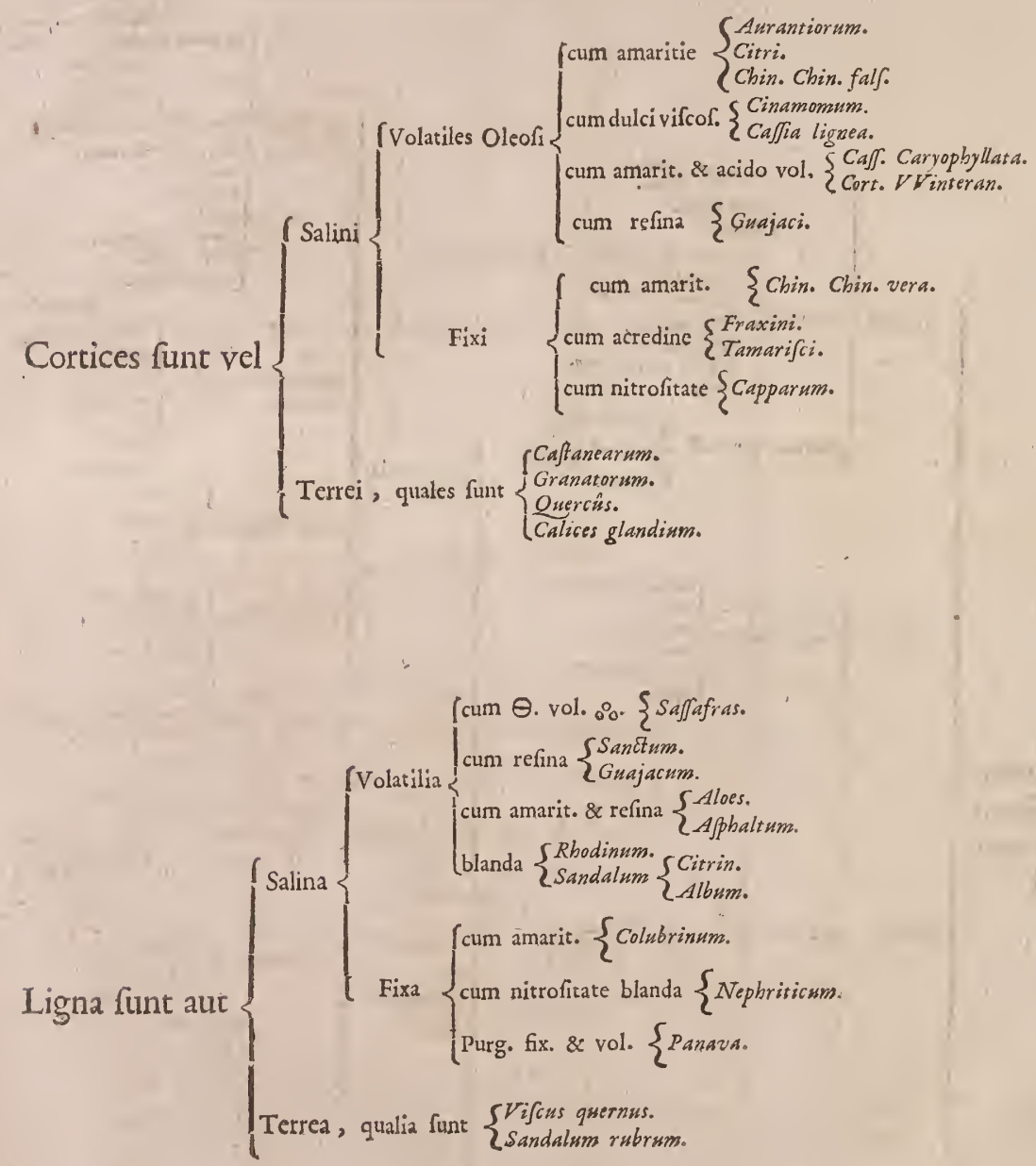

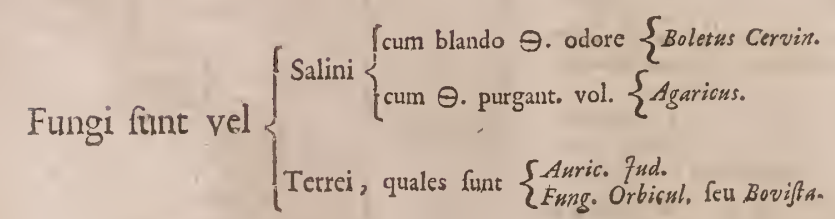




\section{CLASSIS VIII.}

\section{DE MINERALIBUS.}

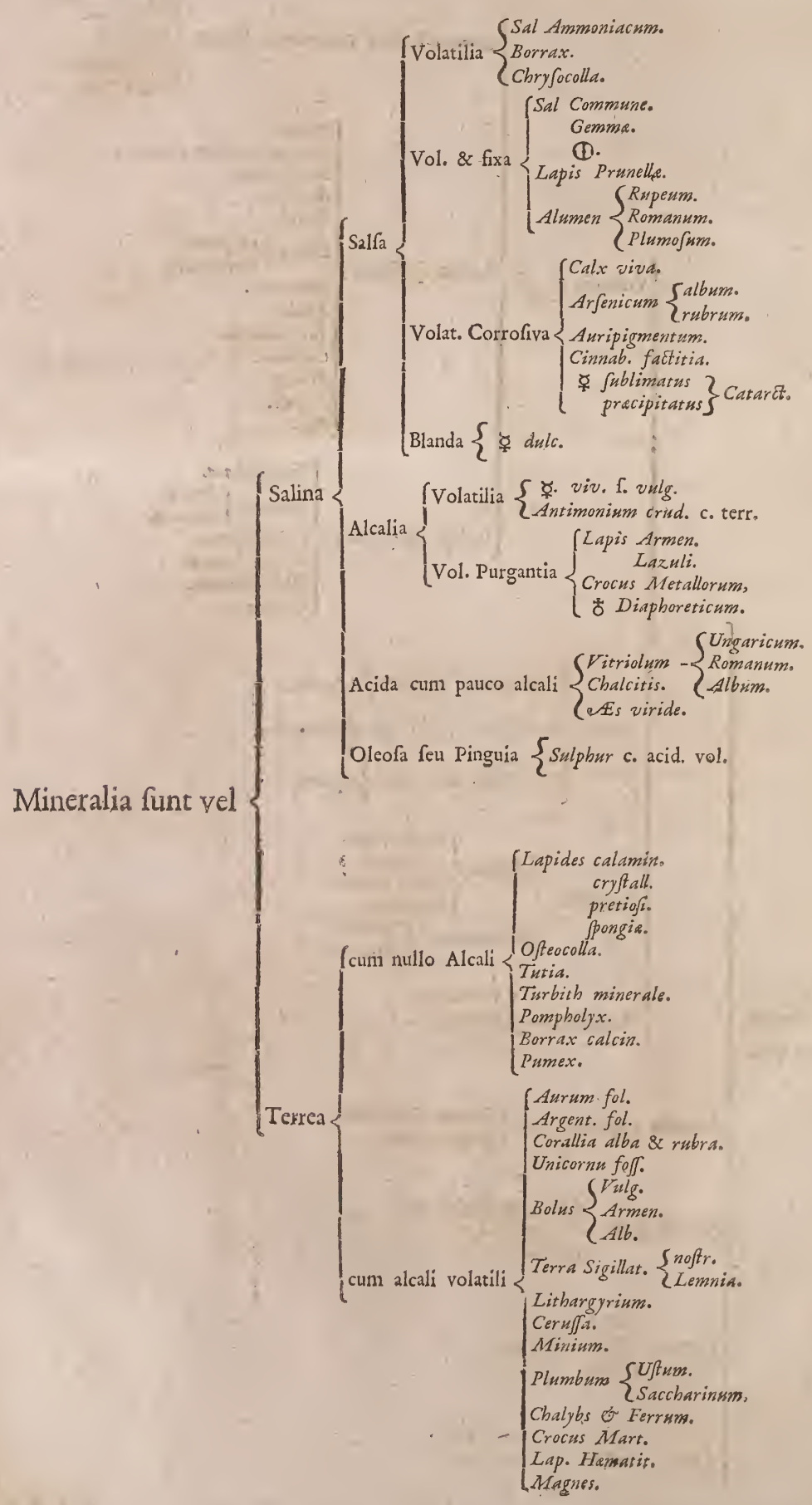



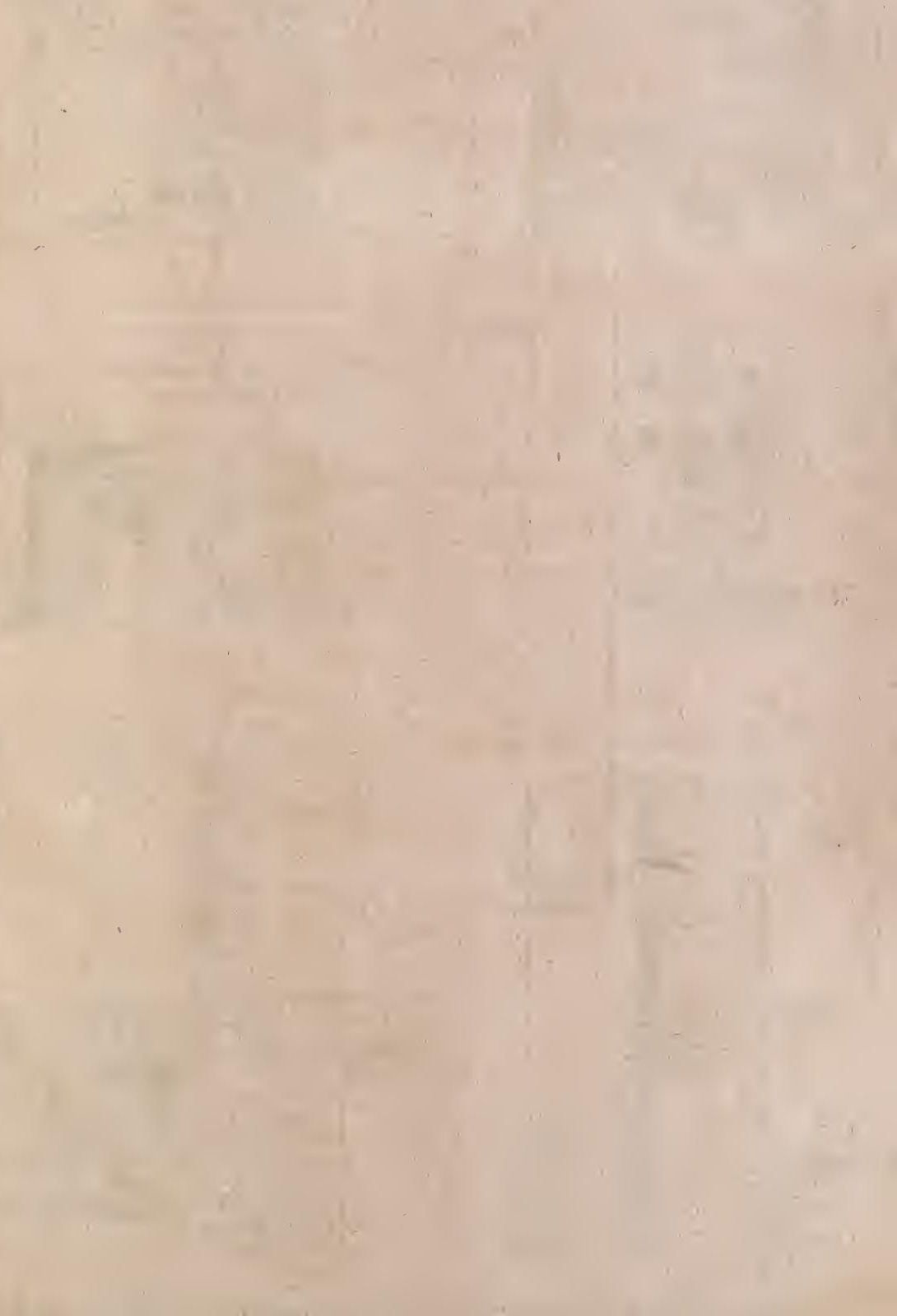

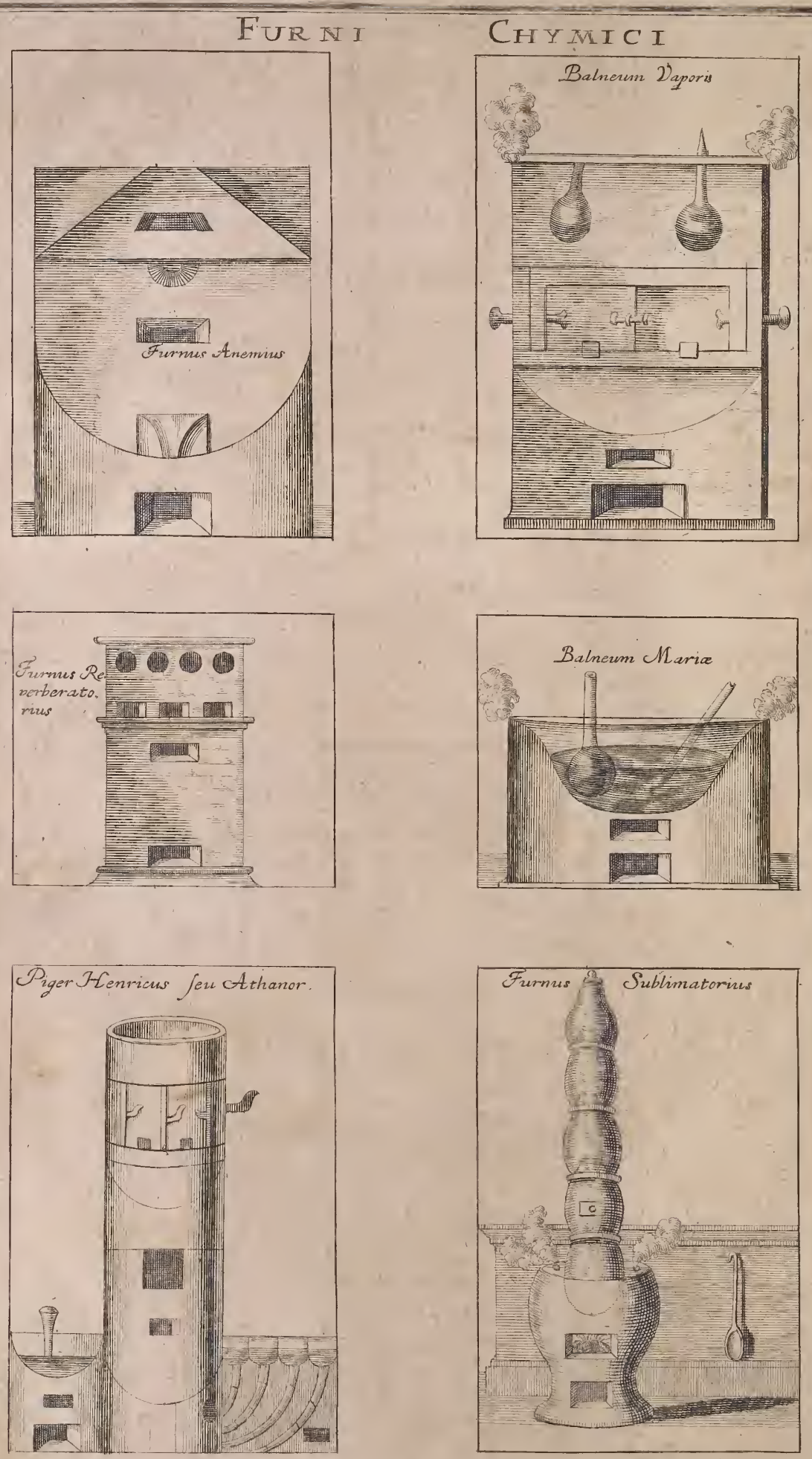


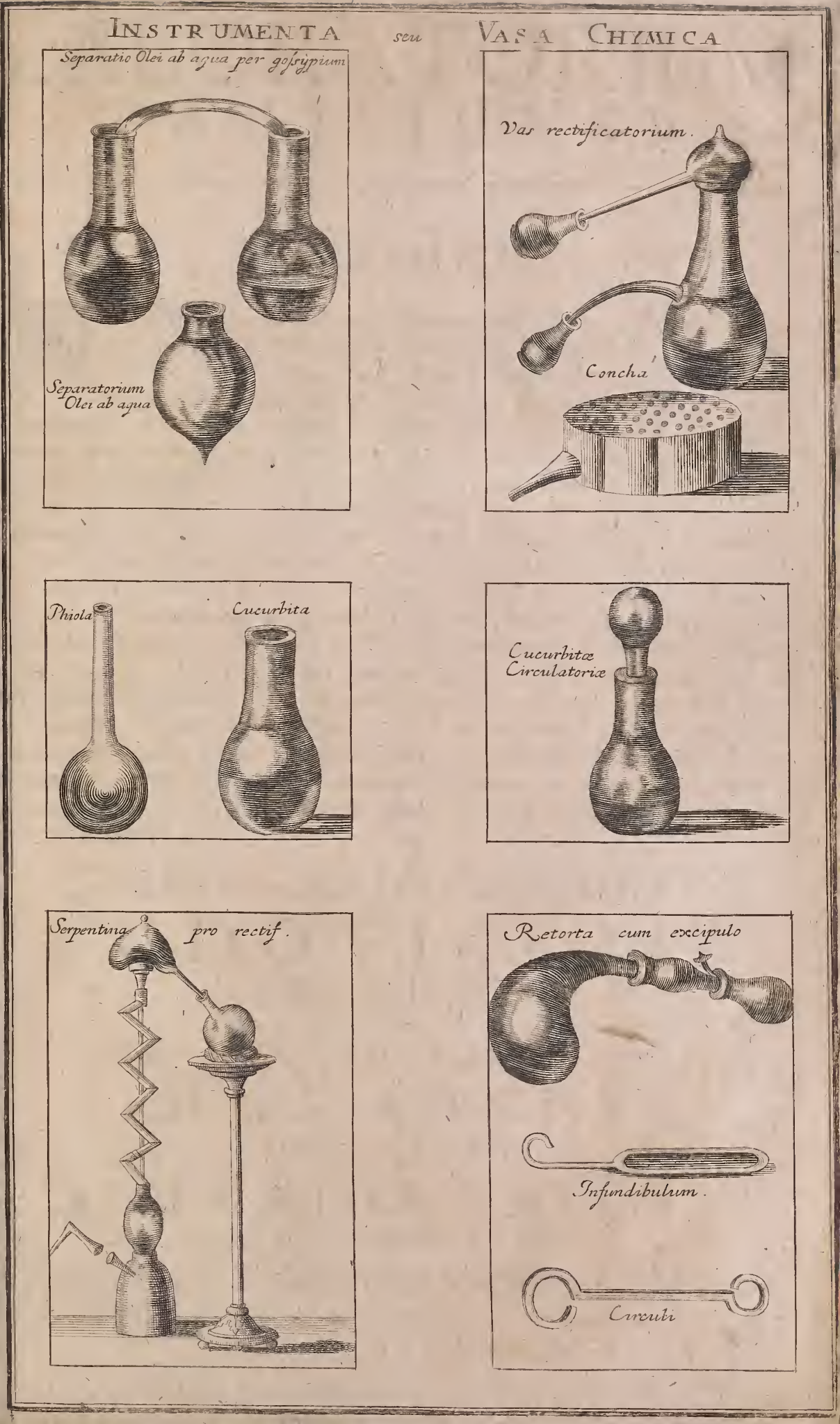


twolylsion

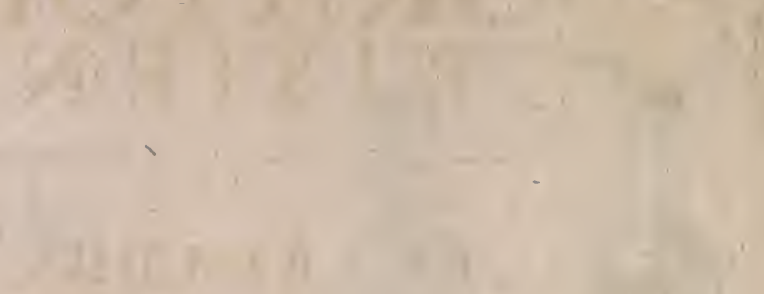

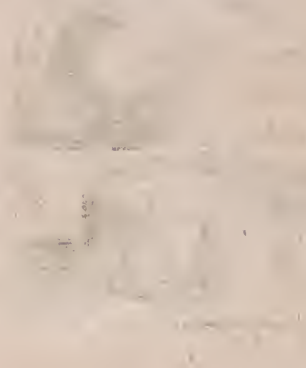

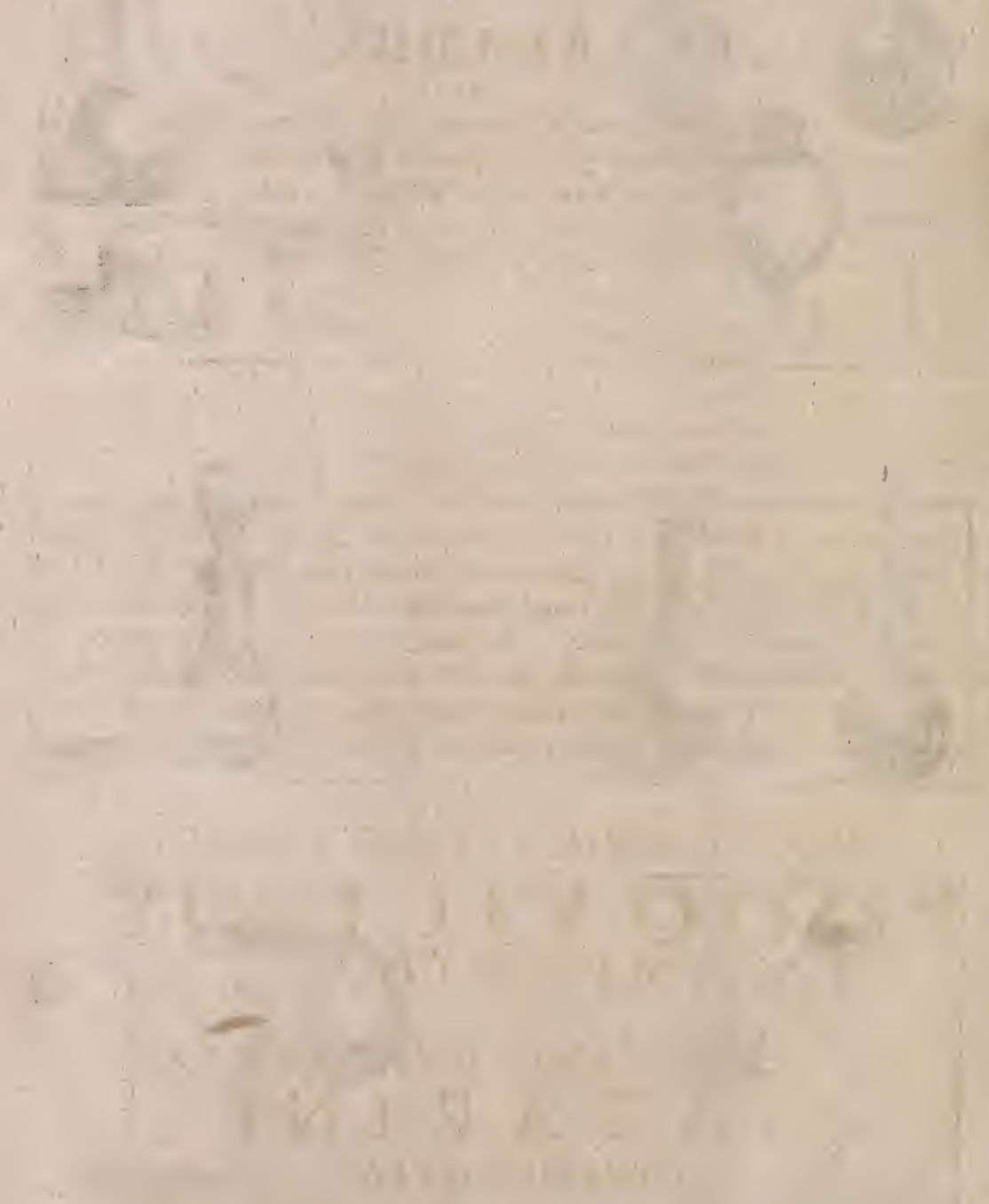

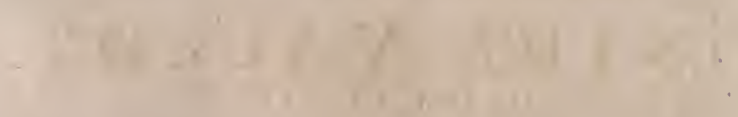

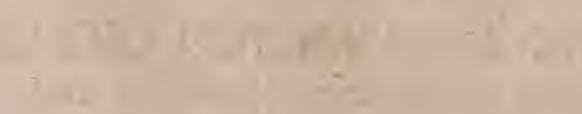

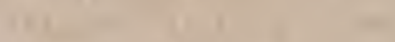




\section{LABORATORIUM \\ P A R I S I E N S E.}

\section{N T R O I T US.}

W Vantoperè peregrinationes Es itinera, verfus Exteros fufcepta, elegantioris Literature Studiofis. cumprimis autem Artis Medica Cultoribus, fint proficua, prater alios Willius in tribus Differt. de Itineribus Philiatrorum Germanorum 85 "Thomas Bartholinus in Tractat. de
Peregrinatione Medicâ jamdudum oftenderunt. Prout autem varia funt peregrinantium propofita fcopique diverfi, ita varia quoque illic requifita EF cautela obfervanda-funt. Quemadmodum enim Theologo futuro ea, que facra concernunt, templa fanaque publica, ritus EO Oratores Ecclefiaftici thorumque geftus cura cordique funt: quemadmodum Es Legum Statusque publici periti Regum Principumque Aulas E Curias pre alis frequentant; ita Medici eorumque Cultores de Hortis publicis, Laboratorris Chymicis, Theatris Anatomicis E Nofocomiis invijendis magis funt foliciti, qua Lutetia Pariforum, in Suburbio S. Victorii, conjunctim ES Iimul pectari poffunt, cum in atrio Horti Regii non tantium Laboratorium Chymicum, Jed ES Theatrum Anatomicum \&5 Mufeum Curiofum: E regione vero maximum S. Ludovici Nofocomium (pectentur. Vt autem agris bic denfo agmine decumbentibus eo factlius \& promptius fuccurri posfit, binc laboratorio proxime adjacet Pharmacophylacium pauperibus dicatum, in quod omnia illic à Cbymico Profeffore elaborata reponi folent, ut è feq. Infcriptzone foribus adfcripta, elucefcit:

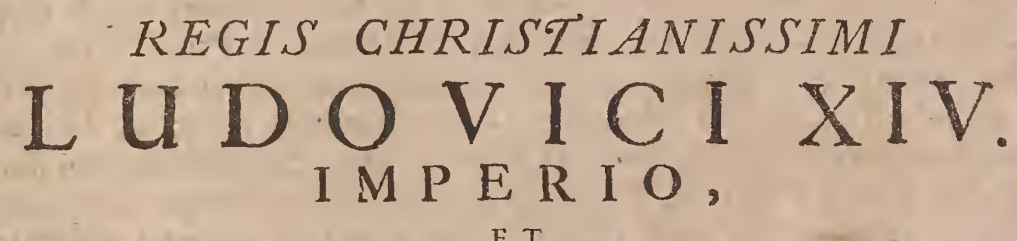

EMINENTISSIMI CARDINALIS

M A Z A R I N I

MUNIFICENTIA,

\section{A NTONIUS VALLOT}

ARCHIATRORUM COMES

OFFICINAM HANC PHARMACO.CHYMICAM

IN PAUPERUM SUBSIDIUM ET PUBLICI COMMODI GRATIAM

EXSTRUXIT ET INSTRUXIT. 
Et quamvis laboribus Chymicis, publicè illic infitutis, Pharmacopaus qudam Regius defunsi Joleat, uplurimum tamen id Jub dircetione Profeljorts ES Horti Regii Infpectoris feri, è fequenti Programmate, ex Piodiomó Commentarii in Petri Severini Medicinam Philofophicam, à Wilhelmo Davilfonio editi, petito videre licet:

\section{AUSPICIIS REGIIS \\ WILLIELMUS DAVISSONIUS, Scotus, Confiliarius \& Medicus Regius, Horti Regii Plantarum Medicinalium PR ÆFECTUS,}

B Otanicum \& Chemicum Fontem aperiet cognitionis \& fcientix cllpidis. Ex illo ftudiofum cultum, novum ordinem plus feptingentarum plantarum acceffionem videbunt. Ex hôc Animalium, Vegetabilium \& Foffilium Aualyfin accipient. In Antimonii preparatione \& exaltatione multus erit: quia non fufficiunt nomina ad tam divitem naturam appellandarr, qux principium vitæ, balfamun \& medentem mumiain in fe habet. Verum verum dico. Non eft fub coelo medicina fublimior.

In Aula Horri Regii Plantarum Medicinalium, qux Parifiis eft, die. 23 jul. \& deinceps horâ fextâ matutinâ. Anno 1648.

\section{In Suburbio S. V. A.}

Idem temporibus jubfequentibus quoque ad noftrum usque feculum obm timuiffe vel exinde conftat, quod Botanicus toto Orbe Celeberrimus, Jofeph Pitton de Tournefort, prater Scholas \& Demonftrationes Botanicas, nunguam non elegantiores etiam Medicamentorum Chymicorum praparationes Auditoribus juis infillaverit : quarum defcriptiones quum haud ita pridem, una cum AEtrologiis EF ufbus, à Venerando Dn. Parente meo adjectis, obtinuerim; havd ingratum fore duxi harum rerum Curiofis, fi easdem reliquis Touncortii laboribus, in compendium redactis, hic maritavero, non alium in finem, guàm ut propriis aque ac Commilitonum fudiis velificando glori. DEI T. O. M. Proximique commodum indies magis magisque amplificetur. Dab. Giefse è Mufeo, die 13. Dtartii A. 1715 .

Christoph. Bernhard. Valenttini, M.C. 
extraverfa funt, vis emetica defideretur, non fecus ac in "ö diaphoreticô,ubinimium figuntur aut abiguntur. Quando igitur ipfum $\delta$, aut minera ejus, five in terræ vifceribus à natuta (quale mihi ad manus eft) aut enchirefi Chymica calcinatur, utrobique etiam particulæ $\triangle$ rex fub agitatione à reliquiis extricantur, quibus \& color puniceus aut fuccincus adfcribendus eft. Sienin caput mortuum poft cinnabaris \& butyri of fublimationem in vitrum mutaveris, ob defectum particularum frrearum plane album \& omnivi emetica deftitutum erit, obfervante W'ILLISIO, in Pharm. Rat.S. 4. c, 4. p. 38. Cur atutem Vitrum do potius, quàm Crocum Metallorum $q$ hic combinet Autor? ratio forte eft, quod particule vitri antimonialis, tanquam craffiores, non tam facile poros lacinix, per quam colari debet $\frac{7}{7}$ imbutus, tranfeant, quàn crocus metallorum, qui in fubftantia affumtus peffima fymptomata inducere valet. Inde enin eft, quod $q$ emeticus, etiam cum croco metallorum abfynthiaco paratus, tantas fiepe hyperemefes \& hypercatharfes moveat, ut Medicos noverin celeberrimos, qui voto feaditrixcrunt, quod nunquann illô pofthac in Praxi ufuri fint. Poftquam enim à Pharmacopoeis (defcriptioni MYNSICHTI hic ftrictè inhærentibus) folutio $q$ croco metallorum ebria per manicam Hippocratis colatur, non poffunt non particula quædam è croco affricari q, qux intus affumpt:x turbas ejufmodicierc folent. Quodfi ècontra Tartarus Emeticus, LUDOVICI more, è croc. metall. ac 7 purioris vel cryftall. Tana in duodecuplo $\nabla$ calidx paretur,digeratur,coquatur, calideque per duplicem chartam bibulam filtretur, tantum abeft finiftros hujufcemodi effectus inde pertimefcendosefle, ut potius eundeminfantibus, etiamanniculis, tutiflimè propinarim.

\section{Ufus.}

It Emetici ef ampliffimus, fiquidem omnes ventriculi cruditates, morbis quamplurimis, tam chronicis, quìm acutis, fomitem prabentes, longè certius \& tutius, quàm decantata hodic ventriculi excutia (die Magenböft vulgòdiâta) tollit \& quafi vectibus excludit. Hinc non tantùm anorexiam, apepfiam \& difpepfiam, cardialgiam \& alios ftomachi affectus, fed \& varios inde per confenfum exortosmorbos, cephalalgiam, vertiginem, epilepfiam, apoplexiam, lethargum, timnitum aurium \&c. coradicitus exftirpare poffumus. Quid in febribus, tam intermittentibus, quà m continuis, etiam malignis, preftet, ipfa Praxis loquitur, cum utrobique unicum emeticum, tempeftivè adhibitum, aut lufficiat, aut fundamentum pro curâ feliciori jaciat. In Dyfenteriâ Ipecacuanhæ fuccedaneum cféc in Polychreftis exoticis jamdudum oftenfum eft. In venenis, philtris \& finilibus affumtus in principio omnibus alexipharmacis palmam eripit. Interim \& cautelx, à MYNSICHTO traditæ, ante cjus exhibitionen probè expendendr funt, ne in picrocholis \& advomendun difficilibus movendo quid, fed non promovendo, cardialgiam, in gravidís abortum, in chlorofi \& menftruorum obftructione anxietatesaut convulfiones \& in phthifi confirmatâ hæmoptyfin lethalem procrecmus. Ex altera verò parre nec meticulofi nimis aut fuperftitiofi fimus, fi vel in Hectica aut Phthifi incipiente vomitoris ufus indicetur, cum LUDOVICO tefte plures ex emeticorum \& opiatorum intermiflione pereant, quam illorum ufu.

\section{Sit modus in rebus, fint certi denique fines. \\ Temporibus Medicina valet, dasa tempure profint, \\ Et data non apto tempore multa nocent.}

Dofis in infantibuseftgr. ß. ad j. In Adultis à gr.ji. ad iij. In duriflimis gr.iv.aut ad fummum v, Præfcribitur ita:

Re. Q. emet. gr. iij.

Sacch.gr.vi. M. F. Pulv. pro dofi.

\section{III. \\ Antimonium Diapboreticum.}

8\%. Reguli o. pulveris. EBß. M. cum

(D. candidifimi tbj. \& detona in ctucibulo: Pulverem gryfeun, fcoris liberatum, folve in aquâ communi fervente: Solutionem filtra, \& in filtrô remanebit pulvis candidiffinus, qui itera. tis vicibus edulcorandus, \& nomine of. diaphoretici affervandus. In folutione poft aliqualem evapo: rationem concrefcentcryftalli ex (D), qui Nitrum antimoniatum vocantur.

\section{Ratio Procefjus.}

Quum particula $\delta$. $\triangle$ rex, ut in antecedentibus demonftratum fuit, vomitum ciere folcant; hinc ad obtinenday folam vim diaphoreticam, autabforbentem, ill $x$ penitus fubjugand $x$ erant. Fit autem hocper additionem $(\mathcal{D}$. in majori, quam ad reclufionem of tequirebatur, quantitate, qua aut omninò figuntur, aut fub detonatione violentiori penitus abiguntur fulphureæ ejufdem portiuncul$1 x$; eumque in finem in vulgari $\delta$. diaphoretici preparatione $\delta$. crudo triplum, ant quadruplum $(D$. additur, hxcque fimul aut trinâ, aut ( quam alii magis laudant) unicấdeconatione in pulvercm illum diaphoreticum convertuntur. Cur aurem in proceflu Autoris noftri Regulo to tantum duplum $(\mathbb{D}$ addatur, ratio cft, quòd fub præparatione Reguli t Salia alcalia $q \&$ (1) fixi, tanquam nimiscauftica \& corrofiva (explicante ETTMULLERO in Colleg. Chym.) multum de 4 宁. jain abforpferint \& infcorias depofuerint, unde tantum (1. nonrequiritur, quantin in deconatione 8 crudi, juxta vul- 
garem procedendi modum, neceffarium erat. Non enim omne è Regulô Antimonïi Á ablatum effe, tum infufiones \& pocula emetica è Reg. to parara, tum Regulus to Medicinalis, à multis hactenus contra febres intermitrentes in arcanis habitus, teftantur, utpote qui præter fudorem fape vQ. mitus quofdam, non finc euphoriâ, movet, \& fecundum VIGANI ductum ita paratur:

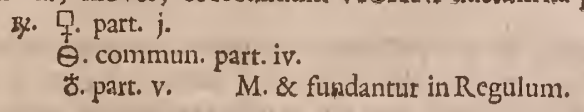

\section{Uus}

of Diaphoreticiexipfo nomine \& cognomine innotefcit. Quamvis enim WILLISIUS in Phar. mac: Ration.Scet. V. Cap. I. virtutem ejus diaphoreticam in duhium videatur trahere, nefciendo cujufmodi cjus particulis vis hæc debeat attribui, adeoque profiftendis feri aut fanguinis fluxionibus tantùm commendet, eò quod hæc terra propriis falibus orbata alienos (quibus fortè in corpore noftro occurrit) acidos 'fales imbibat, ficque abforbendo magis agat; attamen \& hoc intuitu reliquos humores circulantes ab acido vindicando \& ad liberaliorem tranfpirationem difponendo diaphorefin, experientiâ tefte, egregiè promovet, eaque de causâ in febribus intermittentibus, ETTMULLERI. vetbis, plus confert, quàm fpecificum antifebrile Crollii, aut Strobelbergeri, cumprimis, fi cum $\Theta$. armoniaco (in Hectica cum (1) fociato) propinetur. Non minus in febribus continuis, tam benignis, quàm malignis petechialibus, pleuritide benigna \& malignâ, eryfipelate alijique à fanguine plus minus grumofo oriundis morbis, falibus volatilibus CC. fuccini, cinnabarinis, \& quaridoque opiatis maritatum, eft egregium. Quid quod \& in Lue Venereâ diaphoreticum non contemnendun conftituat, cumprimis è Regulo t. ad ductum Autoris noftri paratum, \& Ceruffe talis nomine alioquin cognitum, utpote quod prater effectum diaphoreticum falivationem quandam, şriahbus aliàs familiarem, excitare dicitur ab ETTMULLERO, in Collegio Chymico, Dofis ejus eft à $\partial j$. ad $z$ R. Præf́cribitur ita :

Bz. t. diaphor. Эj.

$\Theta$. vol. CC. gr. v.

Ther, cocl gr.ji. M. F. Pulv.

\section{V. .}

\section{Diaphoreticum Martiale anticacbecticum.}

R\%. of crudi pulveris.

Squamarum ferri ana p. $æ$.

M. probèatque inde crucibulo, quod expone igni forriffimo \& matcria liquefcet, vel in maffam conerefcet. 'Hac fluens ex crucibulo in pavimentum projicitur, ut refrigeretur: abhinc pulverifatur atque cum duplo (1) - mifta detonatur, prout in pracedente $\delta$. diaphoretici preparatione fieri folet. Tandem in aquam frigidam injectapluribus lotionibus edulcoratur. Quodfi verò materia hæc in maffam concrefcat, hæc per integram horam in igne relinquitur \& probè ignitur, hosque facto pr $x$ paratur ut ante dictum.

\section{Ratio procedendi}

Eadem, qux in prxcedenti operatione, fubeft, nifi quodad majorem vim abforbentem medicamento conciliandam addatur or.acido p. $n$. in hypochondrio \& primis viis nidulanti chronicofque morbọs alenti quam maximè contrarius.

\section{Ujus}

Ejusin cachexiâ \& chlorofi, in İterô, dyfenteriâ malignâ omnibufquue affectibus cutaneis, fcabie \& fimilibus non faris decantari poteft à LUDOVICO, in Pharmacia moderno feculo a pplicanda, ut \& Mifcellancis S.R.I. Academ. Nat. Curiof. Dec. I. Anno VIII. Obr. LXV. Dofis eft Zj. ad $3 ß$. Præfcribitur ita:

$$
\begin{aligned}
& \text { V. } \\
& \text { Regulus Antimonii oralis. }
\end{aligned}
$$

By. Clarorum ferreorum itß. in crucibulo cooperto igni fufionis exponaintur, donec exactè fuerint igniti: cujus indicium eft, fi forcipe exemti \& ä̈ri expofiti non ftatim nigrefcunt. Tum adde $t$ thiß . fundantur fimul per horam circiter: Poftea injice per vices $(1)$ puriflimi pulverifati prater propter pugillos octo: relinque adhuc per quadrantis hora fpatium in igne: abhinc injice, vel mortario ferreo, vel cono fuforio. Refrigeratum Regulum libera à fcorìs, atque denuo in 
igne funde, addendo, ut ante, pugillos aliquot $(1 . \&$ fi lubet, multoties hanc praparationem repete, ut politior \& confpectior fiat ftclla.

\section{Ratio Proceffus.}

Quum focilimè, ơ verò difficulter in $\Delta$ fluant, hinc non fimul fundi, fed ferrum priuscandefieri debet. Abhinc fimul fufa abeunt in unam maffam, quum $\Delta \Rightarrow \& \Delta \delta$, in radice conve. niant, \& fe invicem facilè uniant, quod à $(1)$ fixo poftmodum abforptum in fcorias abit, è quibus haud difficulter prxcipitari poteft.

\section{vfus}

Reguli hujus ơti expetitur à nonnullis ad antimonium diaphoreticum ơale, exinde per detonationem cum triplo (1) parandum: fed prattat compofitio Autoris. Reliquas virtutes cum Regulo t vulg. \& fimplici communes habet.

\section{Sulpbur auratum t.}

Fx. Scorias Reguli t vel croci metallorum, vel \& antimonii diaphoretici, pulverifa ac folve in aqua communi, cui filtratx affunde acetum deftillatum, \& pulvis ruber ad fundum precipitabitur, qui exficcatus Sulphuris aurati to nomine venire folet.

\section{Ratio procedendi.}

Quandoquidem Scorix, in Regulorum praparatione remanentes, \& in fummitate coni fuforii reperibiles, nihil aliud funt, quàm falia alcalia fulphure $\delta$, quod abforpferant, imprægnata, hinc ad hujus feparationem \& præcipitationem folutioni illarum contrarium quid, fc. acetum inftillandum crat, juxta regulam Chymicorum: Similia fimilibu's folvuntur: Contraria contrariis pracipitantur.

\section{Ujus}

Admodumvariat, pro diverfa wnum repetitione. Eprimis pracipitationibus vomitorium: è mediis purgans perinferiora : ex ultimis certâ ratione inftitutis, anțepilepticum nobilifimum, Panaceæ Glauberi analogum, obtinebis, ad pauca tantum grana propinandum. Solutio fcoriarum, feu lixivium, per inftrumentum Glauberi,aut phiolam oblongiori collo inftructum, fub formâ fuffitus menftria prolicit: In Clyfteribusalvum ciet : Lotione autem fcabiem \& ulcera antiqua cacoëthea, imòipfam gangrænam inftantemabigit, cum partibus falinis abftergentem, fulphureis verò balfamicam virtutern exferat.

\section{VII. \\ Cinnabaris Antimonii.}

3*. đ̛ pulverifati \& ఫ̧ fublimati ana, mifce exactè in mortariô marmoreô, \& ex retortâ vitreâ ampli \& longioris colli in $\therefore$ igne mediocri deftillata dant Butyrum $ち$. Poftmodum augetur ignis, daturque infuper ignis fupprefforius, \& in collô retortæ fublimabitur Cinnabaris t, qua fraetả retortâ colligenda, \& cum capite mortuo in duobus crucibulis, fibi fuperimpofitis, (quorum commiffuræ probè lutatæ fint, oportet) denuò fublimanda eft. In hac ultimâ autenı praparatione ea notanda eft enchirefis, ut ignis non fuperet inferius crucibulum: Si enim fuperius quoque attigerit, ope-

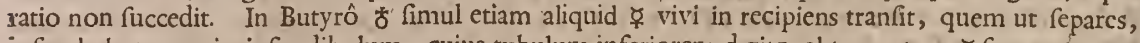
infunde butyrum in infundibulum, cujus tubulum inferioren digito obtura, tum $\Varangle$ feu argentum vivum, utpote corpus gravius, defcendet: quem remoto digito per tubum transmittere poteris in vas fuppofitum: Hunc tandem ablue probè cum aqua aliquoties \& per corium trajice. Talis refufcitatus vulgò dictus, purifimus \& $\mathrm{ab}$ omni adulterio immunis eft.

\section{Ratio Procejsus}

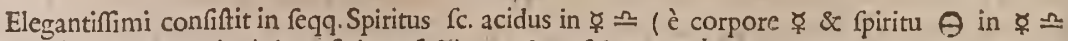
concentratô conftante) ignis beneficio exfufcitatus \& refolutus rodic partenı metallicam fen Mercurialem antimonii corrofamque fecum in receptaculum precipitat, ut ita maritati abcant in liquorem craffiufculum, odore admodum fulphureo, ob \& $\$$ inibi refolutum, gaudentem, qui ob finilitudinem, quam cum butyro ratione conffitentix habet, Butyrum t vocatur. Interea argentum vivum à fpiritu $\theta$, partem metallicam rodendo devorante, derelictus \& à vinculo ejus liberatus, partim fub antiqua formâ cum butyro to prodit, partim fe cum $\hat{\text { S a }}$ antimonii 
conjungit, qux duo fubjecta tandem in tertium, ex illis compofitum, fc. Cimabarim to abeunt.

\section{Usus}

Horum productorum \& Pharmacopocis \& Medicisadmodum proficuus eft. Priores enim unicum in hanc operationem nummum uncialem impendendo, ex calculatione LUDOVICI, juxta communem Myropolarum taxam, centum Imperiales inde lucrantur. Medici pharmaca inde contra morbos contumaciffimos, tam internè, quàm externè adhibenda obtinent. llî́c cinnabar is t in omnis generis convulfionibus \& ipfo caduco medicamentum præbet nobilifimum, adeòquidem, ut clogium illud, quod trium Imperatorum Archiater CKATO cinnabari nativæ, quam Magnetem epilepfix vocat, tribuithuic cinnabari otiam deberi dicatETTMULLERUS. Cumprimis autem Epilepfix accidentali omnibufque doloribus vifcerum fibrarumq; nervofarum (pafmodicis validè refiftit, ficque in Colica convulfiva, à fumis \& evaporationibus mineralibus oriunda (in Der SBcrgfake )

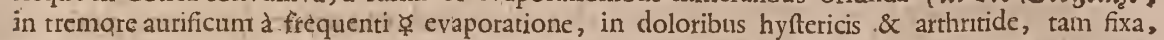
quam vaga, egregiè fefe gerit. In eryfipelate, in fpecie caput affligente aliifque capitis affectibus tantum valet, ut a Practico quondam feliciffimo D. MICHAELE in fpecificum ceplaalicum recepta fuerit. In febribus, cumprimis malignis, fua quoque laude non caret, adeò, ut POTERIO fudoriferum antipeftilentiale dictum fuerit. Multum quoque in morbis puerperarum preftat, non tantum dolores poft partum \& fpafmos uterinos fiftendo', fed \& partum ipfum, ob contractionem uteri fpafinodicam retardatum, promovendo. Dofis eft $\partial ß$. ad $\ni j$. five fola, five cum $\theta$ volat. CC. fuccini \&c. detur, qux fine ullo periculo illi combinari poffunt, dum ècontra alia falia fixa ipfi

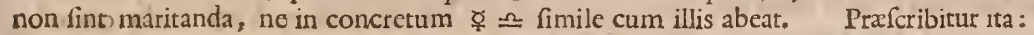

в. Cinnab. ठठ. $\ni j$.

$\theta$ vol. CC.

Succini ãă. gr. v.

Ther. coel. gr. j. M. pro dofi.

Externè Butyrum to potifimum ad excitandos fonticulos, ad cradicandos abfceffus malignos, carbunculos peftilentiales, gangranam \& fphacelum fummoperè laidatur, de quibus pluribus in Prax. infallib. Part. 2. Chirurgicâ agitur. De fpiritu (Q) Philolophicô, ఫ̛̣ vita \& Bezoàrdico minerali inde preparandss eorumque ufibus in fpecie jam, Autoris noftri ductu, paucis adhuc tractandum elt.

4.57
1,51
.13

\section{VIII.}

\section{Bezoardicum Minerale.}

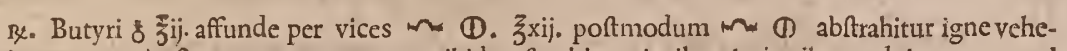
mentiori, ut materia ficca remaneat, qux albida eft; hinc pluribus lotionibus edulcoratur, vel etiam $V$ cum eâdem digeritur \& abhinc deflagratur.

Aliầs autem cum Croco metallorum ita fit :

13. Croci metallorum $亏_{3 i j}$.

$\sim$ (1). Żxij. $\quad M$. in retortâ : ebullitione \& fumis ceffantibus procedatur, ut fupra.

\section{Ratio procedendi.}

In hujus prxparatione WILLISIUS obfervat, quod, dum liquores hi acerrimi committuntur, fales mox-fibi invicem occurrentes ftrictè combinentur. Interin particula fulphurex, qux uberi copiâ fiuppetunt, prorfus exclufx \& manu qf. miffix avolant, atque falina quxdam corpufcula fecum auferentes calorem \& fumım (qf. aliquid actu combureretur; valdè tetrum cient : quibus abactis falinx relictx eum paucis torreis frictè combinantur, demumque ignem paffa, ut $\Delta$ emeticum penitus exhalet, atque falia aculeis corrofivis priventur, diaphoreticum infigne conftiruunt, quarenus $\theta$ medicamenti corporis noftri falibus occurrendo \& qf. imbibendo fanguinis \& humorum circulantium compagem laxant, ut particula ferofex è faciliıs feccdere poffint.

\section{Ufus}

Intuitu Bezoardicum Mineralc optimum eft fudoriferum in febribus omnis generis, cumprimis malignis, petechiis \&r ipfa Pefte: fi quidem in Pefte Neapolitanâ egregiè profuifre dicitur. Valet quoque in lcabic \& aliis morbis cutaneis. Dofis à gr. viij, ad gr. $x$. 


\section{PARTITIO II. \\ De \\ M E R C U R I A L I B US.}

Uemadmodum fervi fugitivi rarò abfque fpolio fe fubducunt, ita Mercurius, illis accenfitus, è priori tmematc pulverem quendam rapuit, fuoque nomine infignivit, qui

\section{I.}

\section{Mercurius Vite,}

Aliis autem Pulvis Algaroth audire folet, cùm, fi genuinos ejus natales fpectemus, potius ad Antimonialia referendus fit. Paratur enim ita:

R. Butyri to rectificati q. v. infunde in $\nabla$ communem, quæ exinde lactefcet, \& fucceffivè in

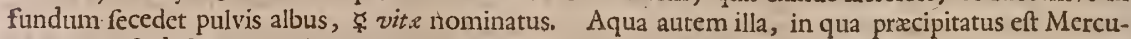
rius vita, fi deftilletur \& à phlegnate feparetur, exhibet fpiritum acidum, qui vulgò Spiritus 6 Pbilofophicus vocatur.

\section{Ratio procedendi.}

Cum butyrum to nihil aliud fit, quam Regulus to à falibus corumque $\sim$ acido corrofus, hinc, fi aquâ affusâ falia illum compedibus quafi detinentia folvantur, pulvis ille regulinus gravitato fuâ fundum petit, quı hanc ob caufam talis potius, quàm ợrialis eft profapix, quod tam à priori, quam pofteriori demonftrari poteft. Illîc enim fpiritus mineralium acidi, ob textur $x$ mechanicam, libentius cum metallis \& femi-metallicis (quale $\delta$ eft) corporibus fe jungit, quam aliis. Hîc $\not{T}$ vitæ fufus $I$. in crucibulo in priftinum $\forall$ corpus reducitur. 2. Etiam fine additione $\not=\Omega$ ex ${ }^{t}$ obtinetur, quando butyrum $\delta$ deftillatur ex $\delta$, regulo aut \& vitro $\delta$ cum $\Omega$ f faturatis, aut (D) B \& latcribus contufis adjectis, quod ETTMULIERUS fequenti ratione fieri docet:

Be. Antimon. parto j.

$\Theta$. decrepitat. part. ij.

Q. ad albed. calcin, part. iv.

Mifc. \& deftill. per retortam, \&obtincbis butyrum $t$, fed abfque cinnabari, ob defeetum è quo tamen eadom, ut in priori proceffu, ratione ơ vitæ precipitari poteft. E quibus ad oculum patet, $\mathrm{Me}_{\lambda}$ curium vitæ, vulgò ita dictum, non tam à ợiô, quàm $t$ procedere, Q. E. D.

\section{U/us}

Ejus multis eft exofus, adcò, ut ob fincceffus infelices eundem potius Mercurium mortis, quàm viť dicere malint. Aft partim injurian faciunt præparato huic, partim falsâ hypothefi nituntur., exi. ftimantes hoc ipfium à ơ $\stackrel{\Omega}{2}$. procedere, quod tamen falfifimum effe, ex antecedentibus haud difficulter colligi poteft. Quin dantur potius cafus, ubi neceffarius ejus uftus eft, v.g. in apoplexiâ, paralyfi lingux \& deglutitione impedita, in quibus ori inflati, aut lingux imponi poterit. Mitior tamen eft qui è regulo $t, \&$ quidem orali, paratur, quia fub hujus calcinatione $\widehat{\uparrow}$ fubrile partim avolat, partim à fulphure fixiori ò corrigitur. Quid quod adeò domari poffit, ut tantum per inferiora laxet, ficque $\delta$ per inferiora iaxans audiat, fi fc. per lixivium $q$ pracipitetur, aut $v$ qrifatus ab codem aliquoties abftrahatur. Dofis ejus in fubftantia funt gr. ij. \& in infusô (quod tutius) gr. $r$. Infunditur autem in vino per noctem, abhinc per chartam filtratur \& $a b \xi_{3} \mathrm{i}$ ad $\xi_{i} \beta$. exhibetur.

Quod ftagma acidum, poft ejufdem चnem remanens, attinet, illud nihil aliud eft, quam aqua $\sim \theta$. impragnata, qui facile inde per deftillarionem à $\hat{f}$ feparando obtinetur; unde rectius Spiritus falis Pbilofopbicus, quam $\uparrow$ aut $m$ Q $\theta$. Philofophicus diceretur, cum in $\bumpeq$ one $\sigma$ de $\theta$ nihil adfcendat.

Ufus ergò hujus phlegmatis quodammodò coincidit cum wru $\theta$ dulci, ejufque intuitu Tinctura florum bellidis (qua cum illo extrahitur) tam egregia \& decantata eft in reftinguenda fiti: \& ardore febricitantium, infundendo faltem 30 . vel 40 . guttas in pintam potus ordinarii.

Inter ipfa autem łrialia propriè verèque fic dicta reliquorum fundamentum eft

\section{II. \\ Mercurius Jublimatus,}

Qui ita commodius paratur:

R.

(1) exficcati.

Q. decrepitati ana lib.j. 
Mifc. cxactifịmè \& ^utus è curcurbitâ humili; cucurbitx hujus commiffura f. orificium ab initio non adéò exactè claudatur, ut ₹ falium quodammodò exhalare poflit: Vaporibus verò albis comparentibus exactiffimè obturetur circumcirca, $\Delta$. gradatim augeatur \& $\not{q} \bumpeq$ tus in formâ $\Theta$.cryftallini fuperiori fublimatorii parti adhærebit.

\section{Ratio procedendi.}

Hîc Mercurius feu argentum vivum à falibus-in Forti xquè ac mineralibus additis, diföolutus cum hifce aे fubftrato igne in fublime fertur \& propellitur, à quibus partim abforptus quafi \& in poros corum receptus albedinem cryftallinam acquirit \& ob particulas illorum acutas, fuperficiem ejus obfidentes, tantam corrofivitatem nancifcitur, utvenenorum arfenicalium inftar omnes viventium partes arrodat \& corrumpat, juvantefpiculorum aculcorumque actionem ejus mobilitate.

\section{Vus}

Ejusinternus omninò nullus eft, cùm prxfentaneum fit venenum, \& five ftudiô vel malitiâ, five per errorem loco $\Varangle$ dulcis, intus propinatus homines \& bruta ftatim jugulet, prout cafus in Pandectis \& Novellis Medico-Legalibus atteftari poffunt. Hinc peffinè \& periculosè agunt omnes, quotquot ad

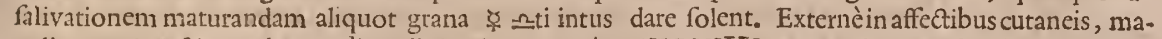
culis, nævis \& ftigmatibus eradicandis' laudatur, unde WILLISIUS aquam fuam cofineticam inde parat, quæ vid. in Pharm. Rat. fect. 3.c. 5. in fine.

Ex hoc fublimato fit

III.

\section{Mercurius Dulcis.}

B2. $\not 2 \Omega \zeta_{i v}$.

vivi f. commun. $\zeta_{i i j}$.

Mifc. probè in mortariô marmorcô, cum piftillô ligneô: poftmodum fublimenturter vel quater in phiola breviori. Sublimationem hancfi repetiveris duodecies, obtinebis Panaceam Mercurialem.

\section{Ratio procedendi.}

Quum particulæ argenti vivi fint globuloßx, hinc ơ fublima to de novô junctæ fpiculifque ejus ap. pofitx impediunt, quòminus aculeis fiuis fibras fenfiles vellicarc: \& quacunque ratione violare poffint, haud alitcr acglobuli ex cera figillatoriâ aciculis aut acubus affixx punctionemillarum impediunt; \& hanc ob caufam dulcis audit, non ratione faporis, qui adhuc falinus eft, fed tatione efficacix, quia dulcium inftar levius \& mitius in linguam \& partes agit. Quodfi tarnen fapor ejus acerbus nimium, anurus \& acris fit, aut operatio minus legitima, aut $\underset{\gamma}{ } \bumpeq$ tus arfenico adulteratus fuerit, tormina atrocia inferre folet, ut in Novell.Medico-legalibus frupra citatis obfervatum fuit. Arfenicale autem virus

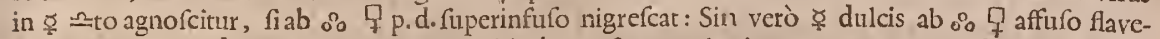
fcat, fignum eft dulcificationis minus legitimè peractx, unde de novo $c$. ఫ্ vulg. fublimandus eft.

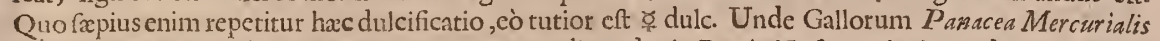
tantoperèlaudatur, de cujus praparatione \& utendi modo, in Rıgio Nofoconio Invalidorum Parifis recepto, plura vid. in Polychreftis noftris Exoticis de Panacea ఫ̛riali.

\section{Ujus}

Mercurii dulcis fatis frequens eft in Praxi,cum purgans nobiliffimum conftituat in cachexia pituie tofa, lencophlegmatia, catarrhis, affectibus cutancis \& cumprinis in Lue ơrê. Quia verò ợialia dentibus funt infenfa, hincnontam in forma pulveris, quam boli, aut pilularum danda funt. Dofis cjus eftà $\ni ß$. ad $\ni$ j. cum ftimulo, v.g.

Be. Extract, panchymag.

helleb. nigr. ãã. $\ni \Re$.

ঔ dulc. Эj.

Scammon. Arat. gr. iij.

c. f. q. Syrup. rof. fol. F. Pil, pond. gr. i. confperg. pulv. liquirit.

Pílulæ tales non funtdeaurand $\mathrm{x}$, cum aurtm foliatum o vulgi qf. revivificare fibique jungere poffit, unde $\$$

Panace ơ rialis intus (afcendendo \& defendendo in dofi) fumpta falivationem movet, \& ita Lucm o funditus exftirpat. Vid. alleg. Polychrefta exotica,

Externè क्ष dulcis fcabiem, pediculos, cimices \& alia infecta, haud fecus ac ఫ̛⿱ vulgi, curat \& enecat. Vid. Mufei Mufeorum Tom. I. Tit. de 字.

I V.

\section{Mercurius precipitatus albus.}

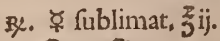

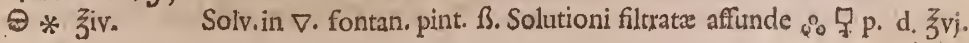


agitato liquori affunde $\nabla$ fontan. pint, ij. Trajice per chartam \& buic adhxrens pulvis vocatur 후 ₹ albus.

\section{Ratio procedendi.}

Ut connubium $\Varangle$ cum falibus tollatur, additur. $\theta *$, quo facto è folutione per contrarium $\therefore$. alcalinum facile precipitatur $\not{x}$, qui albicat, cum fulphur ejus per $\theta *$ folâ folutione in tan. tum non extravertatur, quàn fi in fpiritibus mineralium acidis folvatur, prout in feqq. videre licet.

\section{$\mathrm{V}$.}

\section{Mercurius precipitatus ruber.}

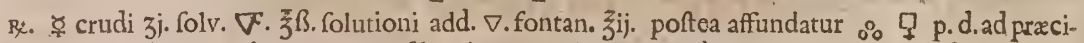
pitandum $\Varangle$ in pulverem rubrum, quem filtratione peracta leviter edulcora, $a b \nabla$ fepaando.

\section{Ratio Procefsus.}

'Evxeģýrsos hujus Chymicx Attiologiam WILLISIUS hanc dicit, quòd ợ ab Frorti diffolvatur, quatenus particulæ falinæ menftrui falibus metalli occurrentes $\cos$ fibi ftatim arripiant, indeque vinculo miftionis foluto cæteræomnes particulæ manumiffe \& quaquaverfus expanfæi inter poros metiftrui delitefcant, quæ affufo liquoremenftruo folventi contrariô facile exinde ad fundum dejiciuntur. Color autem rubicundus hujus præcipitati à proprio $\hat{A}$ argenti vivi oritur, quod per folut. cum $\sim$ (1) vel $\nabla$. magis extravertitur, cum $\sim$ (1) admodum fulphureus texturam ejus citius feriat \& penetret.

V 1 .

\section{Mercurius precipitatus huteus.}

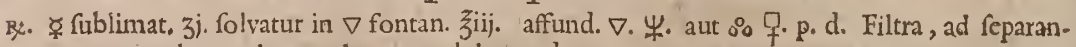
dum pulverem luteum, edulcorandum.

\section{Ratio ProcefJus}

Eadem eft, qux in prioribus, nifi quod color luteus à particulis fulphuxeis ơ rii in minori quantitate extraverfis oriatur.

\section{VII. \\ Mercurius precipitatus viridis.}

R. o. pulv. $\tilde{z}^{\circledR}$. folv. in matrac. exig. cum $\nabla$ orti ziij. admove calorem lenem, ut facilius folvatur, tum recipe $\underset{+}{\Omega} \& \Theta \mathrm{com}$, albiff.anazii. folv.in Fontan. ${ }^{2} \mathrm{vi}$. almbas folutiones mifce \& affunde guttatim $\sim \Theta *$. $\sim$. ad præcipitandum $\Varangle$, tum folutiones leviter evapora, \& obtinebis pulverem præftantifimum.

\section{Etiologia}

Coloris viridis, ob o admitam, cuivis parefcere poterit: de reliquis par parium eft ratio.

\section{Ujus}

Omnium Præcipitatorum magis externus, quàm internus eft, in curandis affectibus cutaneis, ulceribus fordidis antiquis, è quibus carnem putridam, aut fola, aut c. O. ufto abfumunt. Quid in curanda Lue o faciant, lippis \& tonforibus etiam notum eft.

\section{VIII. \\ Bezoardicum Maximum Fabri.}

Re. Stanni žiij. Funde in crucibulo: liquato ftanno adde ఫ̧ vivi pondus æquale, tum citò crucibulum exime igne \& materiam fufam in pavimentum, probè prius à fordibus mundatum \& ficcum, effunde, \& refrigerabitur. Tum $x_{2}$. hoc amalgama atque pulverifa, adde ơ fublimati ${ }^{2}$ vi. \& inde retortæ, cuiadapta recipiens, in quod Fontan. $亏_{\text {iij. }}$ infuderis. Deftilla poftmodum prodibitque liquor, $B u$ tyrum fovis dictus. Tum deluta recipiens atque retortam, ac capiti mortuo fuperfunde id, quod in

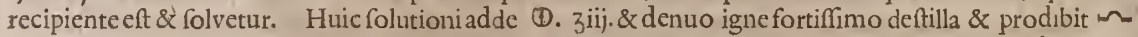
(1) duplicatus, meritò ita dicendus. Caput mortuumaqua poftmodum lavatur \&ab eadem mediante filtrô feparatur, ufuique fervatur. Diaphoreticum eft omnibus ex ơ praparatis præferendum, utex ufibus patefcet.

\section{Ratio procedendi.}

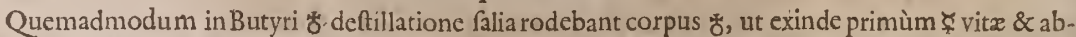
hinc Bezoardicum minerale obtineri poffit:ita hocin proceffu per falia,in fublimato recondita, Amalgana Jovis fimiliter in Butyrum Jovis corroditur, èquo poltmodum pulvisille diaphoreticus obrinetur. 
ficientes particulas metallico - terreftres in fe contineat, qux impediunt, quò femel calcinatumıninus colliquef́cat. Decatcrô $\sim$ \& $\sim$ nonnifi gradu niajoris vel minus aciditatis diffeıunt, ratione effentix autem conveniunt, cum $\%$ tantum aliquot particulas metallicas fecum rapiendo gravius \& concentratiusfit, ut levi dilutione facile in $\Omega$ mutari poffit $\& \Omega(\theta$ viciffim facile in $\% \circ$ (vulgò fic diftum) concentrari poffit.

$$
\text { Vus. }
$$

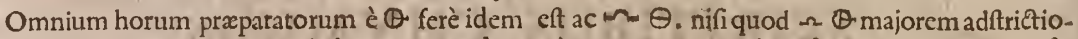
nem \& acrimoniam conjunctam habeat, eaque de causâ pulmonibus æquè ac dentibus noceat: unde utrobique $\Omega \Theta$ illi fubltituendus, illîc in pleuritide, hîcin dentium nigredine \& flavedine tollenda, quamvis preftethoc in cafuabacidis ejufmodi prorfusabftinere, ne ante congruos annos edentuli fiamus. In ardore febrium \& compefcenda fiti $\uparrow \mathbb{Q}$ \& \& cum eô parata Tinctura florum bellidis egregiè conducunt. In ftomachi affectibus, apepfia, anorexia \& fimilib. $\Omega$ (b) tribus aut quatuor partibus clix. propriet. aut menthæmifceri poterit, cumprimis mitigatus, feu ut loquuntur, dulcificatses, cum $V$. digerendo $\&$ cohobando facile parandus: qua ratione $\& i_{0} \theta$ dulcificando Spiritum $\theta$ - volatilem fuum efficere conatur VIG.ANUS, hacratione:

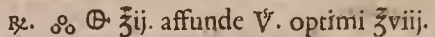

hinc calor orictur intenfiffimus, abfque ebullitione. A pterur excipulum \& $\triangle$. lento vel MB. vel $\therefore$ ab. ftrahatur ad dimidias. Hincrefrigeratiliq̨ıores, tumille, qui in excipulo eft, tum qui in Retorrâ remanfit, confundantur. Renedium eft optimum in omnibus hæmorrhagiis, tam internis, quàm externis fiftendis, quod aliàs Aqua Rabelii, famoli quondam Circumforanei, vocatur:

Si cum ${ }_{4}$ dulcificetur, Spiritus aperitivus PENOTI audıt, quià D. MICHAELE ita parabatur :

$$
\begin{aligned}
& \text { R. (A. calcinati. part. iij. } \\
& 9 \text { Q } \\
& \text { Silicum optime depurati p.j. } \\
& \text { Silutiat. p. vj. }
\end{aligned}
$$

deftillentur $\Delta$. fortifimo per Retortam, \& prodibit $\sim \theta^{*}$ admodum temperatus, in defectu menfum, malo hy pochondraco \& f corbuto cum vehiculo convenienti dandus. Valet etiam in hydrope curando, aliisque obftructionibus vifcerum, quas vocant Dofis eft à $3 ß$. ad $z j$. E capire mortuo clixiviatur c. $\nabla$. pluviali $\Theta$ dig ffivum, àgr. vj. adxij. purgantibus pro ftimulo adjic. \& cum epat.rubr. in dictis modò affectibus propunandum.

\section{Spiritus Salis Armoniaci volatilis, ommibus bactenus cognitis penetrantior. \\ ‥ $\Theta *$. \\ lapid, hrmatit. ana,}

contunde feparatim in mortariô marmorcô: Mifce \& per fpatium 14. præterpropter dierum in cella repone.Poftmodum inde Retorta vitrex, atque in $\therefore$ deftılla igne primùm lentô \& prodibit $\hat{\uparrow}$. Poftmodum adaptetur vasrecipiens \& ignead 4 . gradum aucto egredietur in adinodum penetrans, qui eximendus \& ufui fervandus. Abhinc caput mortuum, in Retortâ refiduum, fractâ hầc eximitur \& pulverifatum in cellâ reponitur, donecliquefcat: Tum ex eô, mediante igne fuppreflionis, elicitur Spiritus Salis. In qua tamen operatione artendendum, ne $\sim \hat{\sim} \theta$, qui adluc in capite mortuo reftat, cum $\sim \theta$ mifceatur. Proinde primò prodiens guftu explorandus elt, nec recipıens prius lutaridebet, quànı $\sim \theta$ percipiamus. Ultima hæc operatio multoties poteft iterari \& f cmper $\sim \theta$ elici. Hic $\sim \Theta$ cum $\sim \vartheta_{*} x q u a l i$ pondere mixtus dat Tincturam coleftem, mixturam ad onnia ftomachi vitia convenientem \& omnibus ftomachicis palmam præripientem. Si ex capite mortuo novum $\sim \theta$ dcitillare aninus fit, adde ad quam!ibet ejus libtam $\theta *$ tbß. atque iterum, ut ab initio, proceditur. Hic proceflus poteft continuari in infinitunı ferè, \& poft multas operationes, filubet, caputmortuumin crucibulo igni expono, \& exinde paro Crocum of adftrictivum.

\section{Ratio procedendi.}

Ad genuinam $\sim \ominus *$ ejusque deftillationisatiologiam explicandam confideranda primùm eft $\ominus *$ noftratis ( nam Veterum nativum erat) praparatio, quxe ex $\Theta . c 0 m$. $\odot \&$ fuligine conftar: fub quâ $\theta$. vol. urinæ \& fuliginis, dum $\neq$ evaporat, fejungit cum acido $\theta$. com. \& ambo abeunt in $\theta$ fum, feu neutrum, quod vocatur Sal armoniacum. Qhodfi jam fali huic nil nifi lapidem hrmatitem cum Autore, aut limaturam ơ cum ZWELFERO addamus, primò quidem n quodammodò alcalinus feu potius $\theta$ fus prodit, alter verò, qui fequitur, nil nifi $\sim \vartheta \mathrm{eft}$, cum hæmatites aut ò addita tantùm ad difcontinuationem particularum $\theta *$ faciant: nifi fors dicere velimus per diuturnam illam 14. dierum digeftionem texturam magis refolvi, ut $\Theta$. vol. -1 . in primâ oper tione quodammodo liberetur \&̂ elevetur. Unde BARNER US $\sim$ hunc ad acidos refert. Quodfi vero $\sim \ominus *$ prorfus alcalinum \& urinofum defideremus, aliud potius alcali eft adjiciendum, quod $\theta$ commune m $\theta *$ iepultum abforbeat atque $\ominus$. vol. urir $x$ à comped bus fuis liberet. Hun ditur, aut\& $\Theta$ ana, vel fi $\theta$ ll nimis preriofum effe videatur, cinerum clavellatorum portio xqualis, lic yue levi caridel vel carbonum calore Spiritum obtinemus penetrantifimum, hac tanien cum differcnti. , ut ficum calce viva fiat operatio $\exists *$ merum fundat firitum : Sin cum $\theta$ t aut cineribus clavellatus, magna cjuspars fub Florum $\theta *$ formâ fé firtat. 
U) $u s$.

Ufus $\sim \theta *$ acidi coincidit cun $\sim \theta$ effectibus. Alter, fcil. $\sim \omega *$ urinofus, fal volatile macrum eft, omnia fere reliqua volatilia fuperans. \&; cum particulis oleofis deftitutum fit, in morbis etiam calidiffimis, (quos per fubitaneum fudoren curat) innoxium. Diaphoreticum igitur optimum eft in febribus, tan intcrmittentibus, quan continuis malignis. Illic \& tertianam \& quartanam curat, unde mantiquartius D. MICHAELI dicitur. Hîc in malignis adeò proficuus eft, ut Pefti etiam peftis fit,attcfante ZwELFERO \& ipfa experientia. In Pleuritide maligna $\sim_{4}$ un hunc admodum proficuum obfervari. In aliis quoque inflammationibus internè \& externè prodeft. Urinam valdè movet, unde Lipfix der 5 anff: Spiritus dicitur, quia [- potatoribus movet. Adhac flatus difcutit \& nervin nus eft, in cardialgia, paffione hyfterica, Colica \& limilibus egregius. Menfes etiani movet, præmif fis tamen aperientibus fixis, tam internè datus, quam externè per inftrumentum GLA UBERI vaporerenus adhibitus. In $\$$ corbuto pariter omnibus palmam dubiam reddit. Dofis à $\theta_{\text {\% }}$ ad $z ß$.

\section{IV. \\ Spiritus Terebintbince, \& Terebintbina in $\nabla$ Jolubitis.}

Rs. Terebinthin. lib. ij,

$\nabla$. Font. lib. $v$.

$\theta$ 足 optin. そ̧iij.

M. \& in Alembico deftilla per balneum Marix : prodibit unà cum co. piofo $\uparrow \backsim$ Terebinthinx optimus, colotis aquei, faporis \& odoris grati. Peractâ deftillatione (cujus indicium ct, quando nulla tria amplius apparent ) à $\uparrow$ feparatur ope infundibuli. Tum refidua aqua lactefcens decantatur à Terebinthina cobta, fundum occupante in Alembico,filtratur acevaporatur ad confiftentiam faponis mollis, nomine Saponis alcalici veniens. Ex Terebinthinâ cocta autem vulgari modo varii coloris Olea Terebintbine deftillari poffunt.

\section{Ratio procedendi.}

Additur hîcalcali, quodretinet craflus \& fpiflus inquinamentutholeofum terebinthinæe, finulque heberat acidum, ut $\Omega$ volatilis penetrans \& $z$ efficacifimus prodeat: non fecus ac è fuccino (cui finiliseft tetebinthina) $\Theta$ vol. fimule obtinetur.

\section{Ufus}

Ejus in affectibus renum \& veficx non tantùm, fed \& pulmonium læéfơnibus internè eft laudatis fimus. Externè vi balfamica in vulneribus, cumprimis nervorum, neminem deferit. Dor. g. v. ad Эi. in vitello ovi.

\section{$P A R T I T I O \quad I V$. \\ TIN.C. I U R I S. \\ I.

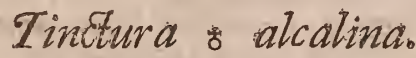

pe. w. crud. pulveris. attque lénto igne fenfim exficcasquoufque cinereum colorèm obtinuerit. Pofted mifce cum xquali pondere $\theta$ q. Mifturam funde in crucibulo, atque perfpatium 3. horarum in $\Delta$ relinque. Hinc effundcin mortarium maimoreum adipeillitum, ut indưfefat. Tum pulverifetur ftatim ac: pulveri calenti adhuc affundatur $V$. defaccatiflimus, ad eninentiam 3 . vel 4. digitorum, matracium pro. bè obturetur, ficque $V$. colorem purpureum mox induet.

\section{Ratio procedendi.}

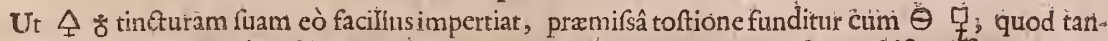
quam menftrum fem-univerfale extractionem ejus juvat Hins mirum non eft $y$ rectificatiffrmum ab eo ftatim tingi; quamvis\&hujus partes $\triangle_{\hbar}$ rex, ut in Tinctura $q$, multum ad rubedinem ejus contribuanit.

Nec obflat dari etiam $\mathcal{T}$ incturam ơ cum acido, quam Autor nofter quóogue habet \& ita parat:

ik. Croci metallor. Žiij.

Affunde $\Omega+$ penetrantifinum, ad fupereminentiam 3. vel 4. digitorum, \& poit digettionem 3 . vè 4. dierum evaporetur ad conliftentiam extracti. Hinc affunde $\sqrt[t]{ }$ defæcatifímum ac digere.

Qhod enin $\vartheta$ G agit in priorideferiptione, hoc (D) fixum fub detonationejàmdum egèrat in cro-

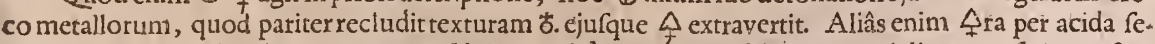
cretanon tam per folutionem aut extractionem, fed per folam fubitantiæ łrrialis corrofionem fieri ETTMULLERUS inde probat, qitod 'Aे, quod à menftruo acido intactum relinquebatur, tali folutioni partim fupernatet, partim of fruftulis inftar cruft $x$ adhæreat.

$$
\text { Uries. }
$$

Tinçư⿱ alcalinalaudaturà Chynicis in curatione morborum chronicormm, obftructionibus 
vifcerum ab Antiquis adfcriptorum, cachexix v.g. fcabiei contumacioris aliorumque morborum cutaneorumab humorum circulantium inipuritaribus or torum. Valct quoque plurimùm in obftructione menftruorum, fanguinemqque purificat. Dofis ejus efì gutt. xij. ad xv. vel xx,

\section{II. \\ Iinctura of Sanguinea.}

je. $\bar{\nabla}$. fol. ㅁ. 3 iii.

Qu or optimè exficcat. 3 ij. Pulvetifatis affunde $V$. 3 vj. Digere per aliquot dies.

\section{Ratio procedendi.}

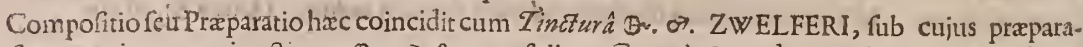

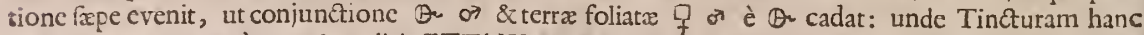
magis tartaream, quàm orąlem dicit ETTMULLERUS. Aliquid tamen de 4 or accedere faturatifima rubedo innuit, cujusintuitu etiam fanguis ò à GeilfufoSen. Practiço quondam Haflix faniggeratiffimo dicebatur: quo titulo adhuc proftatin Officinis Giflenis, Butisbacenfibus \& Francofurtenfibus.

$$
\text { Vjus. }
$$

Fortitus deobftruit quàm $\mathrm{R}$ t, in hypochondriacis, fcorbuticis, cachecticis: cumprimisautem in chlorofi \& obftructione catameniorum valde utilis. In fcorbuto tamen palmam illi dubiam reddit Tinctura or caruled D. ETTNERI, cujus genuinam defcriptionem ab Imperatrice Sorote obtinuit Epifcopus Auguftanus, ad cujus preparationem requiruntur feqq. 1. Crocus or. Be. Lim. or. purif. vel chalybis fere impalpabilis lib. j. (‥ Ungar. optim. ఫ্ণ. viv. ana lib. iv. immitte omnia in ollam terream \& vitreatam, quibus fuperfunde + vini albiacerrımum ad eminentiam 4 . dig. Pone fuper $\Delta$. lentum carbonum, \& fpatulâ ligneâ fenfim fenfimque materiam move, \& fic intra horam, vel fummè bihorium accipies ãã̃a ơale, quod $\nabla$ pura lava,\& quando puriffimum erit,tunc ficca, colloca in Retortâ in $\therefore$. \& $\triangle$ fuppreffionis per gradus evoca o.Sic in fundoRetorta manebit crocus ơ rubicundiffimus, ad colorem $q$ vergens. Hunc crocum tere \& pro ufu ferva. 2. Spiritus $\theta *$ cum xquali parte $\theta$ … a. preparatus, qui dein decap. nortuo proprio evaporatione exficcato faturatur, ufque dum nil aniplius de cô imbibat \& filtretur. Bz. igitur -ita inprægnati parum, fuperfunde fuper crocum of pulverifatum inque vitroagita, \& poft hæc effunde $\sim$ ficque repete \& crocus caruleo colore infectus afpicitur. Elue coloren cum in \&fic continua, ufquedum, quantum illiusadlaborem neceffariun eft, folutusfit, quod ex colore faturato animadverterc potes. Filtra coloratum fpiritum \& cum alrerô non co-

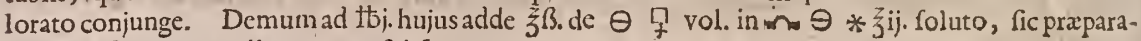
ta eft Elfentia * oralis, quam ufui ferva.

\section{III.

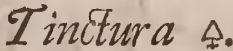

в. 合. 引j.

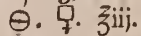

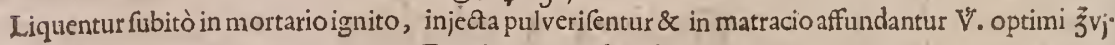
Ratio procedendi.

Cum $\triangle$ commune preter párticulas of fas balfamicas etiam terreftres \& $\leadsto$ acidum contincat, hinc ut priores ab his fegregentur \& feorfim obtincantur, cum menftruo appropriato fulphureo, fe. $\checkmark$. ex. trahendxerunt, cujus actionem ( $\hat{\mathrm{f}}$ texturam aperiendo) juvat $\theta$ 뭏 adjectum. Sic particulx sof folutx Tincturam fuppeditant rubicundam, cum $\theta *$ etiam alembicum tranfeuntem, ut in $R \Delta$ BOYLEI fieri folct.

$$
\text { Ujus. }
$$

Tinctura haceadem preftat, qux Ballamo $\triangle$ tribuuntur, quo gratior longè \& guftui acceptior clt. Confert igitur in omnibusvifcerum internorum, cumprimis autem in pulnonum lafionibus, in phthif, tuff, afthmate. Optima quoque eft in curandis affectibuscutaneis, fcabie \& fimilibus, tam internè propinata, quam externèillita. In curandis fiftulis injiciatur eum effentia Myrrha aut Elix. proprietatis, fine acido. In ulceribus antiquis \& vulneribus pariter cum emolumento adlubetur, cumprimis in illis fubjectis, quorum cutis of \& \& emplaftra perferre nequit.

\section{V.

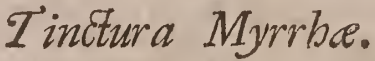 \\ 3. $\theta$ 口 $\xi_{i j}$. \\ Myrrh. 亏ैvi. \\ $V$ rectif. lib. iß. M.}

Digerantur leni calore, donec purpureum colorem elegantem fpiritus extraxerit. Liquor filtre. cur, \& ufui fervetur. 


\section{$-g)(0)(50$ \\ Ratio procedendi.}

Similia fimilibus folvuntur. Cum igitur Kyrrha fubjectum fit refinofum \& $\therefore$ fum, tale quoque menftruum, $\mathrm{fc}$. V reatif. requircbatur. 9 q additum juvat $\&$ facilitat $\triangle$ rearum particularuas extraCtionen, particulis fuis acutisadirum faciendo moleculis oofis $\mathrm{V}$. haud aliter ac mechanici, pro meliori clavorum intufione, terebrando prius aditum parare folent.

$$
\text { VTus }
$$

Tincturx hujus adcò latè patet, utD. LANGIO olim E/fentia falutis dicta fuerit. Quid quod ab HELMONTIO ipfa myrrha pro corporis humani balfamo \& vitæ confortativo habcatur; quò etiam refpexiffevidentur Magi ex Oriente venientes, \& Salvatori thus, aurum \& myrrham offerentes. Vi enim fuâ balfamica refiftit omni putredini: unde loco præfervativi contra Peftem à Paracelfo commendata olim fuit Sterzigenfibus. Quemadmodum igitur tempore peftis \& aliorum morborum contagioforum Medicos nunquam ægros vifitare juber ETTMULLERUS, nifi maftichis \& myrrhæ mafticatione pritus fe muniverint: ita pariter effentia \& tinctura myrrha hunc in finem aliis prefervativi loco prafcribi poterit: quam ipfo, quo hæc fcribo, annô, febre petechiali Giffx, (quo milites præfidiarii in ultima Landavii obfidione capti, per Galliam ducti \& duriflimè habiti, tandem in Haffiam remiffi eandem deportaverant ) graffante \& metum peftis inducente, arcani nomine venditando Practicus qu:dam,non fine fonore infigni,per fchedulas publicas commendabat. Adhæc egregium expulfivum eft in variolis \& morbillis, carameniis \& lochiis obftructis, unde \& foetum demortuum potentiffimè expellit. Pro fanguine fcorbutico depurgando feq. ratione candem prefcribit ETTMULLERUS :

Be. R. t. è fcor. $3 \mathrm{ij}$.

Myrrhe $3 j$. M.

Dentur 30. vel 40. guttx in vehiculo domentico aut appropriato.

In fcabic idem

R. R. aut effent. Myrrh. 3ij.

lignor. comp. 3iij.

\section{D. ad 40. guttas.}

In ftomacho aliifque vifceribus roborandis \& à verminofa putredine prefervandis pariter valdè prodeft, eamque obcaufam Elixir proprietatis PARACELSI ingreditur.

Externè laudaturin vulneribus \& ulceribus antiquis, cumprimis filtulofis, ope fiphonis injecta. Quin \& in fcorbuto oris vel fola, vel cum $\mathrm{K}$. ligni fancti, aut, fi hrmorrhagia gingivarum infignior conjungtrur, cum R. Laccæ maritata.

\section{$\mathrm{V}$. \\ Tinctura q̣ extemporanea.}

Hanc ante V \& quod excurrit luftrain Laboratorio Regioita parari vidi : Calcinaverant fc. \& in $\triangle$. detinuerant $\theta$, per triduum : huicadhuc calido \& ferventi infundebant $\hat{V}$. qui ftatim \& in continenti colore rubicundo tingebatur.

\section{Ratio procedendi.}

Cum Tinctura hæc, ut alibidictum fuit, potius oofis $V$. particulis quàm $\theta$ t tribuenda fit, hinc nirum non eft eafdem à $\Theta$ 궁 per diuturnam \& continuam hanc calcinationem \& calorem actualen fummè activo reddito \& $\mathrm{q}$ f. volatilifato ftatim refolvi, fuamque Tincturam fubitò de fe fpargere: haud aliterac falià volatilia cunı $\therefore$ digefta rubedinem induunt.

$$
\text { Vjus. }
$$

Tinctura $q$ egregium medicamentum in obfructionibus Vifcerum antiquis, malo hypochondriaco, alvo contumaciori, calculo \& menfibus pellendis conftituit. HARTMANNUS eandem tempore fomni affumendam fuadet: aft \& tempore matutino \& vefperi, aliifque horis Medicis funi poteft, \& quidem à gutt. xx. ad xxx. in ecrevifia, aut vino calido, vel aliis vehiculis.

Poteft mifceri cum aliis appropriatis, five nephriticis, v.g.

耿. Tinct. 号.

\section{Vel}

Elfent. બ). ana zij. M.D.gutt.xxx.ad xxxx. in vehic. conven.

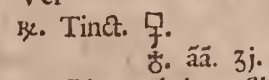

Liq. nephrit, ex filic. Glaub. $3 \mathrm{ij}$.

M. D.gutt. xxx. in $\nabla$. faxifrag.

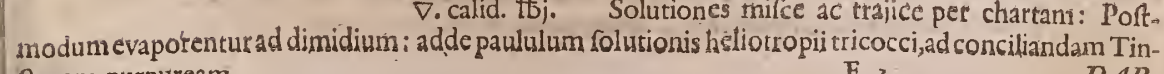

32. Qn albi zij. dilfolv. in

V. calid. tbj. Poftmodum $\mathrm{Rs}$.

O. rubri $\xi_{i j}$. diffolve itid. in

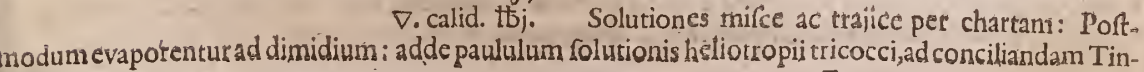




\section{I.}

Tartarus folubilis.

Be. ㅁ. crud. pulverif. tibj.

$\Theta$ 마. thß. M. ac folve in Fontan, pint. V. folutionem calefac in fartagine, cavendo, ne liquor, qui in fpumamabit, extra fartaginem emergat. Tandem trajiciatur per filtrum \& evaporetur.

\section{Ratio Procejsîs.}

Cum in vino aut cerevifia affumere ament, hinc illi combinatur fal $\square$, quod facilimè folyitur in quovis humido. Ubi tamen obfervandum eft, ut ftatim fub ipfa folutione, dum adhuc quodammodo sbutlit, abforbeatur, cùm $q$ depuratusfacilimè connubium $\Theta$ q deferat \& furdum petat.

\section{Ujus}

q folubilis eft egregius pro digętivo \& zlaxativô in hyy pochondriacis, quibus cremor \& cryftalli $q$ aciditate fua tormina fxpe movent, qux in $q$ folubili corrigitur per $\Theta$ q alcalinum. Abftergit egregiè pituitam, ventriculum \& inteftina obfidentem, \& blandâ itritatione alvun laxat. Unde in curâ acidunlarum, fi fortealvus contumacior reddatur, falutaris ejufdem ufus eft, cùn operationem acidularum perfeceffum juvet. Datur à $\ni j$. ad $z^{ß}$. in poculo vini.

\section{II. \\ Tartarus olatus.}

\section{Bz. Spirit. $\oplus$.}

$\therefore$ Q. p.d.ana. M. \& ceflante ebullitione affunde $\nabla$. calid. q. f. evapora ad medictatem \& repone, ut concrefcant cryftalli, quos cxime, iterum evapora, idque totiesrepete, donecomnem

\section{Ratio procedendi.}

Cum $\sim$ - e. nimium acidus \& corrofivus fit, hinc per additionem $\therefore$ 우 무 per deliq. tanquam $\theta$ alcalicontrarii cicurandus erat; adeòque duo hxc proportione anaticâ maritata fal tertium, quod netıtrum \& enixum vocant alii, exfurgit, \& de utroque participando mediam, falfam \& abftergentem gualitatem nancifcitur.

\section{Vous.}

Tartarum hunc $Q$ latum laudatus fxpius ETTMULIERUS in Comment. Schrod. elegans \& univerfale digeftivum ante purgationem pro affectibus vencriculi \& inteftinorum vocat; ut $\&$ aperitivum primarum viarum. Sapore enim fuo falfo \& vi nonnihil laxativa \& diuretica infigniter abftergit \&5 tenperat; hinc in morbischronicis remedium merito iaudandum eft. Obfervatidem, quodfi $\mathbb{Q} \theta$.

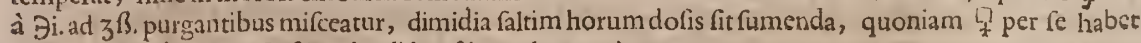
vim proritandi alvum \& fimulandi inteftina ad excretionem.

\section{III. (1)

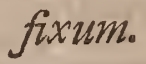

B\%. (1) crucibulum candens \& deflagratione finitâ remanebit fal, quod neutıquam defagrabit in prunas iñ jectum.

\section{Ratio procedendi.}

Cum (1) nihil aliud fit quam $\theta$ compofitum ex $\theta$ alcali \& fpiritu acido fulphureo, hinc, fialcali ex illo defideremus, ,piritus acidus ex eô abigendus eft, five per accenfionem cum carbonibus, five perdetonationem cum aliis fubjectis $\Delta$ reis: unde poft croci metallorum \& $\delta$ diaphoretici praparationem illud gratis obtinemus. Ut verò omnes $\sim$ acidi particula, fi qux poft accenfionem remaneant, penitus cnerventur, non fine cauffa Autor notter adjecit $\underline{\text { g }}$, fub calcinarione $\ominus$ fuum fixum pariter fuppeditantem \& acidum illud magis cortigentem. 


\section{Ufus}

Hujus $\theta$. Chymicis admodum proficuus \& expetitus eft ad plures folutiones inftituendas, adeò quidem, ut GLA UBERUS liquorem exinde per deliquium paratum pro decantato liquore Alkekeft venditare non dubitaverit.

\section{$1 \mathrm{~V}$.}

\section{Arcanum Duplicatum.}

Hoc nihilaliud eft quàm $\theta$ extractum è capite mortuo aquæ fortis. Eft fc. Sal neutrum, ex parte fixiore $\oplus \& \otimes$. Pro hâc operatione caput mortuum minutiffimè pulverifatur, folvitur in $\nabla$. filtratur \& evaporatur in fartagine ferreâ, remanetque Sal fixum, quod vocatur $\Theta$ ex duobres, Arcanum duplicatum Mynfichti \& Panacea Holfatica. Aliter autemà D. LUDOVICO paratur ita:

\section{Be. Q. lib. i. Solvarur in}

$\nabla$. calid. lib. iij. Solutio filtretur, \& infundatur

(1) fixi in aq. font. $ろ$ viij. folut. \& præcipitabitur terra $\theta$. Hinc liquor per chartam filtrandus eft, ut remancat terra, qux exficcanda. Poftmodum liquor evaporetur, \& remancbit $\Theta$. arcanum duplicatum dictum, quod in crucibulo reverberandum.

\section{Ratio Proce/sûs.}

In utraque operatione $S a l$ fixum (1) arripit acidum $\theta$. ficque $\mathbf{v}$ tat metallum, fimul tamen partem $\theta$-metallicam aggrediens \& aliqquid de $\triangle$ cjus fixo \& anodyno arripiens tandem in $\theta$ falfum feu enixum abit.

\section{Usîs}

Intuitu non tantum convenit cumaliorum falium mediorum qualitate abfterfiva \&diureticâ, fed \&. . intuitu vim poffidetanodynam \& fonujuferam in vigiliis diuturnis aliisque affectibus. Hinc optimum eft remedium in affectibus chronicis, malo hypoch. Scorbuto, febribus intermittentibus \& continuis lentis omnibusquelym?ph $x$ per vafa \& rencsabundantiis; it. in fuppreffione menfium, deliriis melanchol. \& mania. Dor. Эj.

\section{$P A R T I T I O \quad V I$ \\ De \\ M A G I $S$ T E R I I $S$. \\ I. \\ Lac Sulpburis.}

z. A fubtiliffimè triti,

$\stackrel{\vartheta}{\vartheta}$ ana. Liquentur in vafe fictili vitreato, hinc coq. in $\nabla$. font. Hanc $\nabla$. filtra per chartam \& inftilla acetum, fic præcipitabitur ad fundum pulv, albicans, Lac 全. dictus.

\section{Ratio procedendi.}

Contraria contrariis præcipitantur: qux Regula in Magifteriorum præparatione potiffimum obfervanda eft. Cum igitur $\theta$ fub coctione roferit fibique junxerit $\triangle$ particulas, hinc illi, ceu alcalino fubjecto, menftrum feu potius precipitans contrarium, $\mathrm{fc}$. acidum,opponendum erat, quod $\theta_{f}$, devorando particulas $\hat{f}$ à compedibus liberat \& feparat, qux fua gravitate fundum petunt. Colorem autem albicantem harum prarticularum BARNERUS à duplici causâ derivat, primò à falibus, \& 2. ab aëre; adcoque Lac vocatur Magifterium, non ratione confiftentia, fed ratione coloris, quod in inferiptione formularum oblervandum, ne cum ineptis Candidatis illud pro liquore habeamus.

\section{Ujus.}

Decantatum eft in plurimis affectibus pectoris, tuffi, afthmate, phthifi, fcabie item \& affectibus cutaneis internè \& externè. Aft licet non omni virtute balfamica deftitutum \& ita non omnino pro calce inerte habendum fit, certum tamen eft, quod virtus illa maximè caftrata fit, adcò ut $3 j$. florum 全 aut $\hat{A}$ com. purioris plusagat, quam $z_{j}$. Magifterii.

HincETTMULLER US alium, eumq; convenientiorem, habet modum Lac $\hat{f}$ abfque acido parandi, quando balfamum $\Varangle$ ad extracti confiftentiam infpiffatum extrahit cum $V^{5}$. rectificato \& abhinc pracipitat cum $\nabla$ fimplici. Convenit nontantùm in Phthifi, fed \& in Pefte rorulis prafervativis mifceri poteft. Externe Varos curat \& cofmeticum eft: 
II.

\section{Refina Falappe \& Scammonei.}

3. Jalapp. aut Scammon.contrit. q. plac. affunde V. rectif. q. 1. \& extrahetur Refina. Solutioni filtrata affundatur $\nabla$. com. \& Relina fundum peter. Spiritum vini igne lenro in Alembico vitreô denuò abitrahere poteris. Poftmodum Refina exemta aliquoties lava. turaquâ, priorem rejiciendo \& novam affundendo. Denique exficcatur \& ufui fervatur. Eodem modo proceditur in aliis Refinis parandis.

\section{Ratio procedendi.}

Quum Refina horum fubjectorum fit naturx $\circ \circ$ fx, hinc per fimile menftruum, ic. V. rectifica. stum extrahenda crat; \& cum ${ }_{0} \mathrm{O}$ nihil magis lit contrarium quam aqua communis, qux illi mifcerí nequit, hinc per hujus affufionem poriin menftruo ampliores redditi folutum amplius continere nequeunt, fed ad fundum fecedere pernittunt; quod facile in majori copia obtinetur, fi Refina in radice jalappa quodammodo extraverfa lit, \& fplendore fc prodat.

\section{Uins}

Horum Magifteriortim idem elt quifimplıcium, hâctamen cum diftinctione, quòd Refina Jalappæ in minore quantitate \& fortius, quàm mixtum integrum : Refina Scammoniiauten mirius \& debilius, q̨uàm mixtum integrum, fub eadem dofi, agant. Quod enim Rad. Jalappx $\ni j$ efficit, hoc Refin. Jalappa $\partial$ ß. praftare valet, quæ conmunis ejusdofis eft. Aliter autem res fe habet cum Scamnonio, quod in fubitantsa vix ultra grana quadam tuto datur, cum tamen Refinaduplum propinari ponits. Rationem in Sal, particulis fulphurcis combinatum, rejicit WILLISIUS, quod fub extractione Scanmonei maximam ad partem evafiffe, in folutione verò Jalappæe permanfiffe dicit ; unde \& Refinx hx faporem acriorem habentes fortius operari \& purgare folent. Conveniunt autem ad eliminandum feruns \& aquas hydropicorum aliifque in affectibus, à colluvie ferola oriundis.

\section{III. \\ Magifteria Teftaceorum.}

3e. Teftarum Oftrearum bene lotarum, \& inmortar. contuf. q.v. \& in vafe vitreo vel figt:lino fuperaffunde $\sim$ B Philofophicum, vel acetum deftillatum: Repone in digeftionem per biduum vel triduum, donec menftruum particulis folutis probè fưrit impragnatun, cujus fignum eft, quando affuro ஃ ㄴ. per deliq. folutio lacteicit: Tum folutionem filtra \& affunde $\because$. ad fundum precipieabitur, à liquore ope decantationis feparandum.

\section{Ratio procedendi.}

Cum corpora ejufmodi teftacea ad extractionem propriè fic dictam fint inepta: hinc in D Phil. aut $※$ illis affunditur, ut faltem rodat \& abradat quafdam illarum particulas. Quamprimùm autem liquor menftruo contrarius, \&o ㅁ. aut $\curvearrowleft \vartheta *$ affunditur, oritur effervefcentia arque lueta inter utrumque, fiub cujus motu pori folventis majorem nancifcuntur dıametrum, adè, ut particulæ teftaceorum abrafe illis excidant, \& ad fundum fecedant.

\section{Ujus}

Horum Magifteriorum nullus aut perquam exiguts eft. Cìm enim omnia ejufmodi marina \& teAtacea potifinum acidumabforbendo agant, hinc acido extra corpus humanum imbuta, \&, ut loquuntur, faturata, acidum parile in corpore humano oberrans non amplius attingunt. Præftat ergò fimplicibus \& integris adhuc uti, quàm caftratis.

Nec obftat ratione Salis, à menftruo illis adhærentis, iftis vim quandam faponarjam, abfterfivam aut deobftruentem competere :

Re. Habemus enim alia deterfiva magis tuta, cùm falia à menftruis his quodammodò corrofiva fint; \& quia nulla arte omminò poffunt elui, hinc mirum non eft, quod poft ufum Magifteriortum illorum, etiam pretioforum, fc. perlarum \& coralliorum, ventriculus quandoquc corrofus inventus fuerit, 


\section{N D E X}

\section{GENERUM PLANTARUM.}

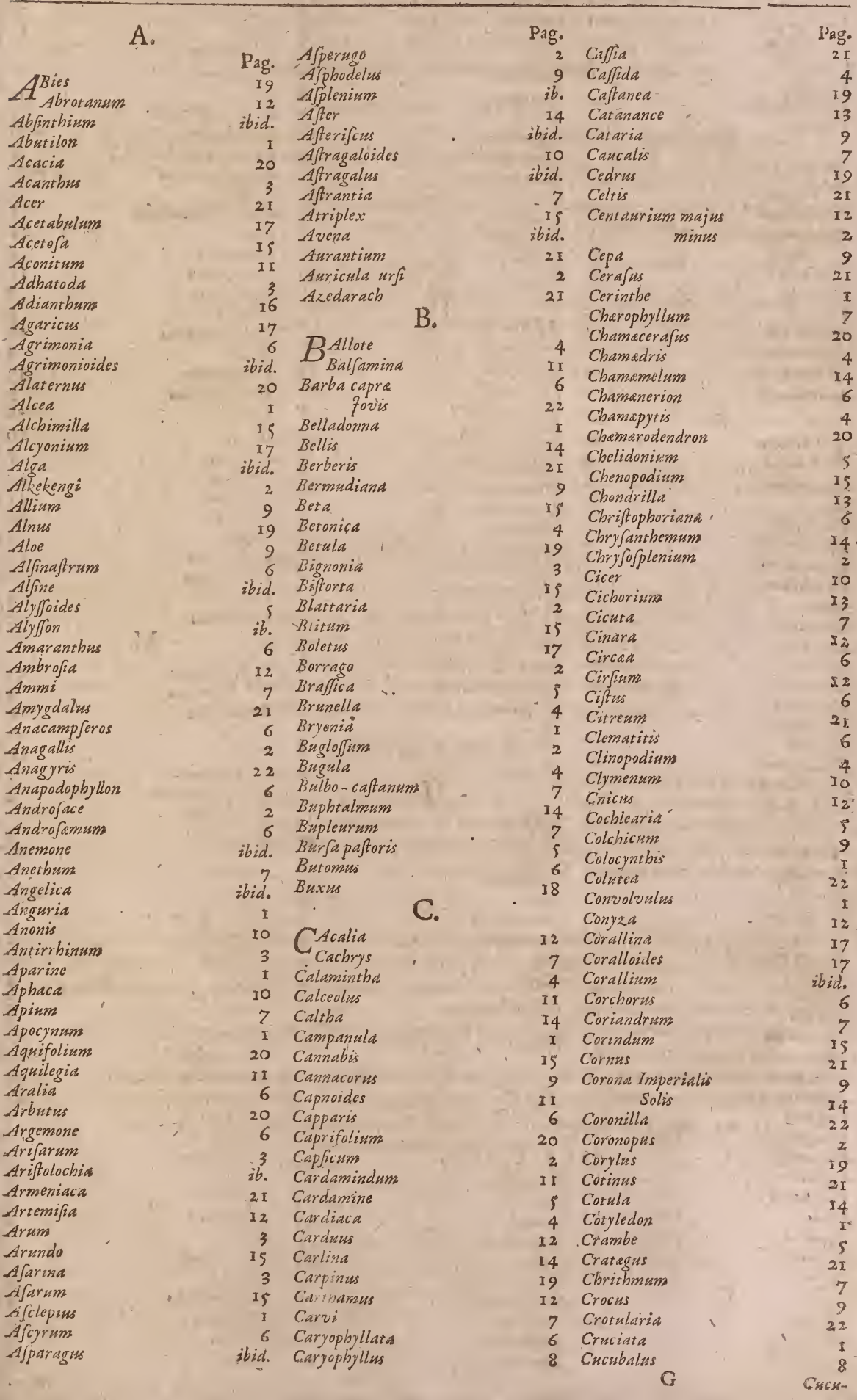




\begin{tabular}{|c|c|c|c|c|c|c|c|c|}
\hline & & I & Garidetta & & & 2.2 & & \\
\hline Cucurbita & & ibid. & Genipa & & & ibid. & Lentifcus & 18 \\
\hline Cupreffus & & 19 & Genifta & & & ibid. & Leonurus & 4 \\
\hline Cyantus & & 12 & Genifto-partism & & & ibid. & $\begin{array}{l}\text { Lepidium } \\
\text { Lencantbenzums }\end{array}$ & T4 $>$ \\
\hline Cyclamen & & $2^{2}$ & $\begin{array}{l}\text { Geniftella } \\
\text { Gentiand }\end{array}$ & & & $\begin{array}{r}22 \\
1\end{array}$ & $\begin{array}{l}\text { Lencantbenzum } \\
\text { Lencojum }\end{array}$ & I4 \\
\hline $\begin{array}{l}\text { Cydonia } \\
\text { Cyroglofsum }\end{array}$ & & $\begin{array}{r}2 I \\
2\end{array}$ & Geranium & & & 6 & Lichen & 16 \\
\hline Cyperoides. & & Is & Genu & & & sibid. & Ligufticum & 7 \\
\hline Cyperus & & ibid. & Gladiolus & & & - 9 & Ligüfrum & 20 \\
\hline Cytifo-Genifta & & 22 & Glancium & & & 6 & Lilac & 20 \\
\hline Cytifus & & ibid. & Glawx & & & I & $\begin{array}{l}\text { Lilio-Appodelus } \\
\text { Liliaftrum }\end{array}$ & ibid \\
\hline & D & & $\begin{array}{l}\text { Globularia } \\
\text { Glycyrrbiza }\end{array}$ & & & $\begin{array}{l}12 \\
10\end{array}$ & $\begin{array}{l}\text { Lillajtrum } \\
\text { Li'io-hyacintbus }\end{array}$ & $\begin{array}{r}2680 . \\
9\end{array}$ \\
\hline D. Amafoniums & & 6 & Gnaphalium & & & 12 & Lilio-Narciffus & ibid. \\
\hline Daucus & & 7 & Gnaphalodes & & & ibid. & Lilinm & \\
\hline Delpbixium & & 9 & Gramen & & & IS & Lilium Convallism & \\
\hline $\begin{array}{c}\text { Dens canis } \\
\text { leonis }\end{array}$ & & $x 3$ & $\begin{array}{l}\text { Granadilla } \\
\text { Groffularis }\end{array}$ & & & 6 & Lim & 21 \\
\hline Dentaria & & 5 & $\begin{array}{l}\text { Groffularia } \\
\text { Guajacana }\end{array}$ & & & $\begin{array}{l}2 \mathrm{~L} \\
20\end{array}$ & nium & $\boldsymbol{I} \mathbf{I}$ \\
\hline Digitalis & & 3 & & & & 30 & groftis & \\
\hline Dipsacus & & 12 & & & & & Lin. & \\
\hline Doronicum & & $\begin{array}{l}14 \\
10\end{array}$ & $H_{\text {Hedera }}^{\text {Armala }}$ & & & $\begin{array}{l}6 \\
21\end{array}$ & wa cervina & 16 \\
\hline Dorycnium & & 4 & Hedypnois & & & 13 & & \\
\hline $\begin{array}{l}\text { Dracocephalon } \\
\text { Dracunculus }\end{array}$ & & 3 & Hedyfarum & & & 30 & ophyton & 17 \\
\hline & $\mathrm{E}_{\text {。 }}$ & & Heliantbemum & & & 6 & $\begin{array}{l}\text { Permum } \\
\text { bitis }\end{array}$ & $\begin{array}{r}2 \\
16\end{array}$ \\
\hline FChinopus & & 12 & $\begin{array}{l}\text { Heliotropium } \\
\text { Helleborine }\end{array}$ & & & 2 & Lotus. & 10 \\
\hline Echium & & 2 & Helleborus & & & $\begin{array}{r}11 \\
6\end{array}$ & Lunaria & \\
\hline Elichryfum & & 12 & Hemionitis & & & 16 & $\begin{array}{l}\text { Lupinus } \\
\text { Lupulus }\end{array}$ & IO \\
\hline Emery & & $\begin{array}{l}22 \\
18\end{array}$ & Herba Paris & & & 5 & ulus & 1 \\
\hline Empetrum & & $\begin{array}{r}18 \\
9\end{array}$ & Herniaria & & & Is & $\begin{array}{l}\text { Luteola } \\
\text { I.ychnis }\end{array}$ & \\
\hline $\begin{array}{l}\text { Ephemerum: } \\
\text { Epimedium }\end{array}$ & & 5 & $\begin{array}{l}\text { Hejperis } \\
\text { Hieracium }\end{array}$ & & & $3_{3}^{5}$ & Lycoperdon & 37 \\
\hline Equifetumo & & 15 & $\begin{array}{l}\text { Hieracium } \\
\text { Hippocaftanum }\end{array}$ & & & 21 & Lycoperficon & ? \\
\hline Erica & & 20 & Hordeum & & & is & Lycopus & \\
\hline Erinacea & & 22 & Horminum & & & 4 & Lyfimacbia & \\
\hline Eruco & & ibid. & Hya & & & 9 & M. & bat \\
\hline Erucago & & $\begin{array}{r}10 \text { rad } \\
10\end{array}$ & Hydrocotyle & & & 7 & WAdrepora & 17 \\
\hline Ervum & & $\begin{array}{r}10 \\
4\end{array}$ & Hydrophyllon & & & I & Majoran & \\
\hline $\begin{array}{l}\text { Eryngium } \\
\text { Eryfinum }\end{array}$ & & 5 & $\begin{array}{l}\text { Hyofciamus } \\
\text { Hypecoon }\end{array}$ & & & $\begin{array}{l}2 \\
5\end{array}$ & $\begin{array}{l}\text { Malacoides } \\
\text { Malva }\end{array}$ & . \\
\hline Efchava & & 17 & $\begin{array}{l}\text { Hypecoon } \\
\text { IIypericum }\end{array}$ & & & 6 & Malus & $2 \mathbf{I}$ \\
\hline Eunonymus & & 21 & Hy flopus & & & 4 & Mandragora & $2 \mathrm{I}$ \\
\hline $\begin{array}{l}\text { Eupatorium } \\
\text { Euphrafis }\end{array}$ & & $\begin{array}{r}32 \\
3\end{array}$ & & & & & Marrubiaftrams & c. \\
\hline Euphrajtse & $F_{0}$ & & $\mathcal{F}_{\text {facea }}^{\text {Acea }}$ & & & $\$ 2$ & $\begin{array}{l}\text { rrubium } \\
\text { tricaria }\end{array}$ & ibid. \\
\hline$F A b a$ & & 10 & Talapa & & & $\begin{array}{r}14 \\
2\end{array}$ & ys & \\
\hline Fabago & & & fagminum & & & 20 & dica & 10 \\
\hline Fagonia & & ibid. & Mlex & & & 19 & Medicago & ibid. \\
\hline Fagopyrum & & 15 & Imperatoria & & & 7 & Melampyrum & 3 \\
\hline Fagus & & $\begin{array}{l}19 \\
20\end{array}$ & fontblappi & & & 5 & Melianthus & II \\
\hline $\begin{array}{l}\text { Ferrums equinsm } \\
\text { ierula }\end{array}$ & & $\begin{array}{r}20 \\
7\end{array}$ & Iris. & & & 9 & & 10 \\
\hline Perula & & 7 & Ifatis & & & $\frac{5}{6}$ & gend & \\
\hline $\begin{array}{l}\text { ilago } \\
\text { ilicula }\end{array}$ & & 16 & $\begin{array}{l}\text { tzencago } \\
\text { funcus }\end{array}$ & & & ibid. & pepo & \\
\hline $\begin{array}{l}\text { Flicula } \\
\text { Filipendula }\end{array}$ & & 6 & $\begin{array}{l}\text { tuncus } \\
\text { funiperus }\end{array}$ & & & $30 z a$. & Mentba & \\
\hline Filix & & 16 & & & & & Menyanthes & 2 \\
\hline Foniculum & & 7 & T>Ali & & & & ialis & 15 \\
\hline esum & & 10 & $K_{\text {Ketroig }}^{\text {Alt }}$ & & & 1 & & 21 \\
\hline ragarin & & 6 & & & & 1 & & \\
\hline & & 21 & & & & & & \\
\hline & & II & LAcryma fobi & & & Is & folism & 14 \\
\hline & & $\begin{array}{r}18 \\
9\end{array}$ & Lactuca & & & 13 & & 20 \\
\hline $\begin{array}{l}\text { ritillaria } \\
\text { ucus }\end{array}$ & & 17 & $\begin{array}{l}\text { Lamium } \\
\text { Lamp }\end{array}$ & & & 13 & & \\
\hline$a$ & & iI & $\begin{array}{l}\text { Lamp Jat } \\
\text { Lapathus }\end{array}$ & & & 13 & davica & \\
\hline ungoides & & 17 & Lappa & & & 12 & ordica & $x$ \\
\hline Fungus & & 17 & Larix & & & 19 & & 19 \\
\hline & & & Laferpitium & & & 7 & atellina & \\
\hline Al & & ro & Lavandula & & & 10 & & \\
\hline $\begin{array}{l}\text { Galeopjis } \\
\text { allinm }\end{array}$ & & $\begin{array}{l}4 \\
1\end{array}$ & $\begin{array}{l}\text { Lavandula } \\
\text { Latrocerafiss }\end{array}$ & & & 24 & $\begin{array}{l}\text { Mujcari } \\
\text { inusans }\end{array}$ & \\
\hline & & & & & & & & \\
\hline
\end{tabular}


Ayagrkm

Myofotis

Myrrbis

Myrtws

$N^{\text {Apus }}$

Narciffu

Nefturtzam

Nelumbo

Nerion

Nicotianx

Nidus avis

Nigella

Nix

Nymphas

o.

Ochrus

Ocimum

Oenanthe

Olea

Omphalodes

Onagra

Onobrychis

OphiogloJum

Ophris

Opulus

Opuntia

Orchis

Oreofelinum

Origanum

Ornithogalum

Ornithopodium

Orobanche

Orobus

Oryza

Ofmunds

Oxys

P.

PoEonia

Panicum

Papaver

Parietaria

Parnafja

Paronycbia

Paftinaca

Pedicularis

Pelecinus

Pentapbyllodes

Pepo

Periclymenum

Periploca

Perfica

Perficaria

Pervinca

Petafites

Peucedanum

Phalangium

Phajeolus

Phellandrium

Phillyrea

Pblotwis

Pbytolacca

Pimpinella

Pinguicula

Pinks
Pag.

5 Piftem

6 Plantago

7 Platanus

21 Plumbago

Poinciane

Polemonium

Polium

5 Polygala

s Polygonatum

5 Polygonum

6 Polypodium

25 Populago

2 Populus

II Porrum

6 Portulaca

I9 Potamogeton

6 Primula veris

Prunus

Pfendo-acacia

Pfendodictamnus

Io Pfyllium

4 Ptarmica

7 Pulmonaria

20 Pulfatilla

2. Punica

Pyrola

Pyrus

$1 \mathrm{I}$

20

\section{Uamochitl}

Quercus

Qinenquefolium

4

9

10

$3 R_{\text {Rapa }}^{\text {Anunculus }}$

Is Raphaniftrum

16 Raphanus

I Rapiftrum

Rapunculus

Rapontium

Refeda

6

Rbabarbarum

21 Rbagadiolus

I5 Rbamnus

Rhros

Ricinus

Rofa

Rofmarinus

Ros Solis

Rubeola

Rubia

Rubus

Rufcus

20 Ruta

I Ruta muraris

$2 x$

IS

2

12

7

9
10

7

20

4

Satureja

2 Saxifraga

3 Scabiofas

19 Scandix

Salix:

Salvis

Sambucus

Samolus

Sanicula

Santoline
Pag.

Io Scirpus

Sclarea

Scolymus

Scorpioides

Scorzonera

Scrophularid

Secale

Securidaca

Sedum

Senecio

Senna

Serpillum

Sefamoides

Sicyoides

Sideritis

Siligua

Siliquaftrum:

Sinapi

Sinapiftrum

Sifarum

Sifymbrium

Sifyrinchiums

Sium

Smyrnium

Solanum

Soldanella

Sonchus

Sorbus

Sparganium

Spartiume

Spondylium

Spinachia

Spiraa

Spongia

Stacbys

Stapbylondendros

6 Statice

5 Stochas

ib. Stramonium

Styrax

Suber

Symphyrum

Syringa

Pag.

is

4

ro

I 3

3

$\times 5$

10

12

2 I

4

II

18

22

ibid.

7

5

8

sbid?

2

I

Is

$2 I$

I5

22

is

35

गु 7

4

8

4

3

20

39

2

2 II

I

13

S.

SAlicaria
20

$2 \mathrm{I}$

I5

2 I

4

6

2

2 I

I

6

16

$T_{\text {Tamnus }}^{\text {Agetes }}$

Tanacetum:

Taxis

Telephium

Terebinthus

Teucrium

7 balidtrum

Thapfia

Thlajpi

Thlapidium

Thuya

Thymbra

Thymelaa

6 Thymus

19 Thyfelinum

Tilia

Tinus

Titbymalus

Tordylium

Tormentilla

Toxicodendron

Tracbelium

Tragacantha

Tragopogon
54

I

12

II)

6

18

6

7

5

I 9

4

20

4

7

2. I

20

I 
$05)(0)(50$

Tragoelinon

Tribulus

Trichomanes

Trifolium

Triticum

Tubera

Tubularia

Tulipa

Turritis

Tufsilago

Typha

VAleriana
Pag.

7 Veratrum

6 Verbafcum

16 Verbena

Io Veronica

Is Viburnum

17 Vicia

ibid. Viola

9 Virga amrea

$5 V i f c u m$

14 Vitex

Is Vitis

V.

\section{Ulmaria}

2 Ulmus

$i \dot{b}^{2}{ }^{2}$ Ulmus

Pag.

Vva urja

Vulneraria

Pag.

20

10

$\mathrm{X}$.

XAnthium

22

14

Xiphion

Xylon

Xylofteon

$2 I$

20

6

is $Z_{Z_{\text {iziphus }}}^{\text {Acintha }}$

Z.

33

$2 \pi$

\title{
F I N I S.
}

\author{
SPHALMATA ILIAPSA.
}

Pag. 6. Col. I. lin. 2. loco verb. IX. Genera lege IX. Sectiones. Pag. 33. Lin. 7. Loco Catharctica lege Cathæretica.

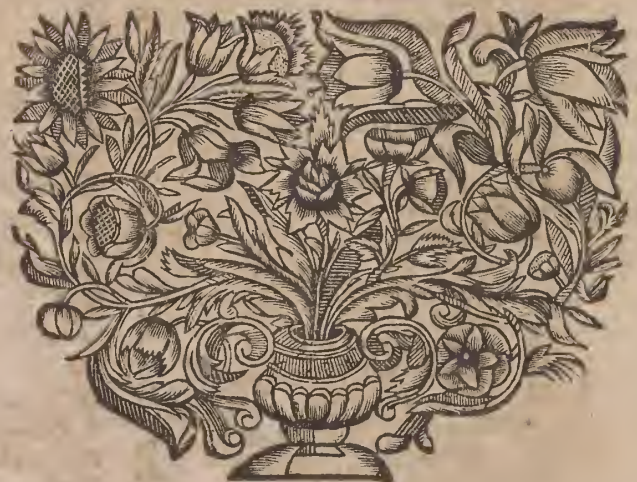




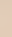
, 



$$
9
$$






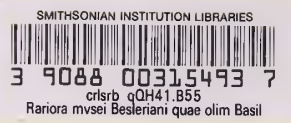

